\title{
SPEAR
}

$3 \mathrm{GeV}$ Booster Synchrotron

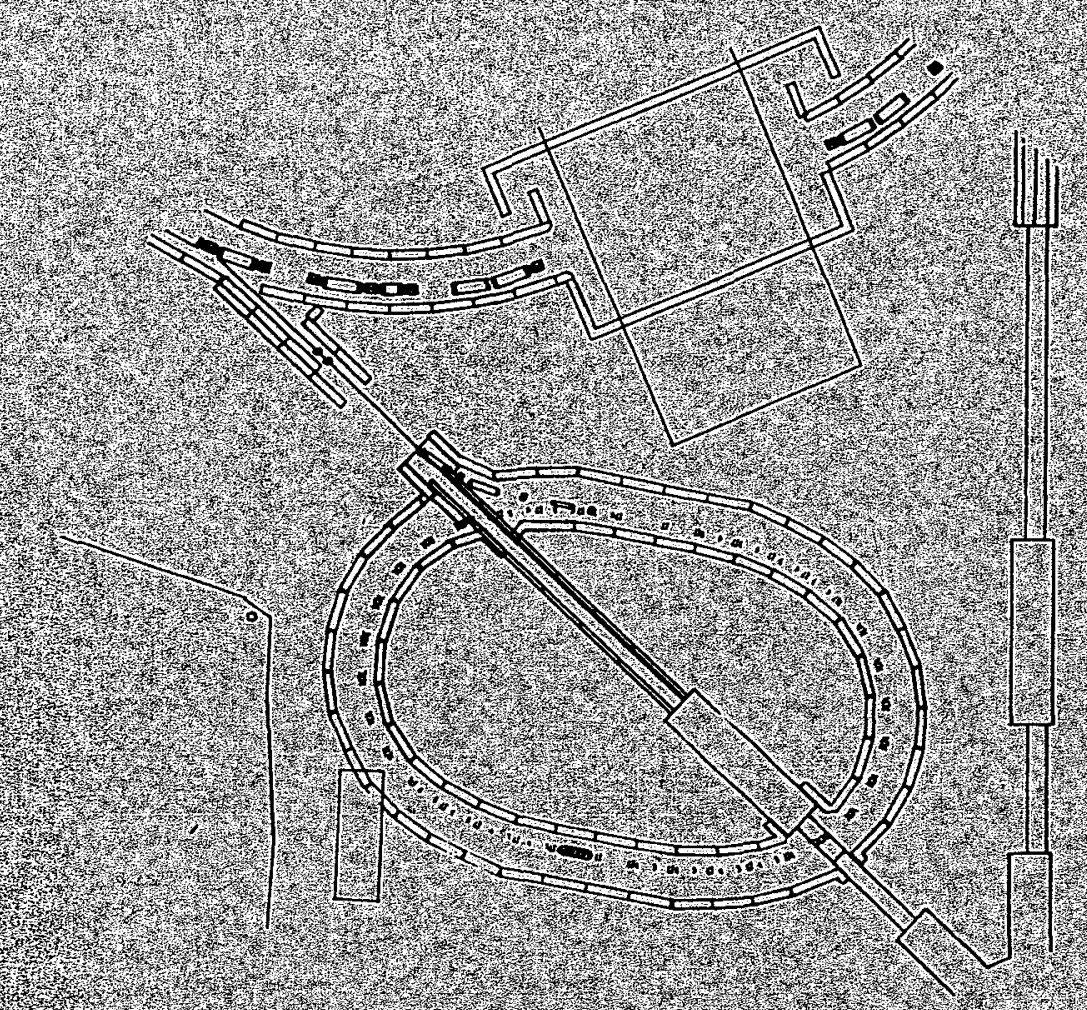

August 1987

Stanford Synchrotron Radiation Laboratory, SSRL

Stanford University, Stanford, Californing 94305 


\title{
$3 \mathrm{GeV}$ \\ BOOSTER SYNCHROTRON \\ for SPEAR
}

\section{Conceptual Design Report}

\author{
August 1987
}

Stanford Synchrotron Radiation Laboratory, SSRL

Stanford University, Stanford, California 94305

Prepared for U.S. Department of Energy under Contract \# DE - AC03 - 82 ER 13000 
CONTENTS

1. INTRODUCTION $\ldots \ldots \ldots \ldots \ldots \ldots \ldots \ldots \ldots \ldots$.

1.1 Overview ................................ 1

1.2 Rational for a Dedicated Synchrotron Booster Injector ....... 6

1.3 Review Process for the Injector $\ldots \ldots \ldots \ldots \ldots \ldots \ldots \ldots \ldots . \ldots$

$1.4 \mathrm{R} \& \mathrm{D}$ Effort for this Injector $\ldots \ldots \ldots \ldots \ldots \ldots \ldots \ldots \ldots \ldots \ldots$

2. GENERAL DESCRIPTION OF INJECTOR AND

PARAMETERS $\ldots \ldots \ldots \ldots \ldots \ldots \ldots \ldots \ldots \ldots \ldots \ldots$

2.1 Performance Goals ............................. 12

2.2 General Design Concept of the Injector ............... 14

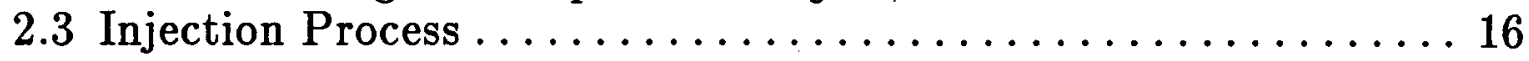

3. CONCEPTUAL DESIGN OF INJECTOR SYSTEM $\ldots . .17$

3.1 Lattice Design and Beam Characteristics ............... 17

3.2 Technical Components ........................... 27

3.2.1 Preaccelerator Linac $\ldots \ldots \ldots \ldots \ldots \ldots \ldots \ldots \ldots . \ldots 27$

3.2.2 Magnet System .............................. 35

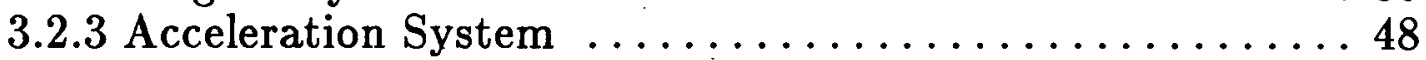

3.2 .4 Vacuum System $\ldots \ldots \ldots \ldots \ldots \ldots \ldots \ldots \ldots \ldots \ldots \ldots \ldots$

3.2.5 Instrumentation and Controls .................. 54

3.2.6 Injection and Ejection ...................... 57

3.2 .7 Utilities . . . . . . . . . . . . . . . . . . . . . . 58

3.3 Shielding and Support Buildings $\ldots \ldots \ldots \ldots \ldots \ldots \ldots \ldots \ldots$

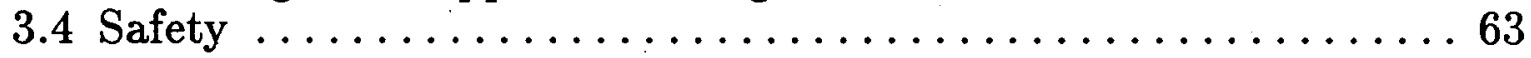

APPENDIX $\ldots \ldots \ldots \ldots \ldots \ldots \ldots \ldots \ldots \ldots \ldots \ldots$ 


\section{Introduction}

\subsection{Overview}

Synchrotron light can be produced from a relativistic particle beam circulating in a storage ring at extremely high intensity and brilliance over a large spectral region reaching from the far infrared regime to hard $x$-rays. The particles, either electrons or positrons, radiate as they are deflected in the fields of the storage ring bending magnets or of magnets specially optimized for the production of synchrotron light. The synchrotron light being very intense and well collimated in the forward direction has become a major tool in a large variety of research fields in physics, chemistry, material sciences, biology and medicine.

The first SLAC storage ring enhanced for synchrotron radiation research was the SPEAR ring. This development began in 1972, with the first beam line becoming operational in mid-1974. SPEAR has a 234 meter circumference and operates at energies up to $3.5 \mathrm{GeV}$ with currents up to 100 milliamps. The storage ring can accomodate 16 insertion device beam lines (not including all bending magnet beam line possibilities) without interference with a high physics energy experiment operating in the ring's West Pit. Additional beam lines can be implemented upon the completion of the high energy physics program.

Although SPEAR's emittance, $460 \mathrm{~nm}$-rad at $3 \mathrm{GeV}$, for the regular mode of operation is larger than those of the most modern synchrotron radiation sources, a low emittance configuration, with a design emittance of $130 \mathrm{~nm}$-rad, was tested in 1984. The existing SPEAR injection system, however, makes its utilization on a day-to-day basis difficult because of limitations in the present injection configuration. Modifications of the injection system are described in this Conceptual Design Report.

At present, SSRL operates 21 experimental stations on nine beam lines on the SPEAR storage ring. In the next two years, one more beam line $(\mathrm{X})$ 
and one station will be added to SPEAR. A layout of the SPEAR facilities is shown in Figure 1. The experimental stations of SSRL are used by more than 500 scientists from 99 different institutions in 32 states and 11 foreign countries. These institutions include 51 universities, 15 private corporations and 12 government laboratories.

Particle beams usually circulate in the ultrahigh vacuum environment of a storage ring for several hours. After the beam current has decayed to a low value new particles are injected from a separate accelerator referred to as the injection system.

Injection of particles into the SPEAR storage ring has been traditionally performed from the existing 2 mile linear accelerator at the SLAC. This injector has been specified and designed for very high particle energies and is too big an injector for a $3 \mathrm{GeV}$ storage ring. To obtain reasonable injection efficiencies it is necessary to accelerate the particles in the linear accelerator to about 10 to $15 \mathrm{GeV}$ and then decelerate them again to the low injection energy of $2.3 \mathrm{GeV}$. This sequence of acceleration and deceleration is necessary to assure that a significant amount of particles survive the electromagnetic interaction with the accelerator sections while traveling over 2 miles during acceleration. As a result of this complicated acceleration process it has been difficult to run the injector in a reproducible way and injection into SPEAR has been less reliable than is desirable or readily achievable.

This situation is expected to get aggravated in the SLC phase of operation which started in fall of 1986. In this mode of operation intense bunches of positrons and electrons are accelerated in the SLAC linear accelerator to energies up to about $50 \mathrm{GeV}$. After acceleration they are guided through two transport lines, one for the positron bunch and one for the electron bunch, which after $1400 \mathrm{~m}$ aim at each other. At that point both the electron and the positron bunches collide and produce the high energy reactions to be studied by the high energy physics community. During this mode of operation of the linear accelerator low energy injection into SPEAR is highly interruptive for the high energy physics program and as a consequence, only two SPEAR fills per day are planned to be available. With this schedule still the high energy physics program is interrupted for 2 hours every 12 


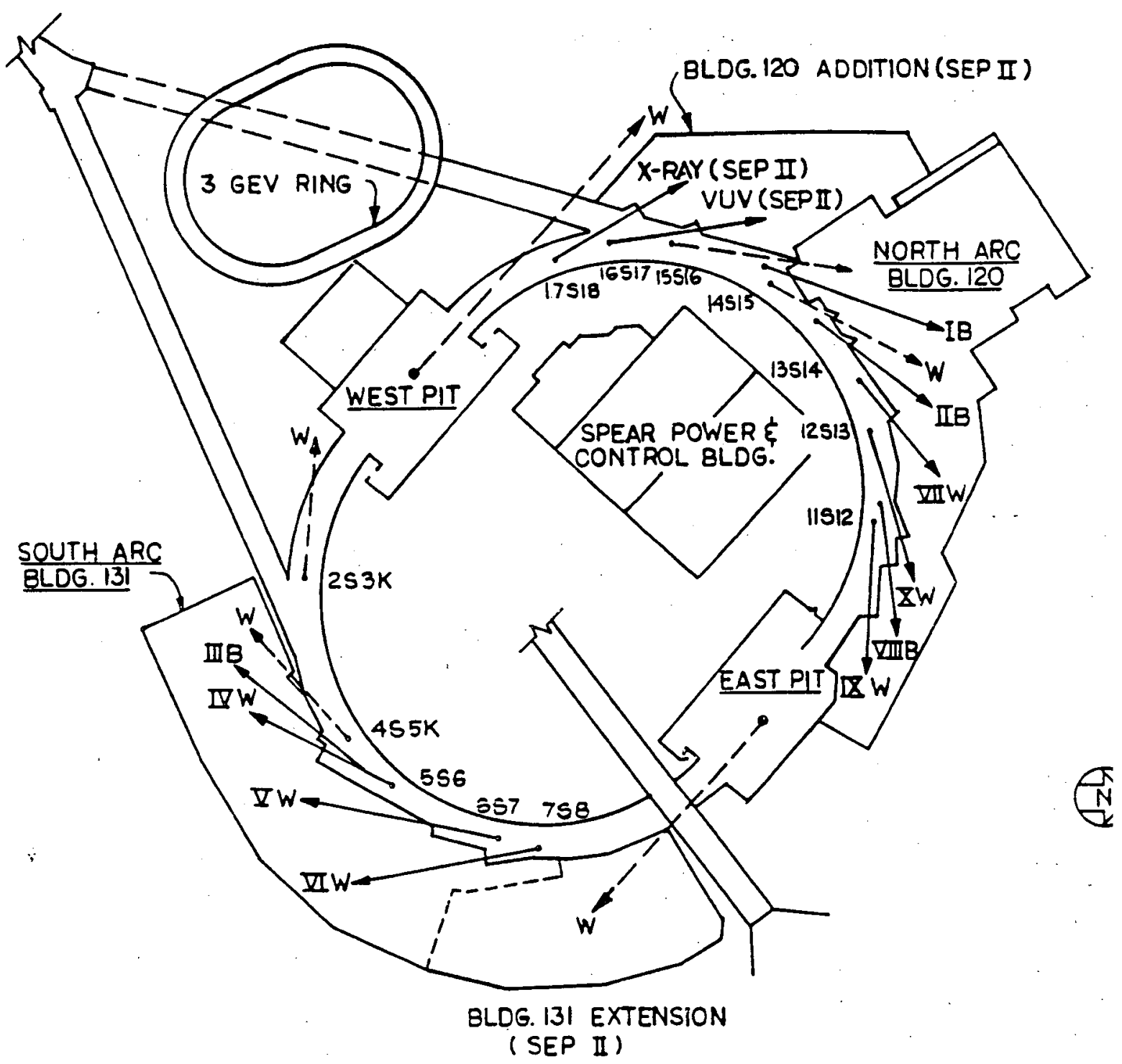

$$
\begin{aligned}
& \rightarrow \text { IMPLEMENTED BEAM LINES } \\
& \rightarrow \text { FUTURE BEAM LINES } \\
& \bullet=\text { KICKER TANK LOCATIONS } \\
& w=\text { WIGGLER/UNDULATOR ORIGIN } \\
& B=\text { BEND MAGNET ORIGIN }
\end{aligned}
$$

Fig. 1: Layout of the SSRL Facilities at SPEAR 
hours. The running costs of the linac during these two hours are very high for SSRL since the linac must be kept operating at full power so as not to change the delicate thermal balance in the accelerating sections for SLC operation.

This schedule greatly limits the synchrotron radiation experimental program at SSRL. To keep SPEAR operating at a high performance level and develop improvements, machine physics shifts must be available. For such machine developments it is crucial that on-demand injection be available. In the SLC era, however, this is not the case and if the beam is lost during machine physics the efforts are stopped until the next 12 hourly scheduled injection. This makes machine physics experimentation and scheduling extremely inefficient.

The nature of this interruption comes from the required precision control of the SLC beams at $50 \mathrm{GeV}$. To accelerate the very high intensity beams during SLC operation many strong quadrupoles are required along the linear accelerator to prevent a beam break-up. These quadrupoles are much too strong to allow the passage of a 2 to $3 \mathrm{GeV}$ beam for SPEAR and, therefore, must be turned off. While this is not a problem for SPEAR injection, it takes considerable time to recover from SPEAR injection back to SLC operation. This is because it generally is difficult to reproduce exact beam conditions after magnet strengths have been changed. Recovery from machine physics runs at PEP as well as at SPEAR traditionally have been difficult because of this reason. A change in the injection energy at SPEAR and at $\mathrm{PEP}$ is therefore done very rarely. A change in the injection energy requires at least several hours to be set up. For the SLC to obtain beam collision again after a SPEAR injection, the position of the electron as well as the positron beam must be reproduced at the end of the 2 mile linac to $0.1 \mathrm{~mm}$ and an angle of 1 microradian.

Consequently, dedicated injector for SPEAR appears to be the proper facility to both preserve the goals of the high energy physics community with the SLC and to assure the availability of photons for the synchrotron radiation user community. In addition such a dedicated injector can be optimized for SPEAR injection alone and therefore can provide greatly improved injection conditions. Since the operating costs of this injector 
will be much less than those for the 2 mile SLAC accelerator, SSRL should be able to provide synchrotron radiation for a much larger fraction of the year than it can now.

In this Conceptual Design Report, CDR, an injection system which would allow the accumulation of electrons into SPEAR at an operating energy of up to $3.0 \mathrm{GeV}$ is described. To obtain optimum performance of a storage ring dedicated to the production of synchrotron radiation a full energy particle injector is highly desirable. That is, means the particles are injected into the storage ring at the operating energy. The feature of full energy injection provides several advantages. All storage ring components are left in their running conditions during injection since it is not necessary to change the storage ring energy from the operating energy to the injection energy. If the injection energy were different from the operating energy the excitation of the ring magnets would have to be changed for injection and a special magnet training routine must be followed to establish the desired magnetic fields again in the presence of hysteretic effects. For a large number of experiments it is very critical, however, to keep the photon beam as stable as possible over a long period of time which is very difficult to achieve when magnetic fields in the storage ring must be changed. In case of a full energy injection the photon beam steering is done once and will stay adjusted over many shifts.

For economic reasons often an injection energy lower than the operating energy of the storage ring is chosen. In case of a full energy injector, however, higher beam currents can be stored in the storage ring than would be possible at lower energies. All known instabilities allow higher storage ring beam currents to be reached as the beam energy is increased. Moreover, since magnet field training is not necessary the remaining beam current from the previous fill is not lost, the time for beam injection is reduced and the efficiency of the storage ring for the production of synchrotron radiation is significantly enhanced. 


\subsection{Rational for a Dedicated Synchrotron Booster Injector}

To obtain full energy injection different types of injectors can be utilized. In particular, a linear accelerator as well as a booster synchrotron can serve as such a full energy injector. In this proposal a booster synchrotron is proposed in order to take advantage of several favorable features with respect to a full energy linear accelerator. To achieve a beam energy of one $\mathrm{GeV}$ or higher a booster synchrotron can be constructed at a significantly lower cost than a linear accelerator.

With present day technology a $3 \mathrm{GeV}$ linear accelerator would require at least 30 accelerating sections, each 10 feet long, and one $100 \mathrm{MW}$ klystron for each of these sections. This type of klystron has been developed at SLAC for the SLC project and is not available yet from industry. With 35 MW klystrons, which are available from industry, the linac would require 51 stations to reach $3 \mathrm{GeV}$. The length of such linacs would be $120 \mathrm{~m}$ or $190 \mathrm{~m}$ respectively and thereby longer than the circumference of the proposed booster synchrotron. The space available next to SPEAR would not allow the placement of such linacs. The costs for such linacs has been estimated to be more than twice the cost of the equivalent components in a booster synchrotron. In addition the operating and maintenance costs are significantly higher for a linear accelerator than for a booster synchrotron. Assuming a 20,000 hour lifetime on average for each klystron and a running time of 5,000 hours per year, 7.5 klystrons must be replaced every year at a cost of more than $\$ 400 \mathrm{~K}$. In contrast the proposed booster involves only four klystrons, three lower power linac klystrons and one DC klystron for the synchrotron itself.

For these reasons it has been decided to propose a $3 \mathrm{GeV}$ booster synchrotron as a dedicated injector into SPEAR. Such a booster fits well in the space available next to SPEAR (Figure 2).

The technology involved in the construction of a synchrotron is similar to that of the storage ring and therefore the operation and maintenance of both rings is simplified which enhances its reliability. Of course, in the case of a synchrotron, a preinjector in the form of a small linear accelerator or microtron is needed. In this proposal a three section linac is assumed 


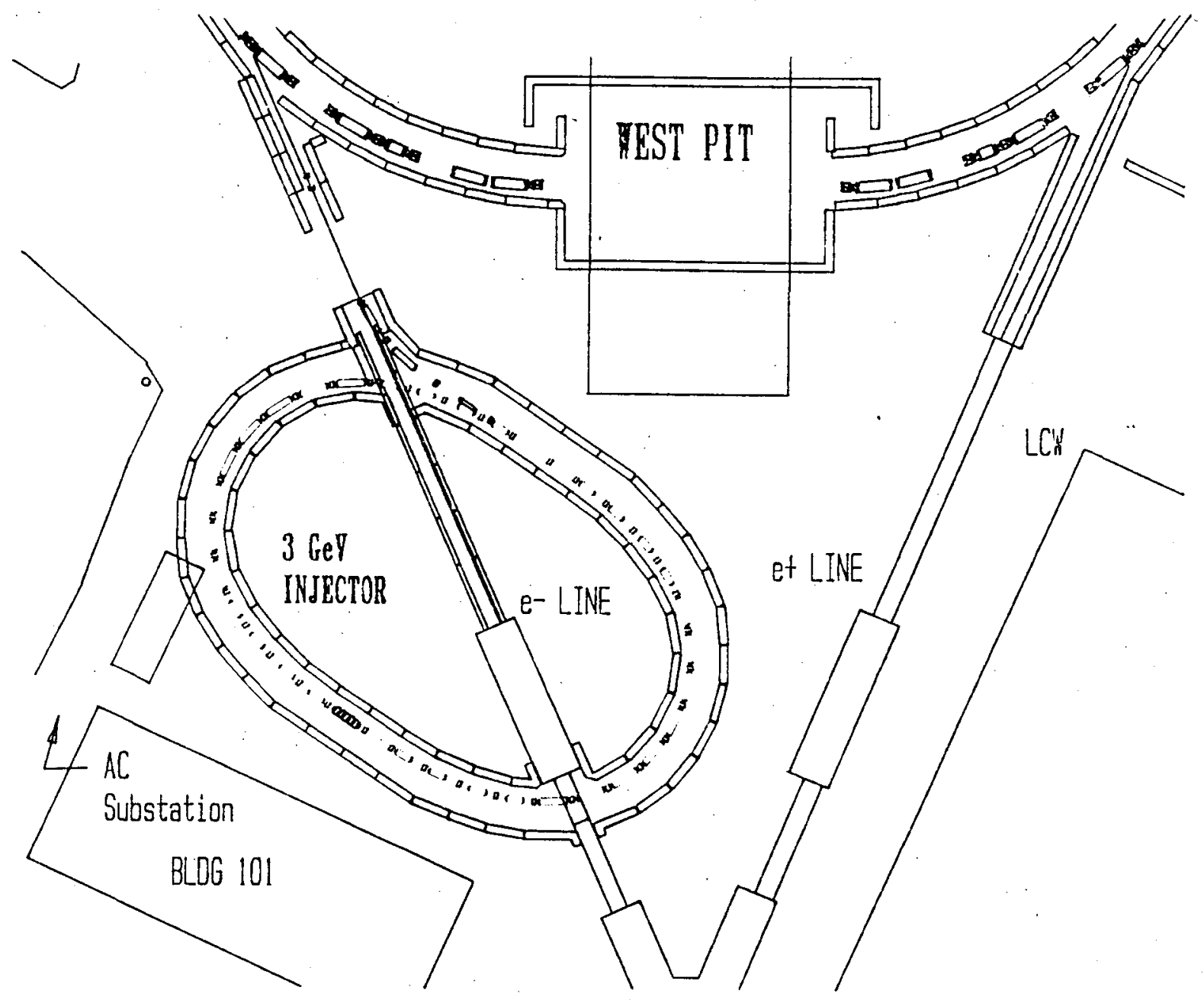

Fig. 2: General Layout of the Injector - SPEAR Complex

which is much easier to operate and maintain. The beam characteristics for a preinjector linac to inject into a booster synchrotron are very much relaxed compared to injection into a low emittance storage ring.

In a linac/synchrotron injection system full energy injection is assured virtually at all times. If a full-energy linear accelerator is used, a loss of any klystron reduces the energy of the linac and therefore the injection 
energy into the storage ring is reduced until this klystron is replaced. In the proposed scheme the loss of one linac klystron would only reduce the injection energy into the synchrotron from the preinjector which, however, has no effect on the ultimate energy the synchrotron can reach. The only detrimental effect would be some increase in the storage ring injection time since the synchrotron probably would no longer be able any more the same beam current at the reduced preinjector energy. The operating parameters of the storage ring, however, need not be altered.

Of course, the loss of the synchrotron klystron would prohibit any further acceleration and injection. In this proposal we have therefore assumed that the $\mathrm{RF}$ system be the same as for the storage ring so that RF components and spares can be shared.

In addition to these operational and maintenance considerations it should be noted that injection into a booster synchrotron from a linear accelerator is much easier than direct injection from a linac into a low emittance storage ring. This is because a much simpler solution for the focusing lattice in the booster synchrotron can be chosen. The beam in such a lattice does not require the tight magnet field and alignment tolerances of a storage ring and allows for a larger physical and dynamic aperture. This significantly reduces the quality of the beam required from the linac preaccelerator and makes the operation of the short preinjector system relatively easy.

On the other hand, for injection into a high brilliance storage ring with limited aperture the injection system must provide a beam of high quality. Beam parameters like beam energy, beam size, and energy spread must be closely controlled for successful injection. This requires a powerful control system if direct injection from a high energy linac is desired. In a synchrotron the beam size and energy spread are determined by the design of the lattice and are therefore well known while the beam energy itself is well defined and controlled by the fact that the synchrotron acts like an energy defining spectrometer. In a linear accelerator these parameters can vary greatly if not closely controlled at all times.

Even in a well adjusted linear accelerator the beam parameters are ultimately determined by the source characteristics. Therefore, should it become desirable to use positrons in the storage ring it would be difficult 
to obtain a high injection efficiency with a linac injector because of the large positron beam emittance which is a consequence of the production process. The beam emittance and energy spread is well determined in a a synchrotron due to synchrotron radiation damping, and independent of the nature of the particles or their sources. Both quantities can be made equal and significantly smaller in a booster synchrotron than in a linear accelerator to facilitate injection into the low emittance storage ring.

In this proposal the synchrotron lattice has been designed for a relatively small beam emittance to provide easy injection into the storage ring. The general design concepts for the $3.0 \mathrm{GeV}$ booster synchrotron are described in the following sections of this CDR.

\subsection{Review Process for the Injector}

In late 1985 it became more and more apparent that the filling of the SPEAR storage ring would cause major interference with the SLAC SLC program since it requires a reconfiguration of the SLAC linac. To recover from this linac reconfiguration is time consuming and therefore costly both from an economic and a scientific point of view. With only two fills per day the interruption of the high energy physics program would be 2 hours for each fill or $16.7 \%$ of the time would not be available for high energy physics because of the filling of SPEAR. Moreover the linac cannot be operated for most of the year for fiscal reasons.

To protect SSRL's research program the SSRL directorate decided to propose a dedicated injector for SPEAR. After internal reviews the proposal was discussed with various committees and review panels. A list of these reviews in chronological order and other action relevant to the proposed SPEAR injector is given below:

1) March 11, 1986 : SLAC reviews injector proposal and in a preliminary statement agrees with technical plan, cost and schedule. 
2) Stanford University administration authorized SSRL to submit a proposal for the SPEAR injector in the form of a Schedule 44

3) April 15, 1986 : DOE/Headquarters review of SSRL's FY1988 Budget Call including SEP II and Injector Proposal

4) April 25, 1986 : Formal submission of Schedule 44 to DOE

5) May 14, 1986 : SSRL users organization executive committee discussed injector proposal and stated in its report to the SSRL director "..support first priority for a new injector system....

6) May 27, 1986 : SLAC concludes its review of injector proposal

7) May 28, 1986 : Director's Review of the whole SEP II proposal by outside 12 member committee chaired by Marvin Weber of LLNL. The report states "Of the various proposal elements, the $3 \mathrm{GeV}$ SPEAR injector and the 12-m PEP undulator beam line were rated at the top or near-top by all panelists."

8) June 9, 1986 : SSRL Science Policy Board reviewed, among other SSRL plans, the injector proposal and supported it.

9) June 26, 1986 : DOE validation Review at DOE headquarters chaired by Mr.Ramsey (DOE). Submission of conceptual design report.

10) February 1987 : The SPEAR injector has been included in the President's budget for FY'1988 at $\$ 13.5 \mathrm{M}$ over three years.

11) February 24, 1987 : Status report of injector project during annual DOE review of the SEP-I project at SSRL

12) March 13, 1987 : Submit new CDR and bottoms-up cost estimate.

13) March 25, 1987 : SSRL program review at DOE headquarters 
14) April 21, $1987:$ DOE program review

15) August 13, 1987 : DOE Construction Review

16) September 14, 1987 : Technical Review

\subsection{R \& D Effort for this Injector}

The design of the SPEAR injector synchrotron is based on well known and well tested techniques as developed over more than 30 years. No Research and Development is, therefore, required. The project schedule, however, has been adjusted to allow the fabrication of engineering models for some of the major components like magnets and a vacuum chamber to verify the technical solution before a large number of these components are fabricated. 



\section{General Description of Injector and Parameters}

\subsection{Performance Goals}

The specifications of the injection system were determined to achieve the following objectives:

The system must provide an electron beam to SPEAR at a maximum energy of at least $3.0 \mathrm{GeV}$.

It must be an independent system that does not interfere with the operation of any other facility or experiment not associated with SPEAR.

The actual SPEAR filling time should be less than 5 minutes to achieve a circulating current of $100 \mathrm{ma}$.

The operation of the injector synchrotron should be reliable, easy to operate and of low maintenance so as to allow the integration of the injector operation with the SPEAR operation.

The dedicated SPEAR injector system consists of a short linear accelerator with a beam energy of at least $100 \mathrm{MeV}$ as a preinjector, a $3 \mathrm{GeV}$ slow cycling synchrotron and a beam transport line feeding the particles into the existing SPEAR injection lines. In the first stage the injector is limited to electrons. If positrons should be desired later, a positron option discussed below could be exercised. The "additional cost" is obvious. The energy of the synchrotron has been chosen to match the usual operating energy of SPEAR for synchrotron light users and the injector therefore is a 
full energy injector allowing maximum use of the synchrotron light source. With a circumference of about $100 \mathrm{~m}$ it is possible to place the synchrotron just next to the SPEAR storage ring (Figure 2). At this location the high costs of tunnel construction can be avoided by constructing above-ground radiation shielding as for the SPEAR ring itself.

The preinjector linac is a slow cycling linac which can produce a string of S-band bunches in a single linac pulse. These bunches are stored around the booster synchrotron and then accelerated to the storage ring energy by slowly ramping the booster magnets to higher fields. At the final energy the bunches then are transferred from the booster to the desired buckets in the storage ring.

The total filling time for SPEAR to a circulating current of $100 \mathrm{ma}$ is expected to take less than 5 minutes, assuming a storage efficiency of only $25 \%$. This filling time is very short and is also compatible with our separate effort to increase the current capability of SPEAR to 150 or even 200 ma. Should it ever become necessary to use positrons, additional equipment must be installed. This positron option requires the extension of the electron linac to say 200 to $300 \mathrm{MeV}$, the addition of a positron converter, a positron focusing system and a 200 to $300 \mathrm{MeV}$ positron linac. The need to use positrons in SPEAR for synchrotron light production has not been positively established yet. Therefore, we propose to construct only an electron injector at this time to minimize costs and construction time.

After acceleration of the electrons to the operating energy of the storage ring the bunches are transferred to the storage ring. At this point the question must be asked if it would be possible to inject, say, every five minutes so as to keep the storage ring current constant. Since this would be desirable, further studies are in order to demonstrate this feasibility. There is no fundamental problem from the injector point of view. In the storage ring, however, the already stored beam would be affected by the pulsed fields of the injection kickers which might be incompatible with experimentation. The scheme might work if the experiments can be interrupted for, say, 5 to 10 seconds every 5 to 10 minutes. In any case, having a dedicated injector, such schemes can be tried out and used if desirable. 


\subsection{General Design Concept of the Injector}

The booster magnet lattice and ring dimensions are shown in Figure 3. The lattice is based on a simple FODO arrangement of the magnets with 18 equal FODO cells forming the total ring. A total of two bending-magnetfree FODO cells provide the space for injection and ejection components, a radio frequency cavity and other minor ring components. Additional space for ring components is provided in the two arc cells adjacent to the straight sections. To minimize the occurrence of synchro-betatron instabilities the dispersion function is chosen to vanish in the straight sections. This is accomplished by using a so-called dispersion suppressor lattice employing different bending angles in the last four bending magnets at the end of the arcs as shown in Figure 3.

Some general parameters of the injection system are compiled in Table 1.

Table 1

General Parameters of the Injection System

Design Energy

Circumference

Particles

Cycling Rate

Intensity

Number of Bunches

Preinjector

Linac Frequency

Energy of preinjector

Storage Ring Filling Rate

(for $25 \%$ filling efficiency)

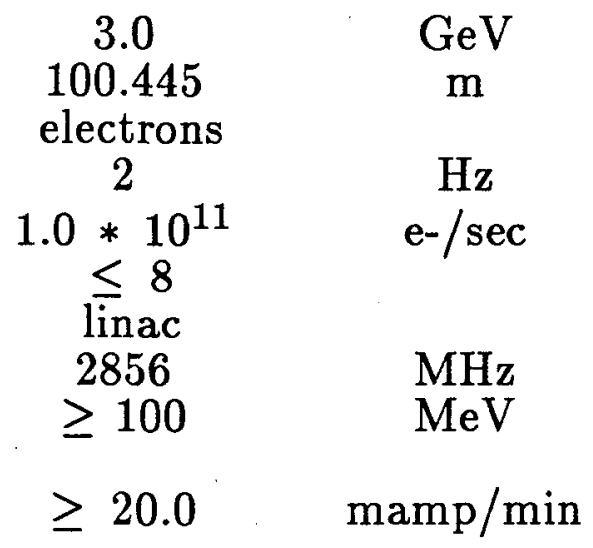

The preinjector linac system is designed to cycle at up to $10 \mathrm{pps}$ which is sufficient for all injection modes considered. Each linac pulse consists of one or more equidistant S-band bunches. These bunches are stored in the booster synchrotron and then accelerated to the storage ring energy 


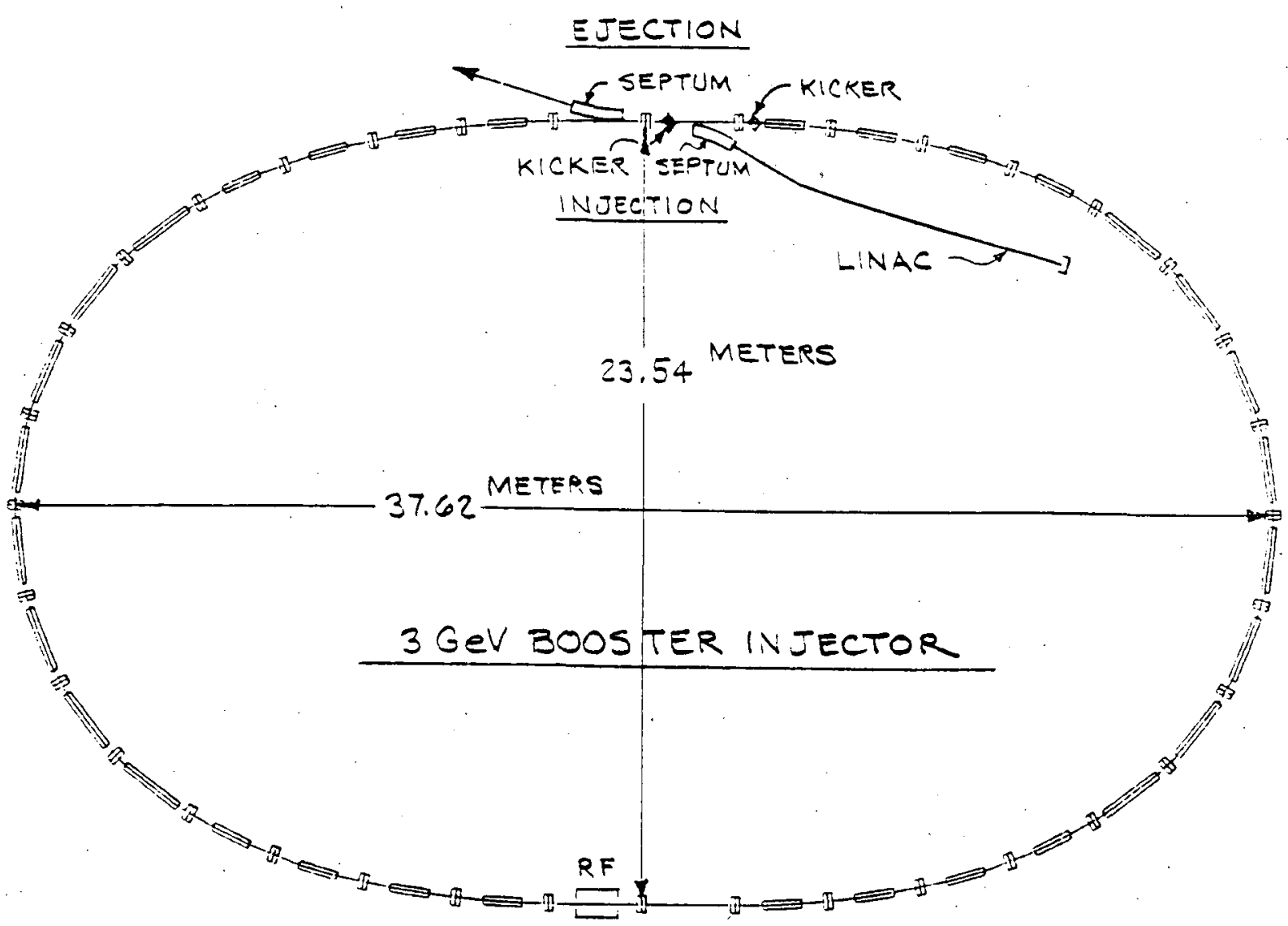

Fig. 3: SPEAR Injector Lattice

by ramping the booster magnets to higher fields. At the final energy the bunches are then transferred from the booster to the desired buckets in the storage ring.

The electrons are generated from a special gun which is designed to deliver a high peak beam current thus avoiding the need for an elaborate prebunching and bunching section in the linac. The linac will consist of standard S-band accelerating structures of the SLAC type. The linac sections will be fed by pulsed S-band klystrons to produce a total beam energy of at least $100 \mathrm{MeV}$. 
For a slow cycling rate of only $2.0 \mathrm{~Hz}$ in the synchrotron the total filling time to accumulate a circulating current of $100 \mathrm{ma}$ in the storage ring is expected to be less than 5 minute assuming a particle transfer efficiency of only $25 \%$. During operation in top on mode, when only part of the full beam current needs to be accumulated, the filling times are still shorter. This filling time is very short even if the storage ring current is increased to $200 \mathrm{ma}$ or more since with time the injection efficiency is expected to increase with increased operational experience and understanding of the accelerators.

\subsection{Injection Process}

The acceleration cycle starts with the injection at $100 \mathrm{MeV}$ of one or more S-band bunches from the preinjector linac after which the magnetic fields of the booster are raised to the energy of the storage ring. At that point the beam is ejected from the booster and transferred to the storage ring. Subsequently the booster magnet current is reduced again to the preinjection value. The actual acceleration time takes about 0.25 seconds for a cycling rate of $2 \mathrm{~Hz}$. Although the damping time at injection is more than 20 seconds long it is quickly reduced as the beam energy is increased and during the short acceleration time to $3.0 \mathrm{GeV}$ the beam has gone through several damping times. At the end of the acceleration cycle the beam parameters therefore are fully determined by the synchrotron radiation in the booster synchrotron and not anymore by the preinjector beam characteristics. This is particular important for positron injection into the storage ring as mentioned previously. 


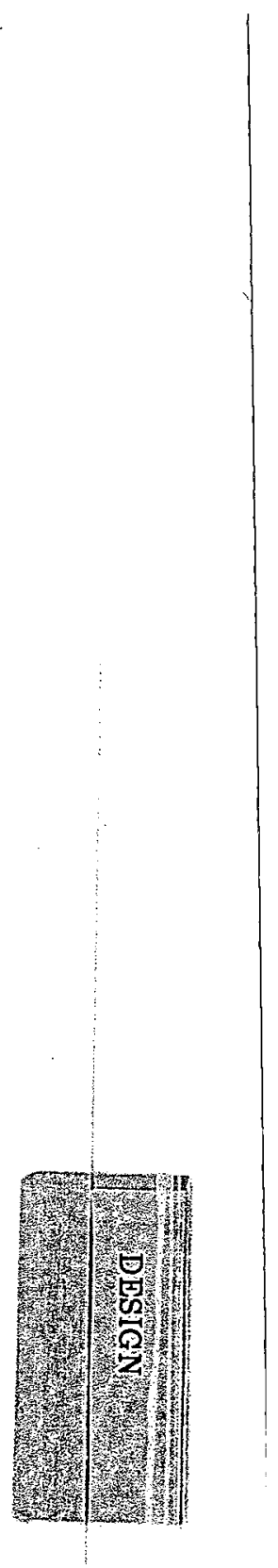




\section{Conceptual Design of the Injector System}

Basically the design of a synchrotron is similar to that of a storage ring, however, with much relaxed requirements.

For the design of a booster synchrotron a very simple lattice can be employed and special design efforts can be directed toward ease of operation and high reliability. After some special attention during commissioning, a synchrotron must eventually operate without the constant presence of an operator.

\subsection{Lattice Design and Beam Characteristics}

The design of the synchrotron in this proposal makes use of a simple FODO lattice which has been used for most synchrotrons constructed so far and has proven to be very reliable in its performance. The whole ring consists of 18 separated function FODO cells of which 8 are regular cells, 8 cells have shortened bending magnets to provide automatic matching of the dispersion function into a dispersion free section, and 2 cells are totally free of bending magnets, providing the space needed for injection and ejection components, the RF-system and other machine components (Figure 3). The actual ring lattice deviates slightly from a fully regular FODO aray. In the bending magnet free sections the central quadrupole has been shifted toward one side to accommodate the installation of the RF cavity. The results in a small assymmetry of the lattice functions which, however, does not result in a degradation of performance due to the insensitivity of the design to any kind of errors. 
The detailed structure and geometrical dimensions of the synchrotron are compiled in Table 2 :

\section{Table 2}

\section{Geometry of the Synchrotron}

Circumference $(\mathrm{m}) \quad 100.34$

Diameter $(\mathrm{m})$ long $\mathrm{x}$ short $\quad 37.647 \times 23.587$

The lattice structure for one quarter of the ring starting at the arc symmetry point of Figure 3 is given symbolically by:

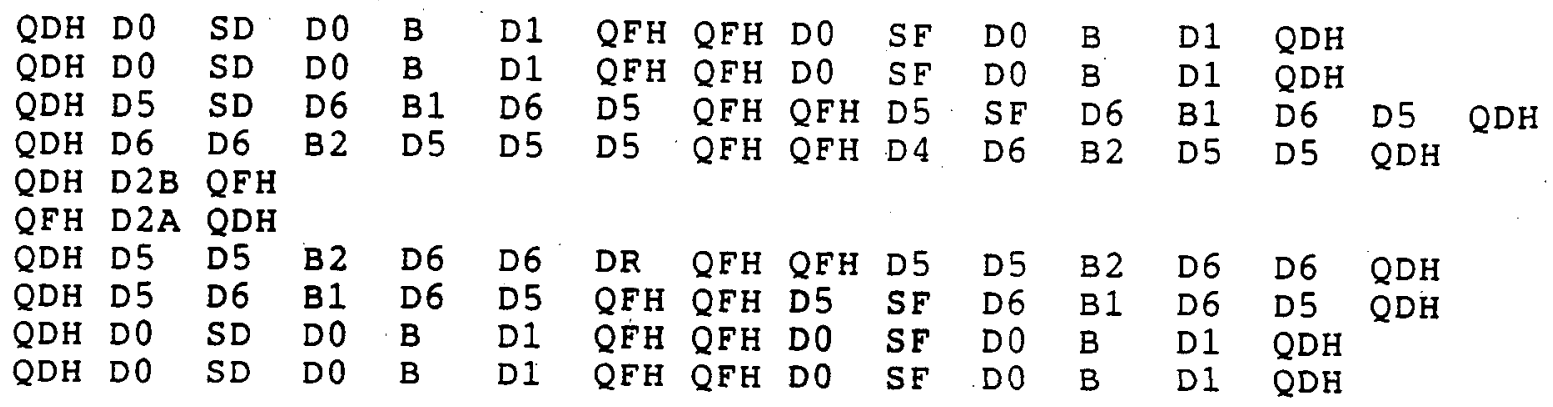

The parameters of these lattice elements are:

DRIFT:

length $(\mathrm{m})$
D0
0.125
D1
0.25
D2A
D2B
$2.00 \quad 3.00$
D3

D5

0.15

D6

0.5
BEND MAGNET:
$\mathrm{B}$
B1
B2
length (m)
2.000
1.200
1.200
bending radius $(\mathrm{m})$
$7.63944 \quad 7.63944$
11.45916
HALF QUADRUPOLES: QFH QDH length (m)
$0.1436 \quad 0.1436$
SEXTUPOLES:*
$\mathrm{SF}$
SD
length $(\mathrm{m})$
0.08
0.08

\footnotetext{
* In the lattice structure the sextupoles are treated as thin lens elements.
} 
All regular FODO cells are $5.574 \mathrm{~m}$ long. To minimize the number of magnet power supplies only two quadrupole families are required in this lattice for focusing and control of the operating tunes. All bending magnets are powered by one single power supply. For chromaticity control, two families of sextupoles are sufficient. Finally a set of vertical and horizontal orbit correctors are placed around the ring to allow the control and correction of orbit distortions. In Figure 4 and 5 the betatron and dispersion functions are shown for one quarter of the ring and some relevant lattice parameters are compiled in Table 3. The dispersion function was chosen to vanish in the straight sections for ease of injection and, particularly in the RF section, in order to minimize synchro-betatron oscillations and instabilities.

\section{Table 3}

\section{Lattice Parameters}

Lattice Type

Magnet Structure

Cell Length (m)

Total Number of FODO cells

Max. Value of Betatron Functions $(x / y)(m)$

Max. value of Dispersion Function(m)

Tunes $(\mathrm{x} / \mathrm{y})$

Momentum Compaction Factor

Natural Chromaticities (x/y)

Beam Emittance (mm * mrad) @ $3.0 \mathrm{GeV}$

Beam Energy Spread (\%)

Beam Emittance $(\mathrm{mm} * \mathrm{mrad})$

Beam Energy Spread
FODO separated function

5.5744

18

$13.0 / 15.4$

1.51

$5.25 / 3.17$

0.05404

$-6.38 /-5.09$

0.478

0.092

$0.053 * \mathrm{E}^{2}\left(\mathrm{GeV}^{2}\right)$

$0.000305 * \mathrm{E}(\mathrm{GeV})$

The chromatic aberrations after chromaticity corrections are very small. The energy acceptance is at least $2.5 \%$ (Figure 6) based on lattice considerations only and not considering $\mathrm{RF}$. limitations. All chromatic and geometric aberrations are very small as is to be expected for such a lattice. 


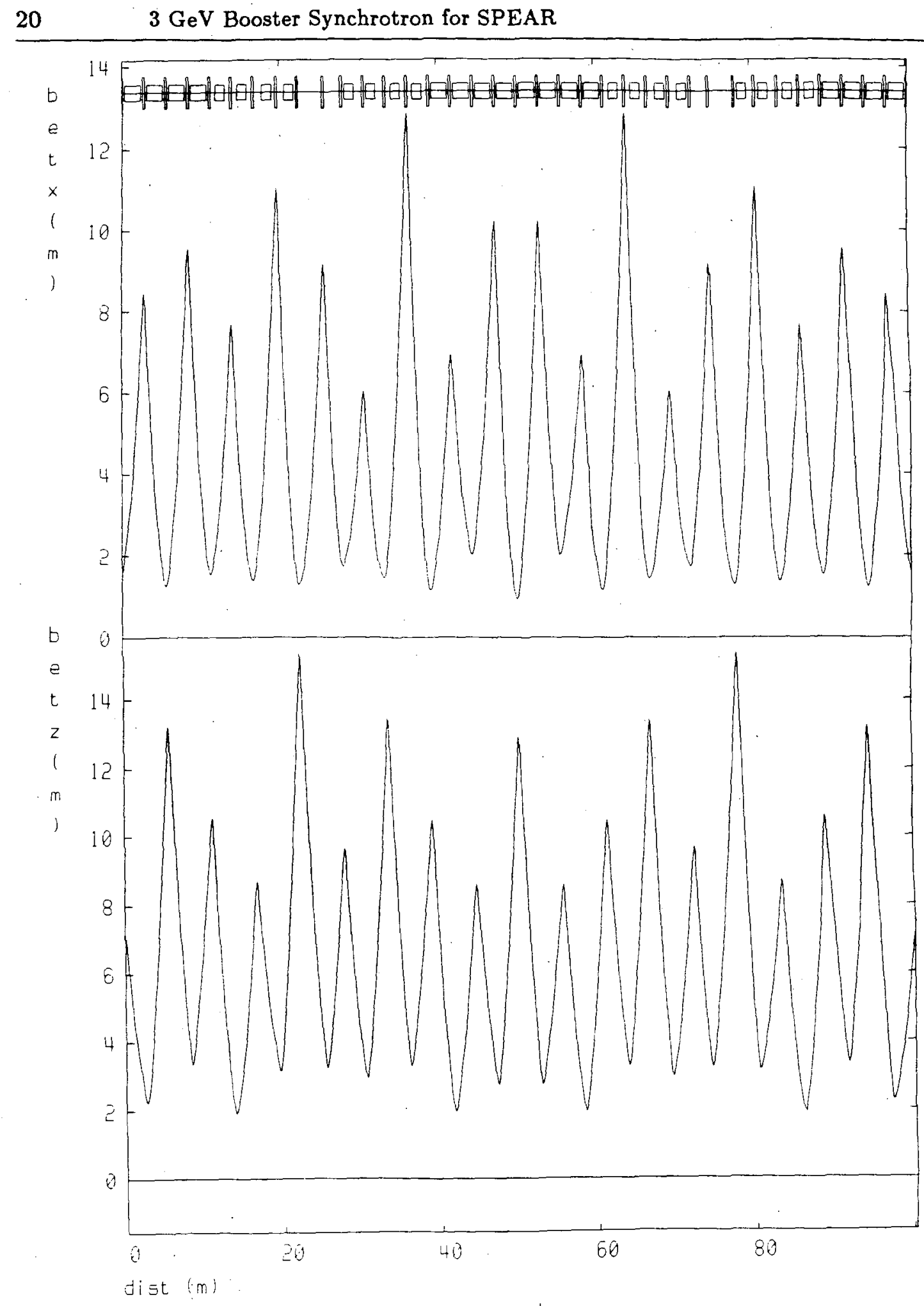

Fig. 4: Betatron Function 


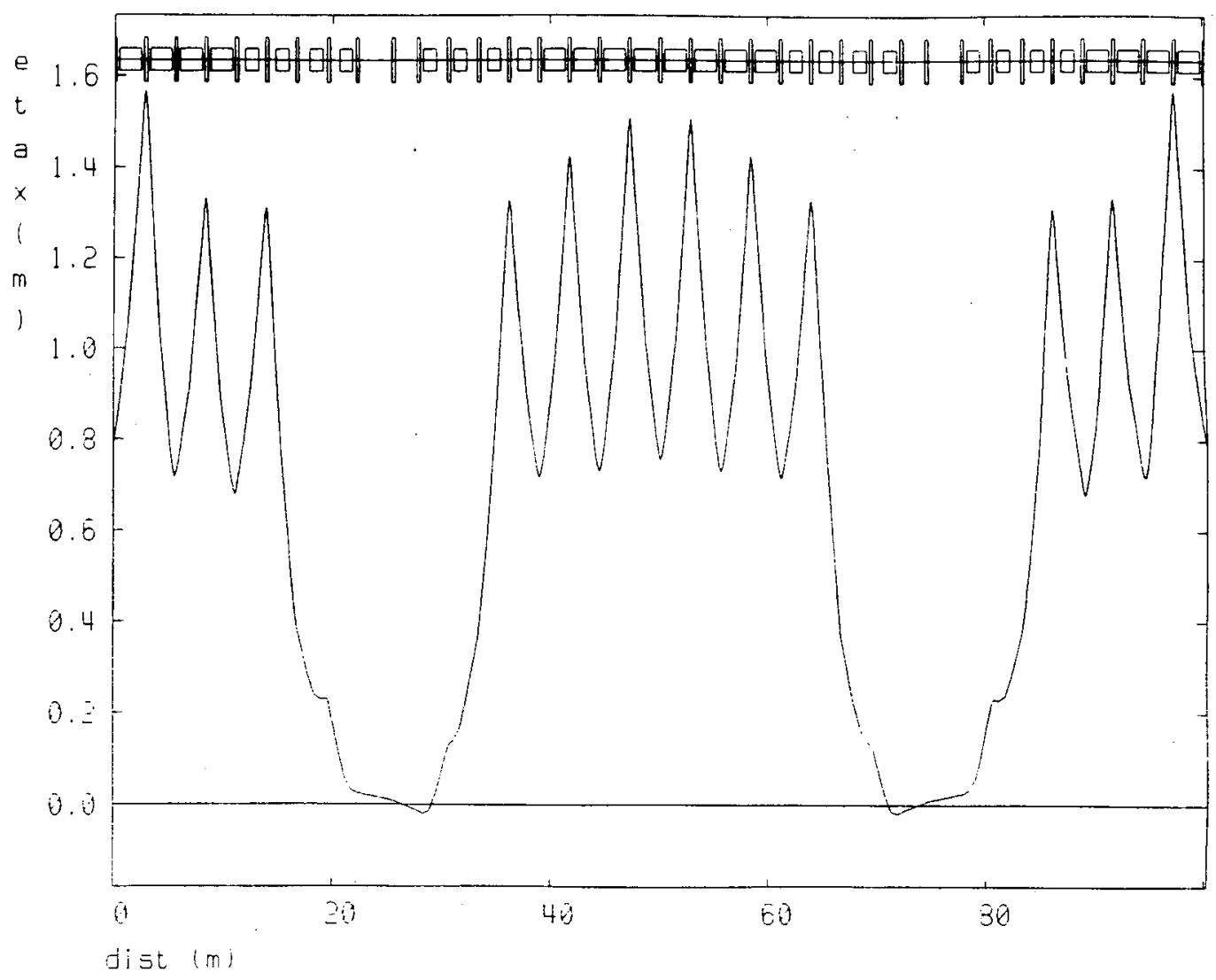

Fig. 5: Dispersion Function

As a result of these weak chromatic and geometric aberrations the dynamic aperture (Figure 7) is much larger than the physical aperture of the vacuum enclosure and provides, therefore, a large margin for unforseen errors.

For ease of injection and specifically in preparation for possible positron injection at a later date a rather large vacuum chamber cross section has been chosen. In Figure 8 the beam stay clear region (BSC) is shown both for the horizontal and vertical plane. The BSC is the maximum cross section a beam may have before particles get lost on the physical or dynamic aperture, whichever is smaller.

The minimum physical aperture or beam stay clear, as shown in Figure 8 , is based on the assumption that eventually it will be desired to accelerate positrons injected at $250 \mathrm{MeV}$. This requires an acceptance in the 


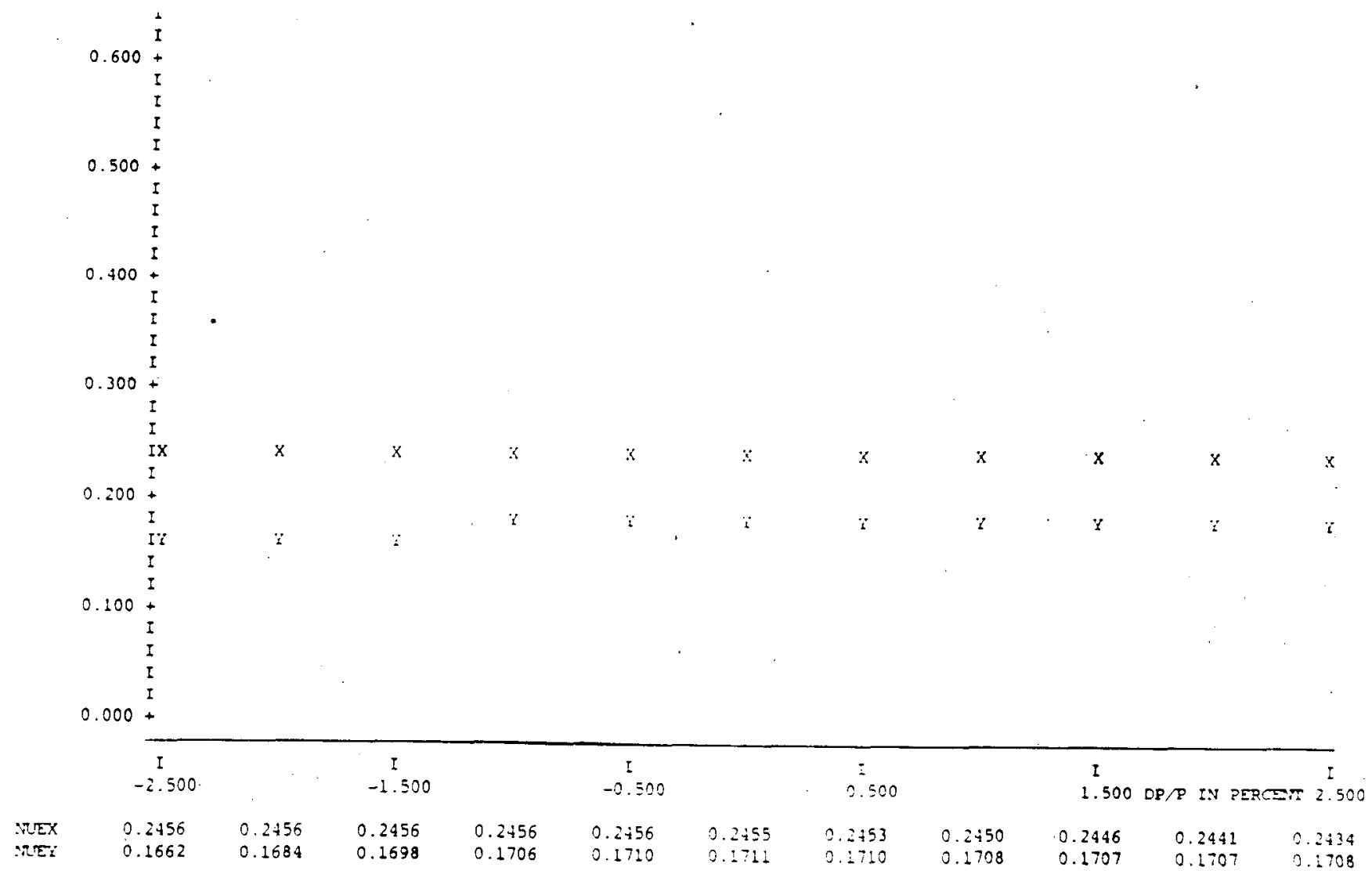

Fig. 6: Tune Variation with Energy

storage ring of at least $18 \mathrm{~mm}^{*} \mathrm{mrad}$ horizontally and $10 \mathrm{~mm} * \mathrm{mrad}$ vertically. During acceleration the beam reaches the equilibrium beam size as determined by the quantum excitation due to synchrotron radiation and radiation damping. The particle distribution becomes a gaussian distribution and scales linearly with the energy. The beam size is defined as one standard deviation of the gaussian distribution. The vacuum chamber aperture must accommodate at least 5 units of the standard beam size in addition to an allowance for orbit distortions to retain a useful beam lifetime. In this design the beam sizes are smaller than the aperture up to $3.50 \mathrm{GeV}$. In more detail the beam sizes under various assumptions (see Table 4) have been calculated and have been used to determine the BSC. Extreme beam sizes as required for positron injection or for a higher end energy of $3.5 \mathrm{GeV}$ 


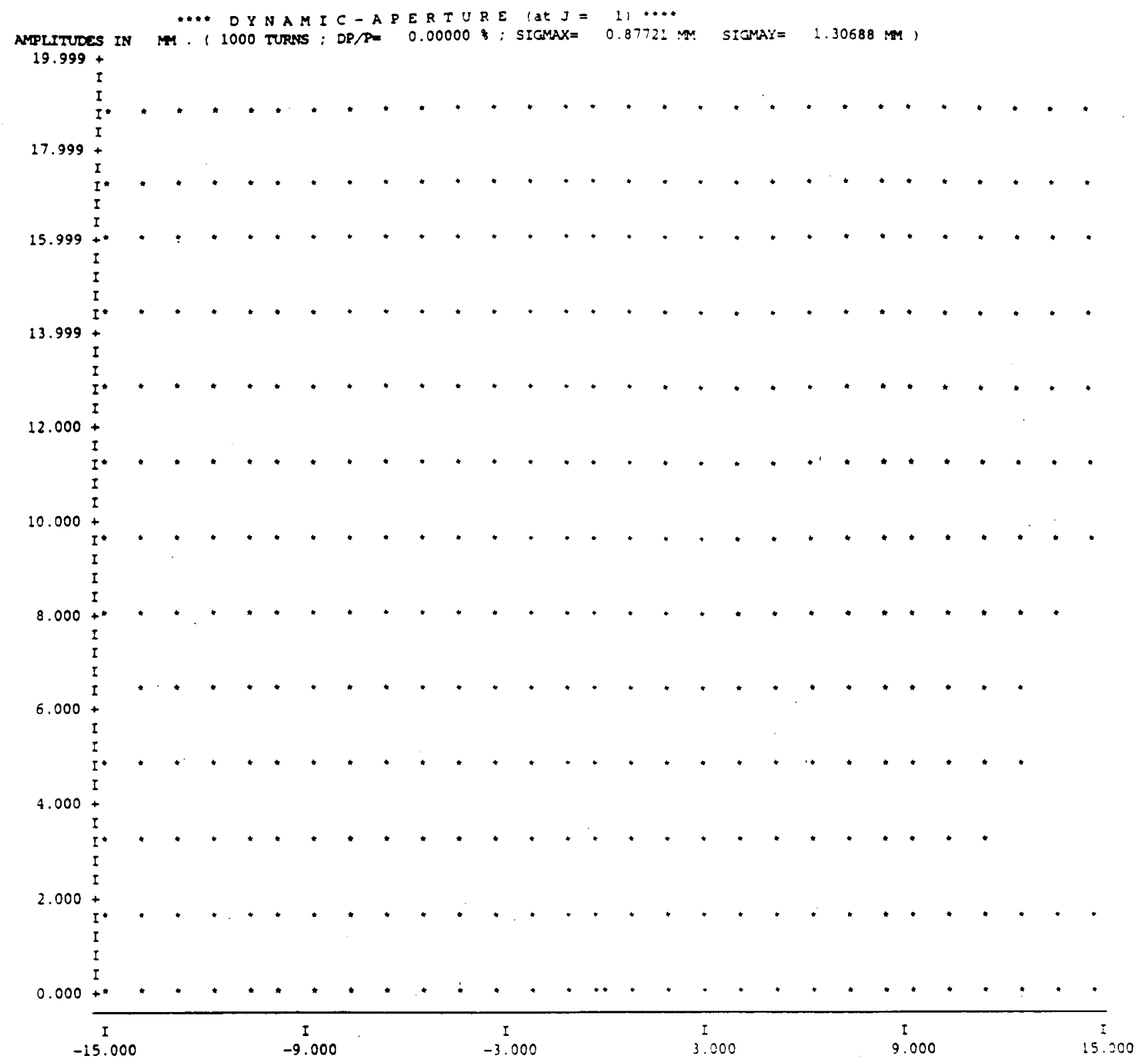

Fig. 7: Dynamic Aperture 

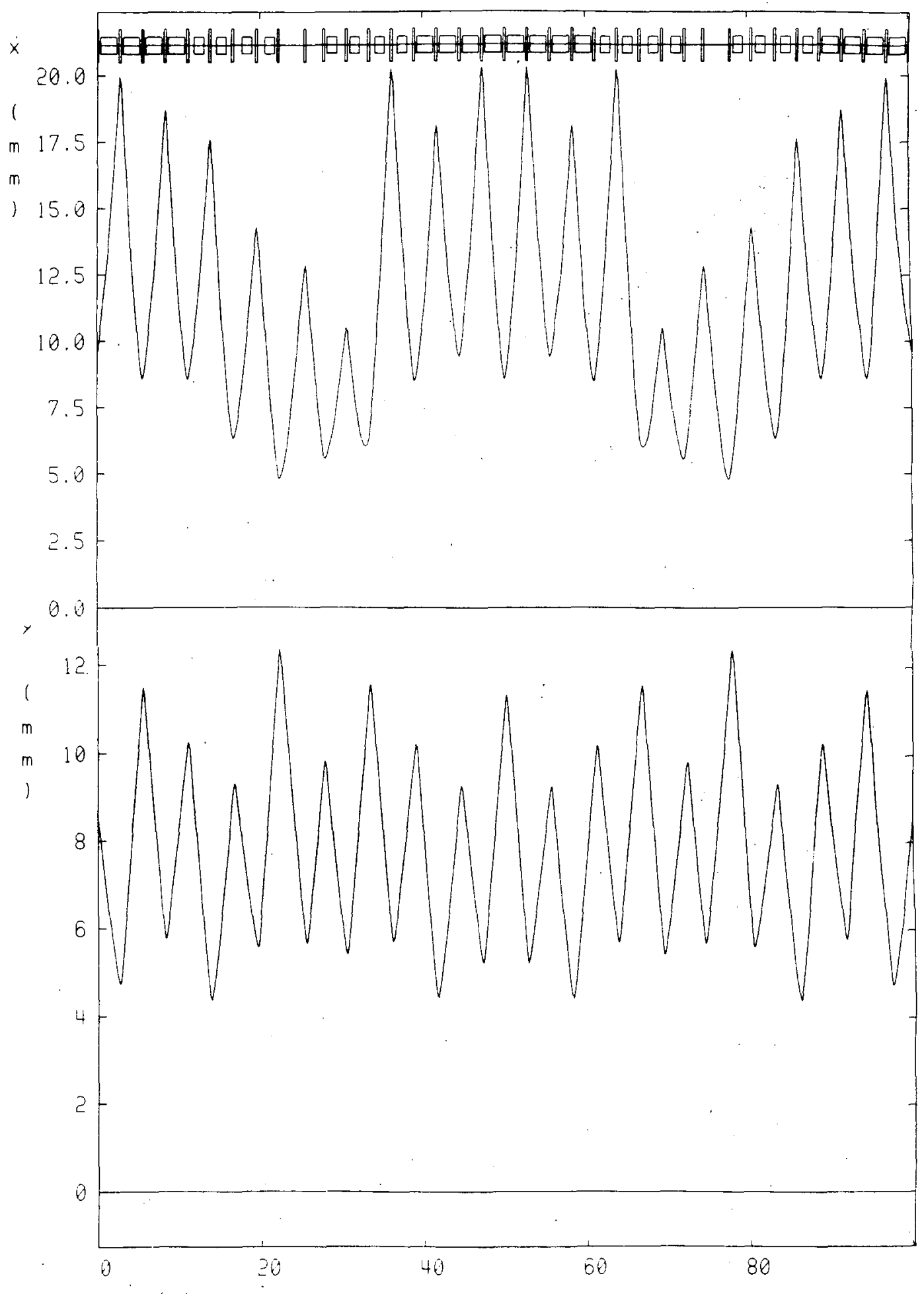

Fig. 8: Beam Stay Clear in the Booster Injector 
have been used to determine the required vacuum chamber aperture.

Table 4

Beam Size under Different Conditions

Electron Beam: at injection $(100 \mathrm{MeV})$ :

Beam Emittance (both planes)

Energy Spread

Max. Beam Width

Max. Beam Height (quad)

$0.10 \mathrm{~mm} * \mathrm{mrad}$

$1.0 \%$

$14.5 \mathrm{~mm}$

$1.1 \mathrm{~mm}$

at a higher energy of $3.0 \mathrm{GeV}$ :

Beam Emittance $(1 \sigma)$

Max. Beam Width $( \pm 5 \sigma)$

Max. Beam Height (quad)

$0.65 \mathrm{~mm} * \mathrm{mrad}$

$32.3 \mathrm{~mm}$

$22.4 \mathrm{~mm}$

Max. Beam Height (bend)

$20.4 \mathrm{~mm}$

Positron Beam:

at injection $(250 \mathrm{MeV})$ :

Beam Emittance (Horizontal)

$18.0 \mathrm{~mm} * \mathrm{mrad}$

Beam Emittance (Vertical)

$10.0 \mathrm{~mm} * \mathrm{mrad}$

Energy Spread

Max. Beam Width

Max. Beam Height (quad)

Max. Beam Height (bend)

$1.0 \%$

$40.5 \mathrm{~mm}$

$24.8 \mathrm{~mm}$

$22.7 \mathrm{~mm}$

at the higher energy of $3.50 \mathrm{GeV}$ :

same as electrons because of damping

The maximum beam width for any beam considered is about $40 \mathrm{~mm}$ and the maximum beam height in the quadrupoles and in the bending magnets is less than $25 \mathrm{~mm}$. A circular free aperture of $50 \mathrm{~mm}$ diameter for the quadrupole vacuum chamber and a clear height of the bending magnet vacuum chambers of $32 \mathrm{~mm}$ is, therefore, assumed for this ring, leaving 10 $\mathrm{mm}$ in both planes for orbit distortions. The dynamic aperture has been determined to be much larger than the physical aperture in both planes. 
A summary of general parameters of the ring and the lattice functions are given in Table 5:

\section{Table 5}

\section{Synchrotron Parameter}

Energy

Circumference

Cycling Rate

Revolution

Frequency

Time

Lattice

Cell length

Beam Emittance

Energy Spread

Energy Loss/Turn

Tunes: $\nu_{\mathrm{x}}$

$$
\nu_{\mathrm{y}}
$$

Lattice Functions

$\beta_{\mathrm{xmax}}$

$\beta_{\mathrm{ymax}}$

$\eta_{\mathrm{xmax}}$

Natural Chromaticity

$\xi_{\mathrm{x}}$

$$
\xi_{\mathrm{y}}
$$

$\mathrm{RF}$ frequency

Harmonic number

Momentum Comp. Factor

Transverse damping time

Vacuum chamber aperture

$$
\begin{aligned}
& \mathrm{x}: \text { (quad) (diameter) } \\
& \mathrm{y}: \text { (bend) (height) }
\end{aligned}
$$

Acceptance $\mathrm{x}$ :

$\mathrm{y}:$
3.0

100.339

2

2987.79

335

FODO

5.5744

.478

0.092

0.896

5.250

3.170

13.0

15.4

1.57

$-6.38$

$-5.09$

358.53

120

0.05404

2.241

50

32

69.4

22.4
$\mathrm{GeV}$

$\mathrm{mz}$

$\mathrm{kHz}$

nsec

$\mathrm{m}$

$\mathrm{mm} * \operatorname{mrad}$

$\%$

$\mathrm{MeV}$

$\mathrm{m}$

$\mathrm{m}$

$\mathrm{m}$

\section{$\mathrm{MHz}$}

msec

$\mathrm{mm}$

$\mathrm{mm}$

$\mathrm{mm} * \mathrm{mrad}$

$\mathrm{mm} * \mathrm{mrad}$

A more detailed compilation of the injector lattice and its parameters is 
attached in Appendix A.

\subsection{Technical Components}

The design of the technical components for the booster synchrotron follows well established technology. No major R \& D is necessary for any of the components. Synchrotrons have been constructed for many years and no special new feature is required to use a synchrotron as an injector.

The main technical components of the injector system are the preinjector linac, the magnet, RF and vacuum systems, beam control and monitoring, injection and ejection and utilities.

\subsubsection{Preaccelerator Linac}

The preaccelerator for injection into the booster synchrotron consists of a linac composed of three accelerating sections of the SLAC type and a microwave gun similar to those used in microtrons to produce the electron beam. The three accelerating sections are each powered by their own klystron. For the initial start up it is assumed that SLAC surplus klystrons at a power rating of at least $20 \mathrm{MW}$ can be secured for this purpose. These SLAC klystrons become available due to the replacement of older klystrons with new $60 \mathrm{MW}$ klystrons as part of the SLC project.

\subsubsection{Microwave Gun}

The electrons are generated in the microwave gun from a $\mathrm{LaB}_{6}$ cathode which, when heated to $1600 \mathrm{~K}^{0}$, can deliver current densities in excess of $100 \mathrm{~A} / \mathrm{cm}^{2}$. This type of gun is used in microtrons as well as in linear accelerators. ${ }^{[R e f]}$ The cathode reaches directly into the high field of a microwave cavity where the electrons are quickly accelerated to relativistic energies.

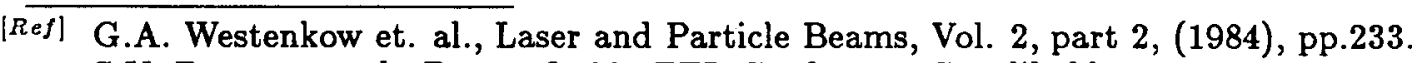

S.V. Benson et. al., Proc. of 1985 FEL Conference Granlibakken. 
After focusing and energy definition the beam is injected into the linear accelerator sections for acceleration to more than $100 \mathrm{MeV}$. This type of a gun can produce an instantaneous electron current of more than $10 \mathrm{amp}$. The advantage of such a gun compared to the often used thermionic gun is that the electrons are accelerated by an $R F$ field to relativistic energies in the very short distance of about $3 \mathrm{~cm}$, the length of one S-band cavity. This fast acceleration efficiently overcomes the electrical space charge forces which cause a significant increase in beam emittance and beam size. For optimum injection efficiency into the booster we plan to take advantage of this greatly reduced beam blow up in a microwave gun. One further advantage of this type of gun is that no other equipment, like prebuncher or buncher section, is required in the linac since the beam is automatically bunched through the field of the microwave gun cavity. This greatly reduces the complexity of the preinjector and allows easy operation.

With a peak current of $10 \mathrm{amp}$ from the microwave gun we expect a population of $4.210^{8}$ electrons in each $2 \mathrm{~mm} \mathrm{S-band} \mathrm{bunch.} \mathrm{For} \mathrm{a} \mathrm{much}$ longer bunch length the energy spread in the beam becomes large. Some of the gun parameters are summarized in Table 6:

\section{Table 6}

\section{Microwave Gun Parameter}

$\begin{array}{lc}\text { Gun Cavity Frequency (MHz) } & 2856 \\ \text { Particle Energy (keV) } & >500 \\ \text { Cathode Peak Current (amp) } & \geq 10.0 \\ \text { Bunch Length (mm) } & 2.0 \\ \text { Particles/S-Band Bunch } & 4.210^{8} \\ \text { Particles per 3 S-Band Bunches } & 12.510^{8}\end{array}$

\subsubsection{Momentum Filter}

The energy spread of the electron beam from the microwave gun is very large due to the varying $\mathrm{RF}$ field in the cavity. A magnetic momentum filter 
will be used to eliminate all particles with energies outside the acceptable energy bin. This momentum filter makes use of the momentum dispersion caused by the deflecting field of a dipole field. Placement of a slitted absorber at the position of maximum momentum dispersion allows selection of a narrow momentum bin from the beam for further acceleration.

\subsubsection{Beam Chopper}

Without any further devices a long string of electron bunches, separated by the linac RF wavelength of $10 \mathrm{~cm}$, would enter the linac sections (see Figure 9). Not all of these bunches can be accepted by the booster synchrotron or by the storage ring. To reduce the level of radiation caused by these partially accelerated and eventually lost particles, it is prudent to eliminate these particle bunches at very low energies. This is performed by a device called a chopper located between the momentum filter and the linear accelerator. The string of S-band bunches emerging from the microwave gun will be modified by the chopper in such a way as to fit special requirements of the booster synchrotron and storage ring.

Since the booster RF frequency is much lower than the linac RF frequency, it is possible to accept three or even more consecutive linac bunches into one booster RF bucket, where they eventually merge into one bunch by radiation damping. Therefore, a chopper composed of a fast deflector with a slit will be used to generate, from the continuous stream of S-band bunches, a particle beam made up of a string of equidistant triplet bunches. Each triplet consists of three consecutive S-band bunches and the distance between the triplets is equal to the desired bunch distance in the booster synchrotron (Figure 9).

The conceptual layout of the chopper is shown in Figure 10. Here a DC magnetic field deflects the beam from the gun into an absorber. Superimposed is an electrical pulsed field which deflects the beam against the magnetic field toward the slit and allows the beam, during a short time period, to emerge through the slit to be accelerated in the linac. This way a string of S-band triplets can be produced for multibunch injection into 
At the $\mathrm{e}^{-}$gun:

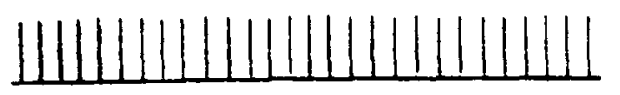

$\uparrow \quad$ INTENSITY

Time

After beam chopper:

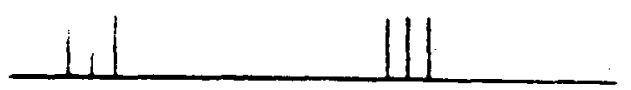

Fig. 9: Bunch Patterns in the Injection System

the booster and SPEAR.

While this multibunch mode of operation is the prevailing mode of operation in SPEAR, there are occasions when a single or few bunches are desired.

For timing experiments it is desirable to make use of the very short storage ring bunch to excite atomic or molecular states with an extremely short burst of photons. To observe the decay of these states a "long" radiation free time must follow. In the extreme case only one bunch would be filled in the SPEAR storage ring providing a radiation free time equal to one full revolution time. For this case also only one bunch is being accelerated per accelerating cycle in the booster. This booster bunch consists of 3 linac 


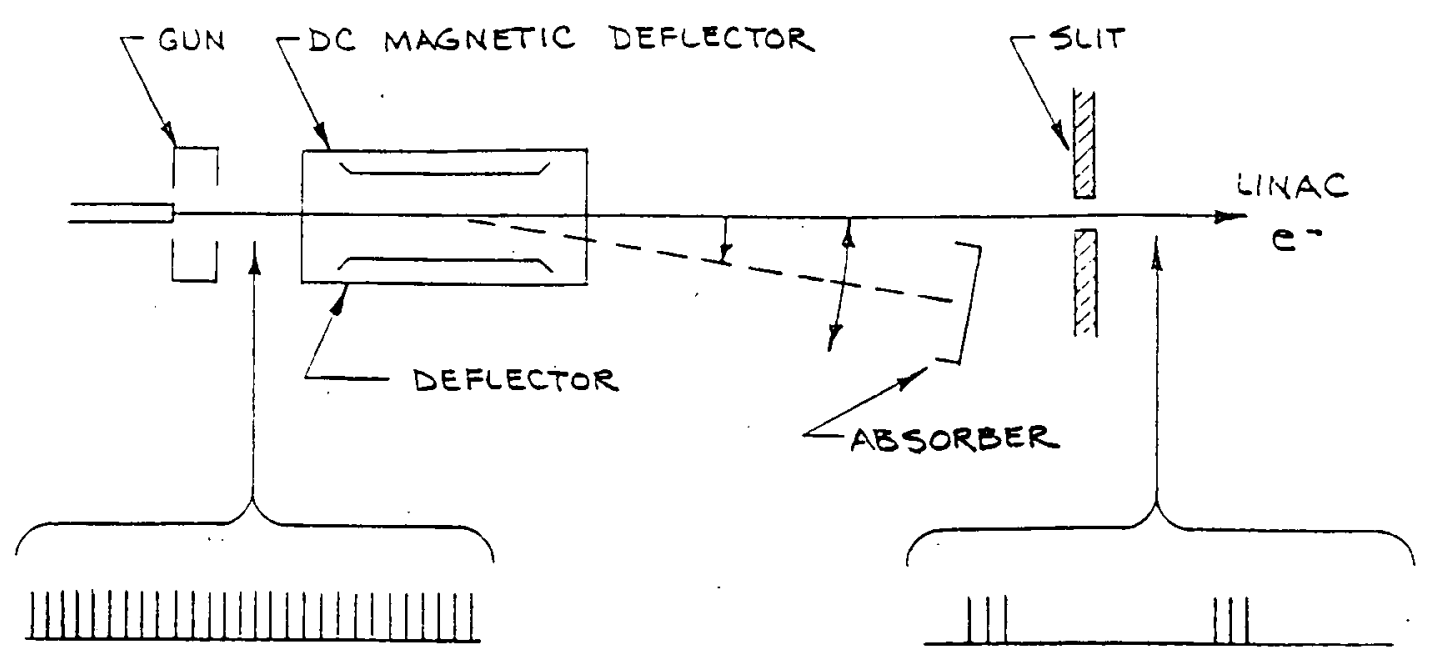

Fig. 10: Beam Chopper System

buckets and therefore $12.510^{8}$ electrons are accelerated per cycle giving an injection rate for a single bunch in the SPEAR storage ring of at least 5.0 mamp/min assuming a $25 \%$ overall transfer efficiency and a booster cycle rate of $2.0 \mathrm{~Hz}$. Since the single bunch current in the storage ring will not be larger than 10 to 20 mamp because of instabilities or Touschek lifetime limitations, a single bunch filling time of less than five minute can be expected from this injector.

When many bunches are desired in the storage ring, strings of bunches can be accelerated and transferred to the storage ring in a single pulse. In this mode of operation the fastest storage ring filling rate of more than $50 \mathrm{ma} / \mathrm{min}$ can be achieved assuming eight bunches to be accelerated per booster cycle and a $25 \%$ injection efficiency into the storage ring. This will also be the most efficient mode of operation for beam cleaning the vacuum chamber in SPEAR to achieve long beam lifetime.

For further planning we will assume the preinjector beam characteristics as compiled in Table 7: 


\section{Table 7 \\ Preinjector Beam Parameter}

Energy from Preinjector ( $\mathrm{MeV})$

Number of Booster Bunches

Number of Particles per Pulse

Pulse Repetition Rate $(\mathrm{Hz})$

Total Energy Spread at full Linac Energy

Normalized Beam Emittance $(\epsilon \gamma)$

Horizontal (m)

$\geq 100$

8

Vertical (m)

$10^{10}$

2

0.010

Beam Emittance
Horizontal (m)
$0.08510^{-6}$
Vertical (m)
$0.04310^{-6}$

With these preinjector beam parameters we expect to achieve the SPEAR injection parameters as summarized in Table 8 . For the multi bunch made we assume 8 bunches to be accelerated in the booster while only a single bunch in accelerated for single bunch mode in SPEAR.

Table 8

SPEAR Injection Parameters

Storage Ring Bunch Mode

Storage Ring Beam Current (ma)

Circumference $(\mathrm{m})$

Total Number of Particles $\left(10^{8}\right)$

Injection Efficiency (\%)

Number of Booster Cycles needed

Booster Cycles per Second

Storage Ring Filling Time (min)

Storage Ring Filling Rate (ma/min)
Single

Bunch

20.0

234.0

975

25.0

312

2

2.6

7.7
Multi

Bunch

100.0

234.0

4875

25.0

195

2

1.6

61 


\subsubsection{Linear Accelerator}

For the acceleration of the electrons coming from the gun to high energies, three 10 foot accelerating sections of the SLAC type will be used. The energy gain per linear accelerator sections is determined by the RF power from the klystrons and is given by:

$$
E_{0}(M e V)=10 *(P(M W))^{1 / 2}=54.8 M e V
$$

This energy gain per section can be obtained straightforward without relying on any RF-pulse compression scheme like the SLED scheme. In the three accelerating sections, therefore, a total "no load" energy of about 164.4 $\mathrm{MeV}$ can be reached if three $30 \mathrm{MW}$ klystrons are used. In reality, however, this "no load" energy gain is reduced by beam loading leading actually to a somewhat lower beam energy of at least $100 \mathrm{MeV}$ depending on the intensity of the beam accelerated. The performance of the booster synchrotron basically improves with increasing injection energy from the preinjector. However, this dependence is rather weak and the additional complexity of a SLED'ed accelerating scheme is not advisable. From a technical view point a SLED'ed mode of operation is also not desirable since it would not allow the acceleration of a long string of bunches.

The proposed mode of operation of the linac sections is straight forward and most components are expected to be, and perform similar to those used at the Stanford Linear Accelerator.

Some of the main parameters of the linear accelerator are compiled in Table 9.

Because of the low repetition rate of no more than $10 \mathrm{~Hz}$, the $\mathrm{RF}$ power requirements for the linac are very modest. This allows a reduced cost and complexity compared to the SLAC high power klystron modulators required for high pulse repetition rates. In Table 10 the klystron and modulator specifications are summarized. 


\section{Table 9}

\section{Linac Parameter}

Accelerating Sections

Length/Section (m)

three

Frequency $(\mathrm{MHz})$

3.0

2856

Type

RF Filling time (sec)

Klystron/Modulators

Pulse Power (MW)

Pulse Length (sec)

Pulse Rep. Rate $(\mathrm{Hz})$

Preinjector Energy (MeV) (no load)

Pulse Length (nsec)

three
3.0
2856
constant impedance
$0.75 * 10^{-6}$
three
$\geq 30.0$
1.5 to $2 * 10^{-6}$
$\leq 10$
164.4
$>330$

Table 10

SLAC Klystron Parameter

Klystron Peak Output Power

Frequency

Peak Beam Voltage

Peak Beam Current

Peak Beam Power

Repetition Rate

RF Pulse Length (max)

Modulator Pulse Length $(\max )$

Klystron Efficiency

AC Power

Focusing Magnet

Cathode Type

$\begin{array}{cc}35 & \mathrm{MW} \\ 2856 & \mathrm{MHz} \\ 265 & \mathrm{kV} \\ 286 & \mathrm{~A} \\ 75.8 & \mathrm{MW} \\ 10 & \mathrm{~Hz} \\ 1.5 & \mu-\mathrm{sec} \\ 3.35 & \mu-\mathrm{sec} \\ 47 & \% \\ 3.32 & \mathrm{~kW} \\ \text { ermanent } & \\ \text { oxide } & \end{array}$

\subsubsection{Beam Transport to the Booster Synchrotron}

A beam transport system will guide the electron beam from the preinjector linac to the booster synchrotron where it will be injected "on axis" through a full aperture kicker magnet. Bending and focusing magnets will match the beam to the optical parameters of the synchrotron at the injection point. A septum magnet close to the synchrotron will align the beam 
direction so as to let the incoming beam cross the booster beam orbit in the middle of the full-aperture kicker magnet. This kicker magnet then will be turned on for not more than one revolution time of $330 \mathrm{nsec}$ to align the injected beam exactly with the ideal booster beam orbit. The kicker magnet must be turned off before the time the first particles, arrive again at the kicker location after one turn in the booster,

Along the transport line beam characteristics like beam intensity, energy and energy spread will be measured and controlled. For this purpose intensity monitors are installed in the transport line. A dispersive section of the transport line will make measurements and determinations of the exact beam energy and energy spread. This analyzing station will be helpful in setting up the preinjector beam while the SPEAR storage ring is used for experiments. For this purpose a downstream bending magnet will be turned off to guide the beam into a separate beam dump. A Faraday cup in front of this beam dump can be inserted into the beam for a precise beam intensity measurement.

Beam position monitors and scintillators with TV cameras will be installed to observe the beam position and quality. Orthogonal steering magnets at the end of the transport line are designed to allow the independent adjustment of the beam position and angle at the injection point.

Because of the low beam energy rather small magnets are required and the power supplies therefore are chosen to be the same as those for the beam steering magnets in the booster.

\subsubsection{Magnet System}

For the booster synchrotron the magnets must be constructed in such a way as to minimize the occurrence of eddy currents during energy ramping. Therefore, the magnet cores are constructed from laminations of low carbon steel stock. All magnets can be split in the horizontal midplane to allow the installation of the vacuum chamber.

The aperture of the magnets is determined by the larger of both the injected beams size and the beam size at high energies plus an additional allowance required for orbit distortion in the vacuum chamber. The space required for the beam, called the "beam stay clear" region or BSC, is shown 
in Figure 8 and was determined mostly by the size of a positron beam during injection at $250 \mathrm{MeV}$. The requirements for the electron beam both at injection and at $3 \mathrm{GeV}$ are smaller.

The magnetic field properties are modeled with the help of a computer program MAGNET which has been used extensively for the design of synchrotron and storage ring magnets at CERN and elsewhere. Finally the magnet quality will be determined by magnetic measurement which allows expansion of the magnetic field into the fundamental field and the higher harmonics. The magnet pole shapes will be determined such as not to cause beam instability by higher harmonic field errors.

Special trim coils and orbit correction magnets in connection with beam position monitors will be used to control the beam orbit during acceleration.

Three different types of magnets are required for the booster synchrotron:

* bending magnets to bend the electrons onto circular paths,

* quadrupole magnets to hold the particles in the vicinity of the ideal design orbit within the vacuum chamber, and,

* sextupole magnets to correct chromatic aberrations which can cause beam instabilities.

The construction of these magnets as well as the alignment follows well established procedure since the simplicity of the lattice does not require high construction and alignment tolerances.

\subsubsection{Bending Magnets}

The main bending magnet system consists of a total of $32 \mathrm{H}$ type magnets. All bending magnets have the same cross section as shown in Figure 11 but have different lengths and field strengths to accomplish the matching of the dispersion funtion to zero in the straight sections. The main parameters of the bending magnets are compiled in Tables 11 and 12 : 


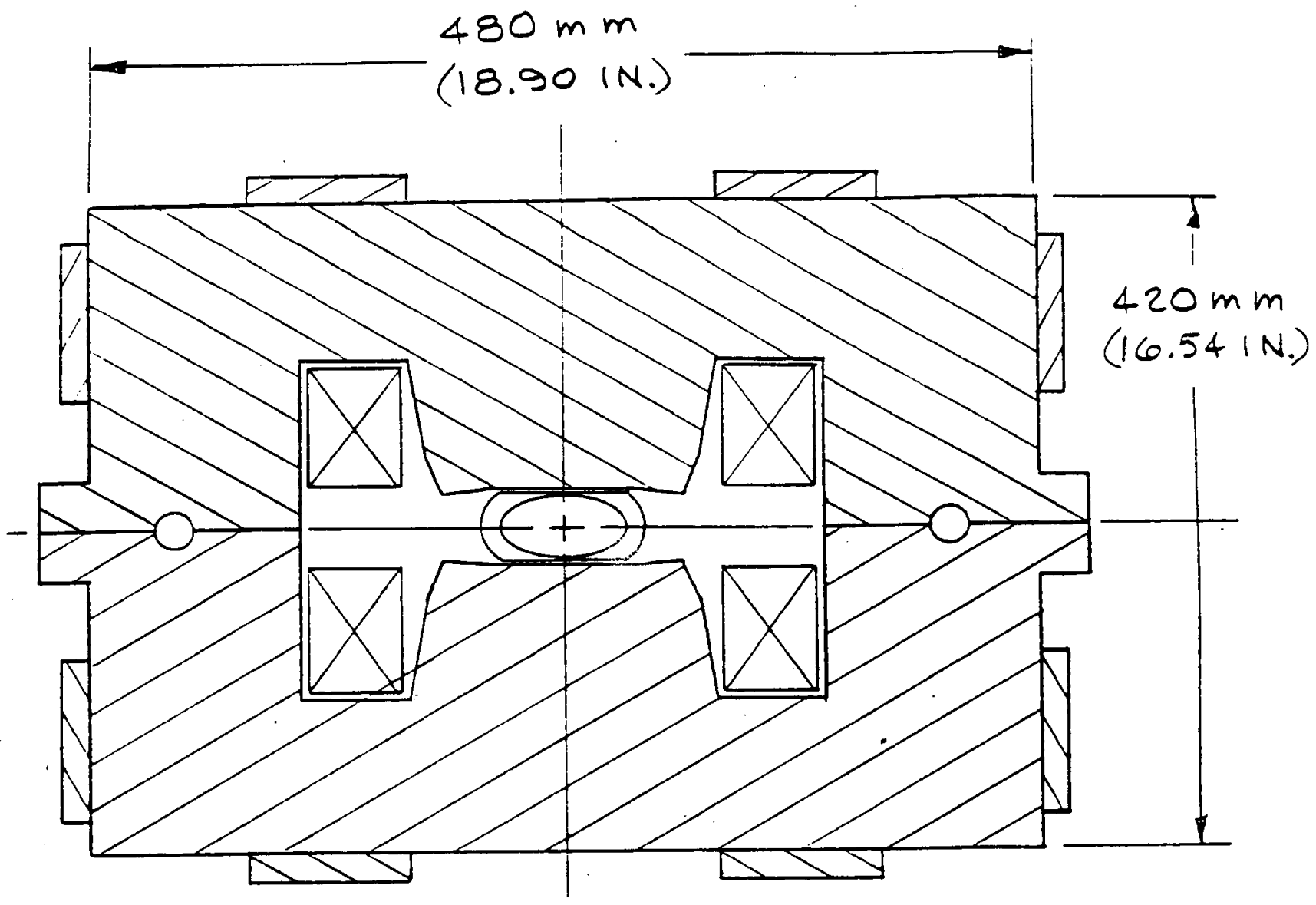

Fig. 11: Bending Magnet Cross Section

Table 11

\section{Bending Magnet Types}

Magnet Designation

Length (m)

Field Strength at $3.0 \mathrm{GeV}$

(kGauss)

Field Strength at Injection (Gauss)

Max. Strength (kGauss)

Number of Magnets

$\begin{array}{cc}\mathrm{B} & \mathrm{B} 1 \\ 2.000 & 1.200 \\ & \\ 13.09 & 13.09 \\ 524 & 524 \\ >15.70 & >15.70 \\ 16 & 8\end{array}$

B2

1.200

8.72

349

$>10.47$

8 
The sagitta of the beam orbit in the longer magnets is quite significant at $65 \mathrm{~mm}$. If one would build a straight magnet the pole width would have to be $65 \mathrm{~mm}$ wider and the total magnet would be $130 \mathrm{~mm}$ wider than required for the beam alone. To minimize the width of the magnets it is planned to "bend" the magnet by splitting the iron core into straight blocks with wedge-shaped spacers in between (Figure 12). Still the whole magnet would be powered by two long excitation coils.

The maximum required strength of all magnets is 13.09 kGauss for 3.0 $\mathrm{GeV}$ leaving a comfortable margin for higher energy operation if so desired. The main specifications for the bending magnets are compiled in the Table 12:

\section{Table 12}

\section{Bending Magnet Specification}

Magnet Name in Lattice

Straight Magnetic Length ( $\mathrm{mm}$ )

Bending Radius ( $\mathrm{mm}$ )

Bending Angle (radian)

Bending Angle (degrees)

Gap Height ( $\mathrm{mm}$ )

Sagitta (mm)

Length of Iron (mm)

Weight of Iron $(\mathrm{kg})$

Weight of Copper in both Coils

Elect.Power at $3.0 \mathrm{GeV}(\mathrm{kW})$
B

2000.000

7639.437

0.314

15.0

34.0

65.4

1966.0

2439.0

333.0

13.9
B1 1200.000 7639.437

0.173

9.0

34.0

23.5

1166.0

1466.0

207.7

8.9
B2 1200.000 11459.160

0.141

6.0

34.0

15.7

1166.0

1446.0

138.4

6.0

The magnetic field properties are shown in Figure 13 where the calculated field errors are plotted for the midplane of the magnet aperture for a field strength of 13 kGauss. No serious saturation effects occur as can be seen from Figure 14 where the permeability is plotted across one quarter of the otherwise symmetric magnet for 13 kGauss. The calculated excitation curve is shown in Figure 15. Obviously below 13 kGauss there is little saturation. 


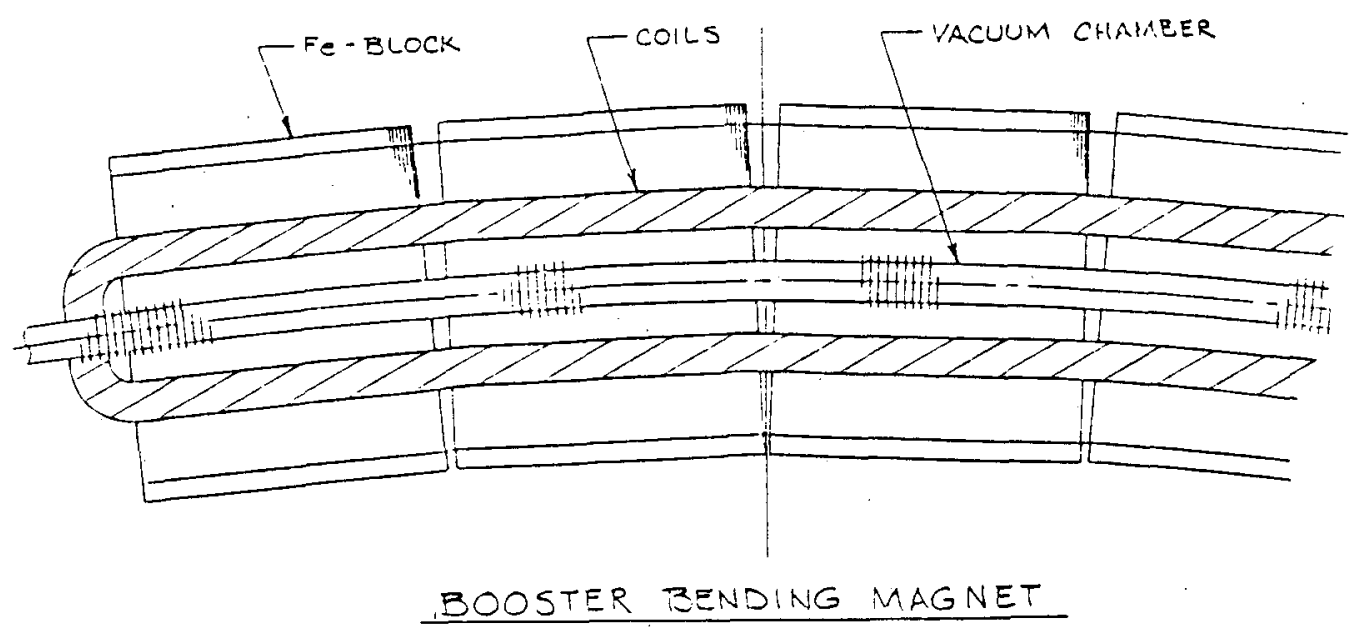

Fig. 12: Construction of the Bending Magnets

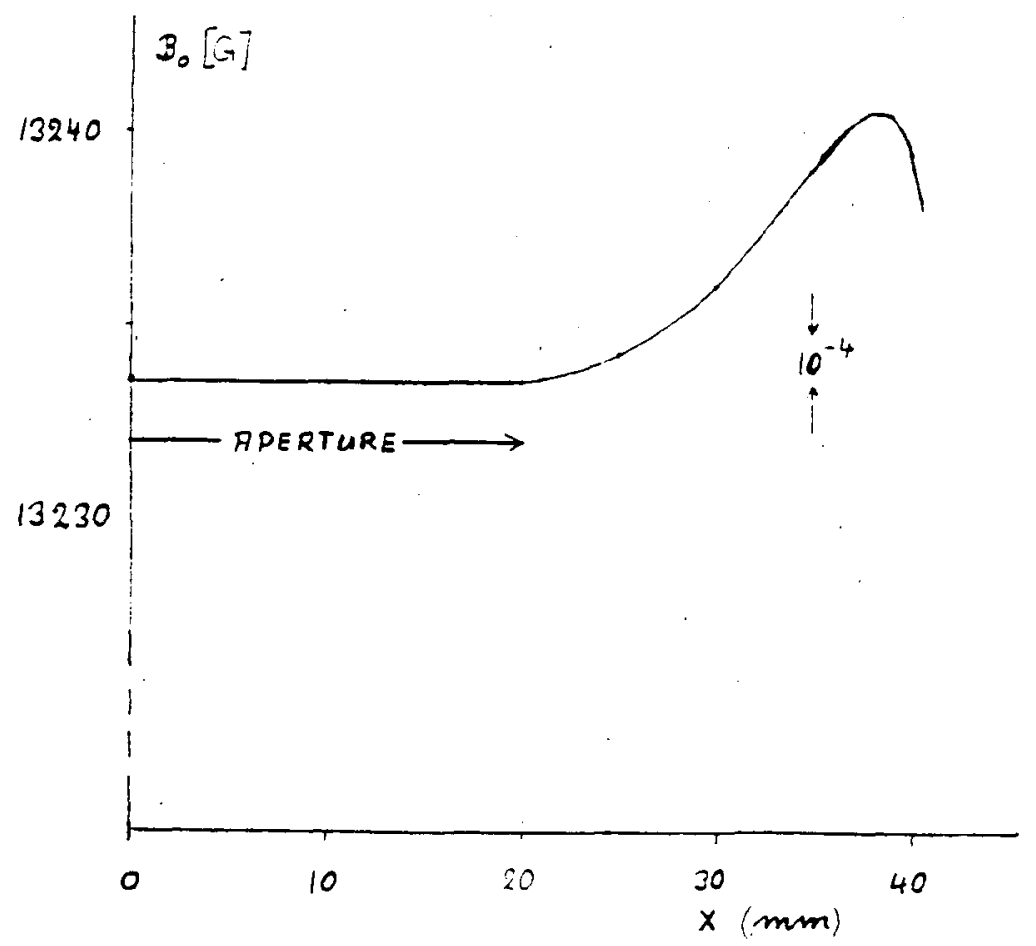

Fig. 13: Bending Magnet Field Errors 


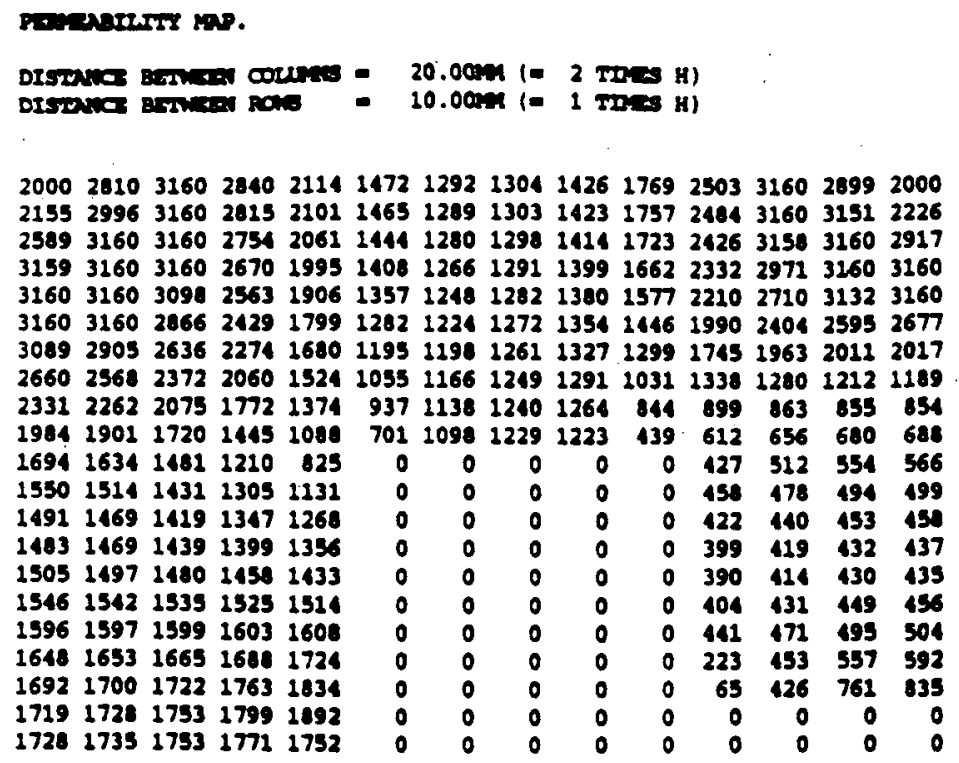

Fig. 14: Saturation of the Bending Magnet at 13 kGauss

Eight bending magnets require a smaller field strength than the rest of the magnets. For these magnets a modified coil with fewer turns is considered such that the correct field strength is obtained for all magnets while being powered in series by one and the same power supply.

All magnets are equipped with trim coils to provide orbit correction capabilities. The maximum strength of the trim coils will be specified as to allow the correction of any reasonable orbit distortion expected in the synchrotron.

The total peak power for the bending magnets is expected to be about $341 \mathrm{~kW}$ while the average power is $33 \%$ of that.

The bending magnet system parameters for the injector are tabulated in Table 13. 


\section{Table 13}

Beam Energy

Total Weight of Iron

Total Weight of Copper

Total el. Power @ $3 \mathrm{GeV}$

Electrical Current

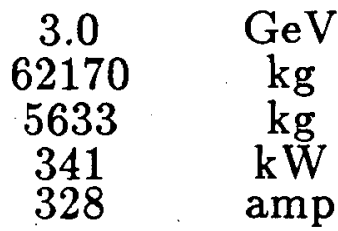

$\mathrm{GeV}$
$\mathrm{kg}$
$\mathrm{kg}$
$\mathrm{kW}$
$\mathrm{amp}$

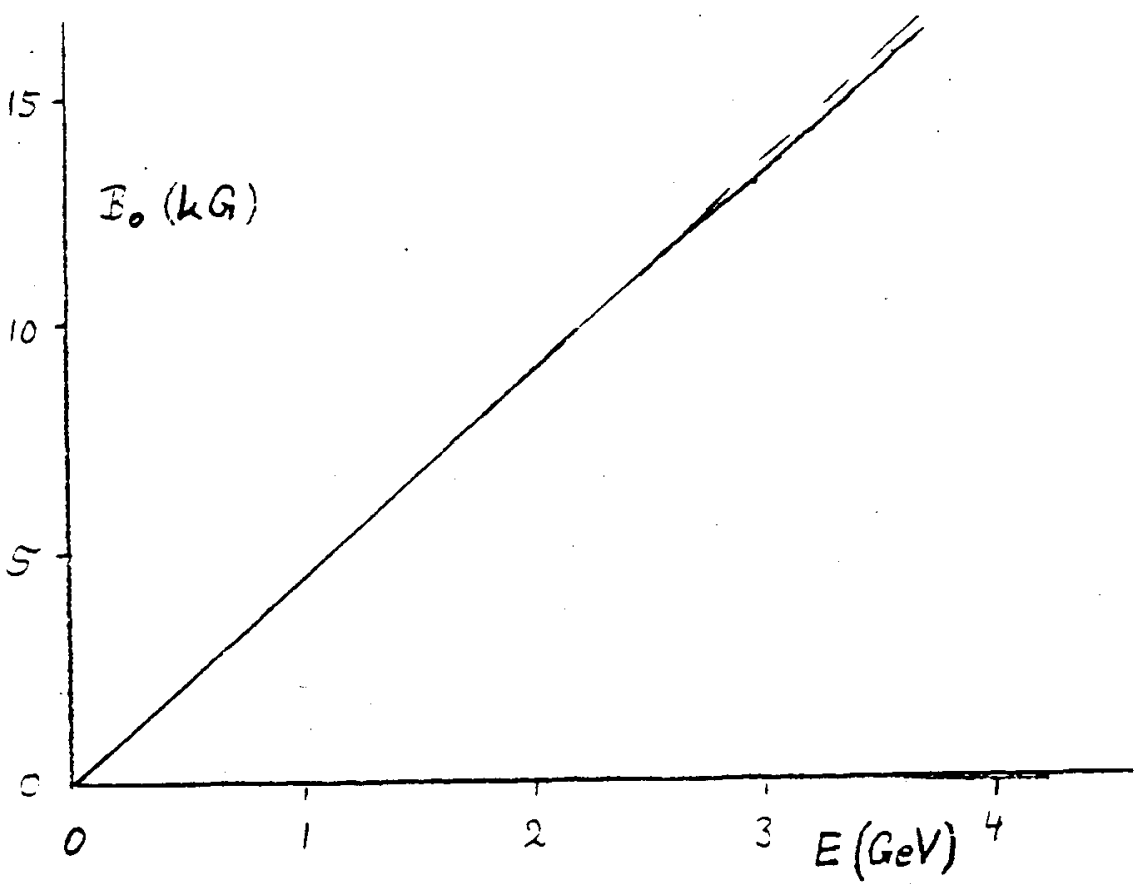

Fig. 15: Excitation Curve for the Bending Magnets

\subsubsection{Quadrupole and Sextupole Magnets}

The focusing is performed by 32 identical quadrupoles, each $0.287 \mathrm{~m}$ long, and the chromatic correction requires 2422 sextupoles with a magnetic length of $0.10 \mathrm{~m}$ each. To avoid eddy currents these magnets also are constructed from low carbon steel laminations like the bending magnets. 
There are two families of quadrupoles, the QF's and the QD's, each forming one electrical circuit. The strength of the two quadrupole types are:

$$
\begin{array}{cll}
Q F: k=-1.9766 m^{-2} & \text { or for } 3.0 \mathrm{GeV}: & g=1.9780 \mathrm{kGauss} / \mathrm{cm} \\
Q D: k=1.4478 \mathrm{~m}^{-2} & \text { or for } 3.0 \mathrm{GeV}: & g=1.4488 \mathrm{kGauss} / \mathrm{cm}
\end{array}
$$

The specifications of the quadrupoles and sextupoles are compiled in Table 14:

\section{Table 14}

\section{Quadrupole and Sextupole Specification}

Magnet Name in Lattice

Magnet Designation

Magnetic Length ( $\mathrm{mm}$ )

Bore Radius (mm)

Maximum Field Gradient (G/cm)

Field Gradient at $3.0 \mathrm{GeV}$

Pole Tip Field at $3.0 \mathrm{GeV}$ (Gauss)

Total Current/Coil (amp*turns)

Length of Iron Block (mm)

Weight of Iron $(\mathrm{kg})$

Weight of Copper (kg)

Number of Magnets

Power per Magnet at $3.0 \mathrm{GeV}(\mathrm{kW})$

Construction

$\begin{array}{cc}\text { QF/QD } & \text { SF } / \mathrm{SD} \\ 30 \mathrm{Q} 287 & 30 \mathrm{~S} 100 \\ 287.2 & 100.0 \\ 30.0 & 35.0 \\ 2400.0 & \\ \leq 1978.0 & \\ \leq 5934.0 & 450.0 \\ \leq 7085 & 358 \\ 257.2 & 100 \\ 338.3 & \\ 59.0 & \\ 36 & 22 \\ \leq 4.60 & \\ \text { laminated } & \text { laminated }\end{array}$

All quadrupoles and sextupoles have the same cross sections as shown in Figure 16 and Figure 20. 
The calculated saturation characteristics for the quadrupoles are shown in Figure 17 where the permeability is plotted across the magnet for a field gradient of $2.0 \mathrm{kGauss} / \mathrm{cm}$.

The magnetic field properties for the quadrupoles are shown in Figure 18 where the calculated gradient errors are plotted for the midplane of the quadrupole aperture for a gradient of $2.0 \mathrm{kGauss} / \mathrm{cm}$.

The calculated excitation curve for the quadrupoles is shown in Figure 19. Obviously there is little saturation for beam energies up to $3.0 \mathrm{GeV}$.

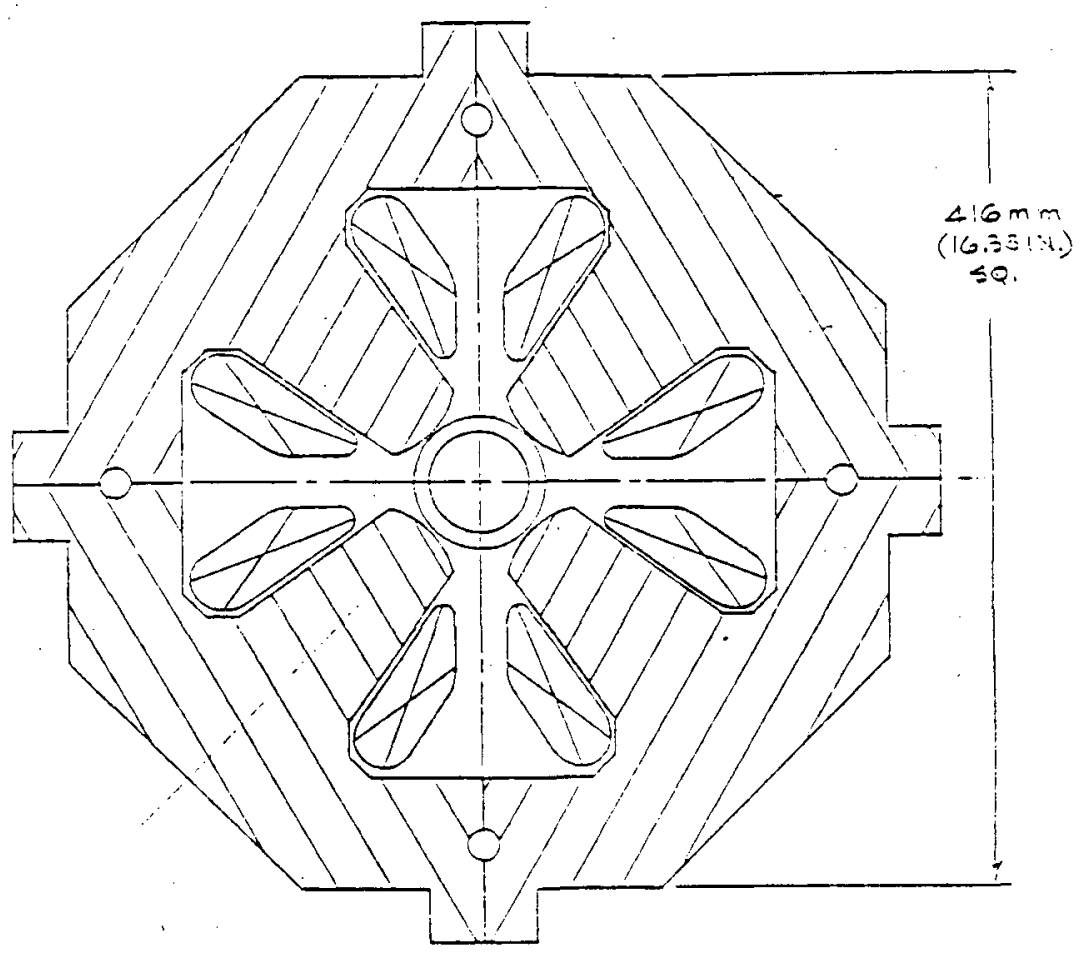

Fig. 16: Quadrupole Cross Section 
pRomedarists mo.

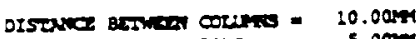

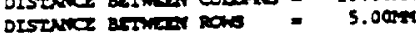

\begin{tabular}{|c|c|c|c|c|c|c|c|c|c|c|c|c|c|c|c|c|c|c|c|c|c|}
\hline & & & & 0 & D & & 0 & & & 0 & 0 & 0 & 0 & & 0 & 0 & 0 & 0 & 0 & 0 & \\
\hline & & & & & & 2000 & 2000 & & 0 & 0 & a & 0 & ? & : & 0 & : & 0 & ? & $\dot{0}$ & 0 & \\
\hline & & & & & & 2000 & 2002 & & $\therefore$ & : & : & : & & & & $:$ & : & $\dot{0}$ & : & o & \\
\hline & 0 & & 0 & & 3090 & 2041 & 2063 & 216 & & : & 0 & 0 & & & & 0 & 0 & 0 & 0 & & \\
\hline & 0 & & : & $\begin{array}{ll}0 & 2 \\
0 & 2\end{array}$ & $\begin{array}{l}2178 \\
2267\end{array}$ & $\begin{array}{l}2131 \\
2230\end{array}$ & $\begin{array}{l}2152 \\
2257\end{array}$ & 234 & & 902 & 0 & 0 & & 0 & & & & o & & & \\
\hline & & & & 437 & 3369 & 2348 & 2381 & 246 & & 619 & & & & & & & 0 & 0 & & & \\
\hline & & & & 534 & 2402 & 2481 & 2527 & 7261 & & 759 & 2978 & 0 & & & & & 0 & & & & \\
\hline & & 269 & & & 2621 & 2648 & 2710 & 280 & & 9932 & 3077 & 0 & & & 0 & & ? & & & & \\
\hline & & 275 & & 751 & 2733 & 2031 & 2931 & 301 & & & & 3078 & & & & 0 & 0 & & & & \\
\hline & & 232 & & $1889=$ & 2977 & 3071 & 3078 & $30^{\circ}$ & & 3078 & 3078 & 3078 & & 0 & & & c & & & & \\
\hline & 2797 & & & 03 & $30 \div 8$ & 3078 & 3078 & 307 & 7830 & 3078 & 3078 & 3078 & 3078 & & & 0 & 0 & & & & \\
\hline & 2792 & 1300 & & 1078 & 30 & & 307 & 307 & & 3073 & 3078 & 3078 & 3078 & & 0 & 0 & 0 & & & & \\
\hline & 2825 & $3 \quad 307$ & & 0078 & $30 \div 3$ & 3078 & 3078 & 307 & & 3078 & 3078 & 3078 & 3078 & $88 \cdot 307$ & & 0 & & & & & \\
\hline & 291 & 307 & & 8079 & 3078 & 3078 & 3078 & 30 & & 3078 & 3078 & 3078 & 3078 & 8307 & & & & & & & \\
\hline & 30 & & & 3078 & 3078 & 2078 & 3076 & 8307 & & 1078 & 3078 & 3078 & 3078 & 8307 & 7830 & 078 & & & & & \\
\hline $9+5$ & 30 & 30 & & 1078 & 3078 & 2663 & & & 030 & 1077 & 3076 & 3078 & 13078 & 18307 & & 073 & 0 & & & & \\
\hline & 3078 & 307 & & 078 & 3078 & 0 & & & & & 3078 & 3078 & 3078 & & & 078 & 3078 & & & & \\
\hline & 307 & 307 & & 3078 & 296 & 0 & & & g & 0 & & 3073 & 3078 & 8307 & & 73 & 3078 & & & & \\
\hline & 3078 & & & 3078 & 3070 & 0 & & 0 & 0 & j & & 3078 & 307 & $88 \quad 307$ & & 078 & 3078 & & & & \\
\hline & 307 & 30 & & 18 & 30 & 0 & & & 0 & & ง & & 307 & $78 \quad 107$ & & 78 & 3078 & 1.307 & & & \\
\hline & 307 & 30 & & 307 & 30 & 0 & & & 0 & 0 & & & & $0 \quad 307$ & & 078 & 3078 & & & & \\
\hline 1078 & 307 & & & 30.78 & 307 & o & & & 0 & 0 & & & & 0 & $0 x$ & 078 & 3078 & 3078 & 3078 & & \\
\hline & 307 & & & 8 & 3078 & 0 & 0 & 0 & 0 & 0 & & & & 0 & 030 & 1078 & 3078 & 3078 & 3070 & 3078 & \\
\hline & 30 & 30 & & 3073 & 30 & & & 0 & 0 & ? & & & & & & & & 3078 & 3078 & & \\
\hline & 30 & & & 307 & 30 & & & 0 & 0 & ? & & & & & & & & & & & \\
\hline & 30 & & & 30 & 30 & & & & & & & & & 0 & כ & & & 3078 & 3078 & 3078 & \\
\hline & & & & 30 & & & & 0 & o & 0 & & & & 0 & & & ว & & & & \\
\hline & & & & & & & & 0 & 0 & 0 & 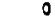 & & 0 & 0 & 0 & & & & & & \\
\hline & & & & & & & & 0 & 0 & & & & 0 & 0 & 0 & & & & & & 8 \\
\hline & & & & & & & & 0 & ? & & & & & 0 & 0 & & & & & & \\
\hline
\end{tabular}

Fig. 17: Saturation Characteristics for the Quadrupoles

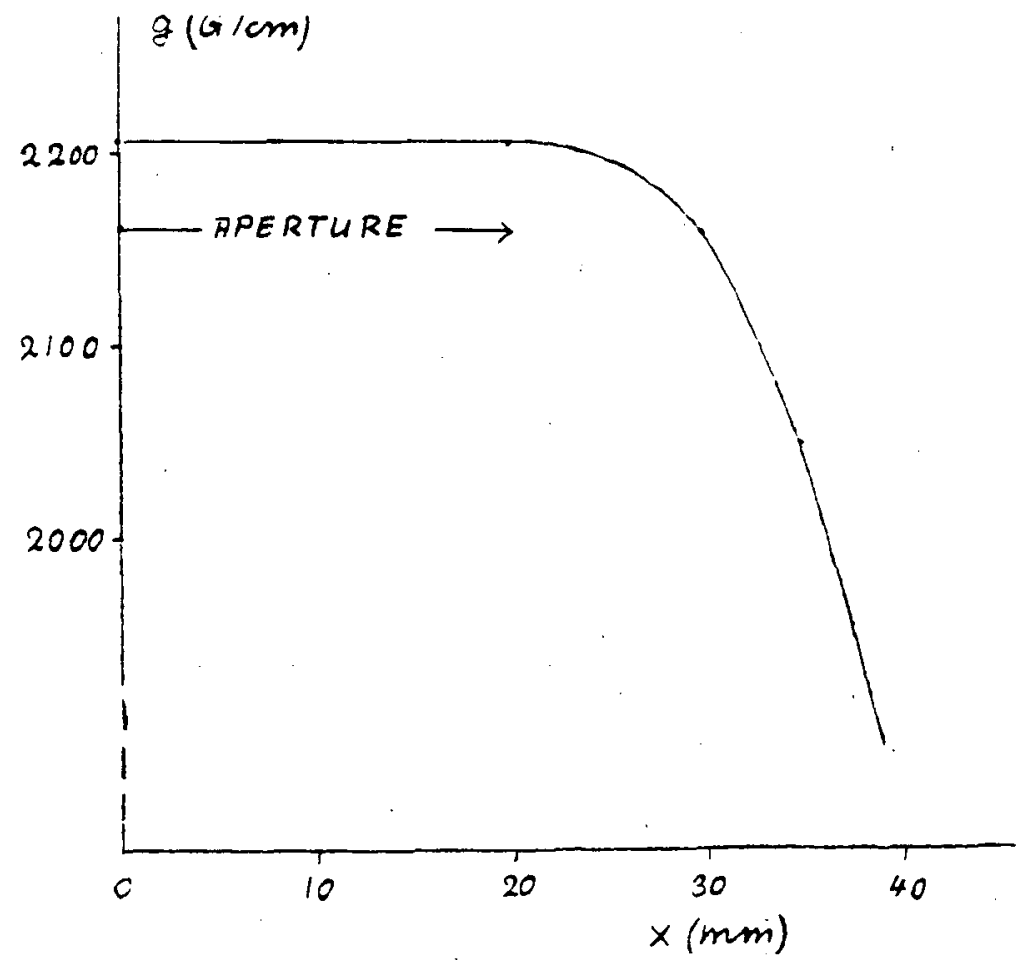

Fig. 18: Quadrupole Gradient Errors 


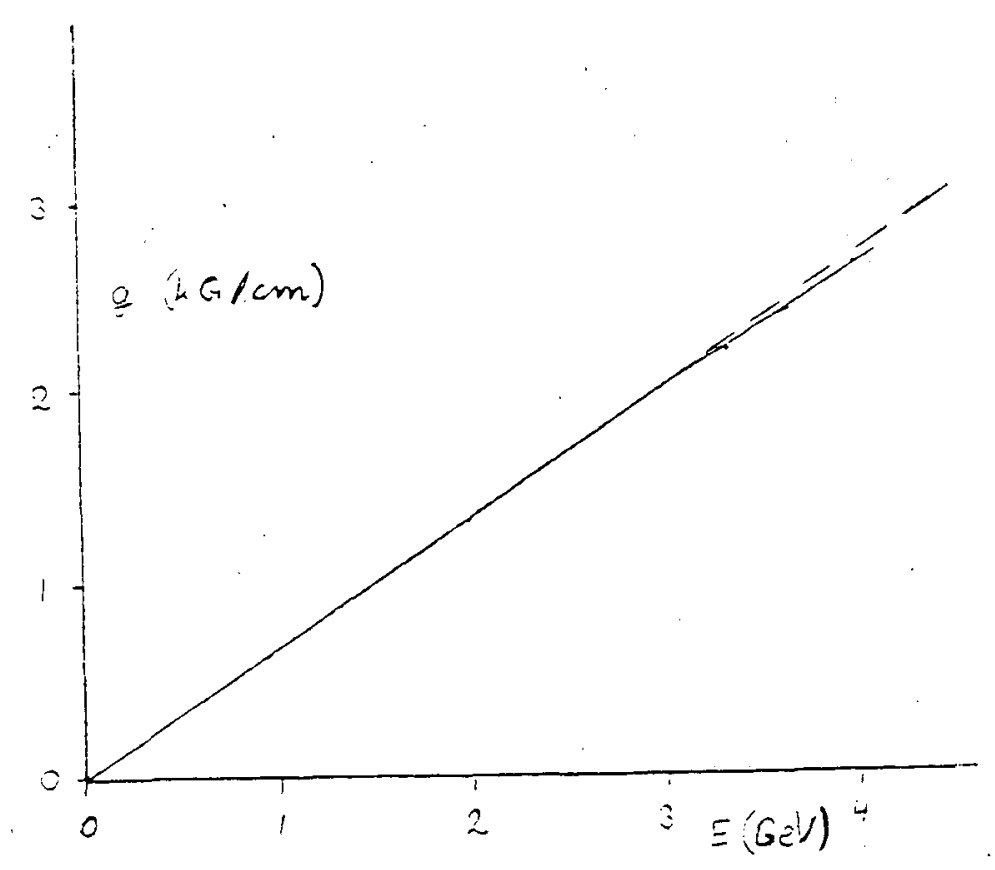

Fig. 19: Excitation Curve for the Quadrupole Magnets

\subsubsection{Special Magnets}

Most magnetic fields used for orbit correction will be generated by trim coils in bending magnets and quadrupoles. They will be powered by independent, DC power supplies With trim coils in time-varying fields, like for the bending and quadrupole magnets, a significant voltage is induced in each trim coil which is too large for the small power supplies. Hence the alternating voltage must be removed from each correction circuit. Following the suggestion by the ESRF group for their booster, we propose to add a special "bucking" magnet in the dipole circuit. $[R e f]$ This will be a separate dipole magnet connected to the main dipole circuit but not part of the ring lattice. Each correction circuit will have an auxiliary winding on the core of this magnet with the number of turns and the polarity chosen such as to

$[R e f]$ ESRF, Foundation Phase Report, February 1987, Grenoble (France) 


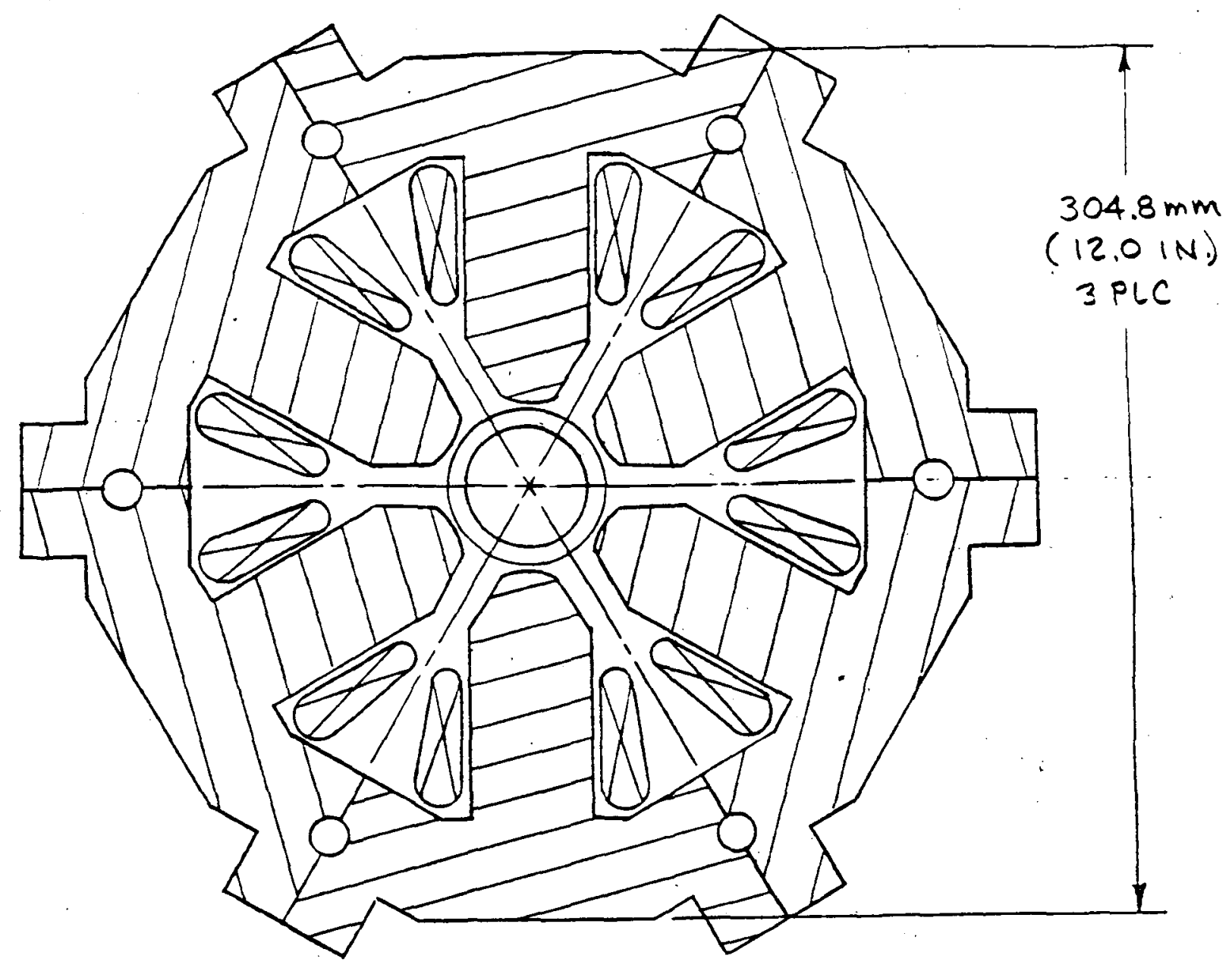

Fig. 20: Sextupole Cross Section

cancel the voltage induced in the main correction winding.

\subsubsection{Magnet Power Supplies}

The power supplies must be designed such as to excite the magnets from the injection energy of $100 \mathrm{MeV}$ to high field levels corresponding to $3.0 \mathrm{GeV}$ operation up to 2 times a second. To accomplish this it is proposed to use 
a a computer controlled DC power supplies or classical "White" circuits as used in many previously constructed synchrotrons. The latter power circuit consists of a combination of one DC supply and two AC supplies. Together with a choke and two capacitor banks, this "White" circuit provides an oscillating current for the magnets between zero and a maximum value. An internal filter is incorporated to minimize the harmonic content of the output current.

A total of five power supplies will be needed, one for the bending magnets, two for the QF and QD quadrupole circuit and two simple pulsed power supplies for the SF and SD sextupole circuits.

No special AC power supplies are required for orbit control. In a properly designed synchrotron the orbit changes little during the acceleration process. It is, therefore, anticipated that only DC correctors are required, for which standard DC power supplies can be used. Of course, in this case the significant induced voltage from the main bending fields must be compensated in a bucking magnet as outlined above, to use these ordinary DC supplies.

For the proper functioning of the synchrotron it is important that the fields in the bending magnets and the quadrupoles track together. Tracking errors can be caused for example by mechanical variations of the magnet gaps during the magnetic field cycle. It is, therefore, important to construct the magnets so as to produce maximum rigidity. This is a strong argument for designing the bending magnets as $\mathrm{H}$-magnets rather than $\mathrm{C}$-magnets. Another source of tracking errors can come from the power supply characteristics which are different for the bending magnet and quadrupole circuit. If a computer controlled power supply is used each circuit $\mathrm{cn}$ be controlled appropriately. In case of the White circuit, the bending magnet circuit will be adjusted to a fixed frequency to minimize the power rating of the invertor to generate only a pure resistive load on the power mains. This will cause the quadrupole circuits to oscillate at a slightly different frequency and, therefore, a phase control servo system will be required to keep all magnets tracking properly. More detailed engineering is required to choose between both types of power supplies to suit best the SPEAR injector requirement and environment. 


\subsubsection{Acceleration System}

To accelerate the electrons from the preinjector energy to the final storage ring operating energy, a $358 \mathrm{MHz} \mathrm{RF}$ system will be used. This system makes use of a 5-cell cavity which has been used in SPEAR and has been secured from SLAC surplus. One such cavity is sufficient to accelerate the electrons up to $3 \mathrm{GeV}$.

If the RF-system were operated just like in a $3 \mathrm{GeV}$ storage ring at a constant RF-voltage level the system would require a RF-power of $150 \mathrm{~kW}$ of which about $135 \mathrm{~kW}$ are losses in the cavity walls. These losses can be greatly reduced if the RF-voltage is modulated during the accelerating process to the minimum values needed by the particles at any time. This modulation can be easily achieved by control of the klystron drive. At the highest energy of $3 \mathrm{GeV}$, however, the klystron power must reach a maximum instantaneous power of $150 \mathrm{~kW}$ to generate a sufficiently large accelerating voltage in the cavities to overcome the synchrotron radiation losses. This power rating is less than that for the klystrons presently used in SPEAR. To simplify maintenance it is proposed to use the same klystrons as for the SPEAR storage ring although they are, at $500 \mathrm{~kW}$, overrated. The relative small cost difference between a $150 \mathrm{~kW}$ and $500 \mathrm{~kW}$ klystron makes this decision simple.

The low level electronics and power supplies will be of the same design as for the SPEAR or PEP RF-systems. No new development is necessary.

The choice of the accelerating system is mainly determined by the available surplus accelerating cavity from SPEAR. This cavity operates at a frequency of $358 \mathrm{MHz}$, has a shunt impedance of $30 \mathrm{MOhm}$ and can absorb in its cooling system an average power of about $100 \mathrm{kWatt}$. The cavity consists of five cells coupled together in $\pi$ mode by two slots in the common wall between the cells. The construction material is Aluminum 6061. A layer of Titanium Nitride deposited on the surface of the cavity serves to prohibit field breakdown by multipactoring. A water cooled loop in the center cavity is used to couple the RF power from the klystron into the cavity.

The cavities are equipped with a movable tuner and a sampling loop. The tuner is used to compensate for the thermal expansion of the cavity which causes a change of the resonance frequency. The field amplitudes are 
monitored by the sampling loop and the signal is compared with a reference signal to set the desired RF Voltage in the cavity. The resulting difference signal is applied to a variable attenuator in the drive line to the klystron. The whole system is similar to the SPEAR or PEP control system and could also be equal to the system used for the storage ring.

The accelerating system of a synchrotron, in addition to providing the accelerating field $U_{\text {accel }}$ to raise the electron energy from $120 \mathrm{MeV}$ to 3.0 $\mathrm{GeV}$, also compensates for the loss of energy due to synchrotron radiation $U_{r a d}$ and the energy lost due to the excitation of parasitic modes $U_{p m}$.

The energy balance can be written like:

$$
U_{t o t}=U_{a c c e l}+U_{r a d}+U_{p m}
$$

where

$$
U_{\text {accel }}=\left(E-E_{0}\right) /\left(T_{c} * f_{\text {rev }}\right)
$$

where $\mathrm{E}=3.0 \mathrm{GeV}, E_{0}$ the linac energy, $T_{c}$ is the ramping time of the synchrotron and $f_{r e v}$ is the particle revolution time in the synchrotron.

For this synchrotron we have at $3 \mathrm{GeV}$ :

$$
\begin{aligned}
f_{r e v} & =2974 \mathrm{kHz} \\
T_{c} & =0.10 \mathrm{sec} \\
U_{\text {rad }} & =1 \mathrm{MeV} \\
U_{\text {accel }} & =10.0 \mathrm{keV} \\
U_{p m} & =0.4 \mathrm{keV} \\
U_{\text {tot }} & =1.01 \mathrm{MeV}
\end{aligned}
$$

Here we have assumed that the maximum cycling rate for the synchrotron is $10 \mathrm{~Hz}$.

The parasitic mode parameter for the SPEAR cavity $K_{p m}$ is $1.5 \mathrm{~V} / \mathrm{pCb}$ and the number of electrons per bunch is at most $2 * 10^{9}$ in a maximum of 8 bunches. The parasitic mode loss in the SPEAR cavity, $U_{p m}$, therefore, is no 
more than $0.4 \mathrm{keV}$. The required accelerating voltage, even for a fast cycling booster at $10 \mathrm{pps}$ and the maximum expected beam loading, is negligible compared to the synchrotron radiation losses. The RF power, therefore, is mainly applied to replace the synchrotron radiation energy loss.

The RF parameters of the injector synchrotron are:

$\begin{array}{lcl}\text { Frequency } & 358 & \mathrm{MHz} \\ \text { Harmonic Number } & 120 & \\ \text { No. of Klystrons } & 1 & \\ \text { No. of Cavities } & 1 & \\ \text { Cavity shunt impedance } & 30.0 & \text { MOhm } \\ \text { Max. Cavity Power } & 130.0 & \mathrm{kWatt} \\ \text { Avg. Cavity Power } & 35.0 & \mathrm{kWatt} \\ \text { Max. Cavity Voltage } & 2.0 & \text { MVolt } \\ \text { Max. Beam Power } & 4.0 & \mathrm{kWatt}\end{array}$

During each accelerating cycle, the electron energy raises from $120 \mathrm{MeV}$ to $3.0 \mathrm{GeV}$ and the synchrotron radiation energy loss per turn increases from $1 \mathrm{eV}$ to $900 \mathrm{keV}$. Therefore, to minimize power consumption and to avoid beam instability the RF power will be modulated from $5 \mathrm{~kW}$ to 135 $\mathrm{kW}$ as shown in Figure 21. This modulation must be split into two regimes: one for energies from $100 \mathrm{MeV}$ to $1.3 \mathrm{GeV}$ and the other for $1.3 \mathrm{GeV}$ to $3 \mathrm{GeV}$. During the first step, the RF power is kept at about $5 \mathrm{~kW}$ which is the minimum stable output power for the klystron. The RF voltage in the cavity is, in this case, $387 \mathrm{kV}$ and provides an energy acceptance of $1.6 \%$ at injection and of $0.5 \%$ at $1.3 \mathrm{GeV}$. During the second step the energy acceptance is kept at a minimum $0.5 \%$ and the resulting $\mathrm{RF}$ power and RF voltage in the cavity are shown in Figure 21 and 22 . This kind of modulation of the RF power can be achieved by controlling the drive power to the klystron. Of course more energy acceptance can be obtained should that be desirable for some reason, by raising the $R F$ power up to the maximum level of $100 \mathrm{~kW}$ as limited by the cavity cooling capacity. 


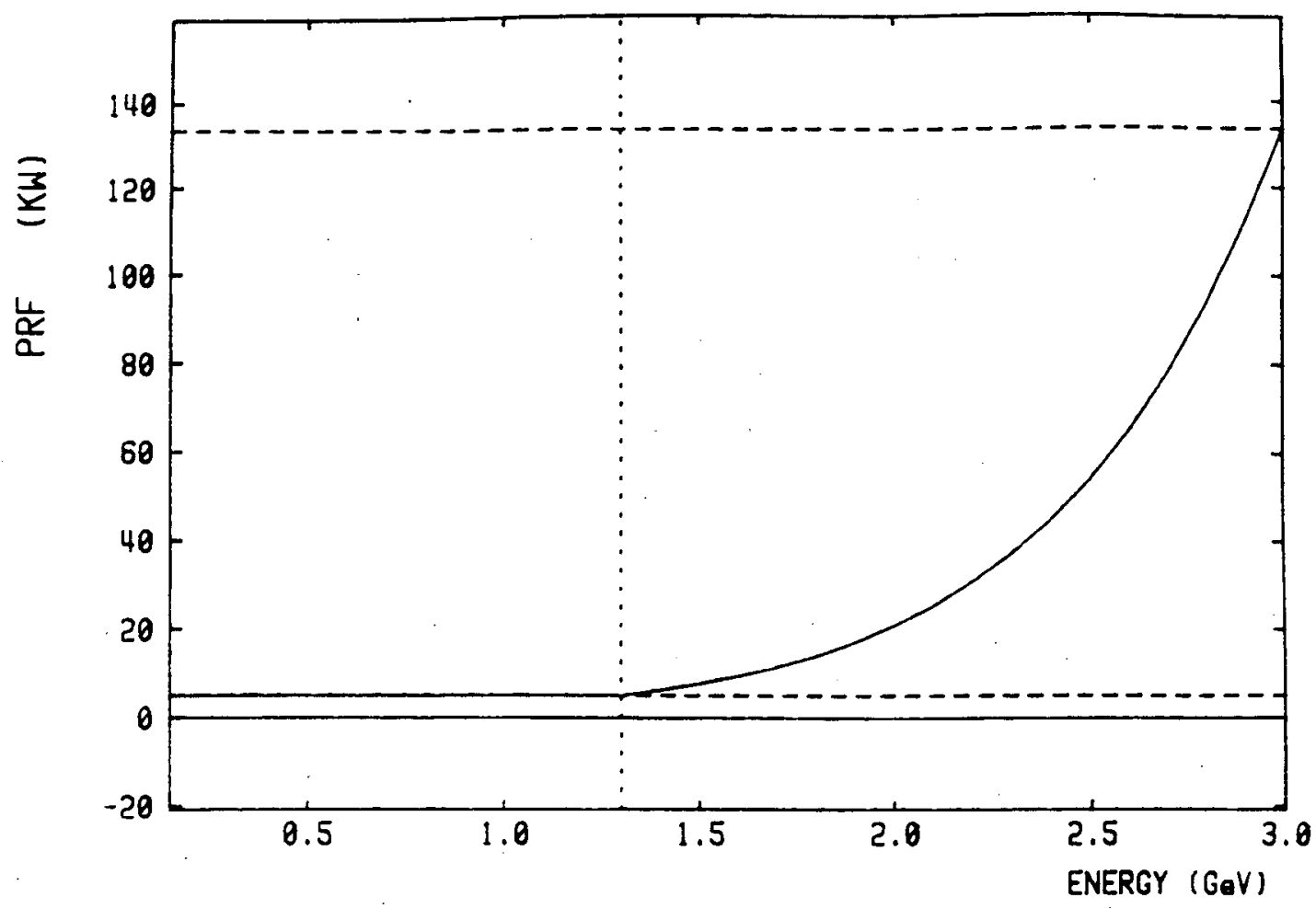

Fig. 21: The Cavity RF Power Variation with Beam Energy

\subsubsection{Vacuum System}

In a booster synchrotron a special design of the vacuum chamber must be employed. Fortunately, since the particles remain in the synchrotron only a very short time, an operating pressure of $10^{-6}$ Torr is sufficient and the high fabrication and maintenance costs of an ultra-high vacuum system can be avoided. Also the synchrotron radiation heating of the wall can be shown to be quite negligible due to the low average current and low duty cycle, so no special cooling of the vacuum chamber walls will be required. However, the changing magnetic fields during acceleration will induce eddy currents in the chamber material which can greatly affect the magnetic field quality inside the vacuum chamber. This effect can be avoided by using 


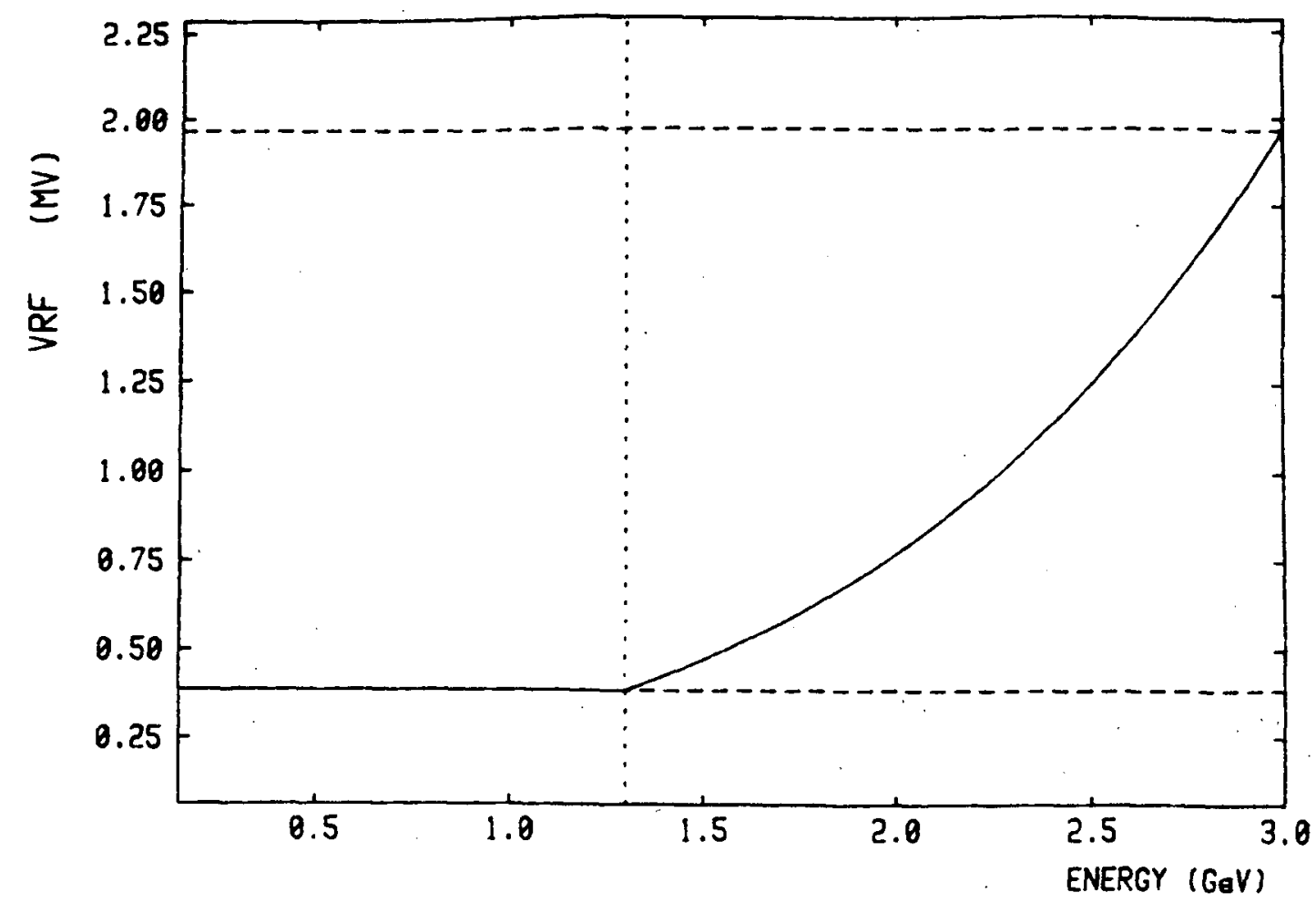

Fig. 22: Variation of the Cavity Voltage with Beam Energy

costly ceramic chambers, or for slow cycling synchrotrons such as proposed here, by using vacuum chambers made of very thin $(0.3 \mathrm{~mm})$ stainless steel pipes. In this proposal such a thin walled stainless steel chamber is used. To avoid the collapse of this chambers under atmospheric pressure external stiffening ribs will be attached to the outer surface at periodic longitudinal intervals. The ribs must be designed to fit within the various magnet pole gaps. Such a design has been successfully used at DESY in the recently constructed $12 \mathrm{GeV}$ synchrotron, and allows the booster to be cycled at up to 12 times per second.

The pumping system design is dictated largely by the cross-sectional dimensions required for the vacuum chamber to fit inside the poles of the magnets. In the quadrupoles and sextupoles, a thin-walled round tube of 
approximately $50 \mathrm{~mm}$ diameter appears to be suitable. A number of round tubings can be partially flattened to an an approximately elliptical cross section of dimension $32 \mathrm{~mm}$ by $40 \mathrm{~mm}$ and used in the bending magnet regions. These dimensions allow the use of external ribs of sufficient thickness to provide the stability against atmospheric pressure within the specified quadrupole and sextupole bore diameters. In the bending magnets the stiffening rips would be only $1 \mathrm{~mm}$ in the pole gap but much wider in the horizontal plane (Figure 23).

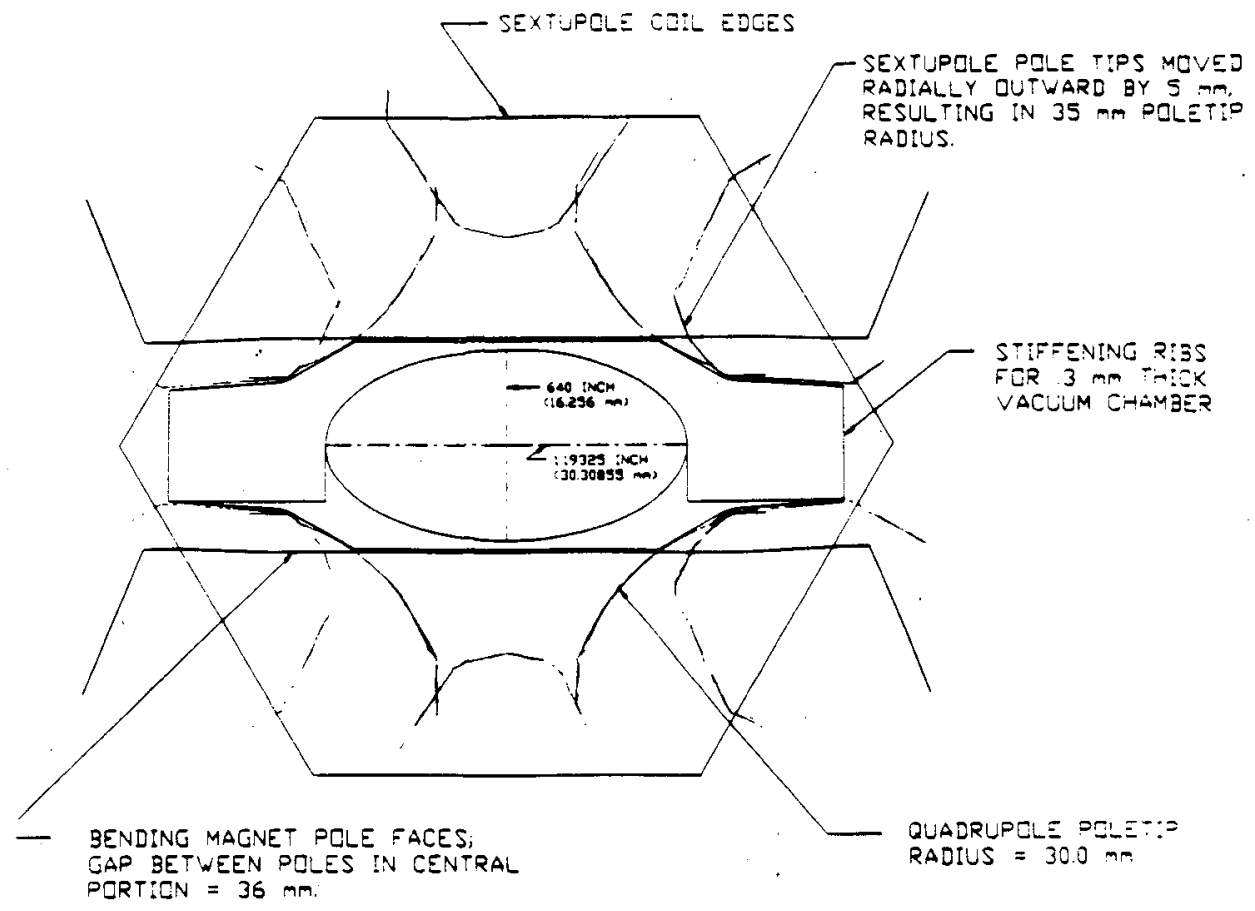

Fig. 23: Vacuum Chamber Cross-section

An analysis has been made of the pressure distribution in a long tube of the above-mentioned dimensions with thermal outgassing rates assumed to be those of clean, degreased but unbaked stainless steel, and ignoring the very small gas desorption due to synchrotron radiation. It shows that an average pressure in the booster ring of about $700 \mathrm{n}$ Torr can be achieved using only lumped ion pumps. In particular one $8 \mathrm{l} / \mathrm{sec}$ ion pump for each 2.8 meter long cell in the lattice is sufficient to reach that pressure. No distributed pumps in the bending magnets are required. Thus, for main- 
taining an adequately low and smooth pressure profile around the ring, 36 ion pumps with a pumping speed of $81 / \mathrm{sec}$, approximately equally spaced, will be installed. To minimize cost several ion pumps at a time will be connected to one power supply. A set of vacuum gauges will be used to monitor the pressure around the ring.

To evacuate the ring from atmospheric pressure down to a pressure where ion pumps can safely be turned on, gate valves are used to segment the ring into sectors that can be evacuated separately. A mobile mechanical roughing pump together with liquid-nitrogen-cooled sorption pumps will be connected to the vacuum chamber at the center of each sector. Each sector is then evacuated separately until the ion pumps can be started. When the vacuum pressure reaches a sufficiently low value in all sectors, the gate valves can be opened.

Taking advantage of the highly periodic magnet lattice only one basic type of vacuum chambers are needed to cover all of the ring. Each chamber reaches through one bending magnet, and one quadrupole/sextupole combination. All chambers are joined by conventional 4.5 inch Conflat flanges.

Each quadrupole/sextupole section consists of a straight round steel tubing with simple circular rings on the outside as stiffening ribs where necessary. The repetitive chambers will be connected by a conventional pump-out tee with bellows. A single ion pump and the valve to the roughing system will be attached here. At one end, near the flange, an axi-symmetric beam position monitor (BPM) module will be installed, and at the other end, a short bellows section to accommodate small manufacturing tolerances. A thin ceramic ring will be incorporated at the end of each chamber to avoid induced current circulation in the ring. The layout of the arc vacuum chamber with pumping is shown in Figure 24.

\subsubsection{Instrumentation and Controls}

The controls of the booster synchrotron components are mostly incorporated into the hardware. The accelerating system, for example, will have an internal feedback system to keep the RF parameters constant at the desired values. During the energy ramping process the quadrupole power supply amplitudes and phases will be controlled by a small computer to assure 


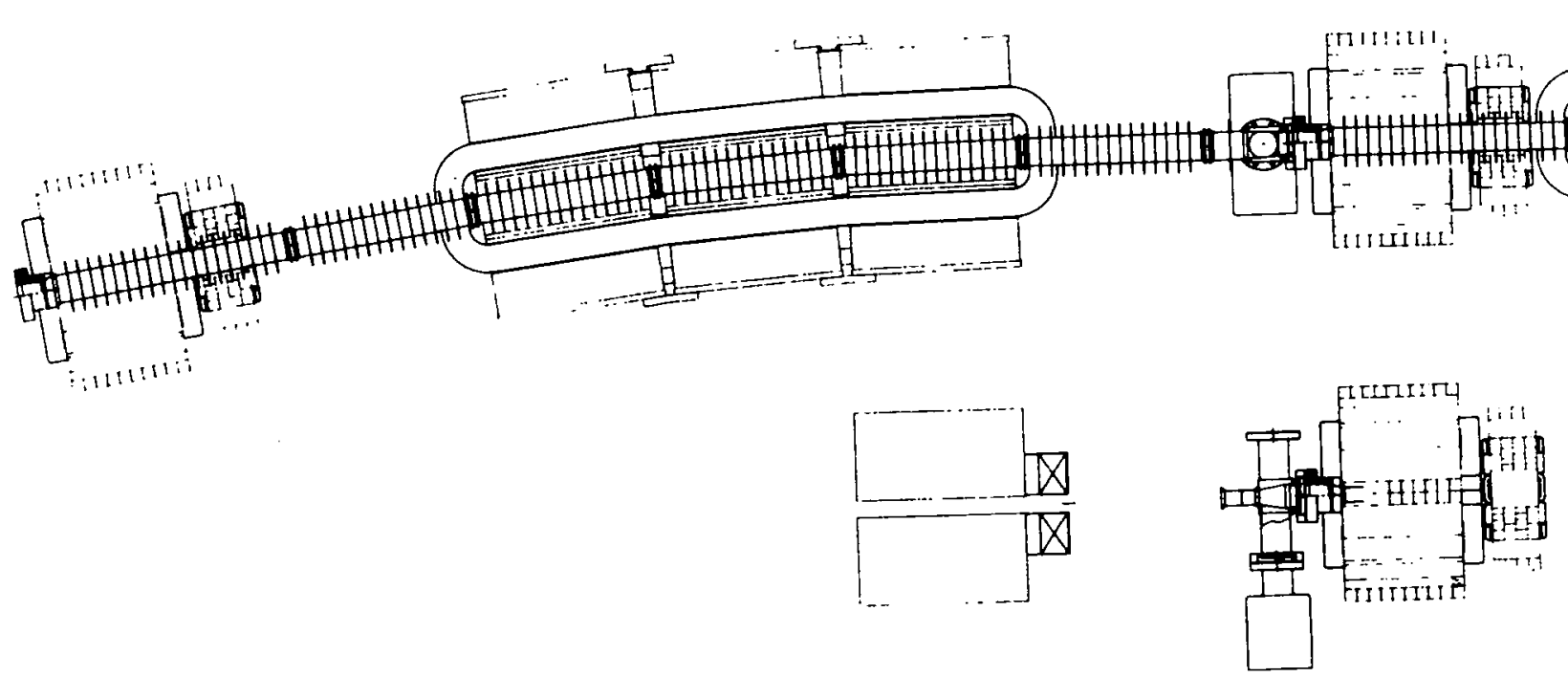

Fig. 24: Arc Vacuum Chamber 
proper tracking with the bending magnet current and field. Similarly the beam current or the beam position will be recorded and displayed during acceleration. In this way it is possible to operate the booster synchrotron independent from the storage ring control computer which will be important during initial debugging. A separate control console with a microcomputer will be available to operate the injector independent from the SPEAR control system. On the other hand the booster components are ready to be controlled by any other computer and therefore can be also connected to the main SPEAR control system whenever this becomes desirable.

Due to the variation of the main dipole field at injection an injection timing trigger with a precision of about $1 \mu \mathrm{sec}$ is required to keep the energy of the beam at ejection to SPEAR within tight tolerances. This trigger is to be locked to the main dipole field variation and is used to trigger the gun, linac and the injection septum and kicker. The timing trigger is derived from a pick up coil and a permally strip to give a signal when the magnetic field is reverted. A special delay unit will be also triggered from this timing signal to later produce the trigger for the ejection septum and kicker magnets.

For particle beam monitoring a current monitor will be installed to measure the beam intensity. Beam position monitors will detect the beam orbit and provide the signals to correct it. During particle acceleration in the booster it will be desirable to control the beam orbit to adjust for slight variations in the magnetic fields of the individual magnets. Trim magnets as part of the quadrupoles or bending magnets will be used in conjunction with the beam position monitors to dynamically control the beam orbit when needed.

The magnet current during acceleration will be computer controlled and a feedback system which monitors the betatron oscillation frequency will be used to keep the betatron tunes of the synchrotron constant during energy ramping.

The controls for the RF system will be similar to those developed for the storage rings PEP and SPEAR.

The linac controls contain mostly a timing system, as well as a phase and amplitude detection system which provides the signals for the purpose of phasing the klystrons. The timing system makes use of a signal from the master oscillator set precisely to a harmonic of the revolution frequency of 
the beam in the storage ring. From these signals the timing for the phasing of the linac RF, the synchrotron $\mathrm{RF}$ and for the chopper cavity are derived. A set of beam monitors, bending magnets and slits will be provided to control the beam energy and the beam energy spread before it is injected into the synchrotron.

For beam monitoring a DC current transformer will be used as well as beam position monitors to control the beam orbit. The magnet current during acceleration will be computer controlled and a feedback system which monitors the betatron oscillation will be used to keep the betatron tunes of the synchrotron constant during energy ramping. The controls for the RF system will be equal to the SPEAR storage ring system with the additional capability to change the klystron drive as required by the beam energy during acceleration. The linac controls contain mostly a timing system and a phase and amplitude detection system, which provides the signals for the purpose of phasing the klystrons. The booster timing system will tie into the SPEAR timing system to allow the filling of any arbitrary bunch pattern in the SPEAR storage ring.

\subsubsection{Injection and Ejection}

The proposed SPEAR injection system involves a series of injections and ejections into and out of the booster and into the SPEAR storage ring. The injection and ejection at the booster is relatively simple since no accumulation is attempted and therefore both injection and ejection is performed during one revolution time only. As a consequence only one kicker magnet and one septum magnet is needed for injection and the same for ejection. Obviously the design of these pulsed magnets is much simpler for the low injection energy of $100 \mathrm{MeV}$ compared to the ejection energy of $3.0 \mathrm{GeV}$. 


\subsubsection{Ejection from the Booster Synchrotron}

After acceleration of the particles to the storage ring energy an ejection process is triggered for the transfer of the beam to SPEAR. A fast full aperture kicker magnet in the booster synchrotron will deflect the beam into the magnetic aperture of a weak septum magnet. This septum magnet will be followed by a stronger septum magnet to finally deflect the beam out and away from the booster components into a beam transport system. The pulsed magnets required for this process are of conventional design and need no further R\&D.

\subsubsection{Beam Transport to SPEAR}

The beam ejected from the booster synchrotron enters a short beam transport system leading into the nearby existing electron injection transport line. Where both beam lines merge a bending magnet will deflect the booster beam onto the existing path of the injection line. If no other modifications were contemplated this beam would then enter the SPEAR storage ring at the now existing entry point through existing injection components. Some existing pulsed magnets, however, would limit the injection energy to $2.3 \mathrm{GeV}$ and therefore need to be replaced with more powerful components. A layout of this beam transport system is shown in Fig. 25. In this proposal we assume that the present $2.3 \mathrm{GeV}$ pulsed magnet system will be replaced by a $3 \mathrm{GeV}$ pulsed magnet system. To provide the operational feasibility of a low emittance configuration it is also proposed to replace the present two kicker magnet system by three kicker magnets. This is necessary to generate a matched beam bump for the low emittance configuration.

\subsubsection{Utilities}

The synchrotron will require electrical as well as mechanical utilities. An overview of existing and planned for utilities is shown in Figure 26 . The maximum total electrical power requirement at $3 \mathrm{GeV}$ is about $1 \mathrm{MW}$ although less than half that will be needed on average during operation. Of 


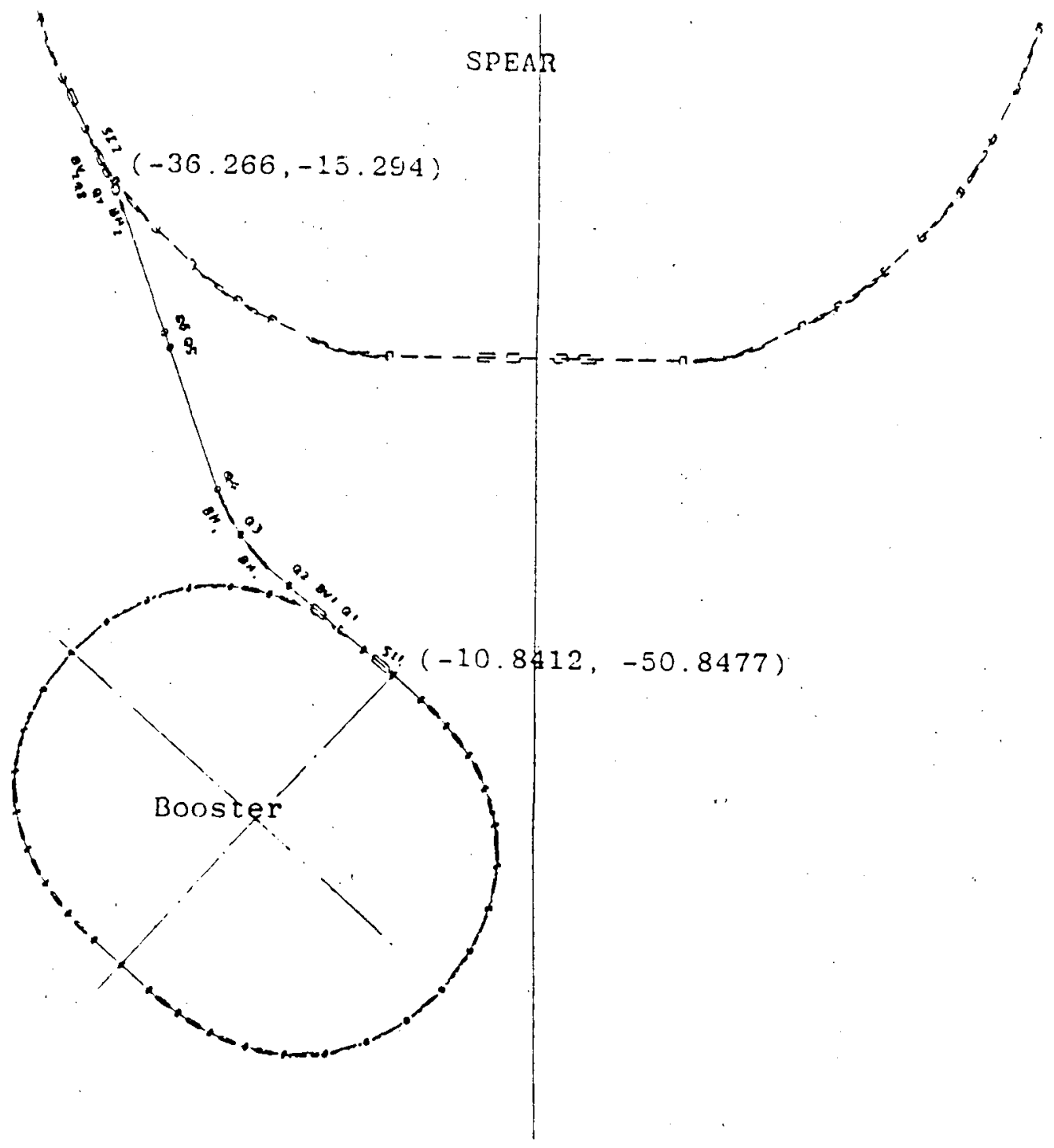

Fig. 25: Beam Transport Line from the Booster to SPEAR Tunnel 
that about $300 \mathrm{~kW}$ is for the RF-system and $400 \mathrm{~kW}$ for the magnets. The remainder for miscellaneous components including house power.

A separate 3 phase, 4 wire, $12 \mathrm{kV}$ power source will be extended from an existing " $\mathrm{H}$ " frame, located located in the north-western corner of the north research yard, about 30 feet away from the booster ring tunnel (Figure 26). A new transformer and switch gear, located near the klystron power supply shelter, will reduce this power to 480 - 120/220 volt for general power distribution systems. Additional metering and switch gear is needed for the synchrotron as well as $\mathrm{AC}$ cabling for the klystron and magnet power supplies.

$\mathrm{AC}$ services including receptacles and lighting is required for the equipment shelters and the ring tunnel. Communications and fire alarm systems will be extended from the existing SPEAR/SSRL system.

Since only about half of the maximum power capacity will be used, on average, the LCW cooling systems are sized for $0.5 \mathrm{MW}$. A six inch stainless steel line, supplying $400 \mathrm{GPM}$ of LCW, will be extended from a nearby source in the research yard (Figure 26).

Domestic water and compressed air will be supplied from nearby existing sources to serve the injector facility.

\subsection{Shielding and Shelters}

The linac preinjector and the synchrotron must be housed in a radiation safe shelter. The accelerators will be housed in an above-ground concrete tunnel, 2 feet thick to protect the outside world from radiation. The inside dimensions of the ring tunnel will be 7 feet high and 10 feet wide with a 7 feet aisle for easy access to the ring (Figure 27). There will be three access ways into the ring. Two can be used for component installation, while another access through the linac tunnel serves as an escape way for emergencies.

Additional concrete shielding blocks will be installed on top of the existing SPEAR tunnel along the injector line to eliminate present radiation concerns.

In addition to the accelerator tunnels there are several light weight shelters to house the linac klystrons, the synchrotron klystron with its variable 


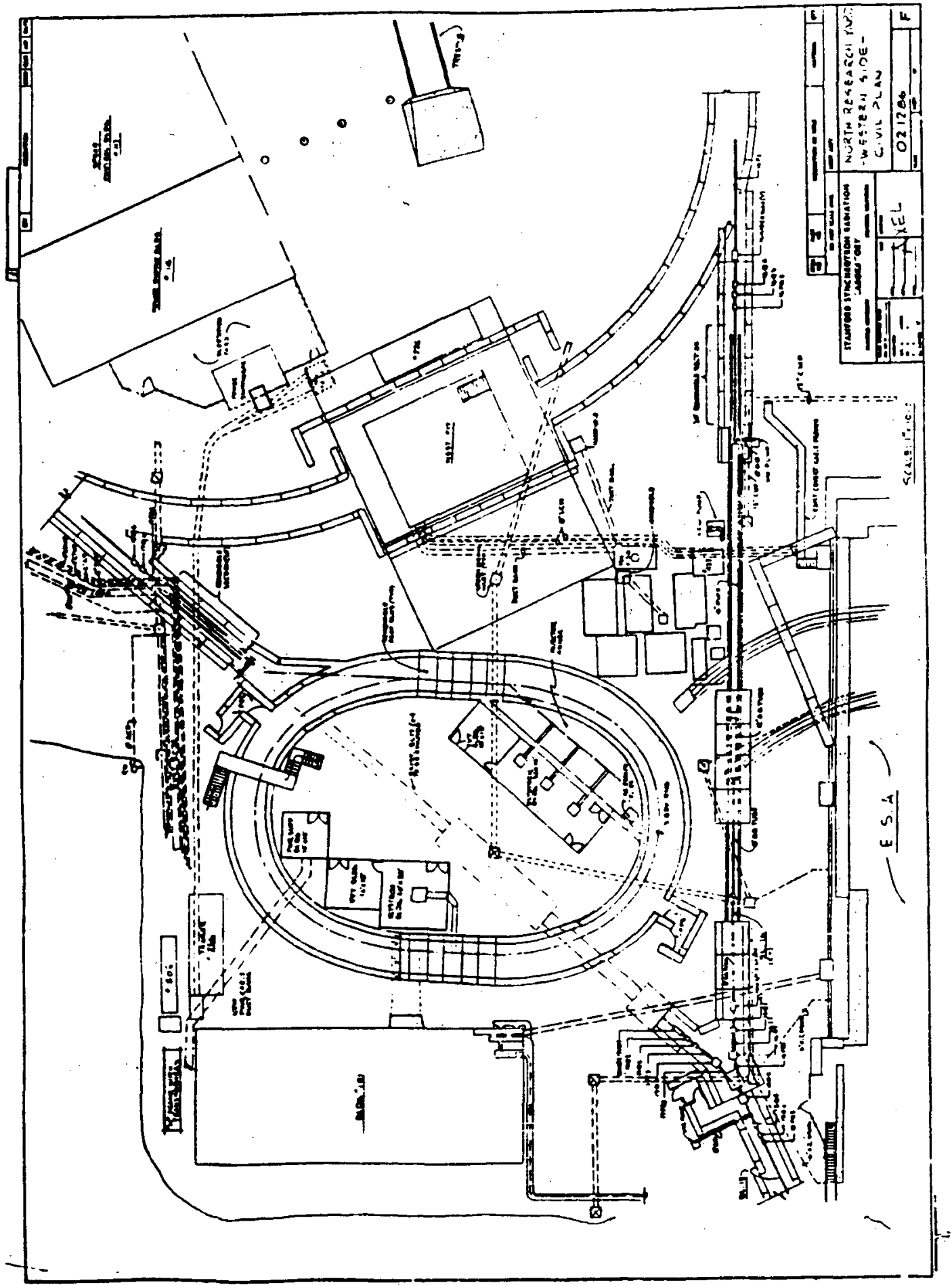

Fig. 26: Injector Utilities Plan 


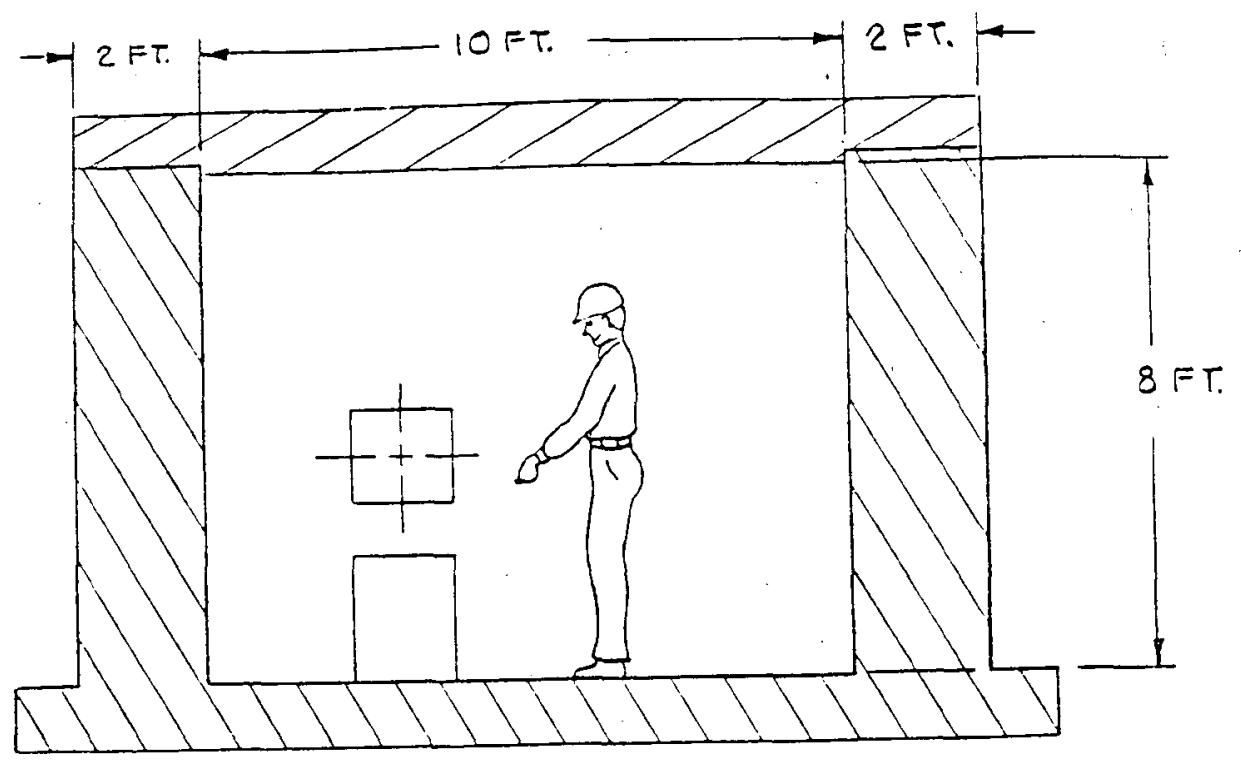

Fig. 27: Ring Shielding Cross Section

voltage transformer and high voltage box, the magnet power supplies and some local electronics.

All shelters will be constructed on a flat surface in part of the SLAC research yard next to the SPEAR storage ring (Figure 1). It is planned to keep the present electron beam line which crosses the synchrotron tunnel operational at least until the synchrotron is commissioned. This is possible since the existing injection line is on a higher elevation than the booster synchrotron beam lines by about 2 feet. The existing electron beam transport line, therefore, is no more than a small beam pipe just underneath the shielding roof where it crosses the ring tunnel.

Most of the ring tunnel walls will be constructed by poured reinforced concrete. It will, however, have removable roof blocks for easy installation of large equipment like the RF cavity. 


\subsection{Safety}

Radiation safety around the SPEAR injector is provided by the passive shielding method as described above. In addition there will be radiation monitoring in accordance with present practice at SLAC and in the vicinity of the SPEAR shielding enclosure.

Personnel safety interlocks will be installed to prevent access to the ring enclosure during operation as well as to exclude beam from enclosures when personnel are present. These interlocks will be of the same design as those employed at SPEAR.

Safety rules will follow the Carlifornia safety code. During installation tunnel safety will be monitored by the SSRL safety group while the primary responsibility for providing and maintaining a safe environment lies with the head of the injector project. The safety group will monitor the safety of operations and review the safety aspects of equipment, structures and shielding associated with installation and operation.

Emergency power will be provided in the tunnel for lighting and protection of sensitive equipment.

All shelters designed such as to comply with the strict SLAC earthquake standards.

Fire safety has been coordinated with the local Palo Alto fire department to insure proper access. For small emergencies fire extinguishers will be located in each of the enclosures. 



\section{Management Plan}

The $3 \mathrm{GeV}$ SPEAR Injector Project Management Plan is under separate cover inasmuch as the plan is subject to regular updating.

In brief, the Project Management Plan (PMP) describes in some detail, the SSRL management procedures that will be used to guide and monitor the Injector Project. The PMP is modeled, to a considerable extent, upon the approved SEP (I) Project Management Plan, plus the requirements of DOE Order 5700.4A.

The Injector Project PMP defines the responsibilities for reporting and review procedures for the project technical, cost and schedule baselines and specifies a system for effecting changes to the established baselines. Organizational realtionships between the Injector Project, SSRL, SLAC, Stanford University administration, the DOE Stanford Site Office (SSO), the DOE San Francisco Operations Office at Oakland (SAN) and the Office of Basic Energy Sciences (BES) are described in the PMP. The various responsibilities and authorities of these organizational units are defined in the plan. The Injector Project PMP also defines the technical specifications of the project and the related performance criteria.

A brief summary of the critical elements of the PMP is given in the following paragraphs.

SSRL will, through the Associate Director for the Accelerator Division and its staff, provide the leadership for directing and coordinating the design and construction activities. This group will have primary responsibility for the design, planning and execution of the project. A small administrative staff within this division will provide the planning, preparation and control of the budget, supervise the schedule and prepare reporting documents as required. These efforts will be supplemented by special assignment of personnel from other SSRL Divisions to the injector project as required. The implementation of the vacuum system for the injector is planned to be performed through the SSRL vacuum group. The SSRL administrative 
staff will be available for special functions like personnel matters, contract administration, receiving and inventory. Purchasing is expected to be done similar to present practice, through the SLAC purchasing department.

The SPEAR injector construction phase is assumed to start at the beginning of FY'1988. By that time an experienced group of engineers and designers will become available from the phase down of the construction effort for the $1.2 \mathrm{GeV}$ high brilliance storage ring at the Stanford Photon Research Laboratory, SPRL.

The technical systems fabrication is planned to be performed to the maximum extent possible by outside industry through competitive bidding. This procedure also has been applied to the construction of the SPRL 1.2 $\mathrm{GeV}$ storage ring and it has been established that outside industry has the ability to fabricate the required components to the specified tolerances, schedule and within cost estimates. To make maximum use of industry's capabilities it is planned to perform all design by inhouse staff and invite bids on subsystems not to exceed the experience and capability of one vendor. The construction group then again takes responsibility for quality control, assembley, test and overall functioning of the systems. This mode of operation does not require the vendors to expand beyond the limits of their expertise and therfore allows many small businesses to effectively compete for contracts.

In this scenario it is obvious that SLAC shops will be invited to participate in the fabrication of injector components as such resouces become available and don't interfere with other SLAC activities. 


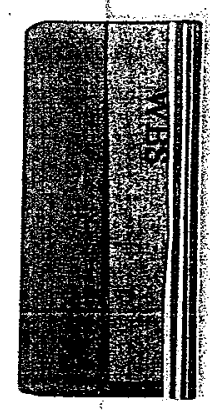


WBS (Level 3) for the SPEAR Injector System

1 The $3 \mathrm{GeV}$ Spear Injector System

1.1 Special Facilities

1.1.0 Non Technical Facilities

1.1.1 Electrical Services

1.1.2 Mechanical Services

1.1.3 Safety Systems

1.1.4 Preinjector

1.1.5 Magnet System

1.1.6 Vacuum System

1.1.7 RF System

1.1.8 Instrumentation and Control

1.1.9 Injection and Ejection

1.2 Project Management and Administration

1.2.1 Technical Project Management

1.2.2 Administrative Services 


\section{WBS (Level 4) for the SPEAR Injector System}

1 The $3 \mathrm{GeV}$ Spear Injector System

1.1 Special Facilities

1.1.0 Non Technical Facilities

1.1.0.0 E D \& I

1.1.0.1 Site Preparation

1.1.0.2 Shelters

1.1.1 Electrical Services

1.1.1.0 E D \& I

1.1.1.1 AC Services

1.1.2 Mechanical Services

1.1.2.0 E D \& I

1.1.2.1 LCW Cooling System

1.1.3 Safety Systems

1.1.3.1 Fire Safety

1.1.4 Preinjector

1.1.4.0 E D \& I

1.1.4.1 Gun Assembly

1.1.4.2 Accelerator Sections

1.1.4.3 Modulators

1.1.4.4 Klystrons

1.1.4.5 Controls

1.1.4.6 Linac Vacuum

1.1.4.7 Beam Diagnostics 
1.1.5 Magnet System

1.1.5.0 E D \& I

1.1.5.1 Magnets

1.1.5.2 Magnet Support

1.1.5.3 Alignment

1.1.5.4 Magnet Measurement

1.1.5.5 Magnet Power Supplies

1.1.6 Vacuum System

1.1.6.0 E D \& I

1.1.6.1 Vacuum Chambers

1.1.6.2 Pumping System

1.1.6.3 Pressure Monitoring

1.1.6.4 Cleaning/Installation

1.1.7 RF System

1.1.7.0 E D \& I

1.1.7.1 RF Power Generation

1.1.7.2 RF Cavity

1.1.7.3 Low Level RF System

1.1.7.4 Computer Interface

1.1.8 Instrumentation and Control

1.1.8.0 E D \& I

1.1.8.1 Beam Diagnostics

1.1.8.2 Control Systems

1.1.8.3 Protection System

1.1.8.4 Communications

1.1.9 Injection and Ejection

1.1.9.0 E D \& I

1.1.9.1 Transport Lines 


\subsubsection{Pulsed Magnets \\ 1.1.9.3 Instrumentation}

1.2 Project Management and Administration

1.2.1 Technical Project Management

1.2.1.1 Technical Coordination

1.2.1.2 Accelerator Physics

1.2.1.3 Installation Coordination and Quality Control

1.2.2 Administrative Services

1.2.2.1 Project Planning and Budget Office

1.2.2.2 SSRL Administration Services 
WBS (Level 5) for the SPEAR Injector System

1 The $3 \mathrm{GeV}$ Spear Injector System

1.1 Special Facilities

1.1.0 Non Technical Facilities

1.1.0.0 E D \& I

1.1.0.1 Site Preparation

1.1.0.2 Shelters

1.1.0.2.1 Ring/Linac Tunnel

1.1.0.2.1.1 Concrete Floor

1.1.0.2.1.2 Ring Wall/Roof

1.1.0.2.2 Equipment Shelter

1.1.0.2.2.1 Ring Klystron

1.1.0.2.2.2 Linac Klystrons

1.1.0.2.2.3 PS/VVT Shelter

1.1.1 Electrical Services

1.1.1.0 E D \& I

1.1.1.1 AC Services

1.1.2 Mechanical Services

1.1.2.0 E D \& I

1.1.2.1 LCW Cooling System

1.1.3 Safety Systems

1.1.3.1 Fire Safety 


\subsection{RF/Cavity System}

1.1.4.1.3 Focusing and Steering

1.1.4.1.4 Momentum Filter

1.1.4.1.5 Beam Diagnostics

1.1.4.1.6 Vacuum System

1.1.4.2 Accelerator Sections

1.1.4.3 Modulators

1.1.4.3.1 HV Power Supply

1.1.4.3.2 Pulse Forming Network (PFN)

1.1.4.3.3 Controls

1.1.4.4 Klystrons

1.1.4.4.1 Tube

1.1.4.4.2 Focusing

1.1.4.4.3 Tank and Cable

1.1.4.5 Controls

1.1.4.5.1 Master Oscillator

1.1.4.5.2 RF Drive

1.1.4.5.3 Timing System

1.1.4.5.4 Diagnostics

\subsubsection{Linac Vacuum}

1.1.4.7 Beam Diagnostics

1.1.4.7.1 Beam Position Monitors

1.1.4.7.2 Current/Charge Monitor

1.1.4.7.3 Beam Steering

1.1.4.7.4 Beam Focusing

1.1.4.7.5 Analyzing Station

1.1.5 Magnet System

1.1.5.1 Magnets 
1.1.5.1.1 Bending Magnets

1.1.5.1.2 Quadrupoles

1.1.5.1.3 Spec. Magnets

1.1.5.2 Magnet Support

1.1.5.3 Magnet Alignment

1.1.5.4 Magnetic Measurement

1.1.5.5 Magnet Power Supplies

1.1.6 Vacuum System

1.1.6.1 Vacuum Chambers

1.1.6.1.1 Bending Chambers

1.1.6.1.2 Quad Chambers

1.1.6.1.3 Straight Section Chambers

1.1.6.2 Pumping System

1.1.6.2.1 Roughing System

1.1.6.2.2 Ion Pumping System

1.1.6.3 Pressure Monitoring

1.1.6.4 Cleaning/Installation

1.1.7 RF System

1.1.7.1 RF Power Generation

1.1.7.1.1 $350 \mathrm{MHz}$ Klystron

1.1.7.1.2 Klystron HV Supply

1.1.7.2 RF Cavity

1.1.7.3 Low Level RF System

1.1.7.4 Computer Interface

1.1.8 Instrumentation and Control

1.1.8.1 Beam Diagnostics

1.1.8.1.1 Beam Position Monitors 
1.1.8.1.2 Intensity Monitoring

1.1.8.1.3 Timing System

1.1.8.2 Control Systems

1.1.8.2.1 Interface/Controllers

1.1.8.2.2 Software

1.1.8.2.3 Racks, Cables, Trays

1.1.8.2.4 Computer Interface

1.1.8.3 Protection System

1.1.8.4 Communications

1.1.9 Injection and Ejection

1.1.9.1 Transport Lines

1.1.9.1.1 Linac Booster

1.1.9.1.2 Booster-SPEAR 3.0 GeV

1.1.9.1.3 Power Supplies

1.1.9.1.4 Vacuum System

1.1.9.2 Pulsed Magnets

1.1.9.1.1 Kicker Magnets

1.1.9.1.2 Septum Magnets

1.1.9.3 Instrumentation

1.2 Project Management and Administration

1.2.1 Technical Project Management

1.2.1.1 Technical Coordination

1.2.1.2 Accelerator Physics

1.2.1.3 Installation Coordination and Quality Control

1.2.2 Administrative Services

1.2.2.1 Project Planning and Budget Office

1.2.2.2 SSRL Administration Services 


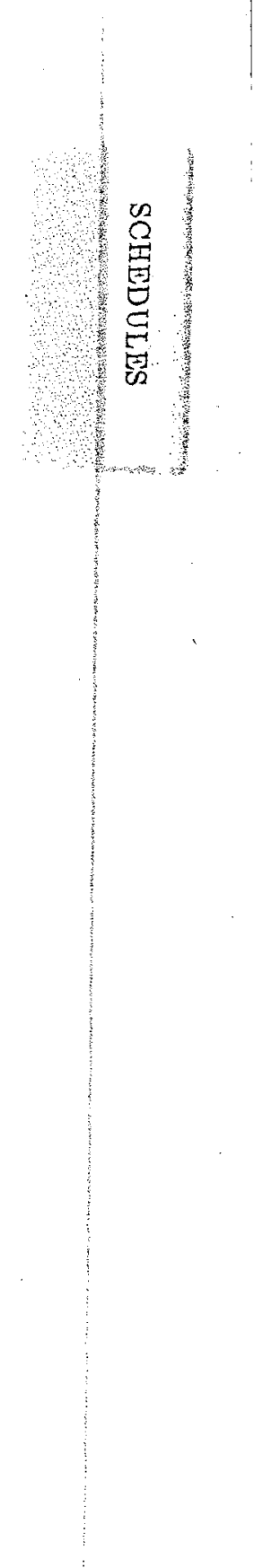




\section{Schedule}

A project schedule has been developed on the assumptions that construction funds become available at $\$ 3.0 \mathrm{M}$ for $\mathrm{FY}$ '88, $\$ 7.5 \mathrm{M}$ for FY'89 and, $\$ 3.0 \mathrm{M}$ for FY'90. With these assumption the injector system can be completed within 27 months. At that time, January 1990, beam tests in the preinjector linac are scheduled to be completed and beam tests in the booster synchrotron can begin. SPEAR injection tests could begin as early as March 1990. The actual start of the SPEAR injection tests, however, will depend on the SPEAR running schedule to minimize interference with the ongoing SSRL and high energy physics programs.

A summary as well as a more detailed schedule is shown in the following pages. A list of general project milestones as well as critical milestones is given in this section. 


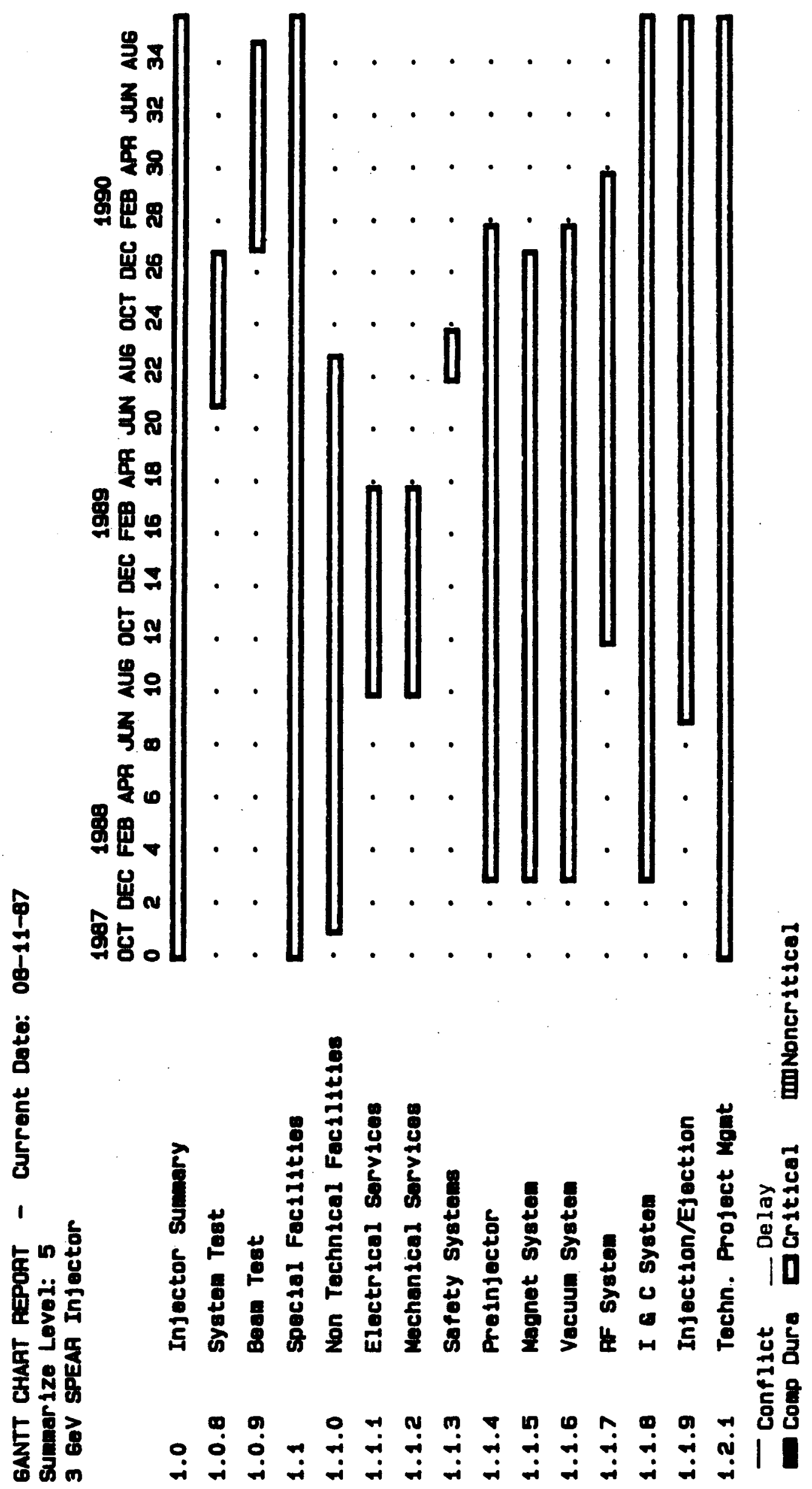




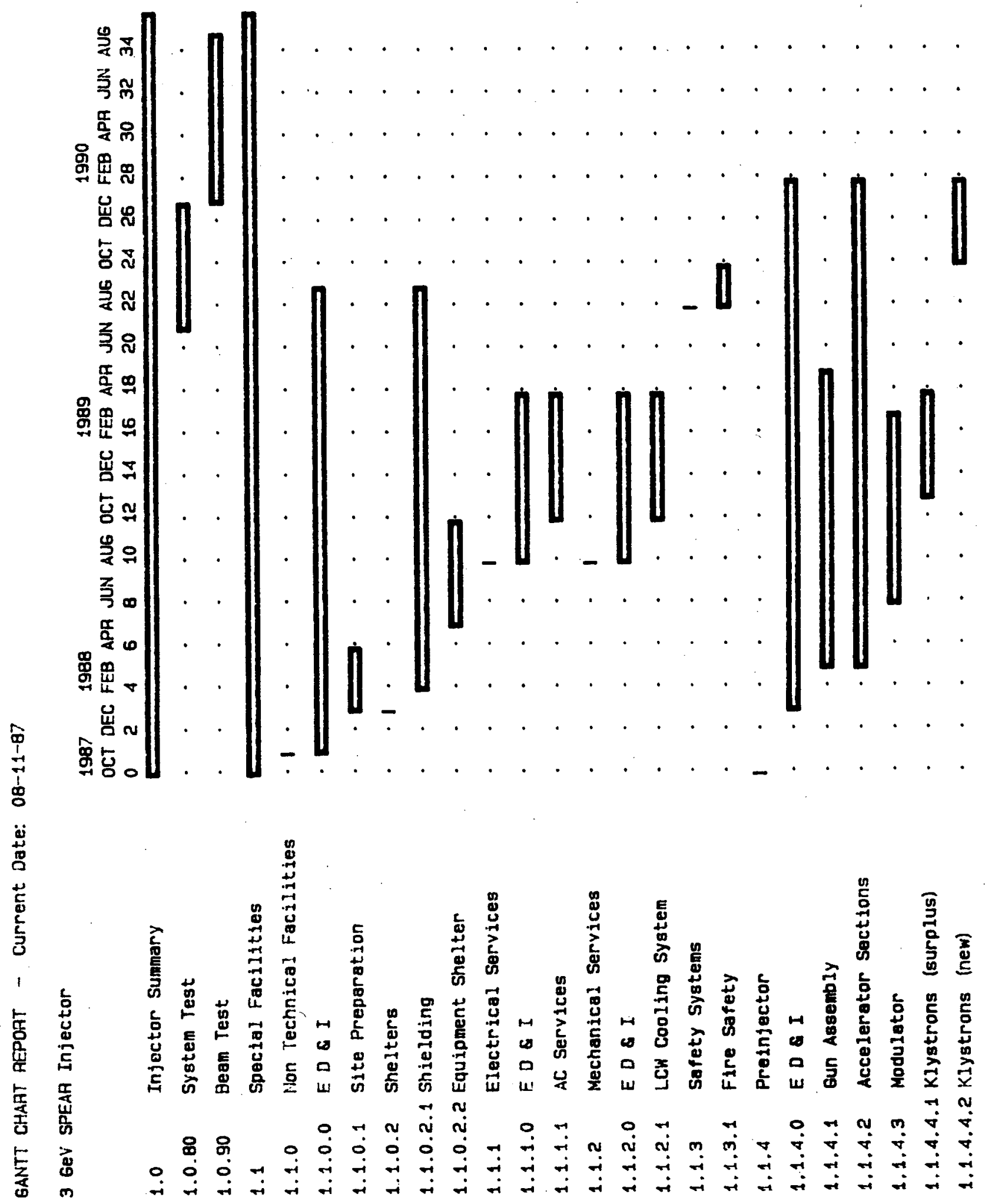



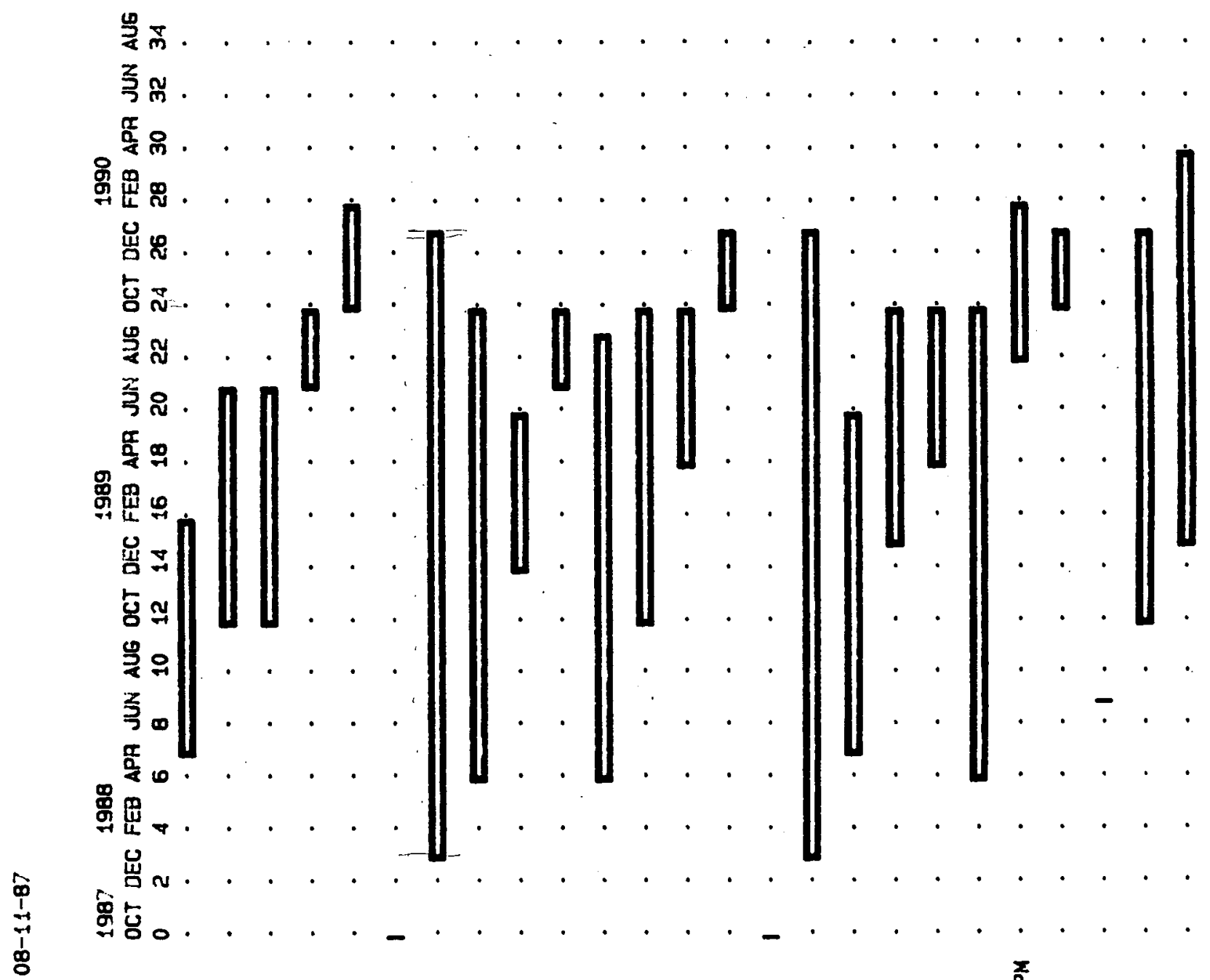

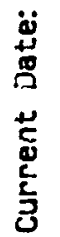

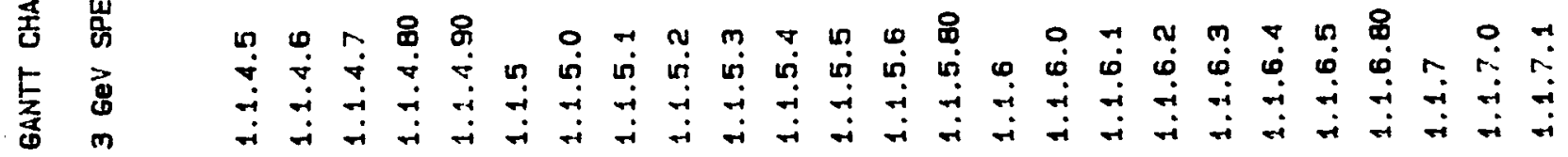




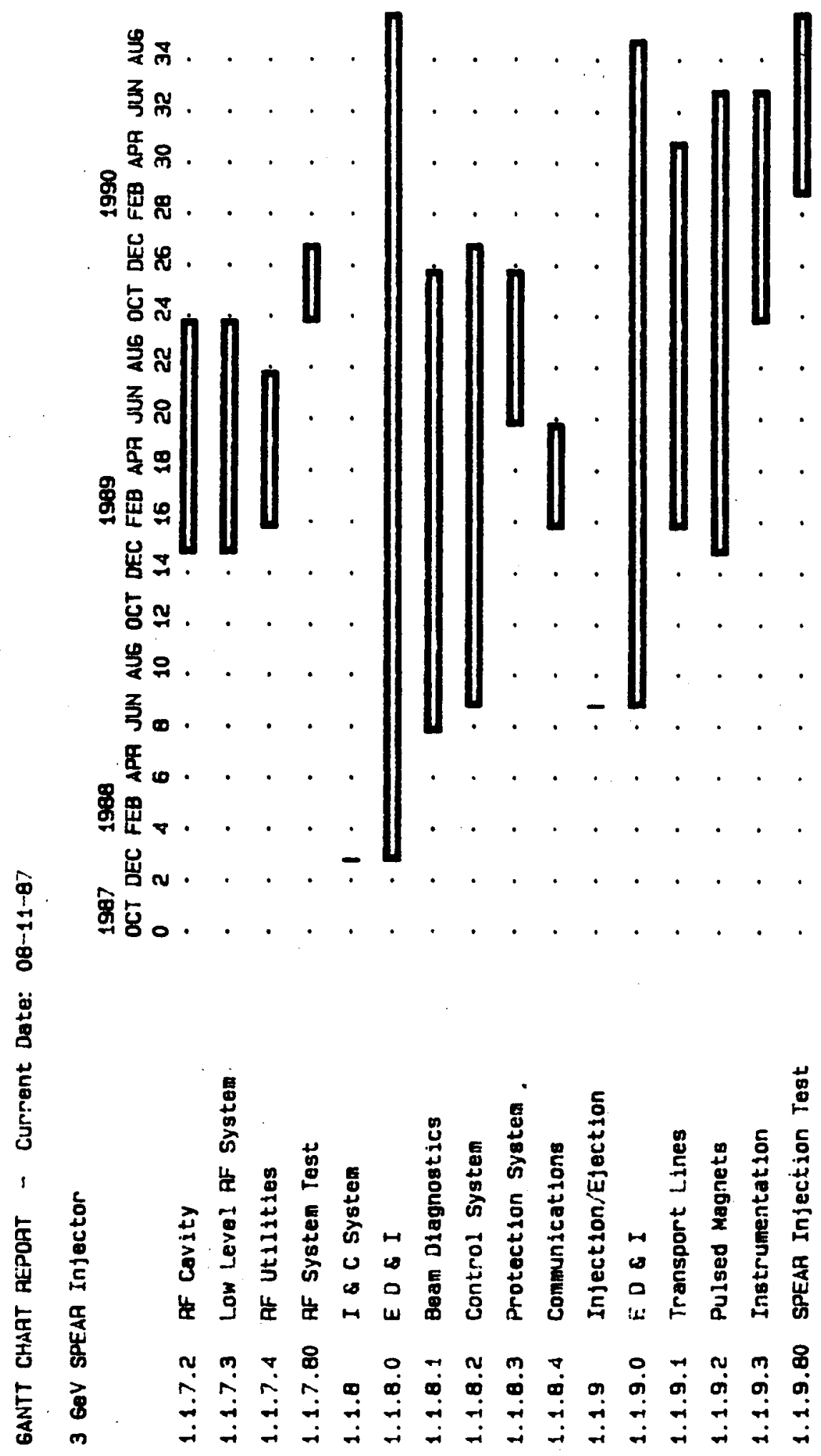




\section{Booster Milestones}

\begin{tabular}{|c|c|c|c|}
\hline & Milestones & Date & $\begin{array}{l}\text { On } \\
\text { Critical } \\
\text { Path }\end{array}$ \\
\hline Funding & Start & $10 / 87$ & YES \\
\hline Facilities & $\begin{array}{l}\text { Equipment Shelters } \\
\text { Electrical Utilities } \\
\text { Mechanical Utilities } \\
\text { Shielding }\end{array}$ & $\begin{array}{c}10 / 88 \\
4 / 89 \\
4 / 89 \\
9 / 89\end{array}$ & YES \\
\hline Linac & $\begin{array}{l}\text { Order Accelerating Sections } \\
\text { Gun Test (Mod \& Klystrons) } \\
\text { Linac Beam Test }\end{array}$ & $\begin{array}{c}5 / 88 \\
5 / 89 \\
10 / 89\end{array}$ & $\begin{array}{l}\text { YES } \\
\text { YES }\end{array}$ \\
\hline Magnet & $\begin{array}{l}\text { Place Main Magnets Orders } \\
\text { Order Big Power Supplies } \\
\text { Power Supply Test } \\
\text { Start Magnet Installation } \\
\text { Finish Magnet Installation } \\
\text { System Tests }\end{array}$ & $\begin{array}{c}4 / 88 \\
10 / 88 \\
10 / 89 \\
4 / 89 \\
10 / 89 \\
10 / 89\end{array}$ & $\begin{array}{l}\text { YES } \\
\text { YES } \\
\text { YES } \\
\text { YES }\end{array}$ \\
\hline Vacuum & $\begin{array}{l}\text { Place Vacuum Chamber Order } \\
\text { Install Vacuum Chambers } \\
\text { Pumpdown }\end{array}$ & $\begin{array}{r}5 / 88 \\
2 / 89 \\
10 / 89\end{array}$ & YES \\
\hline $\mathrm{RF}$ & $\begin{array}{l}\text { Cavity Cold Test } \\
\text { RF System Test }\end{array}$ & $\begin{array}{l}10 / 88 \\
10 / 89\end{array}$ & YES \\
\hline IC & $\begin{array}{l}\text { Complete Timing System } \\
\text { Complete Linac Diagnostics } \\
\text { Systems Tests Complete }\end{array}$ & $\begin{array}{r}9 / 89 \\
10 / 89 \\
12 / 89\end{array}$ & $\begin{array}{l}\text { YES } \\
\text { YES }\end{array}$ \\
\hline Inject./Eject. & $\begin{array}{l}\text { Complete Kicker Magnet } \\
\text { System Test } \\
\text { (Contingent on SPEAR schedule) }\end{array}$ & $\begin{array}{c}10 / 89 \\
3 / 90\end{array}$ & YES \\
\hline Project & $\begin{array}{l}\text { Start Commissioning Booster } \\
\text { Start Injection into SPEAR } \\
\text { (Contingent on SPEAR schedule) } \\
\text { Project Complete }\end{array}$ & $\begin{array}{l}1 / 90 \\
5 / 90 \\
9 / 90\end{array}$ & $7 / 90$ \\
\hline
\end{tabular}


粍

a 
This section of the CDR presents summarized and detailed cost estimates of the $3 \mathrm{GeV}$ SPEAR Injector Project. Computer-generated rounding-off errors account for slight differences between some of the estimate totals.

\subsection{OBLIGATIONS AND COSTS ESTIMATE SUMMARY}

The following table shows the summary of the estimated obligations and costs (in thousands) for the three-year project. This arrangement of the estimated obligations and costs corresponds to the construction Project Data Sheets.

TITLE

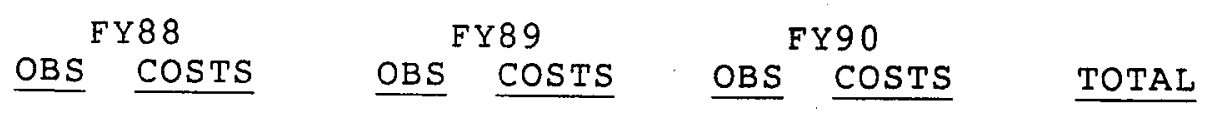

\section{GEV INJECTOR}

\begin{tabular}{|c|c|c|c|c|c|c|c|}
\hline $\begin{array}{l}\text { Special Facil } \\
\text { Engrng \& Design } \\
\text { Proj Mgmt \& Adm }\end{array}$ & $\begin{array}{r}1,878 \\
504 \\
187\end{array}$ & $\begin{array}{r}1,729 \\
504 \\
187\end{array}$ & $\begin{array}{r}5,315 \\
1,148 \\
183\end{array}$ & $\begin{array}{r}5,342 \\
1,148 \\
183\end{array}$ & $\begin{array}{r}1,848 \\
336 \\
220\end{array}$ & $\begin{array}{r}1,970 \\
336 \\
220\end{array}$ & $\begin{array}{r}9,041 \\
1,988 \\
590\end{array}$ \\
\hline $\begin{array}{l}\text { Subtotal } \\
\text { Contingencies }\end{array}$ & $\begin{array}{r}2,569 \\
431\end{array}$ & $\begin{array}{r}2,420 \\
432\end{array}$ & $\begin{array}{r}6,646 \\
854\end{array}$ & $\begin{array}{r}6.673 \\
853\end{array}$ & $\begin{array}{r}2,404 \\
596\end{array}$ & $\begin{array}{r}2.526 \\
596\end{array}$ & $\begin{array}{r}11,619 \\
1,881\end{array}$ \\
\hline Total & 3,000 & 2,852 & 7,500 & 7,526 & 3,000 & 3,122 & 13,500 \\
\hline
\end{tabular}

\subsection{ESCALATION FACTORS}

The FY1986 baseline costs were escalated with the escalation factors shown below. The source for these factors is the Anticipated Economic Escalation Rates for. Energy Research Construction Projects, August 1986 update.

$\begin{array}{lll} & \text { RATE } & \text { FACTOR } \\ \text { FY86 - FY87 } & 2.5 \% & 1.025 \\ \text { FY87 - FY88 } & 4.0 \% & 1.066 \\ \text { FY88 - FY89 } & 4.8 \% & 1.117 \\ \text { FY89 - FY90 } & 5.3 \% & 1.176\end{array}$

7.3 CONTINGENCIES

The contingencies on the various tasks under the project have been 
estimated separately for different systems depending on the complexity and the exposure to fluctuating economic factors. Systems which are very well defined and for which local industry has been tested carry a minimum $15 \%$ contingency. The booster RF system, being an exact replication of the system for the stanford Photon Research Lab storage ring, carries a contingency of only 10\%. A larger. (25\%) contingency must be applied to the Instrumentation and control (I\&C) system and part of the injection and ejection systems since both require incorporation into existing SPEAR systems. Traditionally such incorporations into existing facilities reveal undocumented boundary and interface conditions that require additional funds and design

\subsection{LEVELS 3 AND 4 ESTIMATED OBLIGATIONS AND COSTS}

The tables on the following three pages show the estimated Fy1986 Baseline Costs and the estimated annual (extended) obligations and
costs at Levels 3 and 4 , all rounded to thousands.

\section{3 FY 1986 BASELINE COSTS}

The baseline costs were estimated in FY1986 dollars and are presented in detail following the Level 3 and 4 TEC estimates.

Most of the baseline estimates were based on costs for similar components in recent projects such as the damping rings at sLAC, the $1.2 \mathrm{GeV}$ storage ring under construction at the stanford photon Research Laboratory (SPRL) and on engineering estimates by technical
support groups at SSRL and SLAC. 
INJECT4

DISK $4 / 48$

$8 / 11 / 87$

SPEAR 3 GEV INJECTOR EXTENDED OBLIGATIONS AND COSTS

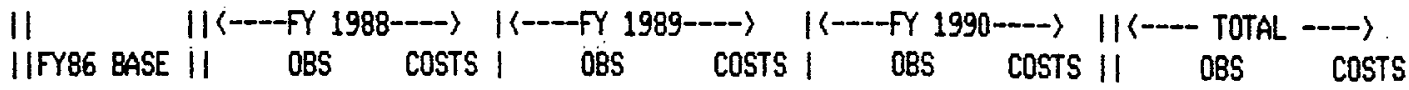

A116

LEVEL 3 SUMARY

13 GEV SPEAR INJECTOR

1.1 SPECIAL FACILITIES

$1.1 .0-$ NON-TECH FACILITIESII

1I

1.1.1 ELECTRICAL SERUICESII

1.1.2 MECHANICAL SERUICESII

1.1 .3 SAFETY SYSTEMS

1.1.4 PREINJECTOR

1.1.5 MAGNET SYSTEMS

1.1.6 VACULM SYSTEM

1.1.7 RF SYSTEM

1.1.8 INST \& CONTROL

1.1.9 INJECTIONEJECTION SUBTOTAL 1.1
II<smiles>[V]=[Tl]</smiles><smiles>[V]=C1CCCCC1</smiles>

67911

3711

$376 \| 19$

309 i1

11

2011

1,29211

$1,29211 \quad 566$

1,91911

659

75611

11

1,21311

1,62211

-

8,344 II
$482 \quad 433 !$

$19 \quad 19$

19

0

587

267

267

0

230

230

28

$\overline{2,198}$

19

01

466

587

267

1.2 PROJECT MANGGEMENT AND AOMINISTRATION

1.2.0 TECH PROU YOMT

1.2.1 ADMIN SERUICES SUBTOTAL 1.2

TUTAL WITHOUT CONTINGENCY

CONTINGENCY

TOTAL ESTIMATED COSTS (TEC) R159

$11 \quad 11$

$$
1,195:
$$

242

36511

$36511 \quad 129$

1,560

11

10,404

II

II 1,676 ॥

11 - - 11

12,08011

0118

$267 \mid 411$

01.643

\begin{tabular}{l|l}
230 & 935
\end{tabular}

281925

\begin{tabular}{r|r}
----1 & - \\
\hline 2,049 & 5,979
\end{tabular}

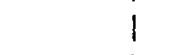

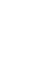


INJECT4

DISK $4 / 48$

$8 / 11 / 87$

$==$
A5

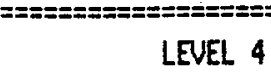

13 GEV SPEAR INJECTOR

1.1 SPECIAL FACILITIES

1.1 .0 NON-TECHNICAL FACILITIES

1.1.0.0 EDSI

1.1.0.1 Site Preparation II

1.1.0.2 Shelters

Subtotal

II.

1.1 .1 ELECTRICAL SERUICESII

1.1 .1 .0 EDSI II

1.1.1.1 AC Services II

Subtotal

1.1.2 MECHANICAL SERUICESII

1.1.2.0 ED\&I II

1.1.2.1 LCW Cooling sys 11

Subtotal

1.1.3 SAFETY SYSTEMS II

1.1.3.1 Fire Safety

1.1.4 PREINJECTOR

1.1 .4 .0 ED\&I

1.1.4.1 Gun Assy
1.1 .4 .2

1.1 .4 .3

1.1 .4 .4

1.1 .4 .5

1.1 .4 .6

1.1 .4 .7

1.1.5 MAENET SYSTEM

1.1 .5 .0 EDSI

1.1.5.1 Magnets

1.1 .5 .2

1.1.5.3

1.1 .5 .4

1.1 .5 .5

1.1.5.6

Accel Sections II

Modulators

Klystrons

Controls

Linac Vacuum II

Beam Diagnostics II

Subtotal

Magnet Suprt

Magnet Align II

Magnetic Measure 11

Power Supls II

Magnet Install II

Suttotal

1.1 .6 UACULM SYSTEM

1.1.6.0 EDCI

1.1 .6 .1

Vacuum Chanters

1.1.6.2 Pumping Sys

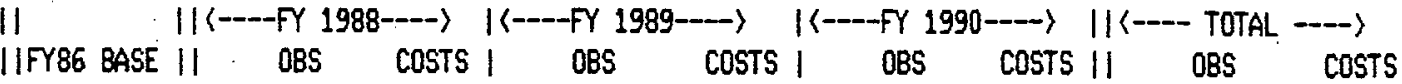

I II

II

II

II

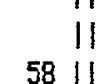

4011

58111

$---11$

67911<smiles>C1CCCC1</smiles>

5211

3241

$---11$

376

11

11

5311

256

$---11$

30911

II

11

2011

11

21511

158 ।

26611

30011

153 ।

9511

46 II

59 ।I

--- 11

1,292

II

40011

7331

21811

5011

9811

33711

8311

-..- 11

1,919

II

16211

147 |I

8811

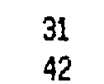

409

$---$

.

19

$\begin{array}{r}0 \\ --- \\ \hline 19\end{array}$

19

19

0
-19$$
19
$$$$
0
$$

104

76

169

161

0
56

56

0

0

566

162

298

70

0
57

57

0

0

587

65

125

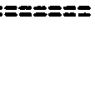

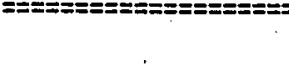

|
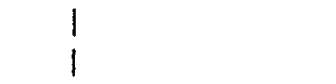

1
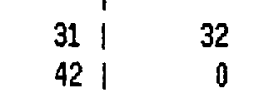

32
0

360

220

433

252

19

\begin{tabular}{r|r}
19 & 39 \\
0 & 362 \\
-1 & -0
\end{tabular}

401

1

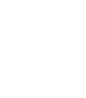

19139

01286

\begin{tabular}{r|r}
--1 & -1 \\
-19 & 325
\end{tabular}

1

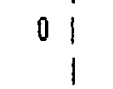

18

1041

107

76

691

98

$161 \mid 166$

0126

$561 \cdot 47$

0151

0166

-01 -

466

597

$162 !$

298

221

506

$701 \quad 170$

0156

$571 \quad 49$

01377

0193

93

5871,472

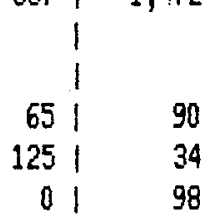

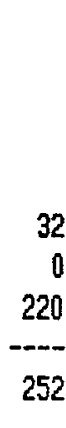

(5)

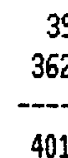

401

1
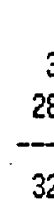

286

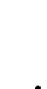

18

1

$$
981
$$

133

166

26

47

511

661

694

694

(1)

221

506

170

561

49

307 I

931

$---1$
129

901

341

241

981

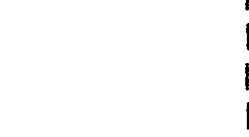

2,118

2,118
II

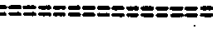

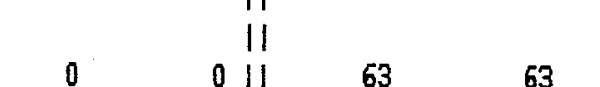

9

34

8

420

8
6
4
4
3

6
4
3
7
9
3
1
6
-
9


INJECT4 SPEAR 3 GEV INJECTOR EXTENDED OBLIGATIONS AND COSTS
DISK $4 / 48$

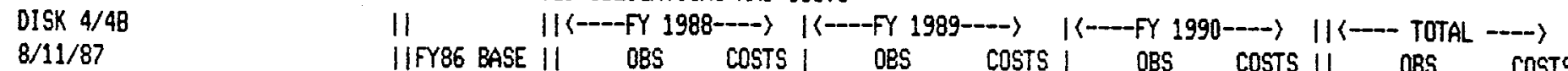

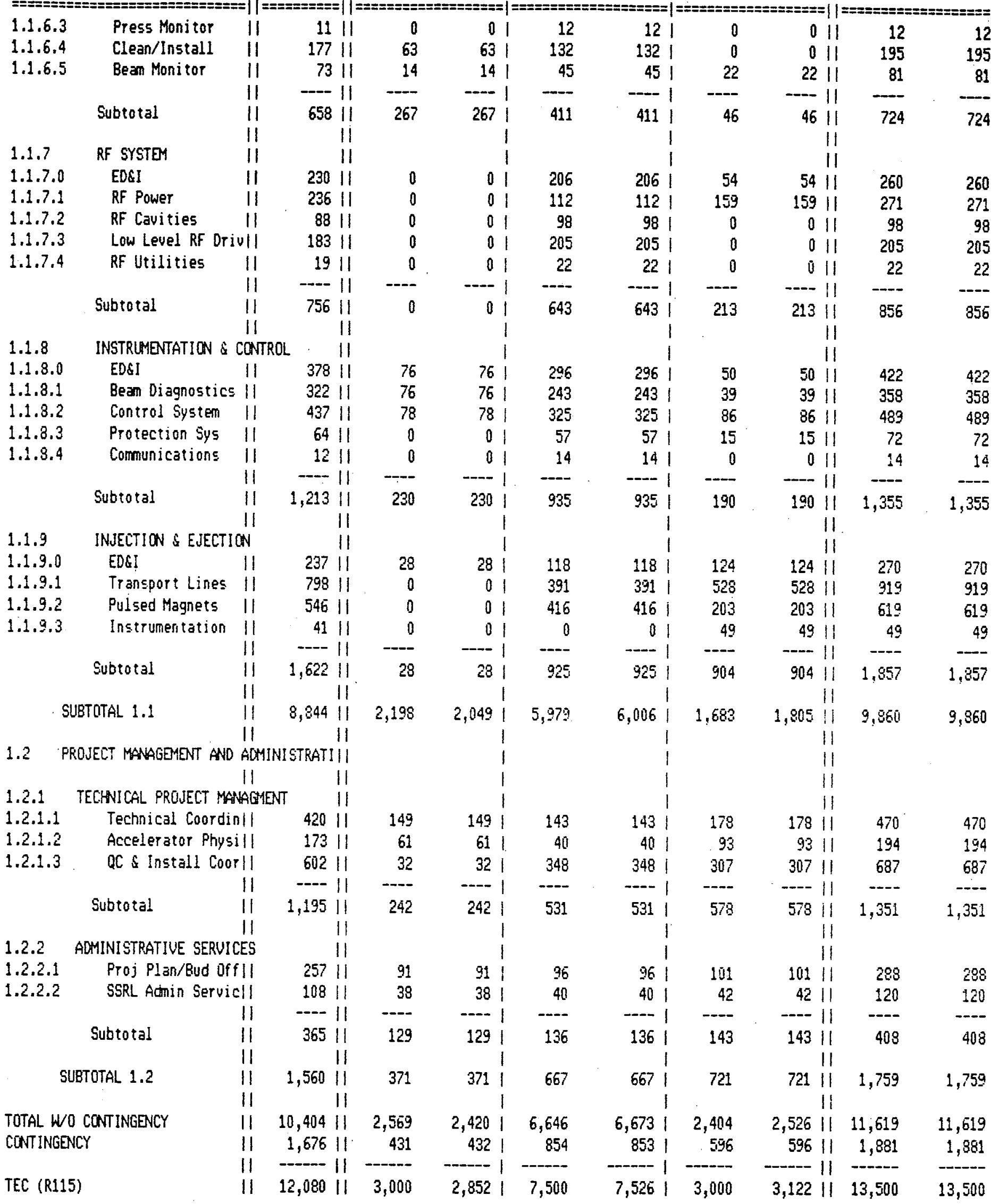


Base Line Cost Estimate (FY'86 Dollars)

\begin{tabular}{|c|c|c|c|c|c|c|c|c|}
\hline \multirow{2}{*}{$\begin{array}{l}\text { Component/Activity } \\
======= \pm======= \pm=== \\
\text { Non Tech. Systems } \\
\text { E \& \& I } \\
\text { Site Preparation } \\
\text { Shelters }\end{array}$} & WBS & \multicolumn{2}{|c|}{$\begin{array}{c}\text { Base Line Budget } \\
\text { by Systems } \\
\text { Materials Labor }\end{array}$} & 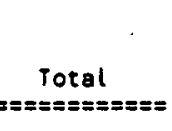 & \multicolumn{2}{|r|}{$\begin{array}{c}\text { Base Line } \\
1989\end{array}$} & $\begin{array}{c}\text { Cost FY'B6 } \\
1990\end{array}$ & $\begin{array}{c}5 \text { Dollars } \\
3 \text { Year } \\
\text { summary }\end{array}$ \\
\hline & $\begin{array}{l}1.1 .0 .0 \\
1.1 .0 .1 \\
1.1 .0 .2\end{array}$ & $\begin{array}{r}0 \\
: 3,890 \\
544,888\end{array}$ & $\begin{array}{l}57,703 \\
20,922 \\
36,280\end{array}$ & $\begin{array}{r}57,703 \\
39,812 \\
581,168\end{array}$ & $\begin{array}{r}28,852 \\
39,812 \\
384,077\end{array}$ & $\begin{array}{r}28,852 \\
0 \\
197,091\end{array}$ & $\begin{array}{l}0 \\
0 \\
0\end{array}$ & $\begin{array}{r}57,703 \\
39,812 \\
581,168\end{array}$ \\
\hline $\begin{array}{l}\text { Electr. Services } \\
\text { E D \& I } \\
\text { AC Services } \\
\text { Mechan. Services }\end{array}$ & $\begin{array}{l}1.1 .1 .0 \\
1.1 .1 .1\end{array}$ & $223,487^{0}$ & $\begin{array}{r}52,491 \\
100,872\end{array}$ & $\begin{array}{r}52,491 \\
324,359\end{array}$ & $\begin{array}{r}17,697 \\
0\end{array}$ & $\begin{array}{r}34,994 \\
324,359\end{array}$ & $\begin{array}{l}0 \\
0\end{array}$ & $\begin{array}{r}52,491 \\
324,359\end{array}$ \\
\hline $\begin{array}{l}\text { E } 0 \text { \& } 1 \\
\text { LCW Cool ing system }\end{array}$ & $\begin{array}{l}1.1 .2 .0 \\
1.1 .2 .1\end{array}$ & $\begin{array}{r}0 \\
174,935\end{array}$ & $\begin{array}{l}52,828 \\
81,096\end{array}$ & $\begin{array}{r}52,828 \\
256,031\end{array}$ & $\begin{array}{r}17,609 \\
0\end{array}$ & $\begin{array}{r}35,219 \\
256,030\end{array}$ & $\begin{array}{l}0 \\
0\end{array}$ & $\begin{array}{r}52,828 \\
256,030\end{array}$ \\
\hline $\begin{array}{l}\text { Safety Systems } \\
\text { Fire Safety } \\
\text { Preinjector }\end{array}$ & 1.1 .3 .1 & 20,000 & 0 & 20,000 & 0 & 15,830 & 4,170 & 20,000 \\
\hline $\begin{array}{l}\text { E O \& I } \\
\text { Gun Assembly } \\
\text { Accel. Sections } \\
\text { Modul ators } \\
\text { Klystrons } \\
\text { Controls } \\
\text { Linac Vacum } \\
\text { Beam Diagnostics } \\
\text { Magnet System }\end{array}$ & $\begin{array}{l}1.1 \cdot 4.0 \\
1.1 .4 .1 \\
1.1 .4 .2 \\
1.1 .4 .3 \\
1.1 .4 .4 \\
1.1 .4 .5 \\
1.1 .4 .6 \\
1.1 .4 .7\end{array}$ & $\begin{array}{r}0 \\
113,330 \\
246,354 \\
224,667 \\
128,601 \\
88,308 \\
42,235 \\
44,731\end{array}$ & $\begin{array}{r}214,709 \\
45,055 \\
19,192 \\
75,076 \\
24,724 \\
6,476 \\
3,286 \\
14,302\end{array}$ & $\begin{array}{l}214,709 \\
158,384 \\
265,546 \\
299,743 \\
153,325 \\
94,784 \\
45,521 \\
59,032\end{array}$ & $\begin{array}{r}97,597 \\
70,909 \\
158,304 \\
151,400 \\
0 \\
52,658 \\
0 \\
0\end{array}$ & $\begin{array}{r}95,641 \\
87,475 \\
32,242 \\
148,342 \\
23,601 \\
42,126 \\
45,521 \\
59,032\end{array}$ & $\begin{array}{r}21,471 \\
0 \\
75,000 \\
0 \\
129,724 \\
0 \\
0 \\
0\end{array}$ & $\begin{array}{r}214,709 \\
158,384 \\
265,546 \\
299,743 \\
153,325 \\
94,784 \\
45,521 \\
59,032\end{array}$ \\
\hline $\begin{array}{l}\text { E \& \& } \\
\text { Magnets } \\
\text { Magnet Support } \\
\text { Magnet Al i grment } \\
\text { Magnet ic Measurem. } \\
\text { Power Supplies } \\
\text { Magnet Instal!. } \\
\text { Vacuum System }\end{array}$ & $\begin{array}{l}1.1 .5 .0 \\
1.1 .5 .1 \\
1.1 .5 .2 \\
1.1 .5 .3 \\
1.1 .5 .4 \\
1.1 .5 .5 \\
1.1 .5 .6\end{array}$ & $\begin{array}{r}0 \\
662,209 \\
204,634 \\
21,925 \\
50,050 \\
286,405 \\
13,050\end{array}$ & $\begin{array}{r}400,049 \\
70,031 \\
13,508 \\
27,988 \\
47,691 \\
50,951 \\
70,189\end{array}$ & $\begin{array}{r}400,049 \\
732,839 \\
218,142 \\
49,913 \\
97,741 \\
337,356 \\
83,239\end{array}$ & $\begin{array}{r}151,858 \\
279,613 \\
65,681 \\
0 \\
53,909 \\
0 \\
0\end{array}$ & $\begin{array}{r}198,186 \\
453,226 \\
152,461 \\
49,913 \\
43,832 \\
337,356 \\
83,239\end{array}$ & $\begin{array}{r}50,006 \\
0 \\
0 \\
0 \\
0 \\
0 \\
0\end{array}$ & $\begin{array}{r}400,049 \\
732,839 \\
218,142 \\
49,913 \\
97,741 \\
337,356 \\
83,239\end{array}$ \\
\hline $\begin{array}{l}\text { E D \& I } \\
\text { Vacuum Chambers } \\
\text { Pumping System } \\
\text { Pressure Monitor. } \\
\text { Cleaning/Install. } \\
\text { Beam Monitoring } \\
\text { RF System }\end{array}$ & $\begin{array}{l}1.1 .6 .0 \\
1.1 .6 .1 \\
1.1 .6 .2 \\
1.1 .6 .3 \\
1.1 .6 .4 \\
1.1 .6 .5\end{array}$ & $\begin{array}{r}0 \\
109,028 \\
87,579 \\
10,704 \\
71,903 \\
37,676\end{array}$ & $\begin{array}{r}161,571 \\
38,117 \\
0 \\
0 \\
104,741 \\
34,914\end{array}$ & $\begin{array}{r}161,571 \\
147,145 \\
87,571 \\
10,704 \\
176,643 \\
72,590\end{array}$ & $\begin{array}{r}60,589 \\
116,837 \\
0 \\
0 \\
58,881 \\
13,093\end{array}$ & $\begin{array}{r}80,785 \\
30,307 \\
87,571 \\
10,704 \\
117,762 \\
40,659\end{array}$ & $\begin{array}{r}20,196 \\
0 \\
0 \\
0 \\
0 \\
18,838\end{array}$ & $\begin{array}{r}161,571 \\
147,145 \\
87,571 \\
10,704 \\
176,643 \\
72,590\end{array}$ \\
\hline $\begin{array}{l}\text { E D I } \\
\text { RF Power } \\
\text { RF Cavities } \\
\text { Low Level RF Drive } \\
\text { RF Utilities } \\
\text { I \& C System }\end{array}$ & $\begin{array}{l}1.1 .7 .0 \\
1.1 .7 .1 \\
1.1 .7 .2 \\
1.1 .7 .3 \\
1.1 .7 .4\end{array}$ & $\begin{array}{r}0 \\
211,783 \\
60,484 \\
153,557 \\
17,265\end{array}$ & $\begin{array}{r}230,477 \\
23,763 \\
27,237 \\
29,713 \\
2,123\end{array}$ & $\begin{array}{r}230,477 \\
235,546 \\
87,721 \\
183,270 \\
19,388\end{array}$ & $\begin{array}{l}0 \\
0 \\
0 \\
0 \\
0\end{array}$ & $\begin{array}{r}184,382 \\
100,546 \\
87,721 \\
183,270 \\
19,388\end{array}$ & $\begin{array}{r}46,095 \\
135,000 \\
0 \\
0 \\
0\end{array}$ & $\begin{array}{r}230,477 \\
235,546 \\
87,721 \\
183,270 \\
19,388\end{array}$ \\
\hline $\begin{array}{l}\text { E D \& I } \\
\text { Beam Diagnostics } \\
\text { Control System } \\
\text { Protection System } \\
\text { Communications } \\
\text { Injection/E jection }\end{array}$ & $\begin{array}{l}1.1 .8 .0 \\
1.1 .8 .1 \\
1.1 .8 .2 \\
1.1 .8 .3 \\
1.1 .8 .4\end{array}$ & $\begin{array}{r}0 \\
226,087 \\
230,047 \\
35,611 \\
7,500\end{array}$ & $\begin{array}{r}378,386 \\
95,899 \\
206,706 \\
28,020 \\
4,670\end{array}$ & $\begin{array}{r}378,386 \\
321,986 \\
436,753 \\
63,631 \\
12,170\end{array}$ & $\begin{array}{r}70,947 \\
71,553 \\
72,792 \\
0 \\
0\end{array}$ & $\begin{array}{r}264,870 \\
217,476 \\
291,169 \\
50,905 \\
12,170\end{array}$ & $\begin{array}{r}42,568 \\
32,958 \\
72,792 \\
12,726 \\
0\end{array}$ & $\begin{array}{r}378,386 \\
321,986 \\
436,753 \\
63,631 \\
12,170\end{array}$ \\
\hline $\begin{array}{l}\text { E \& \& 1 } \\
\text { Transport Lines } \\
\text { Pulsed Magnets } \\
\text { instrumentation } \\
\text { Techn. Project Mgmt. }\end{array}$ & $\begin{array}{l}1.1 .9 .0 \\
1.1 .9 .1 \\
1.1 .9 .2 \\
1.1 .9 .3\end{array}$ & $\begin{array}{r}0 \\
580,503 \\
434,562 \\
34,944\end{array}$ & $\begin{array}{r}237,221 \\
217,958 \\
111,175 \\
6,476\end{array}$ & $\begin{array}{r}237,221 \\
798,461 \\
545,737 \\
41,420\end{array}$ & $\begin{array}{r}26,358 \\
0 \\
0 \\
0\end{array}$ & $\begin{array}{r}105,431 \\
349,864 \\
372,868 \\
0\end{array}$ & $\begin{array}{r}105,431 \\
468,597 \\
172,868 \\
41,420\end{array}$ & $\begin{array}{r}237,221 \\
798,461 \\
545,737 \\
41,420\end{array}$ \\
\hline $\begin{array}{l}\text { Techn. Project Mgmt. } \\
\text { Tech. Coordination } \\
\text { Accel. Physics } \\
\text { inst.Coord/Oal. Con }\end{array}$ & $\begin{array}{l}1.2 .1 .1 \\
1.2 .1 .2 \\
1.2 .1 .3\end{array}$ & $\begin{array}{r}66,048 \\
9,900 \\
217,667\end{array}$ & $\begin{array}{l}353,888 \\
162,952 \\
384,766\end{array}$ & $\begin{array}{l}419,936 \\
172,853 \\
602,433\end{array}$ & $\begin{array}{r}139,979 \\
57,618 \\
30,000\end{array}$ & $\begin{array}{r}128,183 \\
35,891 \\
311,216\end{array}$ & $\begin{array}{r}151,775 \\
79,344 \\
261,216\end{array}$ & $\begin{array}{l}419,936 \\
172,853 \\
602,433\end{array}$ \\
\hline $\begin{array}{l}\text { Administr. Services } \\
\text { Planning Office } \\
\text { SSRL Admin. Serv. } \\
====-==-=====\end{array}$ & $\begin{array}{l}1.2 .2 .1 \\
1.2 .2 .2\end{array}$ & $\begin{array}{r}44,500 \\
0 \\
0=== \pm===5\end{array}$ & $\begin{array}{l}212,295 \\
107,627\end{array}$ & $\begin{array}{l}256,795 \\
107,627\end{array}$ & $\begin{array}{l}85,598 \\
35,876\end{array}$ & $\begin{array}{l}85,598 \\
35,876\end{array}$ & $\begin{array}{l}85,598 \\
35,876\end{array}$ & $\begin{array}{l}256,795 \\
107,627\end{array}$ \\
\hline 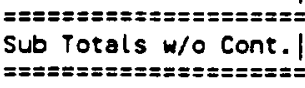 & & $\begin{array}{l}======\pi== \pm= \\
5,756,038 \\
===========\end{array}$ & $\begin{array}{c}========= \\
4,646,710 \\
==========\end{array}$ & $\begin{array}{l}========== \\
10,402,748 \\
=========-=\end{array}$ & $\begin{array}{l}========= \\
2,409,895 \\
======= \pm\end{array}$ & $\begin{array}{l}========= \\
5,949,181 \\
=========2\end{array}$ & $\begin{array}{l}=========x \\
2,043,672 \\
=========\end{array}$ & $\begin{array}{c}===== \pm==== \\
10,402,748 \\
=====\geq====z\end{array}$ \\
\hline $\begin{array}{l}\text { Project Cont ingency | } \\
======:==:==:====\end{array}$ & 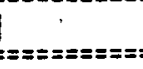 & $===827,952$. & 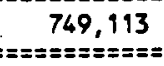 & $==\begin{aligned} & 1,677,065 \\
&=========\end{aligned}$ & $=========$ & $\begin{array}{c}765,233 \\
:==========\end{array}$ & 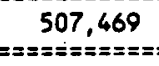 & $=\begin{aligned} & 1,677,065 \\
&=========\end{aligned}$ \\
\hline $\begin{array}{l}\text { Base Line Cost Est. I } \\
\text { =:=:=:=:=:=:=:=: }\end{array}$ & & $\begin{array}{l}6,683,990 \\
=========\end{array}$ & $\begin{array}{l}5,395,823 \\
:=========\end{array}$ & $\begin{aligned} & 12,079,813 \\
&==\geq=======\end{aligned}$ & $\begin{array}{l}2,814,259 \\
=========\end{array}$ & $\begin{array}{l}6,714,614 \\
==========\end{array}$ & $\begin{array}{l}2,551,14 i \\
=========\end{array}$ & $\begin{aligned} & 12,079,813 \\
&==x=x====== \pm=\end{aligned}$ \\
\hline
\end{tabular}




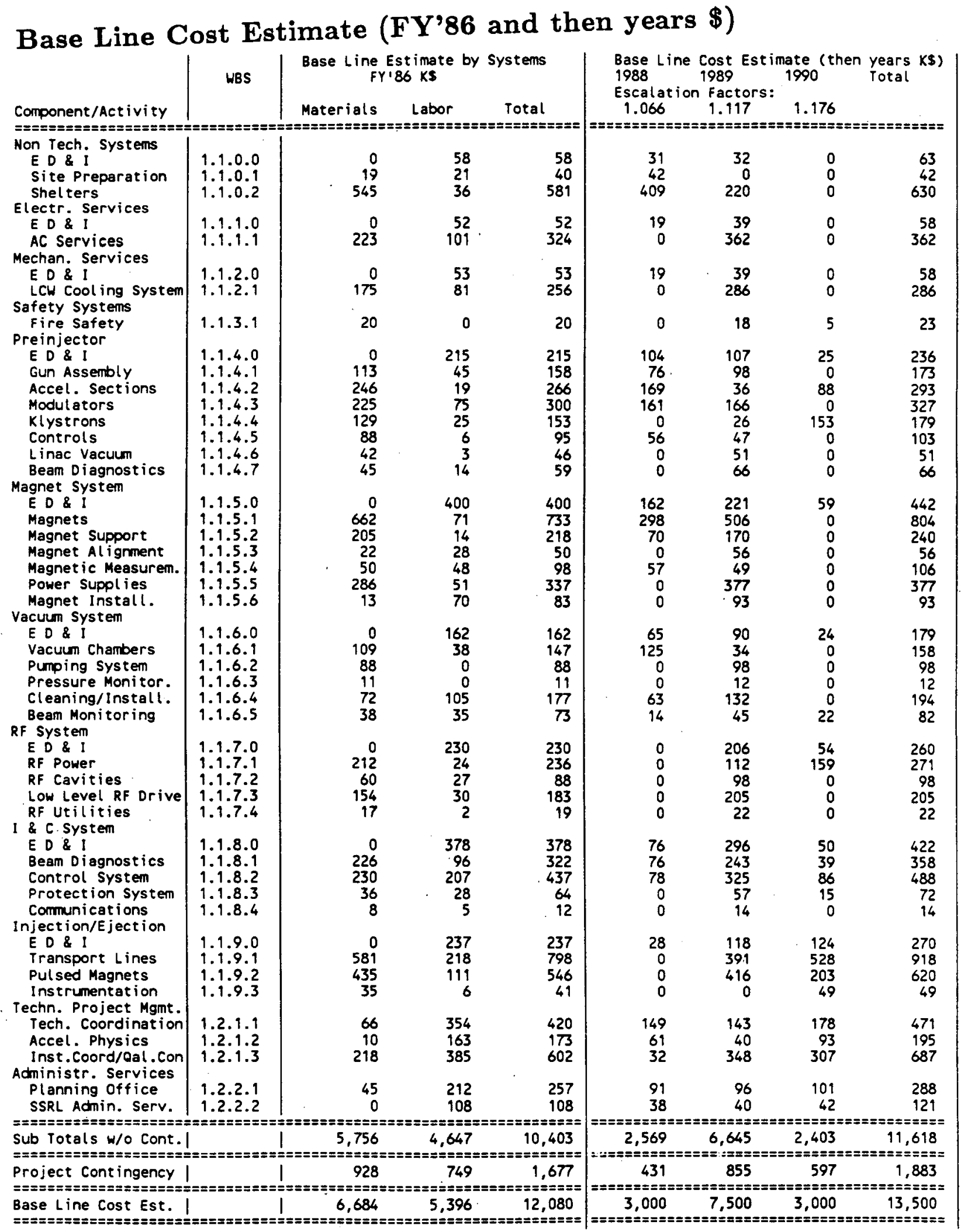




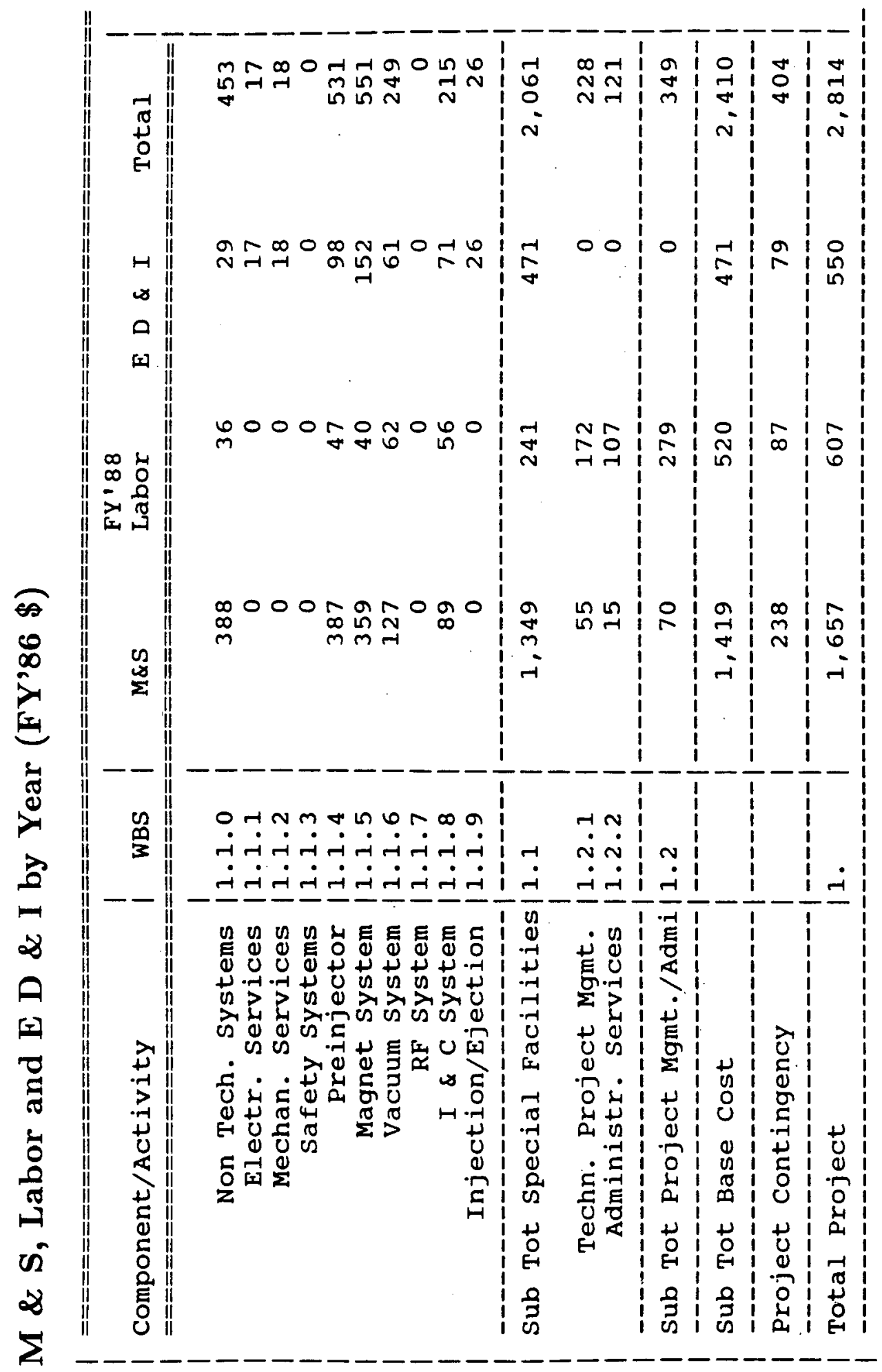




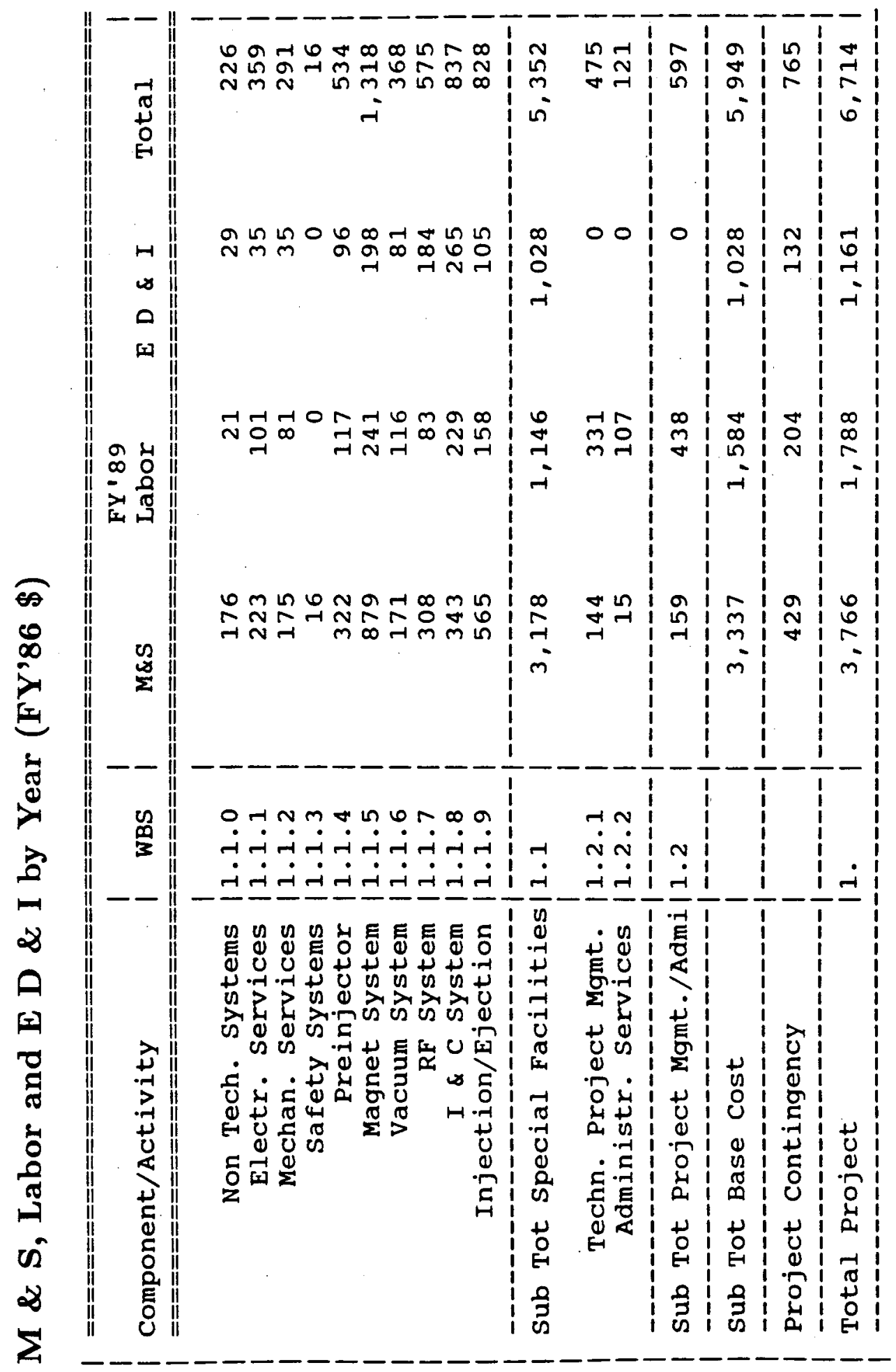




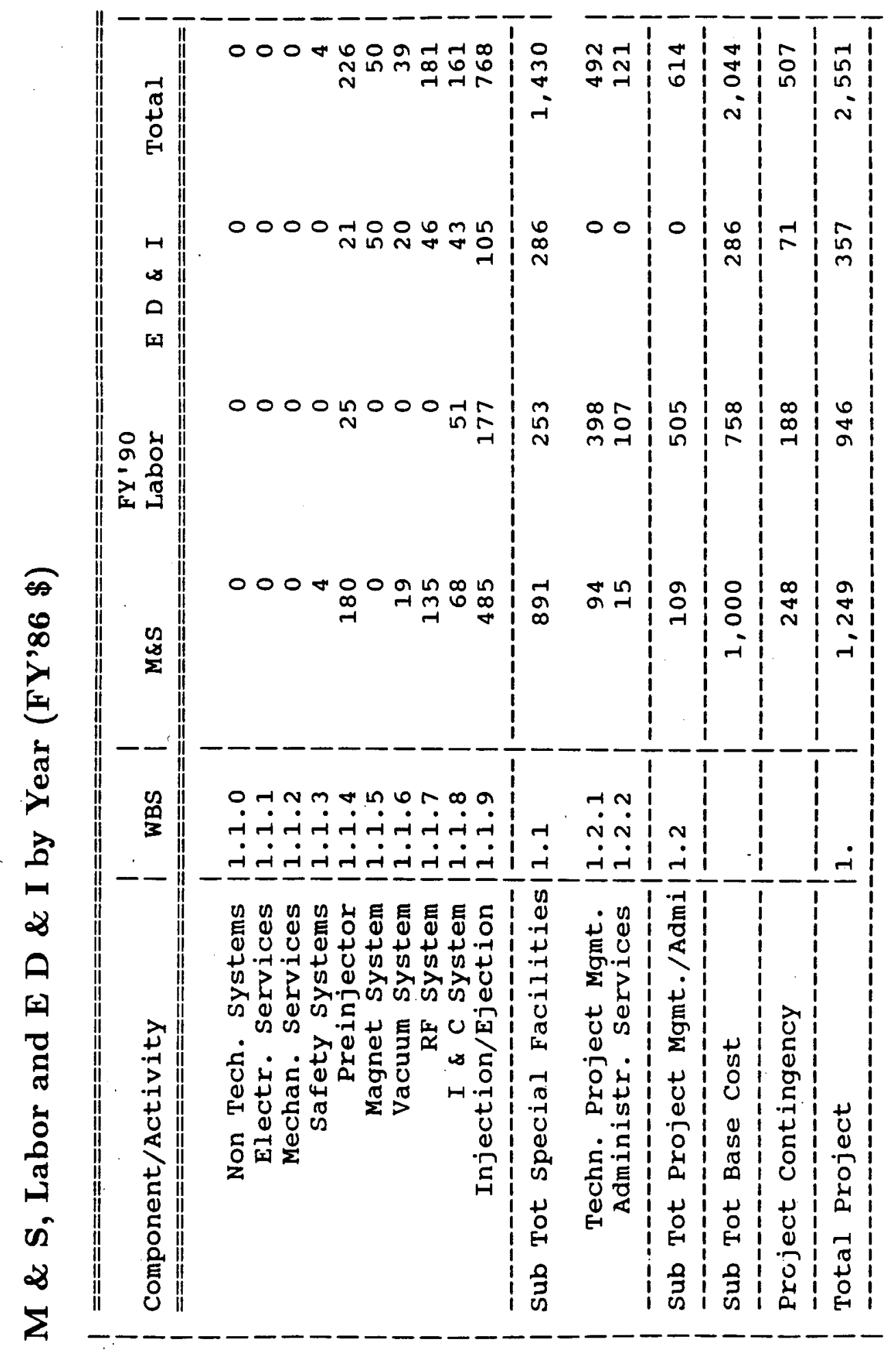




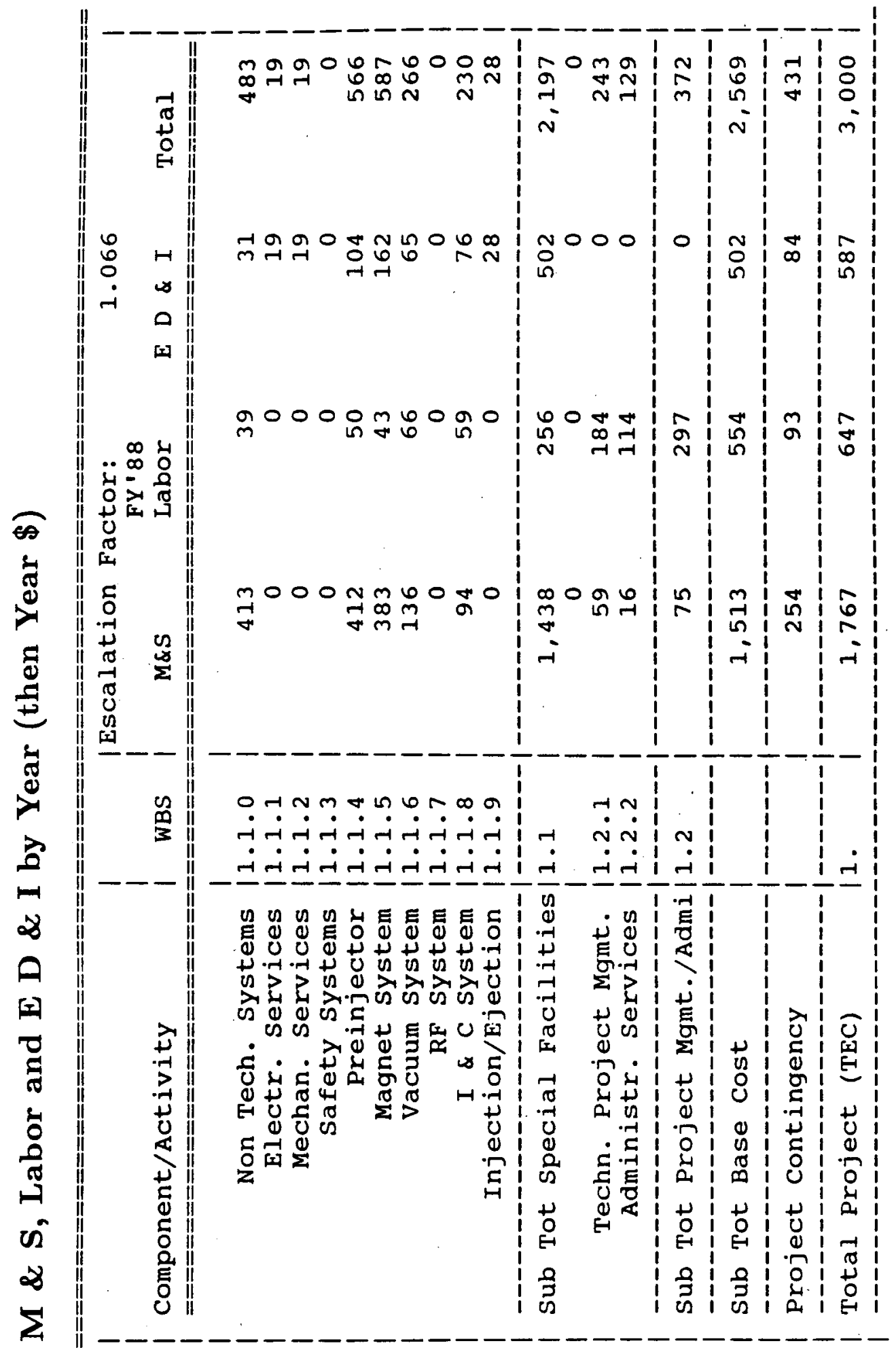




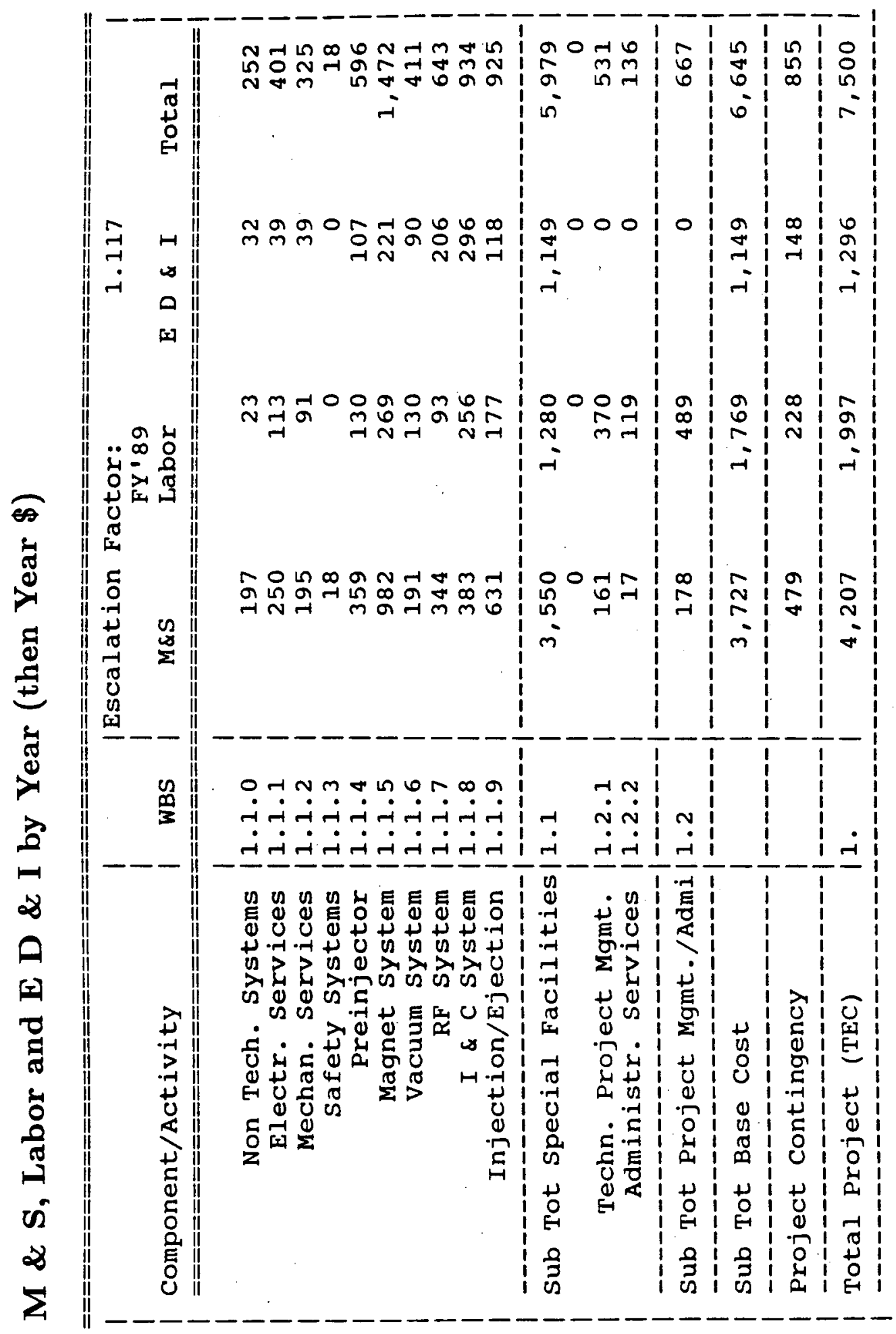




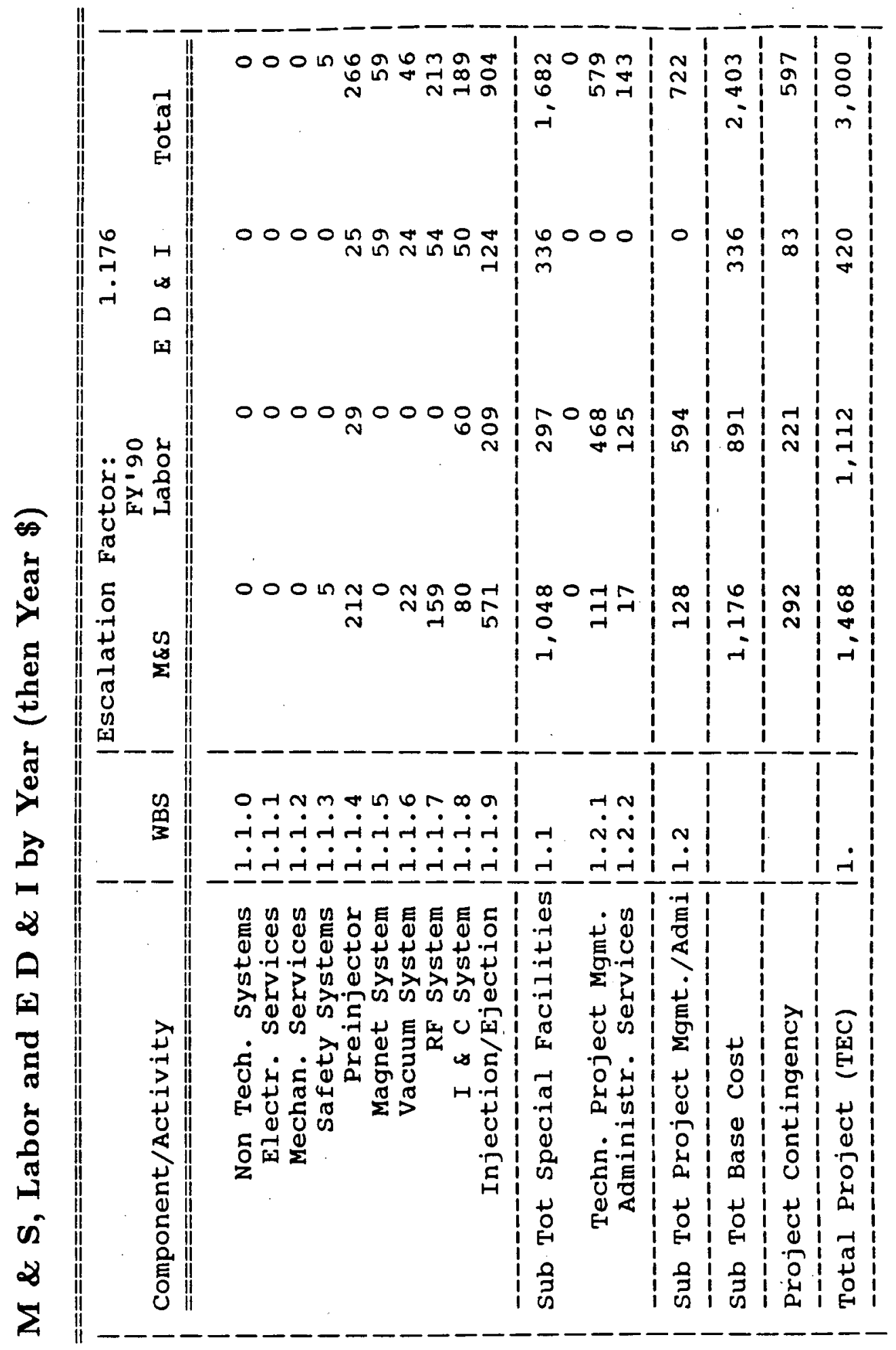




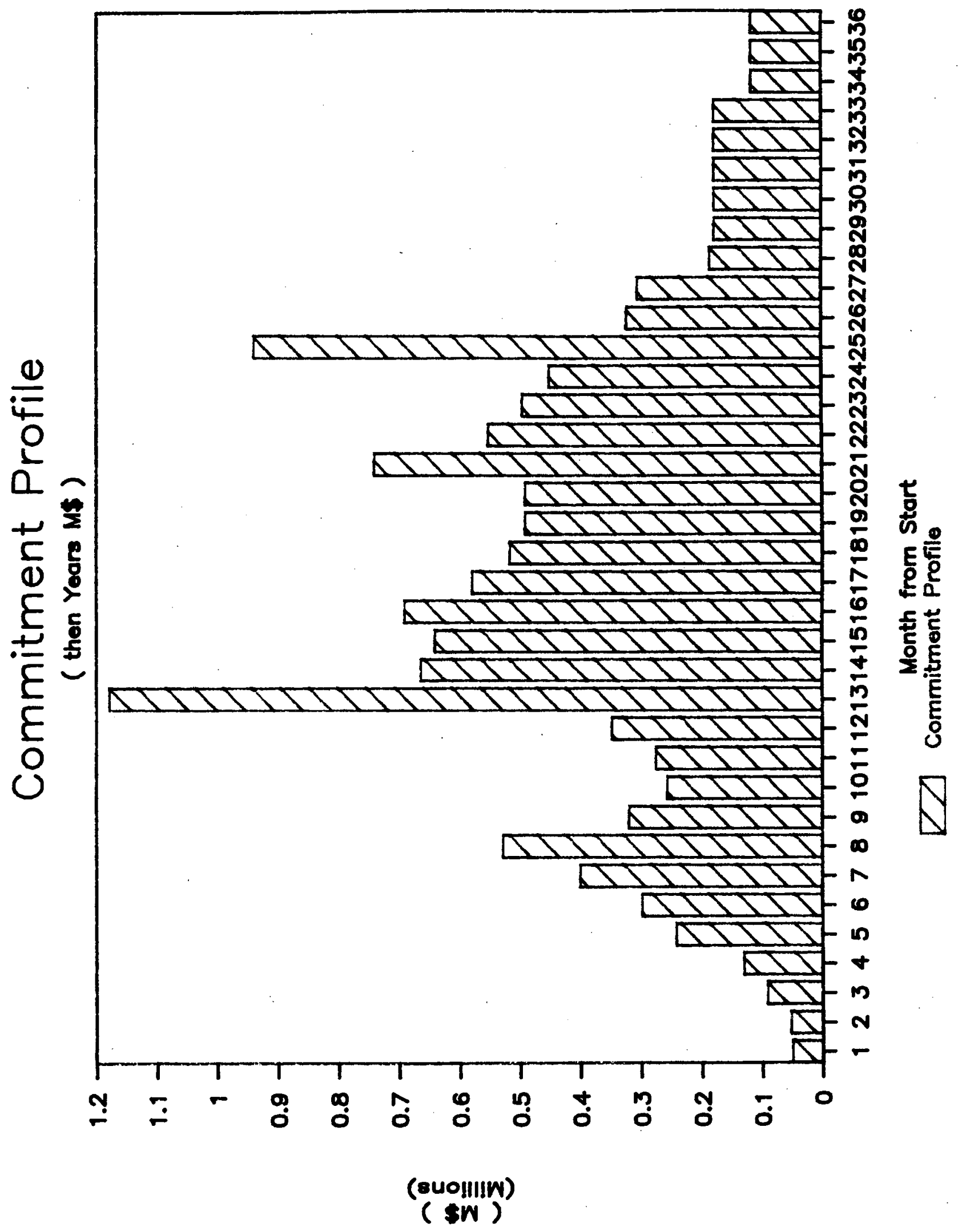




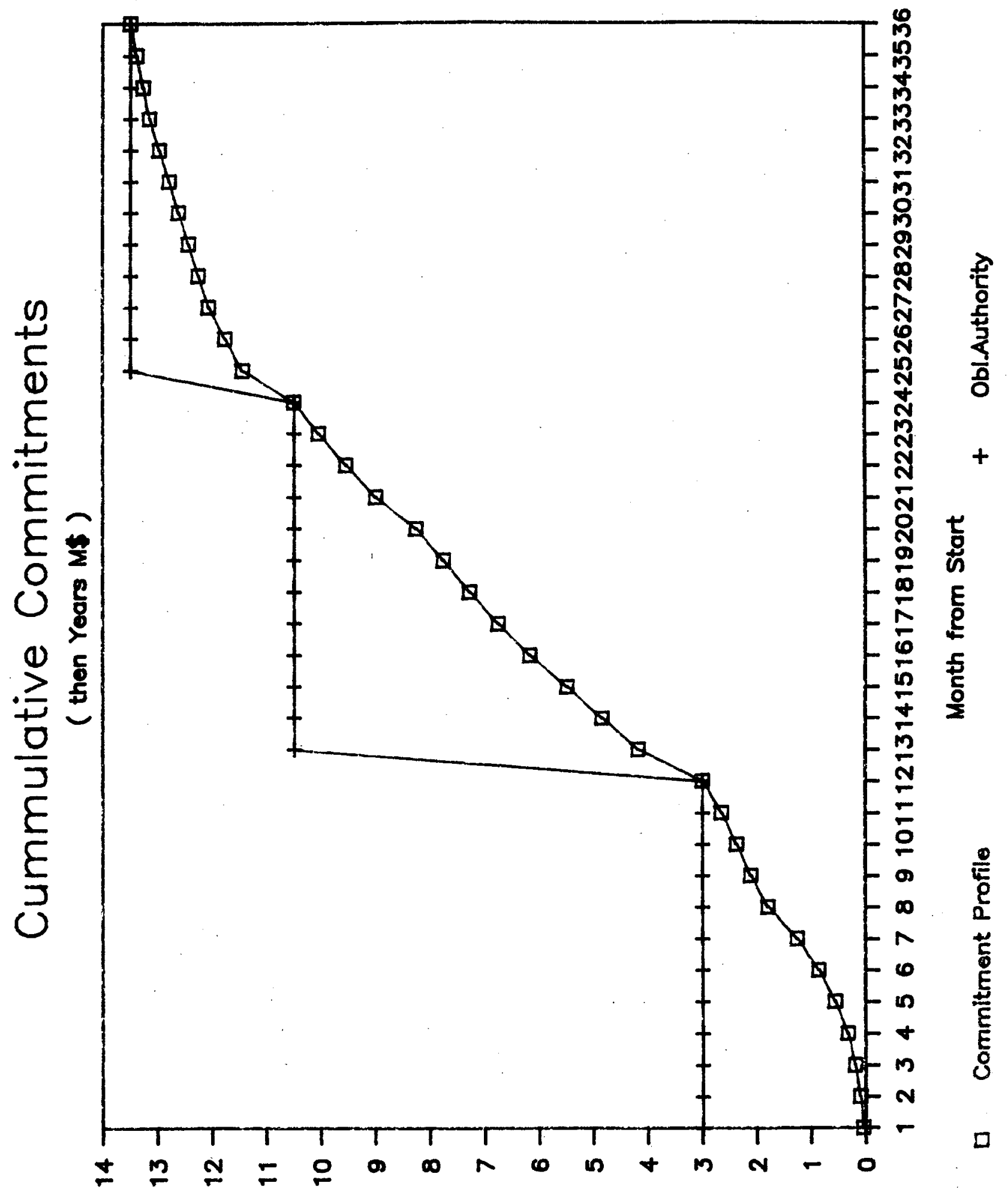

(suoliII)

( $\$ w)$ 


\section{Labor Cost Base (FY'86 \$)}

$3 \mathrm{GeV}$ Spear Injector system

\begin{tabular}{|c|c|c|c|}
\hline 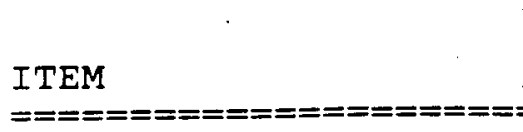 & $\begin{array}{l}\text { SIAC } \\
\text { CODE } \\
====\end{array}$ & $\begin{array}{l}\text { CRAFT } \\
\text { CODE } \\
======\end{array}$ & $\begin{array}{l}\$ / \mathrm{MM} \\
======\end{array}$ \\
\hline CONTRACT SERV. MANAG. & 8 & $A C$ & 11086 \\
\hline FINANCIAL ADMIN. & 9 & AF & 5511 \\
\hline PERSONNEL ADMIN. & 10 & AP. & 4589 \\
\hline SECRETARY & 5 & $S E$ & 3324 \\
\hline $\begin{array}{l}\text { ADMIN. ASSISTANT } \\
\text { DATA AIDE }\end{array}$ & & $\begin{array}{l}\mathrm{AA} \\
\mathrm{DA}\end{array}$ & $\begin{array}{l}4568 \\
2659\end{array}$ \\
\hline ELECTR. COORDINATOR & 18 & $\mathrm{CS}$ & 5254 \\
\hline COORDINATOR/PROJECT & 2 & $C P$ & 8513 \\
\hline ALIGNMENT ENGINEER & 43 & $\mathrm{AE}$ & 6540 \\
\hline ELECTRICAL ENGINEER & 16 & EL & 6969 \\
\hline MECHANICAL ENGINEER & 11 & $\overline{M E}$ & 7720 \\
\hline CONSULTANT & & $\mathrm{CN}$ & 7505 \\
\hline IECHANICAL FAB. & 27 & MF & 4525 \\
\hline COMPUTER PROGRAMMER & & PR & 6390 \\
\hline PROJECT MANAGER & & SC & 10915 \\
\hline RESEARCH ASSOCIATE & & RA & 6390 \\
\hline GRAD. STUDENTS (50\%) & & ST & 1598 \\
\hline EXPEDITOR & 3 & EX & 5661 \\
\hline ELECTRON . TECHNICIAN & 32 & TE & 4246 \\
\hline OPERATION TECHNICIAN & 42 & TO & 4589 \\
\hline DOCUMENTATION CLERK & & DC & 2745 \\
\hline MECHANICAL MACHINING & 27 & MM & 4525 \\
\hline MECHANICAL DES & 52 & MD & \\
\hline TRICAL DESIGNER & 57 & ED & 5487 \\
\hline ELECTRICAL ASSEMBLER & 63 & EA & 2732 \\
\hline DAVIS-BACON LABOR & & DB & 9340 \\
\hline CONTRACT LABOR & & JL & 3106 \\
\hline UTILITIES/ELECT. T\&M & & UE & 8406 \\
\hline UTIIITIES/MECH. T\&M & & UM & 8406 \\
\hline WELDING/VACUUM & 79 & WV & 6491 \\
\hline ELECTRICIAN & 84 & EL & 5207 \\
\hline VACUUM TECHNICIAN & 81 & $T V$ & 6491 \\
\hline MECH. TECHNICIAN & 85 & TM & 6491 \\
\hline ALIGNMENT TECHNICIAN & 76 & TA & 5324 \\
\hline RIGGER & 86 & RI & 5230 \\
\hline ELECTRICAL ENGIN & 66 & EE & 7635 \\
\hline PLANT ENGINEER & 69 & $C E$ & 7822 \\
\hline
\end{tabular}


Rate/MM Craft Manpower Code sumbry
System by WBS:

\begin{tabular}{|c|c|}
\hline ADMIN. ASSISTANT & 4568 \\
\hline CONTRACT SERV. MANAG. & 11086 \\
\hline ALIGNMENT ENGINEER & 6540 \\
\hline FINANCIAL ADMIN. & 5511 \\
\hline PERSONNEL ADMIN. & 4589 \\
\hline CIVIL ENGINEER & 7822 \\
\hline CONSULTANT & 7505 \\
\hline COORDINATOR/PROJECT & 8513 \\
\hline COOROINATOR/SYSTEM & 5254 \\
\hline DATA AIDE & 3263 \\
\hline DAVIS-BACON LABOR & 9340 \\
\hline DOCUMENTATION CLERK & 2745 \\
\hline ELECTRICAL ASSEMBLER & 2732 \\
\hline ELECTRICAL OESIGNER & 5487 \\
\hline ELECTRICAL ENGINEER & 7635 \\
\hline ELECTRICIAN & 6969 \\
\hline ELECTRONICS ENGINEER & 6969 \\
\hline EXPEDITOR & 5661 \\
\hline CONTRACT LABOR & 3106 \\
\hline MECHANICAL DESIGNER & 5487 \\
\hline MECHANICAL ENGINEER & 7720 \\
\hline MECHANICAL FABRICATIO & 4525 \\
\hline MECHANICAL MACHINING & 4525 \\
\hline COMPUTER PROGRAMMER & 6390 \\
\hline RESEARCH ASSOCIATE & 6390 \\
\hline RIGGER & 5230 \\
\hline PROJECT MANAGER & 10915 \\
\hline SECRETARY & 3324 \\
\hline GRAD. STUDENTS & 1598 \\
\hline ALIGNMENT TECHNICIAN & 5324 \\
\hline ELECTRICAL TECHNICIAN & 4246 \\
\hline MECHANCIAL TECHNICIAN & 6491 \\
\hline OPERATION TECHNICIAN & 4589 \\
\hline VACUUM TECHNICIAN & 6491 \\
\hline UTILITIES/ELECTR. T\&M & 8406 \\
\hline UTILITIES/MECH. T\&M & 8406 \\
\hline WELDING/VACUUM & 6491 \\
\hline
\end{tabular}

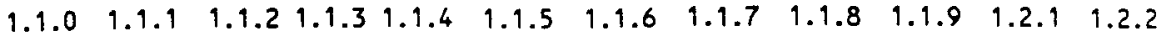

\begin{tabular}{|c|c|c|c|c|c|c|c|c|c|c|c|}
\hline 36.00 & & & & & & & & & & & 36.0 \\
\hline 3.00 & & & & & & & & & & & 3.0 \\
\hline 0.21 & & & & & 0.21 & & & & . & & \\
\hline 6.00 & & & & & & & & & & & \\
\hline 9.00 & & & & & & & & & & & \\
\hline 4.00 & 4.00 & & & & & & & & & & \\
\hline 3.00 & & & & & & & & & & 3.00 & \\
\hline 12.00 & & & & & & & & & & 12.00 & \\
\hline 64.39 & & & & 9.00 & 9.00 & & 12.00 & 18.00 & 1.39 & 15.00 & \\
\hline 18.00 & & . & & & & & & & & & \\
\hline 25.23 & & & & 1.00 & 7.73 & & 1.00 & 6.50 & 9.00 & & \\
\hline 24.00 & & & & & & & 6.00 & 9.00 & & 9.00 & \\
\hline 0.00 & & & & & & & & & & & \\
\hline 54.00 & & 4.00 & & 9.00 & 6.00 & 2.00 & 6.00 & 18.00 & 6.00 & 3.00 & \\
\hline 100.18 & & 4.00 & & 17.20 & 9.52 & 2.00 & 17.00 & 33.00 & 8.46 & 9.00 & \\
\hline 0.00 & & & & & & & & & . & & \\
\hline 0.00 & & & & & & & & & & & \\
\hline 0.00 & & & & & & & & & & & \\
\hline 212.76 & 20.00 & & & 16.25 & 28.68 & 18.00 & 24.21 & 22.01 & 53.62 & 30.00 & \\
\hline 49.00 & 2.00 & & 4.00 & 2.00 & 12.00 & 12.00 & 2.00 & & 12.00 & 3.00 & \\
\hline 83.86 & 2.00 & & 4.00 & 2.92 & 26.96 & 16.16 & 3.00 & & 19.81 & 9.00 & \\
\hline 0.00 & & & & & & & & & & & \\
\hline 9.51 & & & & & 3.14 & 6.37 & & & & & \\
\hline
\end{tabular}

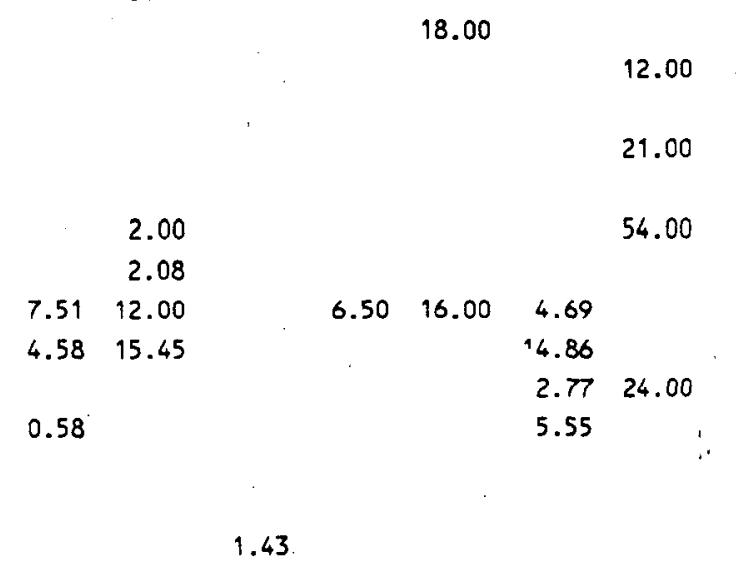

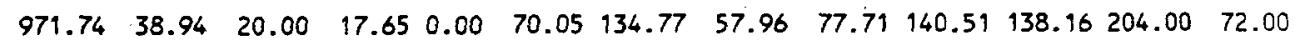




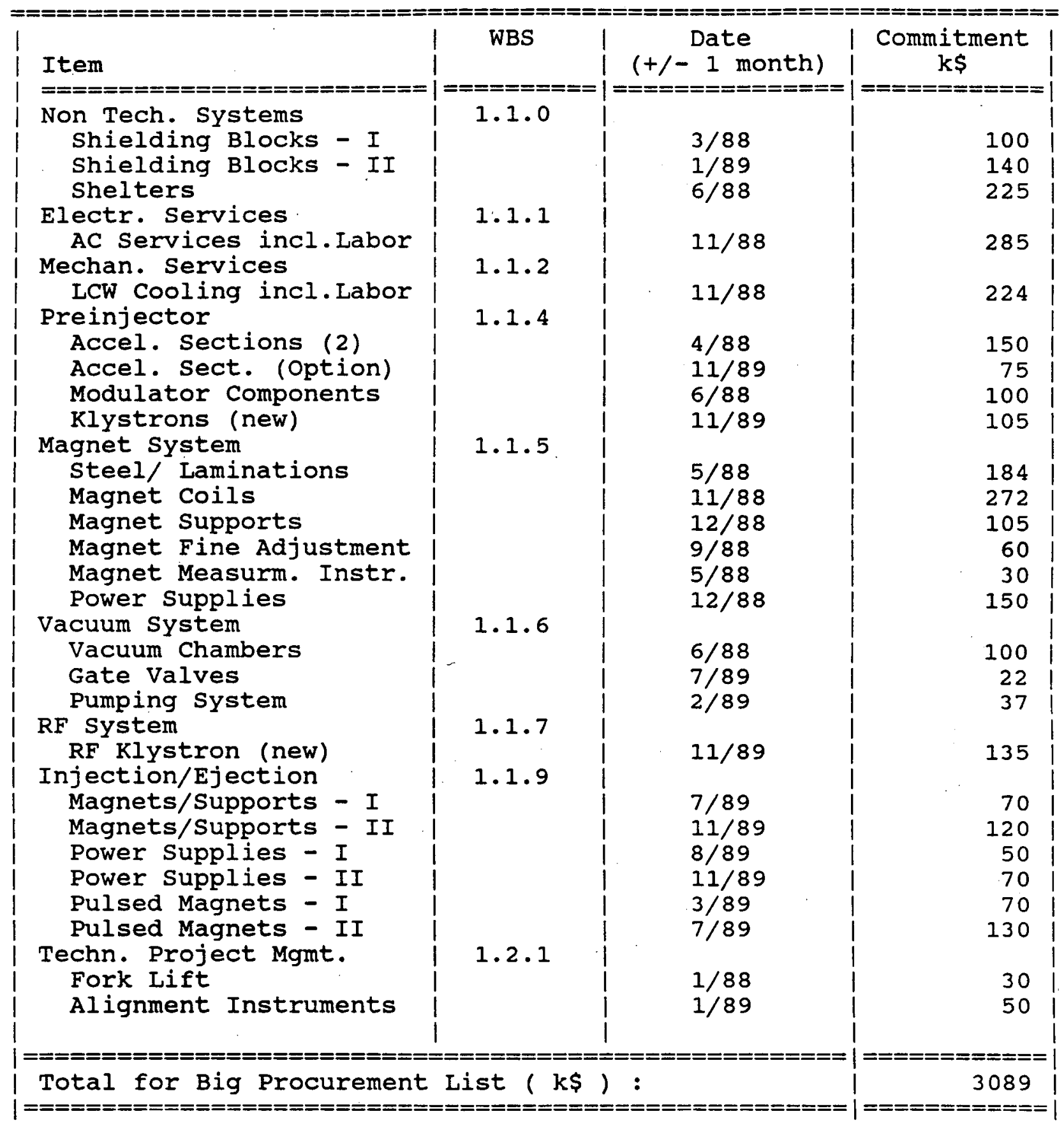




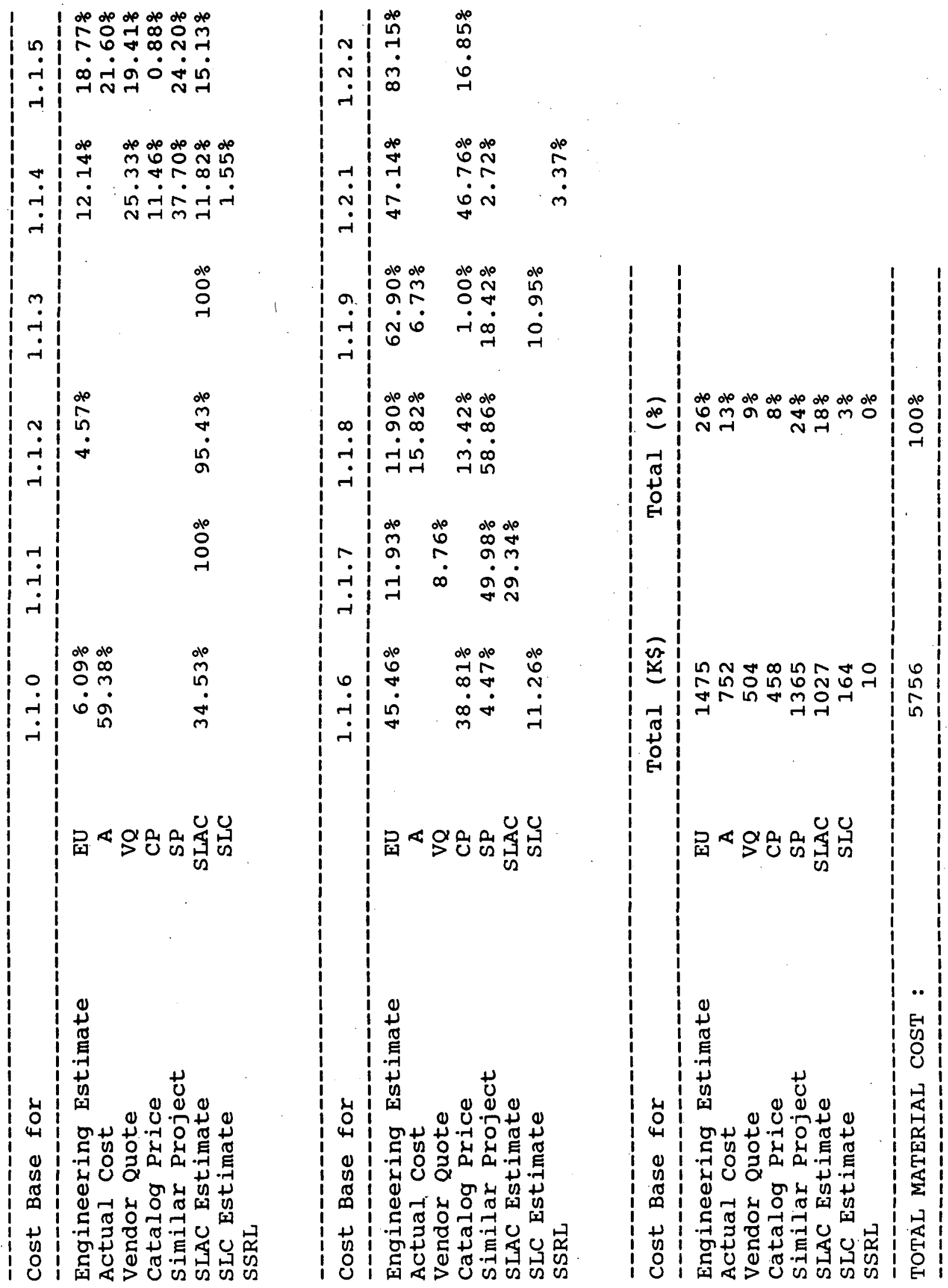




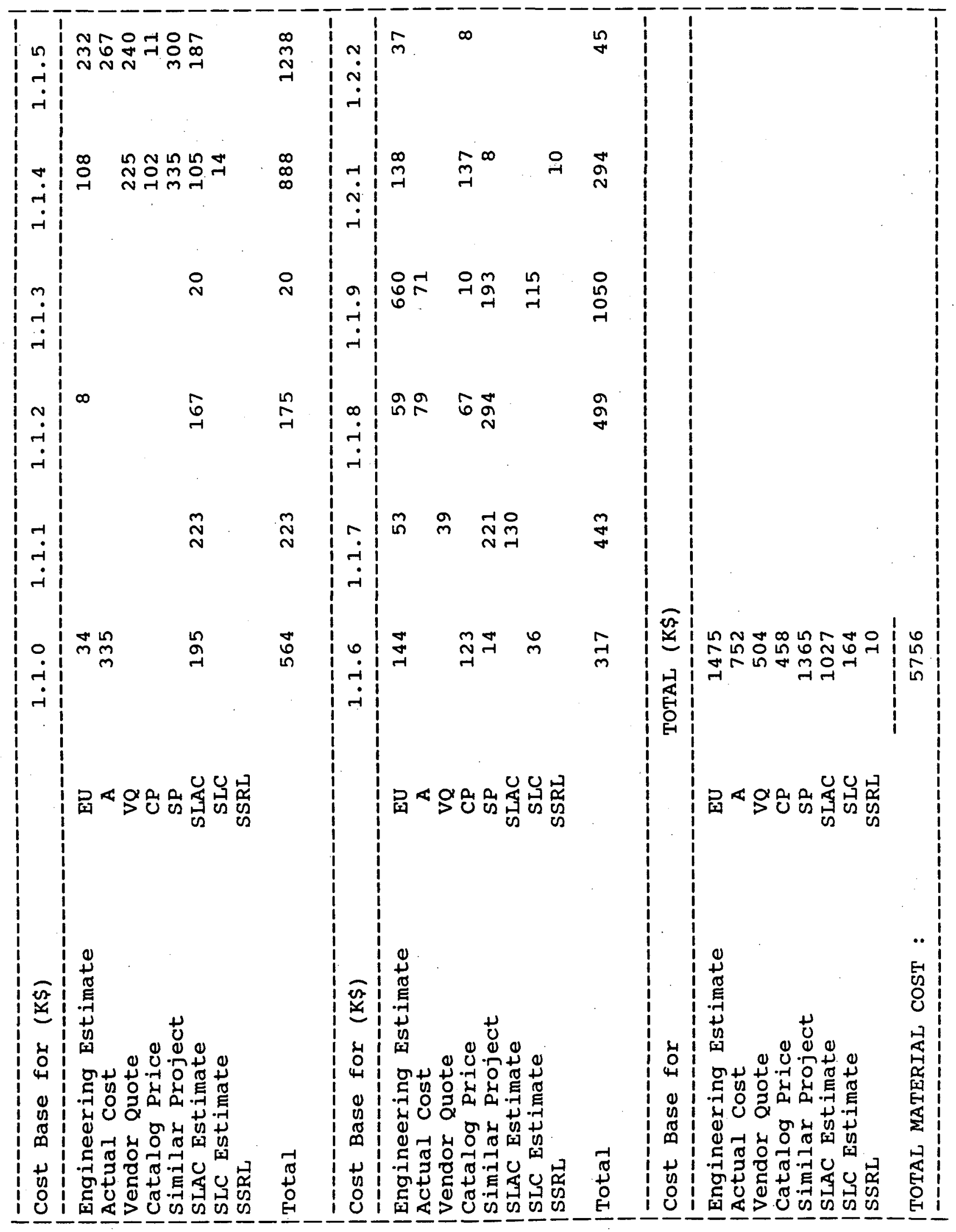


Technical Contingency

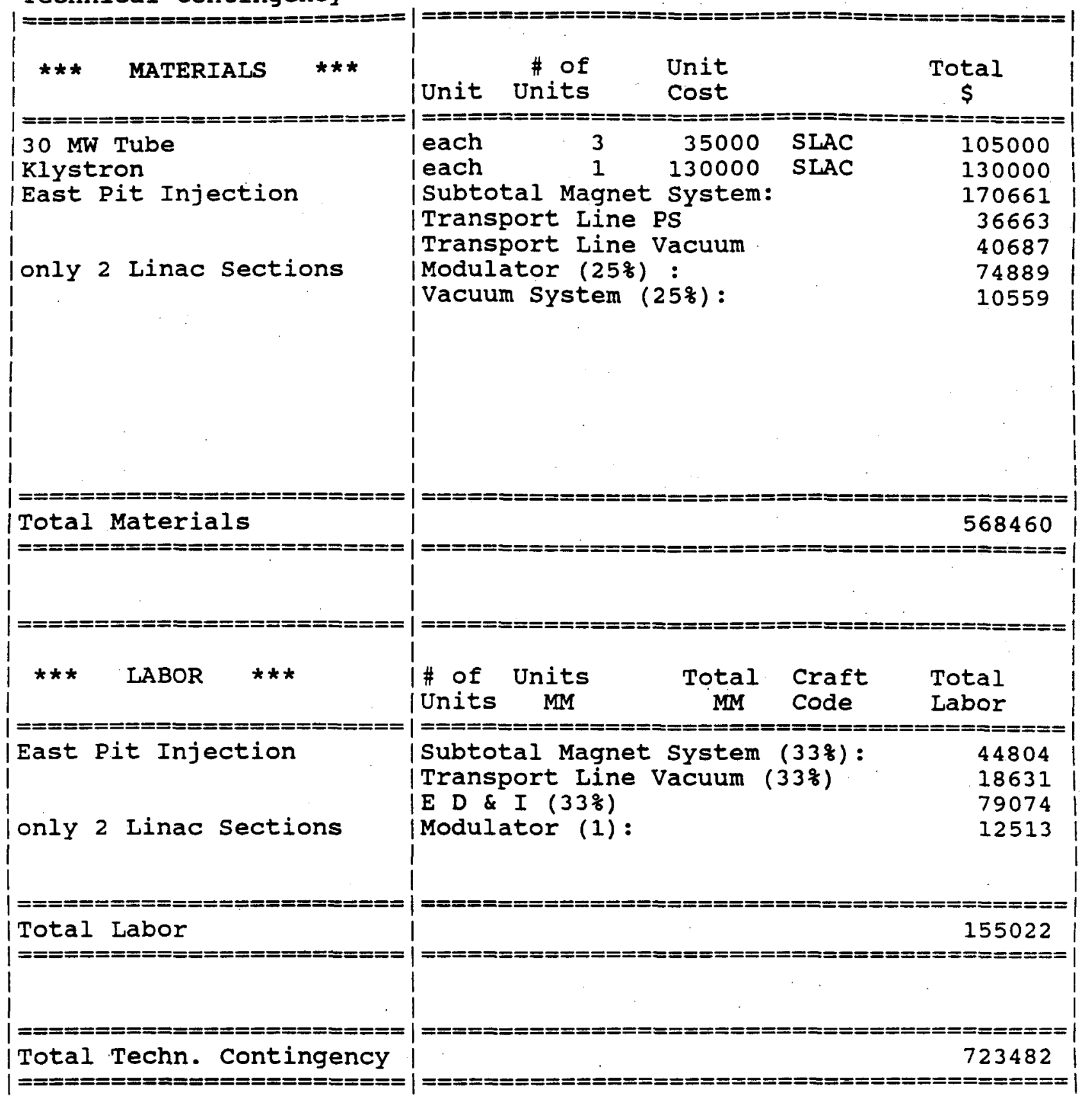




\section{Project Contingency}

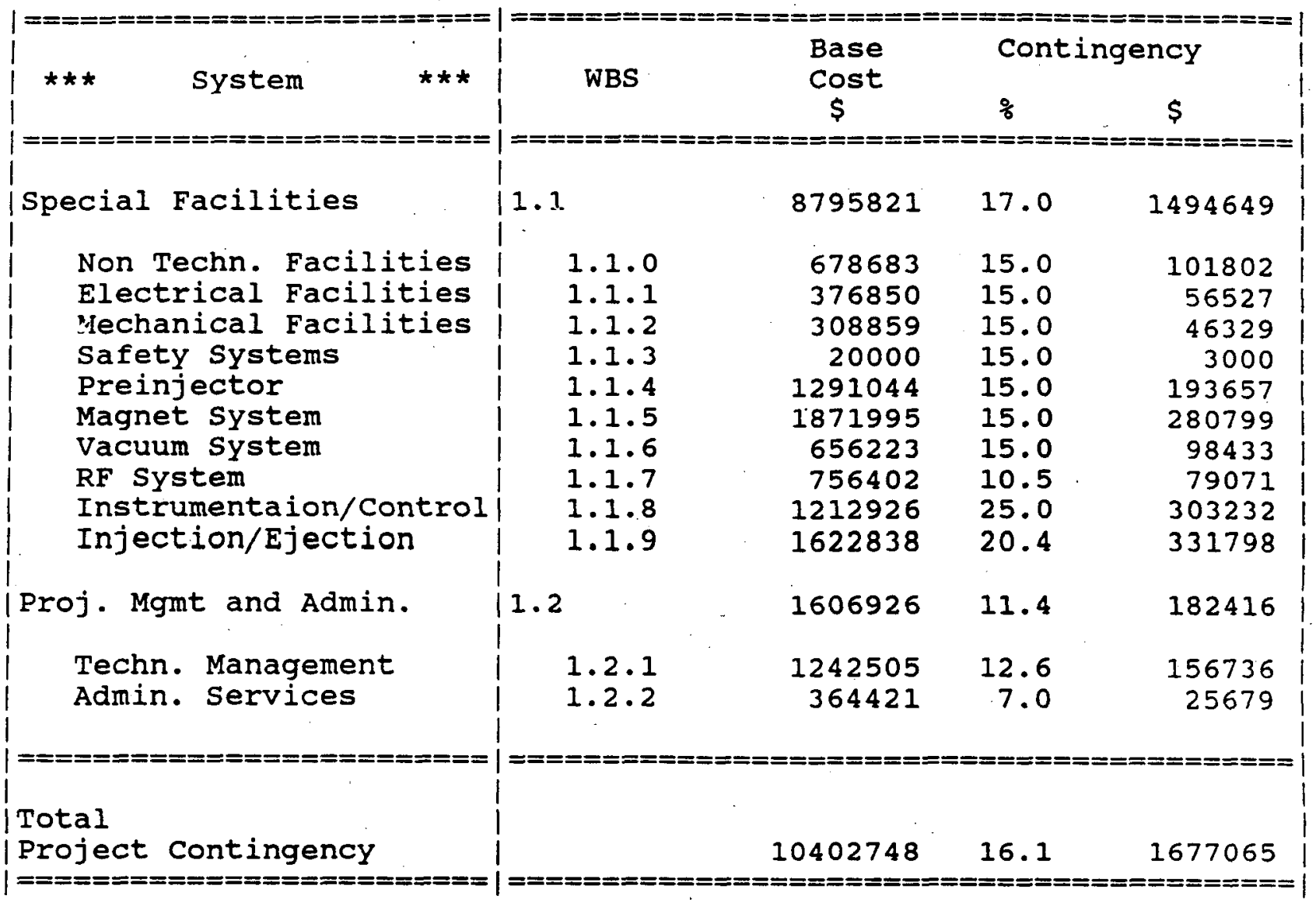




\subsubsection{Non Technical Systems}

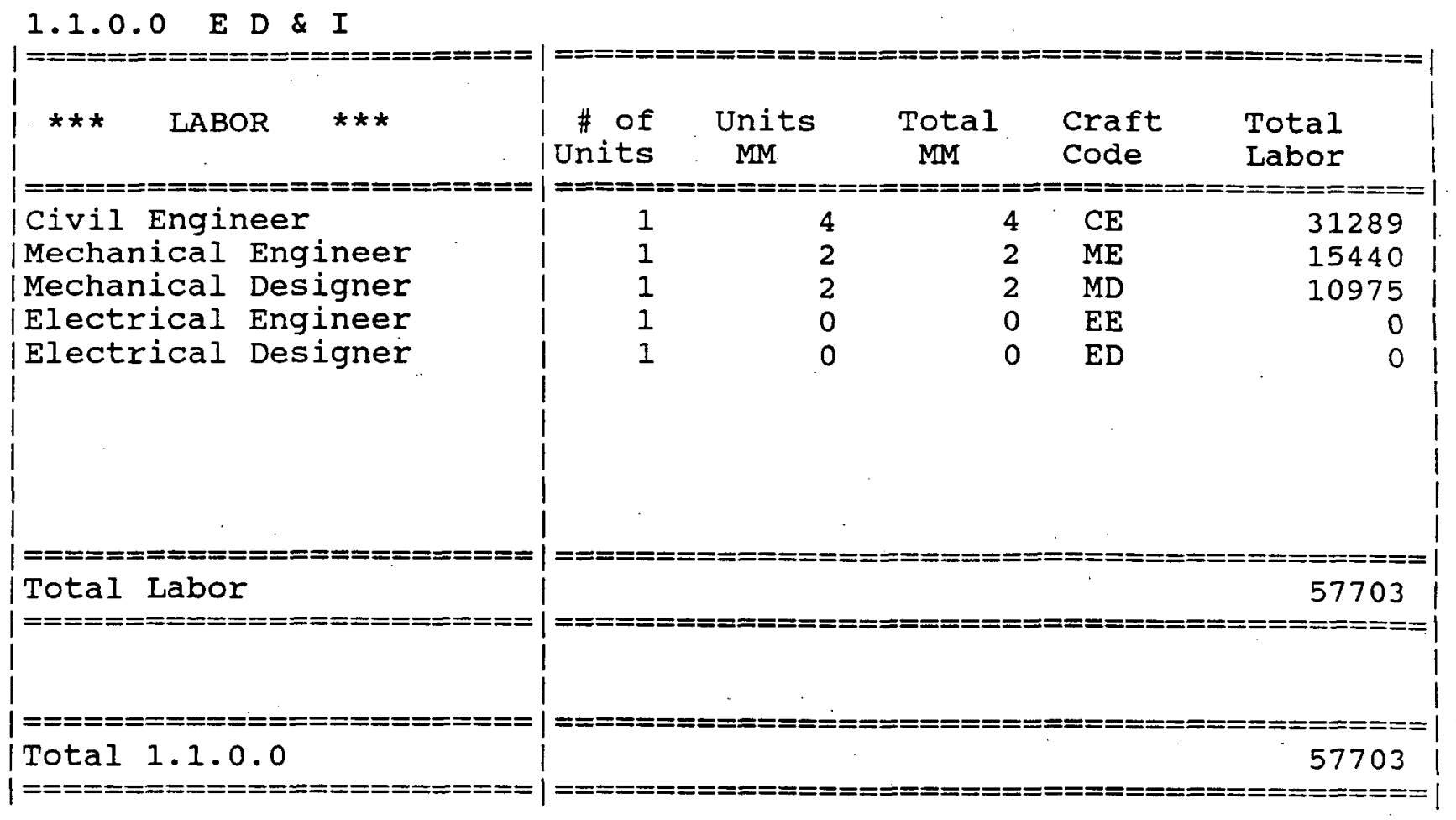




\section{1 .0 Non Technical systems}

\subsubsection{Site Preparation}

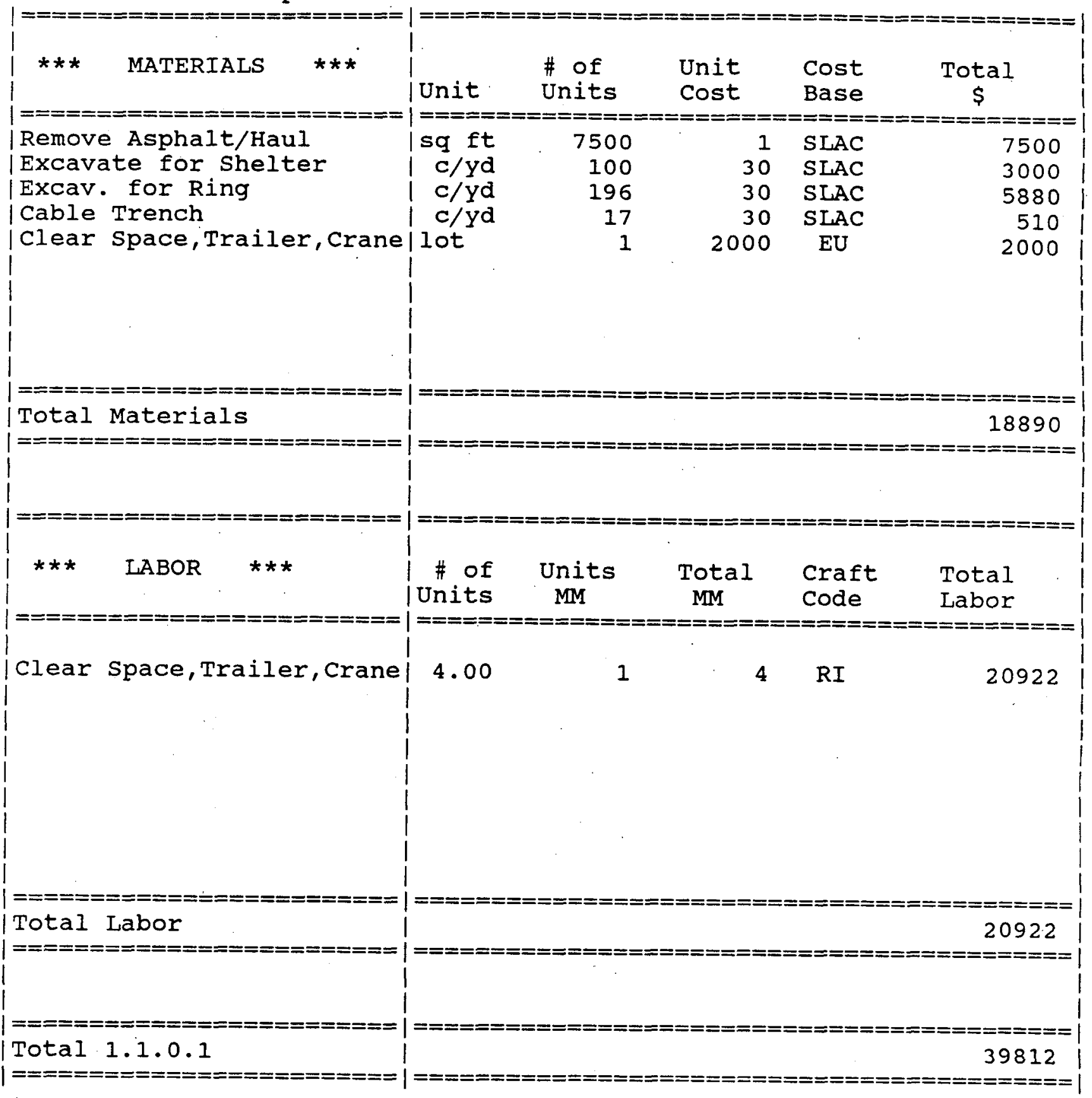




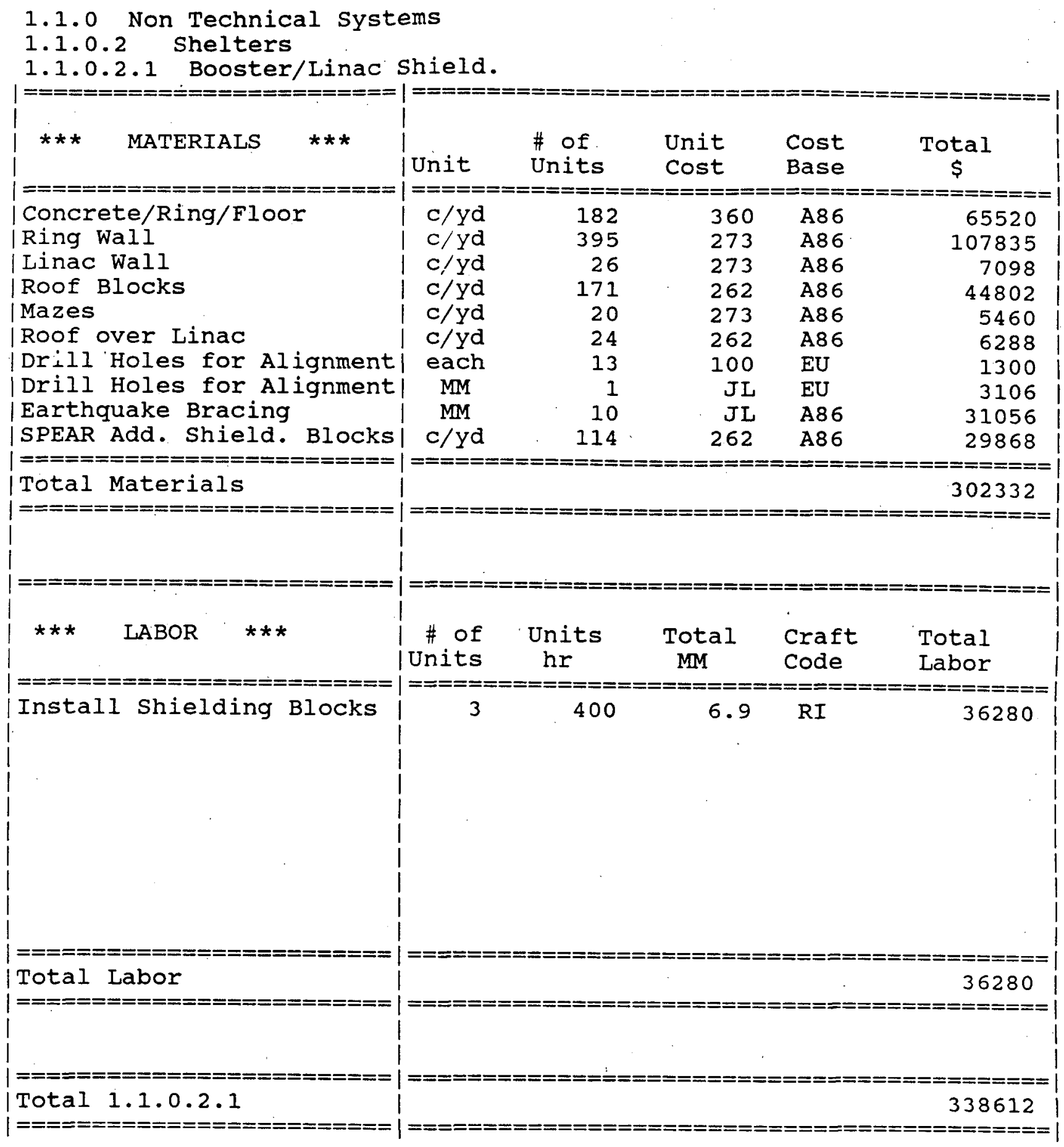




\section{1 .0 Non Technical Systems}

1.1.0.2 Shelters

1.1.0.2.2 Equipment Shelter

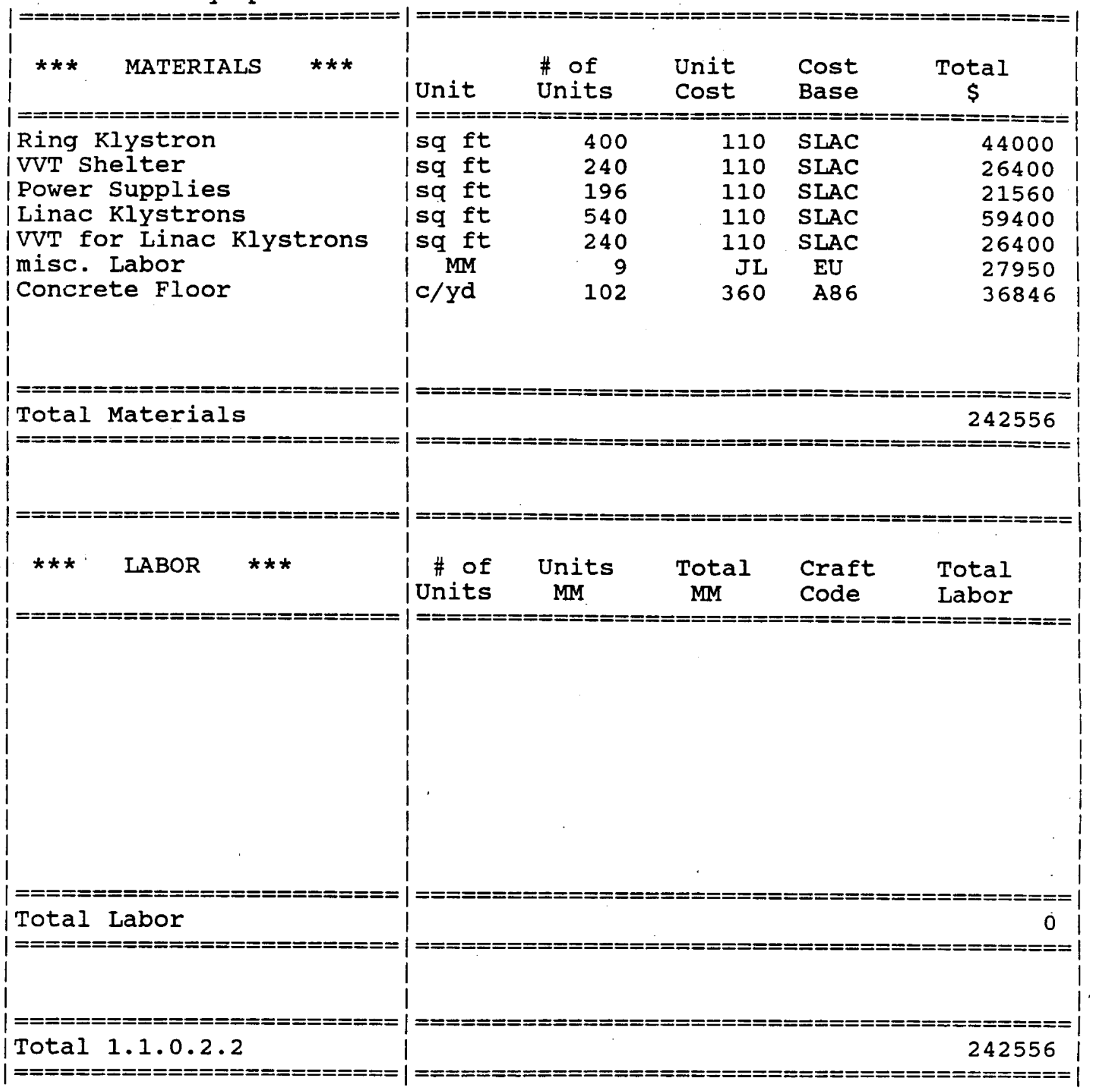




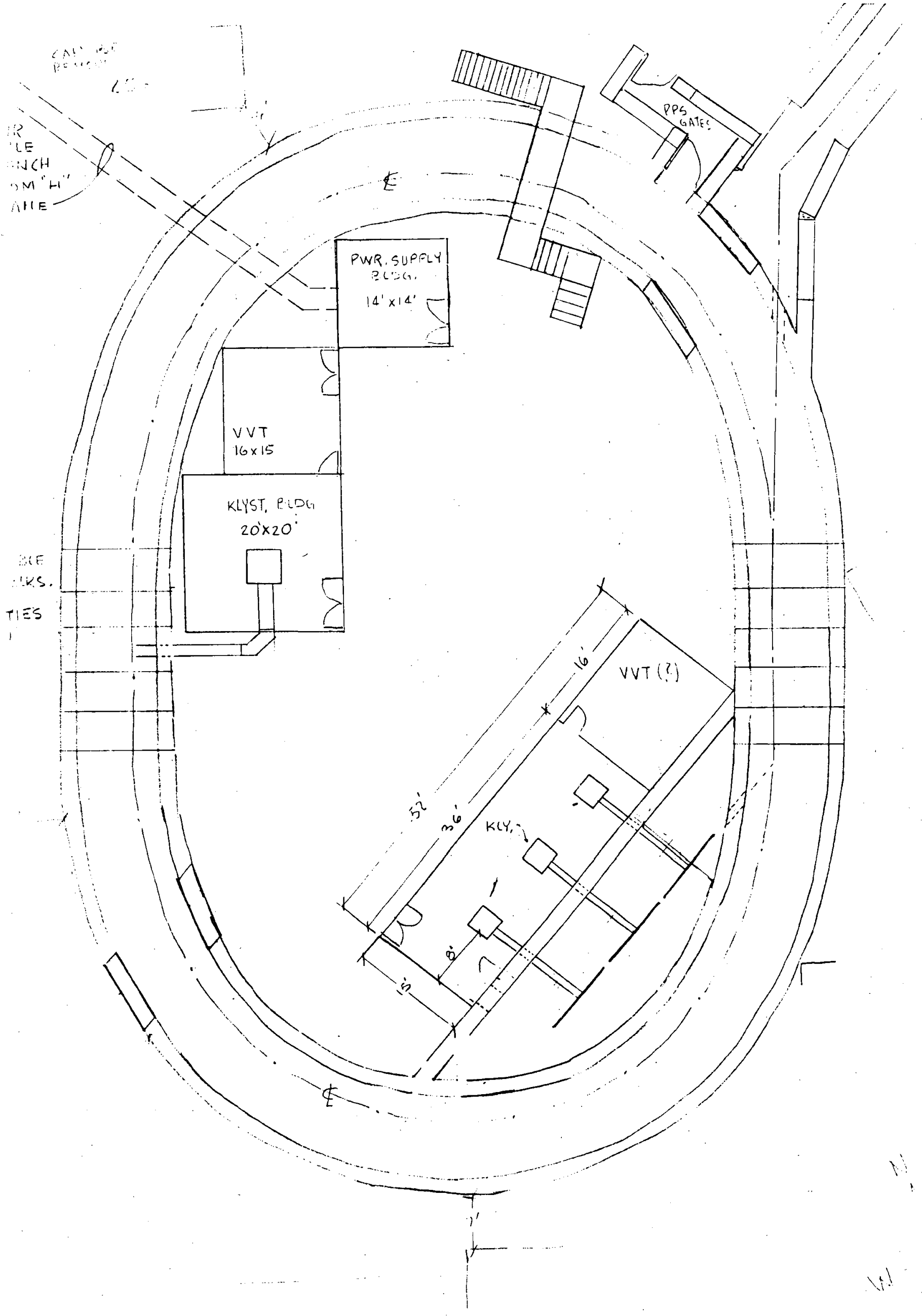




\begin{tabular}{|c|c|c|c|c|c|c|c|c|c|c|c|c|c|c|c|}
\hline & 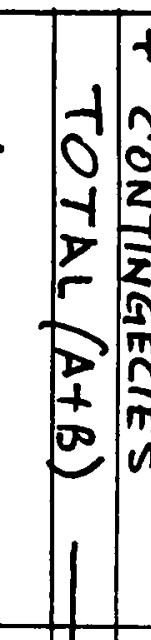 & 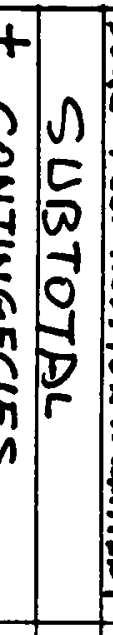 & 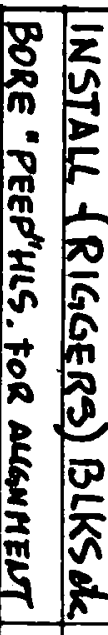 & 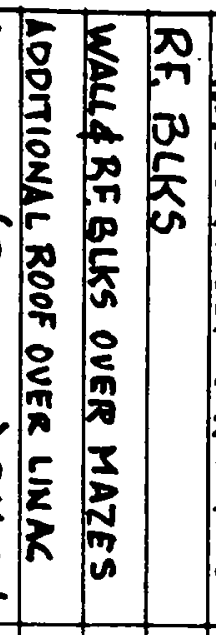 & 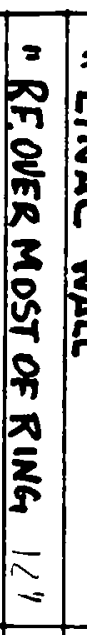 & 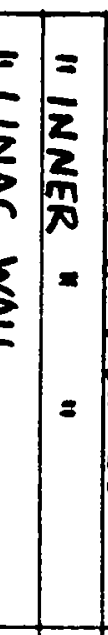 & 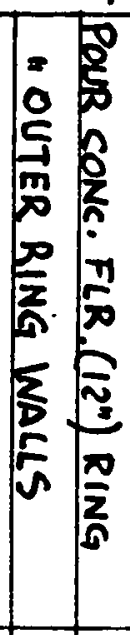 & 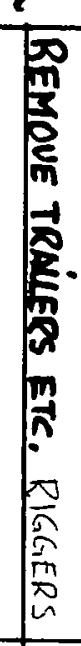 & 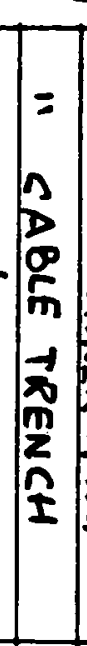 & 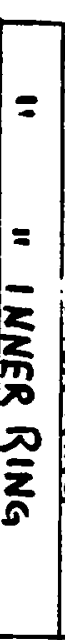 & 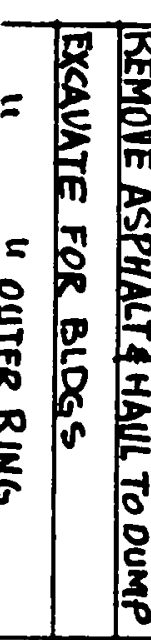 & & 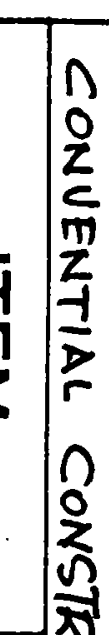 & 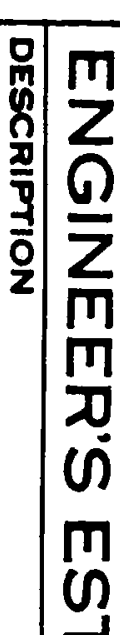 & $\frac{n}{3}$ \\
\hline & & & $?$ & 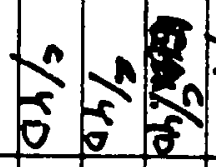 & & $5 \frac{n}{0}$ & $\frac{n}{0}$ & & $=$ & $=$ & $=\frac{n}{0}$ & 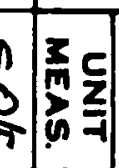 & & $\frac{7}{\overline{3}}$ & $\underset{0}{0}$ \\
\hline & & & $\bar{\omega}$ & $\begin{array}{lll}N & 0 & 0\end{array}$ & $\bar{a}$ & & $\infty_{\infty}^{-1}$ & & $E$ & $\infty$ & $5 \overline{8}$ & & & m & $\frac{\Gamma}{7}$ \\
\hline & $1 \%$ & & $\frac{8}{8}$ & $\begin{array}{llll} & & \\
5 & 8 & \overline{8} \\
0 & 0 & 0 \\
\end{array}$ & $=$ & $==$ & $=0$ & & $=$ & $=$ & $=\begin{array}{c}18 \\
0 \\
0 \\
18\end{array}$ & $=0$ & & 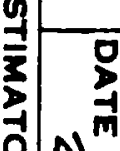 & $\sum_{\pi}^{\pi}$ \\
\hline & 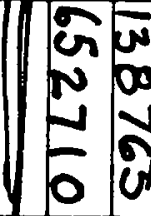 & 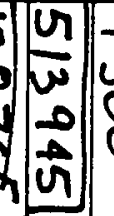 & $\begin{array}{l}\bar{w} \\
0 \\
0\end{array}$ & 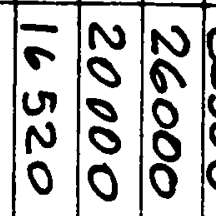 & 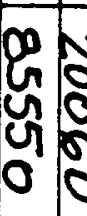 & $\begin{array}{l}\tilde{N} \\
\tilde{w} \\
0\end{array}$ & 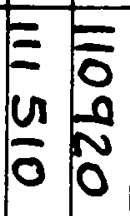 & & $\frac{n}{0}$ & $\begin{array}{c}n \\
\sigma \\
0\end{array}$ & $\begin{array}{l}n \\
\text { w }\end{array}$ & 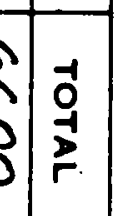 & 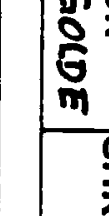 & 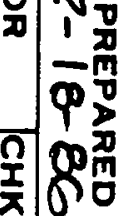 & م \\
\hline & & & 3 & & & & & $\frac{3}{0}$ & & & & 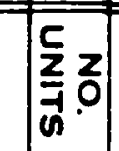 & & $\begin{array}{l}\boldsymbol{\sigma} \\
\mathbf{v} \\
\mathbf{2}\end{array}$ & \\
\hline & & & $\hat{0}$ & & & & & $\begin{array}{l}N \\
O\end{array}$ & & & & $\mid \begin{array}{l}1 \\
0 \\
0 \\
0\end{array}$ & & | & $\frac{8}{1}$ \\
\hline & & & $\mathcal{w}_{\tilde{N}}^{w}$ & & & & & $\bar{n}$ & & & & 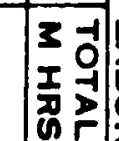 & 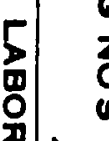 & & 0 \\
\hline & & & $\begin{array}{l}N \\
0 \\
18\end{array}$ & & & & & $\begin{array}{c}4 \\
18 \\
18\end{array}$ & & & & 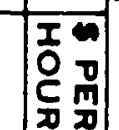 & & l. & m \\
\hline & & & $\begin{array}{l}\infty \\
0 \\
0 \\
0\end{array}$ & & & & & $\stackrel{t}{A}$ & & & & $\begin{array}{l}0 \\
0 \\
⿱ 亠 䒑\end{array}$ & & & m \\
\hline
\end{tabular}


SPRL Camereto Floor

excovate

heavy rebar, profit drilluy candinits

caucsicte

$$
\begin{aligned}
& 3500 \mathrm{ft}^{2}, \mathrm{l}^{\prime} \mathrm{dec} i \mathrm{i} \quad \Rightarrow 119 \% \mathrm{~d} \\
& \text { Cont: } 49 \mathrm{k} \text { it } \Rightarrow 410 \text { \#/yol }
\end{aligned}
$$

$\left.\begin{array}{c}\text { take off excairation } \\ \text { condisto } \\ \text { abrilligy }\end{array}\right\} \Rightarrow 360 \# / y d$

FLOOR: $360 \$ /$ yd FY.6 
SPRL - SHIELDING WALLS

$\left.\begin{array}{ll}\text { Walls } & \begin{array}{l}230 \mathrm{yd} \\ \text { roof }\end{array} \\ 480 \mathrm{yd}\end{array}\right\} \quad \$ 231524$

take off earthquake bracing at 164 /rot

$-37720$

193804

$273 \$ / y d$

Injector:

Outer Wall $371^{\prime} \times 8^{\prime} \times 2^{\prime}=5931 \mathrm{ft}^{3}=220 \mathrm{gd}$

tuner Wall $295^{\prime} \times 8^{\prime} \times 2^{\prime}=4725 \mathrm{ft}^{3}=175 \mathrm{gd}$ 
$\angle A B O R-D E S I E N+F A B$

210 CU YDTOTAL

$$
\begin{aligned}
& \text { DESI } 6 N-220 \text { HRS } \times 26.75=\$ 5885 \\
& F A B=-46^{20} \text { HRS X 17.50 = } 8400+4200=1 / 2600 \\
& \text { POUR }=336 \text { HRS } x / 750=\$ 5880 \\
& \text { * HAnsein } 6 \\
& \text { SUR }=T=\$ 24,365 \\
& \text { Forms } \frac{1 M A T L}{10560} \\
& \text { Concket } 1 / 2 / 2,360 \\
& R=B A R-1315+5541+350 \$ 7206 \\
& \text { M.SC-OTHER I } 146+150+300=\$ 596 \\
& \frac{5 U B-T=30,+22}{\text { TOTAC }=\$ 55087} \\
& \$ 262 \text { PER CU.YARD }
\end{aligned}
$$

81 BLOCKS@656PER BLOCK 
Eoctra SPEAR SHIELDING

1.) exstra I' over $2 / 8$ of ring.

$$
\begin{aligned}
& 90 \mathrm{~m} \times 1 \theta^{\prime} \text { cuide } \Rightarrow 110 \mathrm{yd} . \\
& 110 \mathrm{yd} \times \$ 262=\$ 28.820
\end{aligned}
$$

for still mone shielding at Extion take encisting shielding blochs.

2.) Shielding of Sequim:

Ph hairse

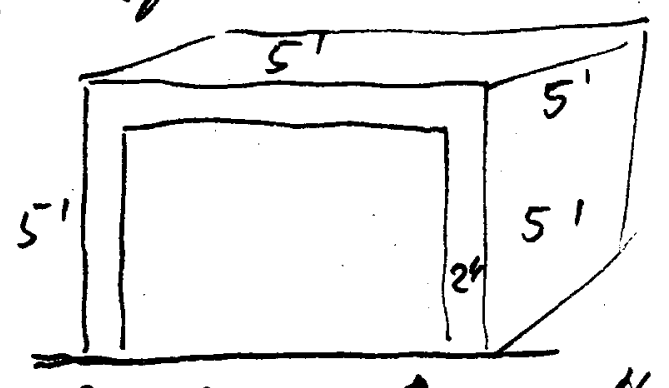

675 lead hmidrs à $\$ 25=\$ 16875$ tor expensin alternative:

Coucrete rool

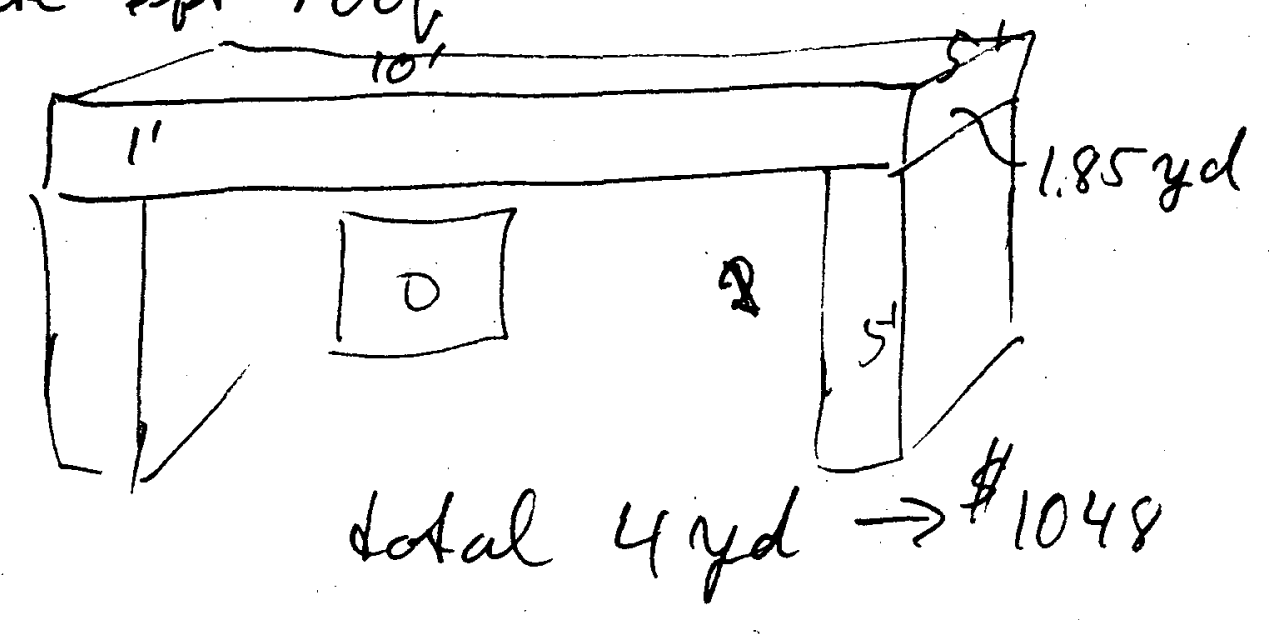


$2-20-87$

Ring Tinunel:

wools $2 \mathrm{ft}$

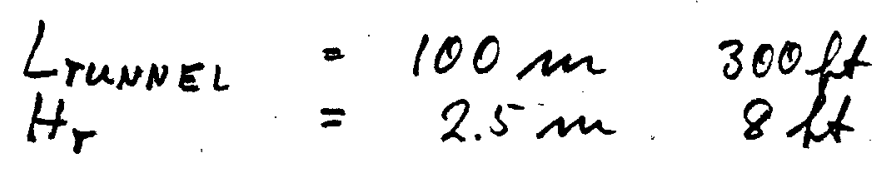

Walls: $9600 \mathrm{ft}^{3}=355.6 \mathrm{yd}$.

Floor: $16 \times 1 \times 300=4800 \mathrm{ft}^{3}=177.8 \mathrm{yd}$

Roof : $12 \times 1 \times 300=3600 \mathrm{ff}^{3}=133.3 \mathrm{yd}$

$\$ 262 / y d$ reiuforced caucrete

total yerds: $\quad 666.7 \times 262=174.7 \mathrm{k} \$$

arinice 6 Blachs/weeh or $7 \mathrm{fl}$ / werech

$\Rightarrow 47$ weeks to do $100 \mathrm{~m}$

Linac Trimul $20 \mathrm{~m} \rightarrow 10$ urelns $\} 12$ worth 
1.1.1 Electrical Services 1.1 .1 .0 E D \& I

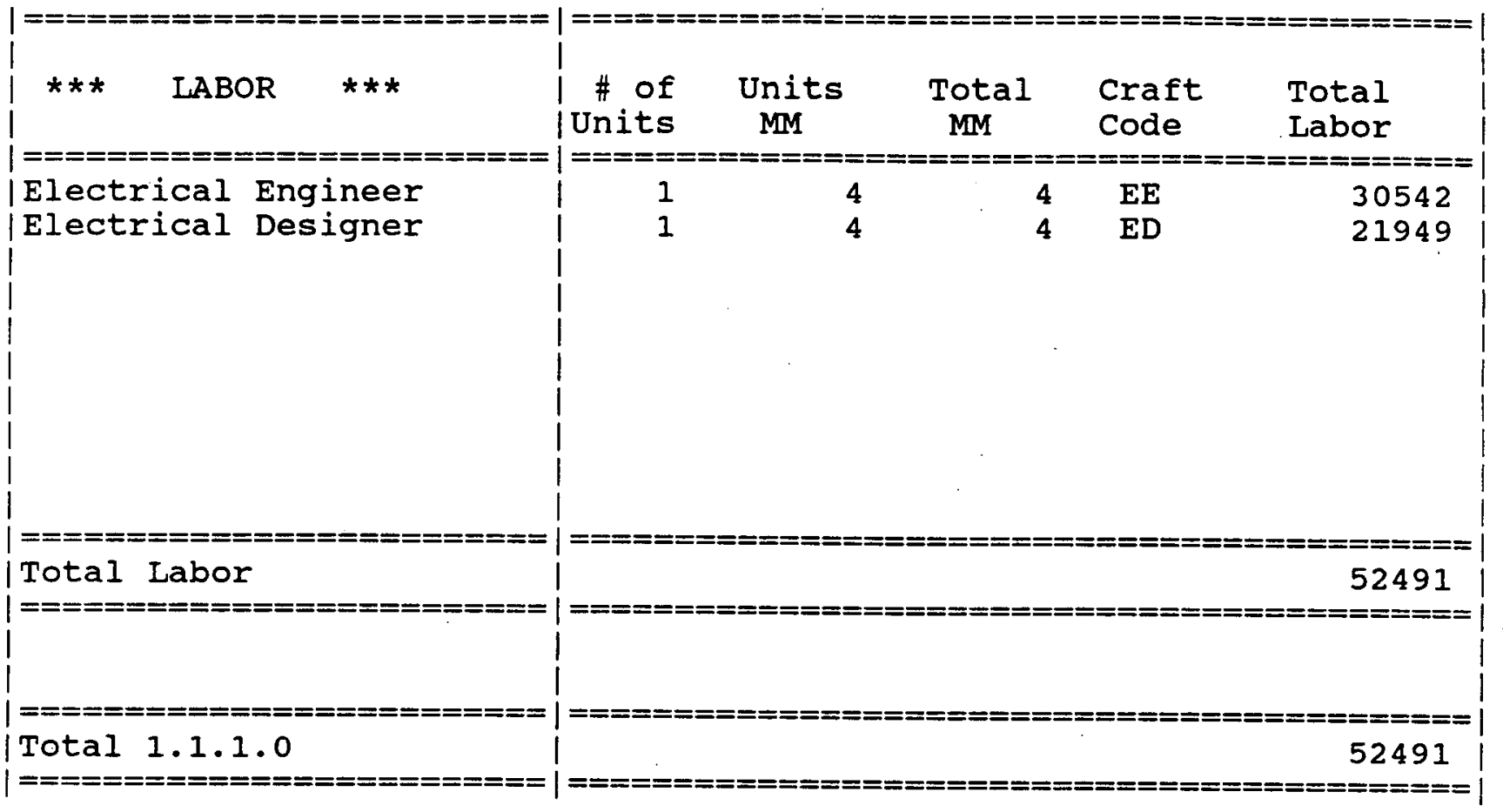




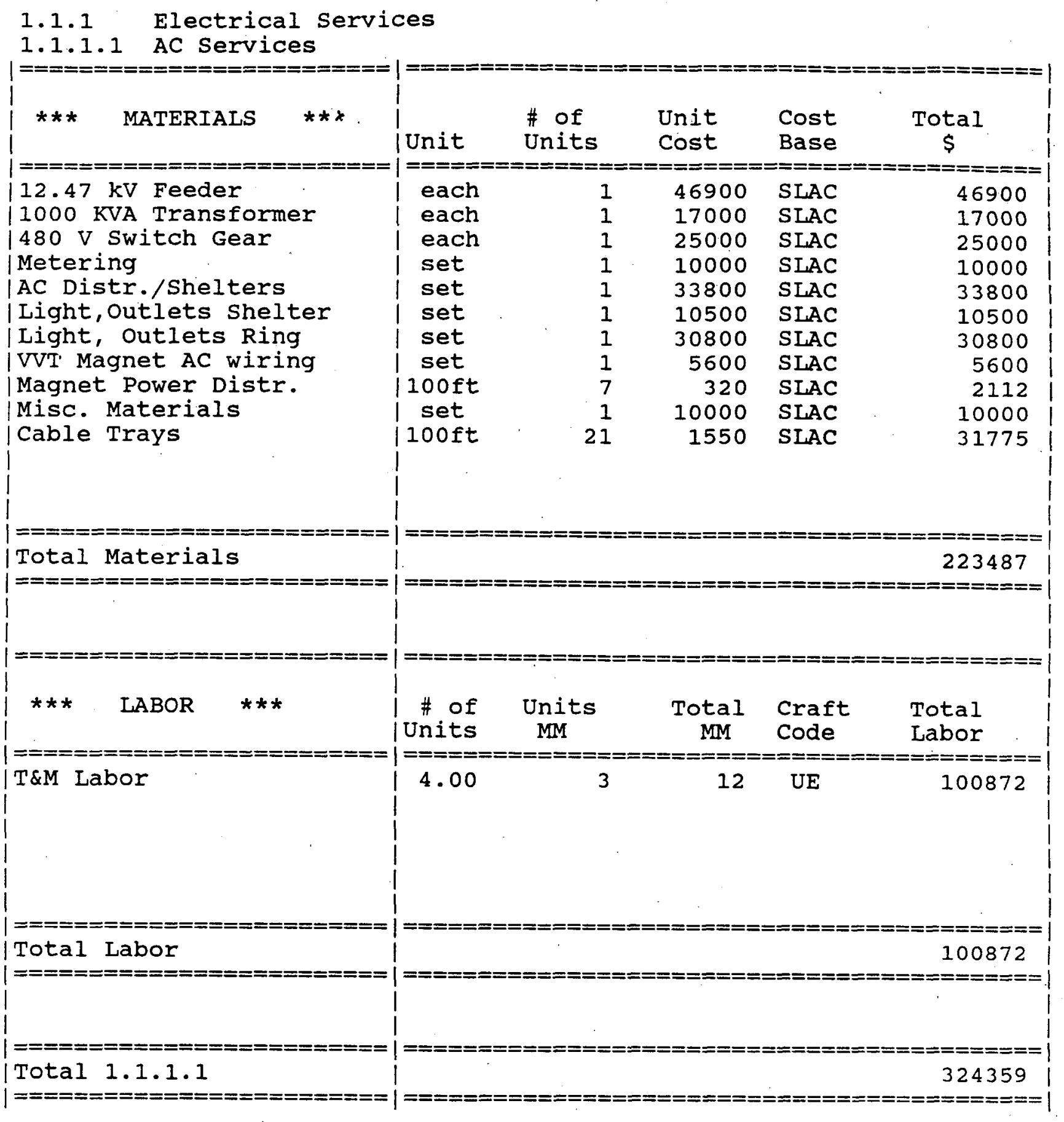




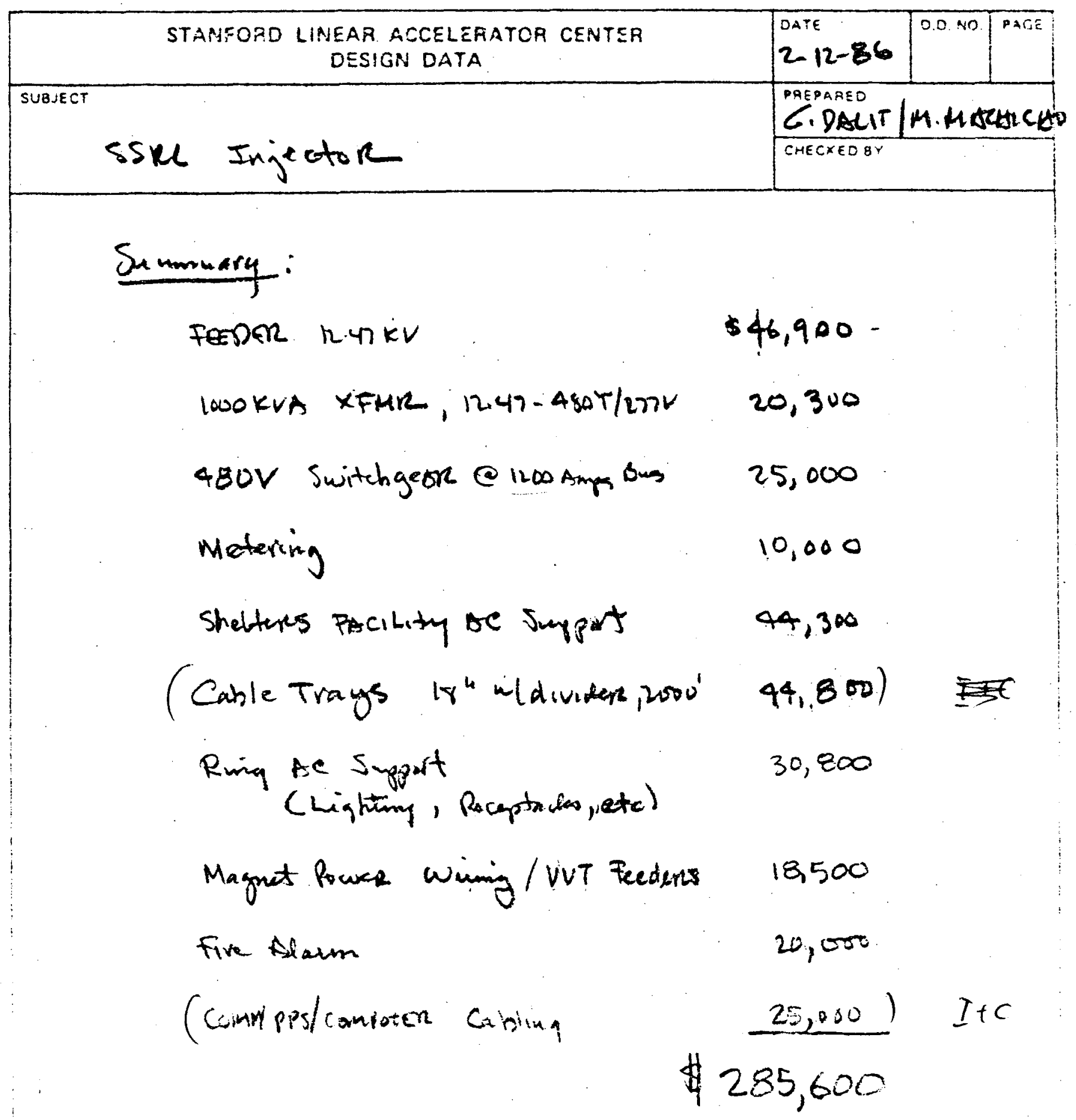

16. in $\sin 20$

Itc cablima

DC Pourere Japaies Carding

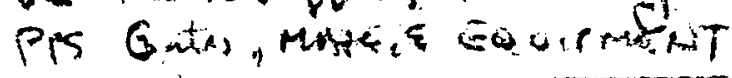

ED: 


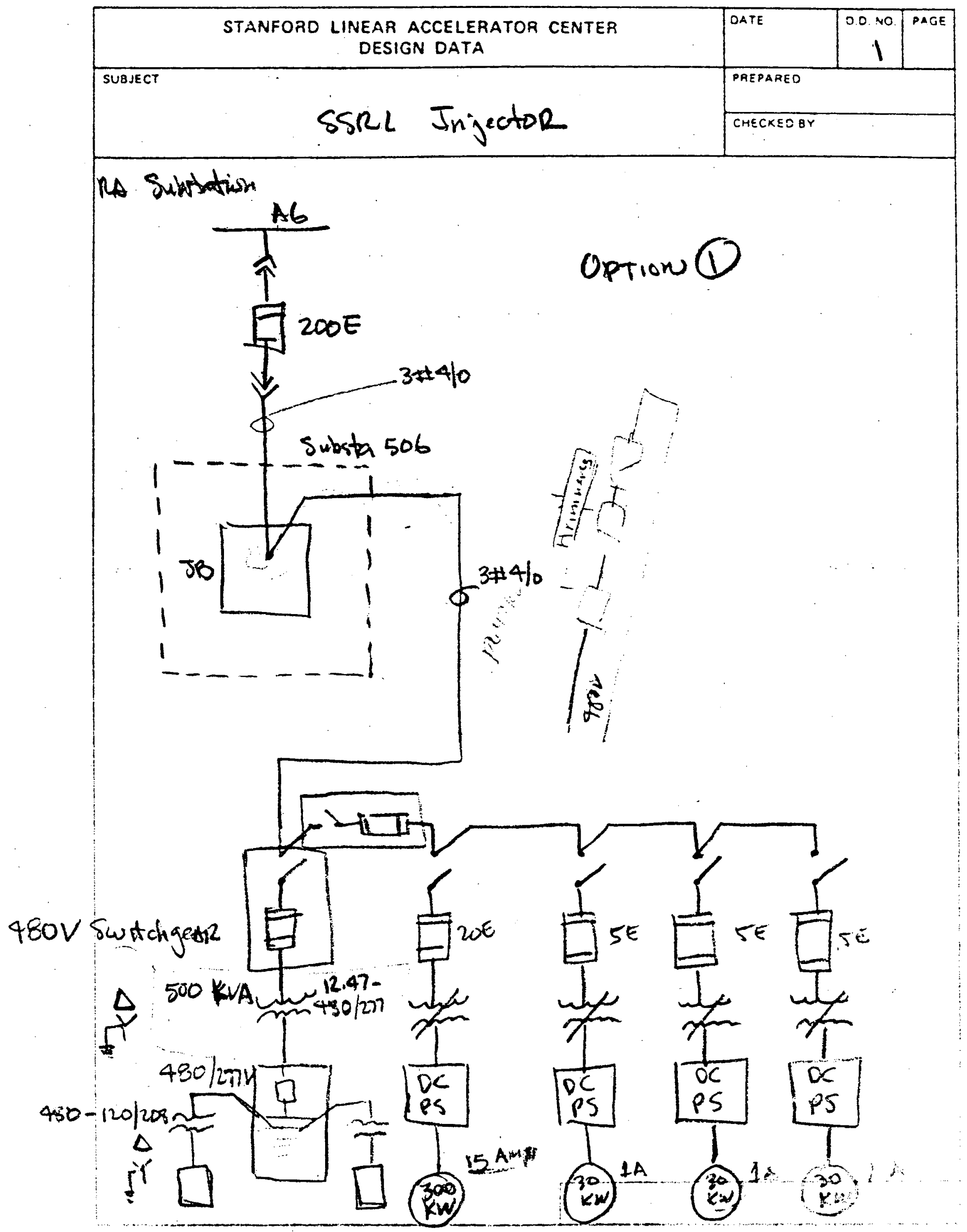




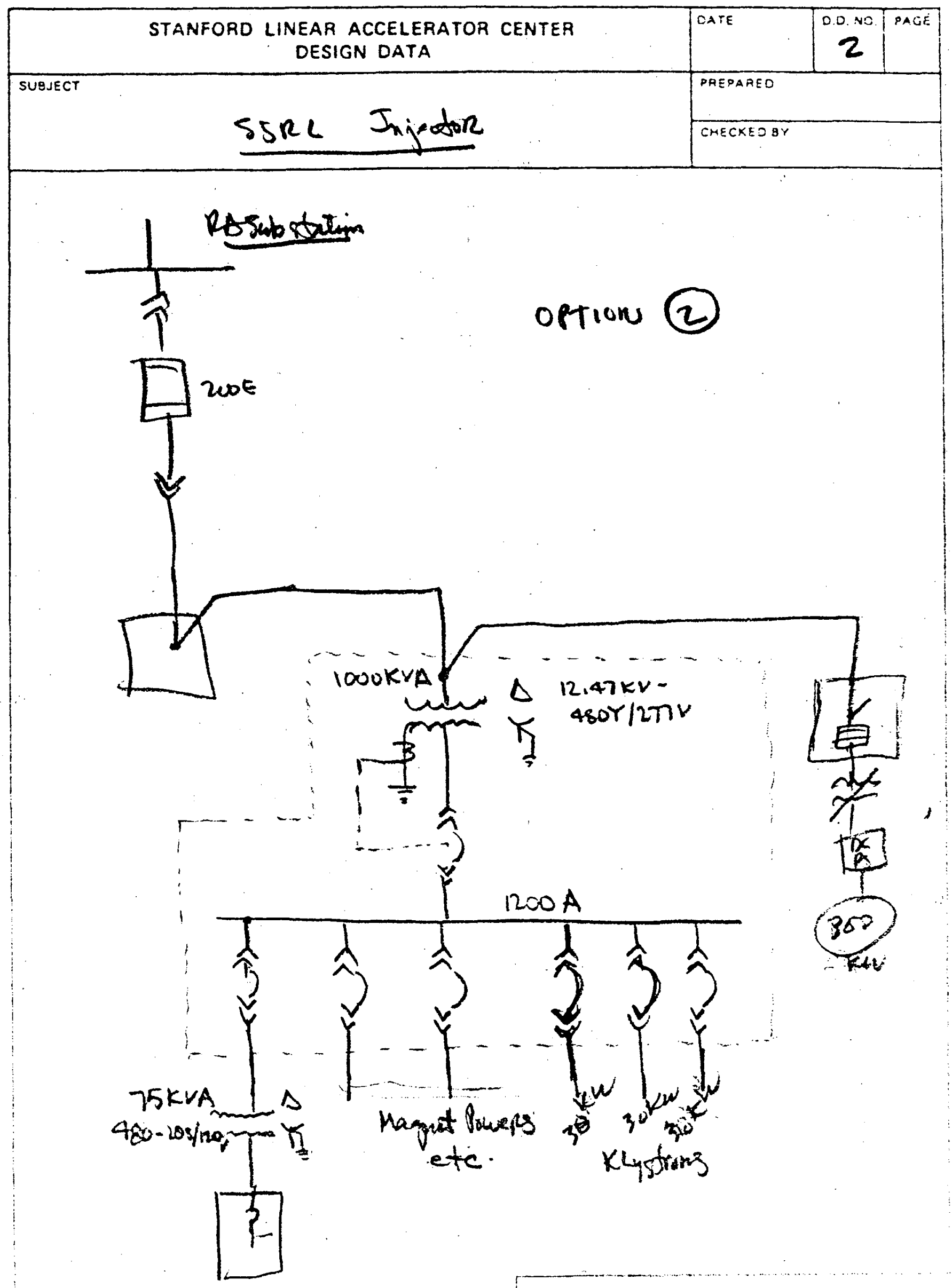




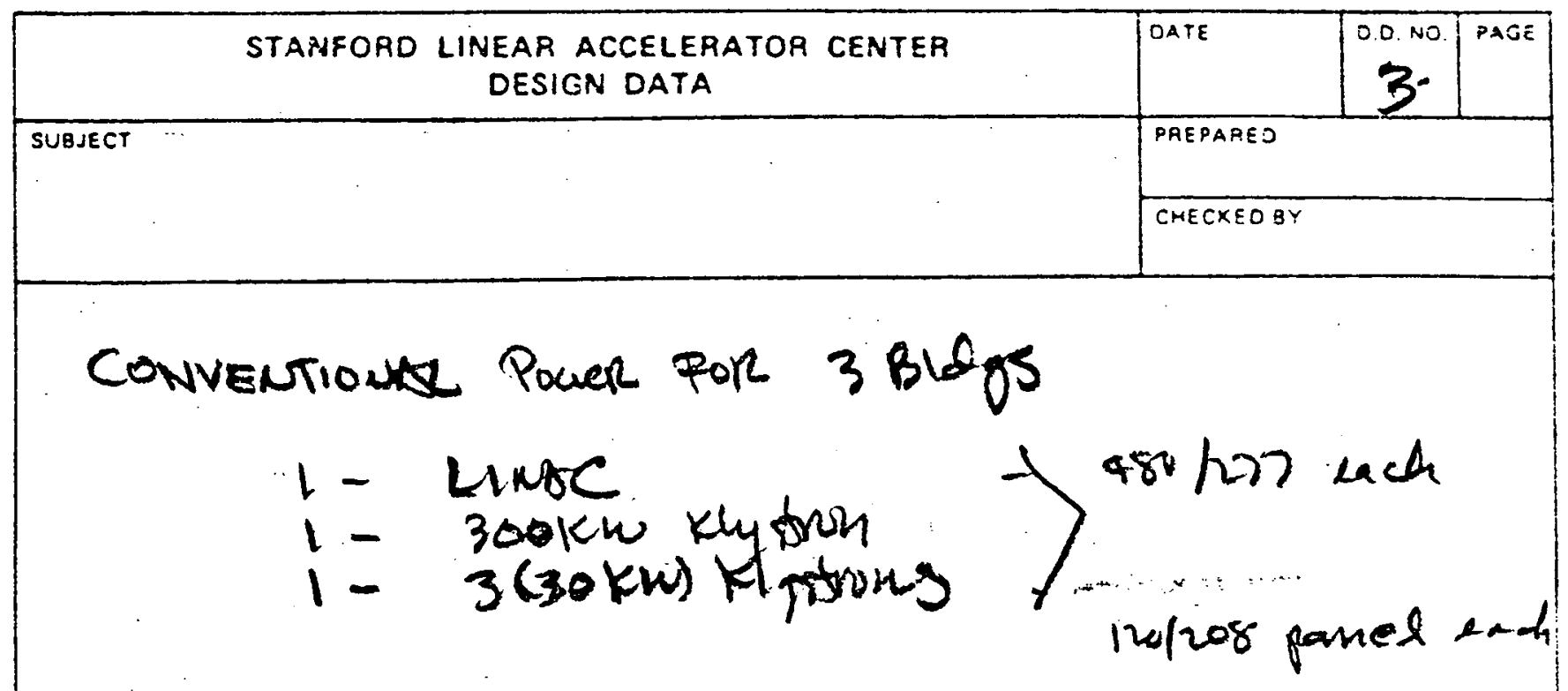




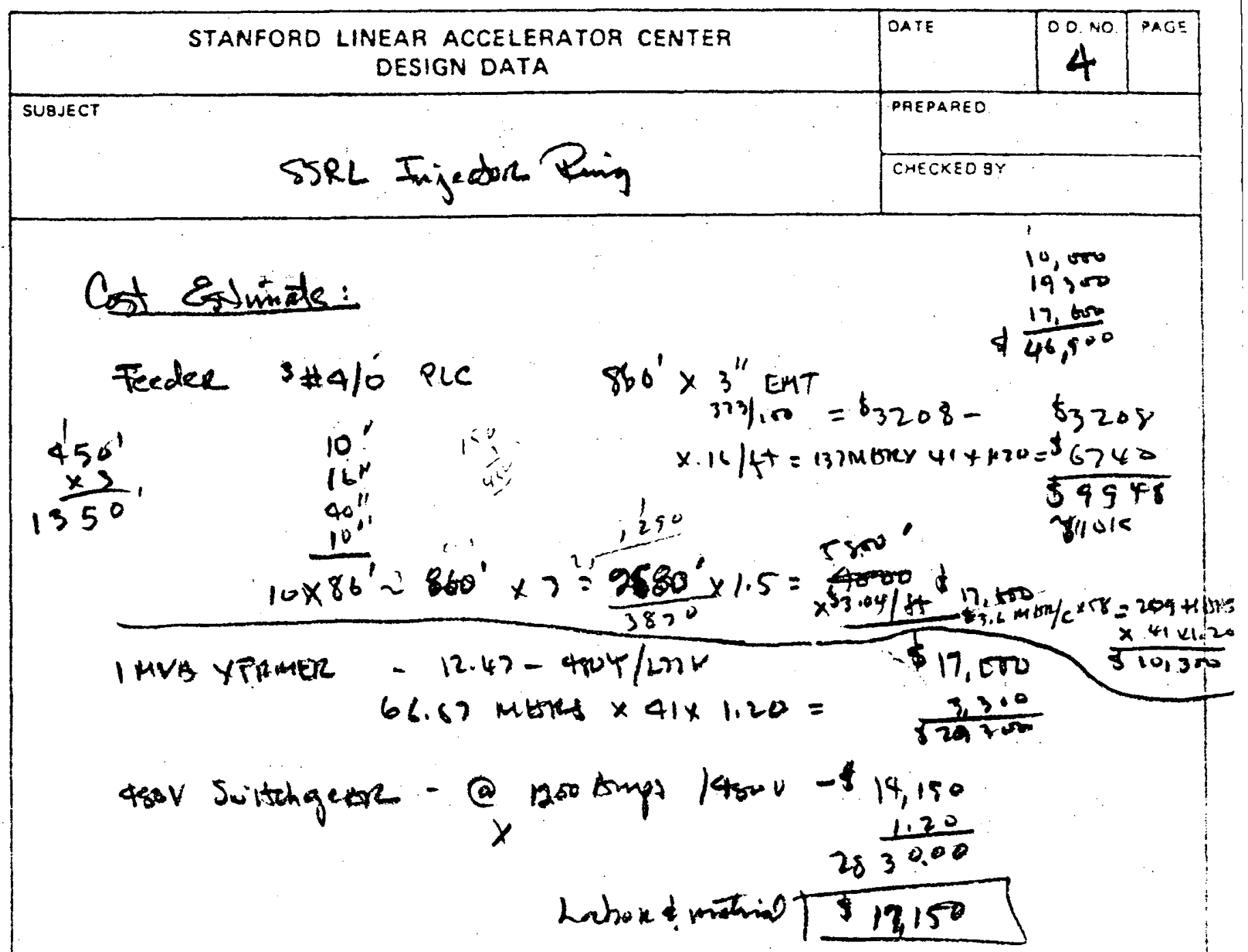

Dut ounk $100^{\prime} x^{5} 50 / f t=\$ 3500$

Apalf ${ }_{100} \times 2 \times 260=\frac{2500}{5,000}$

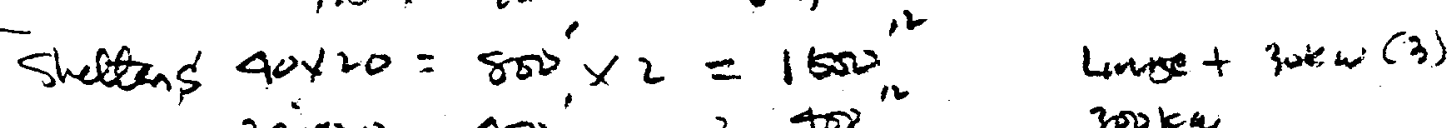

$$
\begin{aligned}
& 20^{\circ} \times 20=400^{\circ}=\frac{400^{\prime 2}}{2000^{12}} \\
& 300 \mathrm{~km} \\
& \text { persint }=320 f^{t} \sim 500^{\circ} \\
& \$ \frac{7.25}{3,65.00} \text { Gimfing }
\end{aligned}
$$

$$
\begin{aligned}
& \text { Ditribition: 277) 480r }-3 x^{b} 4100=13,200 \\
& \text { 1201708 }-3 x^{6} 2400=7,200 \\
& \text { Einoth crimets: } 1.06 \times 2000 t^{2}=\frac{2,500}{\delta 22,900}
\end{aligned}
$$

$$
\text { Lighting } \frac{\$ 4,50 \times 2000^{12}=\$ 9000}{\$ 1.75 \times 2000}=\frac{\$ 100}{\text { Outtis }}=\frac{100}{}
$$




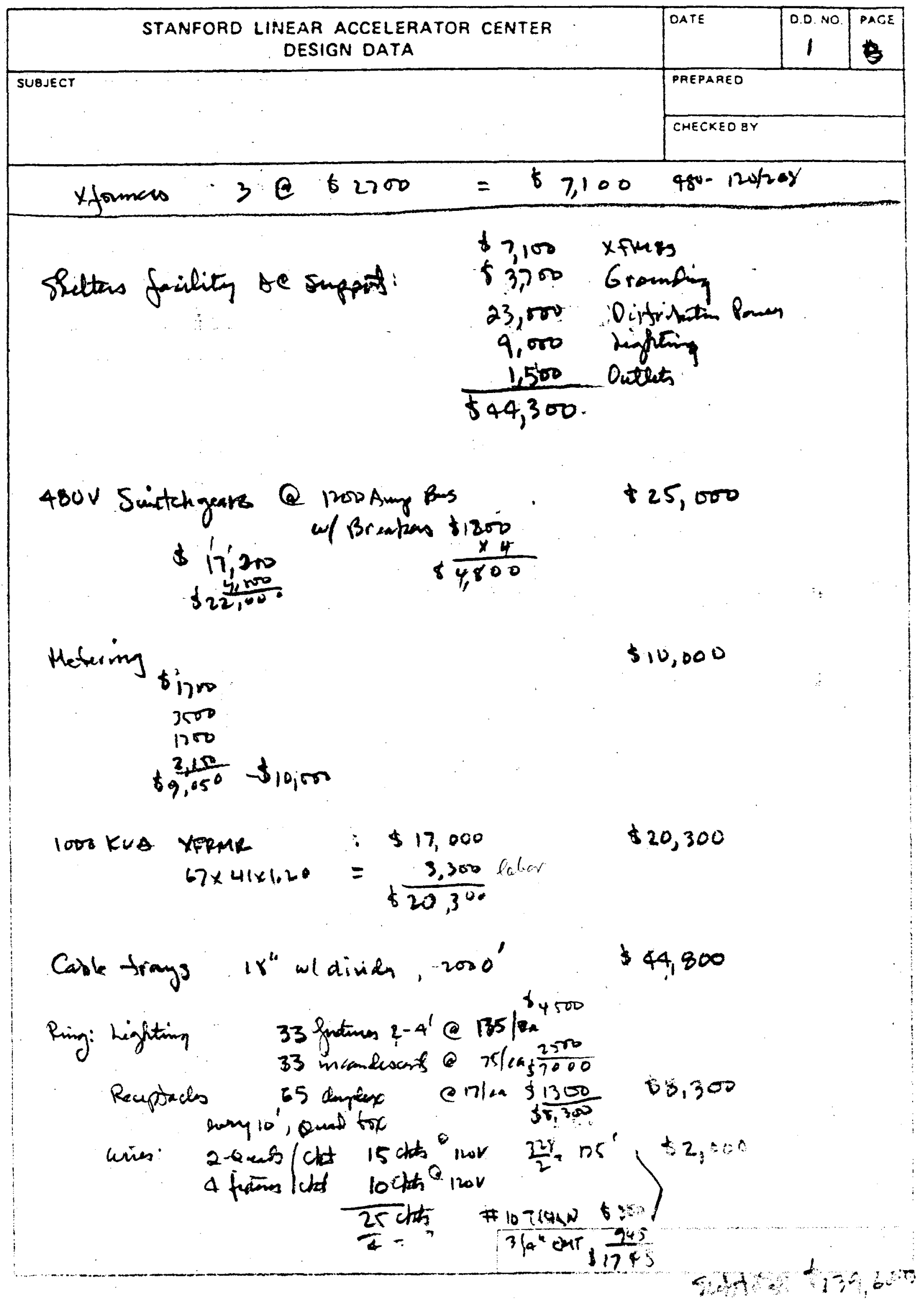




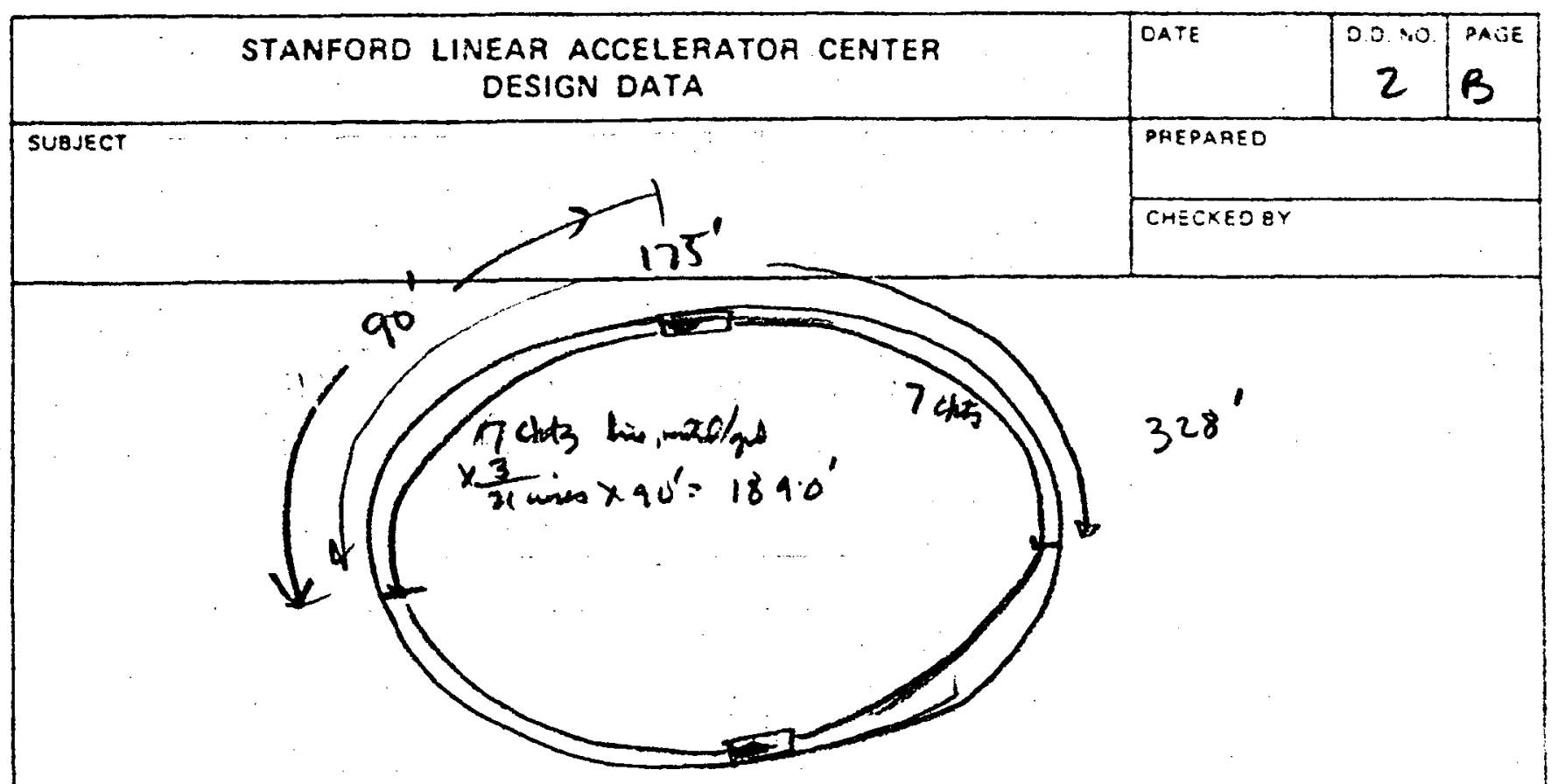

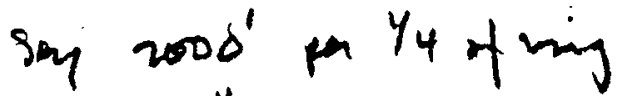

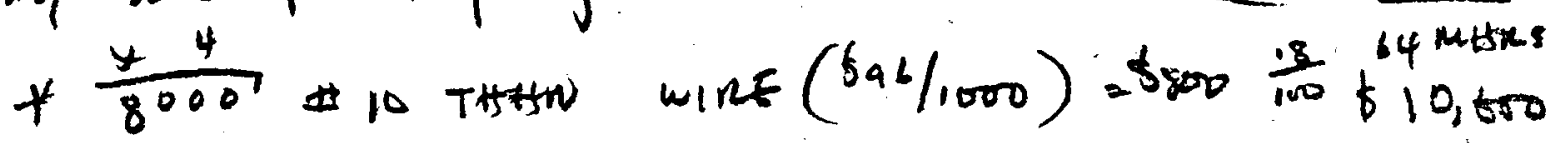

$$
\begin{aligned}
& \text { * } 2504 \times 90^{\circ} \text {, OnT } 3 / 4^{\prime \prime} \quad(\$ 42 / 10)=\frac{8945}{1745} \quad \$ 7,000 \\
& 2 \text { - irkva } \quad x \not 12700 \$ 5,400
\end{aligned}
$$

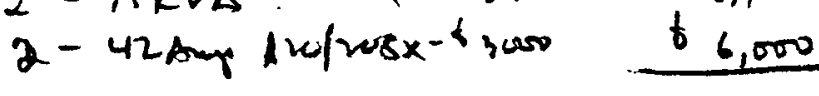

$$
\begin{aligned}
& \$ 31,000
\end{aligned}
$$

Fiveption: $15, \mathrm{~m}$

Comm/nes/compits: t25,000

$$
\begin{aligned}
& 11,400 \\
& 15,000 \\
& 12,000 \\
& \$ 38,400
\end{aligned}
$$

Magnet Power $\frac{\text { perside }}{3 \text { chts }} \times 328^{\circ} \times 5=1420 \quad \mu$ Les

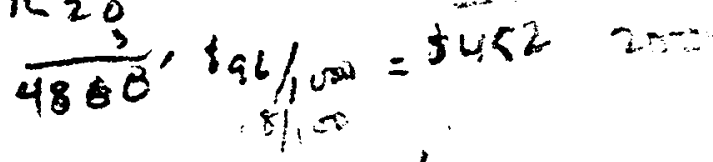

$$
\begin{aligned}
& \text { ext } \begin{aligned}
3 \times 348= & 984 \\
& \frac{\times 1.5}{49250}
\end{aligned} \\
& \frac{\$ 6004400}{2 x+7600} \\
& 1 x^{\prime \prime}-1 \frac{984}{4.76^{2}-142 / ; 00} \\
& =40=4
\end{aligned}
$$




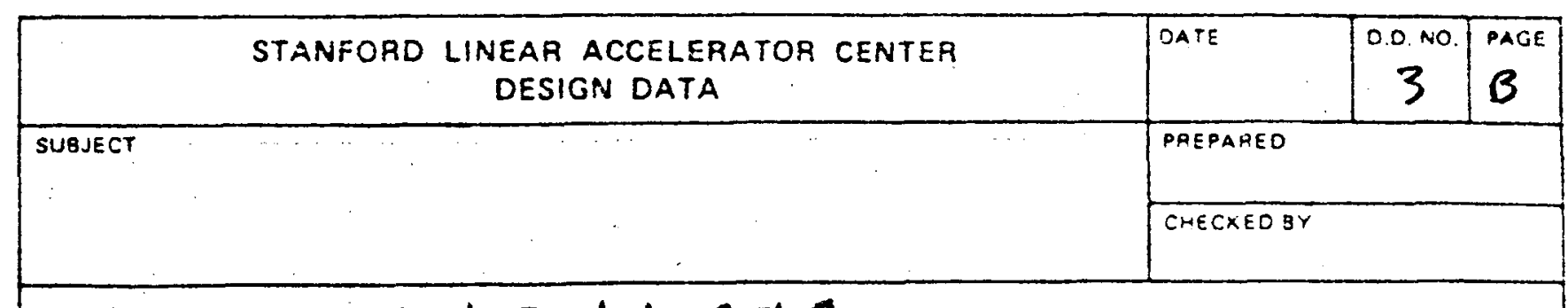

(1) 480v switch Geatr

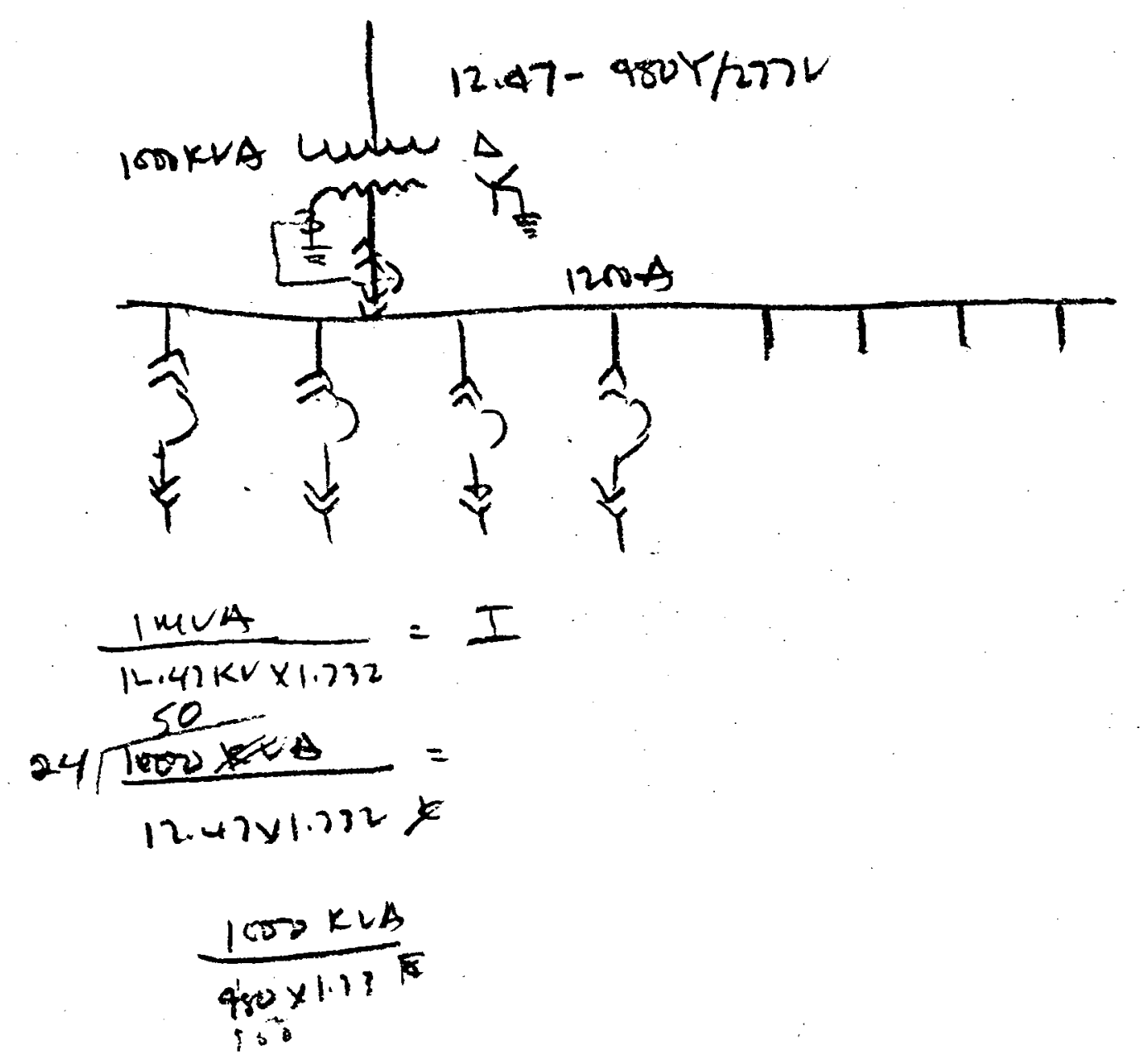

(2) Cabletrays

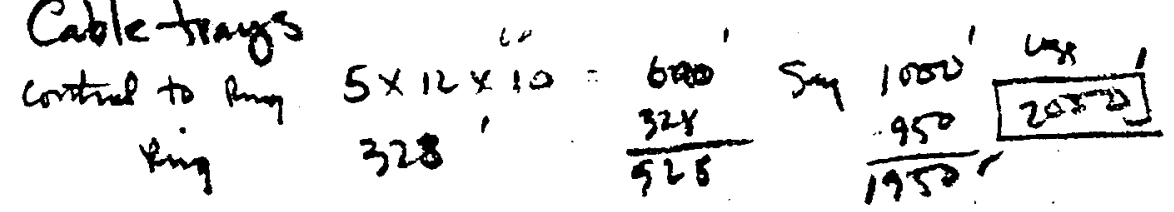

mide 18" $\sin 2000^{\prime} x^{5} 1,5,50=\$ 31,000$

$$
2 \frac{6,360}{37,360 \times 1,20=\$ 4 \div .80}
$$




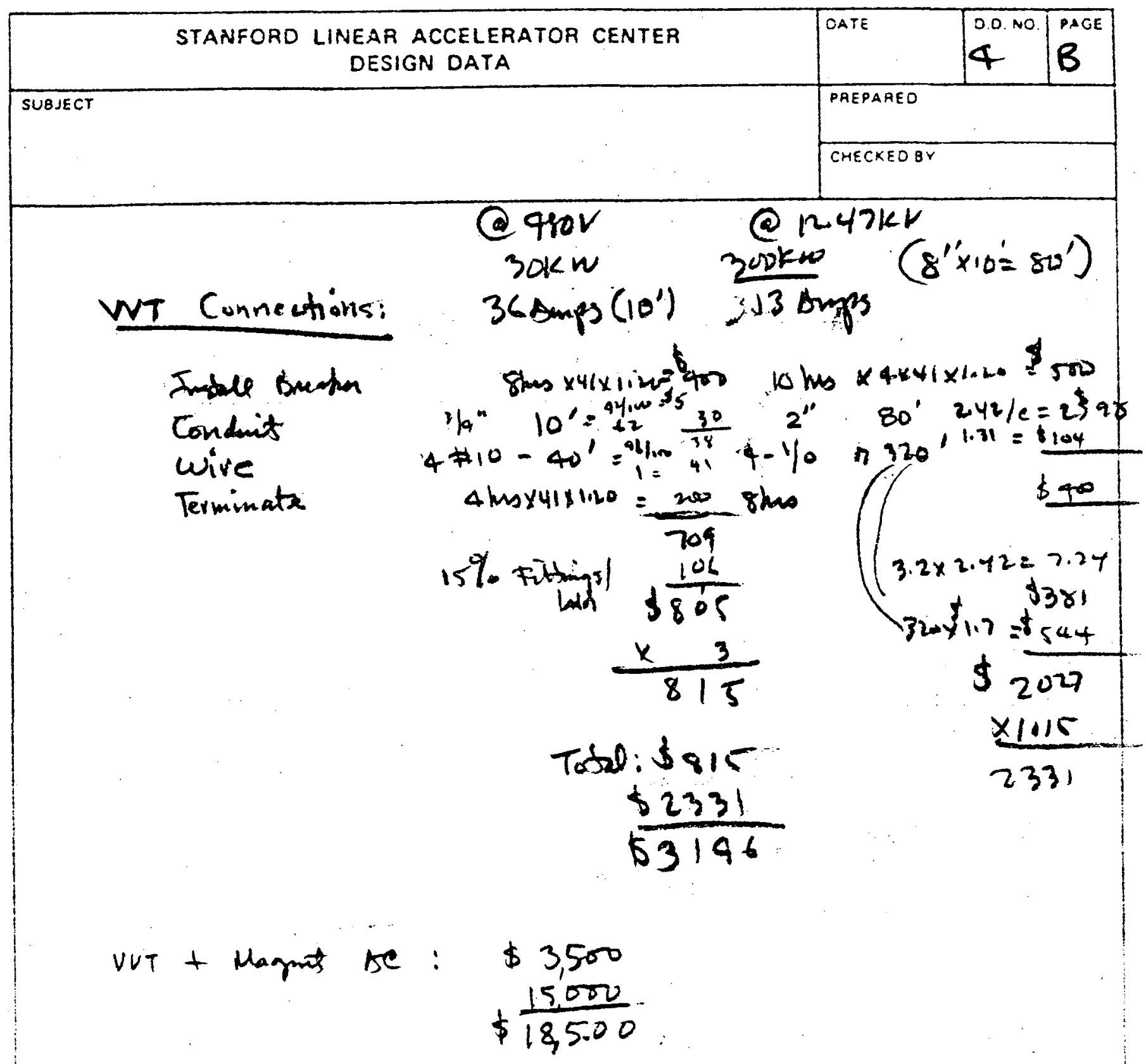


Cable Trays:

Ring two tray à $300 \mathrm{ft}=600 \mathrm{ft}$

$V V T$ - shelter

Ulyatrou shedter

Ps-chebter

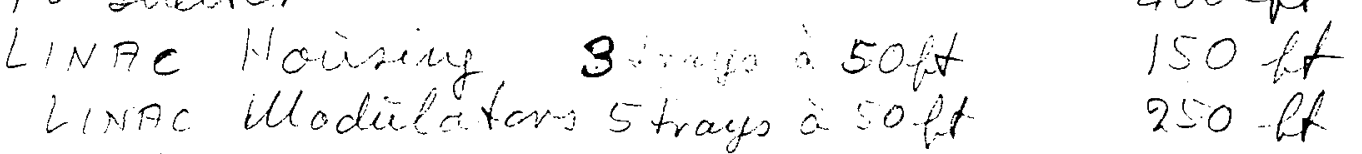

Boozter-SPEAR Franinot Lime $\quad 100 \mathrm{ft}$

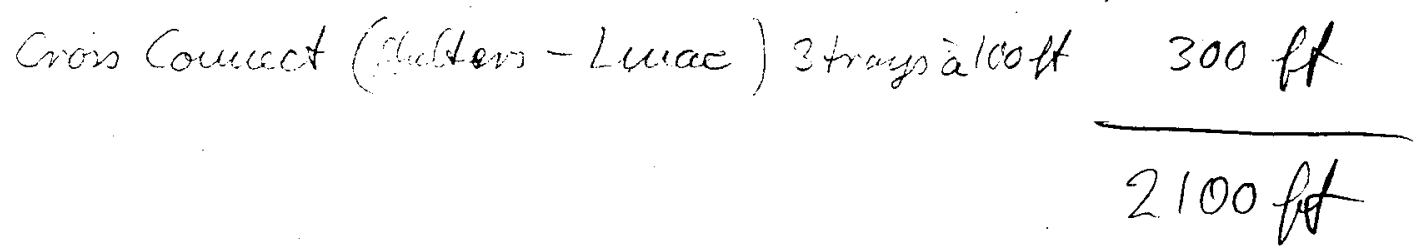

Laber: \#/feot 


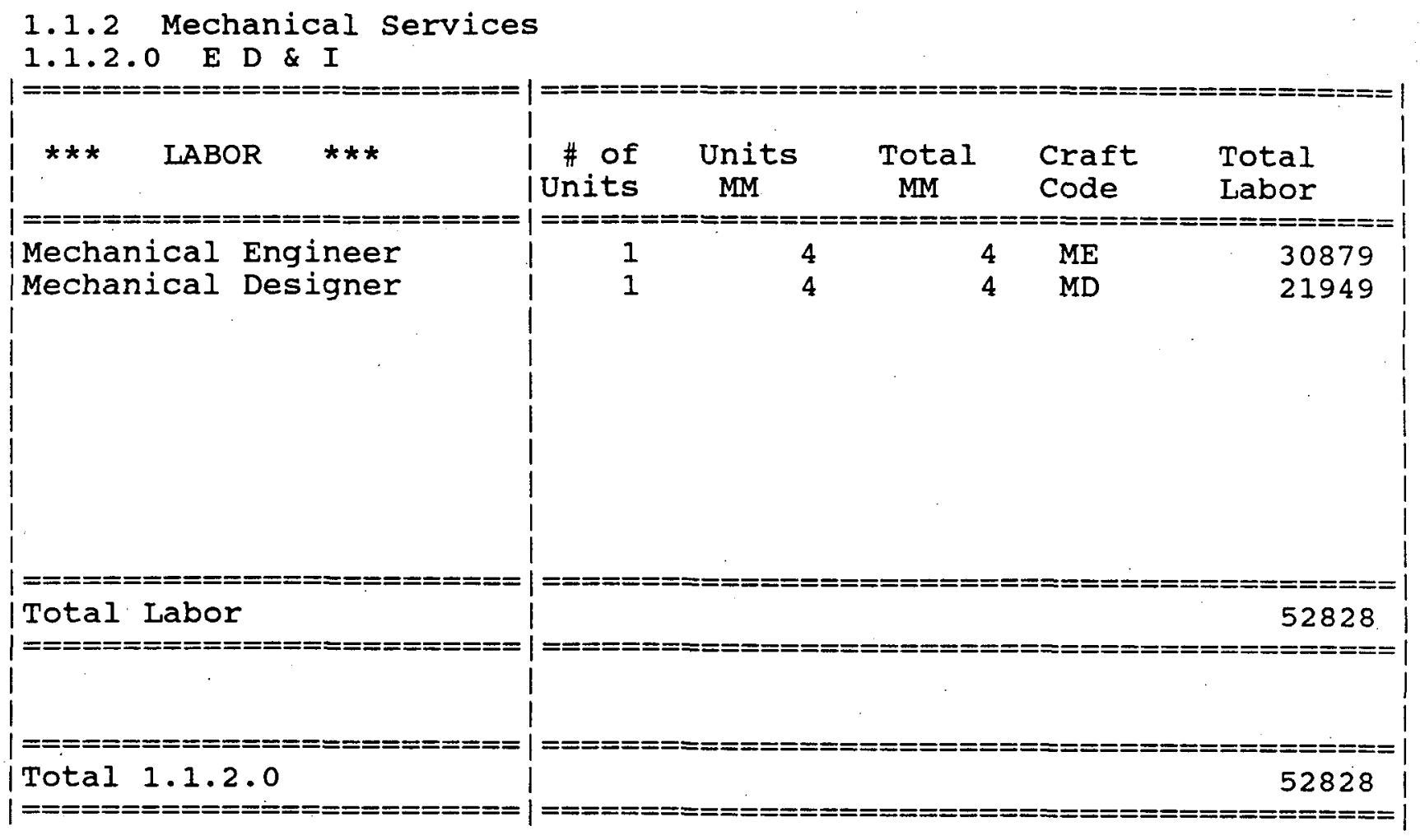




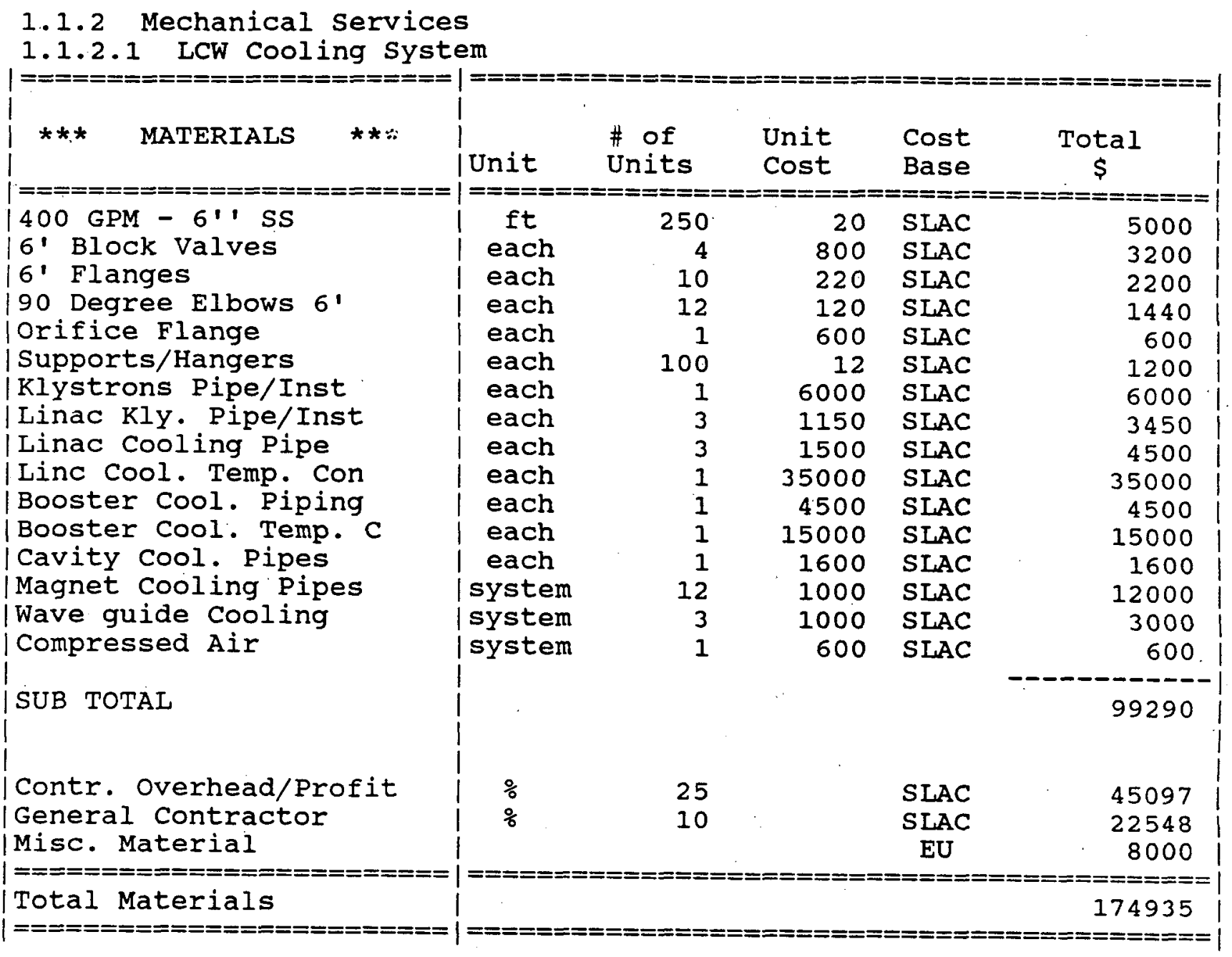




\subsubsection{Mechanical Services (con't)}

1.1.2.1 LCW Cooling system

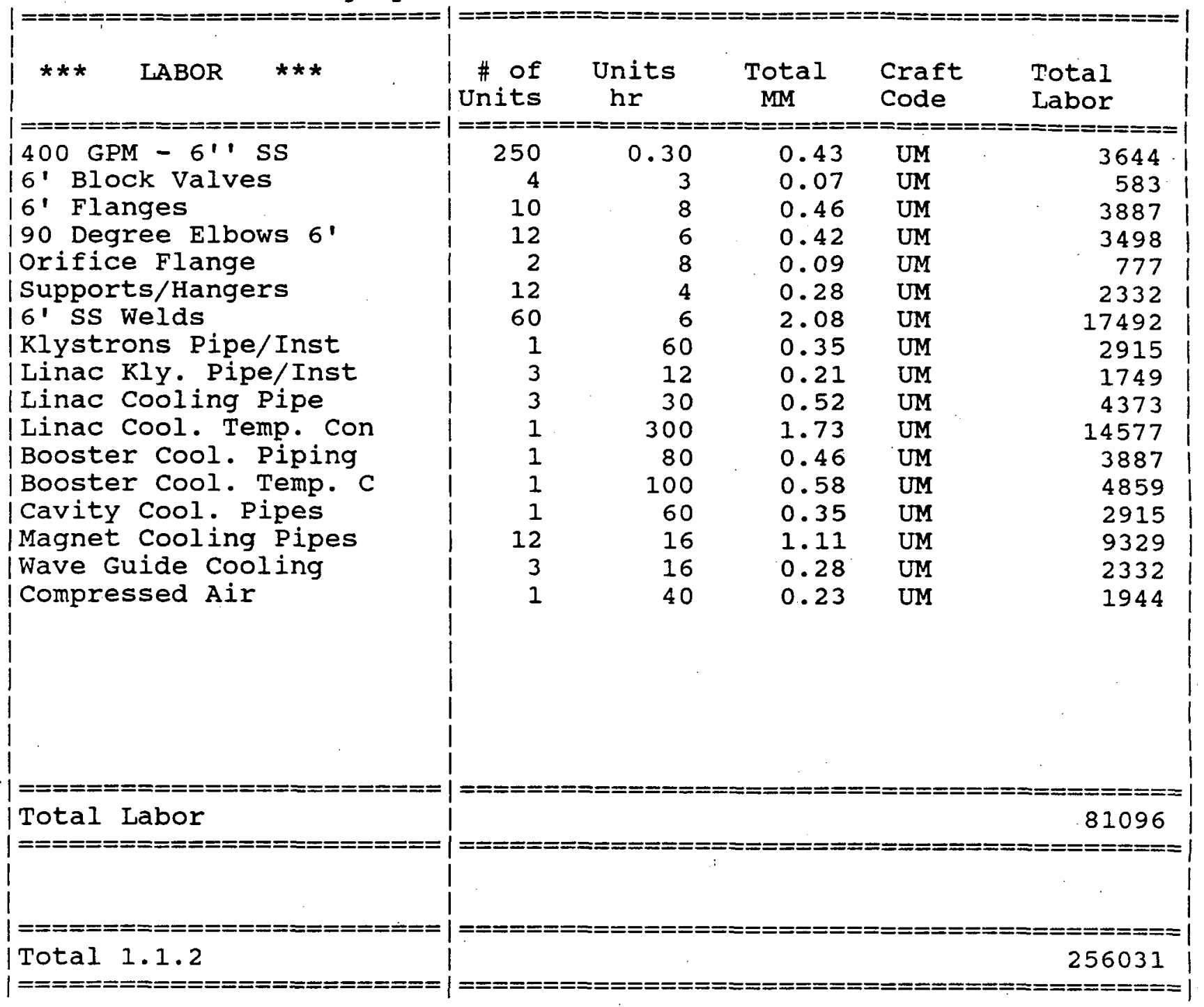




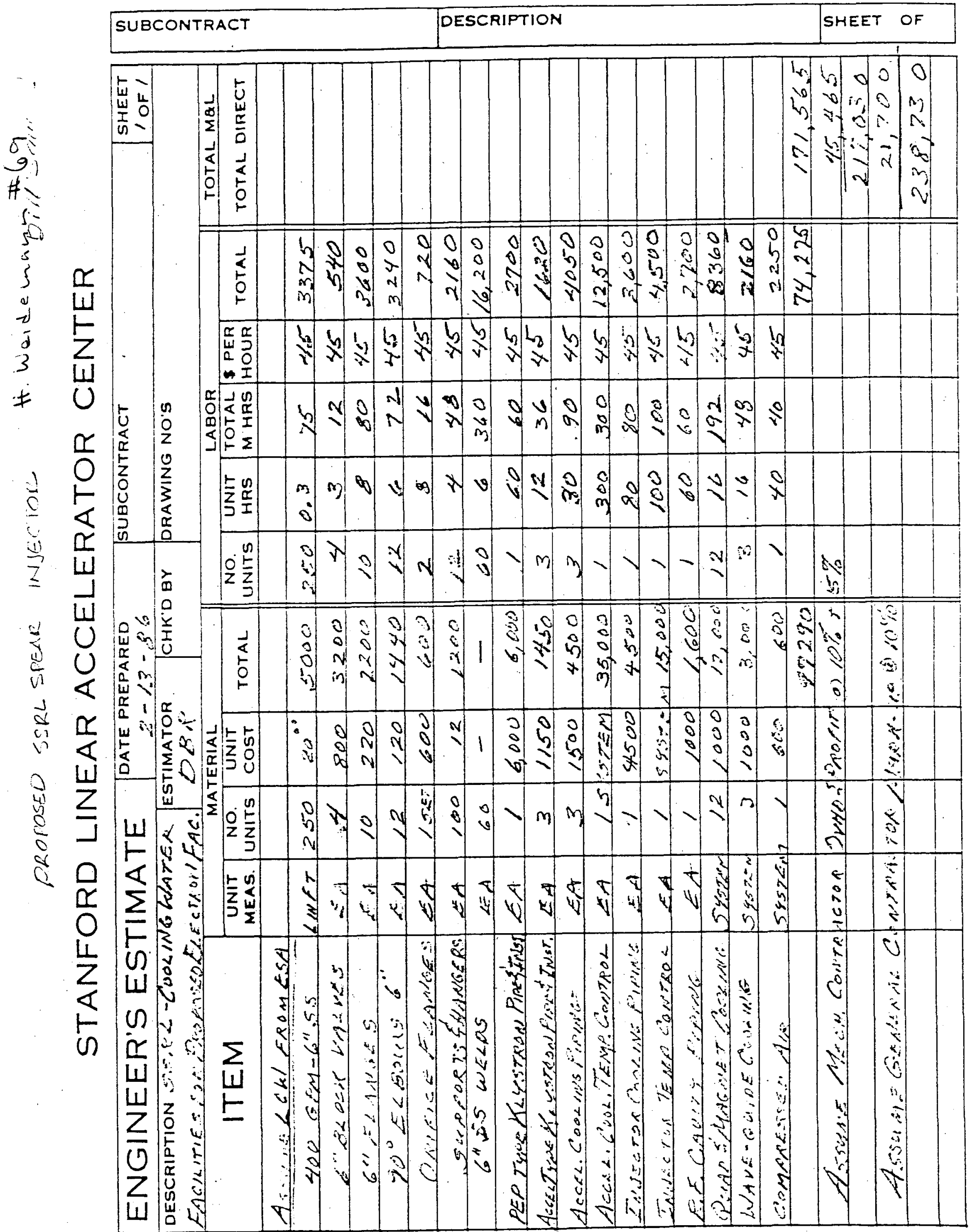




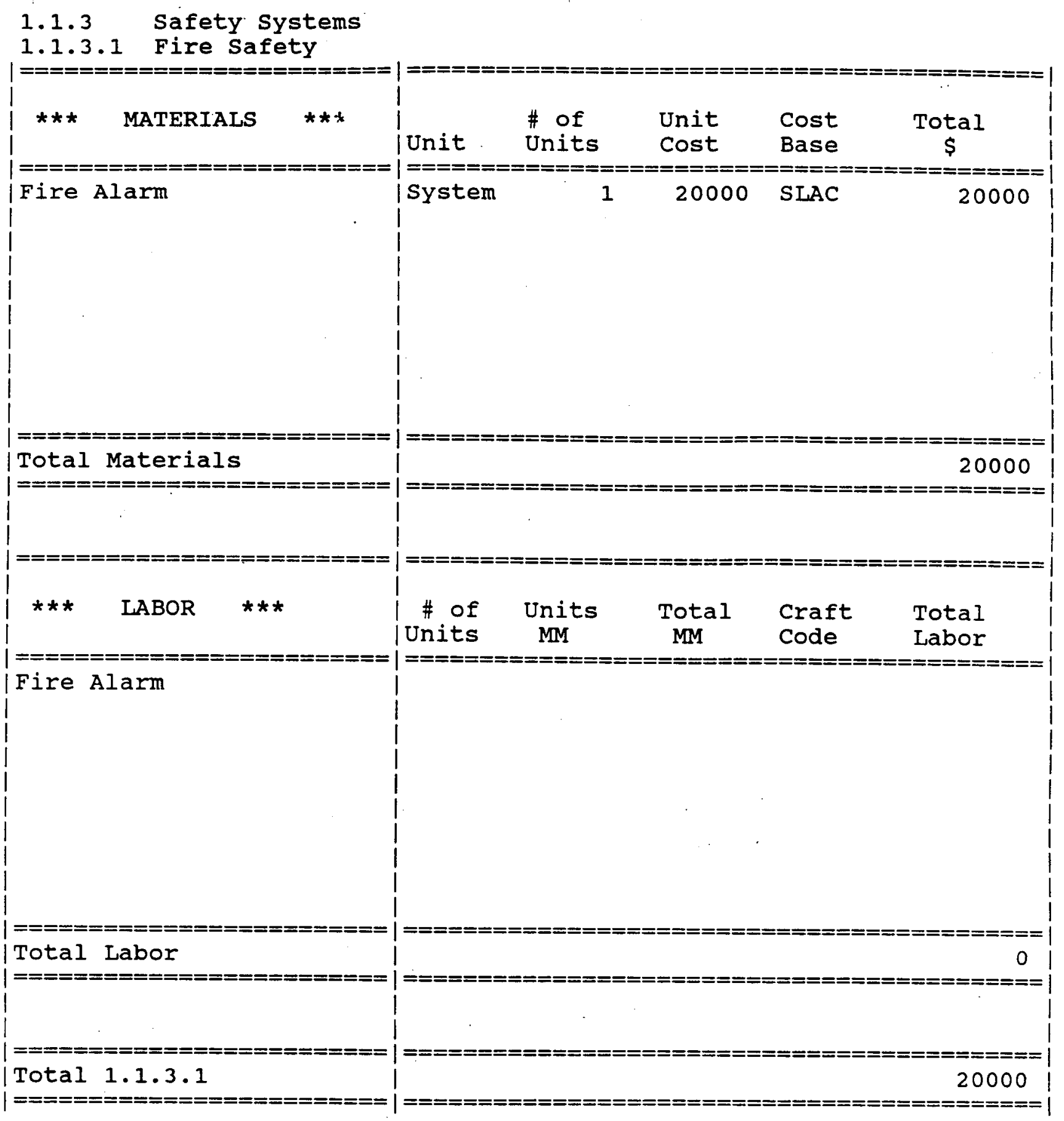




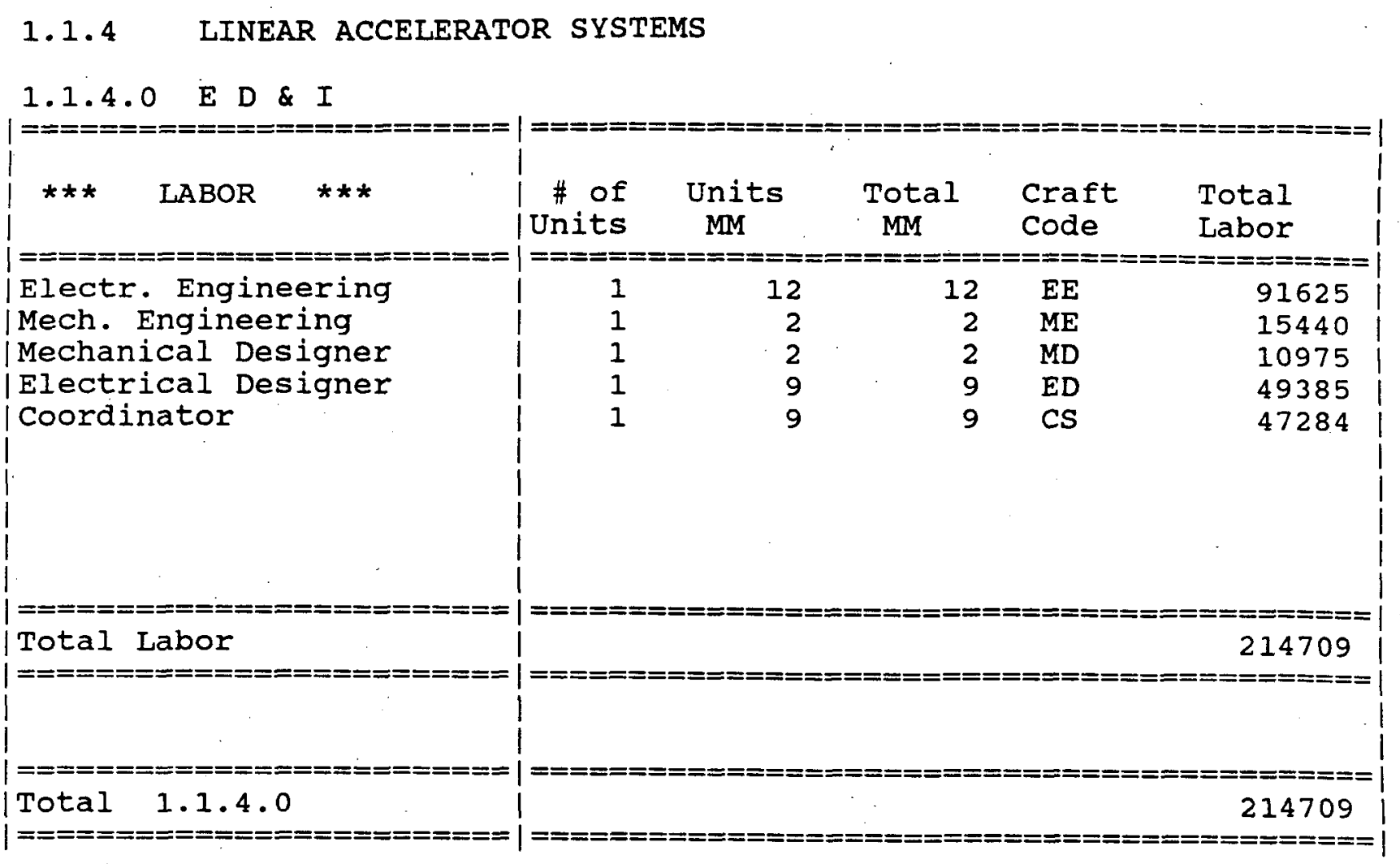




\subsubsection{LINEAR ACCELERATOR SYSTEMS}

\subsubsection{Gun Assembly}

\subsection{Cathode Assembly}

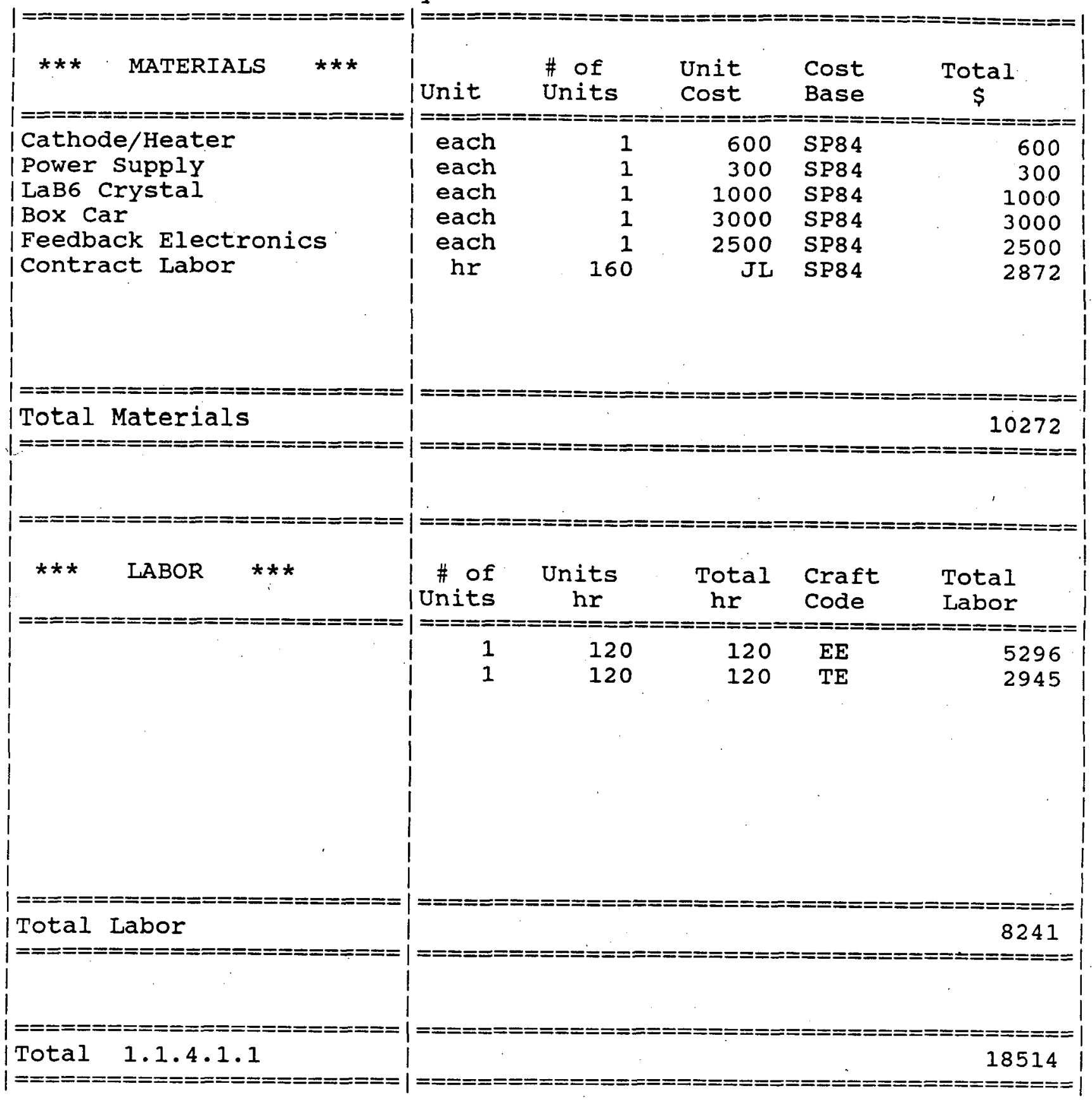




\subsubsection{LINEAR ACCELERATOR SYSTEMS}

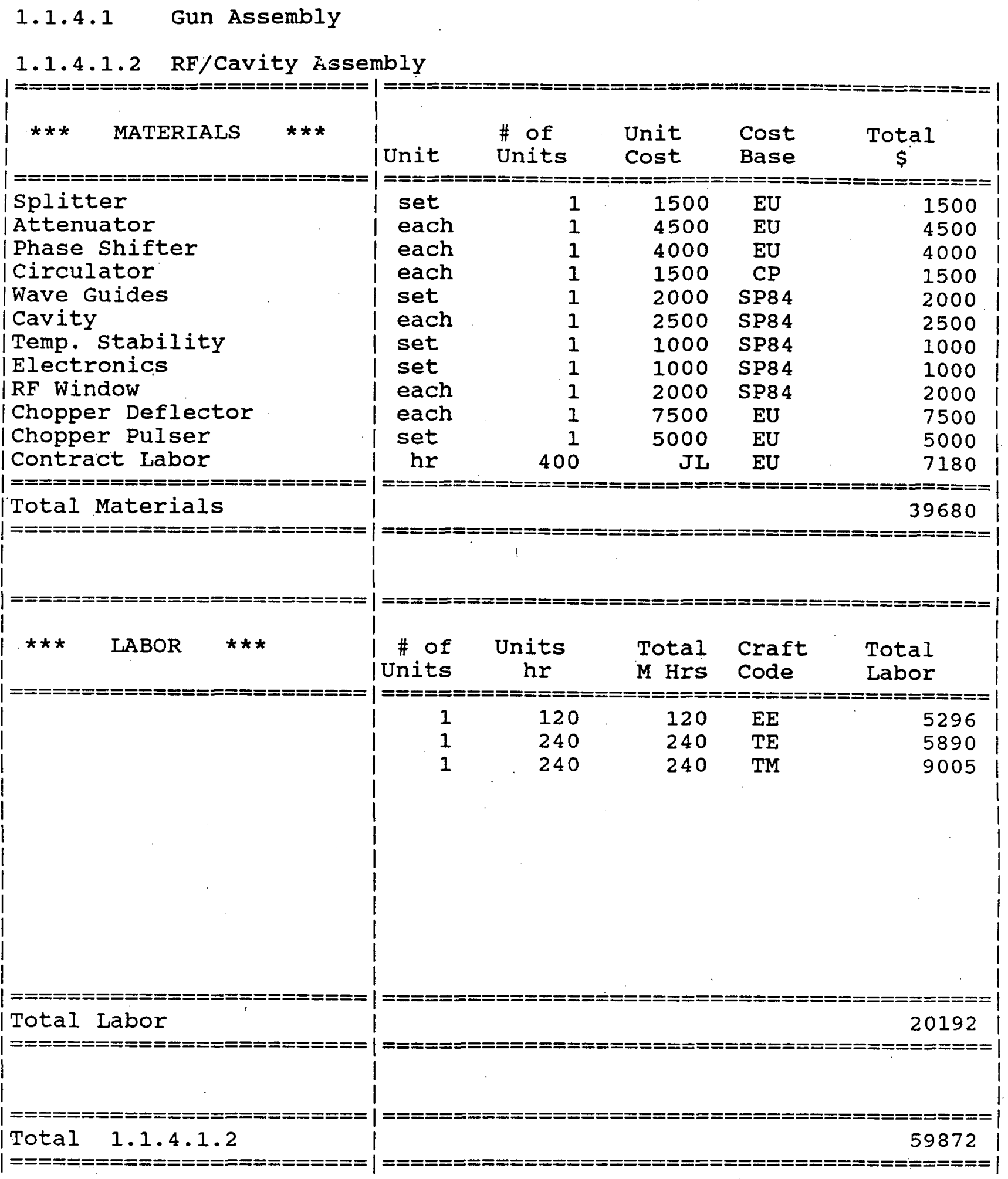




\subsubsection{LINEAR ACCELERATOR SYSTEMS}

\subsubsection{Gun Assembly}

\subsection{Beam Guidarice}

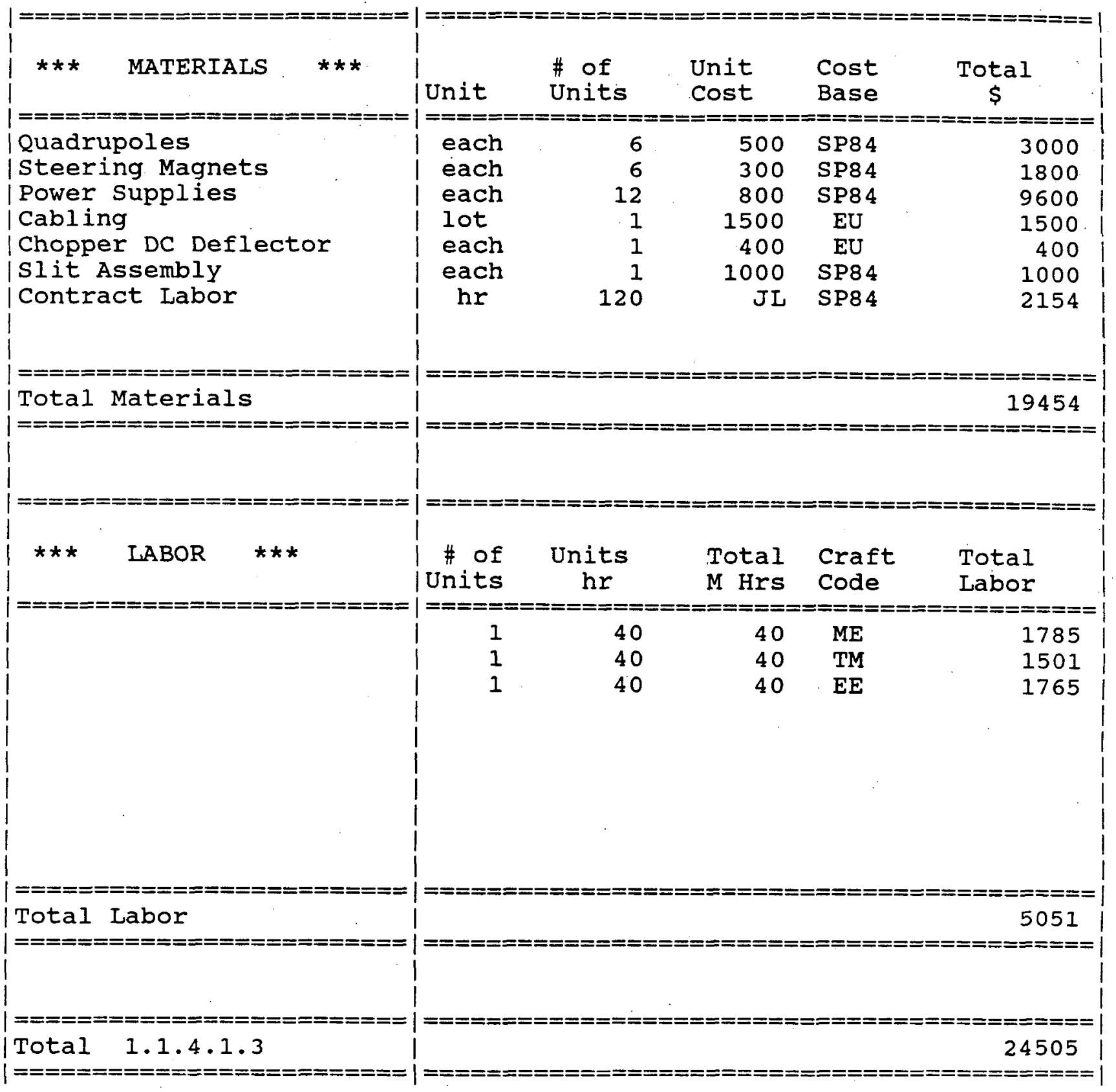


1.1.4 IINEAR ACCELERATOR SYSTEMS

\subsubsection{Gun Assembly}

\subsection{Momentum Filter}

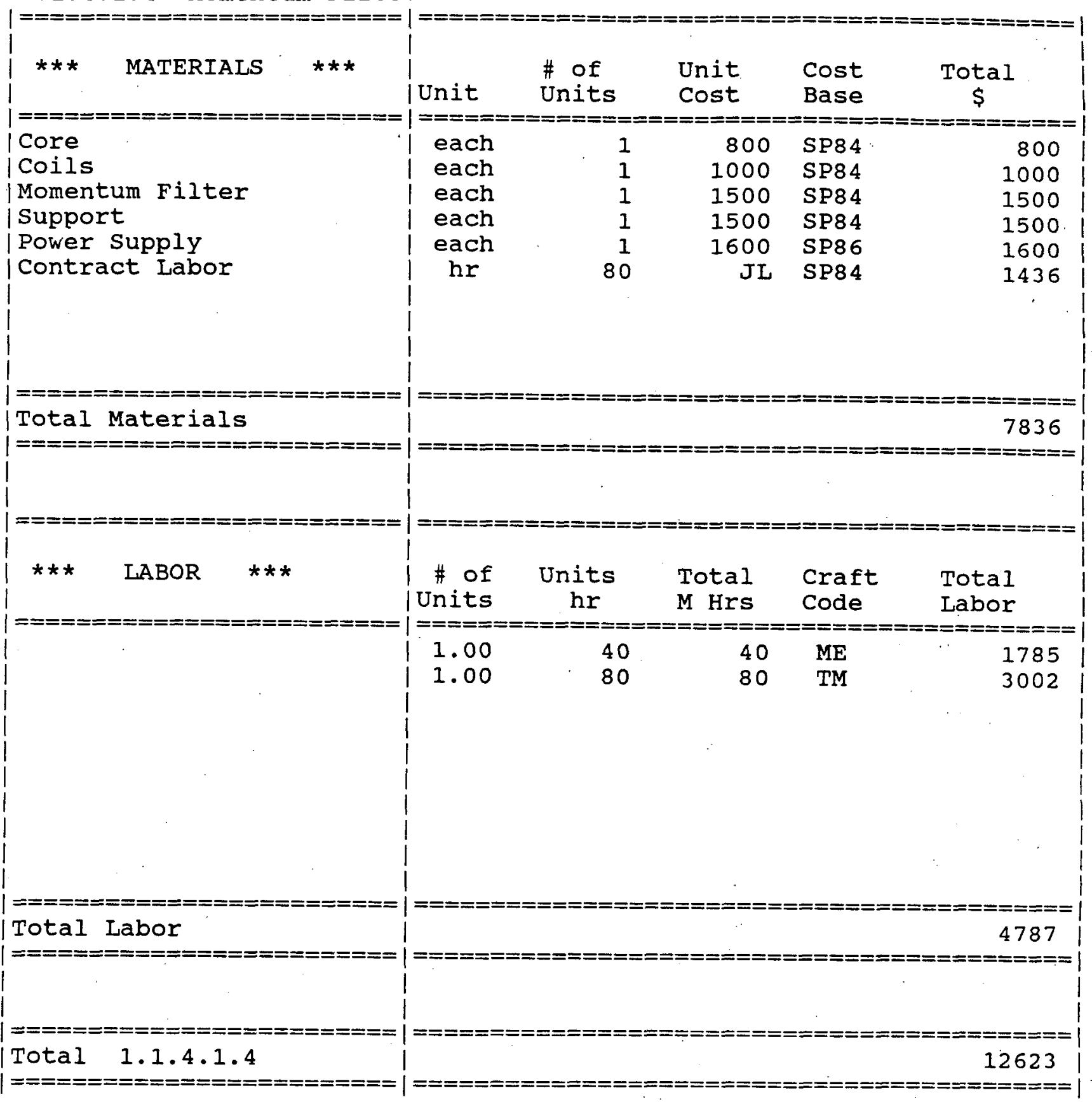




\subsubsection{Linear Accelerator Systems \\ 1.1.4.1 Gun Assembly \\ 1.1.4.1.5 Diagnostics}

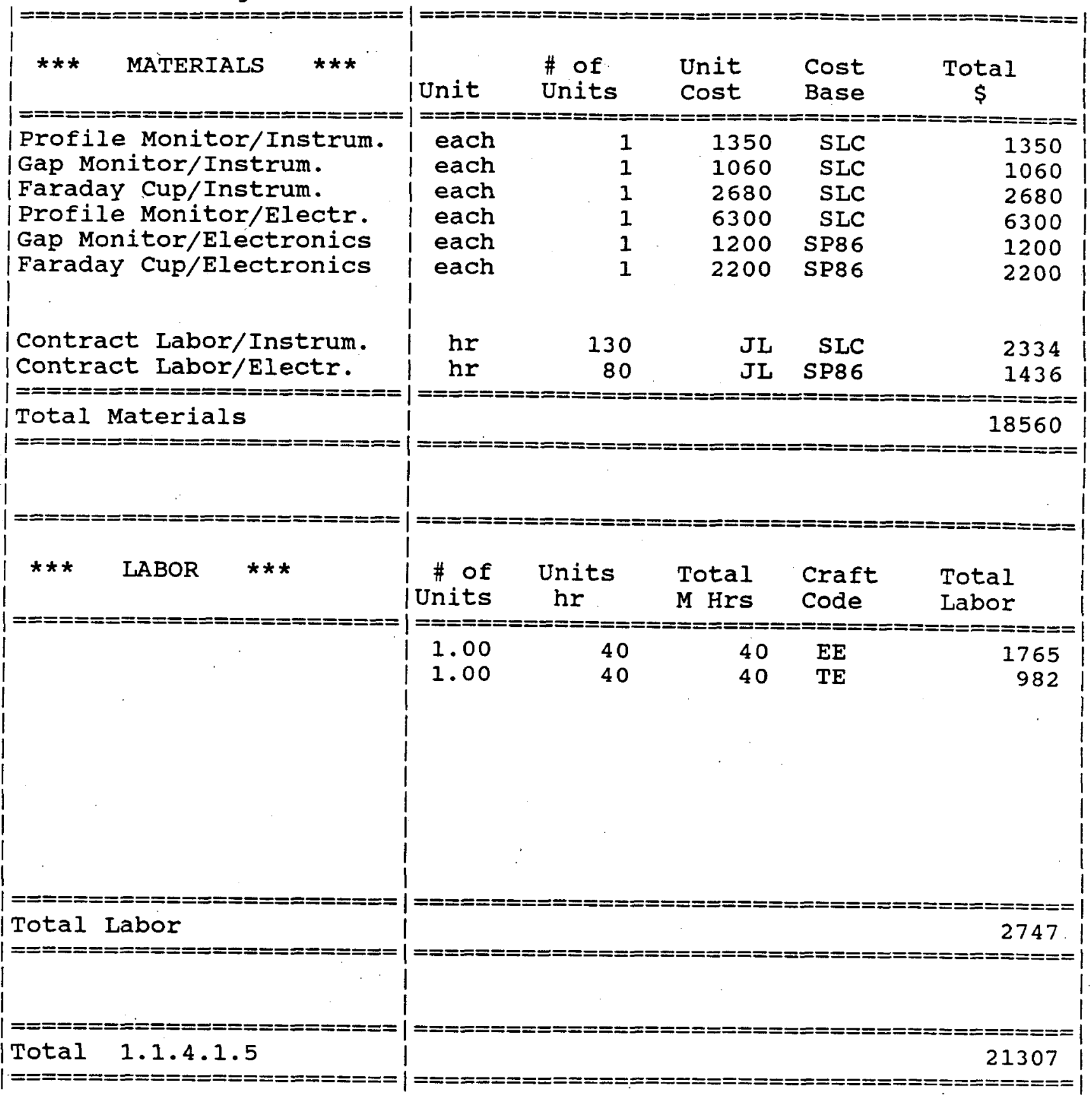




\subsubsection{LINEAR ACCELERATOR SYSTEMS}

\subsubsection{Gun Assembly}

1.1.4.1.6 Vacuum System

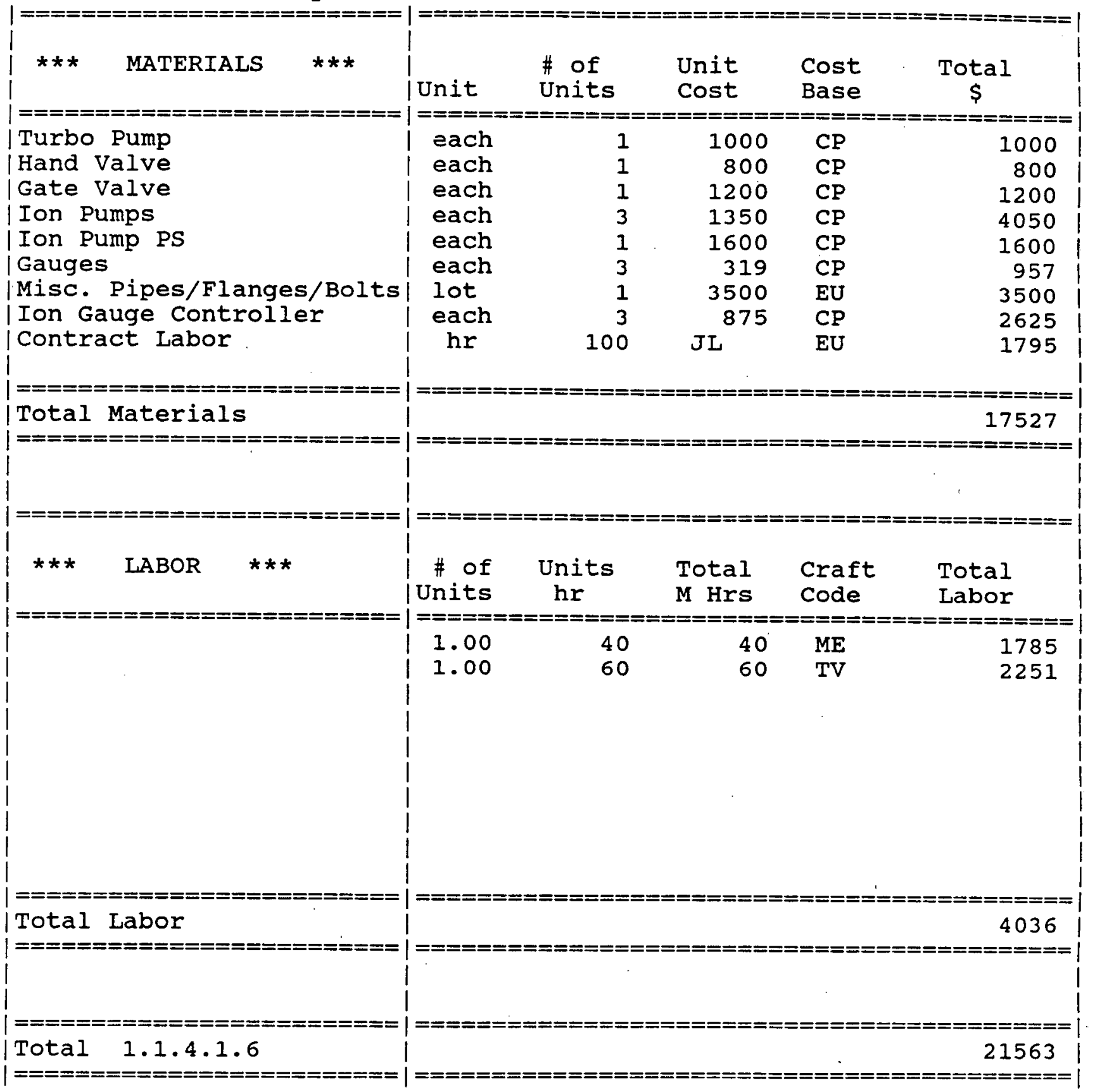




\subsubsection{LINEAR ACCELERATOR SYSTEMS}

\subsubsection{Acceleration Sections}

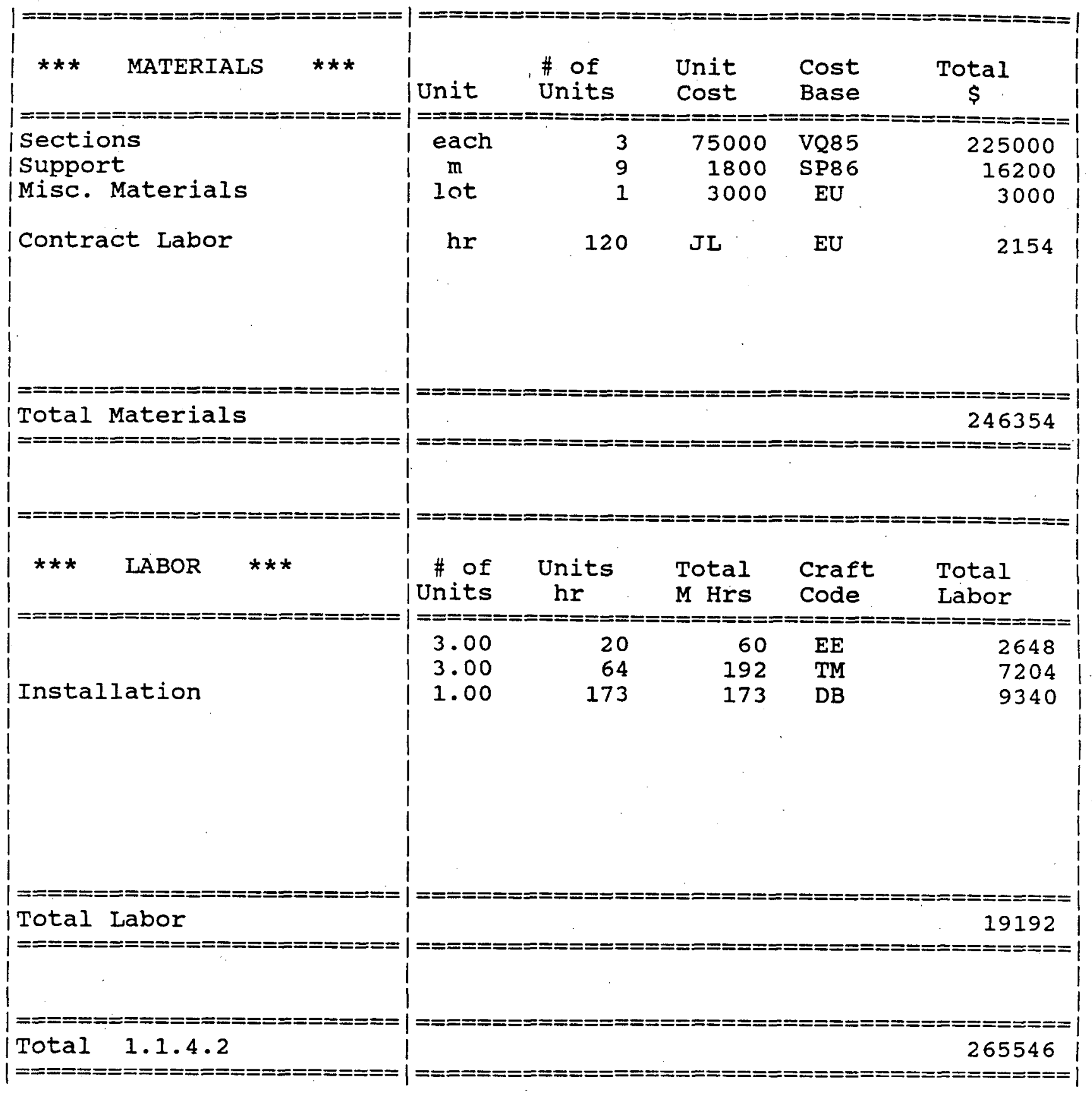




\subsubsection{LINEAR ACCELERATOR SYSTEMS}

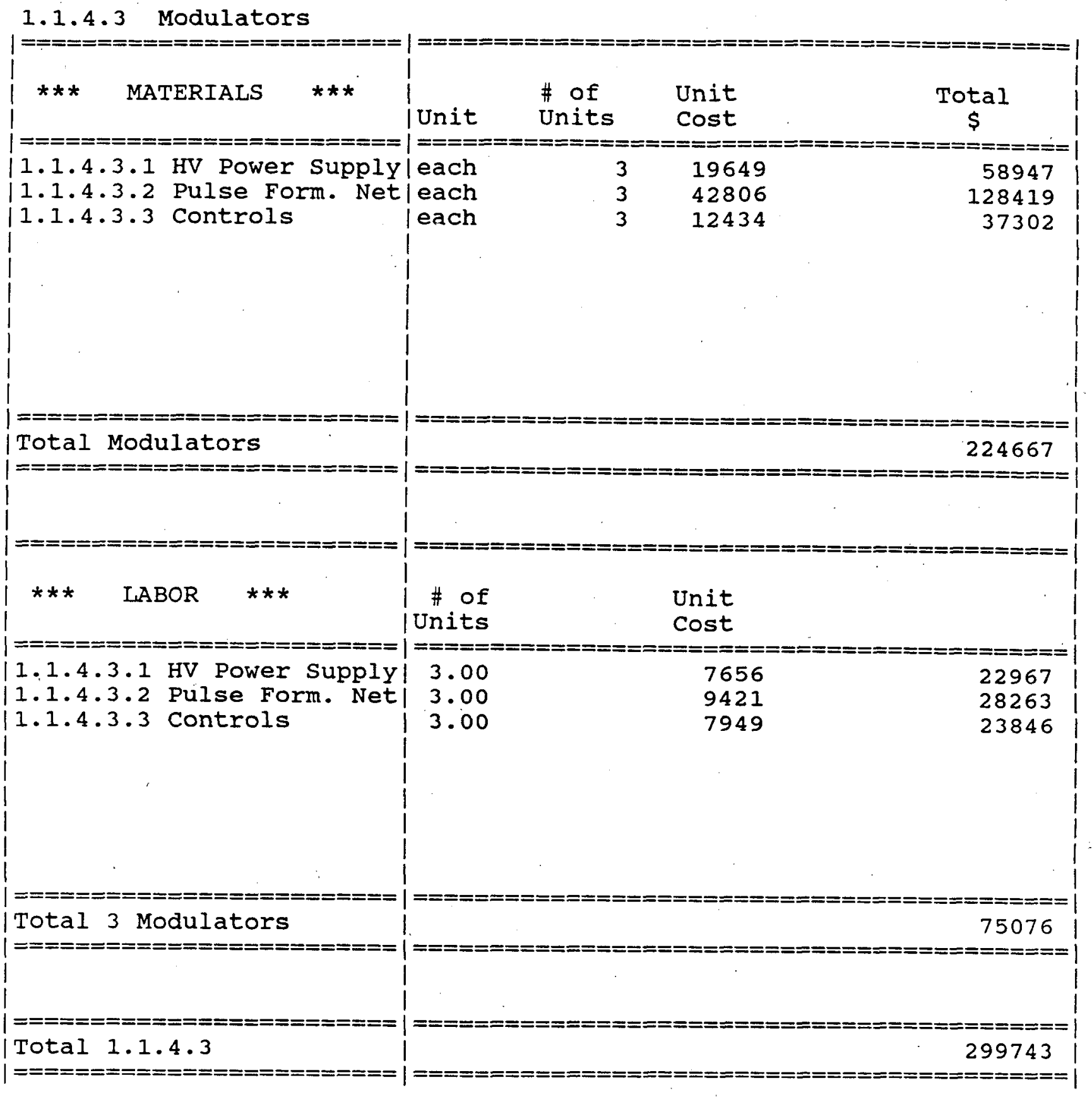




\subsubsection{LINEAR ACCELERATOR SYSTEMS}

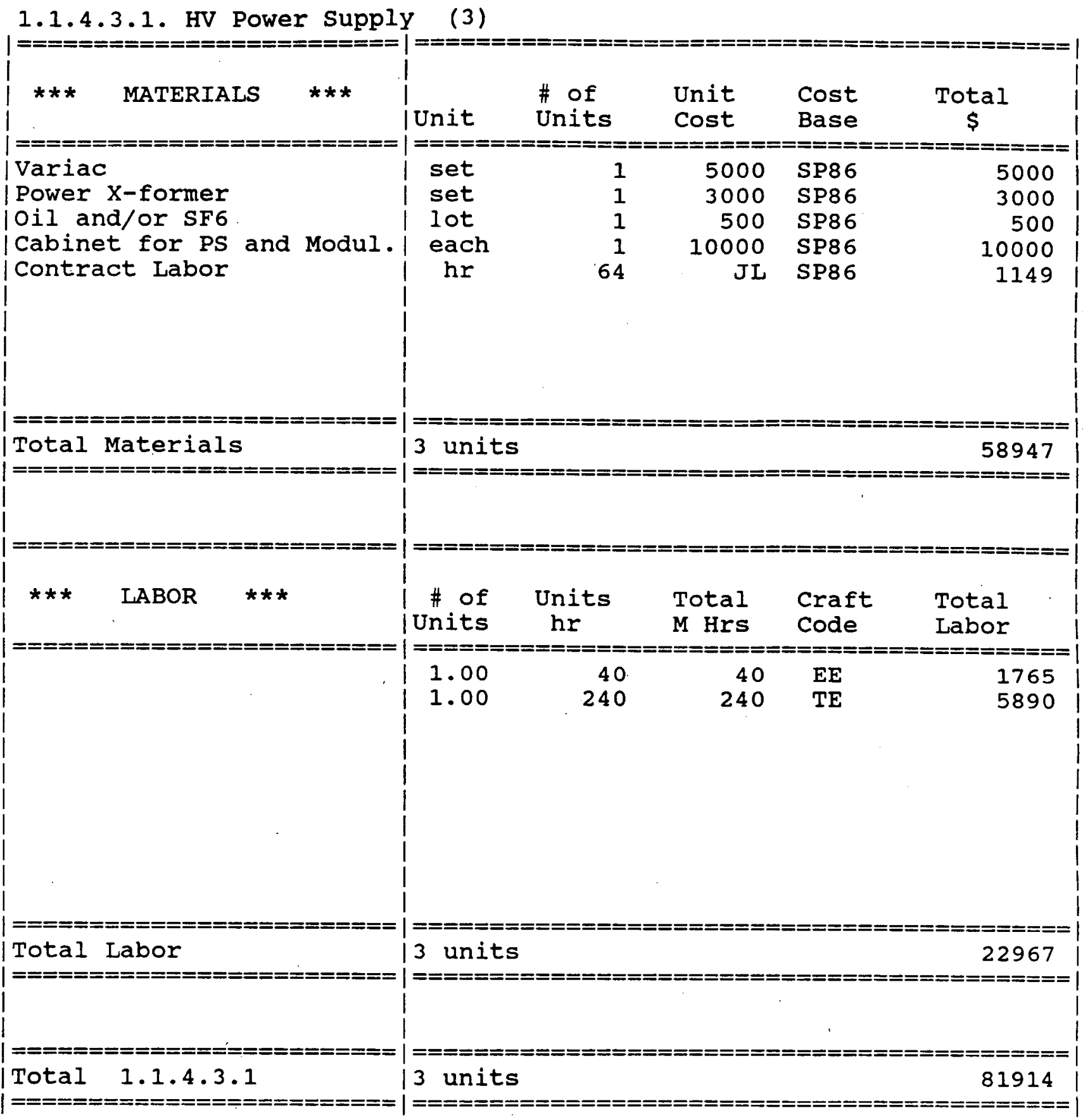




\subsubsection{LINEAR ACCELERATOR SYSTEMS}

\section{$1.1 .4 .3 .2 \quad$ PFN}

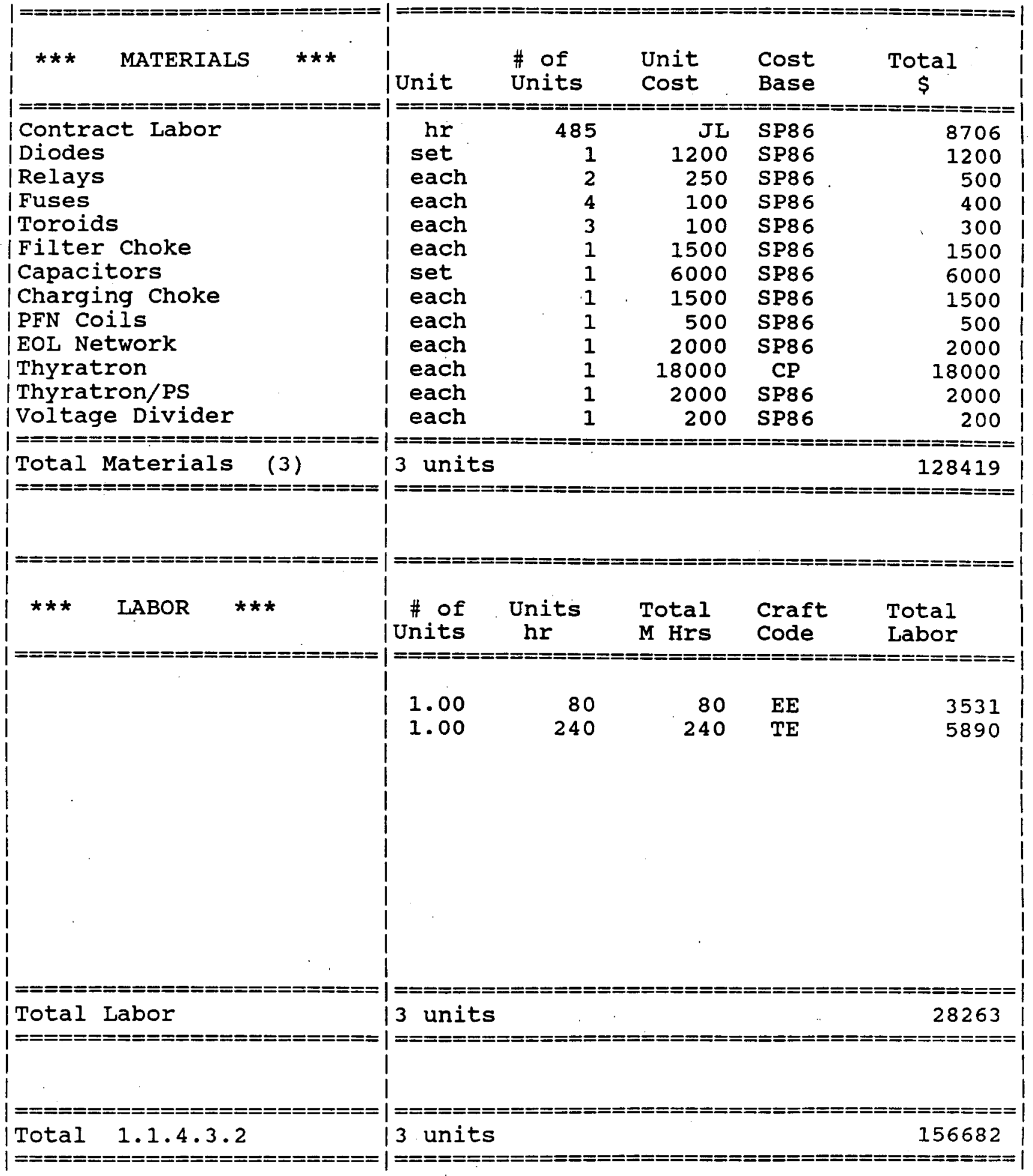




\subsubsection{IINEAR ACCELERATOR SYSTEMS}

\subsection{Controls}

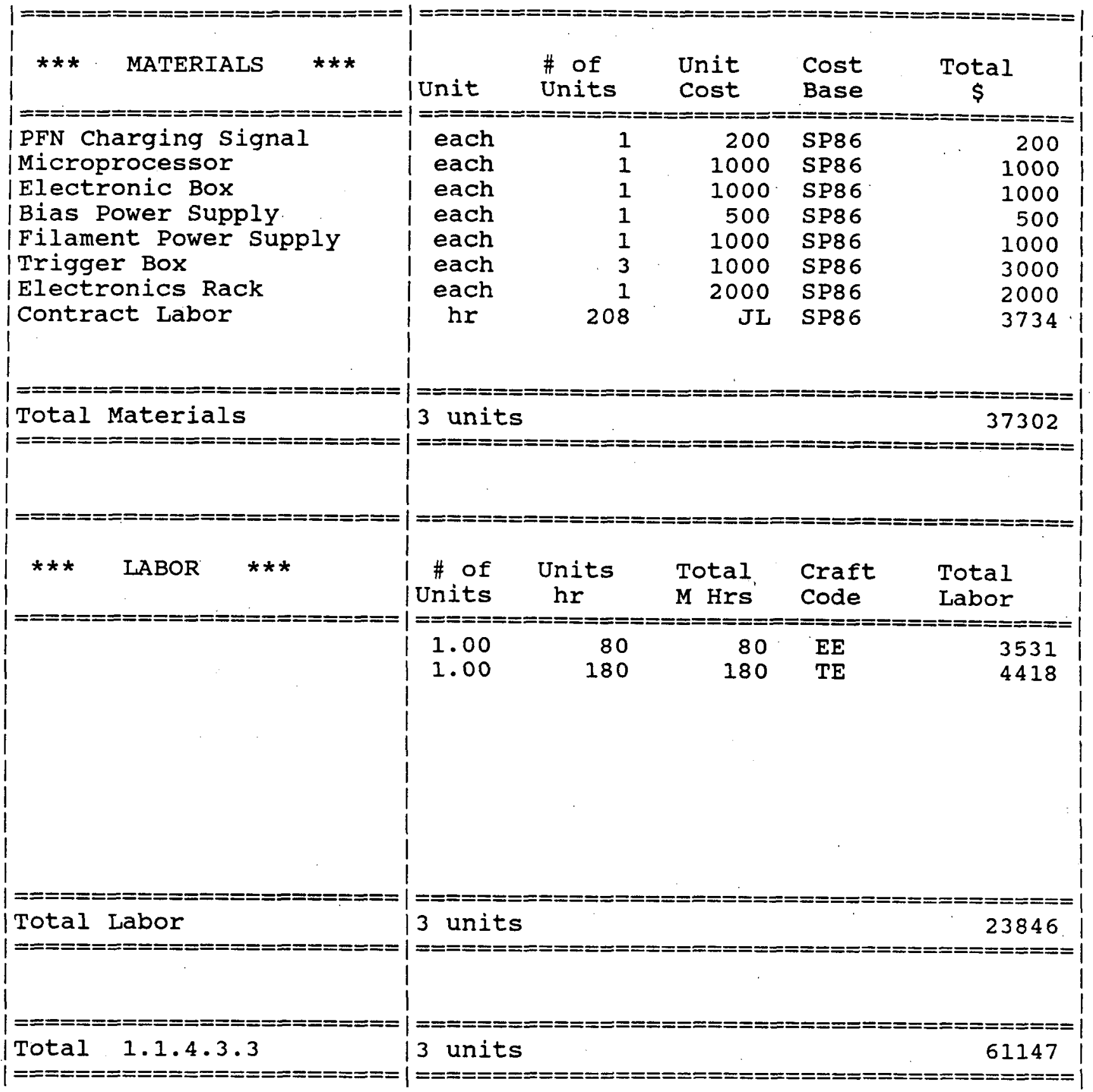




\subsubsection{LINEAR ACCELERATOR SYSTEMS}

\section{1 .4 .4 Klystrons}

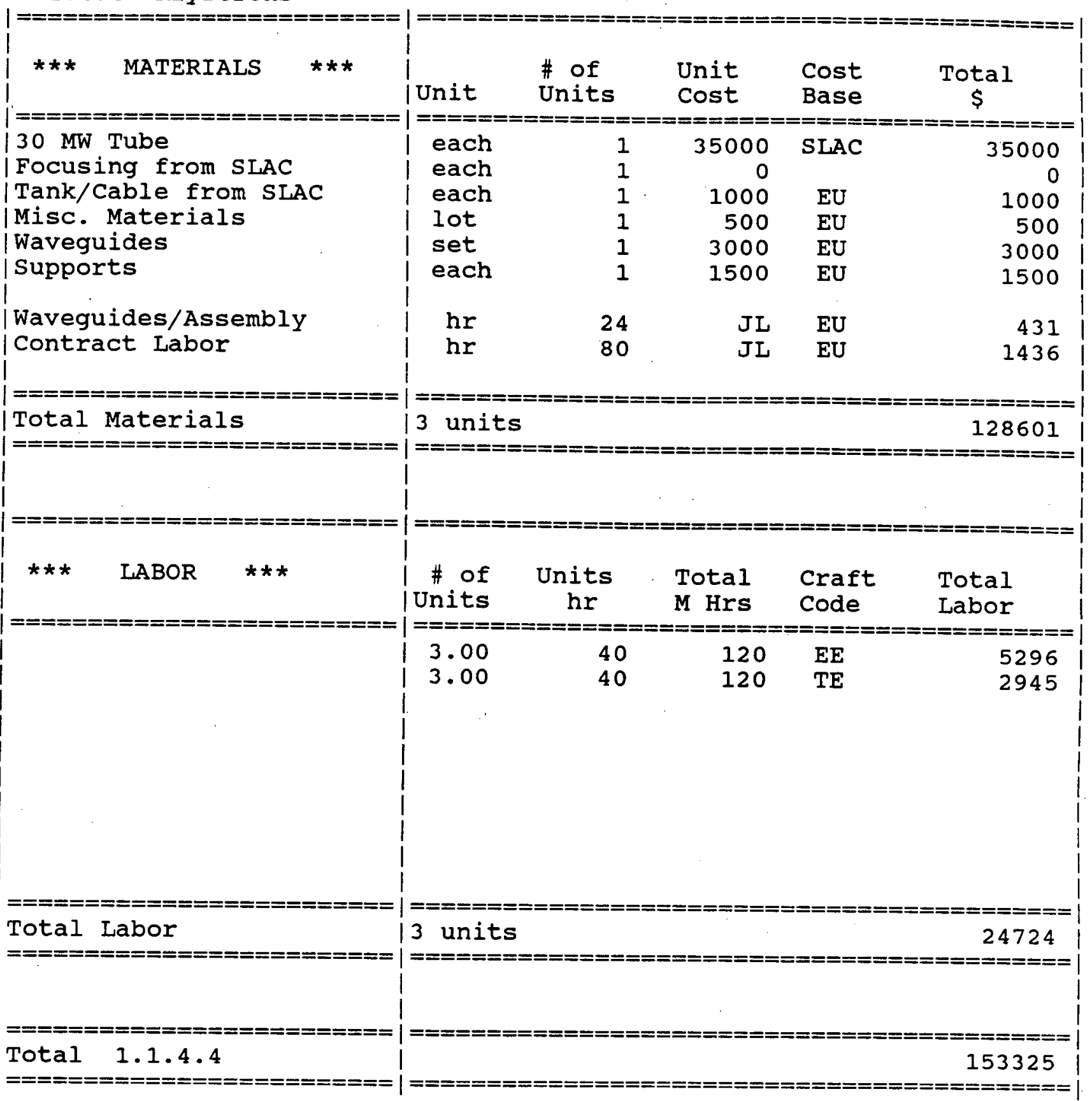




\subsubsection{LINEAR ACCELERATOR SYSTEMS}

\subsubsection{Controls}

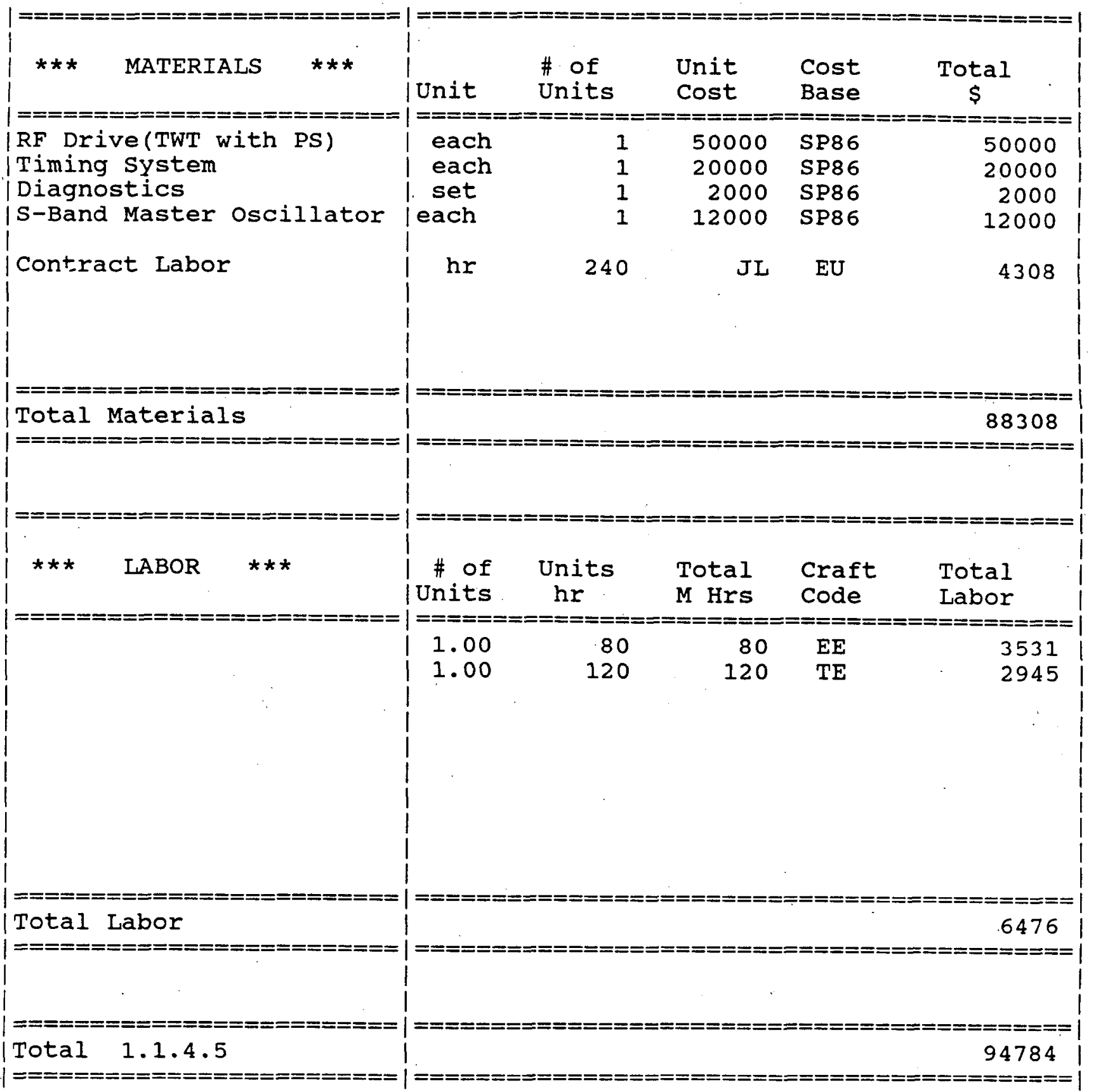




\subsubsection{LINEAR ACCELERATOR SYSTEMS}

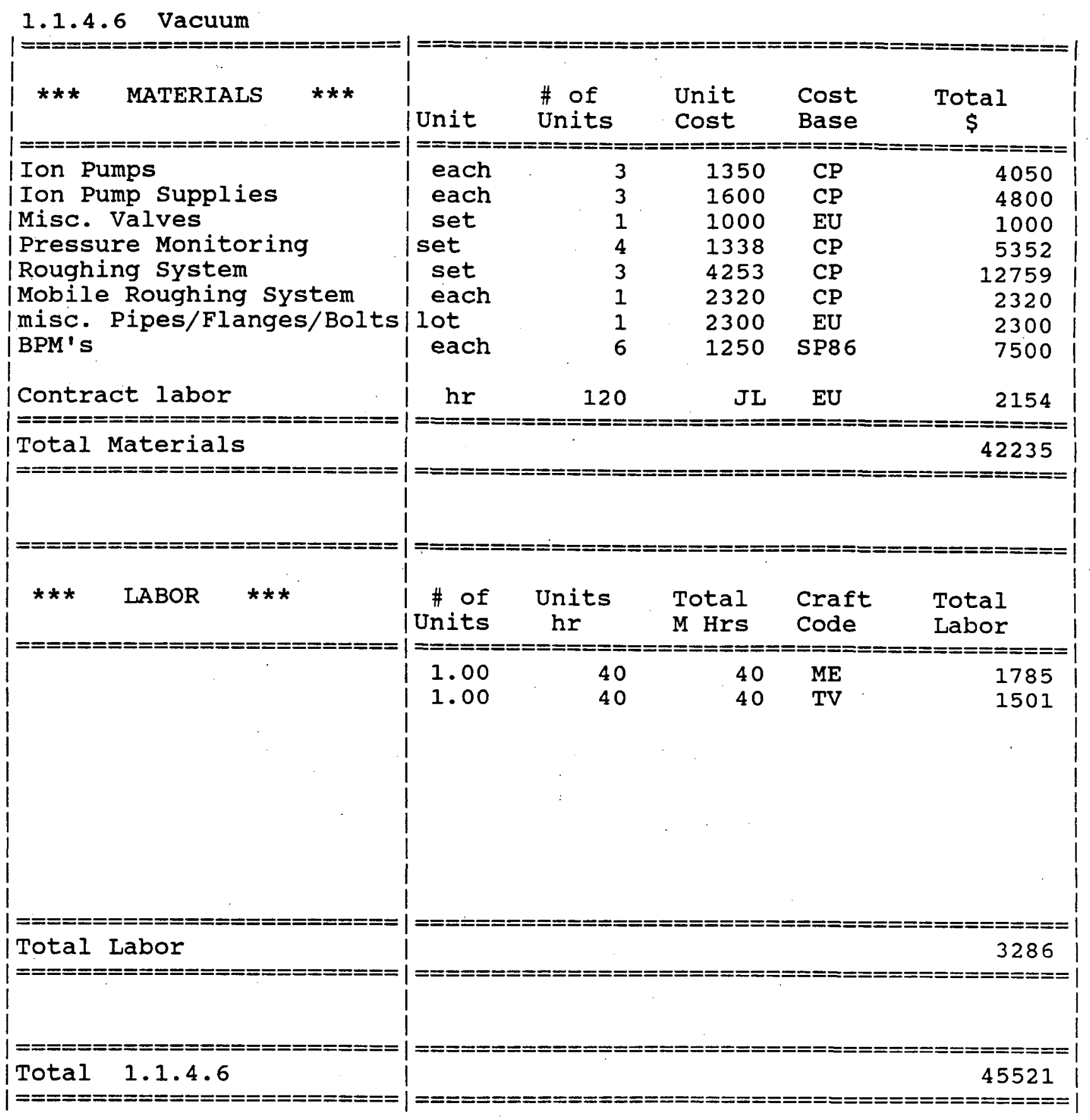




\subsubsection{LINEAR ACCELERATOR SYSTEMS}

\subsubsection{Beam Diagnostics}

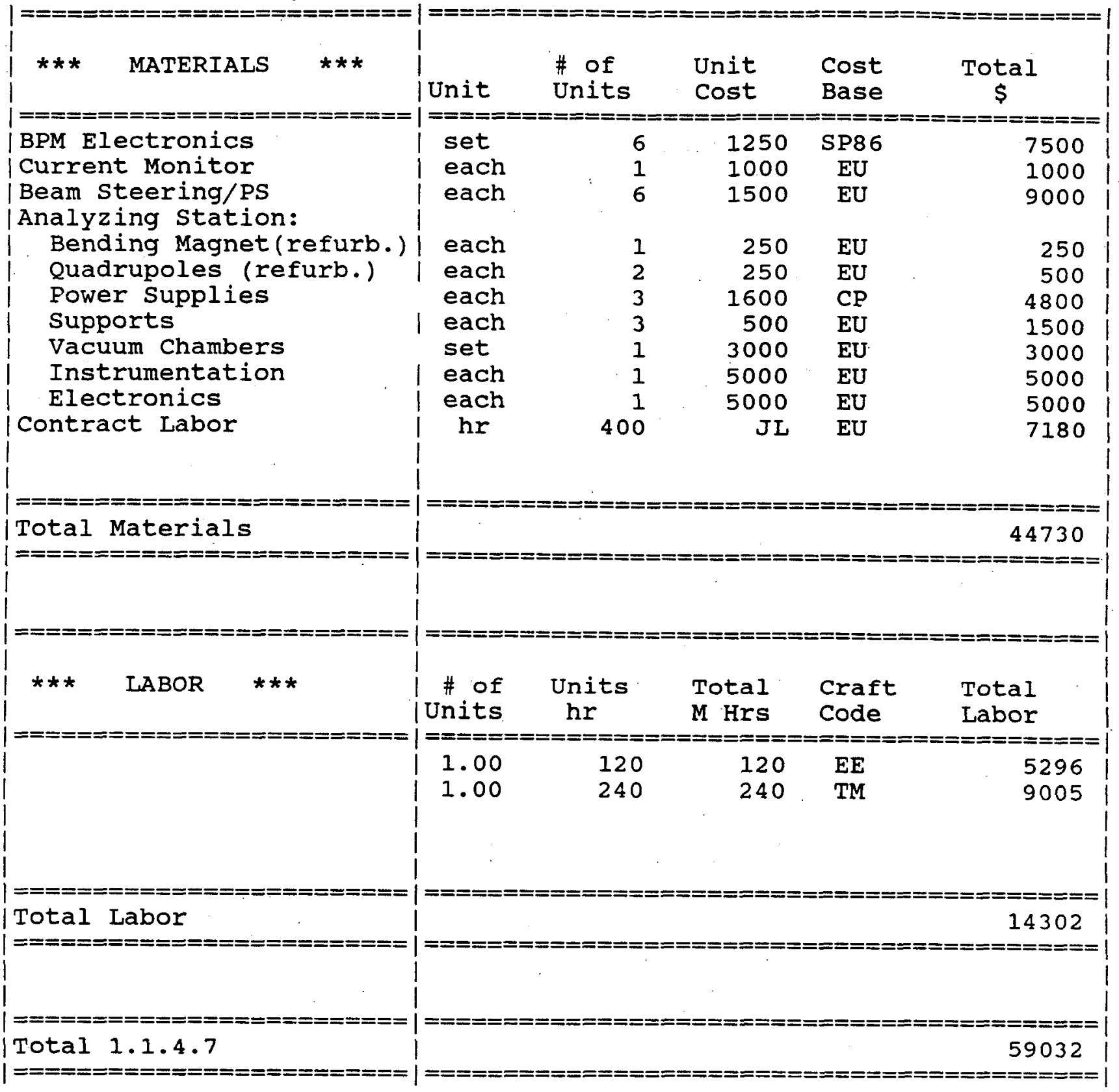




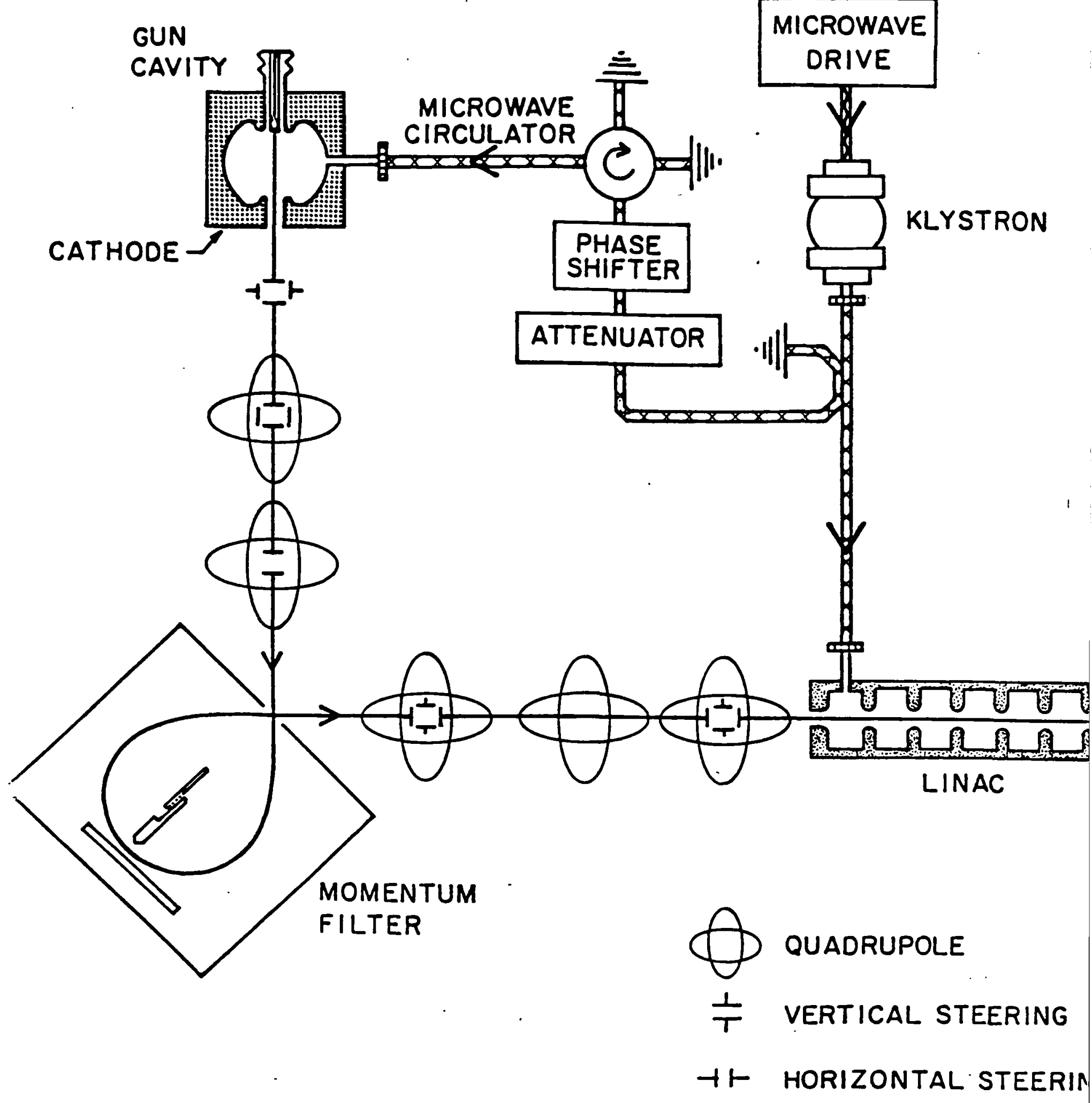


4.9-86 M.MAPW

Wastor Onillave

10

pi te

$y$

10
20
2

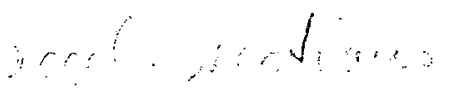

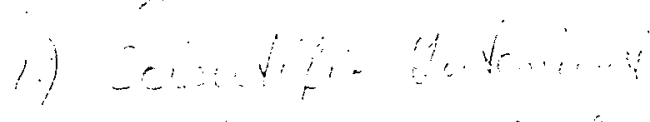

$$
\begin{aligned}
& \text { WTh yokb feb las } \\
& 1417942100 \\
& \text { l: : . } \quad 26 k 8 \\
& \text { - C6\% } 1 \% \\
& 1.602 .0097=16106
\end{aligned}
$$


High pur Moduletars

Meteris Tech Poot

(each mood.) (3 winad.)

HV IVzrice variac

HV I PWR xfmen

$P$ P 1 set of Diodes

\begin{tabular}{l|l}
$P$ & 2 aeluy \\
$P$ & 3 fuses \\
$p$ & 3 Toroide
\end{tabular}

$P 1$ Ghitten ohock

$P \|$ filther erpor capaciton

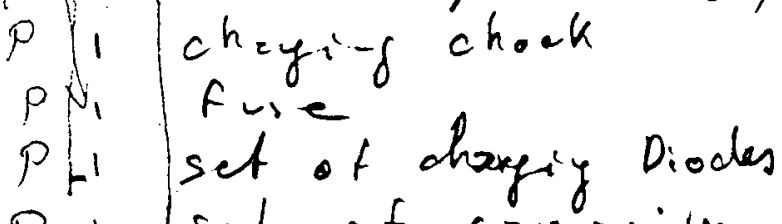

$P 1$ Let of cepreciten P.F.N

$P$, set of coils P.F.N

$P$ I E.0.L Netwar

$K \quad T=k$ RFI

P I Thyoltrom Eigkish Kletric

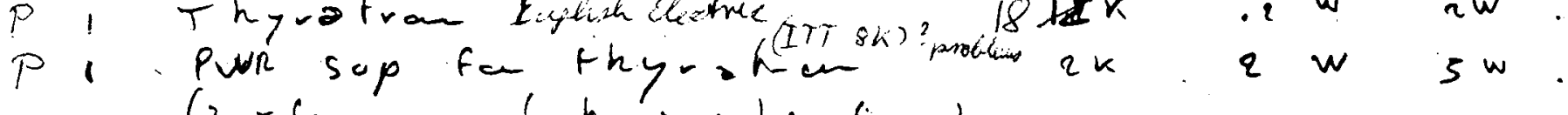

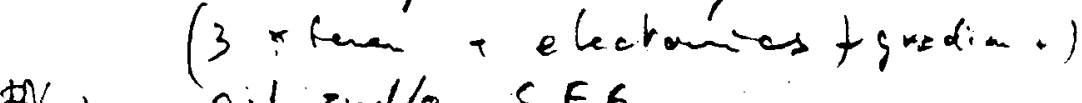

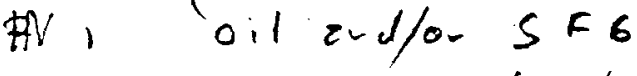

PPEN 1 VOLTAGE dividen

$C$ PFN changing sigm $d$

$C$, Miaro canputer

C 1 electurice Bor

$C 1$ Bias pun sup

C. Filevent pur sup

HV 1 cabint far Pwr supptmod lok 1 w a w.

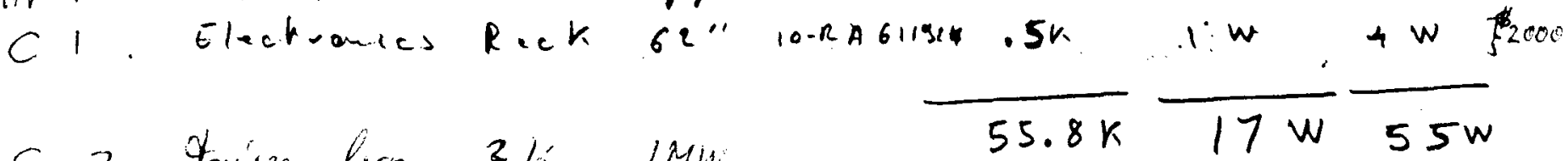

C 3 Frigger ber 3 Li IMn prot

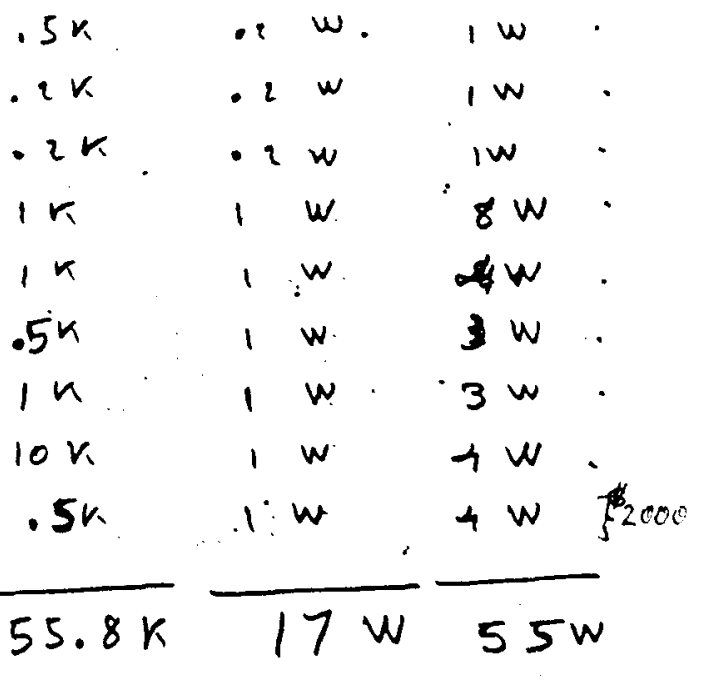

TUNiviug PFN

fraw SLRC

cackb $\}$ fer bibintrow

add labar for: assumbly IMW
4.5 5

$17.5 \mathrm{~W}$

め 


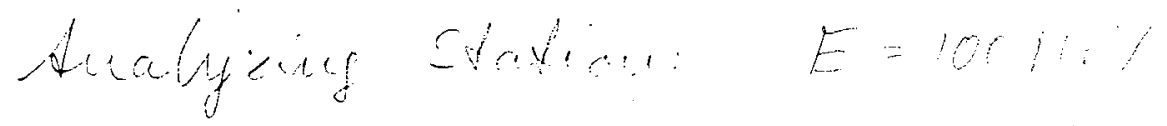

ire at: Clot and:

$$
\begin{aligned}
& \begin{array}{ll}
3=06 \mathrm{~mm} & y=\cdots a m y \\
\mathrm{~d}=13.1 & y=3: y
\end{array} \\
& 4=00 \frac{0.04}{0}=1.57
\end{aligned}
$$

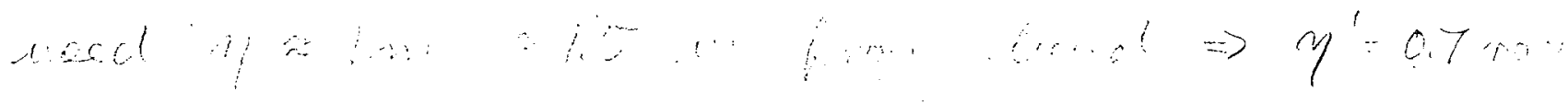

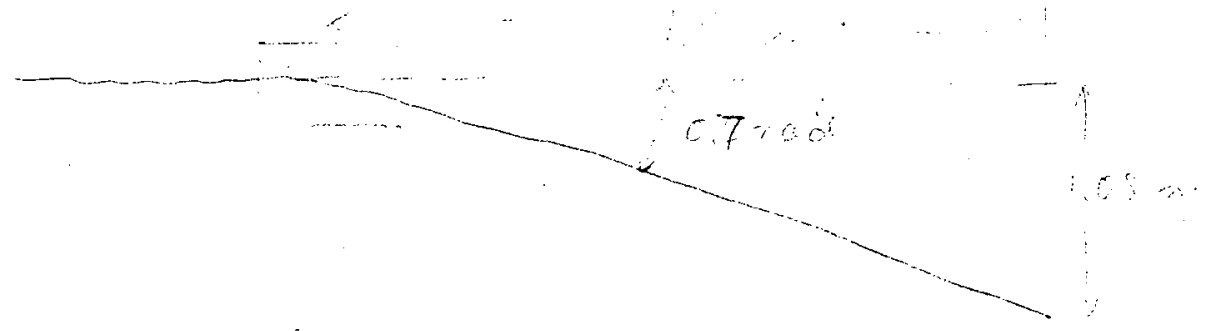

$$
\begin{aligned}
& \text { rat bet, a: } \\
& y=0 \quad I=4.6 \% \\
& b=0.42 \\
& 3=2 \div 6 \%=1 \% \div
\end{aligned}
$$




$$
\begin{aligned}
& \text { cincilacier: FCI FERRITE COMPONENTS INC. } \\
& \text { (617) } 250-1673 \\
& \text { Coutact: ELDO ELICONE } \\
& 10 \text { KIDDER ROA.D } \\
& \text { CHELMSFORD, MA, C.1824 } \\
& \$ 1500 \text {. 3mouth. }
\end{aligned}
$$

wark quidel S-Band

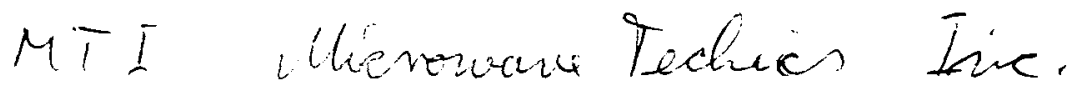

$$
\text { (207) 655-3881 }
$$

Raad 302

$$
\text { RHYMOND, ME, } 04071
$$




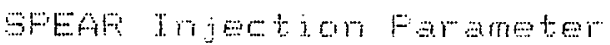

3 DEV SFFAR Imjentiom System

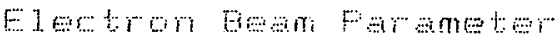

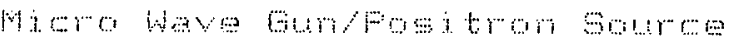

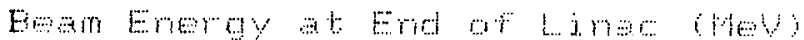

1. "थल

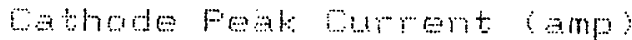

Talel Bumbti Lenoth imm;

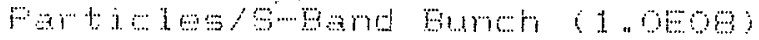

Energy opread due to Bumah Lemoth

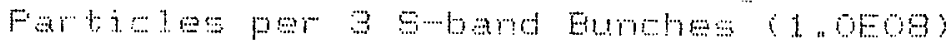

Number at Bowstom Bumehes

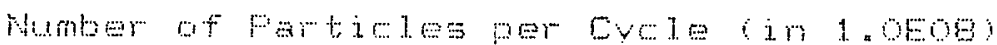

Tot m. Enew

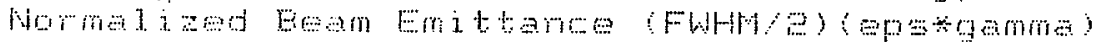

Horjantal (E-mo m)

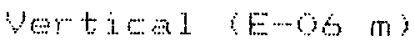

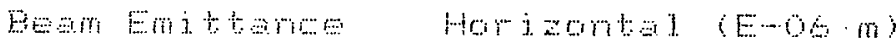

Vation 1 (E)

10,00

e. 010

$4: 16 \%$

in

i...

1.

$10=60$

a.

io "ô

10.00

i. 1.0

(i) 1

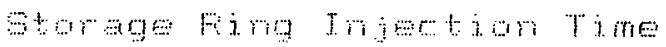

$5179 \mathrm{l}$

inain

[aic] t. 1 .

Bum:?

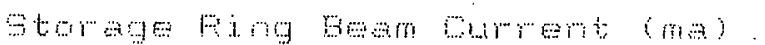

90,00

2040

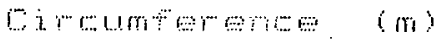

1460

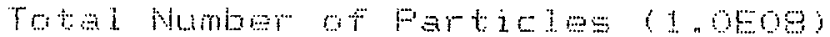

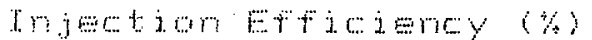

20,00

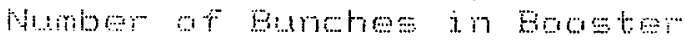

1. 00

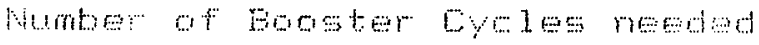

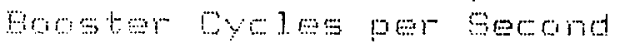

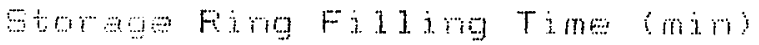

48.00

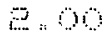

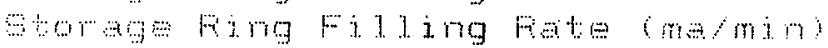

3.9

$7, \ldots$

Deam gas at Injection into boots

Man Eeta Function Hom inmtal (m)

yetation $(m)$

Max Eta Fumbtim

(iii)

Total max = Ban bidth mim)

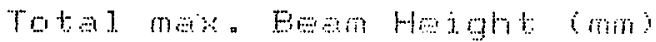

$$
\begin{aligned}
& 100 . \% \\
& \text { क्र : } \\
& \text { का }
\end{aligned}
$$

$\therefore .60$

a.

1., 90

1.

i. 


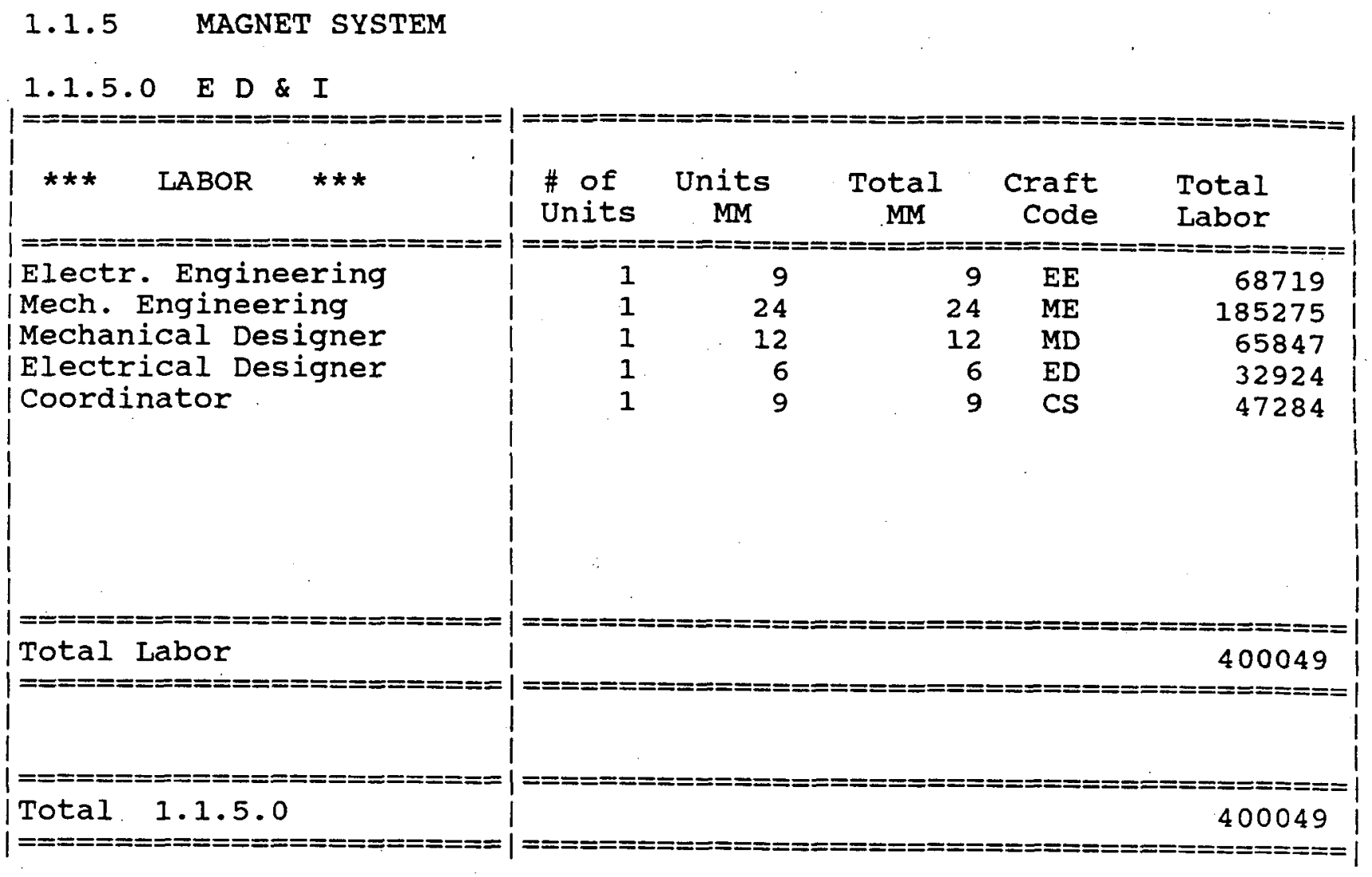




\section{1 .5 MAGNET SYSTEM}

\subsubsection{Magnets}

1.1.5.1.1 Bending Magnet

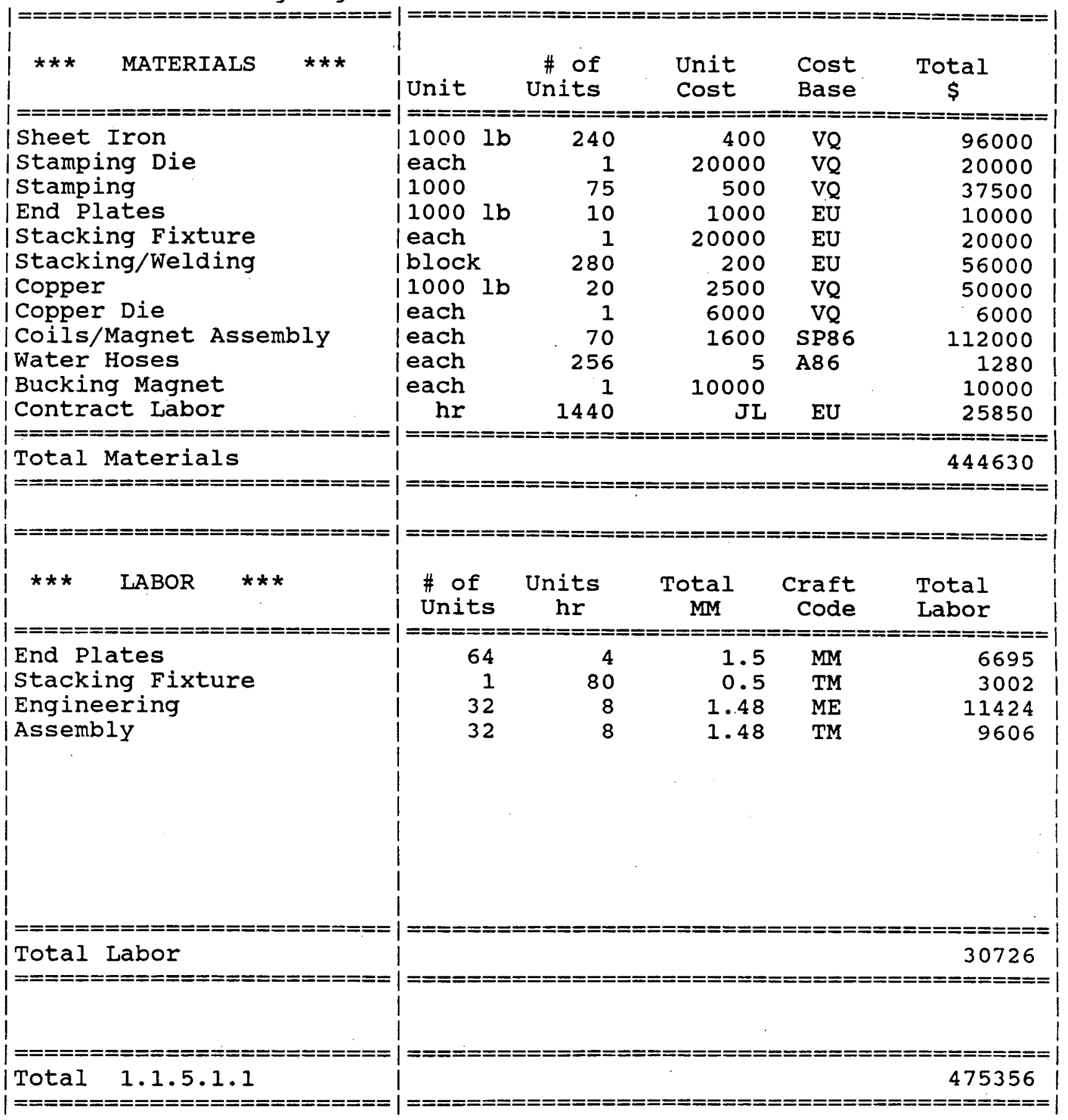




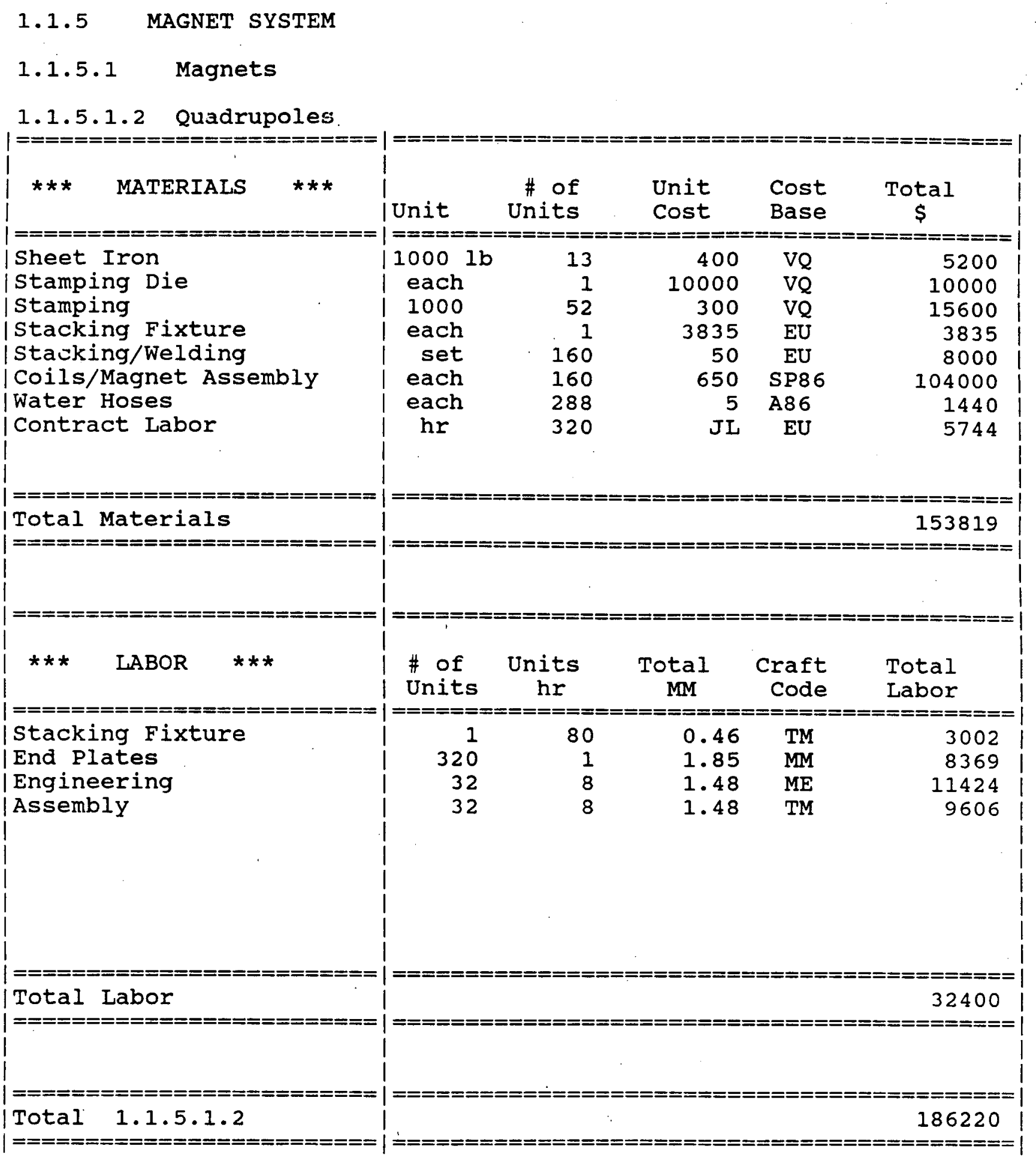




\subsubsection{MAGNET SYSTEM}

\subsubsection{Magnets \\ 1.1.5.1.3 Sextupoles}

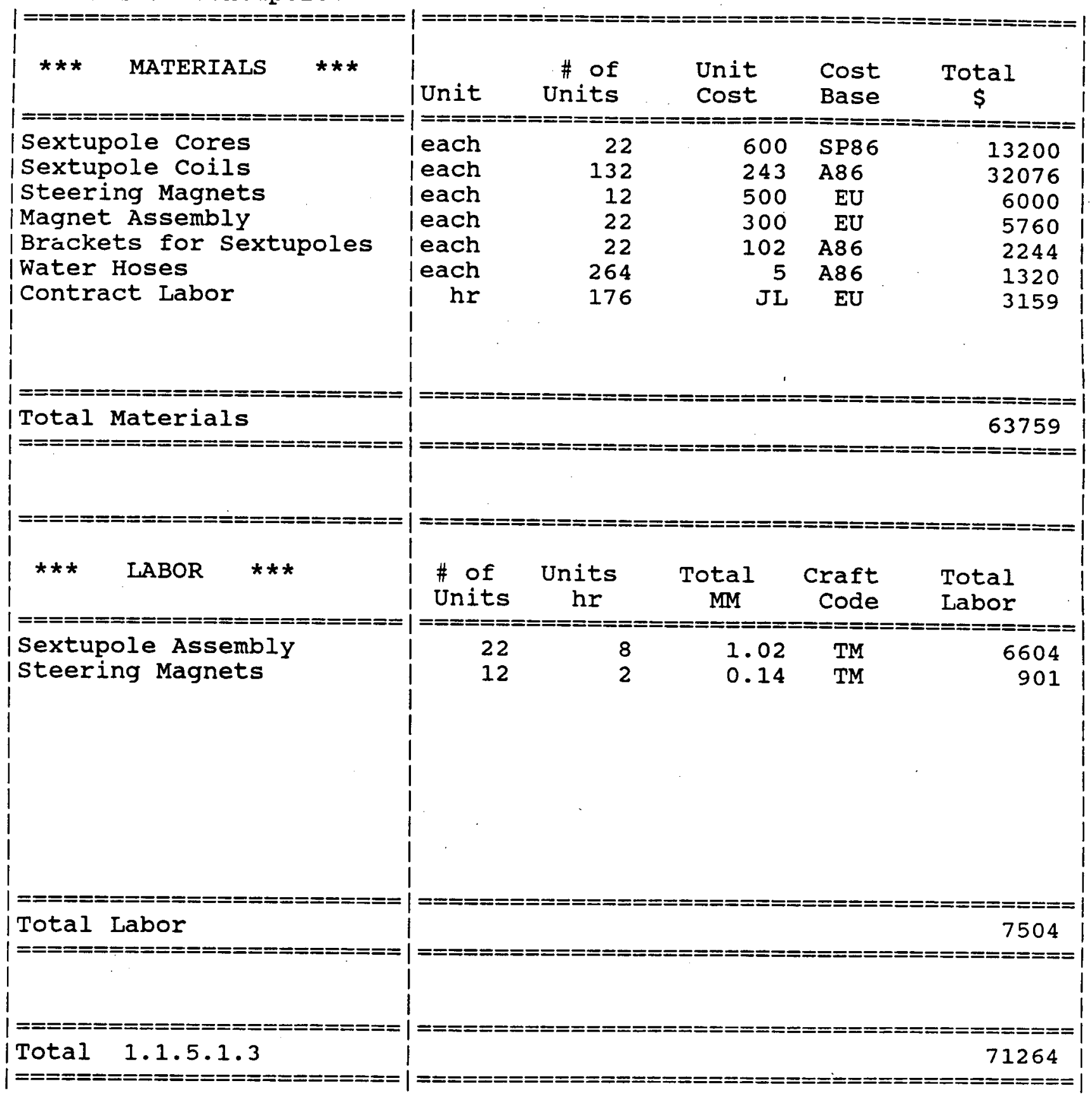




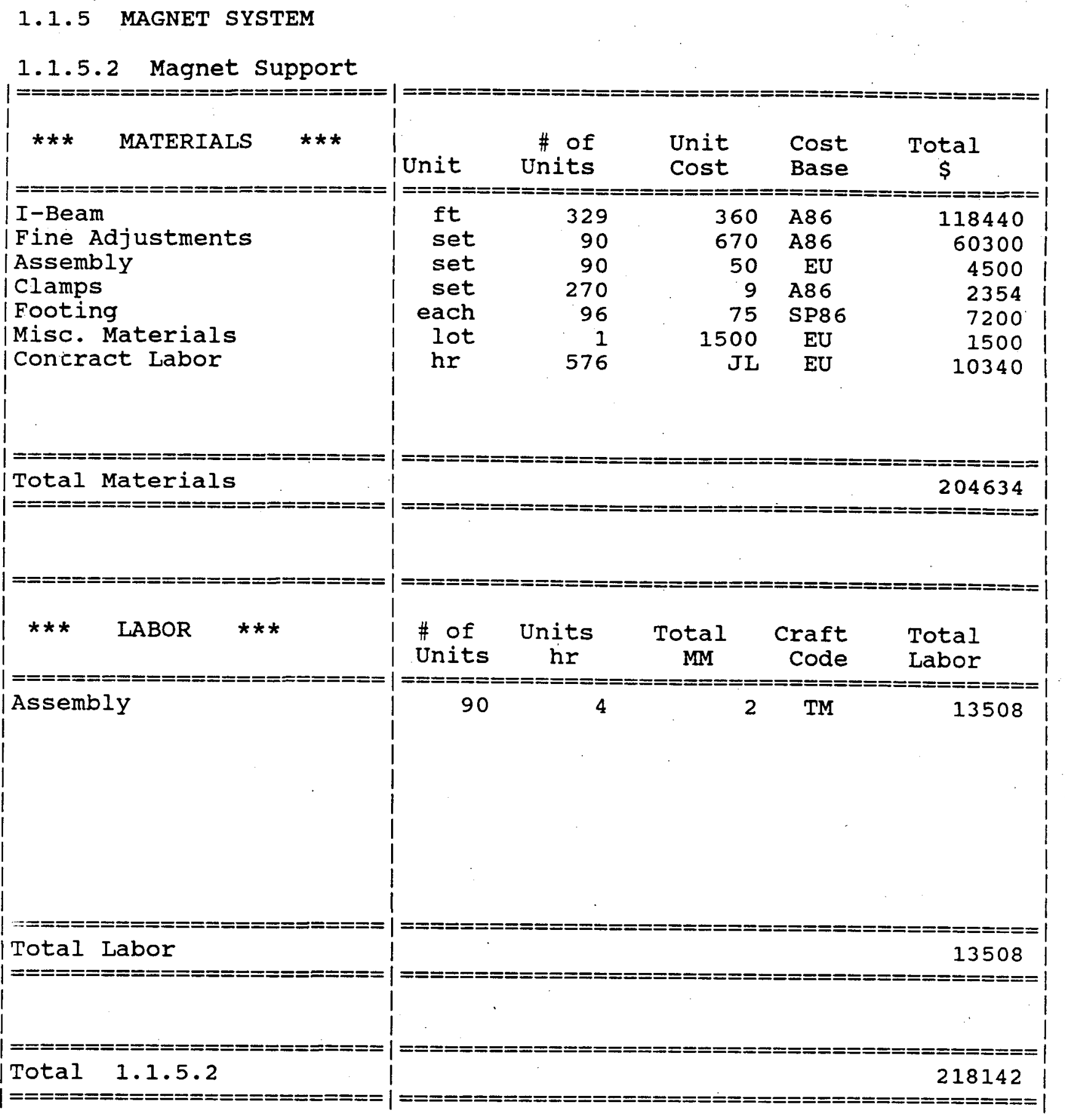




\subsubsection{MAGNET SYSTEM}

\subsubsection{Alignment}

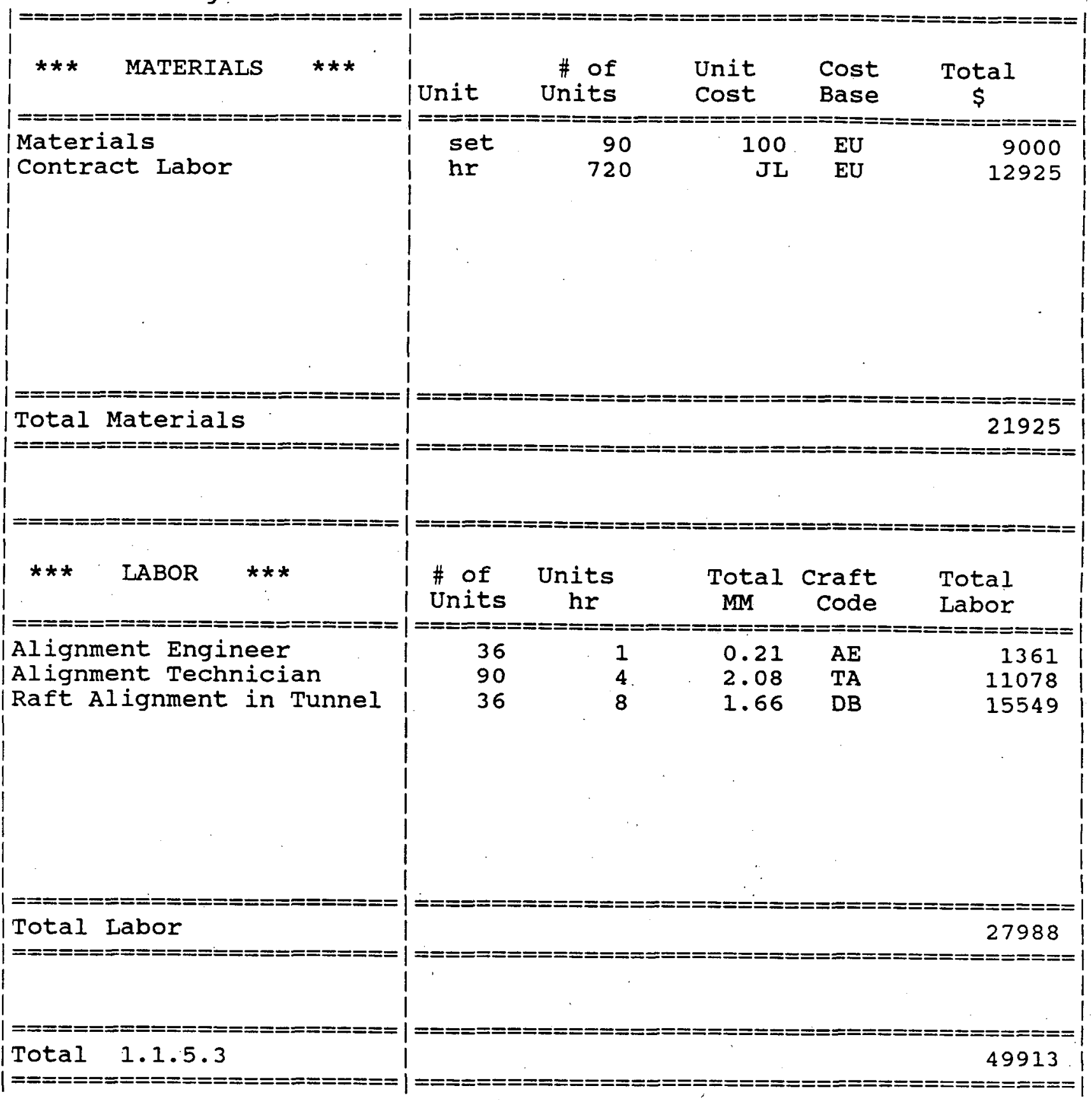




\subsubsection{MAGNET SYSTEM}

\subsubsection{Magnet Measurement}

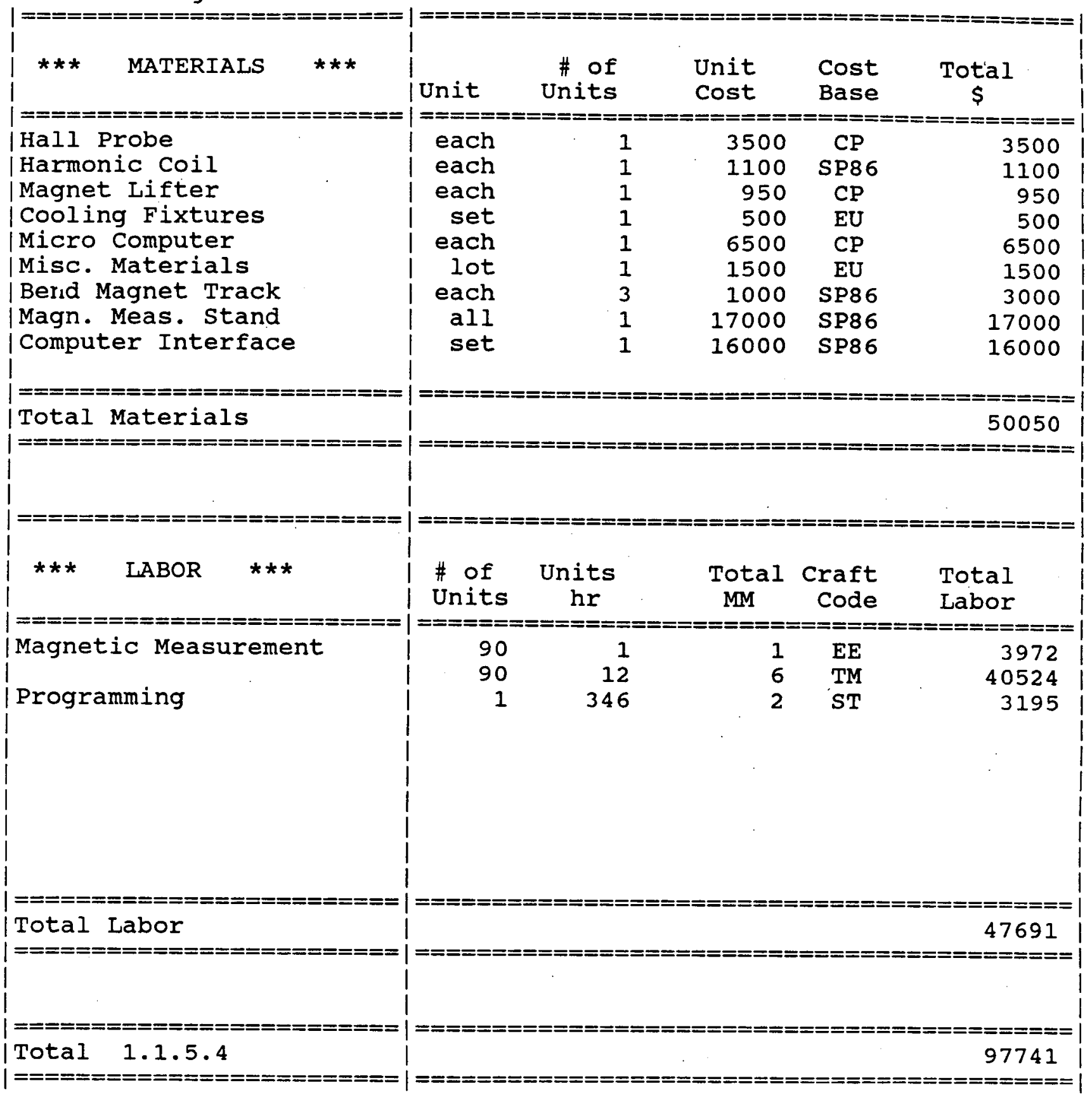




\subsubsection{MAGNET SYSTEM}

1.1.5.5 Magnet Power Supplies

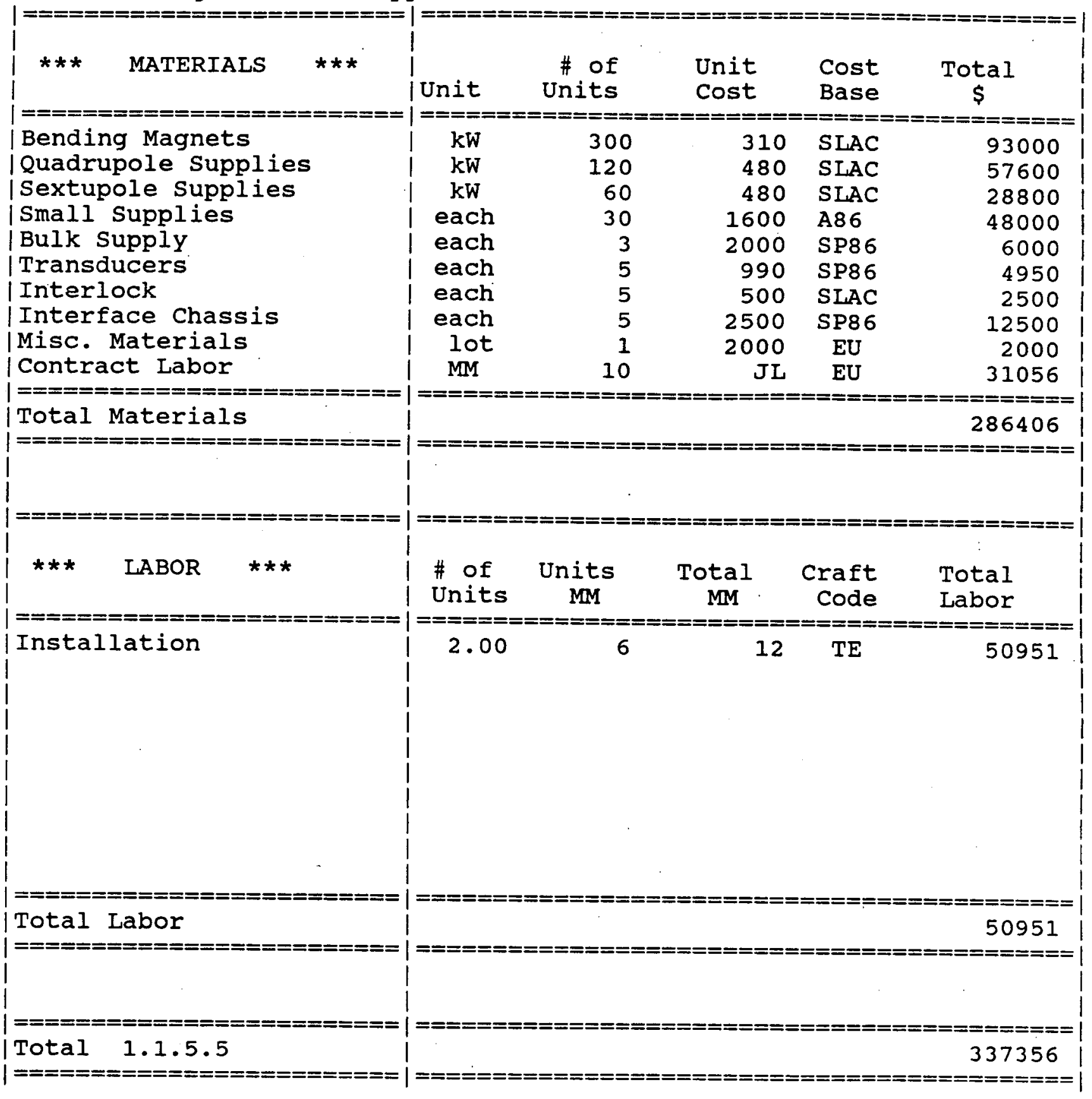




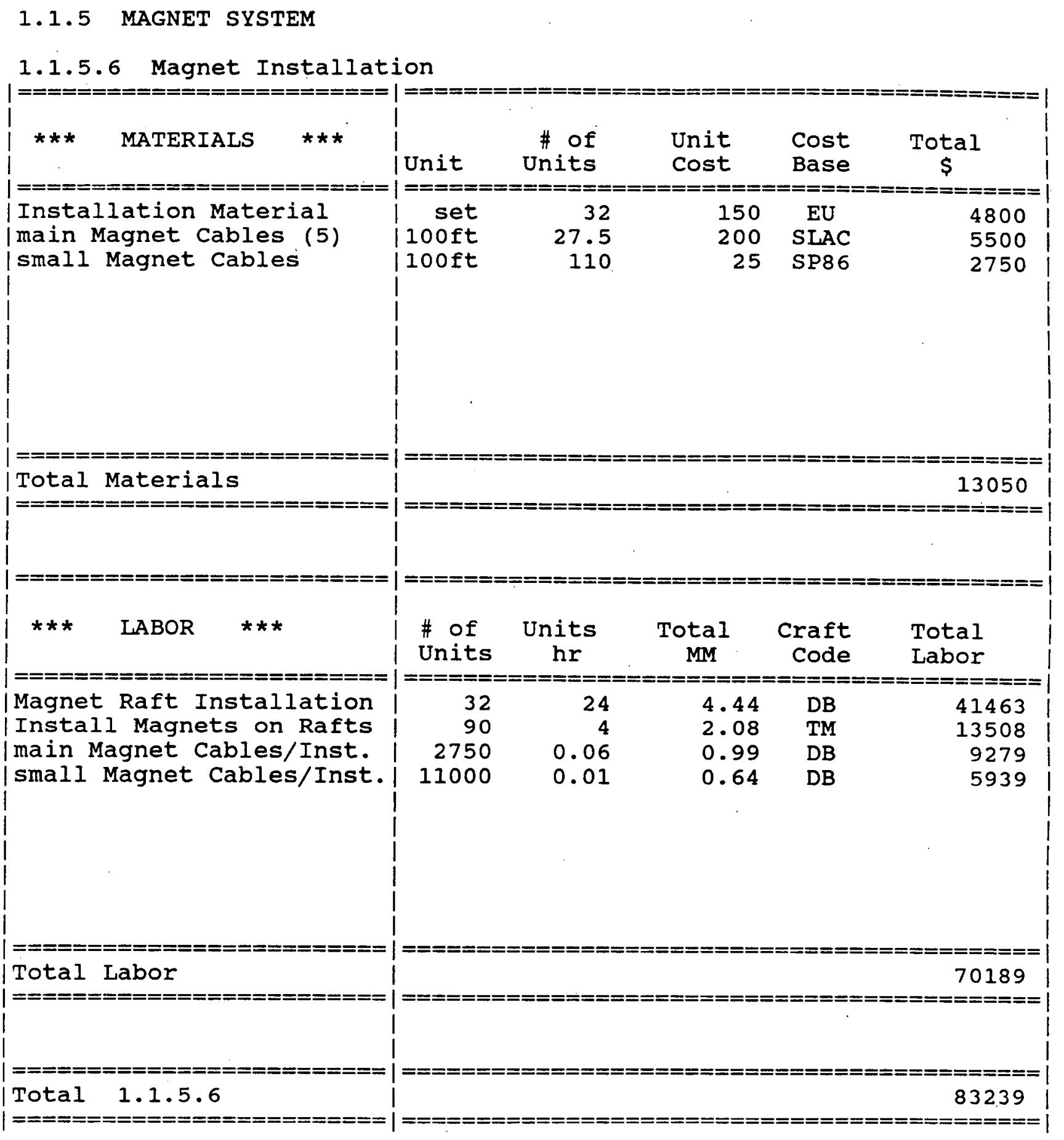


Magnet Name in Lattice

Magnet Designation

Magnet Type

Magnetic Arc Length ( $\mathrm{mm}$ )

Bending Radius ( $\mathrm{mm}$ )

Bending Angle (radian)

Bending Angle (degrees)

Sagitta ( $\mathrm{mm}$ )

Number of Magnets

Beam Energy (Gev)

Gap Height ( $\mathrm{mm}$ )

Field (kGauss)

Maximum Field (kGauss)

Total Current/Coil (amp)

Length of Iron Block ( $\mathrm{mm}$ )

Cross Section/Coil (mm?)

Aluminum $F i l l$ Factor

Power at nom. Energy (kW)

Nimber of Turns/Coil

Current (amp)

Elect. Resist. (Magnet (mohm)

DC-Voltage/Magnet (Volt)

Induction/Magnet (mHenry)

Cycling Rate ( $H z)$

Impedance (morm)

\begin{tabular}{|c|c|}
\hline$B$ & B1 \\
\hline $34 \mathrm{HB} 2000$ & $34 \mathrm{HB} 1200$ \\
\hline laminated & Iaminated \\
\hline 2000.00 & 1200.00 \\
\hline 7639.44 & 7639.44 \\
\hline 0.262 & 0.157 \\
\hline 15.00 & 9.00 \\
\hline 65.36 & 23.55 \\
\hline 16.00 & 8.00 \\
\hline 3.00 & 3.00 \\
\hline 36.00 & 36.00 \\
\hline 13.10 & 13.10 \\
\hline 15.70 & 15.70 \\
\hline 18762.98 & 18762.99 \\
\hline 1964.00 & 1164.00 \\
\hline 7310.00 & 7310.00 \\
\hline 0.75 & 0.75 \\
\hline 17.83 & 11.46 \\
\hline 9 & 9 \\
\hline 2087 & 2087 \\
\hline 4.09 & 2. 63 \\
\hline 8.54 & 5.49 \\
\hline 2.16 & 1. 28 \\
\hline 2.00 & 2.00 \\
\hline 27.39 & 16.27 \\
\hline
\end{tabular}

$B 100 k$

$34 \mathrm{HB} 40 \mathrm{O}$

laminated

400.00

7639.44

0.052

3.00

2.62

1.00

3.00

36.00

13.10

15.70

18762.98

364.00

7310.00

0.75

5.09

0.75

6

2099

1. 69

3.54

0.56

2. 00

7.25

3.00

360.00

188280.58

145988.57

5214.54

436.45

208.99
3.50
360.00
116050.18
89982.73
5214.54
594.06
243.82

3.60

360.00

81018.43

62819.89

52.14 .54

628.49

250.79

3.75

360.00

21909.89

16988.44

5214.54

681.96

$2 \in 1.24$

39589.29

11731.65

11731.65

458.58 


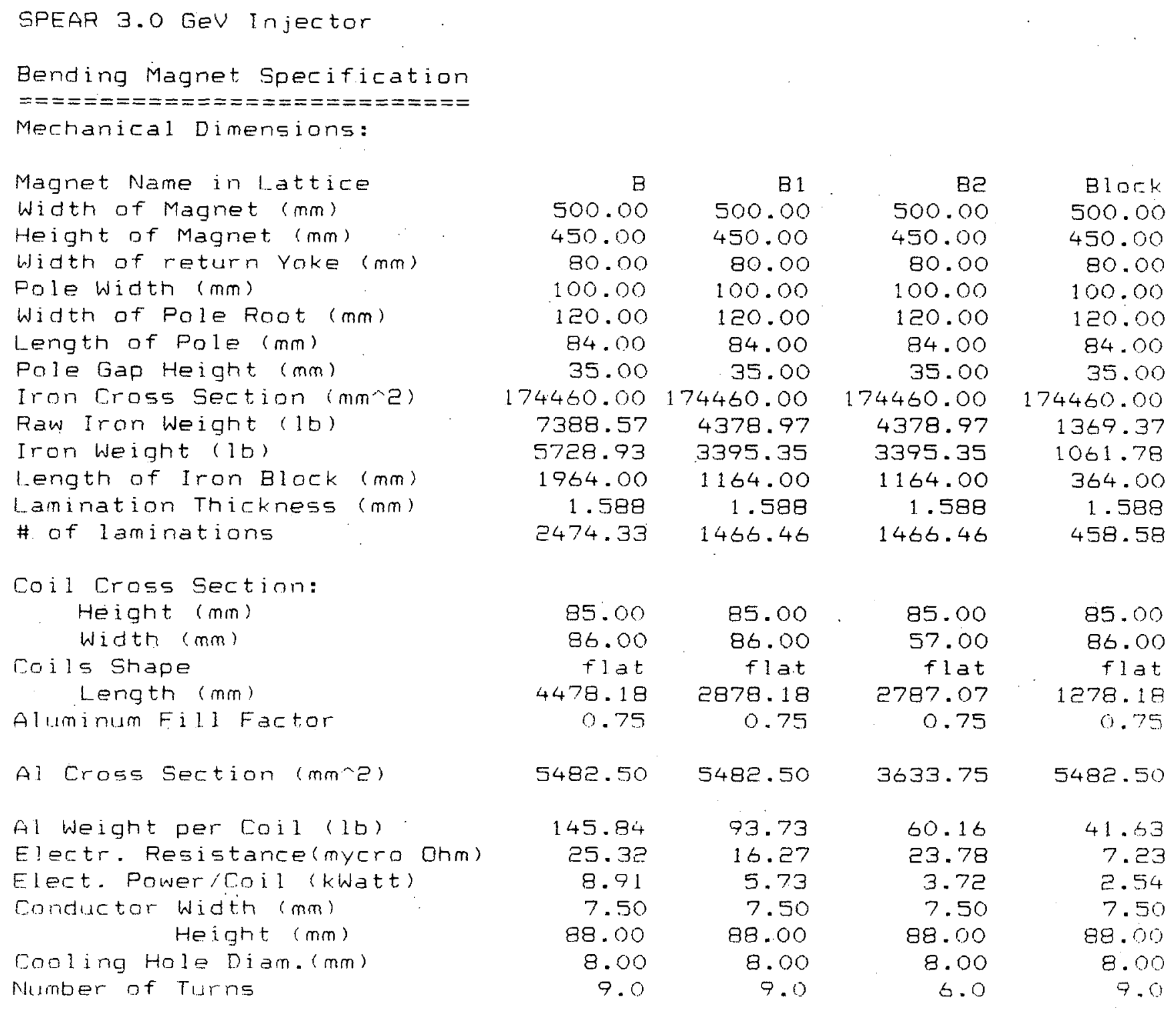




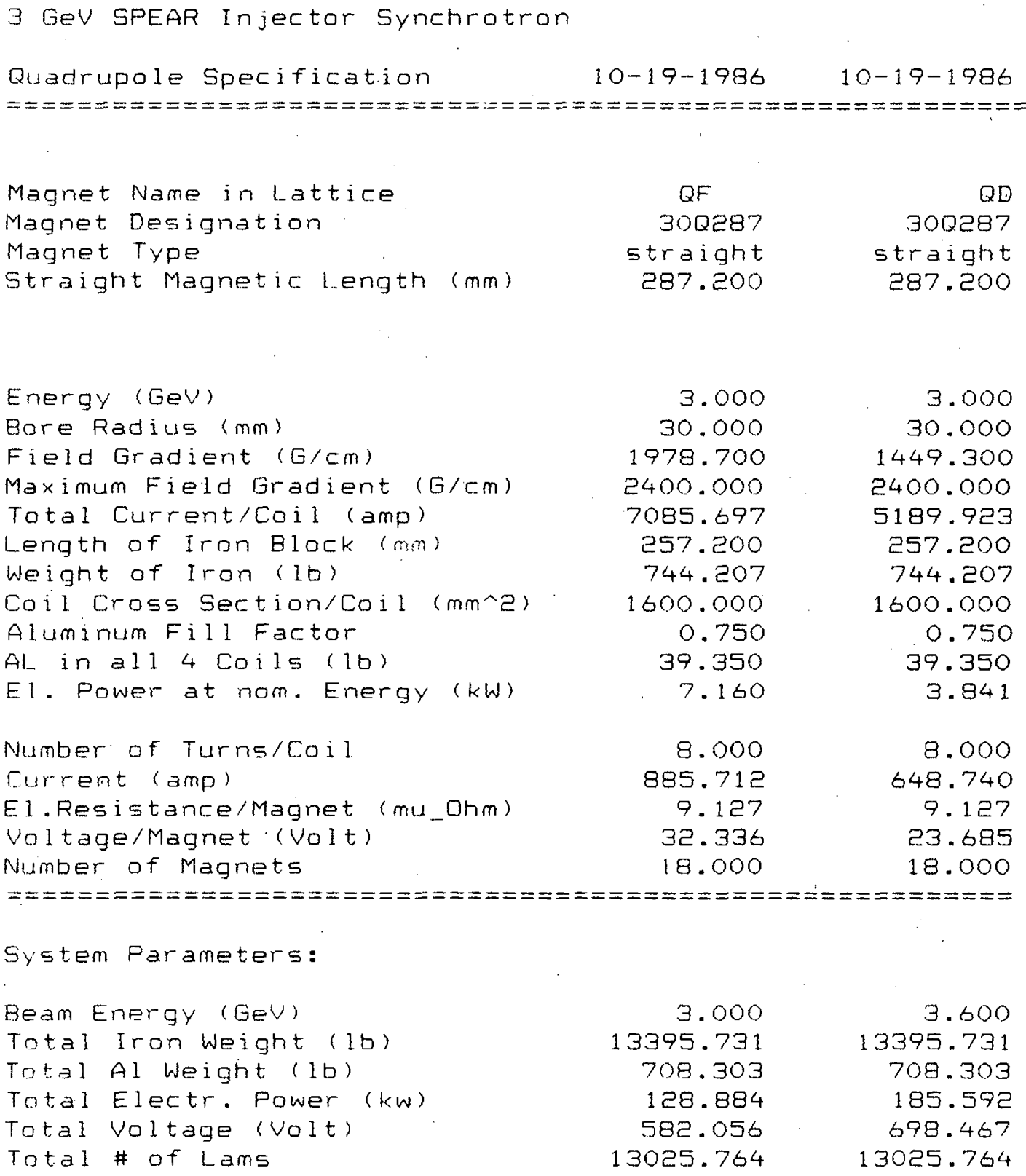




\begin{abstract}
Width of Magnet ( $\mathrm{mm}$ ) Height of Magnet ( $\mathrm{mm}$ )

Iron Cross Section ( $\left.\mathrm{mm}^{\wedge} \mathrm{z}\right)$

Raw Iron weight (lb) Iron length. (mm)

Lamination Thickness ( $\mathrm{mm}$ )

Number of Laminations
\end{abstract}

Coil Cross Section: Height $(\mathrm{mm})$ Width ( $m m$ )

Coils Shape Length ( $\mathrm{mm}$ )

Aluminum Fill Factor

Al Cross Section ( $\mathrm{mm}^{\wedge} \mathrm{e}$ )

Al Weight per Coil (lb) Resistance/Coil (mycro Ohm)

Elect. Powericoil (kWatt)

\author{
416.00 \\ 416.00 \\ 173056.00 \\ 744.21 \\ 287.20 \\ 1.588 \\ 723.65
}
20.00
80.00
flat
1380.13
0.75
1200.00
9.84
35.65
1.79

416.00

416.00

173056.00

744.21

287.20

1.588

723.65

20.00

80.00

flat

1380.13

0.75

1200.00

9.84

35.65

0.96 
Marnet loot 3 GerSsRL Broster Bend Magnets 7is/givoss

No.Lanmations: Maguet $B^{\prime \prime}$ high X 19"Widex 14.33 long ( $\frac{1}{2}$ core)

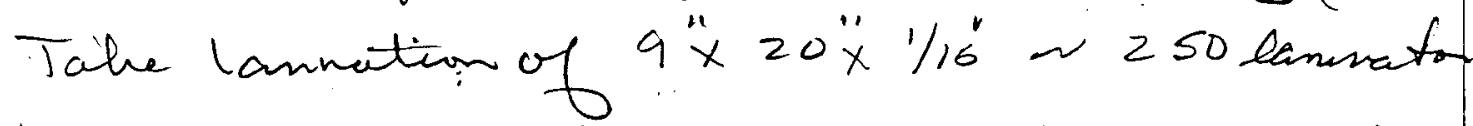
per 光 lore $\times 256$ 1/2 coved $\sim 65000$ lanevalus Say 25000 lanuations with $15 \%$ spares.

Totrant Xake strip stoch 20 "wide-yields $56250 \mathrm{ft}$. of coi\% Laminator weight is $20 \times 9 \times, 0625 \times, 283^{4 / 4} / 3$ $=3.103^{\text {Hp}}$ per cairmator stock, 75000 Lavemalem at 3.21b/lamatum $\sim 240,000 \mathrm{lbs}$ of steel

Heel Cort Verbol budgatary quots fron Lany wanad suse purchasm based on cortact with Pyerson and Writhungtor will yield a costof $404 / 6$ including shippry and packing. 240,00016s $0.404 / 16=$ $\$ 96,000$

Die Cost: Verbal estruates trow kurt Schults-Schults ify $\sim \$ 16,000$ leo Hoigharsa \$, $\$, 000$. Tahe high of $16,000+4,400$ tor Hod fication.

cost per cammatim: $w / 0$ tight tolerance awd straightemg seeder for SUC costper bit for. 25 foor lamations will he, $30 \% / h i f$

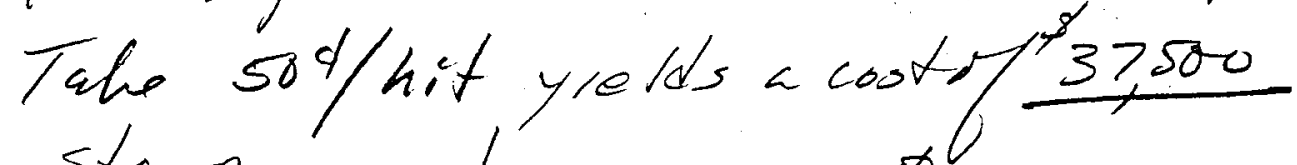

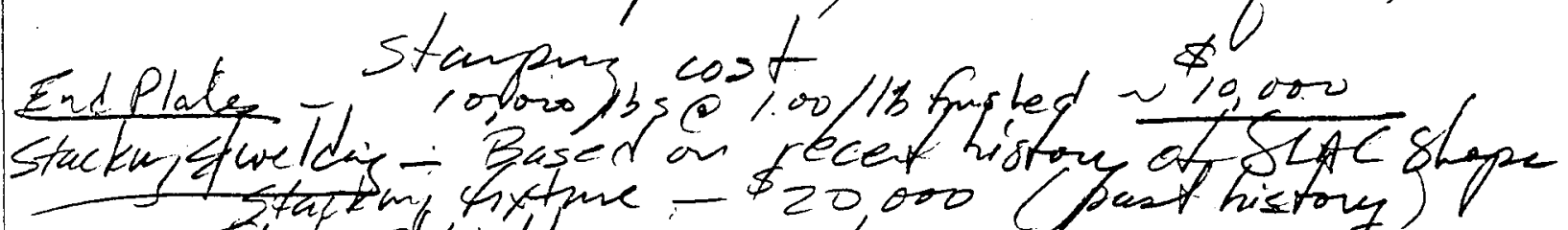

stacking s( Welder - \$20,000 (past history) assembly $\phi_{200}$ matl/slock $\times 280=\$ 56000$

Pase $10+4$ 


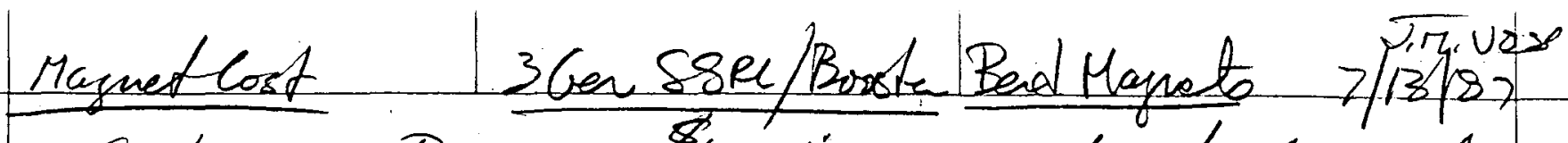

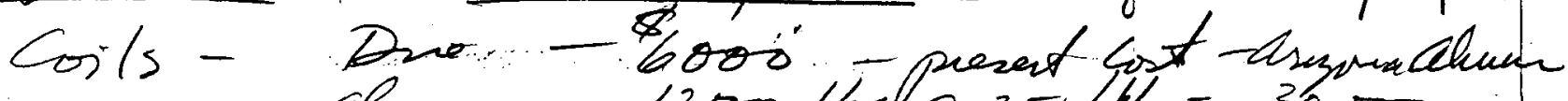

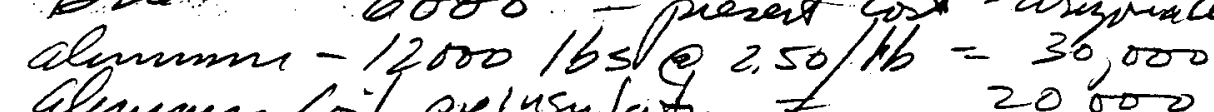

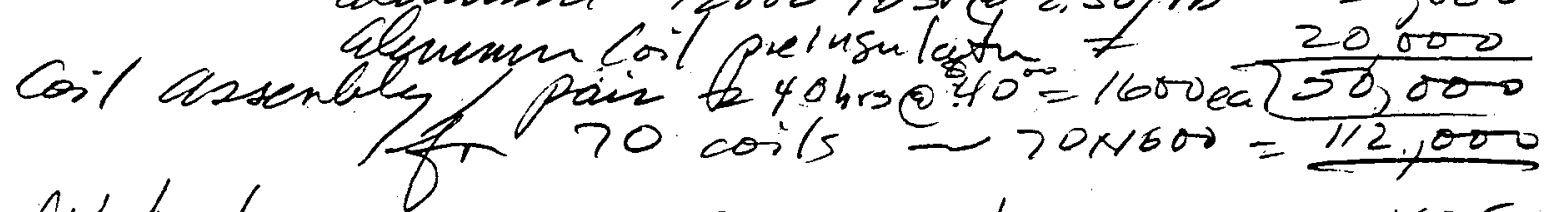
Wate hosen - per SPR made@site $4.75 \mathrm{each}$ Puckry Maguet -10 , 000 contract $\mathrm{La}$ bor

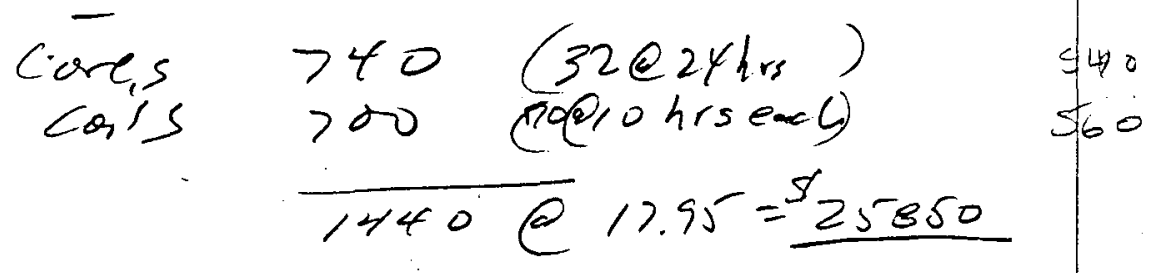

Labor

To be added?

page zof 4 


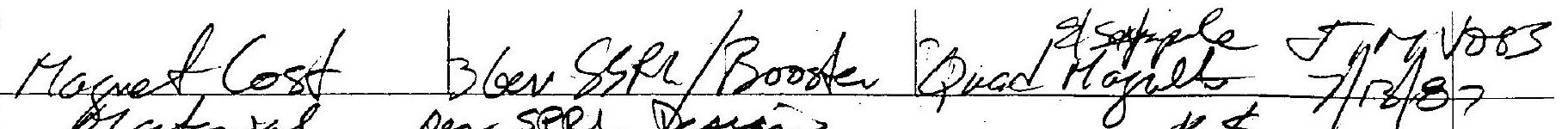

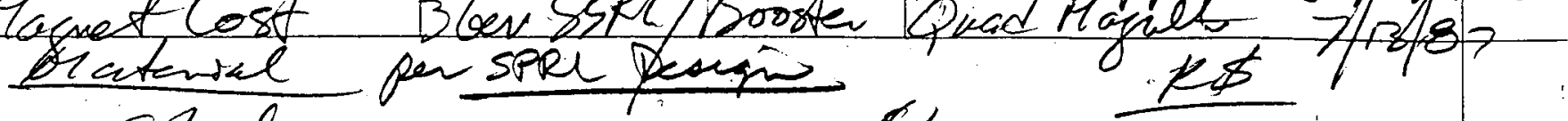
Stcel isto0 isse.408/16 $=\frac{K \Phi}{5200}$.

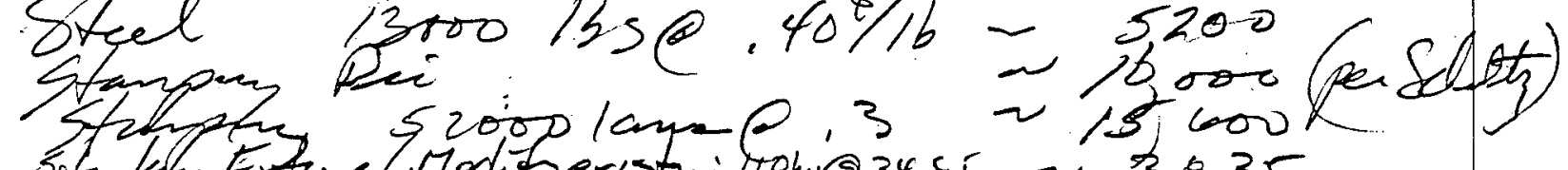

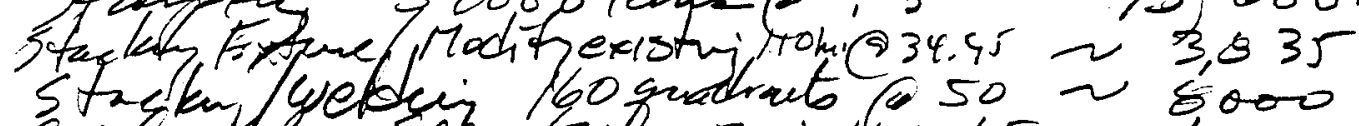

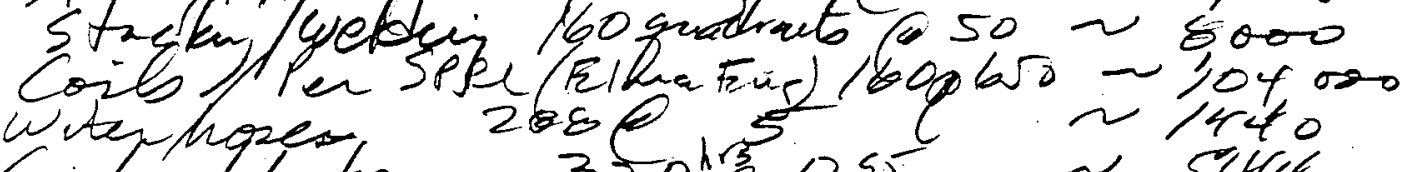

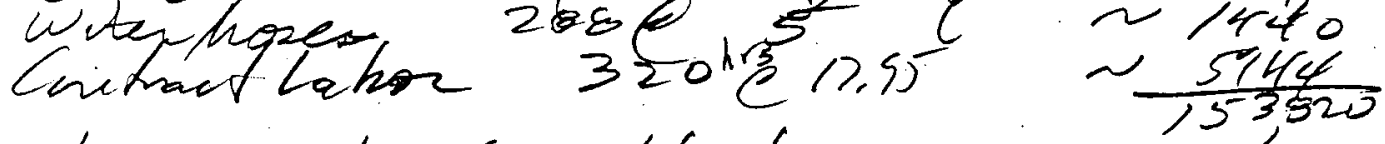

Lukn - to beadded

Sextupole (per SPRL Denigin)/RT Enterpriestrima

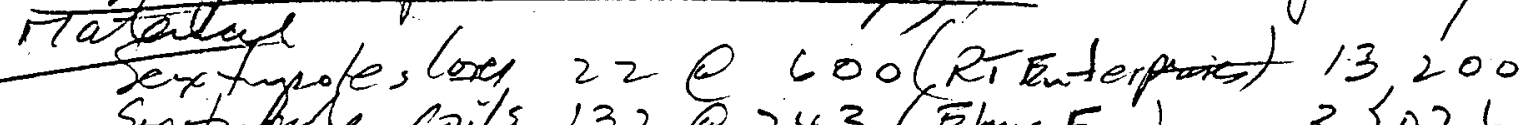

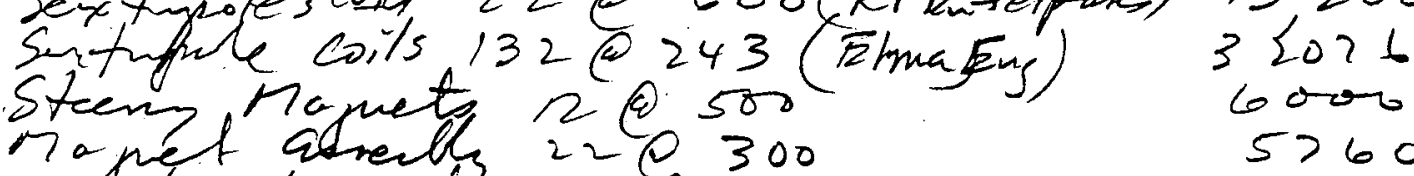

$$
\begin{aligned}
& \text { rapuef adreabl } 220300 \\
& 5>60
\end{aligned}
$$

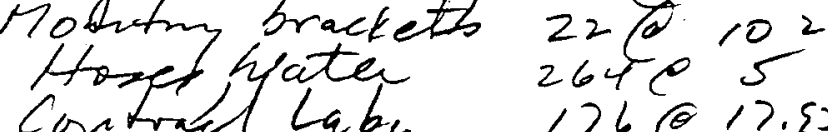

$$
\begin{aligned}
& \text { cantraf labe } 176 \theta 17.55^{-} \\
& \$ \frac{3,59}{63,760}
\end{aligned}
$$

laker to he adsed

Suzpents

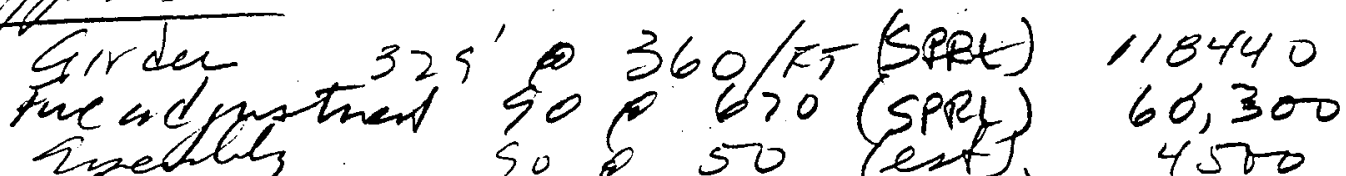

$$
\begin{aligned}
& \text { clamply } 290650 \text { (s) } 450
\end{aligned}
$$

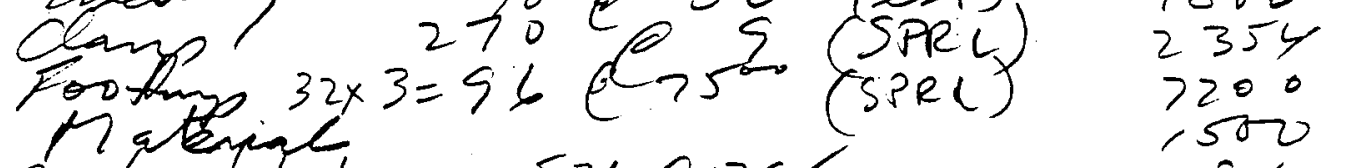

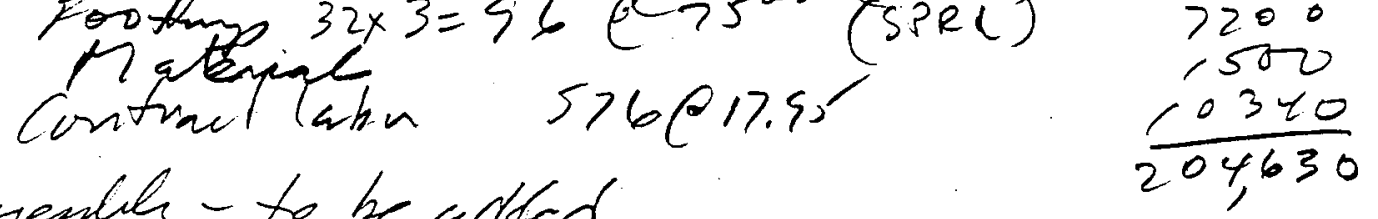

anembly - to be added

Page 3 of 4 


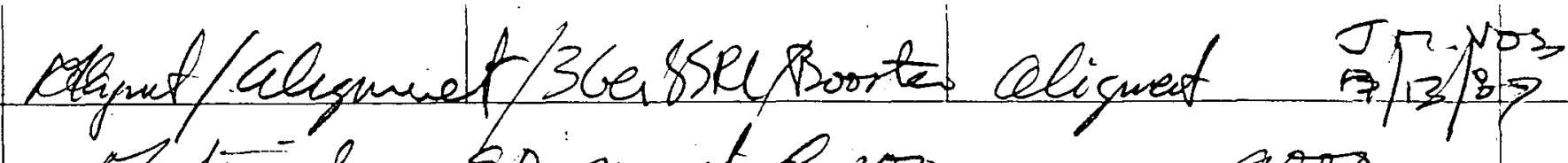

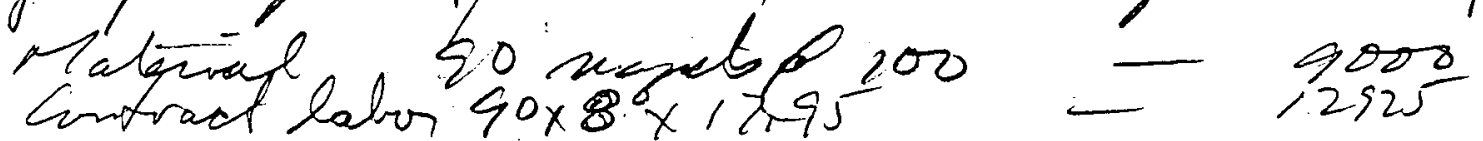
catm - to he oobled

mopuct installation

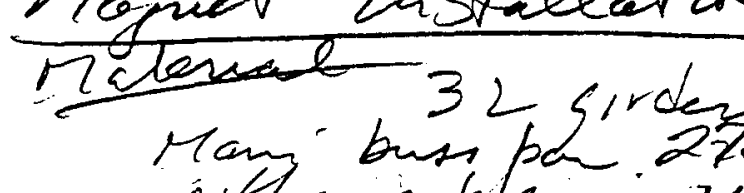

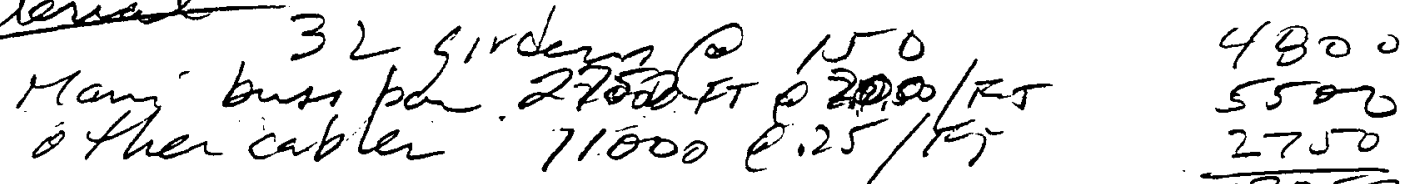

Instaclabim

$\frac{2750}{13050}$

Girdu Fortallotum

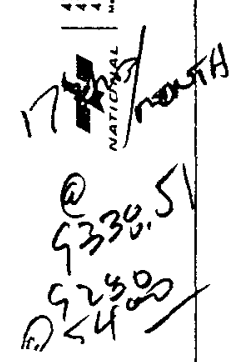

$$
\begin{aligned}
& 50{ }^{3} 20 \times 3 \times 3 \times 9511^{\circ}=41463
\end{aligned}
$$

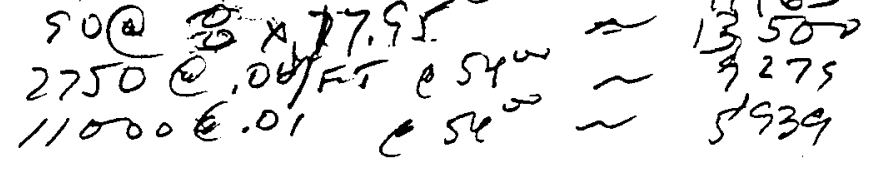

$$
\begin{aligned}
& c 5 e^{\infty}=\frac{5439}{83239}
\end{aligned}
$$

Page yot 4 
Camparisan of Magnet Costs.

BEND:

leugth (m)

ivou bloch*

cails form
SPRL SPRL sealed to tuy;

0.28

$\$ 1789$

doy eared

$\$ 3172$ pair
Zujector Est

$2.0 / 1.2$

$10760 / 6460$

flat

$\$ 900$

$\$ 3200 /$ pain

Tatal cost

IRON

COILS

coppor

\begin{tabular}{ll}
$327 k$ & $\begin{array}{l}275 \\
102 k \\
25 k\end{array}$ \\
\hline $429 k$ & 102 \\
\hline & 377
\end{tabular}

SPRL inou blochs are precision machined all araind. 
Water loses for Ullages.

SPRL Magnet (W, Wadusweiler)

400 hoses each 3 lit with fittings (made at SLAC)

total cost : $\$ 1890$

or. \$ 4.725 /hose 


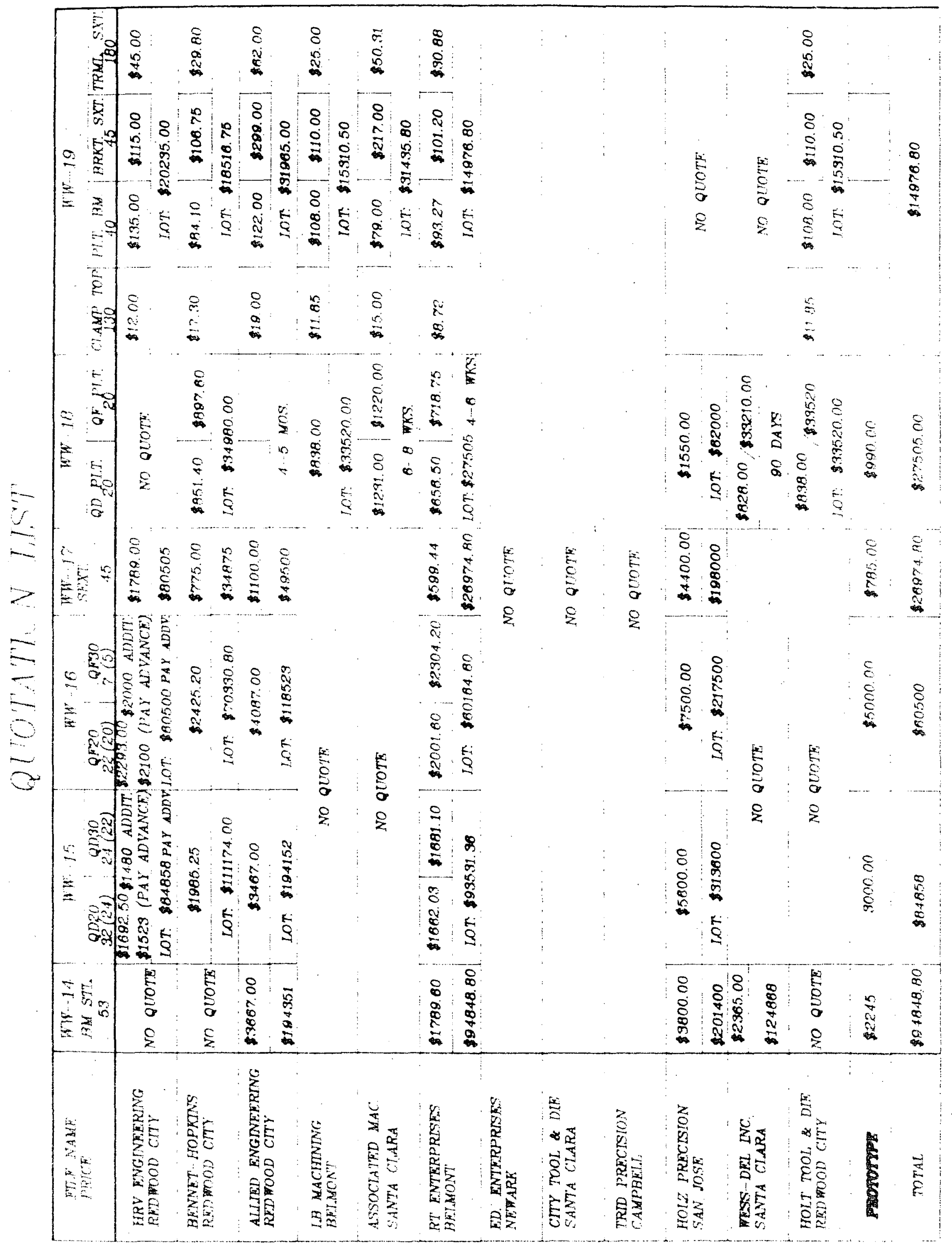




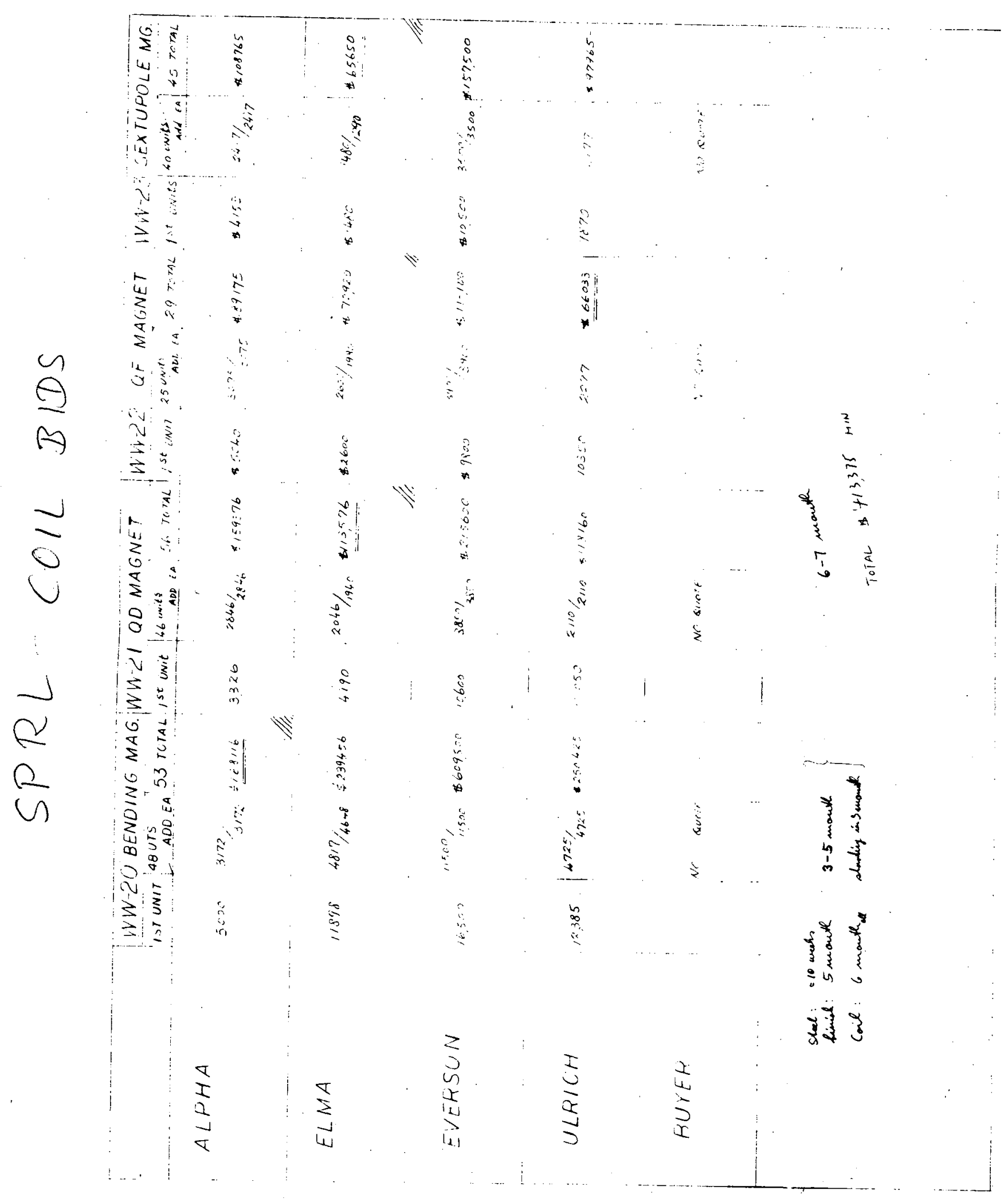




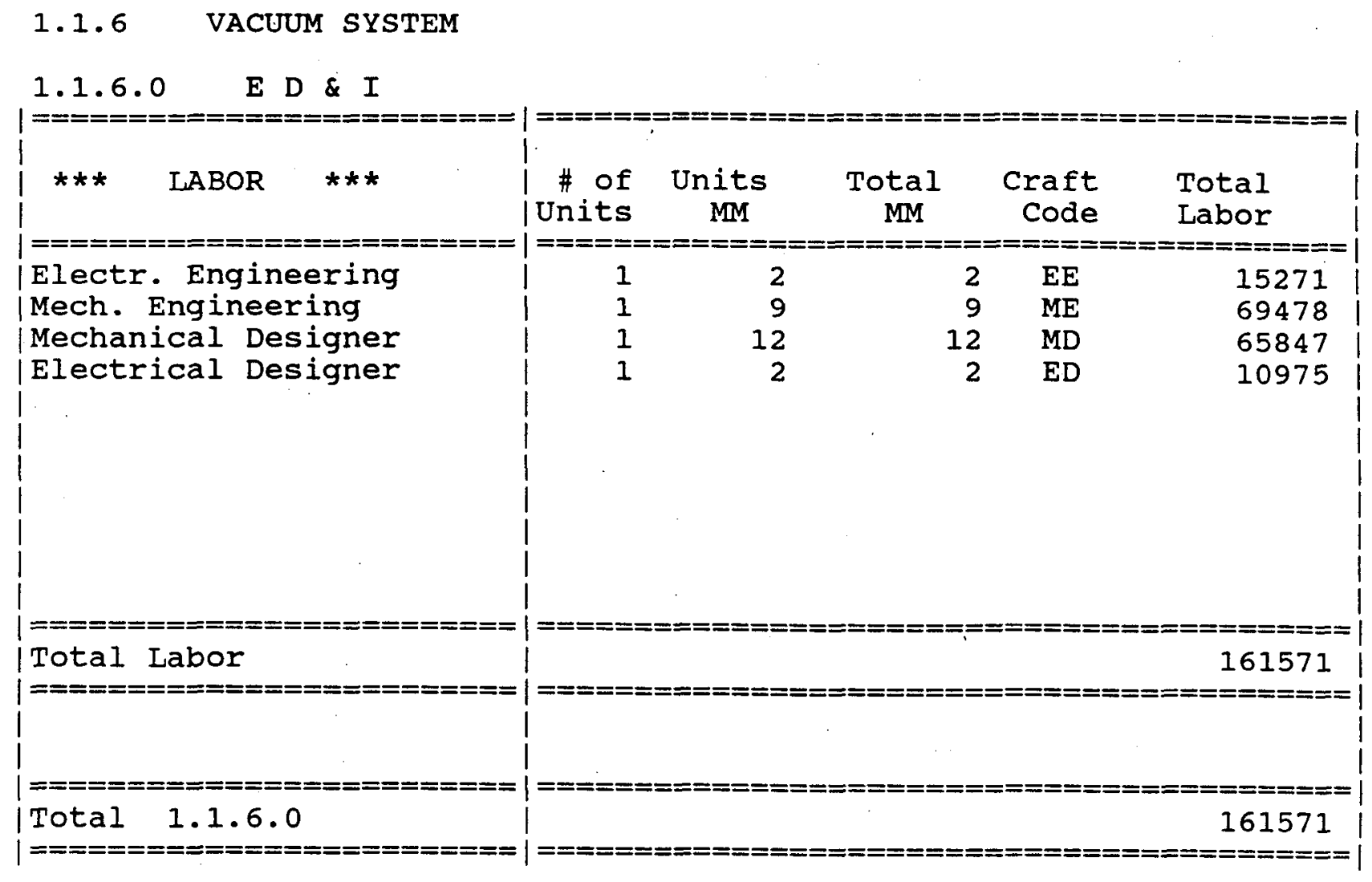




\subsubsection{VACUUM SYSTEM}

\subsubsection{Vacuum Chambers}

1.1.6.1.1 Vacuum Chamber Components

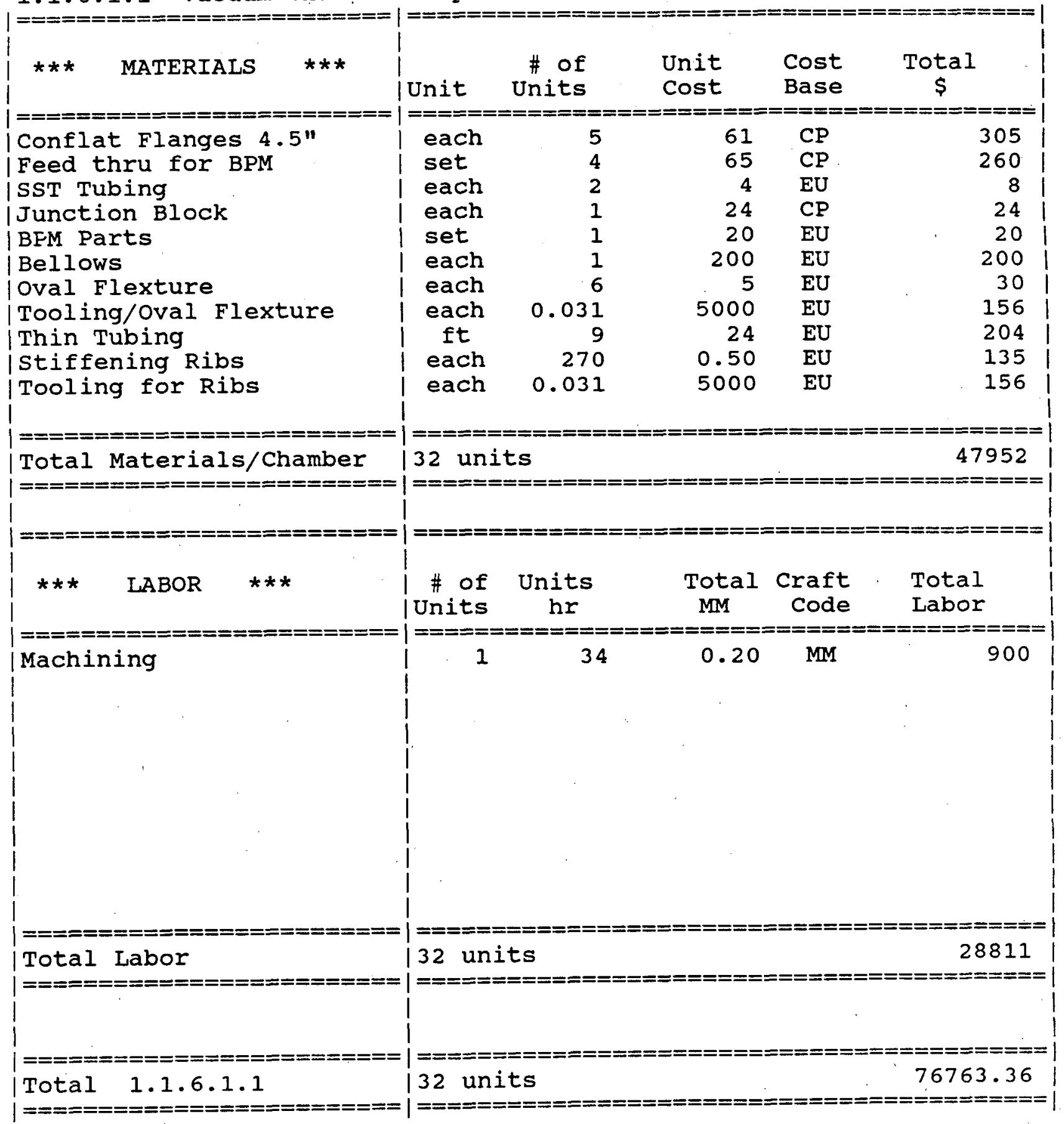




\subsubsection{VACUUM SYSTEM}

1.1.6.1 Vacuum Chambers

\subsection{Vacuum Chairber Assembly}

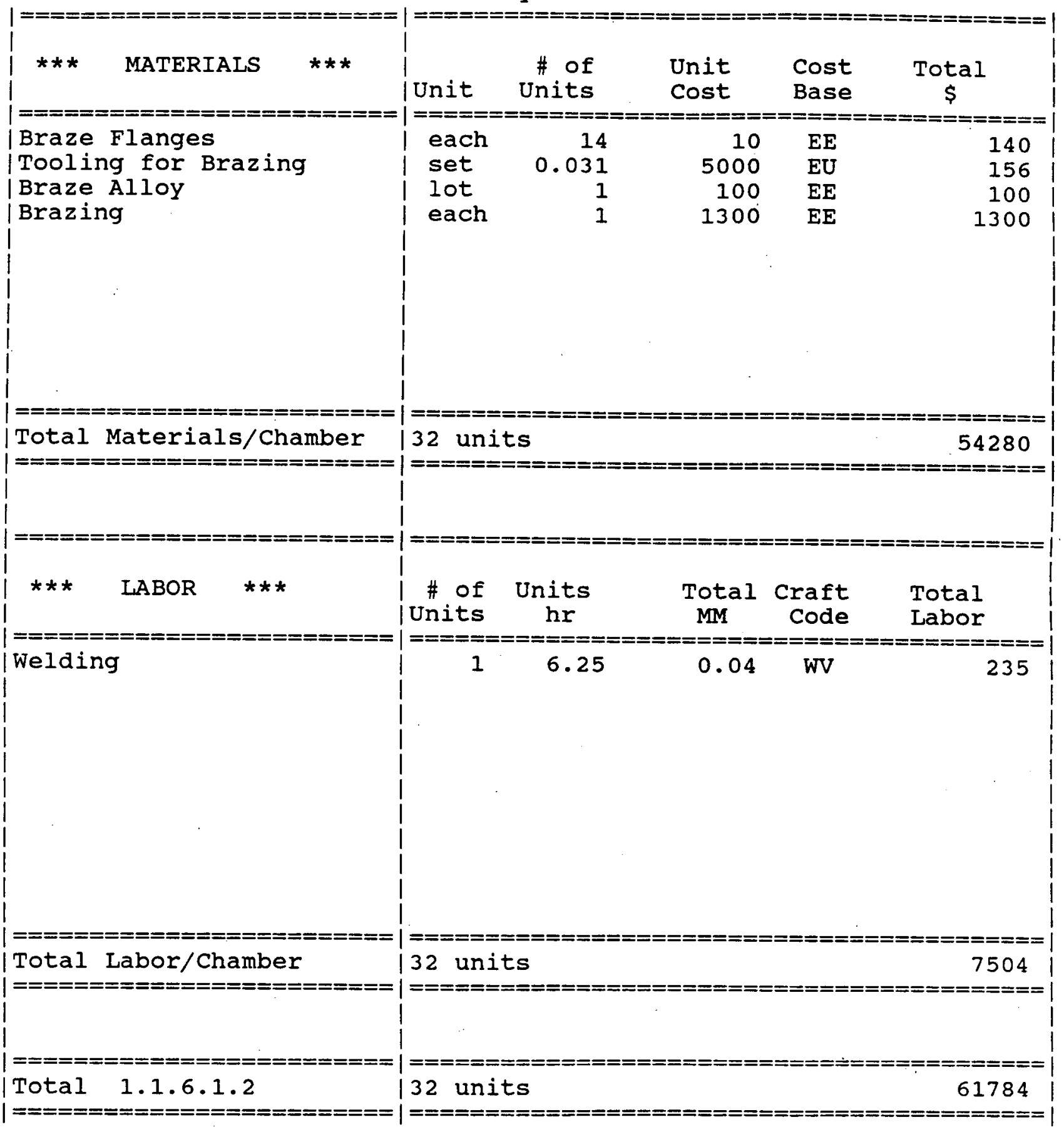




\section{1 .6 VACUUM SYSTEM}

\subsubsection{Vacuum Chambers}

$1.1 \cdot 6 \cdot 1 \cdot 3$ straight $\mathrm{S} s$ ction

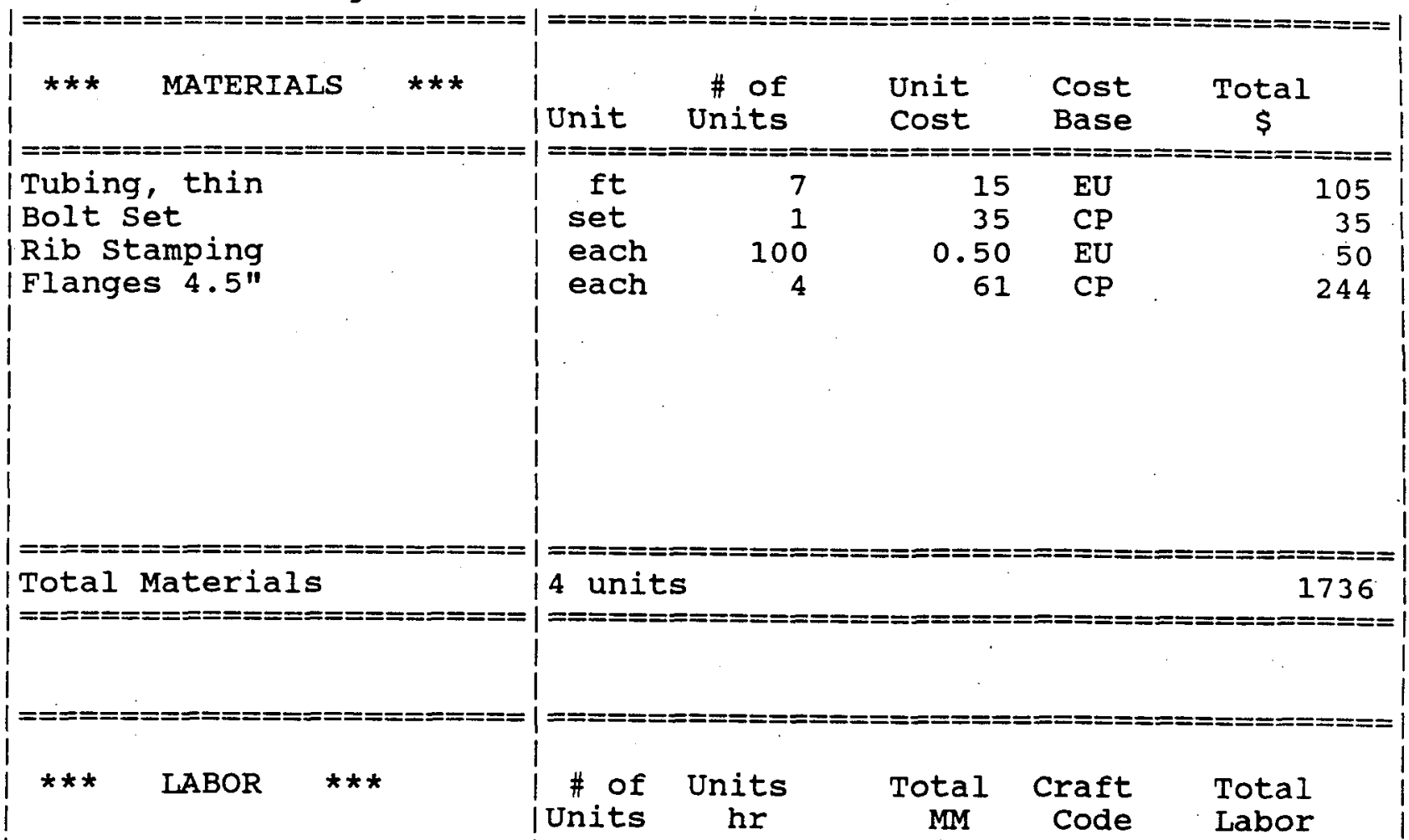

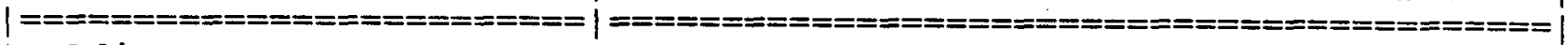

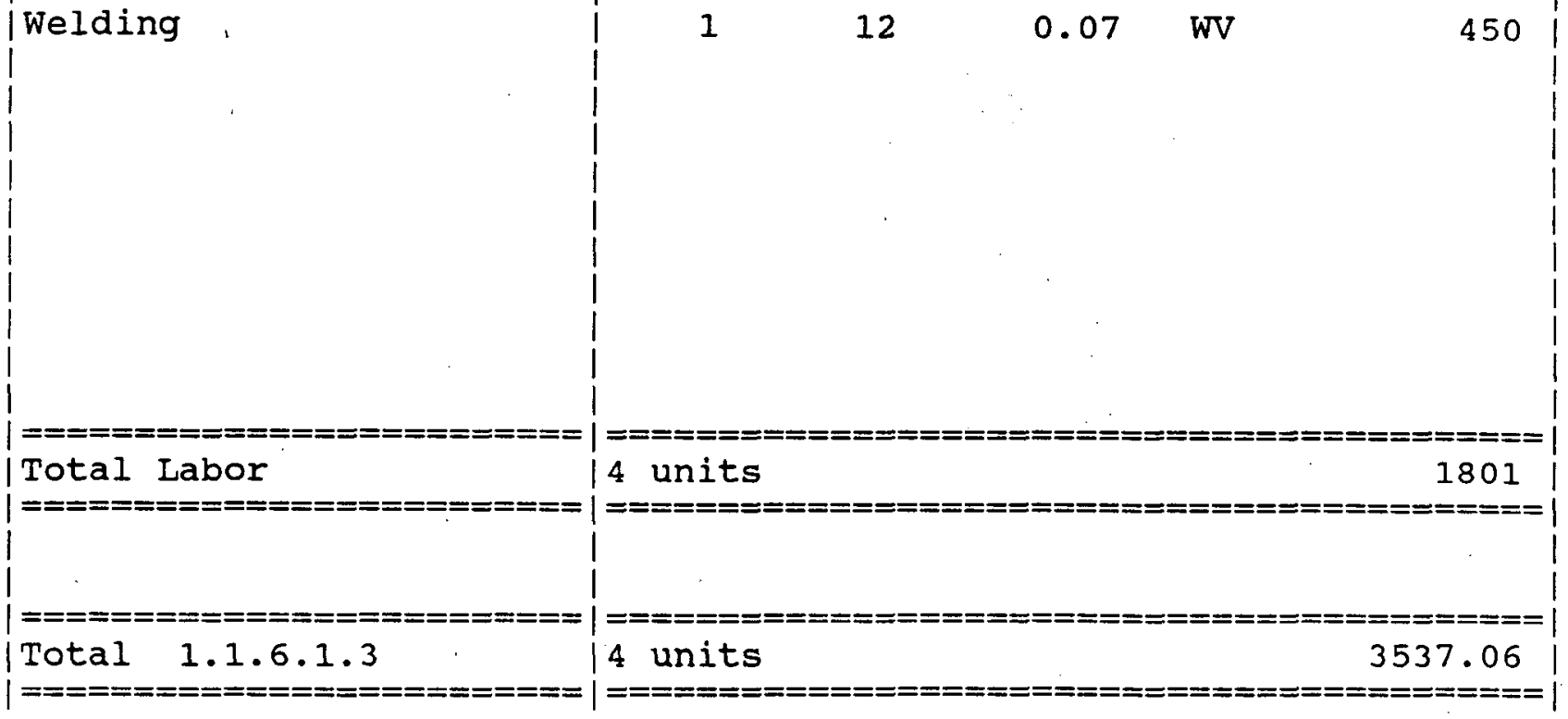




\section{1 .6 VACUUM SYSTEM \\ $1.1 .6,1$ Vacuum Chambers}

1.1.6.1.4 Welding station

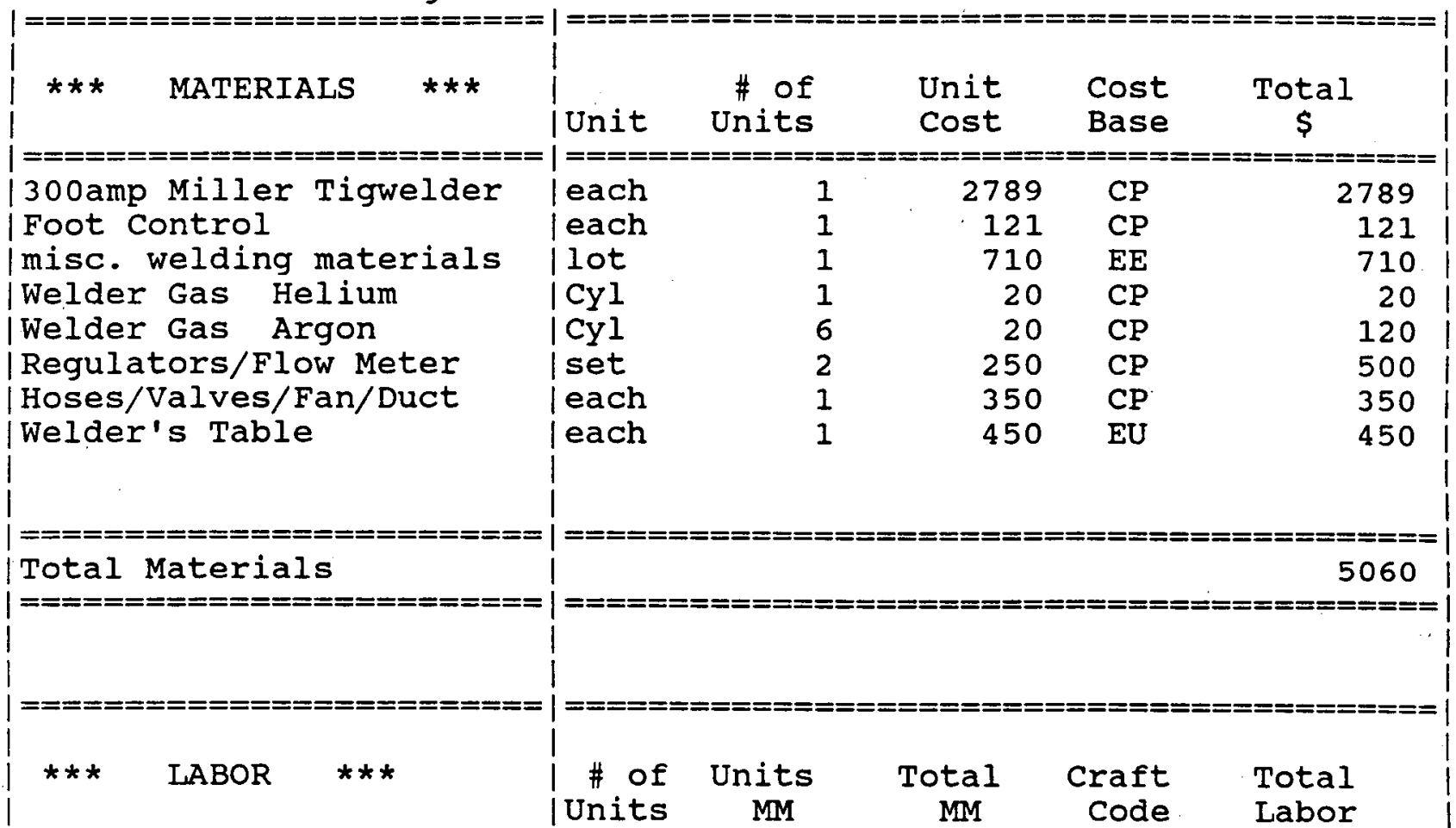

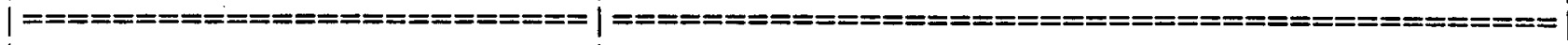

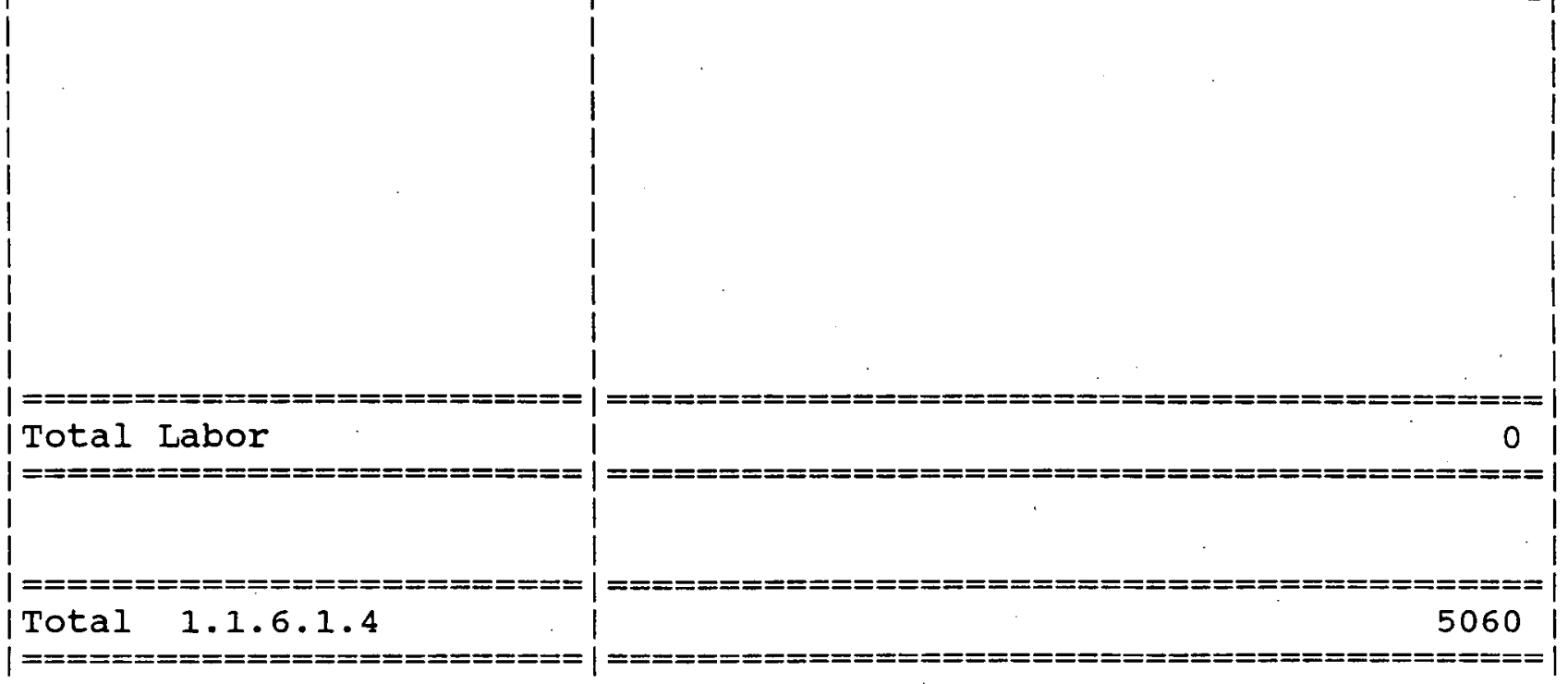




\subsubsection{VACUUM SYSTEM}

\subsubsection{B2 Pumping system}

\subsection{Roughing System}

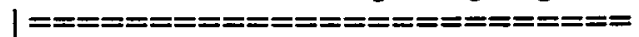

$* * * \quad M A T E R I A L S$
$\mid==\neq * *$

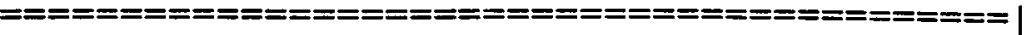

\# of Unit cost Total

Unit Units Cost Base $\$$

=

$=========$

Cross

Double Vacsorbs

I LN2 Dewar

Heating Band

Convection Gauge

Right Angle Valves

Mobile Mech. Pump

misc. Parts

each

each

each

each

each

each

each

lot

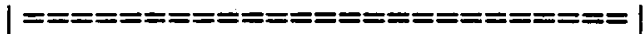

| Total Materials

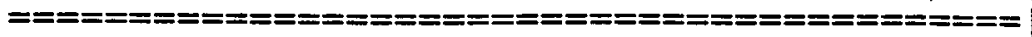

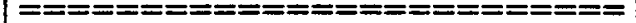

1

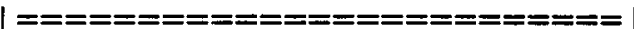

| $* * *$ IABOR $* * *$ |

i $* * *$ LABOR $\quad * * *$

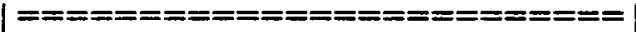

\# of Units Total Craft Total

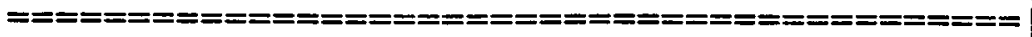

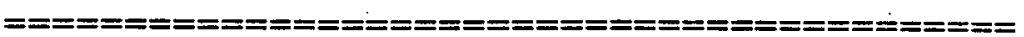

Units MM MM Code Labor

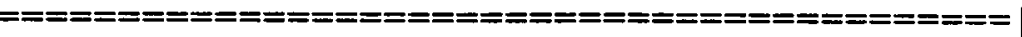

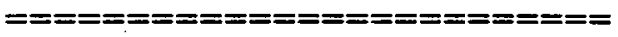

Total Labor

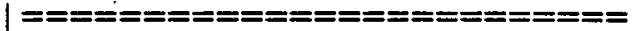

I

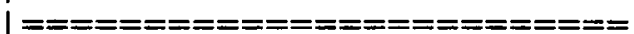

Total 1.1.6.2.1

।

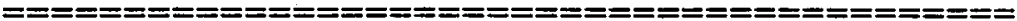

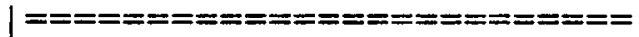

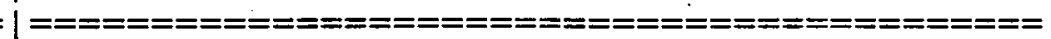




\subsubsection{VACUUM SYSTEM}

\subsubsection{Pumping system}

1.1.6.2.2 Ion pumping system

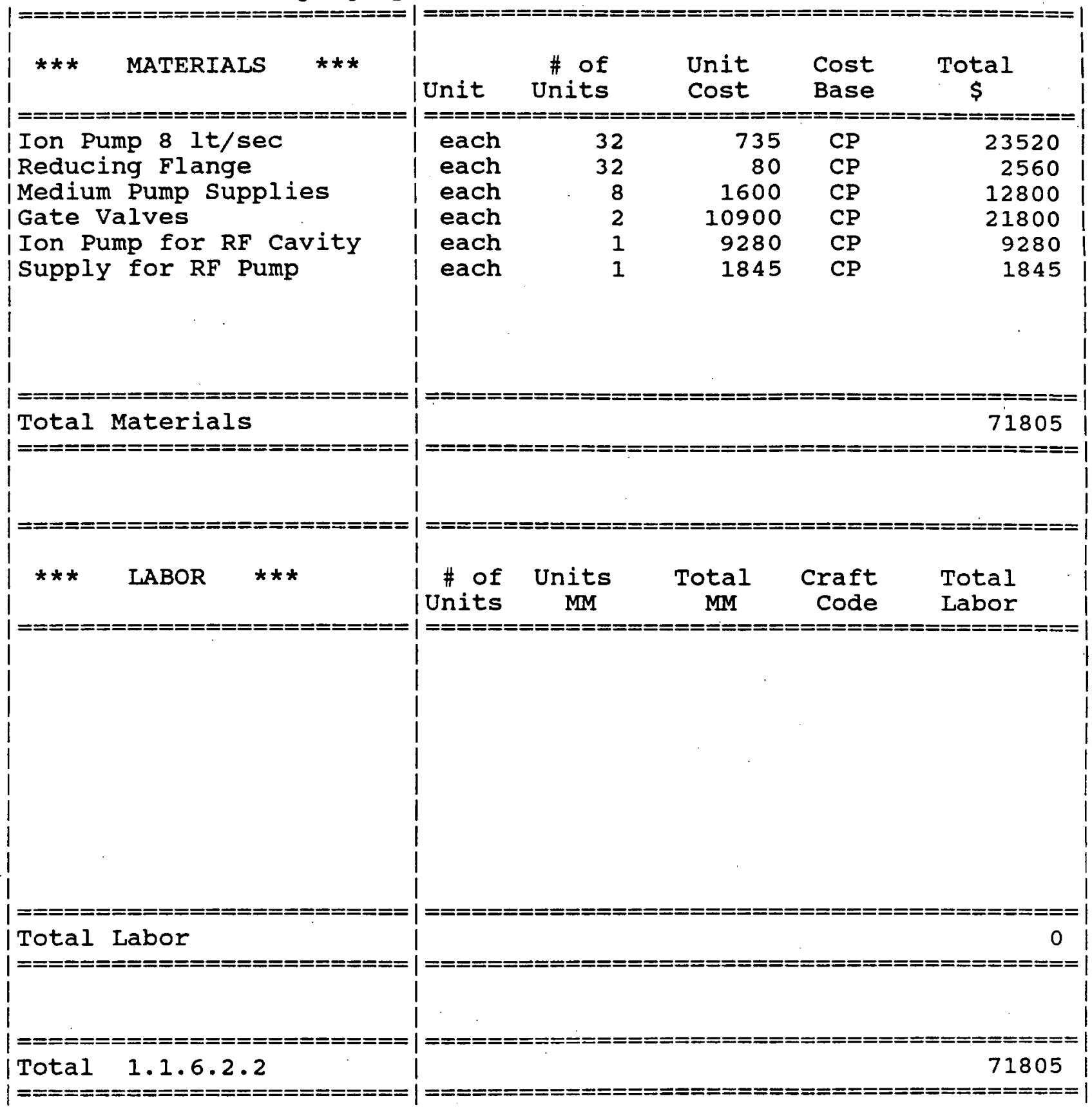




\section{1 .6 VACUUM SYSTEM}

\subsubsection{Pressure Monitoring}

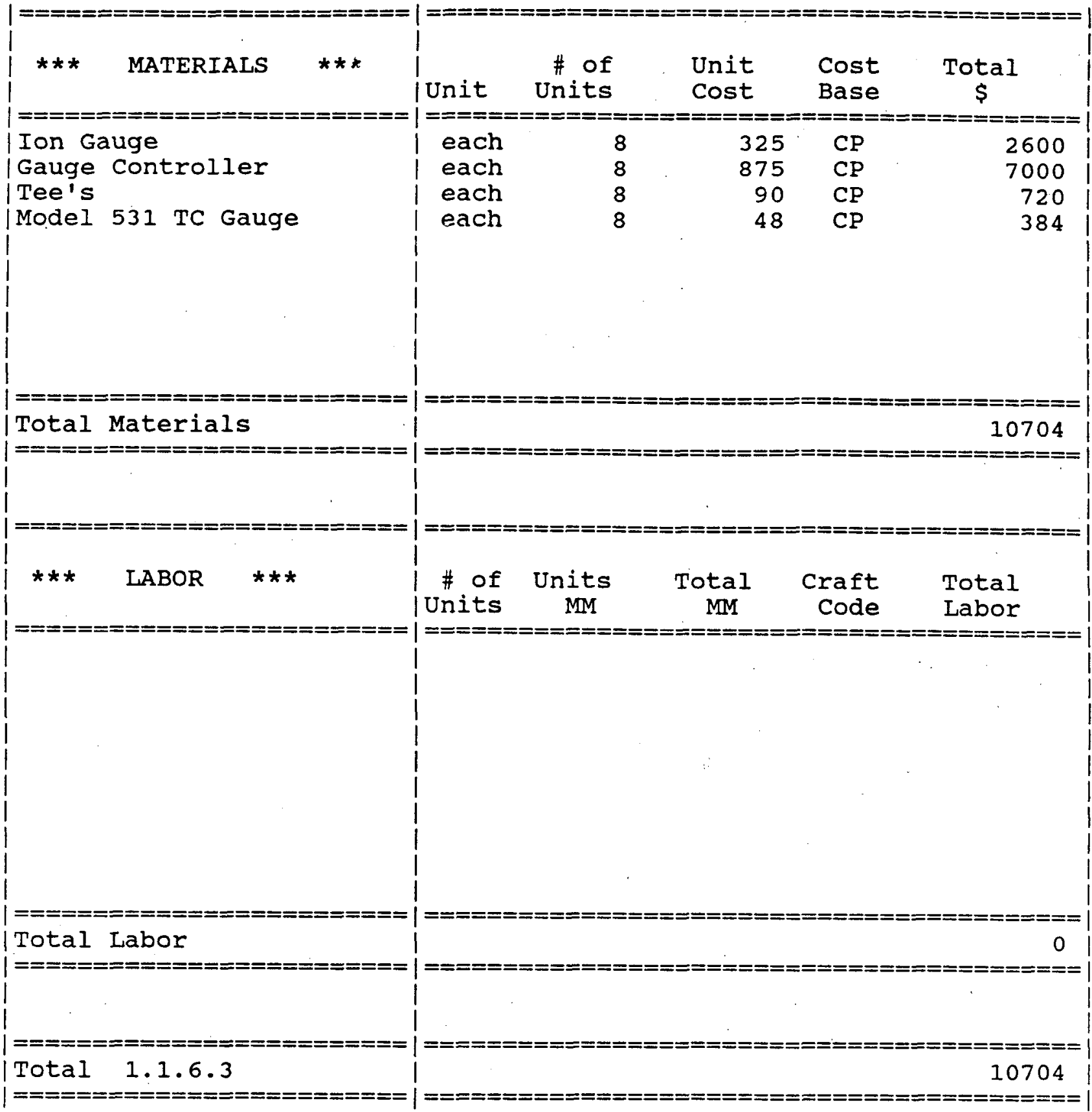




\subsubsection{VACUUM SYSTEM}

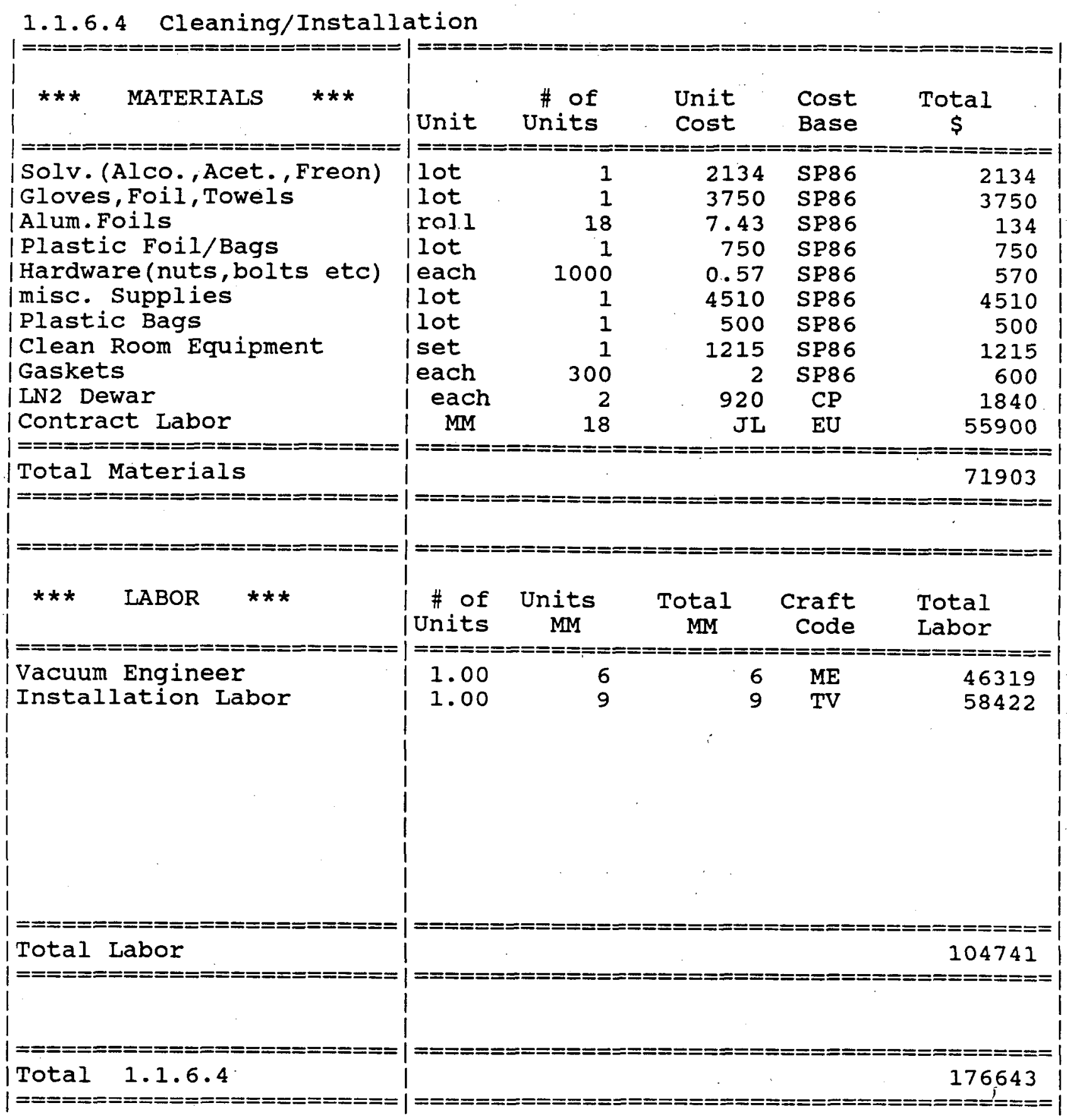




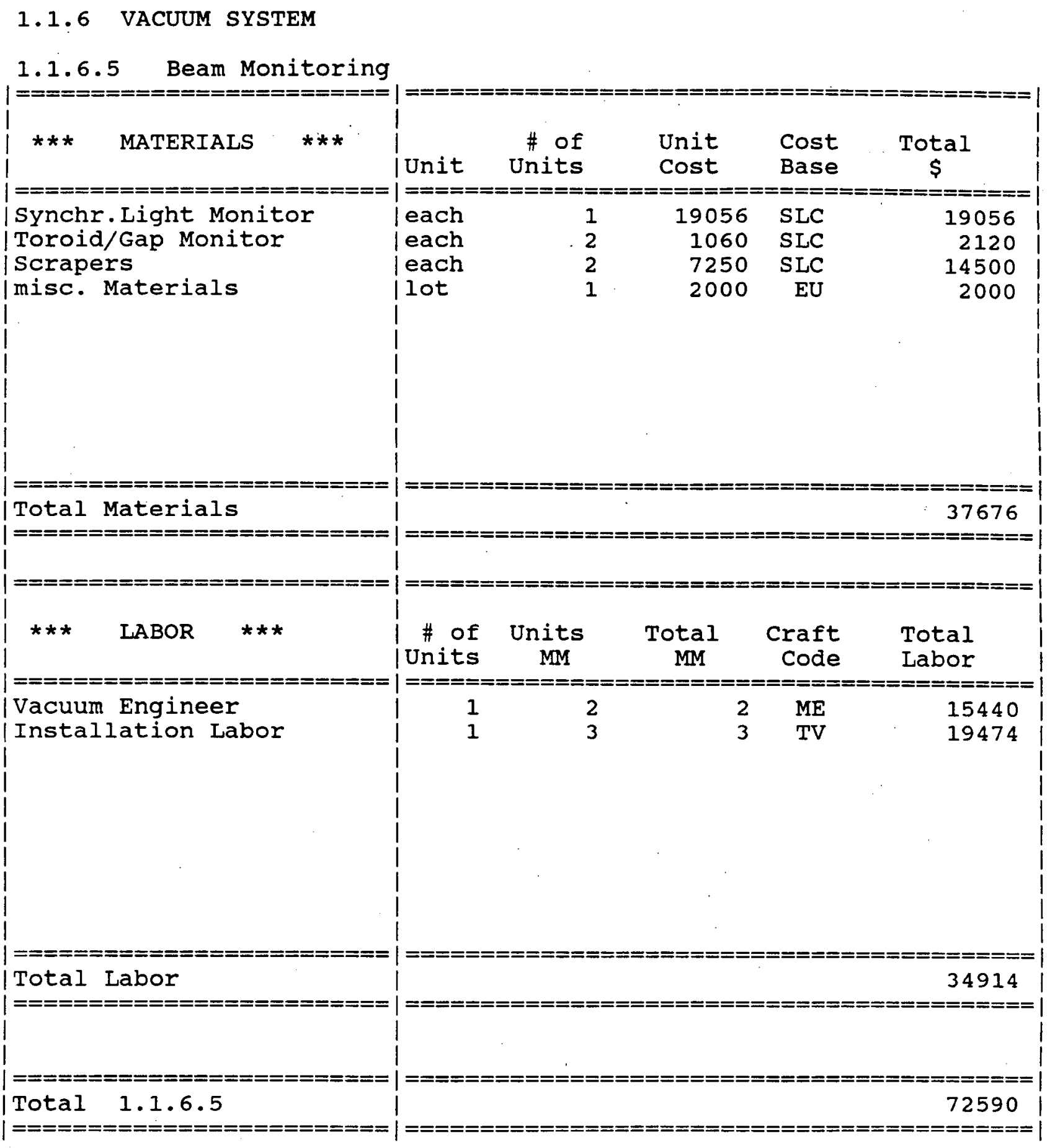


$6 / 16 / 87$

(1)

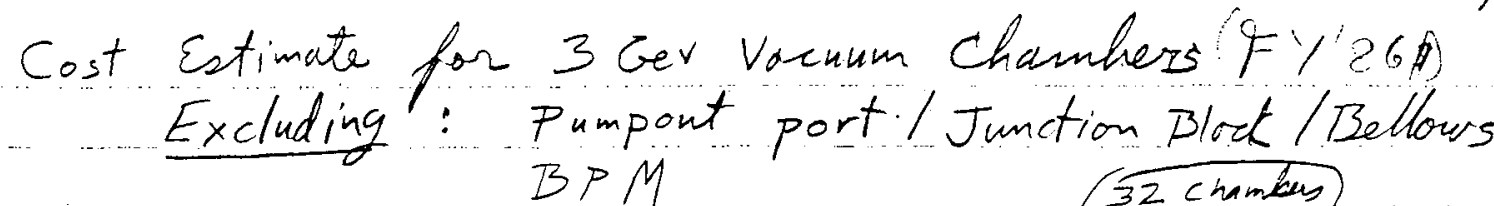

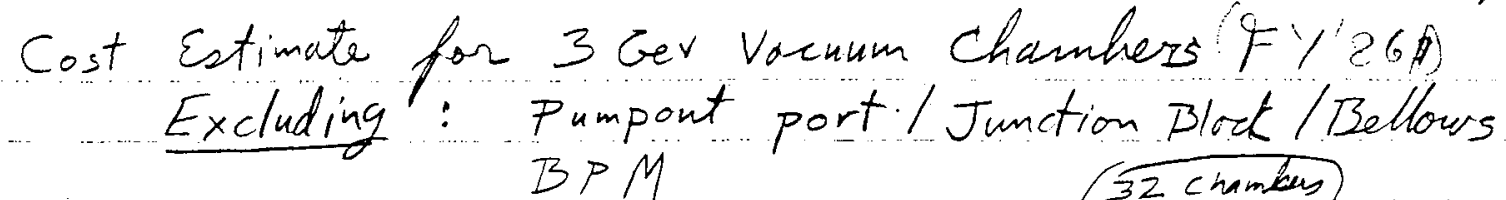

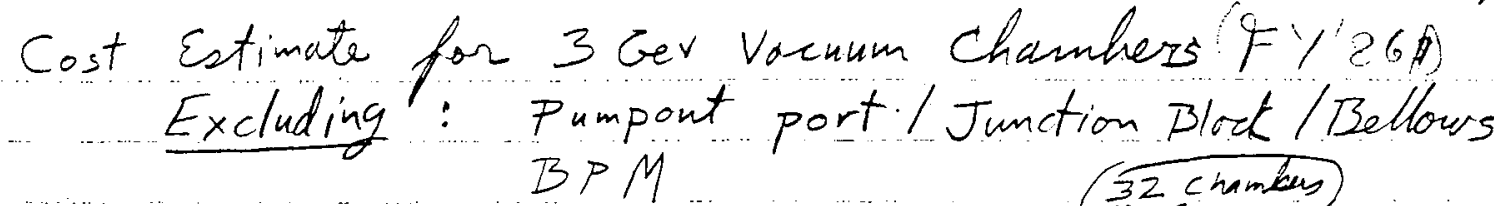

7124

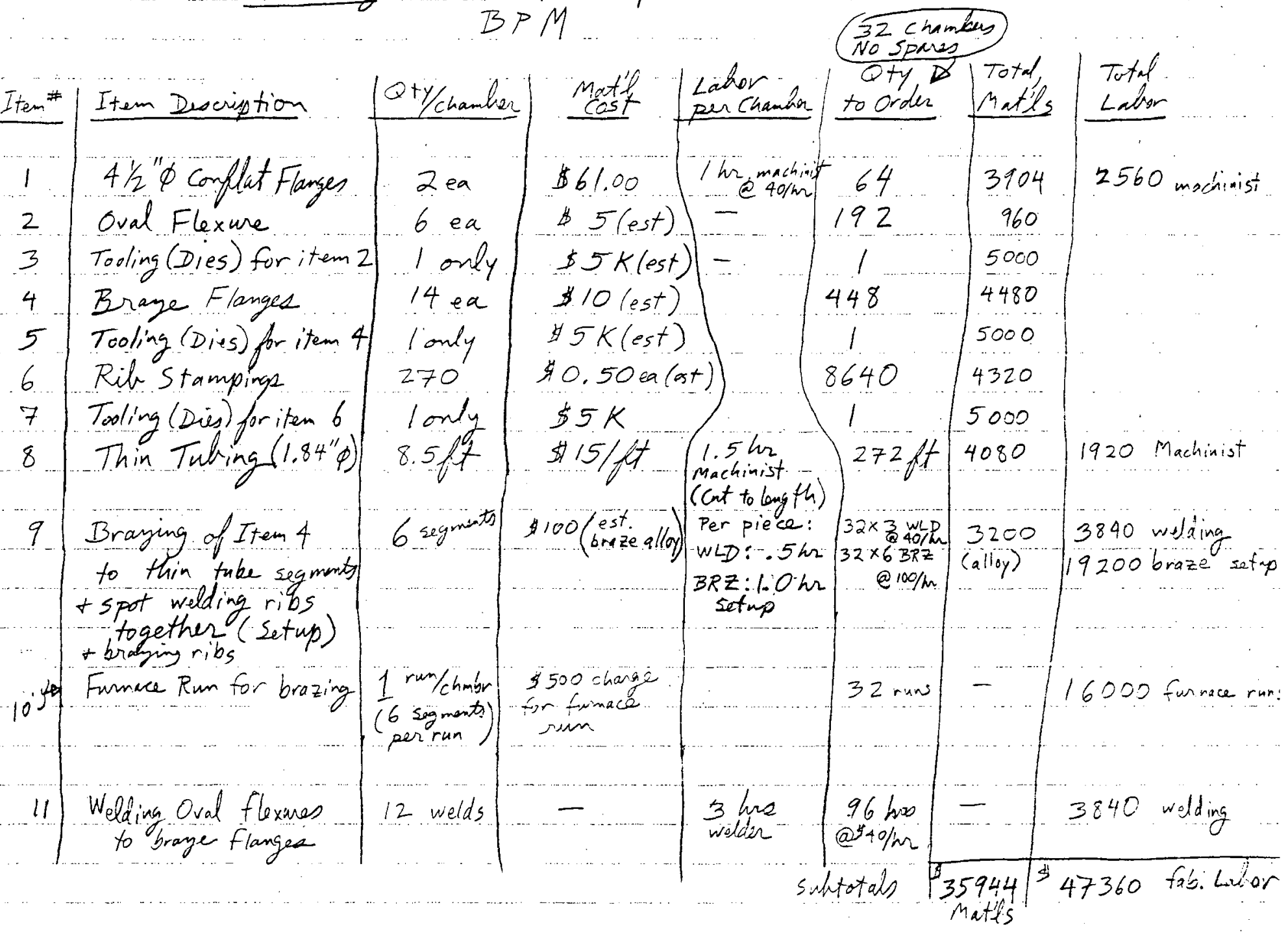

hates + Fa l Labor: \$83,304 or approx. \$83.3K

In addition: Design + Engineering (approx 10 drawings, checked gte $\simeq 4$ weeks, Plus approx 6 weeks vendor nejociations over fabrication options, tooling design + prices, braze pro cedes ate)

- roughly $\$ 20 x$

Expedititer (approx. 3 manmonthe @ $\approx \$ 5 k /$ month) $=\$ 15 k$

Quick Estimate of Prototype additional costs: $\$ 22 k$

Summery: Engin. Design \& $20 \mathrm{~K}$

Expediting, Procure $15 \%$

Fab (Mat 'ls + Labor) $83 K$

with Prototype $\frac{\frac{\$ 118 K}{22 K}}{\frac{\pi 140 K}{\$ 14}}$ 
$6 / 16 / 87$ (2)

Estimated Costs assuming Anteratom builds chambers

Anteratom Quote for 32 chambers 2 meters long:

$$
\$ 165 \mathrm{~K}
$$

Actual Cham bis are 2,4 metes long, so $d$ assume finteratom price would increase by $\left(\frac{2.4}{2.0}=120 \%\right)$ say $10 \%$ :

$$
\Rightarrow 181,5 K
$$

Stanford Engineering Design Staff work regained to adequately specify, review, negociate all details prior to and after award of contract: estimate approx. 6 weeks fl time equivalent engineering $\sigma$ design, spread over a longer calender time, or approx \& ILK.

This brings enteratom grate to approx. $\$ 193.5 \mathrm{~K}$

Of e they have to change cross section, it is gite possible their quote could increase substantially. 
$6 / 16 / 87$

Prototype, if bill t by SSRL (Oval flexure not easy to prototype are to tooling charges)

Drawings : $2 w k s \quad \$ 4 k$

Machining brose flanges

Procurement, thin tubing

Madising ribs

Bragging

Misc.

$4 K$

$\frac{1 k}{6 k}$
$2 k$
$\frac{5 K}{22 K}$

Best Guess Comparison

Interatom final quote plus stamford interface $\approx 300 \mathrm{~K}$ (assuming they can make $32 \times 60 \mathrm{~mm}$ section)

Stanford costs for equivalent items, with prototype $\approx \$ 150 \mathrm{~K}$ 


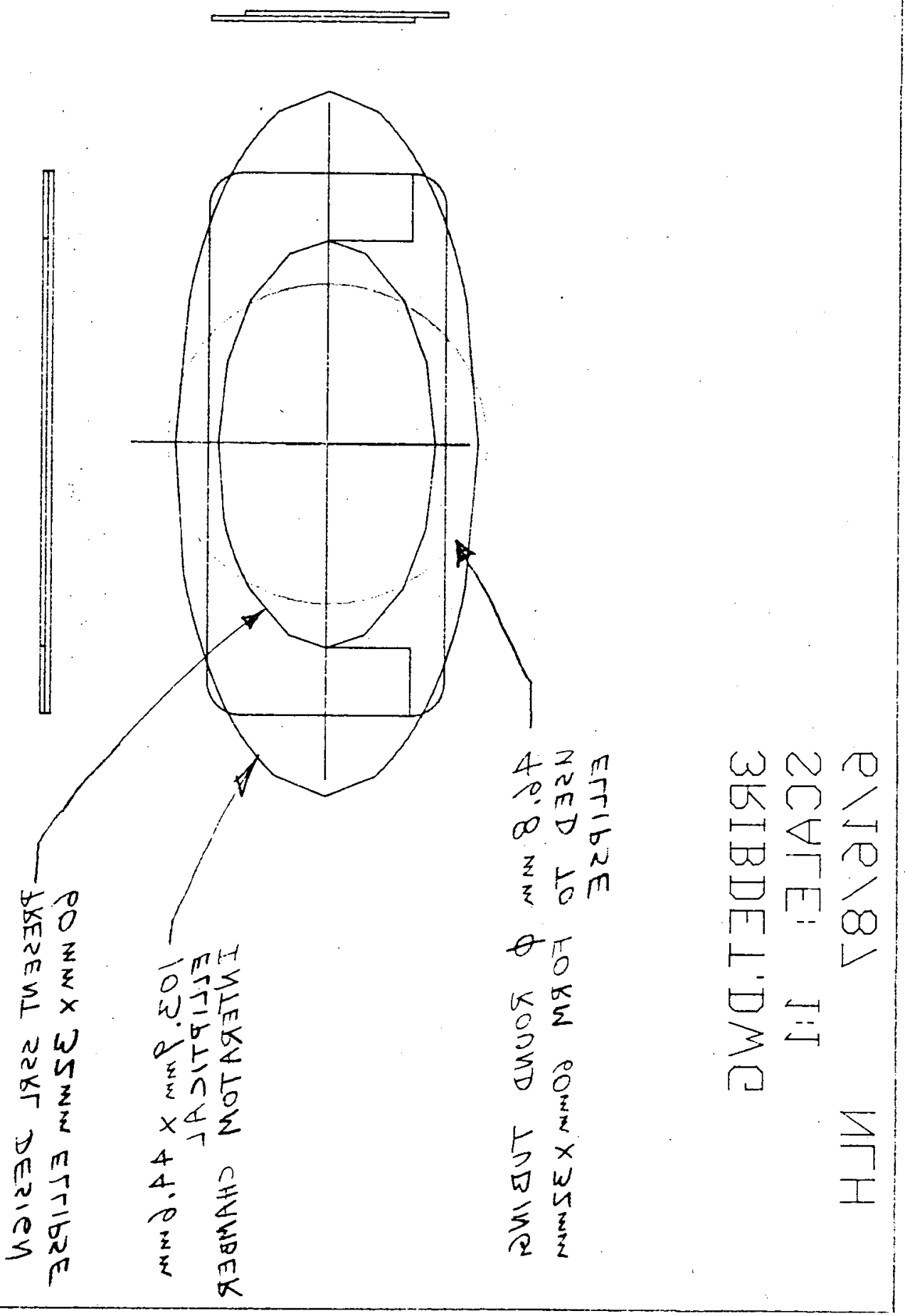




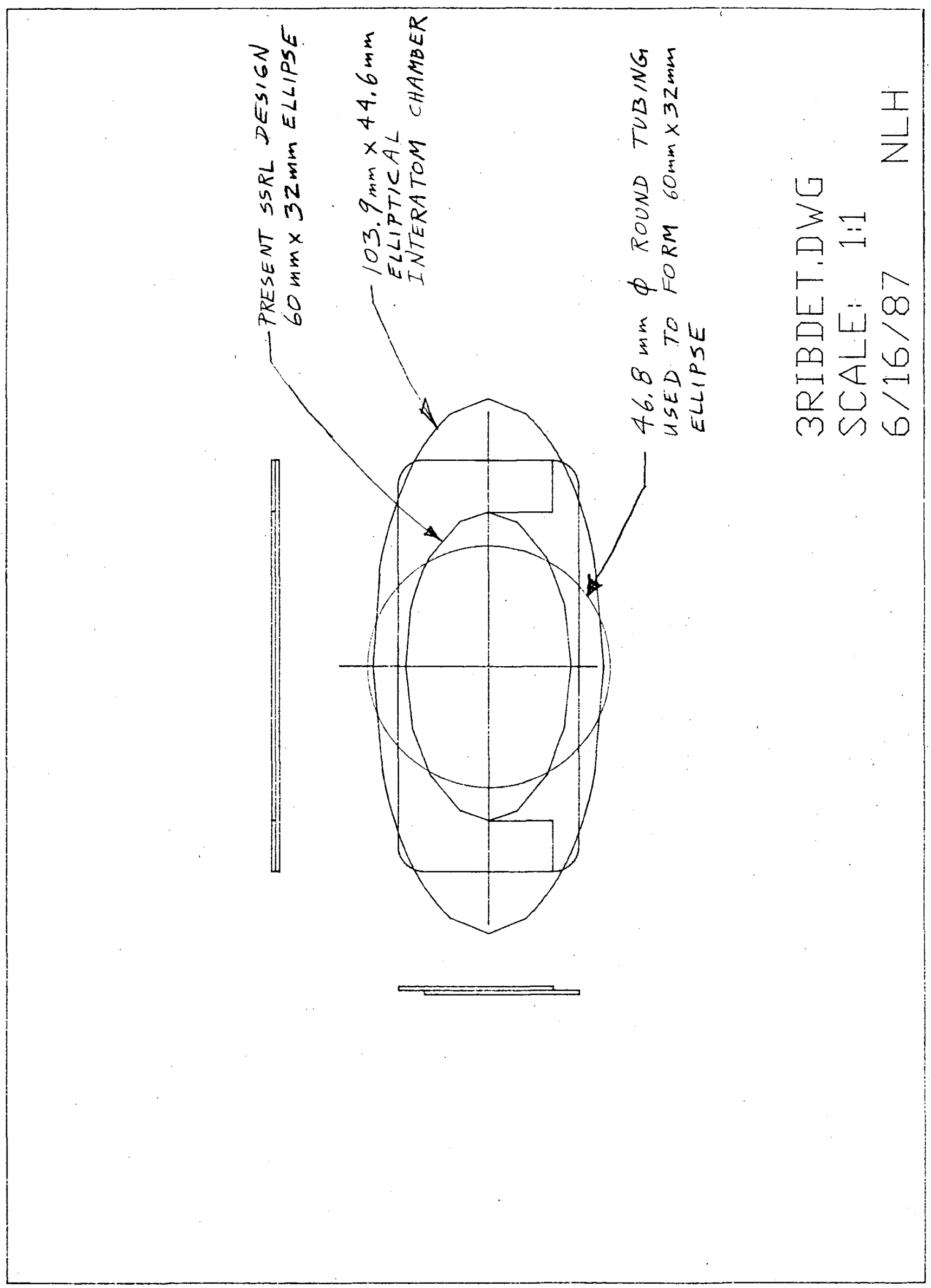


$4 / 8 / 87$

(D)

Review Vacuum Calculations for an assumed chamber Cross Sectional Shape

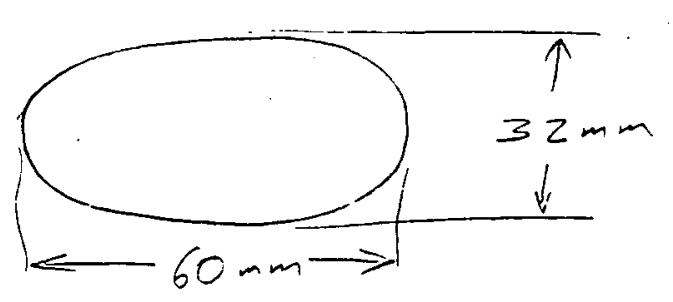

From Calculations found in my notes of $2 / 11 / 86$ ("First Cost Estimate, 3 GeV Synchrotron for new SPEAR Anjector, VACUuM SYSTEM), for regularly spaced pumps (distance between pumps $=L_{p} \equiv Z L$, each pump having pumping speed $S_{p}$ ) in a long duct, the average of the parabolicolly-varying

$$
\bar{p}=q_{p} B L\left(\frac{1}{s_{p}}+\frac{1}{3 C}\right)
$$

where $B=$ duct perimeter

$C=$ conductance of a length $L$ of this duct,

$q_{D}=$ outgassing rate (Torr-liter $/ \mathrm{sec} \mathrm{cm}^{2}$ )

For the latest version of the lattice $(10 / 9 / 86)$, $L_{P}=2.7872$ inters, $L=1.3936 \mathrm{~m}$.

For the elliptical cross section above with

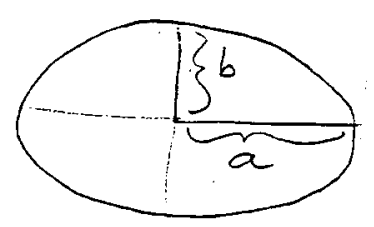

$$
\begin{aligned}
& a=30 \mathrm{~mm} \\
& b=16 \mathrm{~mm}
\end{aligned}
$$

perimeter $B=0.14697 \mathrm{~m}=14.697 \mathrm{~cm}$ area, $A=.00147313 \mathrm{~m}^{2}=14.73 \mathrm{~cm}^{2}$

From Roth, P. 82

$$
C=61.72 \frac{A^{2}\left(A \text { in } \mathrm{cm}^{2}\right)}{B(\text { in cm }) L(\text { in cm })} K
$$

where the factor $K$ is assumed to be given by Table 3.5 .9 .82 in Roth which is for a rectangle with ratio ba. Here $\frac{b}{a}=\frac{16}{30}=.533$ and $K \simeq 1.146$

$$
\text { Then } \begin{aligned}
C=\frac{61.72(14.73)^{2}}{(14.697) L}(1.146) & =\frac{1044}{L(\mathrm{~cm})} \quad I_{\mathrm{sec}} \\
& \equiv \frac{C_{0}}{L}
\end{aligned}
$$


usaf $4 / 2 / 87$

(2)

Sulatitating (3) into (1) $\Rightarrow$

$$
\bar{P}=g_{D} B L\left(\frac{1}{s_{p}}+\frac{L(c-i)}{3 C_{0}}\right)
$$

This yields pressure in Torr provided $L$ and Bare expresses? in $\mathrm{cm}, S_{p}$ in litas/sec, $C_{0}$ is the dimensionless numerator $C=1044)$ of (3), and $g_{D}$ is in (Torr-liters) $\left(\mathrm{sec} \mathrm{cm}^{2}\right.$ ). For the present design we are considering $L=139,36 \mathrm{~cm}$,
$B=14.697 \mathrm{~cm}$, so

$$
\bar{p} \text { (torr) }=g_{s}\left(\frac{T-1}{s-\mathrm{cm}^{2}}\right)(2048)\left(\frac{1}{S_{p}}+\frac{1}{2 z .47}\right)
$$

For unbaked, degroued stainless steed (see Roth Fig 3.44) $q_{0} \approx 2 \times 10^{-9}+-1 / \mathrm{sec} \mathrm{cm}^{2}$, (which could be improved by electropolisting) (or baking),

$$
\bar{P}=4.10 \times 10^{-6}\left(\frac{1}{s_{p}}+\frac{1}{22.47}\right) \text { ls ec }
$$

For various commonly-sized ion pumps, the resulting pressures would be:

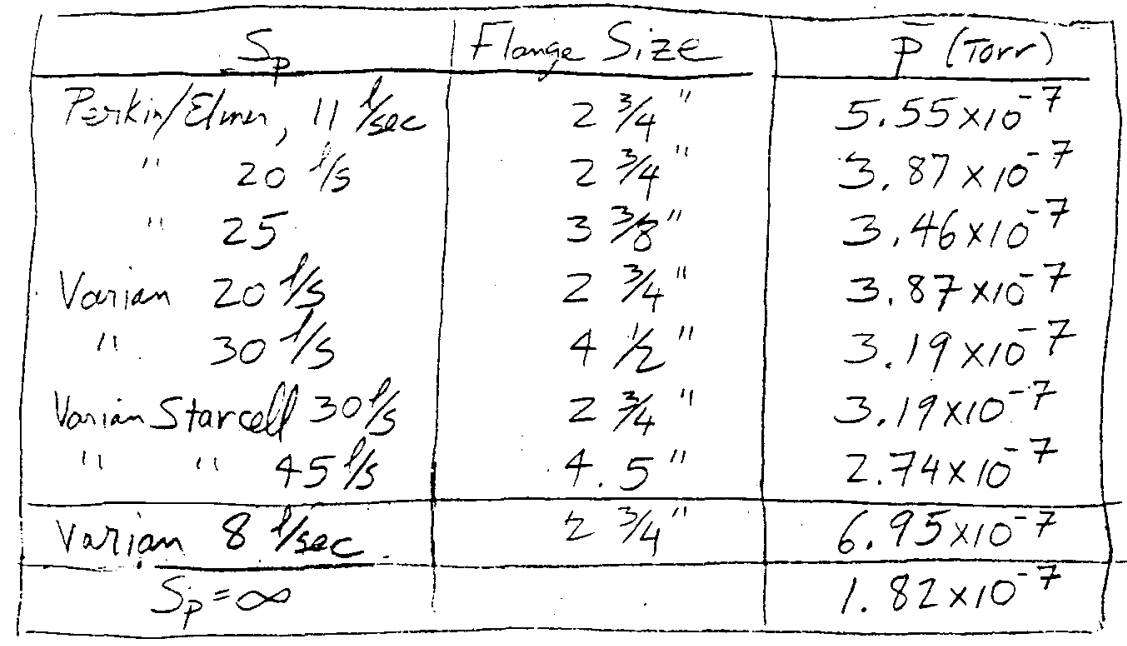

- Minimum achievable for assumed outgaesing rate

The krafts of going to $S_{p}>20$ lase font lick that groat. I would think we could live with $2 \frac{3}{4}$ " purport port flanges. This would still leave possible choices of 8, 11 , 20 , or $30 \mathrm{l} / \mathrm{sec}$ pumps. 
$\theta$

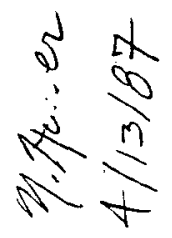

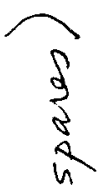

굴

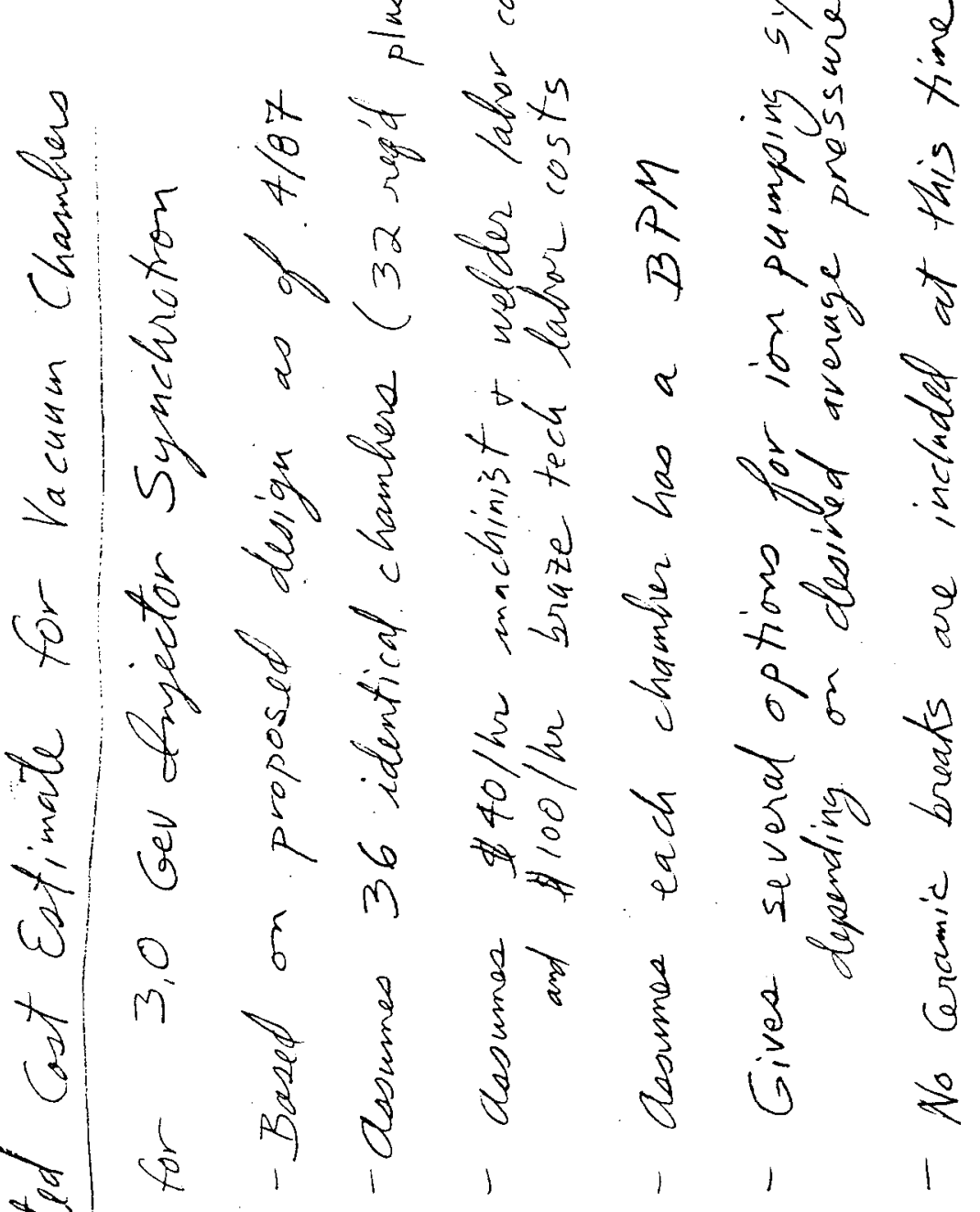

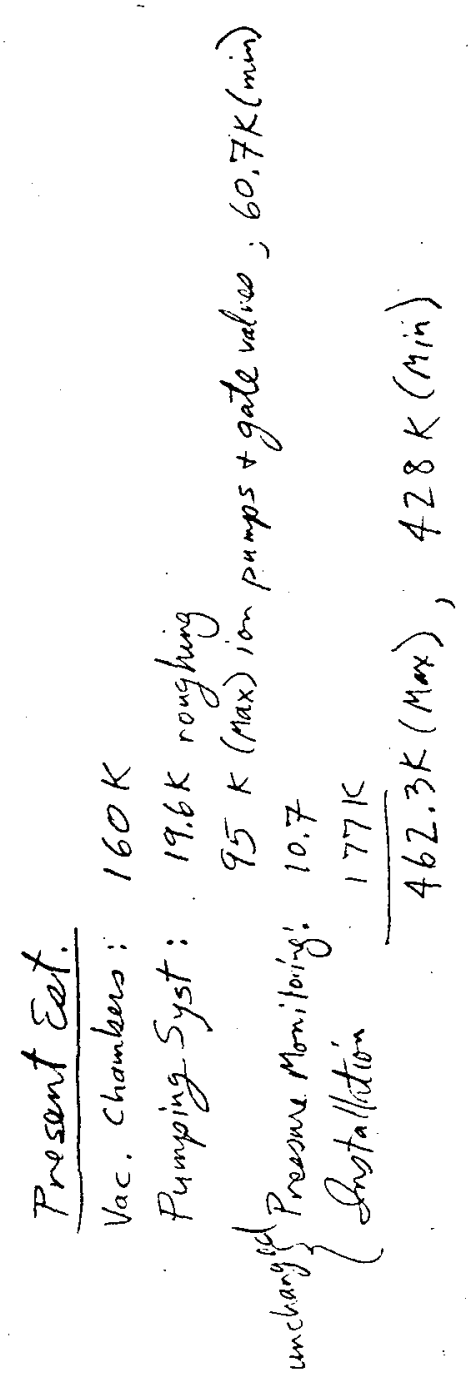

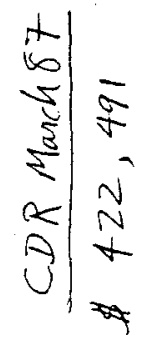


(

in

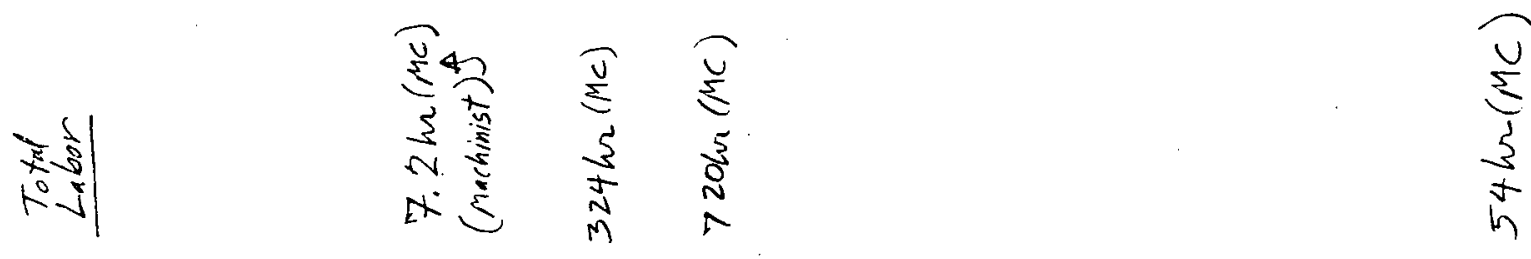

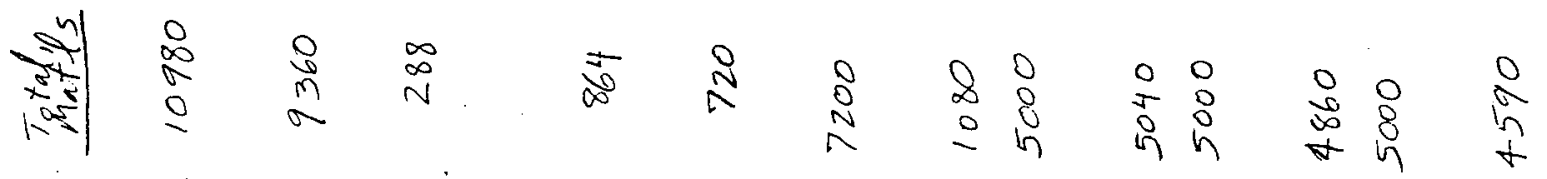

ई

究

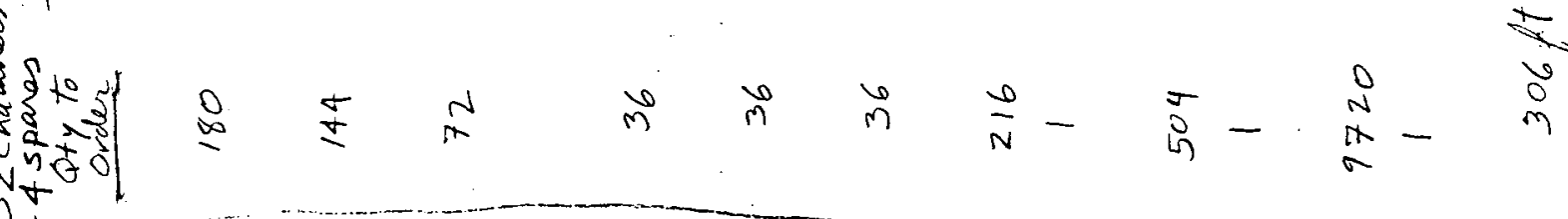

$\mathrm{M}^{+}$

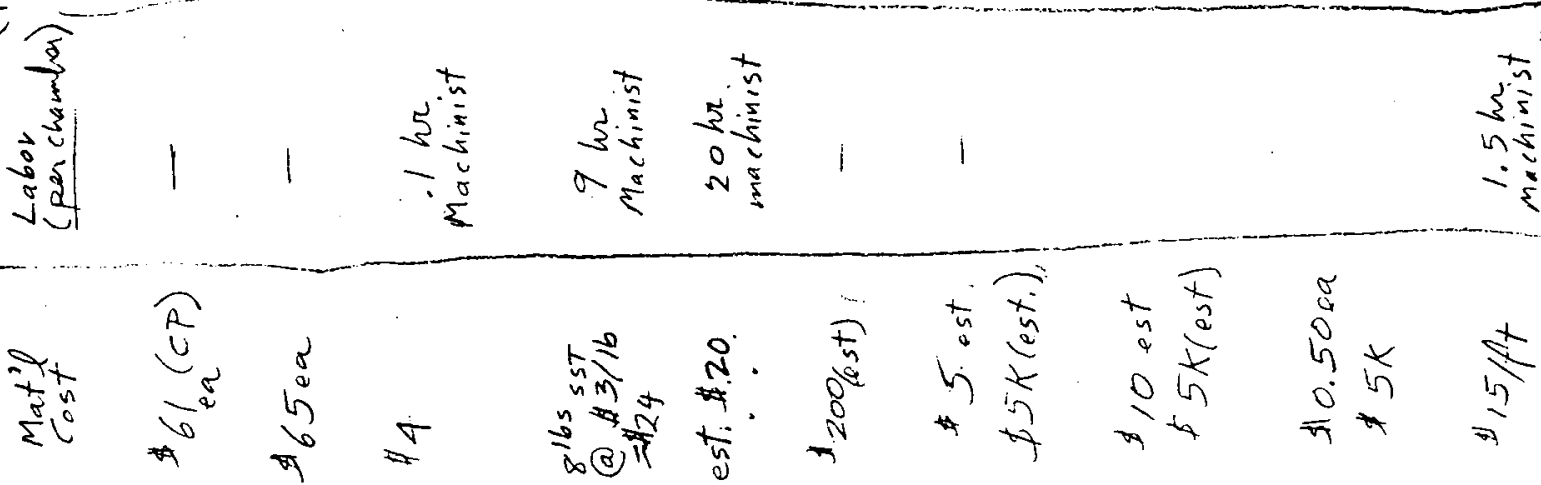

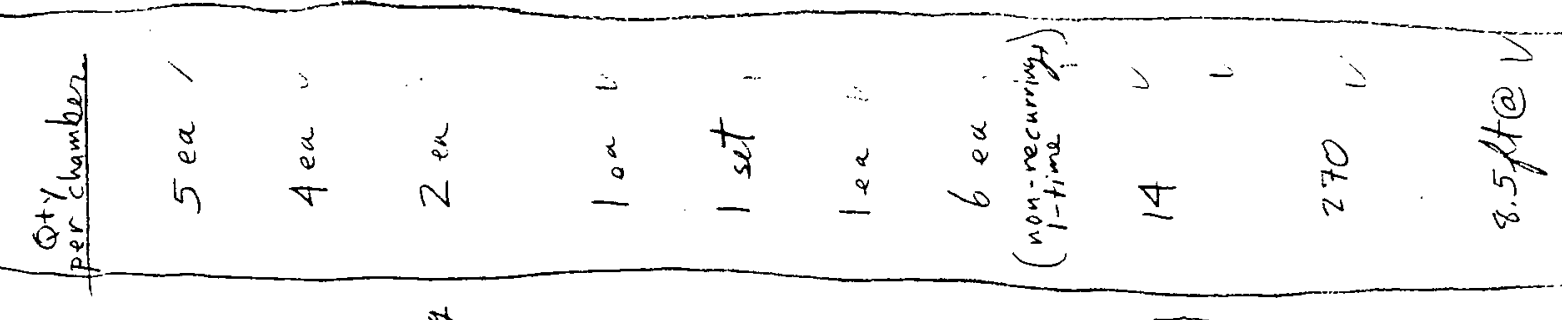

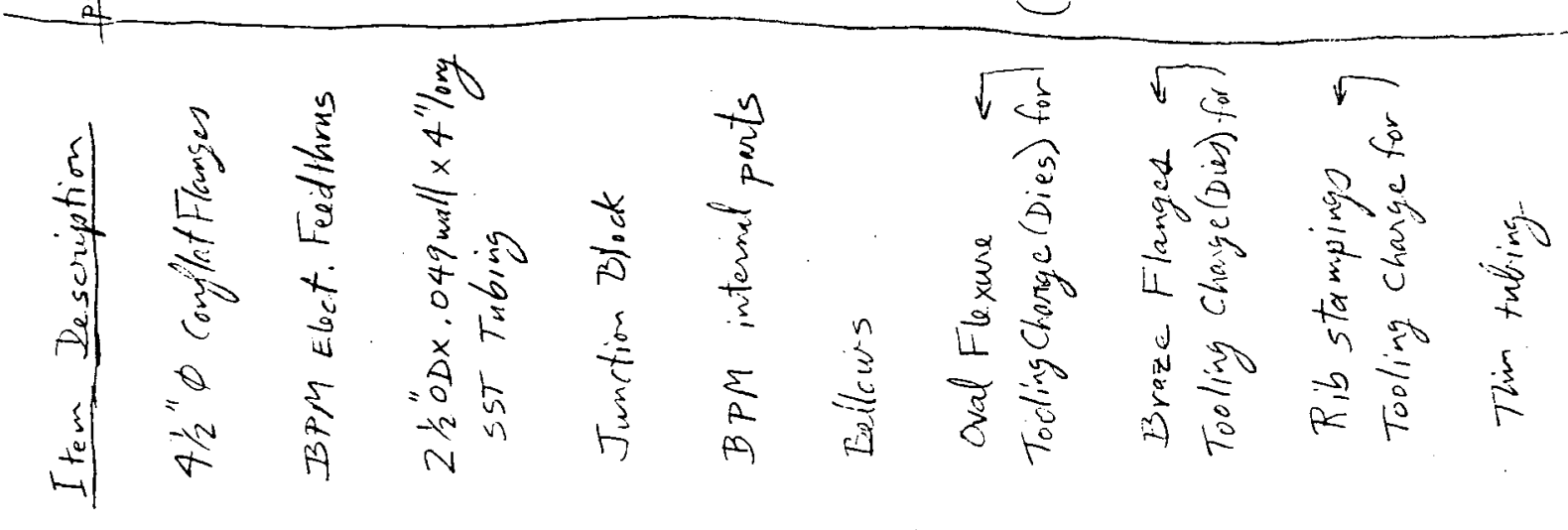




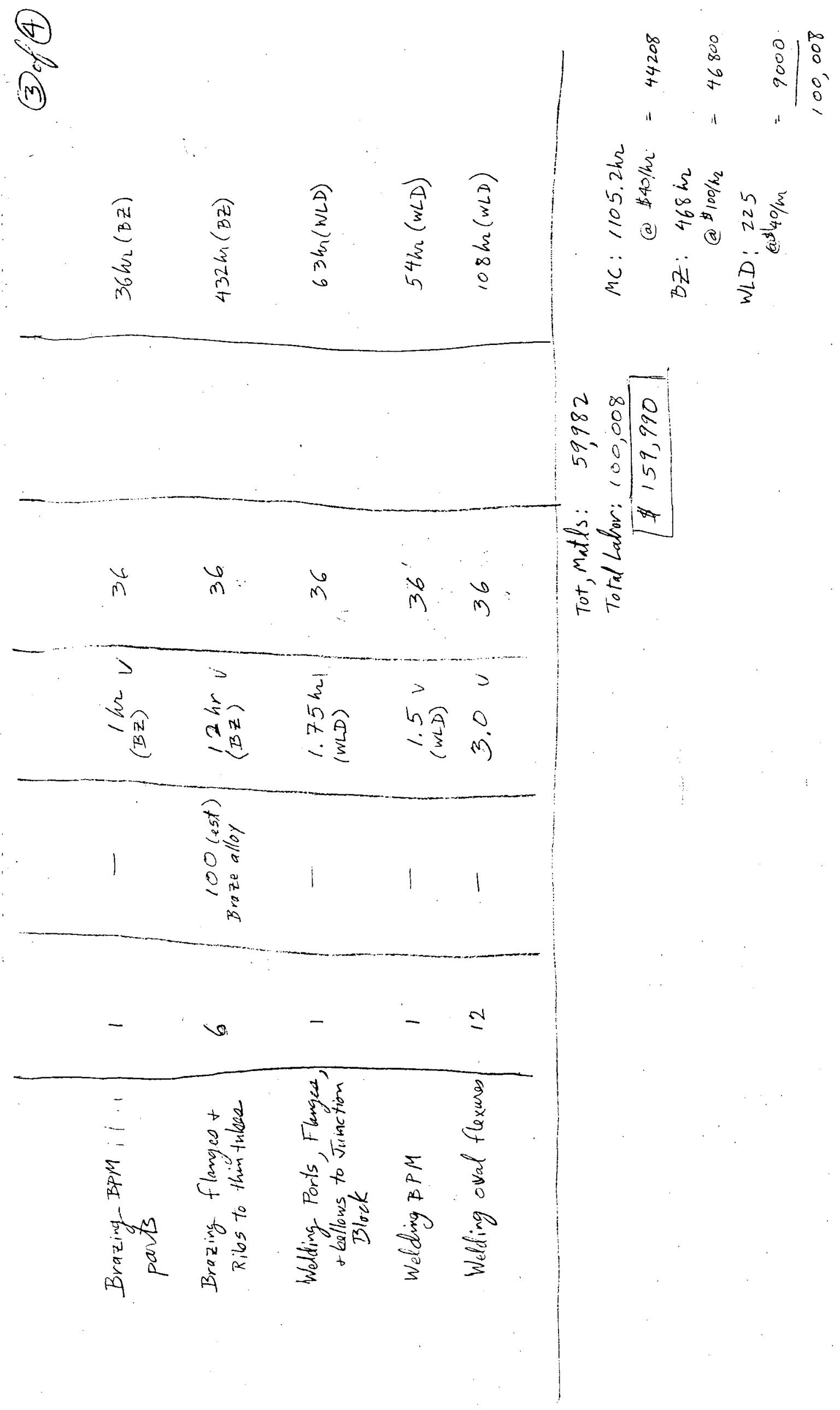


$\theta$

$\theta$
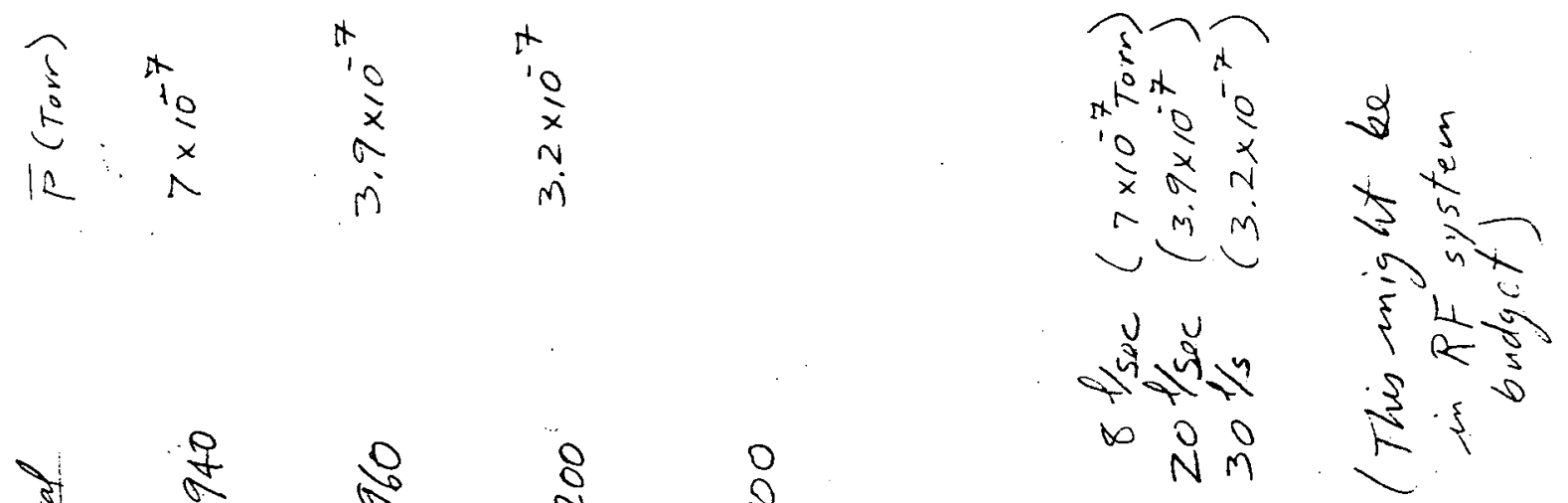

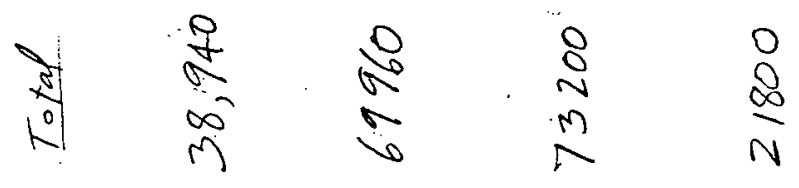

है:

min m

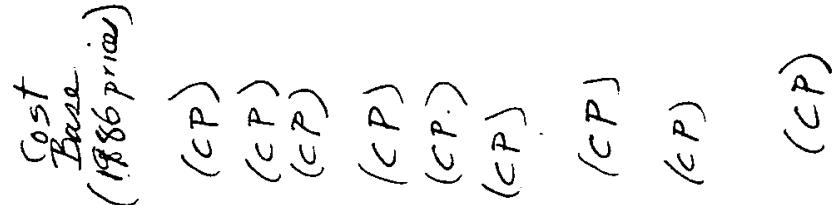

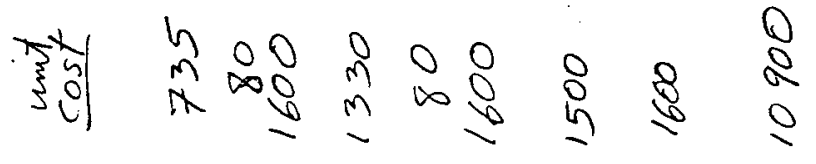
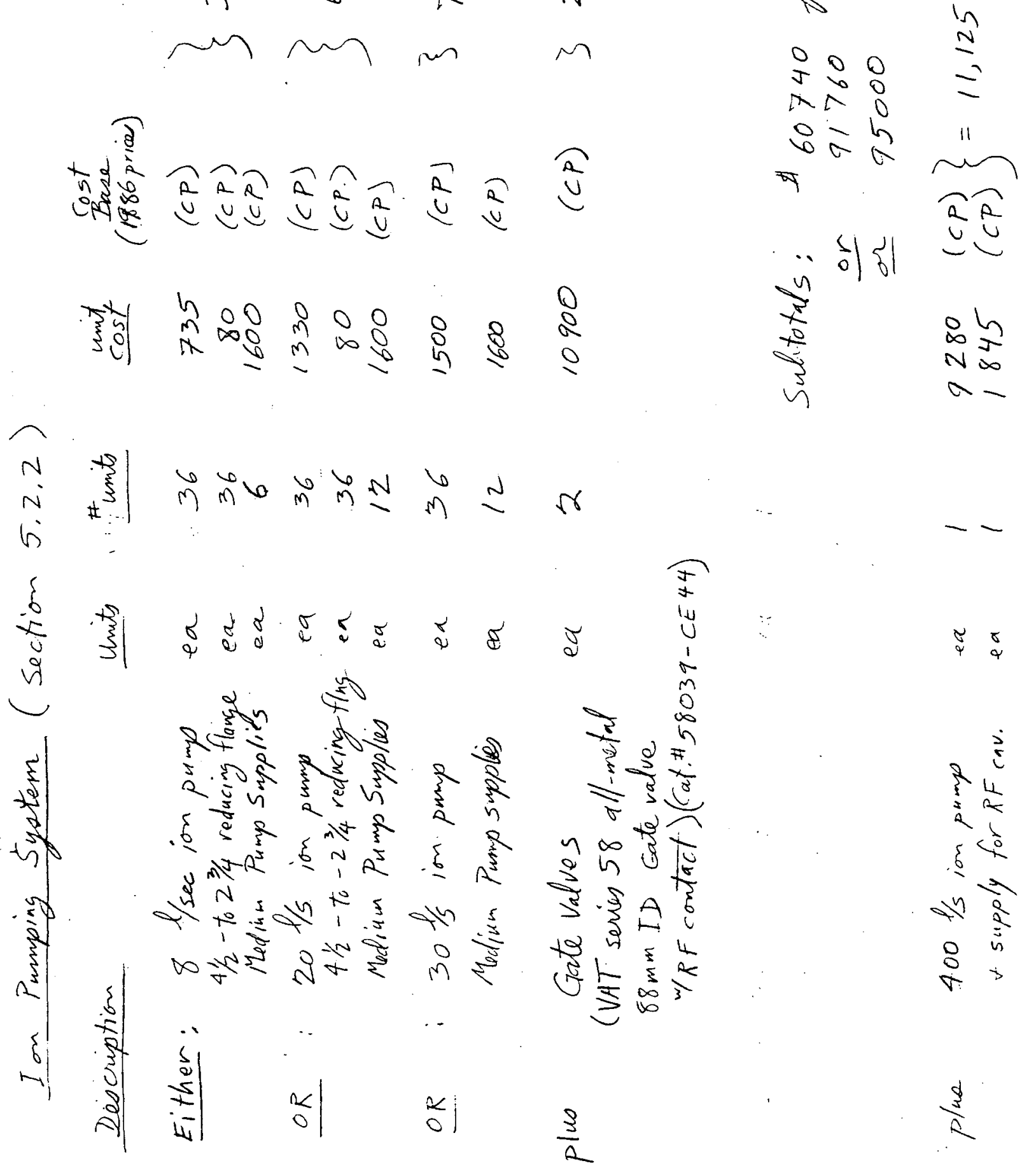
First Cost Estimate

$3 \mathrm{GeV}$ Synchrotron for new SPEAR injector Vacuum System

Prepared by N. Howe, SSRL

$$
2 / 12 / 86
$$




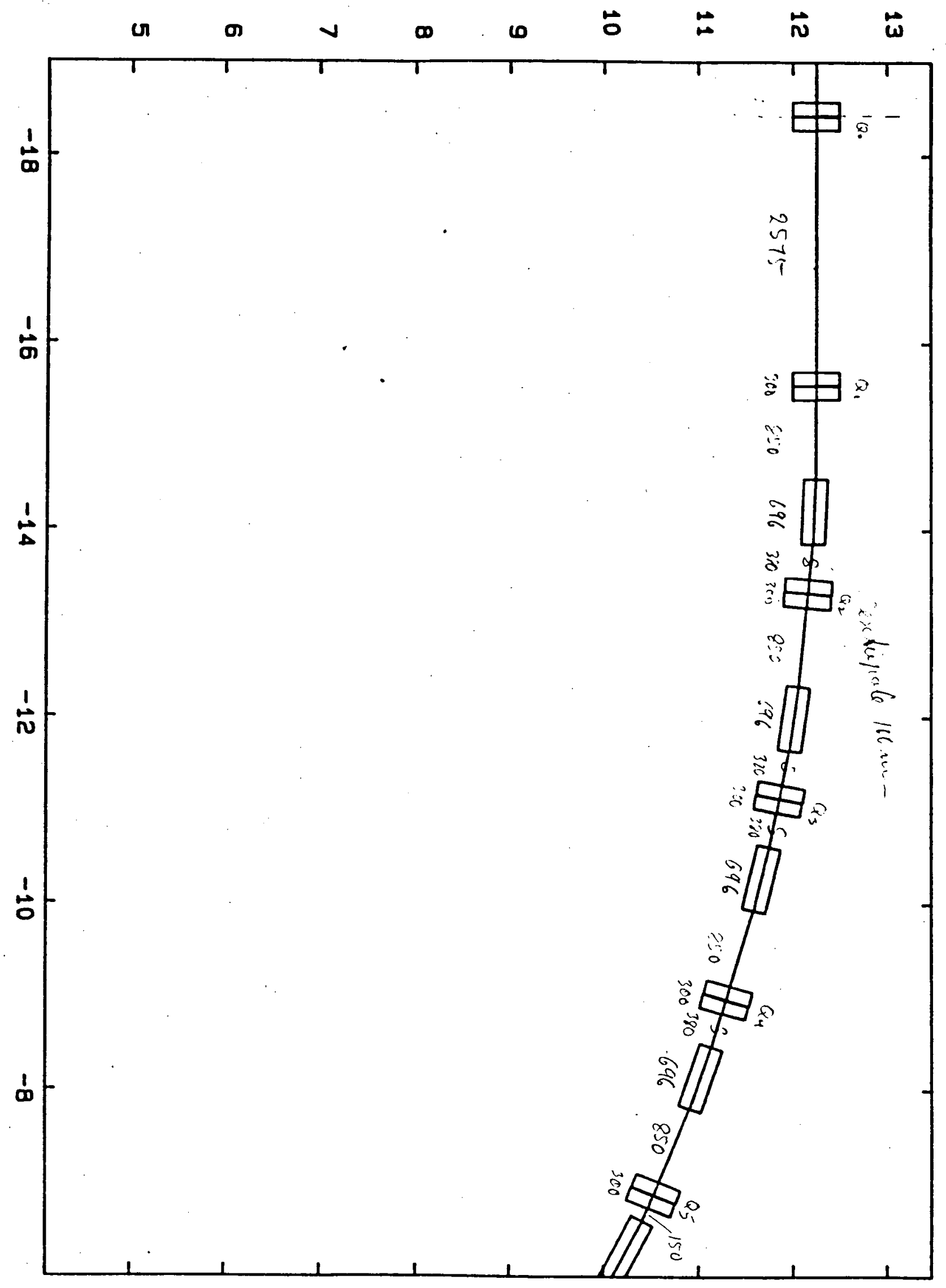




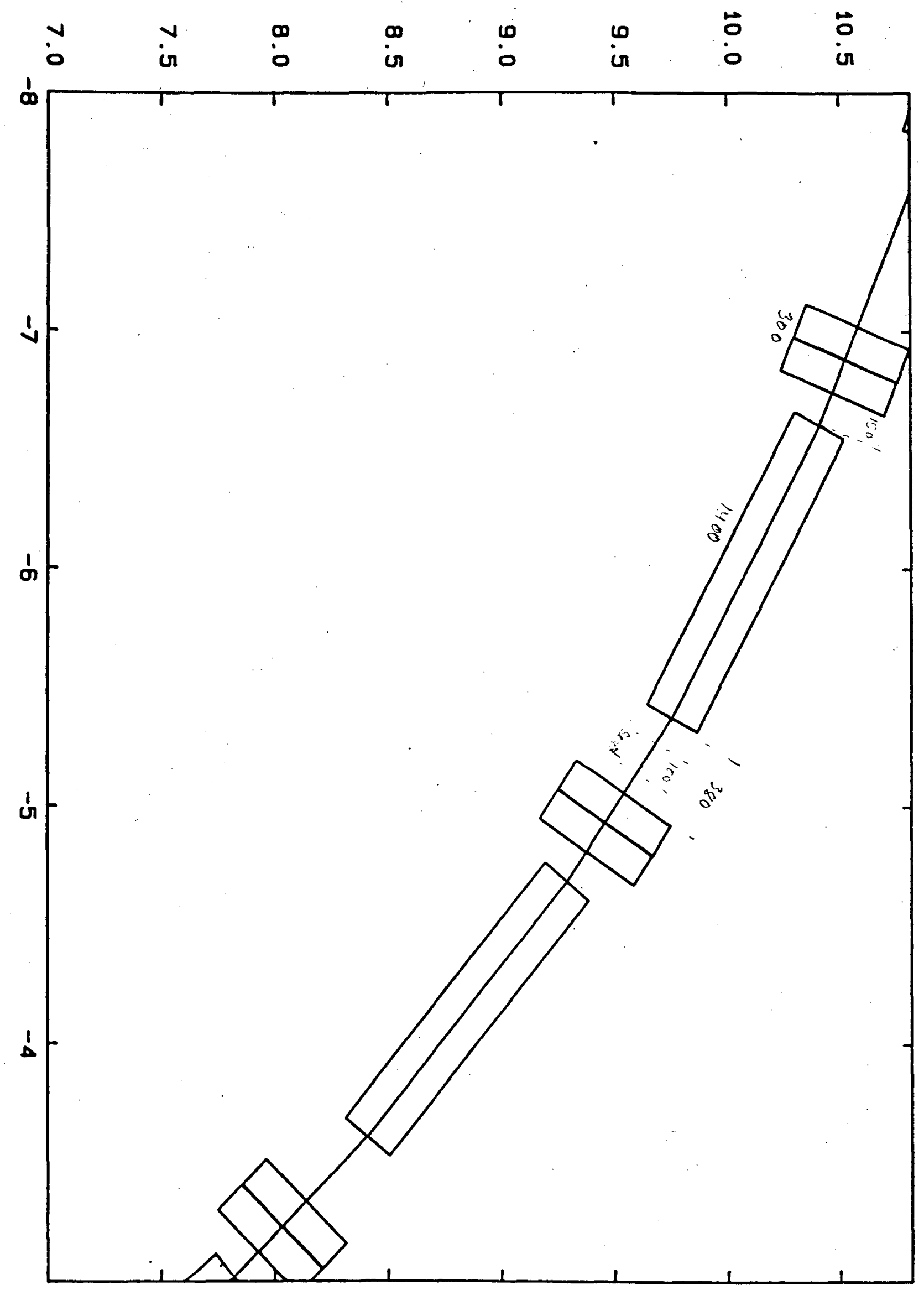




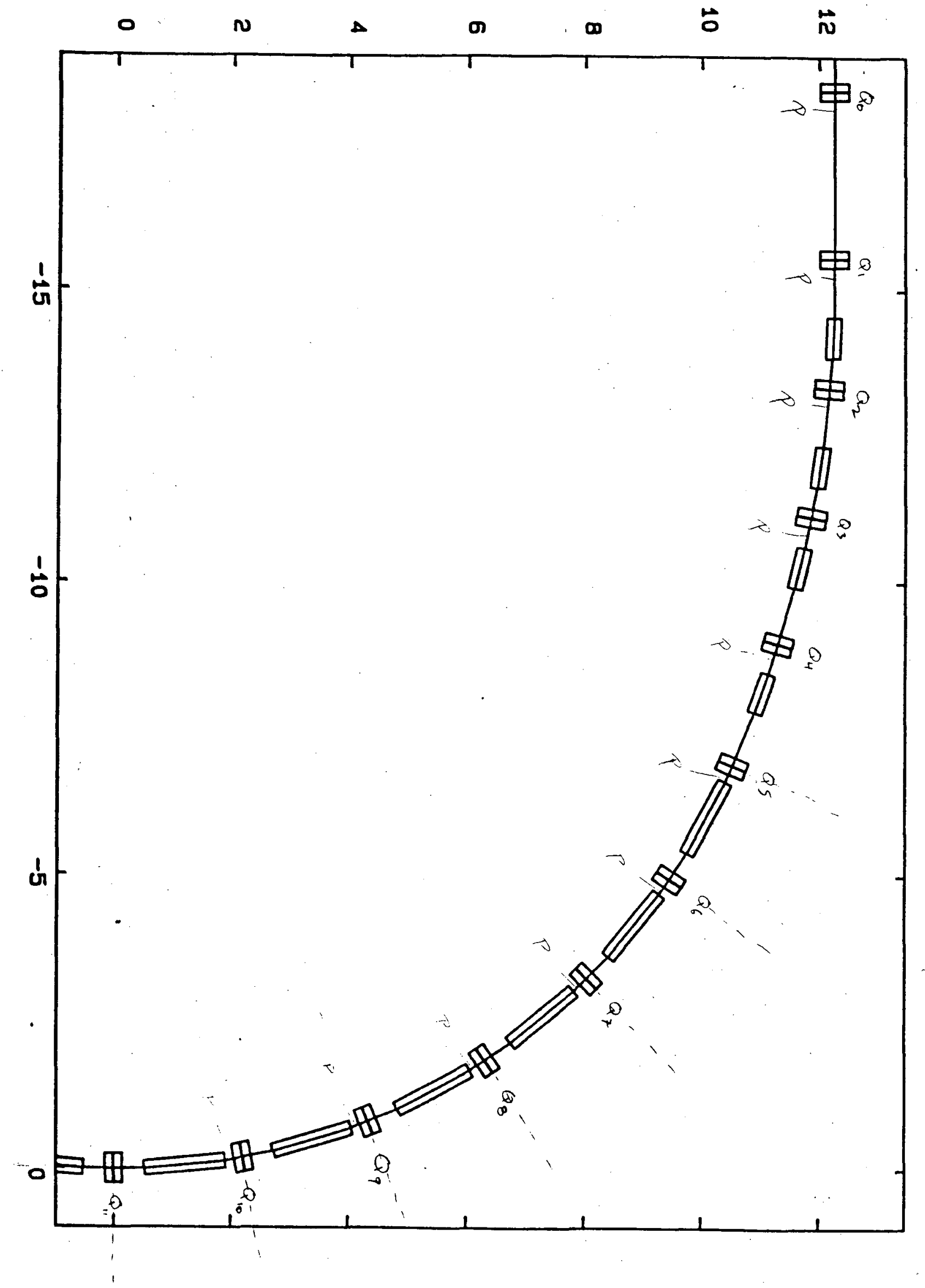




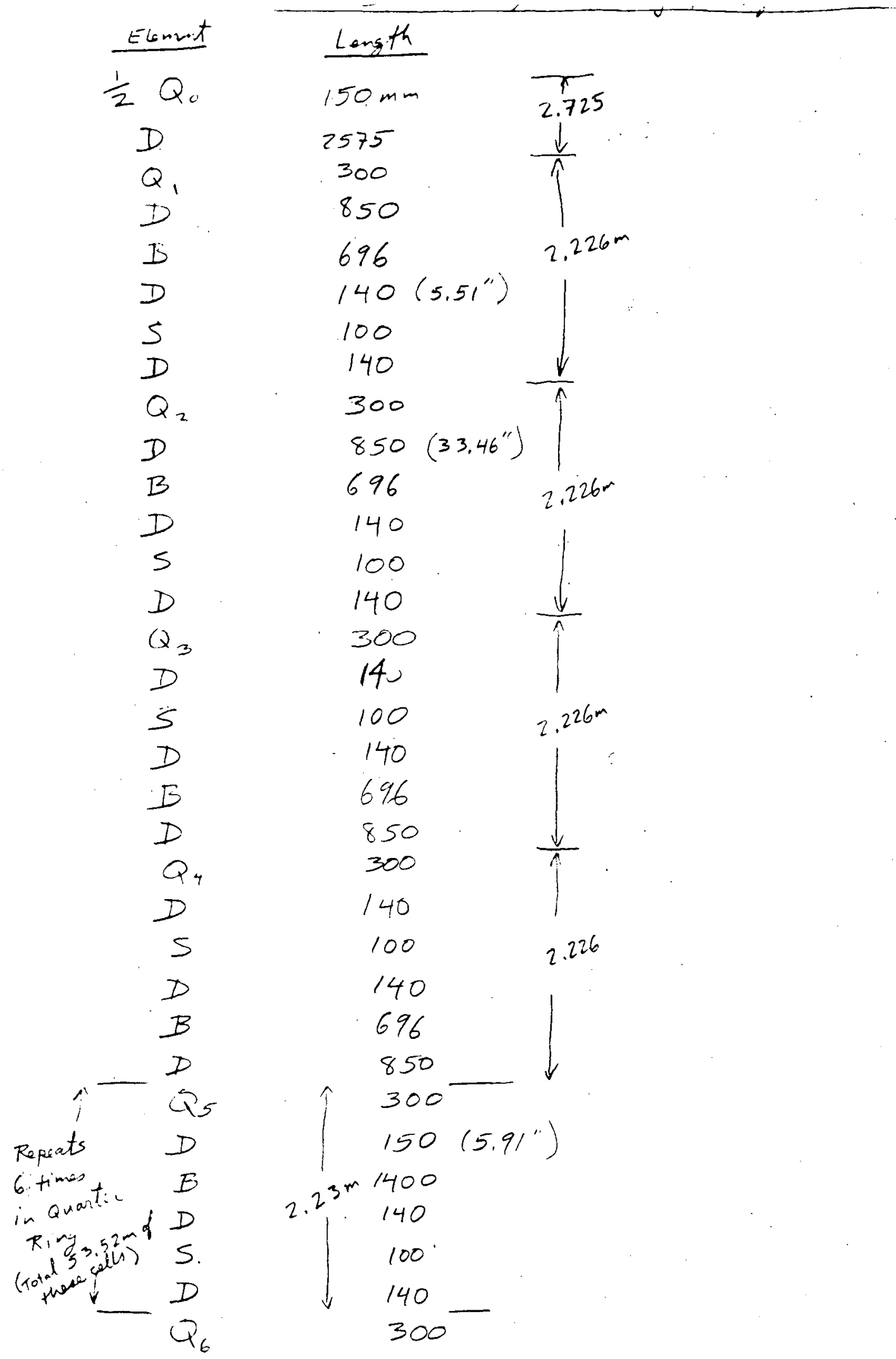


Consider a periedically-pumped duct:

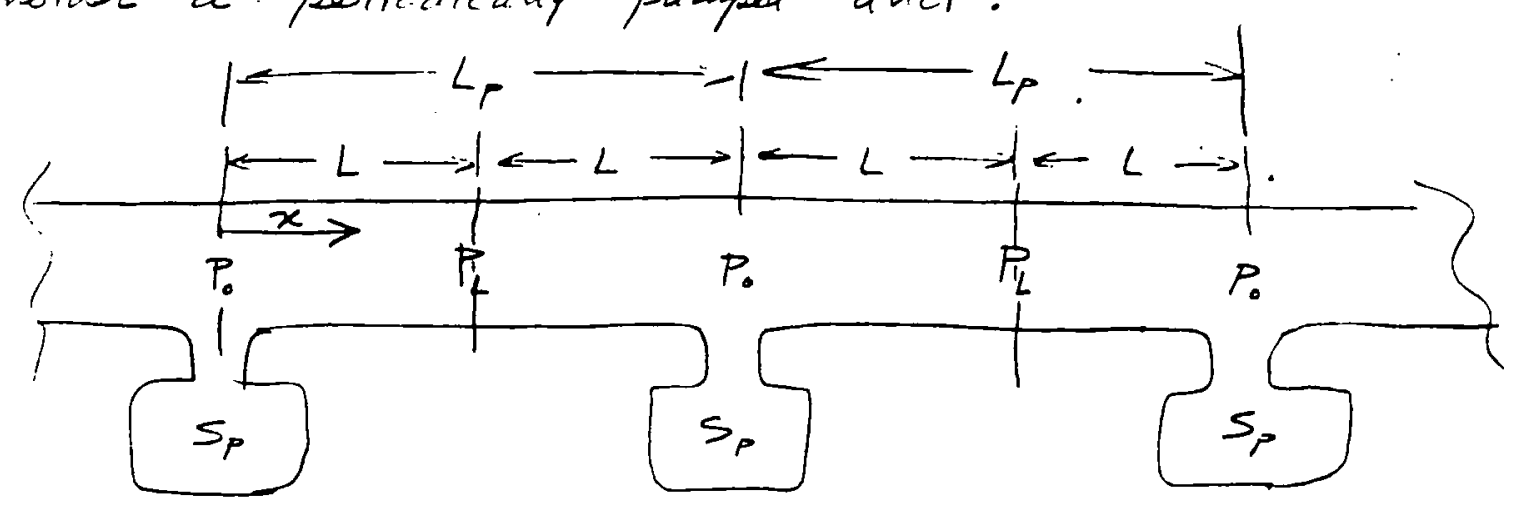

From Roth, Vacuum Technology (North-Holland, 1976) p.129,

$$
\begin{aligned}
& P(x)=q_{D} B\left[L / s_{p}+\frac{x}{C}-\frac{x^{2}}{2 C L}\right]=P_{0}+q_{D} B\left[\frac{x}{C}-\frac{x^{2}}{2 L C}\right] \\
& P_{0}=q_{D} B L / s_{p} \\
& P_{L}=q_{D} B L\left[\frac{1}{s_{p}}+\frac{1}{2 C}\right] \\
& P_{L}-P_{0}=\frac{q_{D} B L}{2 C}
\end{aligned}
$$

in which $q_{D}=$ outgassing rate (Torr-liter/sec cm²)

$C=$ Conductance of a pipe is length $L$

$S_{p}=$ pump speed

$B=$ duct perimeter

The cross-section is approximately elliptical, $20 \mathrm{~mm} \times 70 \mathrm{~m}$ as shown:

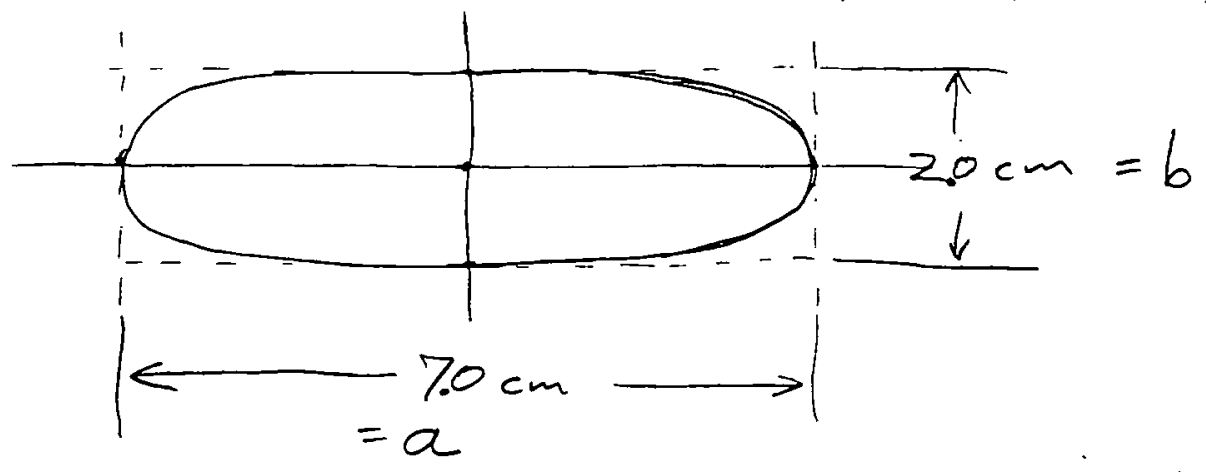

I take as a first approximation the conductance cit tiv is. tube to be about that of a rectangular cross section oc dimensions $a \varepsilon^{\prime} b$, for which (Roth $p, S Z$ ) for $\frac{b}{a}=0.25 \xi$

$$
(K \simeq 1.23)^{\prime} C_{\text {air }}=38.0 \frac{a^{2} b^{2}}{(a+b) L} \text { liter } / \mathrm{sec}
$$

where $a, b, \xi_{1}^{1} L$ are in $\mathrm{cm}$. 
For $a=2 \mathrm{~cm}, b^{\prime}=7 \mathrm{~cm}$, this yields

$$
C_{\text {ain }} \simeq \frac{828}{L(\mathrm{~cm})} \text { lites/sec }
$$

(Thus a 1 meter length has conduct rance of $8.28 \mathrm{l} / \mathrm{sac}$ ).

The average pressure is

$$
\begin{aligned}
\bar{P}=\frac{1}{L} \int_{0}^{L} P(x) d x & =\frac{1}{L}\left\{P_{0} L+\frac{g_{D} B}{C}\left[\frac{L^{2}}{2}-\frac{L^{2}}{2(3) L}\right]\right\} \\
& =P_{0}+\frac{g_{D} B L}{3 C} \\
& =\frac{q_{D} B L}{S_{P}}+\frac{g_{D} B L}{3 C}=g_{D} B L\left(\frac{1}{S_{p}}+\frac{1}{3 C}\right)
\end{aligned}
$$

On the are portions of the ring, the cells repent in units of 2.23 meters long. Suppose we place cue pump every cell, so $L_{p}=2 L=2.23 \mathrm{~m}$ and $L=1.115$.

Then $\bar{P}=g_{D} 2(a+b) L\left(\frac{1}{s_{P}}+\frac{1}{3\left[\frac{82 g}{L}\right]}\right)$

$$
\begin{aligned}
& =q_{D}(2)(9 \mathrm{~cm})(111.5 \mathrm{~cm})\left[\frac{1}{s_{p}}+\frac{111.5}{3(828)}\right] \\
& =2007\left(\frac{1}{s_{p}}+\frac{1}{22.28}\right) q_{D} .
\end{aligned}
$$

A minimum requirement on $\bar{P}$ is that $\bar{P} \leqslant 10^{-6}$ Torn, ai thin: this laves little conservatism. Assuming $\bar{P} \simeq 10^{-6}$ Torr ant $q_{D} \simeq 2 \times 10^{-9}$ Tour-liter/sec $\mathrm{cm}^{2}$ ( See Roth. P. 142 - this is -2

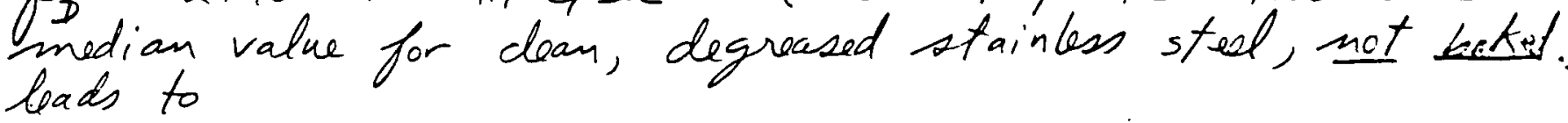

$$
\begin{aligned}
S_{P} & \simeq \frac{1}{\bar{p} / 2007 q_{D}-\frac{1}{22.28}} \\
& \simeq 4.9 \text { liteysec. }
\end{aligned}
$$

Notice that because of the conductance -limited nature \& this cross-section, the minimum average pressure which could ever be reached using one pump per 2.23 .neuter of with $S_{P}=\infty$ and $g_{D} \approx 2 \times 10^{-9} \mathrm{~T}=l / \mathrm{sec} \mathrm{cm}^{2}$ is $\bar{P}_{\min } \simeq 1.80 \times 10^{-7} \mathrm{~T}$ 
'." OC.

(4)

We can summarize the results thus far in the following table, where it is assumed that $q_{D}=2 \times 10^{-9}$ Torr litu/sec cm $\mathrm{cm}^{2}$ and that there is one pump per cell (of hugh $2.23 \mathrm{~m}$ ):

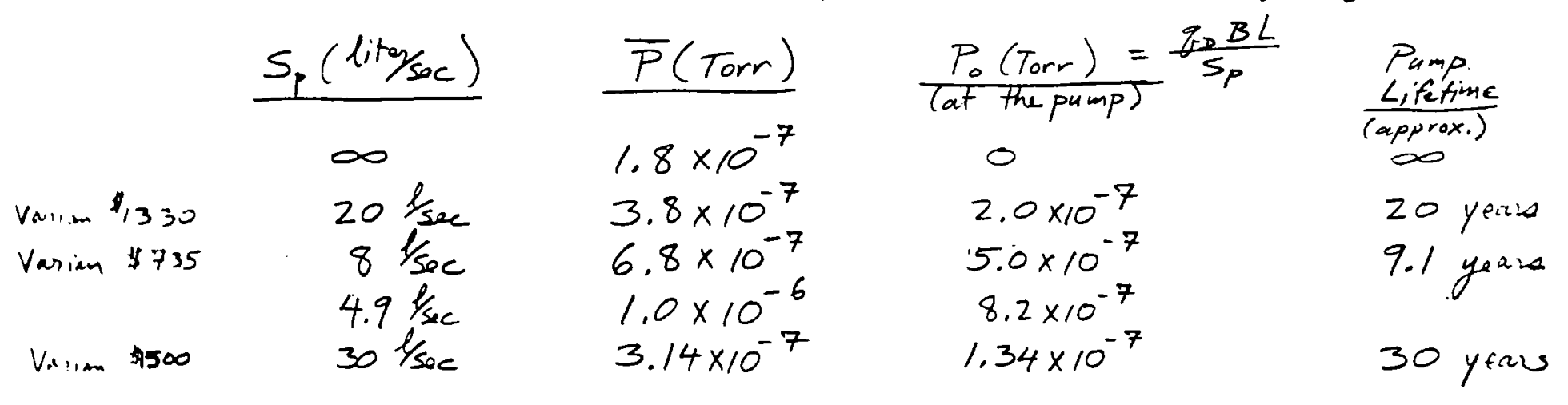

2 we put one pump in every alternate arc cuff, $L=2.23 \mathrm{~m}$ in the previous results and the minimum achievable average pressure would be (for infinitely -fast pumps)

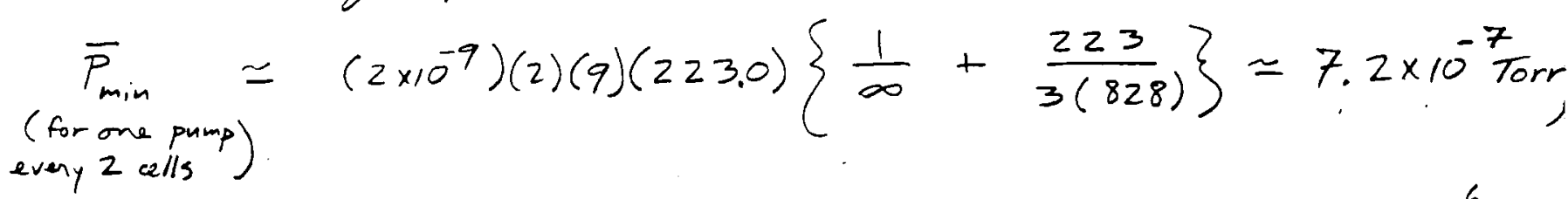

while using, say, $20 \mathrm{l} / \mathrm{sec}$ pumps would give $\bar{P} \simeq 1.12 \times 10^{-6}$ Torr. Thus the omitting of every other pump would probably lead to unsatisfactorily high pressies.

What clout in the remainder of the ring (ie,, in the "flatter" regions:

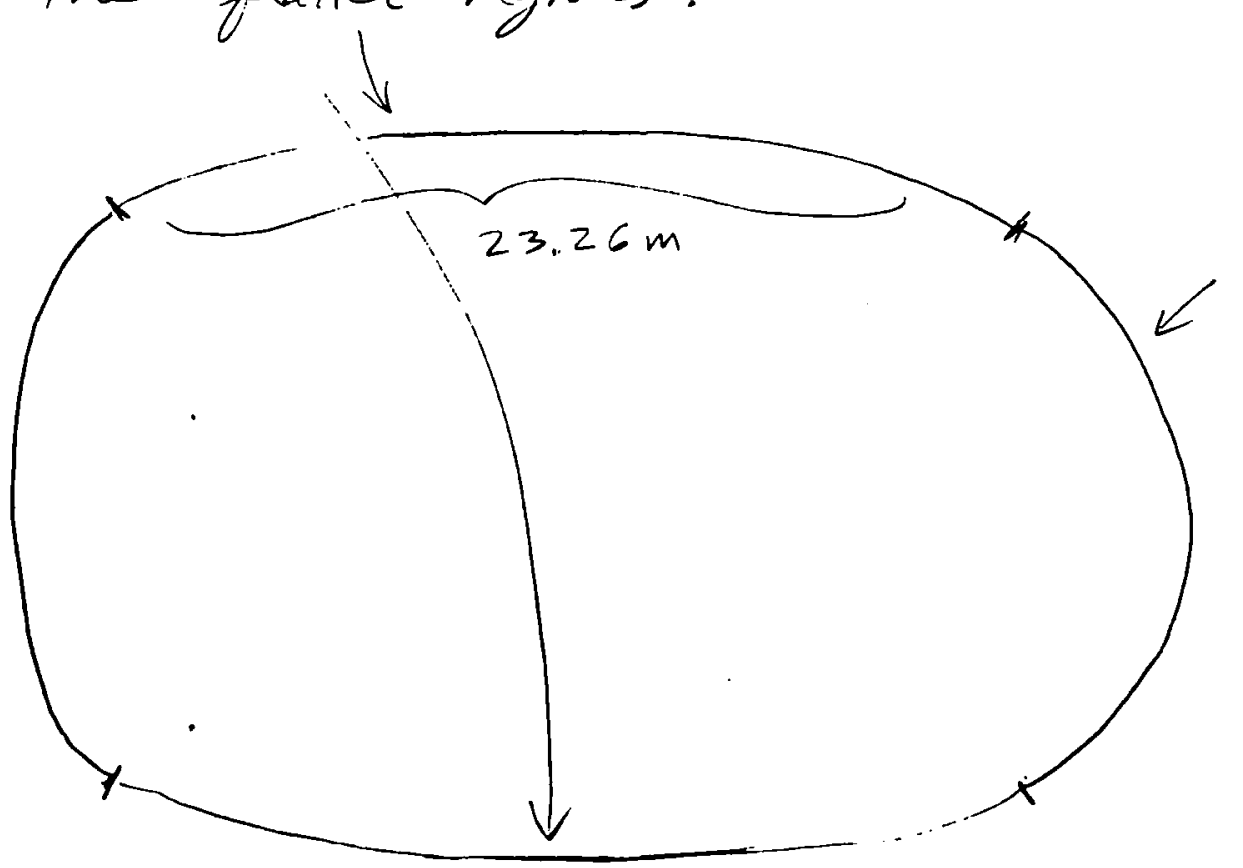

These 2 end regions comprise $\simeq 53.5$ meters of circumfuse 
$\cdots$ (5)

On examining the lattice dimensions on pg 1 above, the cat es of $2.226 \mathrm{~m}$ length are almost the same length ' $2.230 \mathrm{~m}$ ) as those previously considered. While there appear to be move open areas to mount pumps in the "flat" regions, if the vacuum chamber cross section remains the same $20 \times 70 \mathrm{~mm}$. area, the conductance limitation will still exist and the - pumping requirements will remain as found above. As a first-ent design therefore we propose a system of nearly equally-spaced pumps at intervals ff about 2, 23 meters. The number of pumps would be approximately $100 \mathrm{~m} / 2.23 \mathrm{~m} \simeq 45$ pumps. One couth use $20 \mathrm{lsec}$ pumps giving $\bar{P} \approx 3.8 \times 10^{-7}$ Tor ( $\$ 60 \mathrm{~K}$ for pumps or $8 \mathrm{l} / \mathrm{sec}$ pumps giving $\bar{P} \simeq 6.8 \times 10^{-7}$ Torr (\$33K for pump: or $30 \mathrm{lsec}$ pumps giving $\bar{P} \simeq 3.1 \times 10^{-7}$ Torr $(\$ 67.5 \mathrm{~K}$ for purr,

Synchrofirn Radiation Heating of the wall of the vacuum chamber can be shown to be quite negligible, so no cooling is anticipated for the vacuum system.

Items to cost:

I. Pumps (see above)

- II. Matts + Labor to fabricate chambers

- III. Sector Valves (to isolate ring into 2 or 4 sections)

- II. Beam Position Monitors (included in)

- F. Roughout System

II. Pump Power Supplies

III. Misc. Valves + Vacuum Hardware

$\checkmark$ IIII. Pressure Monitoring Devices 
Option A

(6)

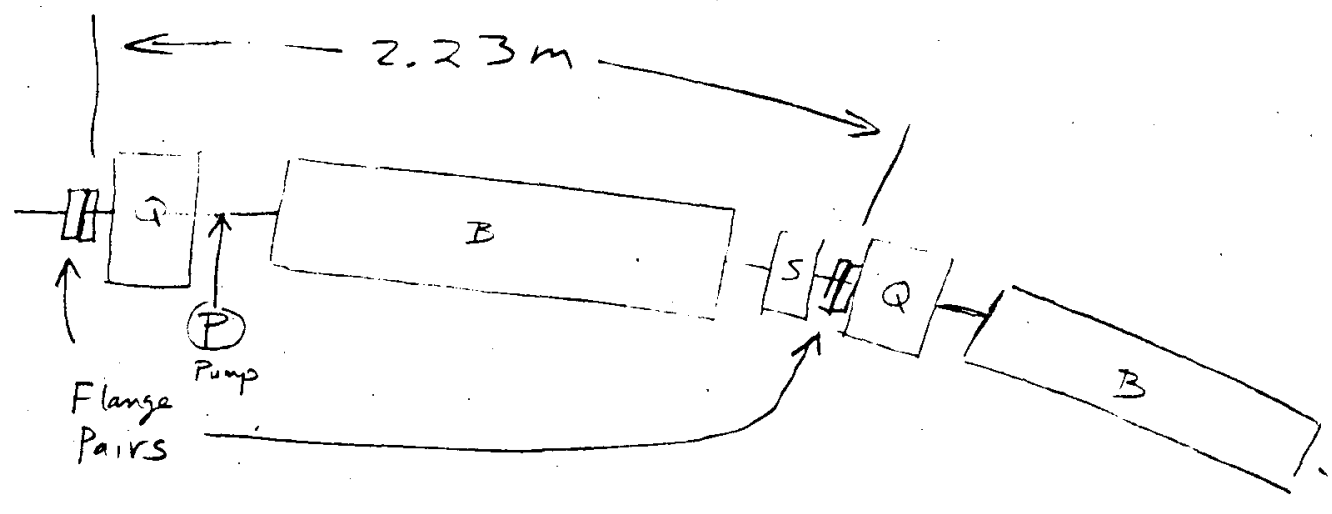

Option B

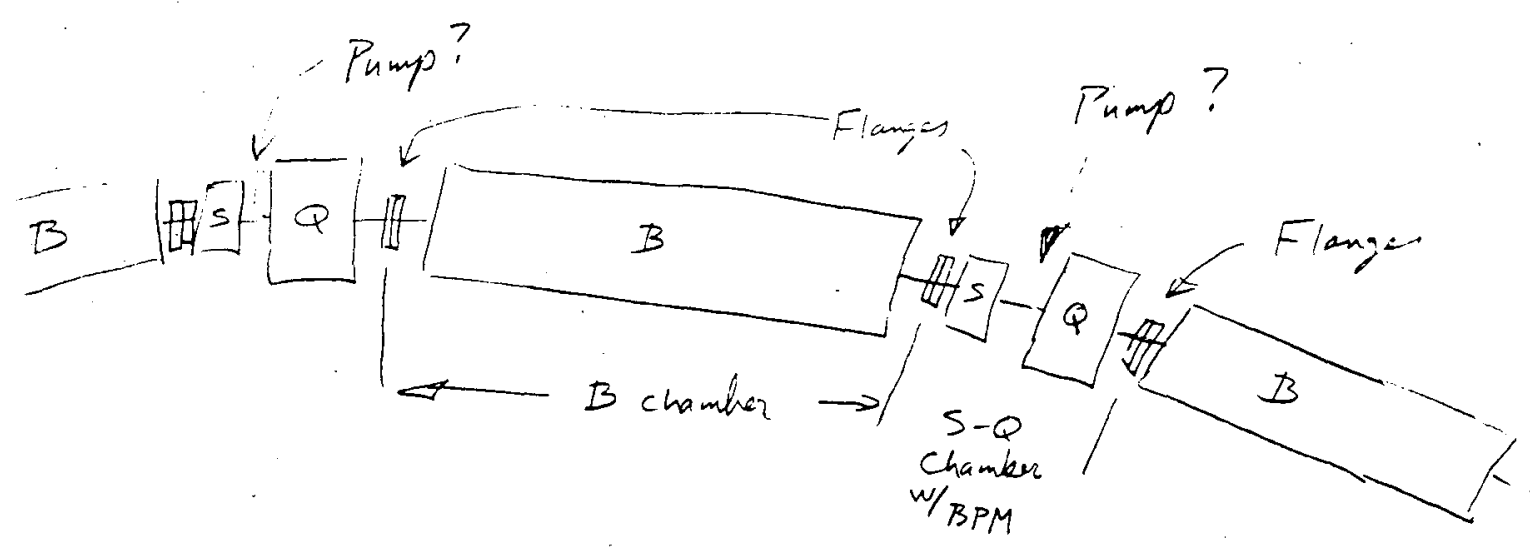

Pro: Shorter chambers to handle

Con: Extra flange pain uses up space possibly needed for purport ports. 
Consider Option B:

(7)

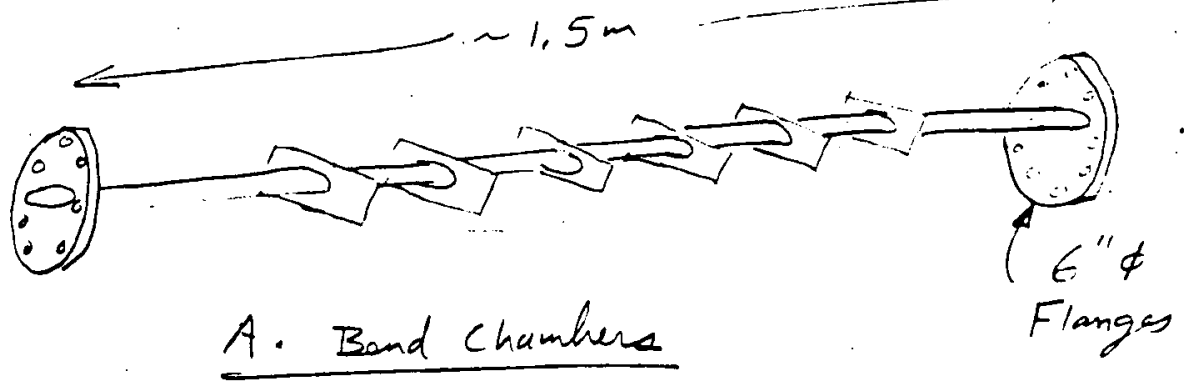

A. Band Chamber e

Flanges

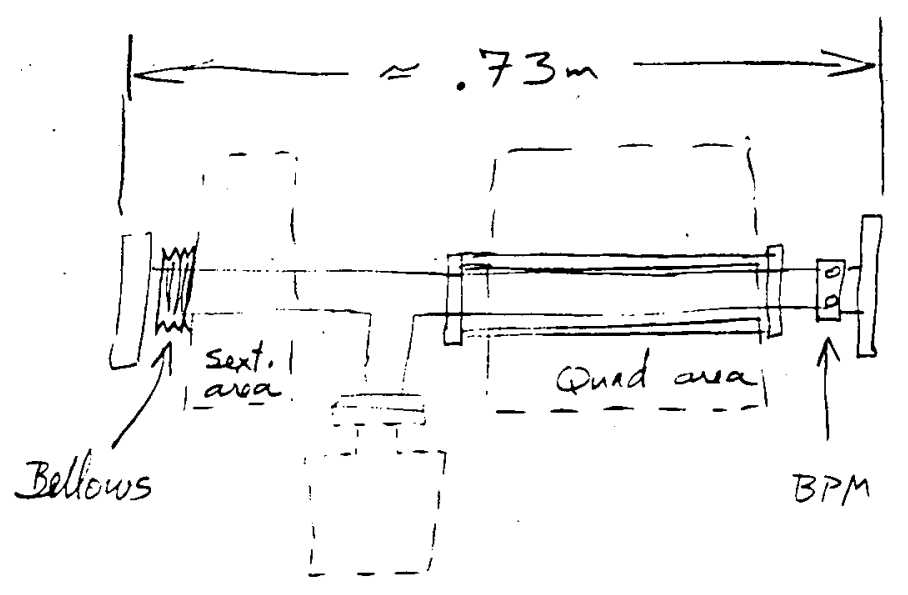

B. Sextupole/Quadrupole Chambers

Estimates:

A. Bend Chambers: 2 ea 6" 6 Flanges (a) 34 ene $=150$ 1 boltset@\$35=35

Tubing, thin@\$15/ft $\cong 75$

Reinforcing rib stampings 15ea@\$5 $\cong \frac{75}{335}$

Labor: 8 hrs welding, Brazing $\$ 50 / \mathrm{m}=400$

6 hrs machining $050 / \mathrm{m} \cdot \frac{=300}{700}$

Total, Bend Chambers $\simeq \$ 1.035 \mathrm{~K}$, ea

B. Sextupole/Quedrupde Chambers

Zea6"申 Flanges @\$75 = 150

1 ea bott set @ 35 $=35$

Tubing@\$15/ft = 35

Special Stiffness (not despoil) $\cong 100$

BPM Feed thus 4@\$65 $=260$,

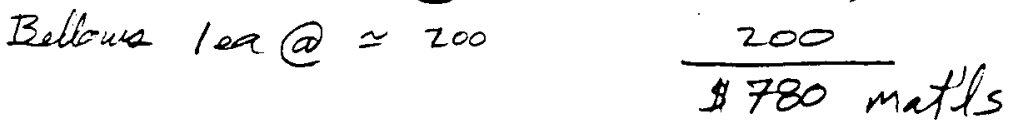


Labor: Machining: (BPM parts, bellows

$(81$ rings, special stifferiss etc)

Estimate 20 hs@ 1000

Brazing/welding:10hrs@50. $\frac{500}{1500 \text { labor }}$

Total, sextupde/Quadrupole champion: $2.28 / \mathrm{K}$

Total: $1.035 K+2.28 K=\$ 3.32 K$

overall length: $2,23 \mathrm{~m}$

Estimated cost/meter $\simeq 1.49 \mathrm{~K}$, say $\$ 1.5 \mathrm{k} /$ meter

$\therefore$ For 100 meter circumference, allow approx \$150 K 
I. Rough ort System

(9)

Starting Previse Reid: $1 \times 10^{-3}$. Torr (or slightly grater) Total Sutermil Volume: $V=\pi a b L \cong 110$ liters.
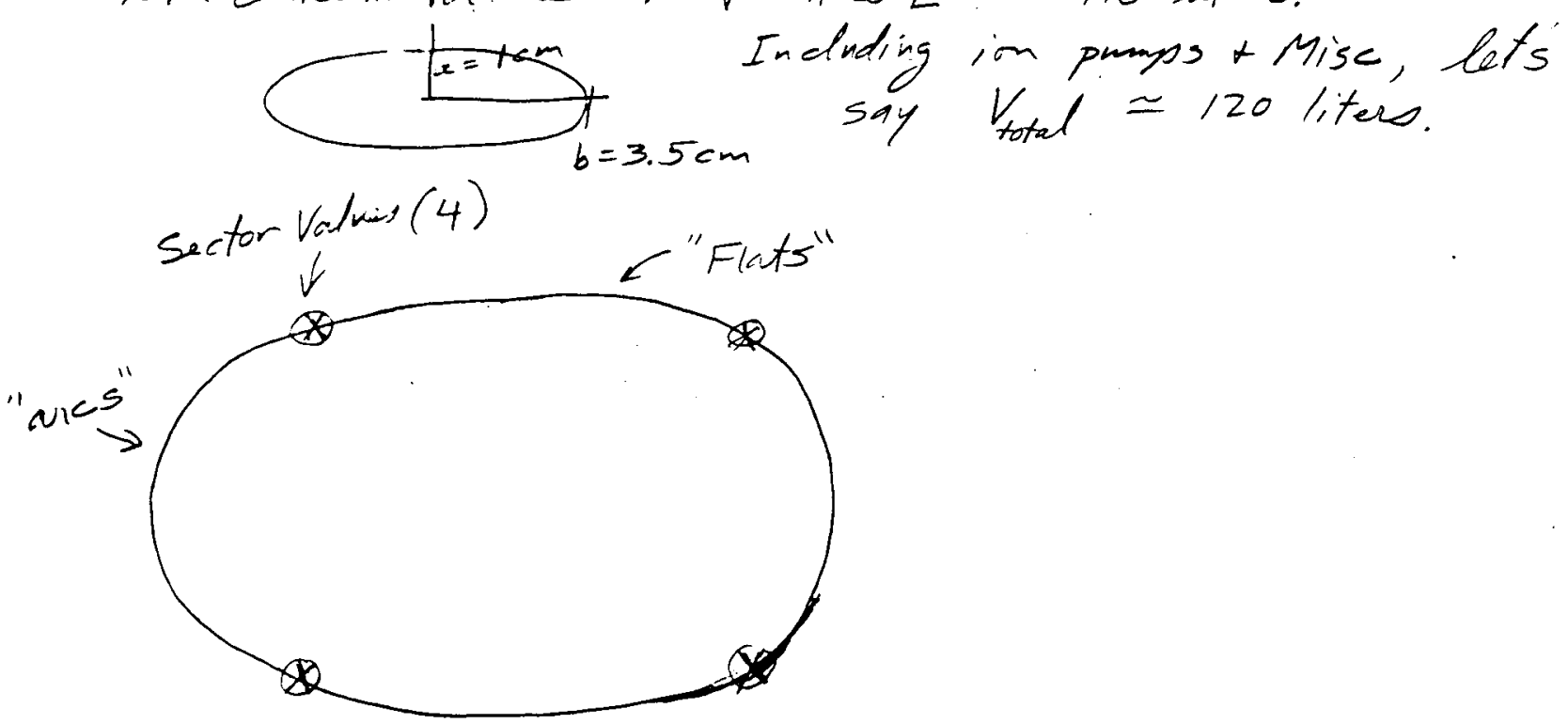

Assume each of the 4 sectors is about equal in volume $(=30$ lifers $)$, length $(\cong 25$ meters $)$, and conductance, and that we rough ont each section separately.

Try one roughout port/ sector:

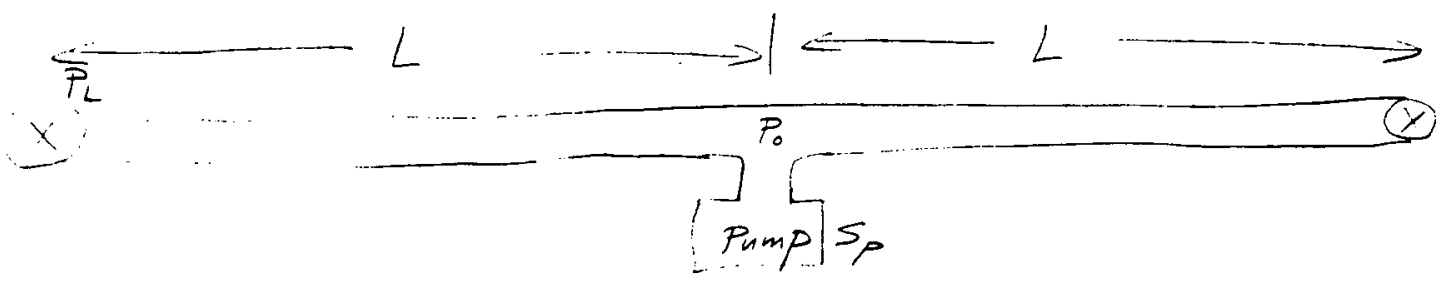

Here $L \simeq 12.5 \mathrm{~m}$

$$
\begin{aligned}
P_{L} & =g_{D} B L\left[\frac{1}{S_{P}}+\frac{1}{2 C}\right] \\
P_{L_{\text {min }}} & =\frac{g_{D} B L}{2 C}=\frac{g_{D} B \cdot L^{2}}{2(828)}=\frac{\left(2 \times 10^{-7} \frac{T-l}{s e c \mathrm{~cm}^{2}}\right)(18 \mathrm{~cm})(1250 \mathrm{~cm} .}{2(828)} \\
& =3.4 \times 10^{-5} \text { Torr }
\end{aligned}
$$

This =court be good enough to stat the in pumps. The total gas load is 760 Tor $\times 30$ liter $=23000$ Torr-liten, well below the 170,000 Tou-liter pumping capacity of a doukif sized Virion Vacsaid pump. 
The proposed roughest system would thus r moist of

(10) the following-

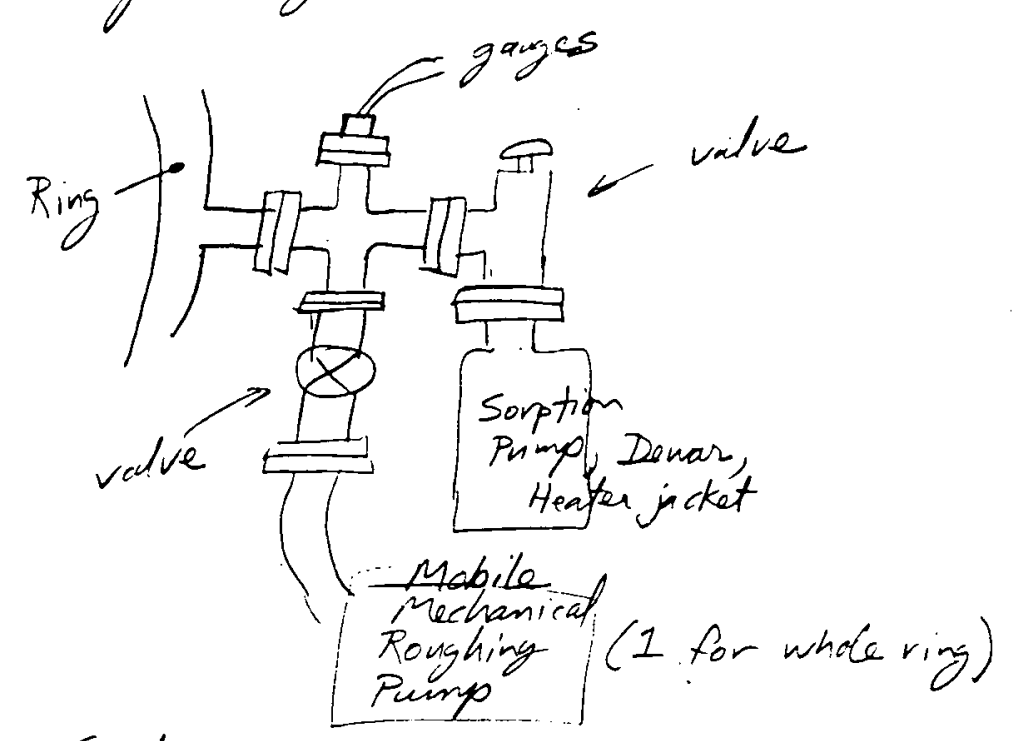

Costs:

4ea-Cros5,23/4"Flanges@\$113 sa = \$4.452 K

4ea-Double Vacsorbs VarianP/N941-6502@897ea = 3.591

4 ea - LN 2 Dewar for $\uparrow, P / N 944-0012 @ 920=3.68$

4ea-Heating Band P/N744-0045@245=0.98

$4 \mathrm{ea}$ - GPSenis 2756onvectron Garizesystem@481=1.92

8 ea - Varian PN951-509211/"
Hand opuatid Right Angle Valves

Lea - Mobile Mechanical Pump (Varia SD-700) Ql $2350 \frac{2.35}{\$ 19.36 \mathrm{~K}}$

Say $\$ 20 K$

III. Sector Valves: Assume 4 ea GP valves (or equiv. radiation-resistent all-metal values)@\$10kea $=\$ 40 \mathrm{~K}$

II. Pump Power Supplies

A more economical system might be possible to dinesen, but due to the fairly high operating pressures o starting presses, $d$ will assume that 1 medium pomes supply (VIrion P/N921-0062@1600ea) is regal for every tires ion pumps, for a total of $\frac{45}{3}=15$ units

Total: $\$ 24 K$ 
(II)

VIII. Pressme Monitoring Dovices

Assume 8 ea Modil 580 Nude @ \$319=\$2.55 K iongange (Varian)

8ea 23"Tees@"90 =.72

8ea Parion Mold $843 @ 875=7.00$

Ion Gayge \&TC Gange

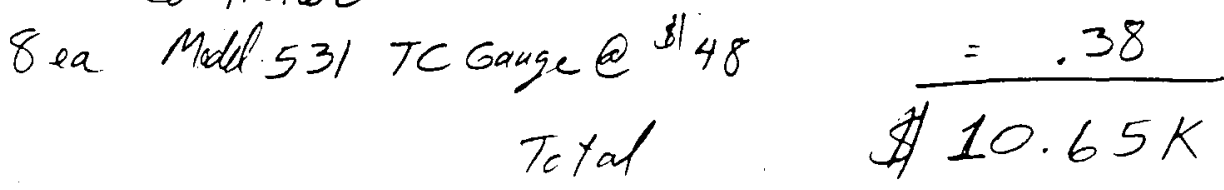

VII. Misc. Valves + Hardware

Estimate approx $\$ 20 \mathrm{~K}$ for as-yet-unspecified hardware. 
$y=7$ (12)

Cost Summary - Vacuum System for $3 \mathrm{GeV}$ Injector Synchrotron

Category Description

Math + Fab. Labor for fabricating thin -walled vacuum system, $100 \mathrm{~m}$ total length ( see pp. 6,7,8), including BP Ms.

2 Sector Valves (sep, 10)

3. Roughen System ( site pp $q+10$ )

4. Pressure Monitoring Equipment (p.11)

5. Misc. Valves \& Vacuum Hardware (p.11)

6. Ion Pump Power Supplies $(p, 10)$

$\% \quad$ Ion Pumps -45 pumps

Assuming $20 \mathrm{l} / \mathrm{sec}$ pumps $\left(\bar{P}=4 \times 10^{-7}\right.$ Torr $)$

Alternate: $8 \mathrm{l} / 5$ pumps $\left(\bar{p} \simeq 7 \times 10^{-7}\right.$ torr $)$
Estimate f cos $x$

$\$ 150.0 K$

40.0

20.0

11.0

20.0

24.0

60.0

$\operatorname{or}(33.0)$

\# $325 \mathrm{~K}$

(or $\$ 298 K$ nosing $8 \mathrm{H} / \mathrm{sec}$ pumps) 


\title{
SCIENTIFIC INTERNATIONAL INC.
}

P.O. Box 143

Princeton, N.J. 08542

Tel. (609) 924-3011

June 4,1987

Professor Helmut Wiedemann

Applied Physics Department

Stanford Synchrotron Radiation Laboratory

Bin 69 - Box 4349

Stanford, CA 94305

Reference: Thin-walled Ribbed Beam Pipes

Dear Professor Wiedemann:

Pursuant to our previous discussions regarding your potential need for thin-walled ribbed beam pipes, and yesterday's verbal telephone offer, we are now able to confirm our offer as follows:

QUANT1TY OF 32 CHAMBERS,

ELLIPTICAL CROSS-SECTION -

\author{
Wall thickness: $0.3 \mathrm{~mm}$ \\ Height of Chamber: $44.6 \mathrm{~mm}$ \\ Width: $\quad 103.9 \mathrm{~mm}$ \\ Length: 2 meters, each Chamber \\ Material: TP 321 \\ Number of ribs per Chamber: 92 \\ One vacuum flange at each end of Chamber \\ Final design according to SLAC specifications \\ Manufacturing of one prototype \\ Leak testing \\ Tooling
}

PRICE: Approximately $\$ 165,000.00$ f.o.b. Princeton, New Jersey.

A vacuum bakeout is not included in the above monetary value. 
Professor Helmut Wiedemann

Stanford Synchrotron Radiation Laboratory

June 4, 1987

Page Two

We must stress that our given price only presents an approximate value, since the detailed specifications are not known at this time. This price is also based on the current \$-DM exchange rate. However, we included in our calculations 8.7\% Import Duty; SLAC can legally be exempted from these latter charges according to Customs Regulation Item 851.60, provided an application for exemption is filed PRIOR to importation of goods.

We hope to have given you adequate information at this point, and we would be delighted to pursue some further discussions in reference to your particular needs.

Sincerely, -

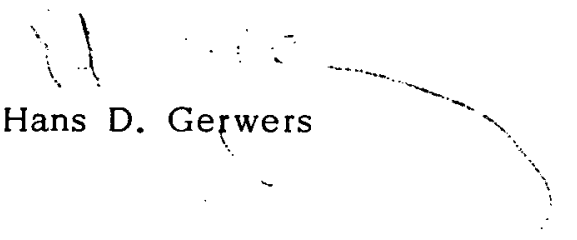

$\mathrm{HDG} / \mathrm{bb}$ 


\section{SCIENTIFIC INTERNATIONAL INC.}

P.O. Box 143

Princeton, N.J. 08542

Tel. (609) 994-3011

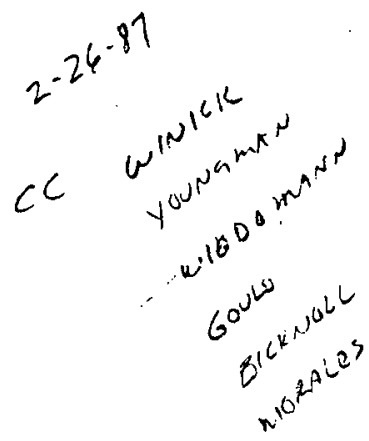

Mr. Richard Boyce

STANFORD LINEAR ACCELERATOR CENTER

P.O. Box 4349

Bin 69

Stanford, CA 94305

Reference: Elliptical-Shaped, Thin-Walled Beam Pipes

Dear Richard:

Pursuant to our several preliminary discussions regarding Elliptical-Shaped, Thin-Walled Beam Pipes, we include herewith some Xerox copies of similar chambers which have been built by the European INTERATOM CORPORATION, a 100-percent daughter company of SIEMENS AG, the latter being a company with over 35 billion dollars in annual sales volume. SCIENTIFIC INTERNATIONAL, INC. is the official U. S. Representative for INTERATOM.

The Beam Pipes, delineated in the photocopies, have a wall thickness of 0.3 millimeters and are manufactured from Stainless Steel. The use of INCONEL material is also possible. INTERATOM recommends, based on their experience, the incorporation of heater elements into the Beam Pipe structure. Such elements can be brazed directly to the Chamber Ribs. The degassing rate of the ribbed beam tubes is in the range of:

equal/less than $10^{-13}$ mbar $x$ liters/second.

The final vacuum in those Chambers can be maintained at:

equal/less than $10^{-11}$ mbar.

INTERATOM presently builds such Chambers for CERN in Geneva, Switzerland, and GSI in Darmstadt, West Germany. For the latter facility, the ribbed beam tubes will be installed in magnets whose fields will vary a few Teslas a second. The ribbed tubes are designed to withstand at least 25 Situ heating intervals over a 24 -hour period, at $300^{\circ}$ Celsius, without damage.

Without being bound to the following price level, the cost for such structures is likely to be around $\$ 3,000$ per meter, without Import Duty. As mentioned on previous occasions, SLAC can legally be exempted from Import charges, provided that an application is filed before importation of goods. Please consider the price above as a ballpark figure only. 
Mr. Richard Boyce

STANFORD LINEAR ACCELERATOR CENTER

February 25, 1987

Page Two

Please take the enclosed information only as a starting point for futher dis-cussions. INTERATOM will exhibit some sample Chambers during the upcoming IEEE Particle. Accelerator Conference in Washington; SCIENTIFIC INTERNATIONAL was informed that the possibility exists for a visit by INTERATOM Personnel to your facility, following the IEEE Conference, if you should so desire.

We look forward to hearing from you in this regard in the near future.

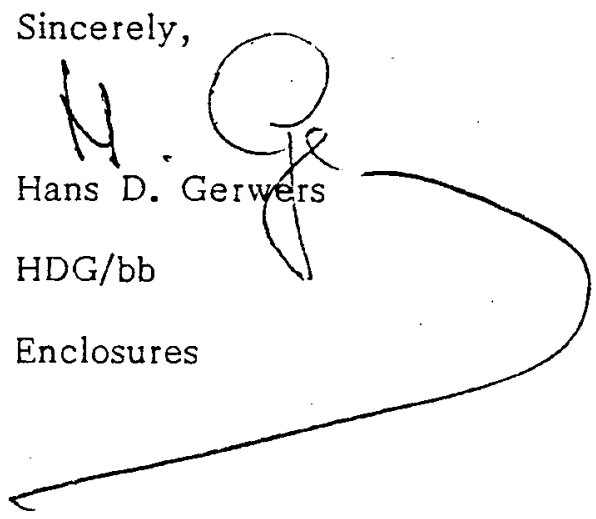


P.0.80x 143

Princeton, N.J. 08542

Tel. (609) 924-3011

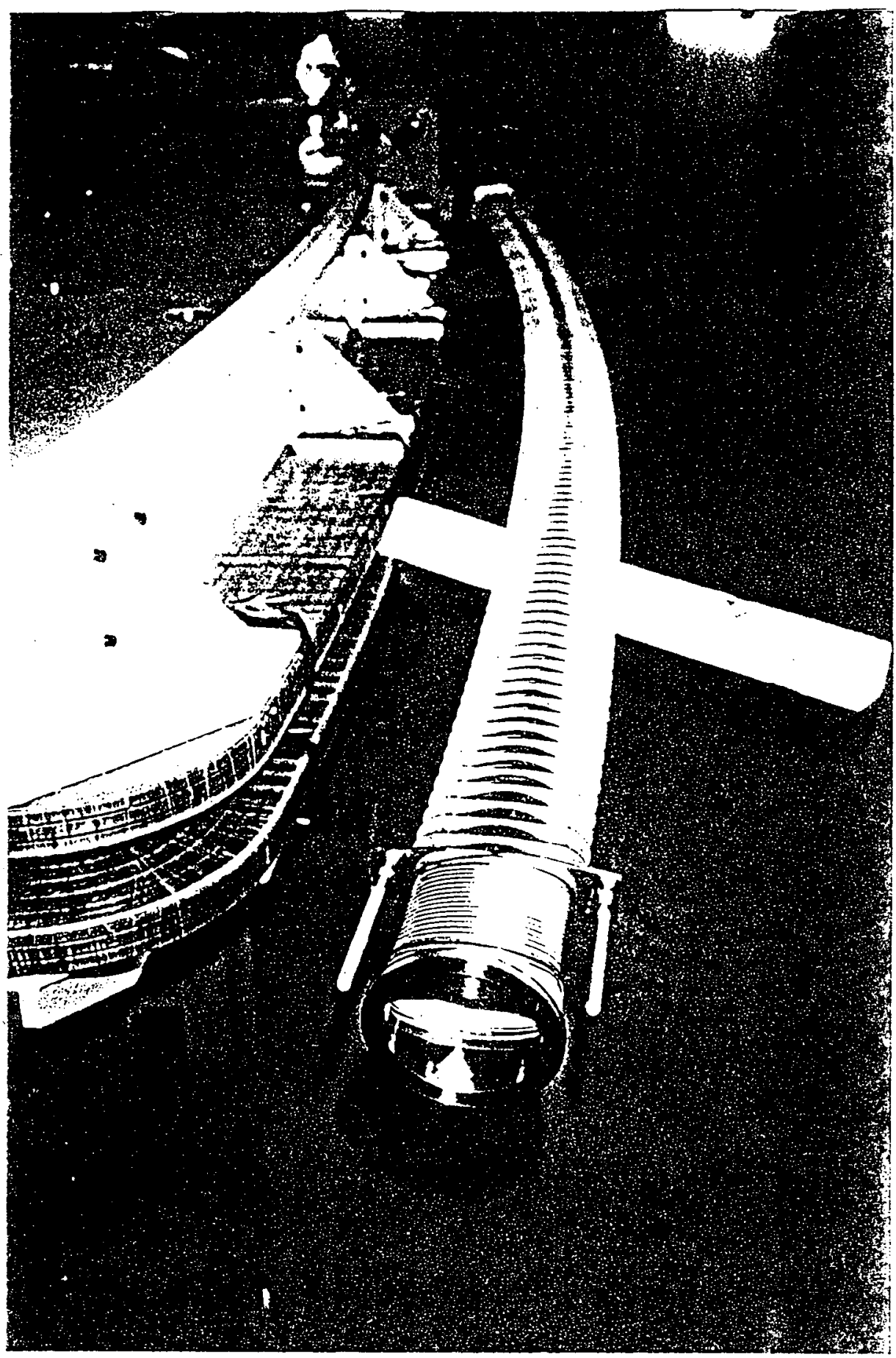


SCIENTIFIC INTERNATIOHAL INC.

P.0.Box 143

Princeton, N.J. 08542

Tel. (609) 924-3011

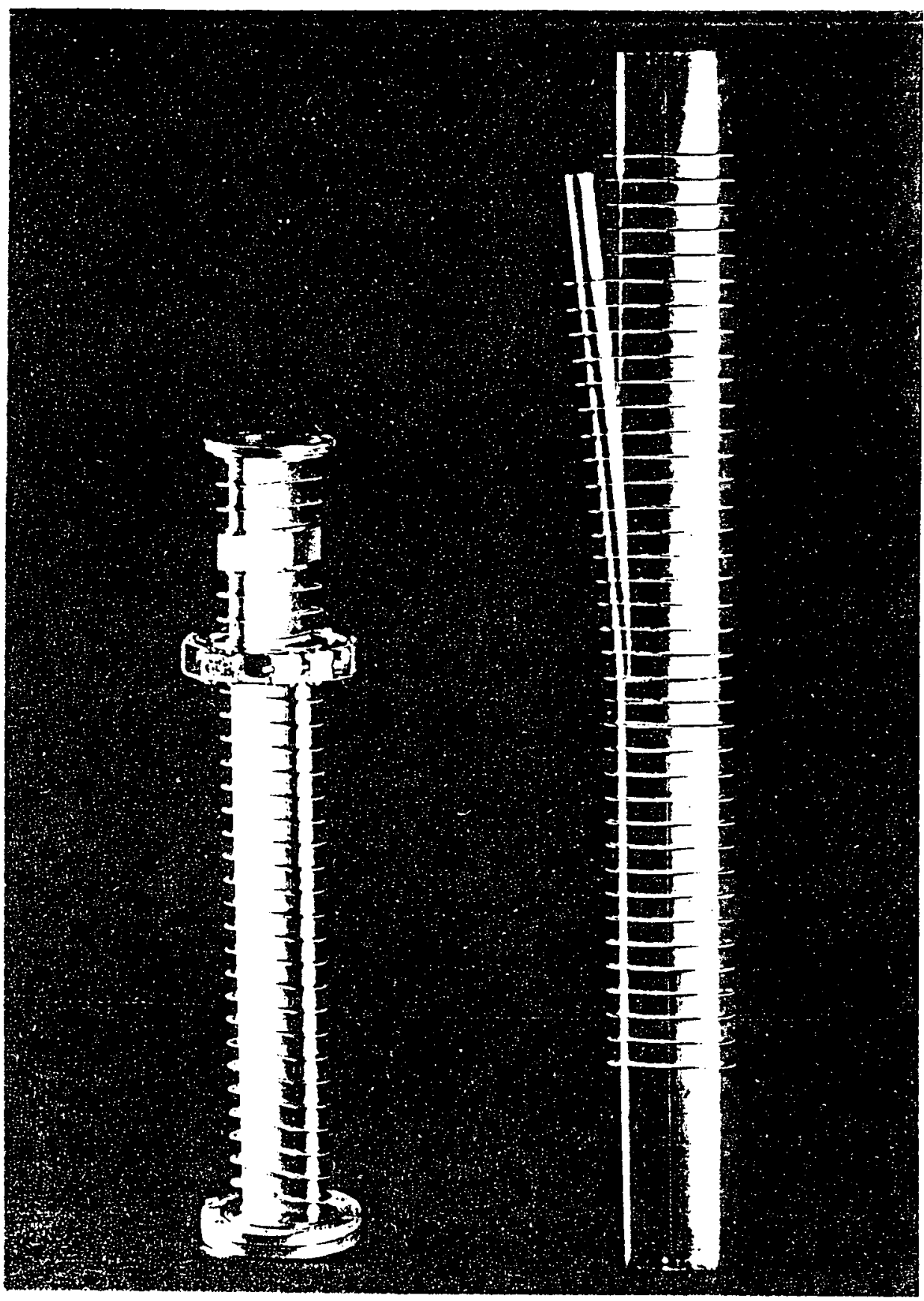

"Magnetic-Vacuum-Chambers

for Accelerators" 


\subsubsection{RF SYSTEM}

\section{1 .7 .0 E D \& I}

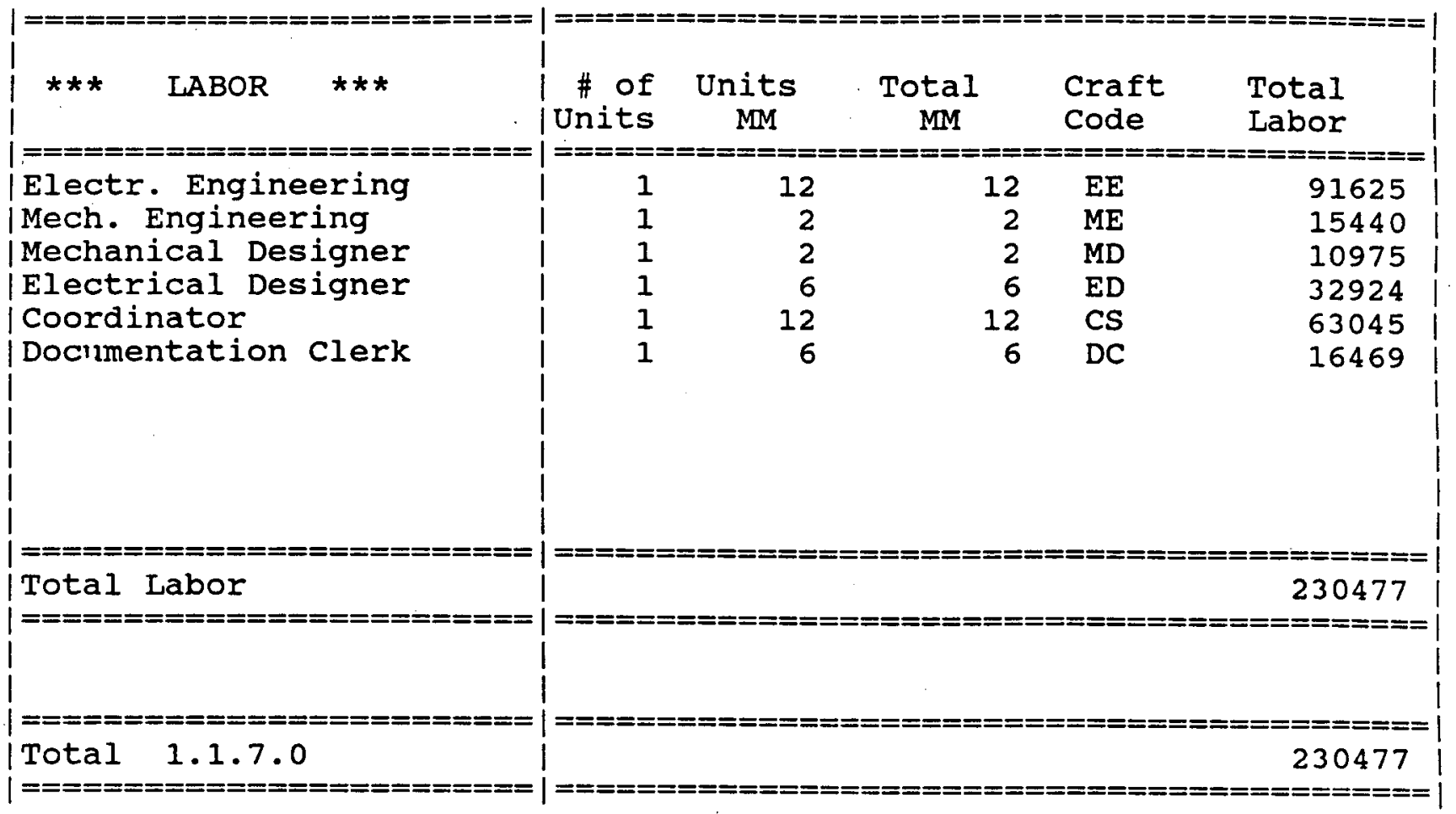




\subsubsection{RF SYSTEM}

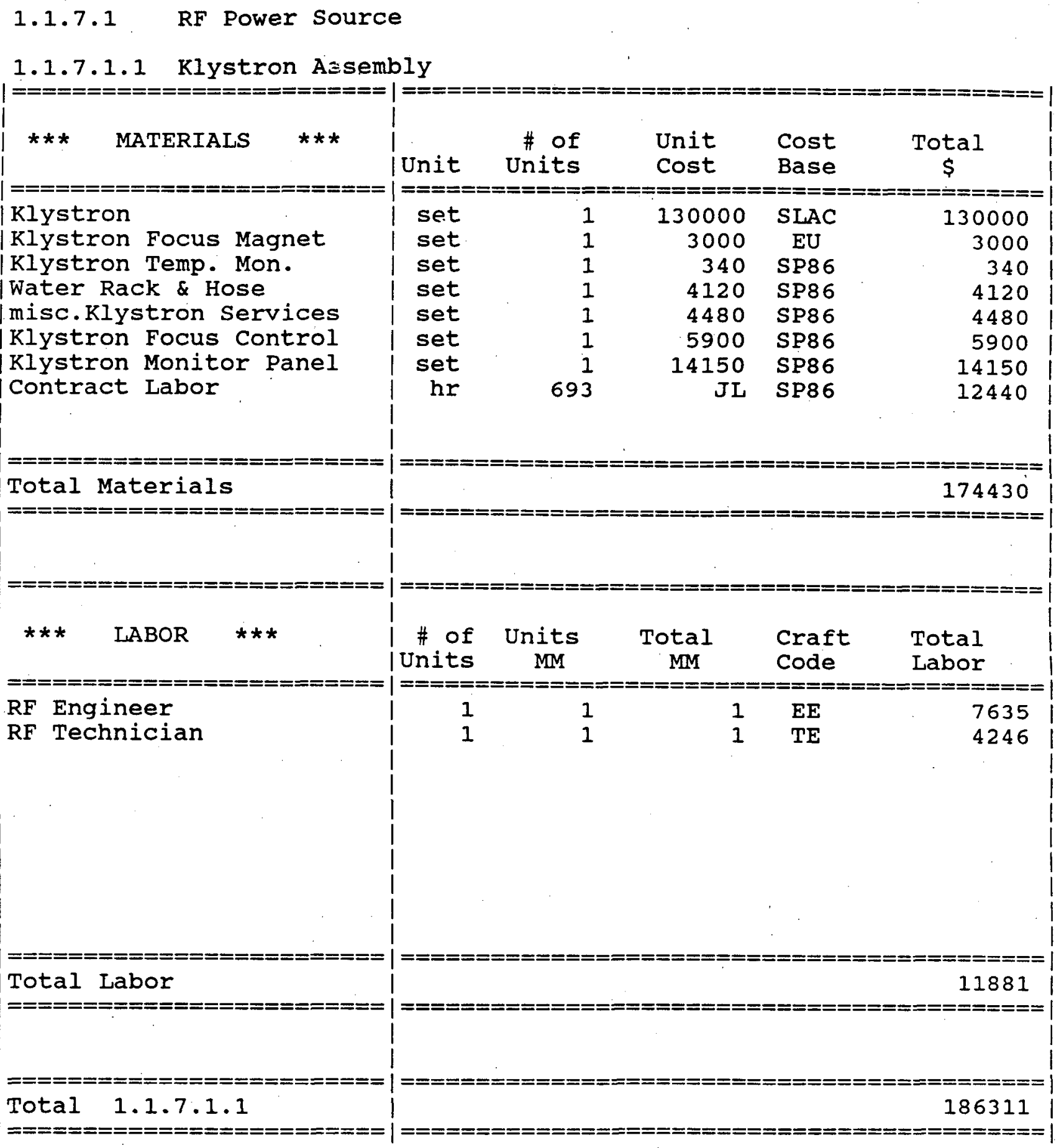




\subsubsection{RF SYSTEM}

\subsubsection{RF Power Source}

\subsection{HV Supply}

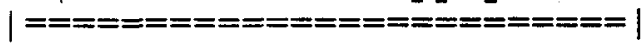

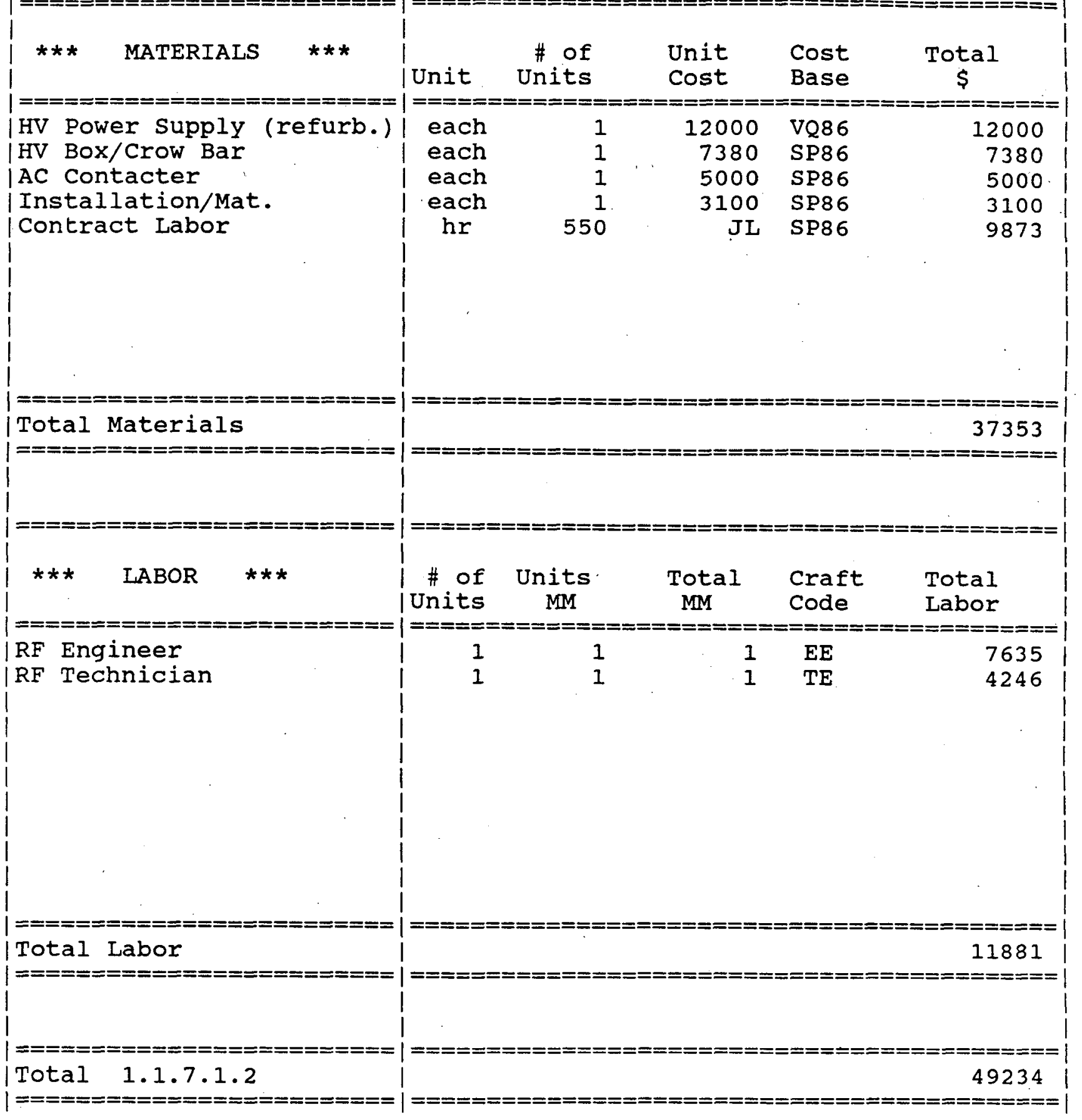




\subsubsection{RF System}

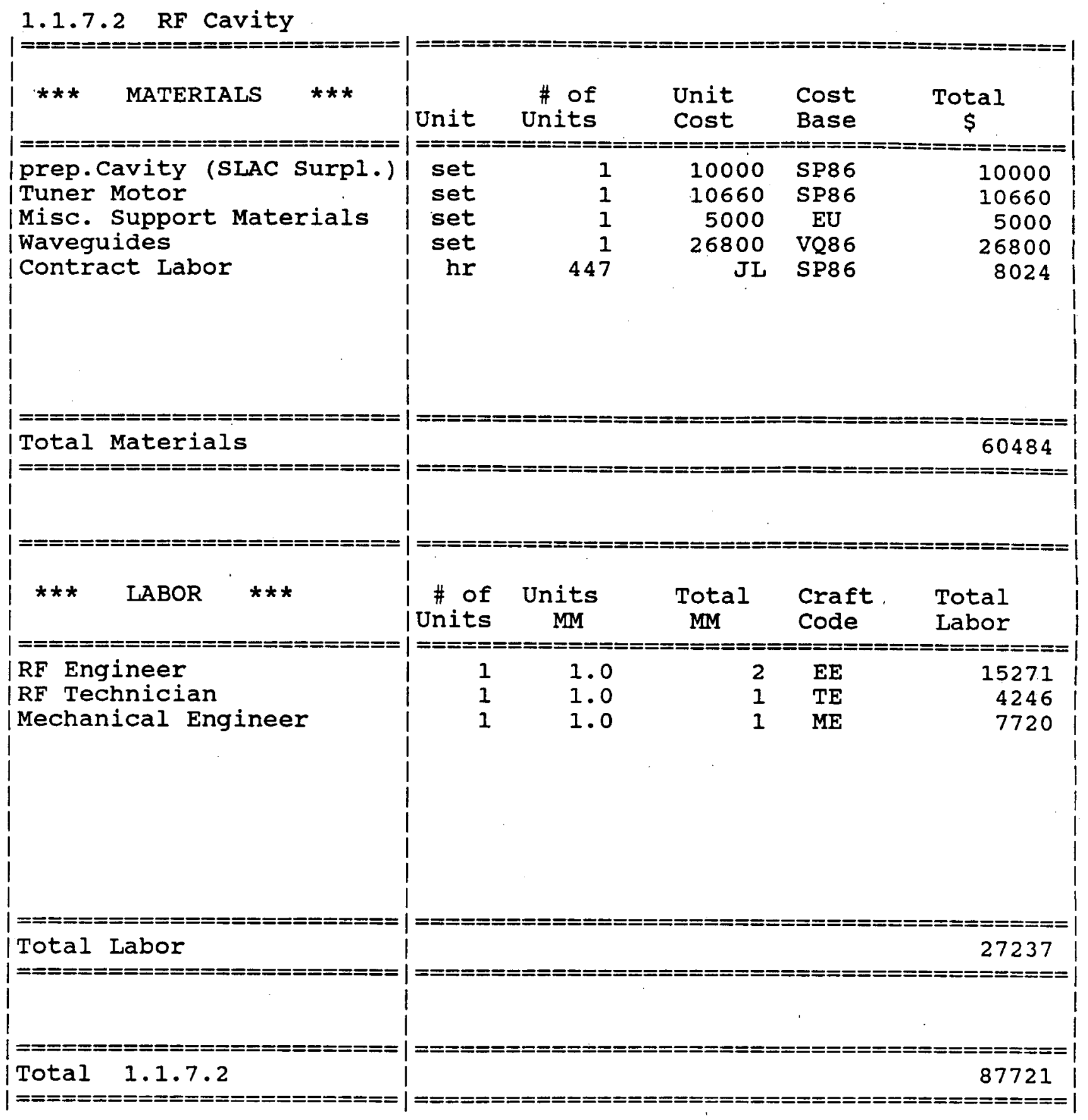




\subsubsection{RF System}

\subsubsection{Drive System}

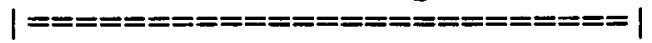

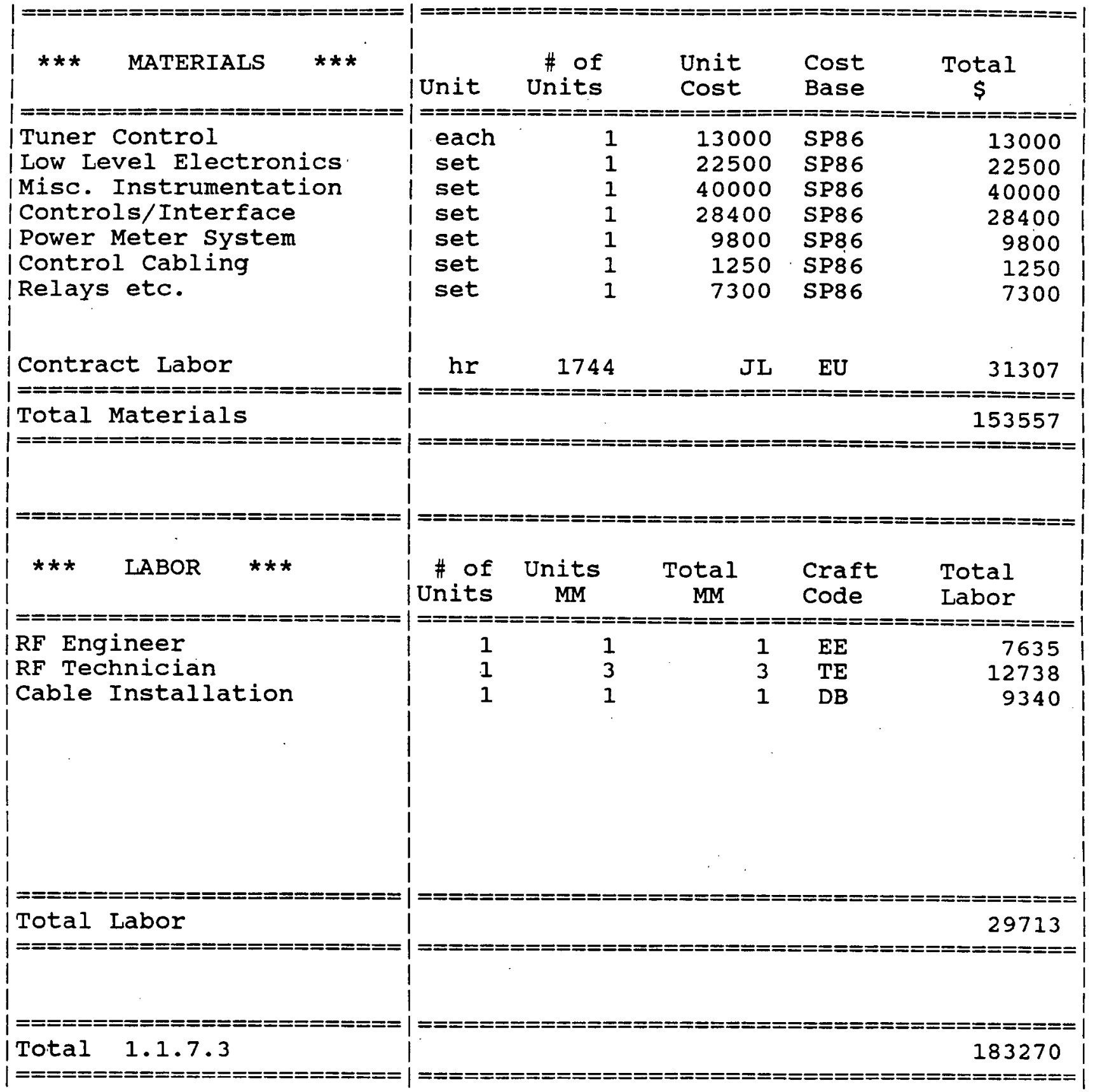




\subsubsection{RF System}

\subsubsection{RF Utilities}

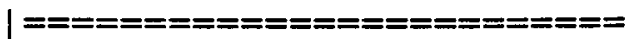

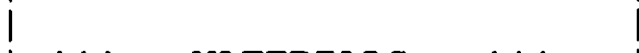

*** MATERIAIS ***

| $===============$

LCW to Klystron

LCW to Cavity

Cables/Trays/Conduits etc

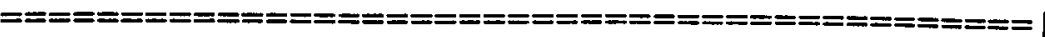

1

\# of Unit cost Total

Unit Units cost Base $\$$

contract Labor

I ==

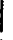

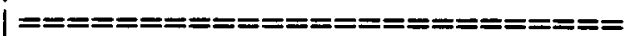

Total Materials

set

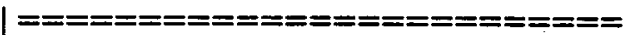

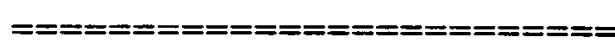

*** LABOR ***

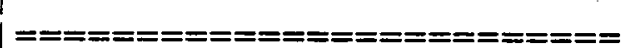

RF Technician

set

set

hr

1

500

SP8 6

500 SP86

$1 \quad 2730 \quad$ SP86

JL EU

754

13535

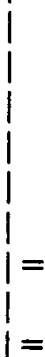

1

17265

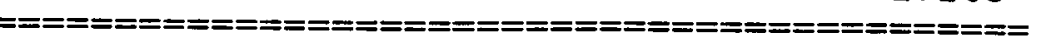

1

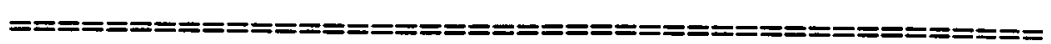

\# of Units Total Craft Total

Units MM MM Code Labor

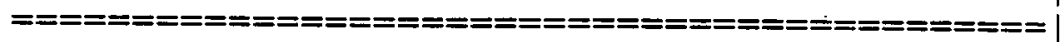

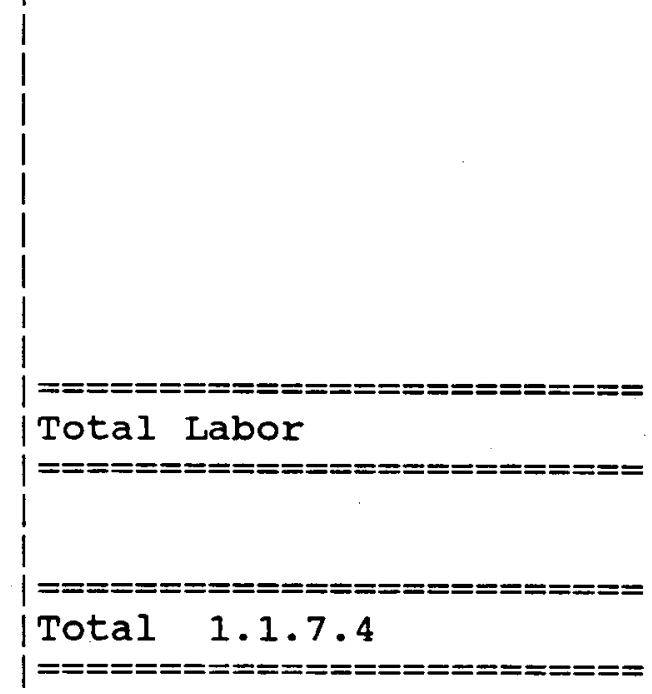

1

0.5

0.5

TE 


$$
7-16-96
$$

TECEPHONE, QUTE. FOR WAVEGUIDE 358 MII 25 ST TH

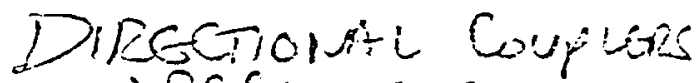

3) REFLECTIVE

b) BEclows

$1680^{\infty}=8 \quad \times 2$ $3,360 \div 0$

c) $90^{\circ}="$ "PCANO BST $1530^{\circ 00}=4$ $6,20 \div 0$

$90(5 w E=P\}$ $880^{\circ 0}=A-X$ $3,520 \%$

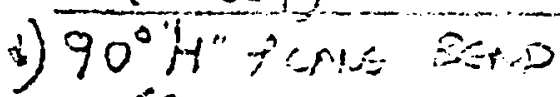
$(S \nu, s=0)$ $103000 \mathrm{EA} \times 1$ $1.030 \%$

e) $160^{\circ}$ H PUIS EERD

a) $12^{\prime}$ STRAITSECTION $430+50 \% \mathrm{~T}$

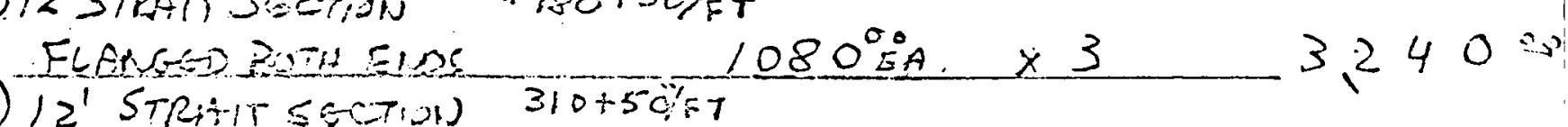

3)

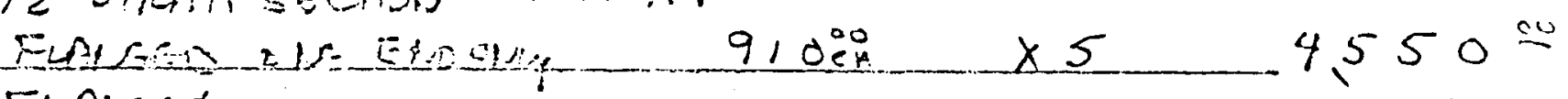

1) FLAISES $165^{00} \times 8 \quad \frac{1,32000}{26,800}$

1) ALL ABOVEmRTERitz will withSTAND 14 "PSIG INTERNAL A'R presSURE

2) WAVEGUIDG = 3/16" WAM THICKNESS

3) MATERIRL ACLMinim

4) ACL ITEOS PAECASED IN PCYUNOD CRAES AT EACTOEY 5) ABOVE PRICES ARE F.OB. RAYMOND MATHS 04071

6) WAVE GUDE HANGEES HOT PRICED

7) WAVEGUDE SUPPXeT SYSTSM HoT InCUDED

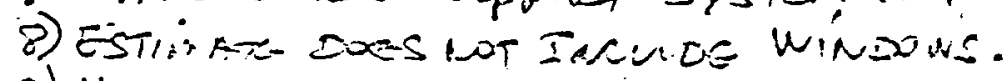

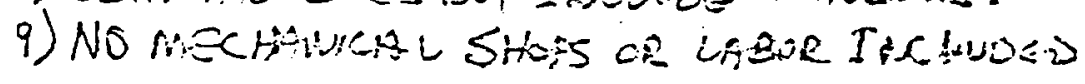

TELAHENS QUOTS FROM

Finom Anetres chisid $7=3-0151$
MICROutre TECHNIQUES AT. ED SAVOIE $(207)-655-3881$ Rovit 302 ReYMOUD ME 04071 


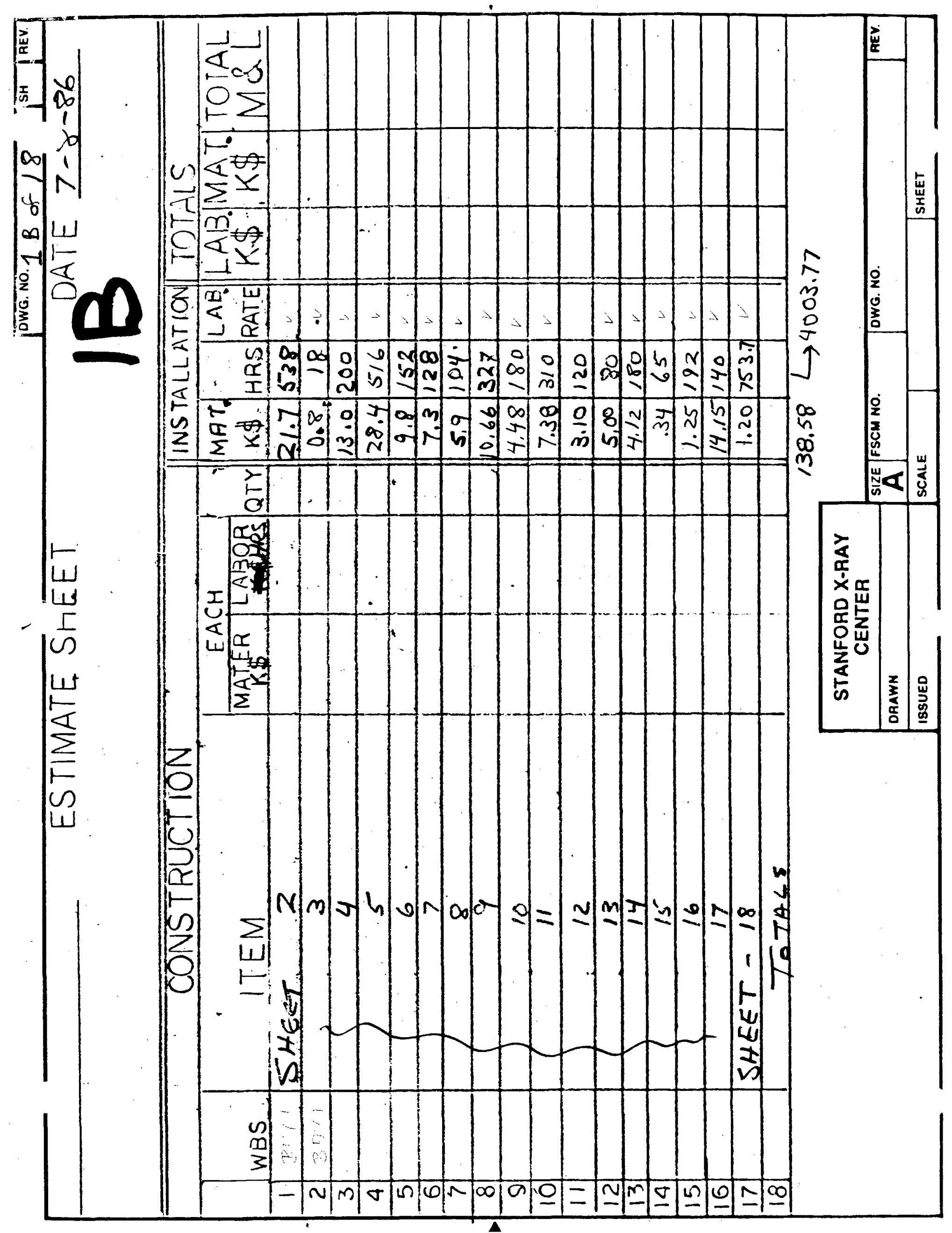




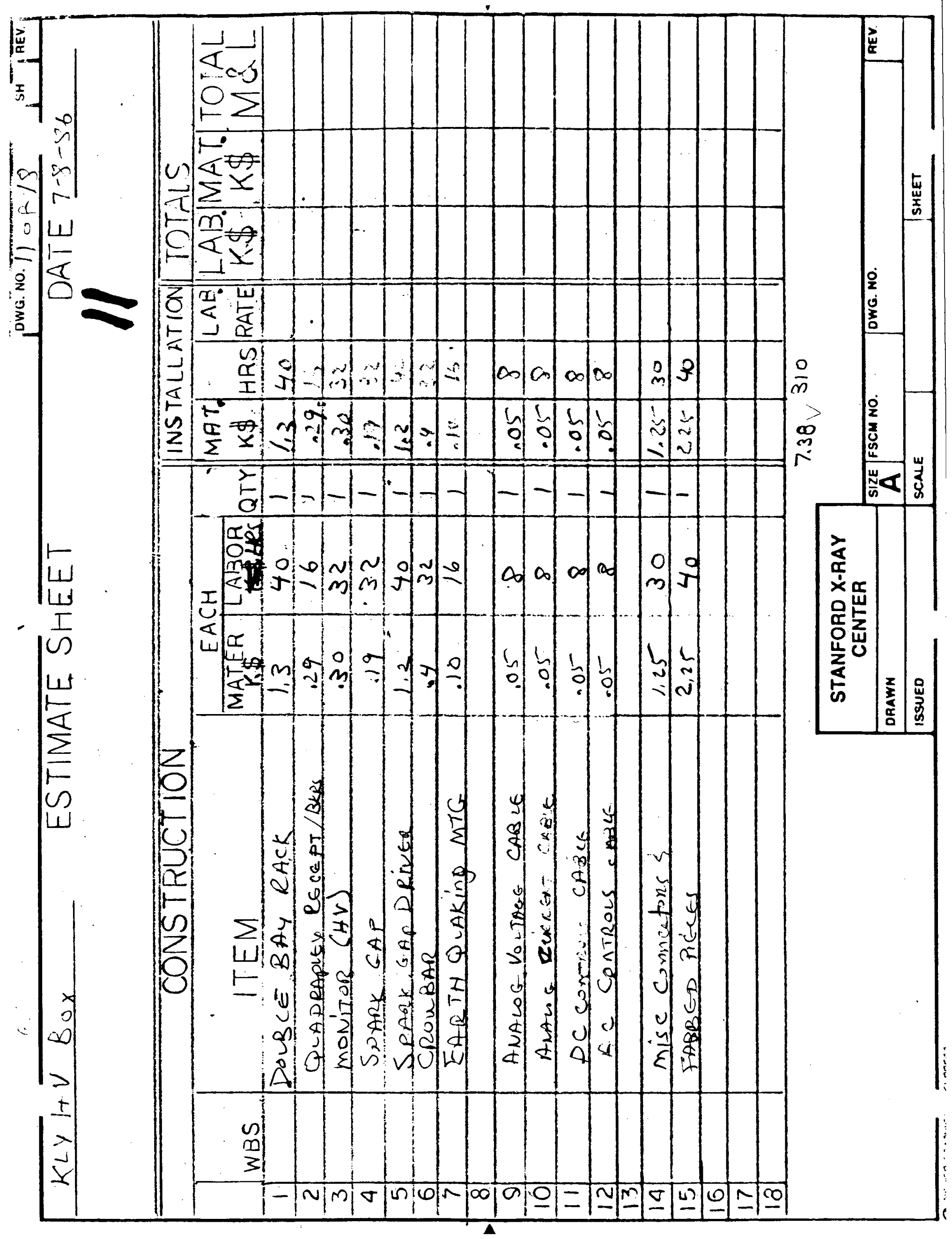




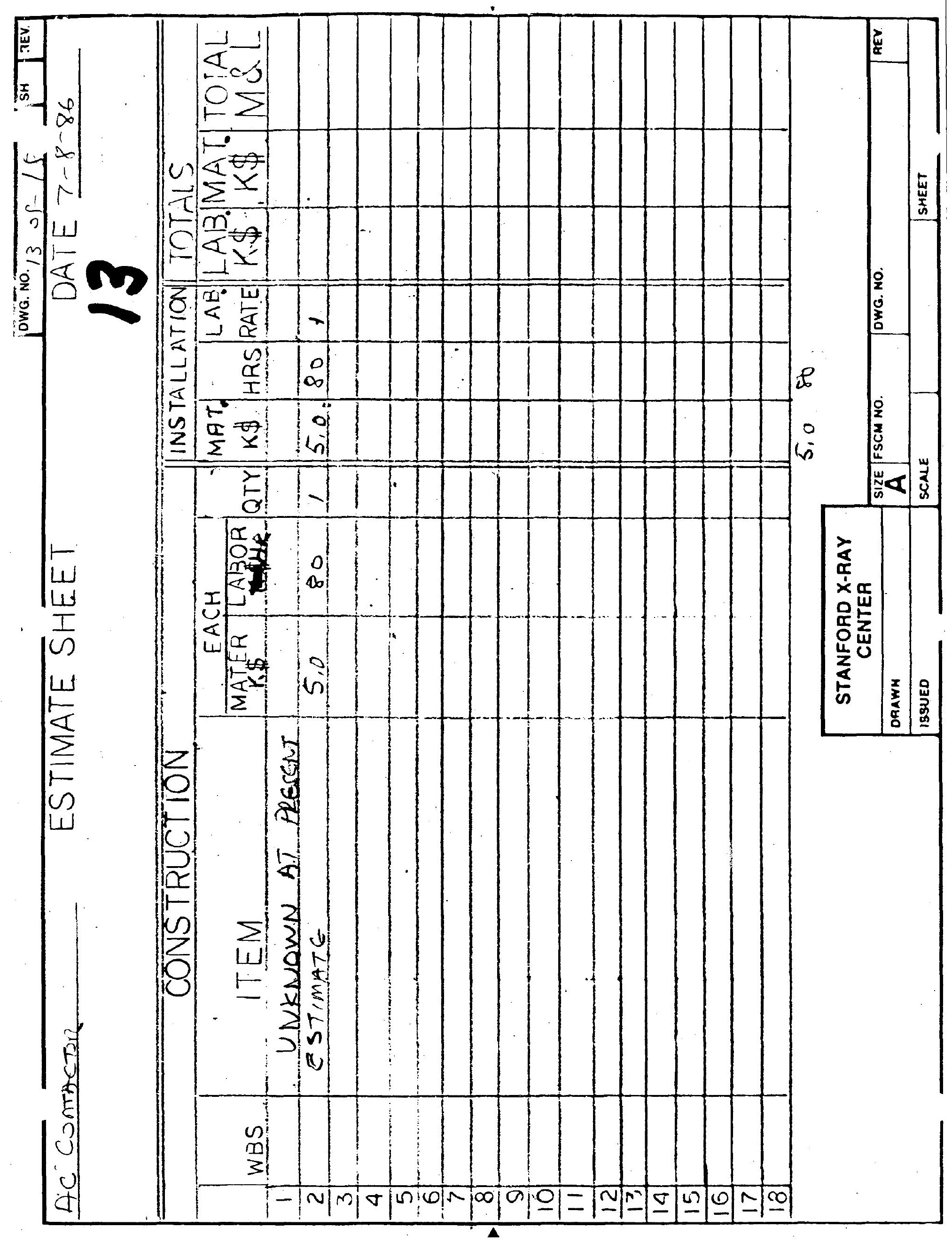




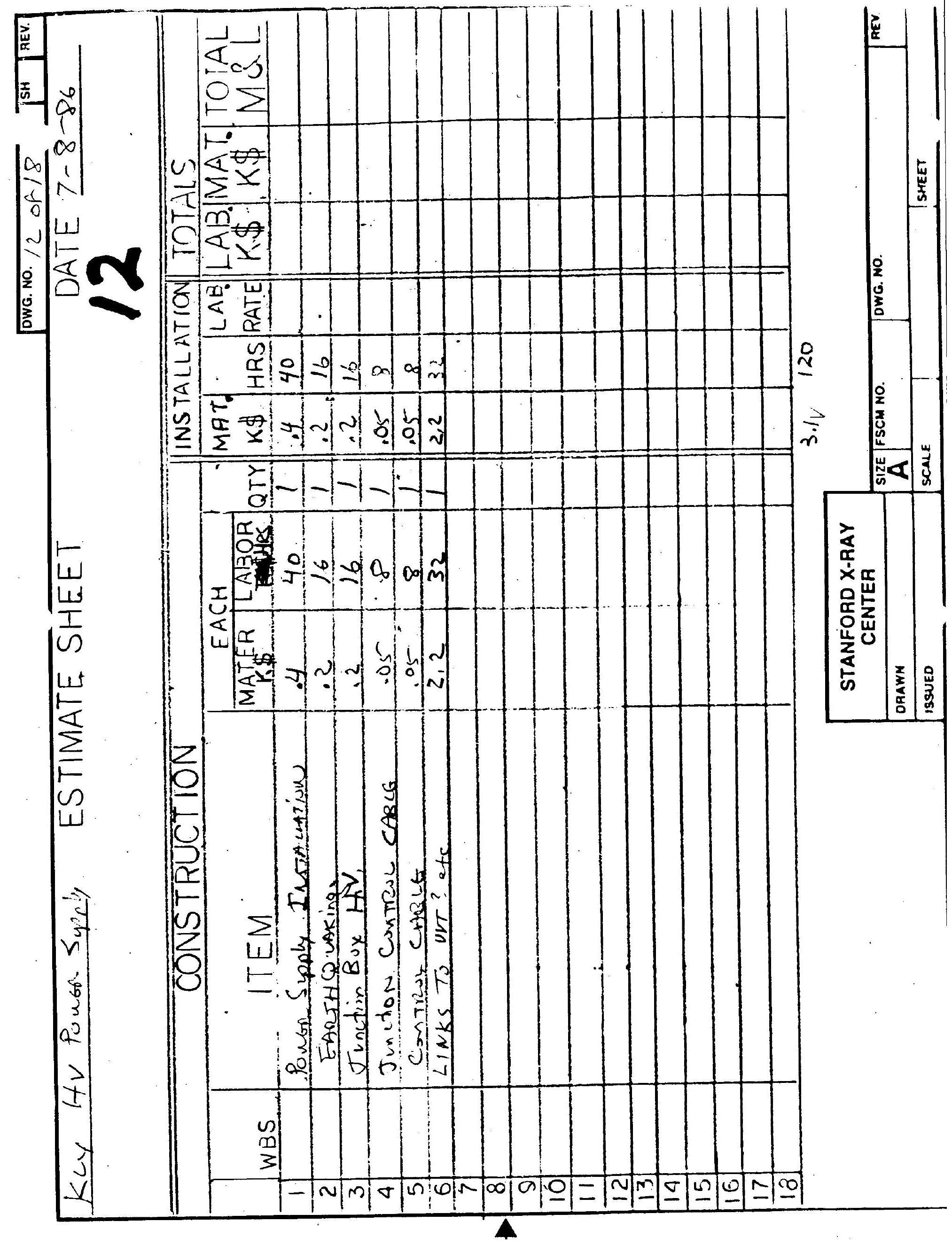




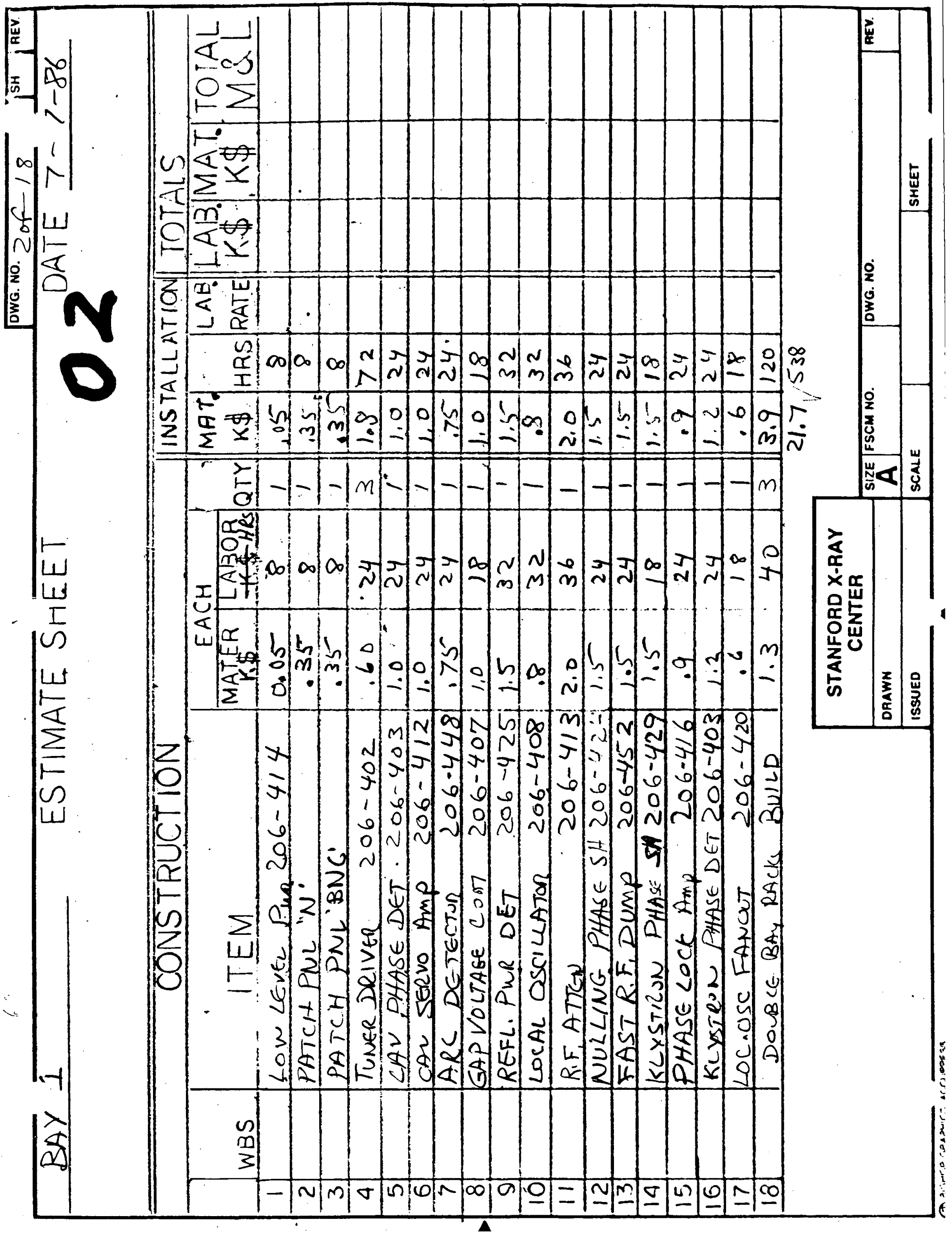




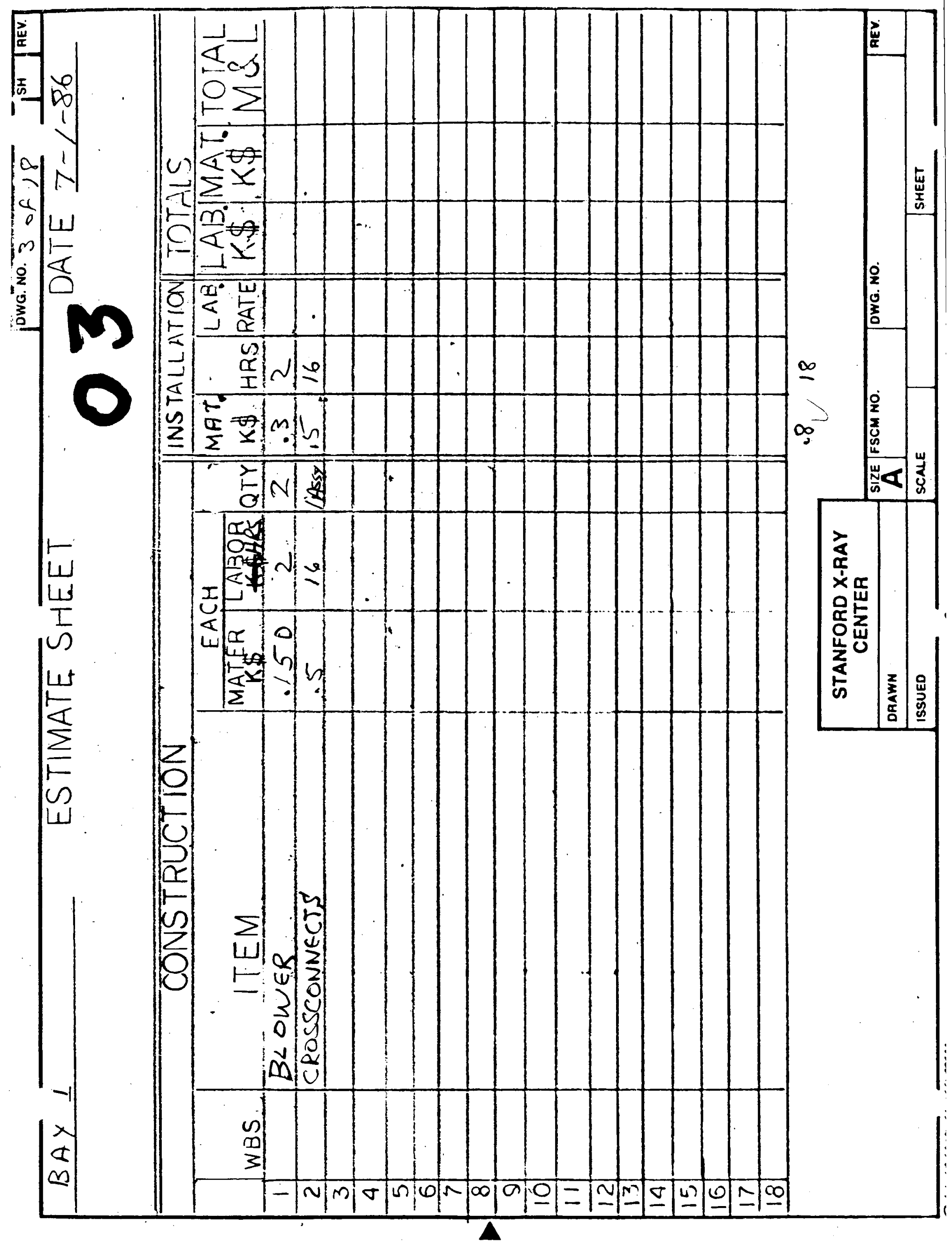




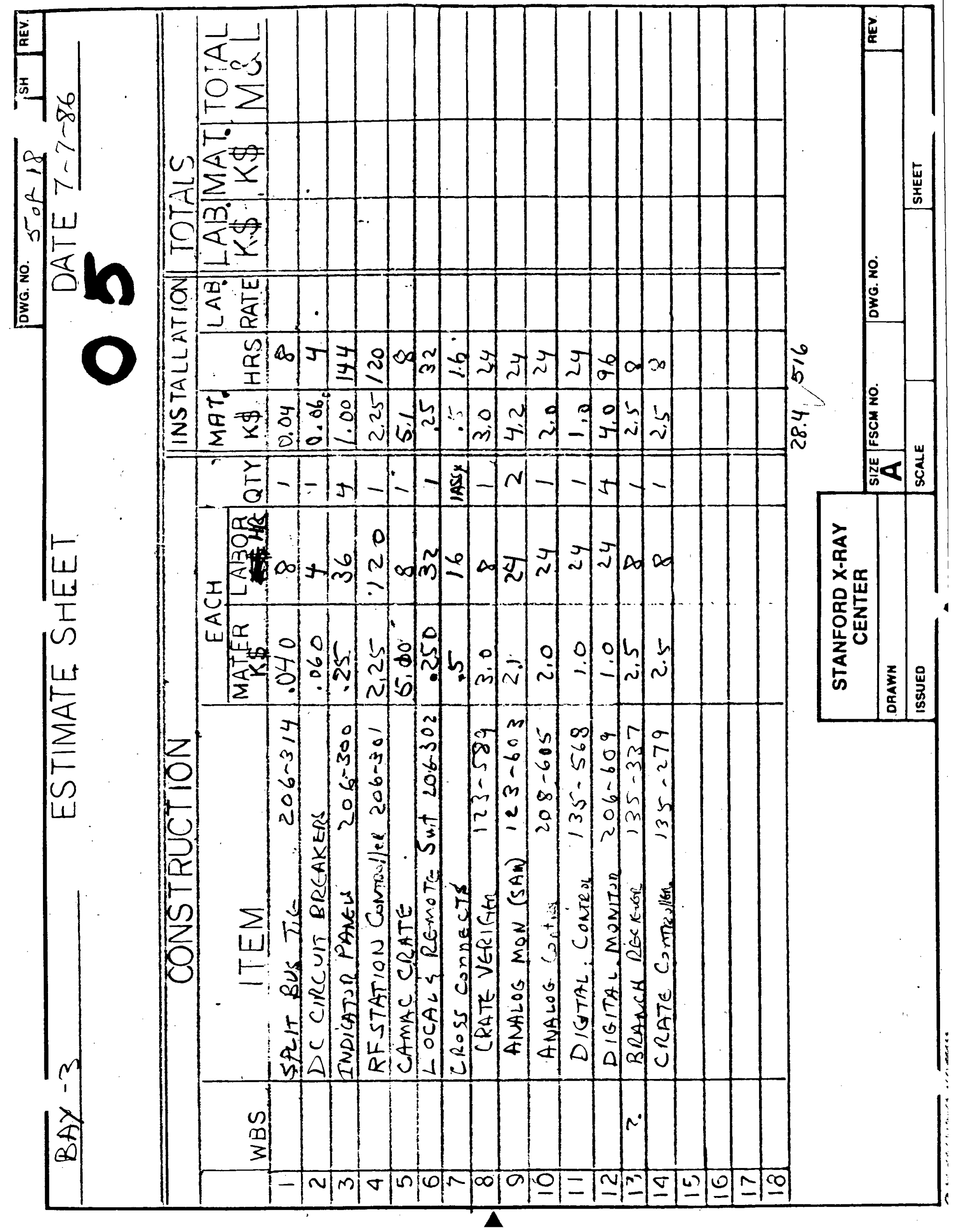




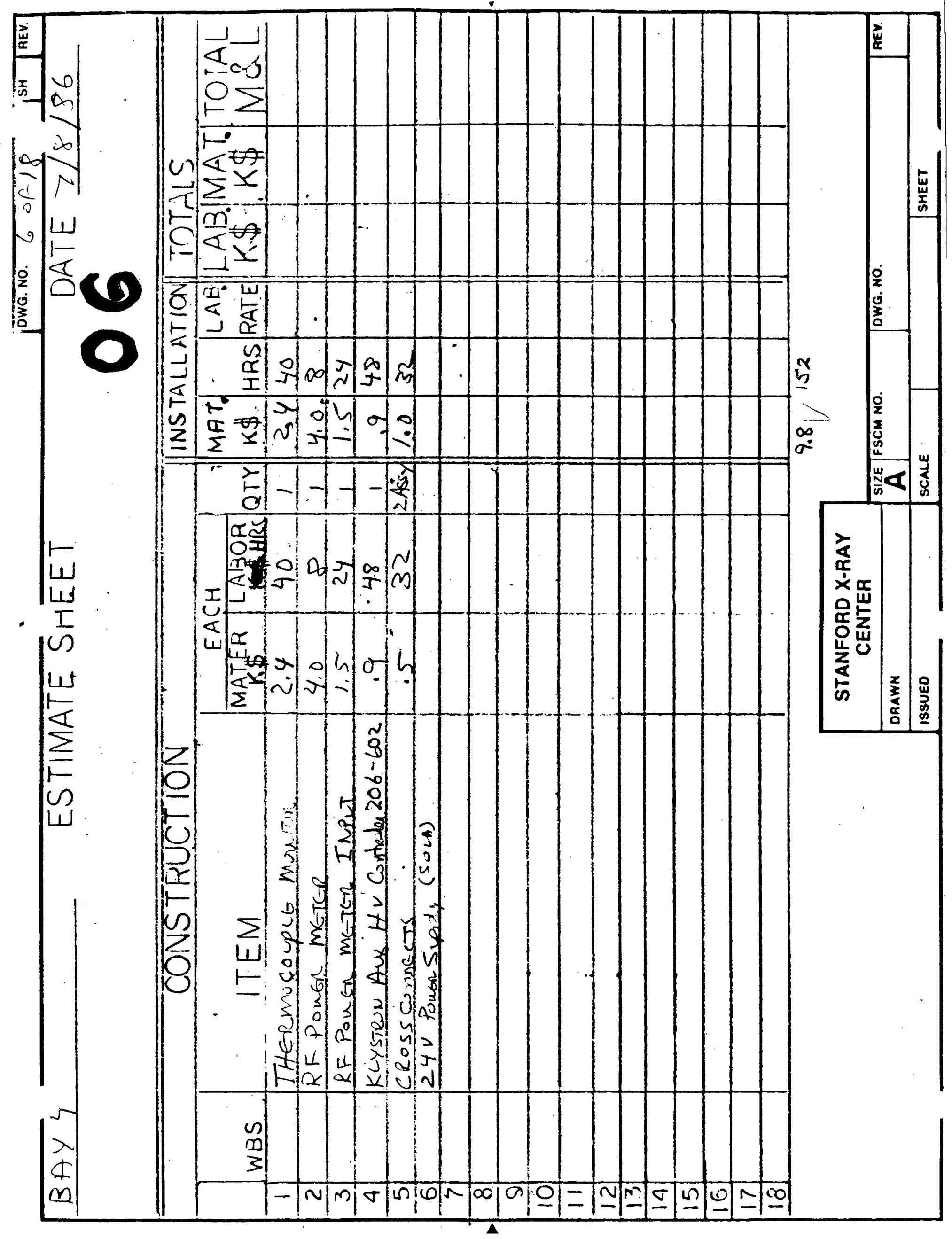




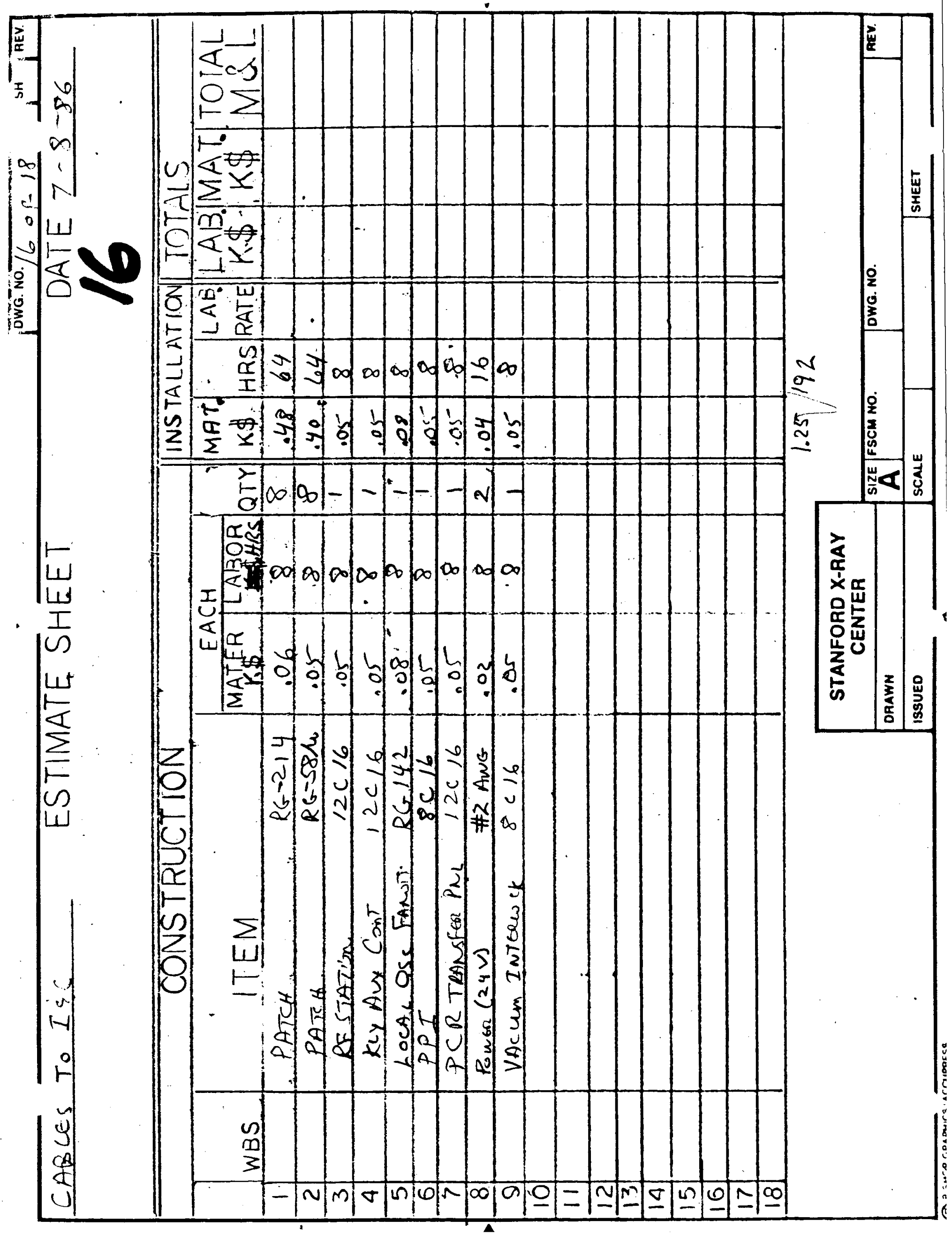




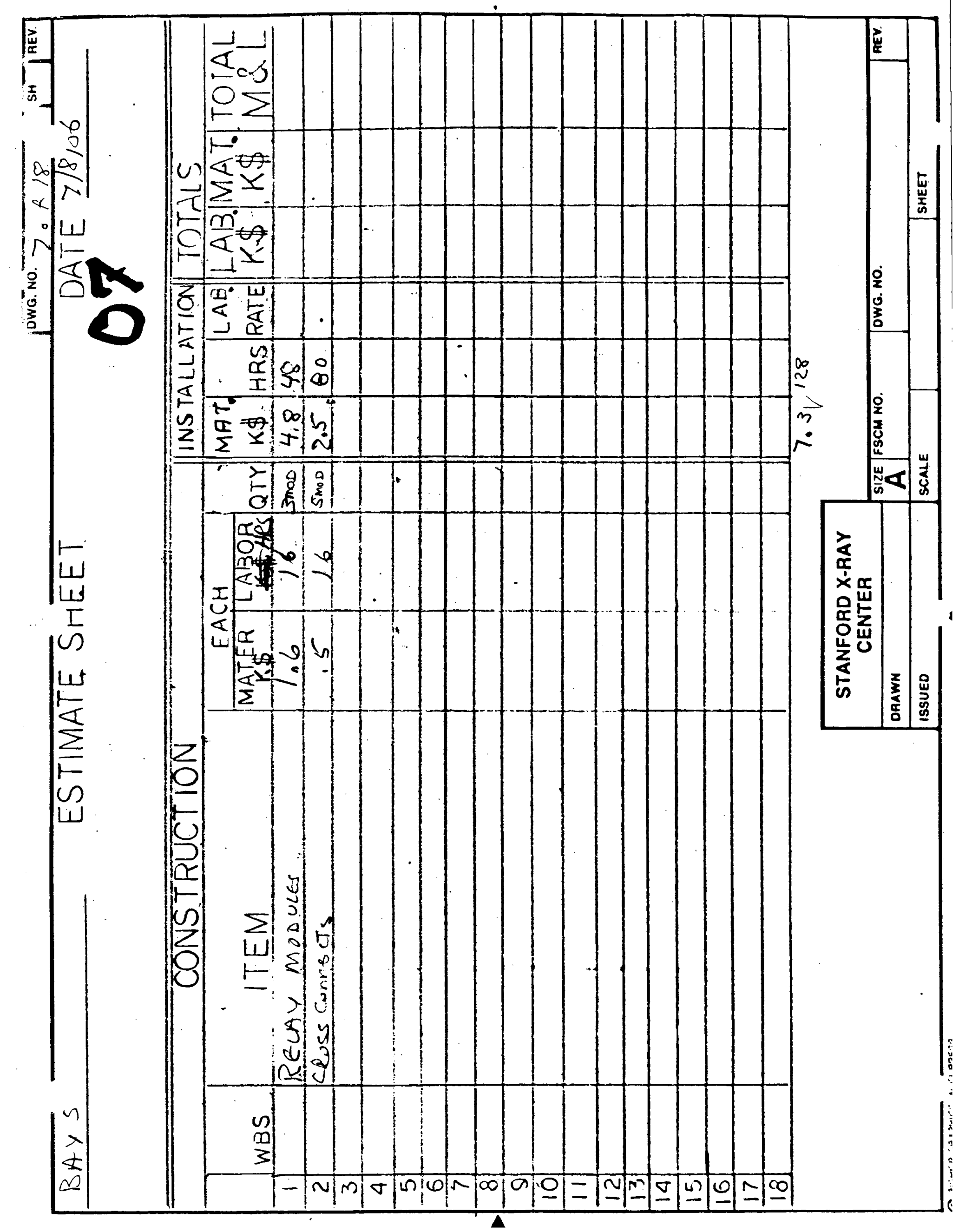




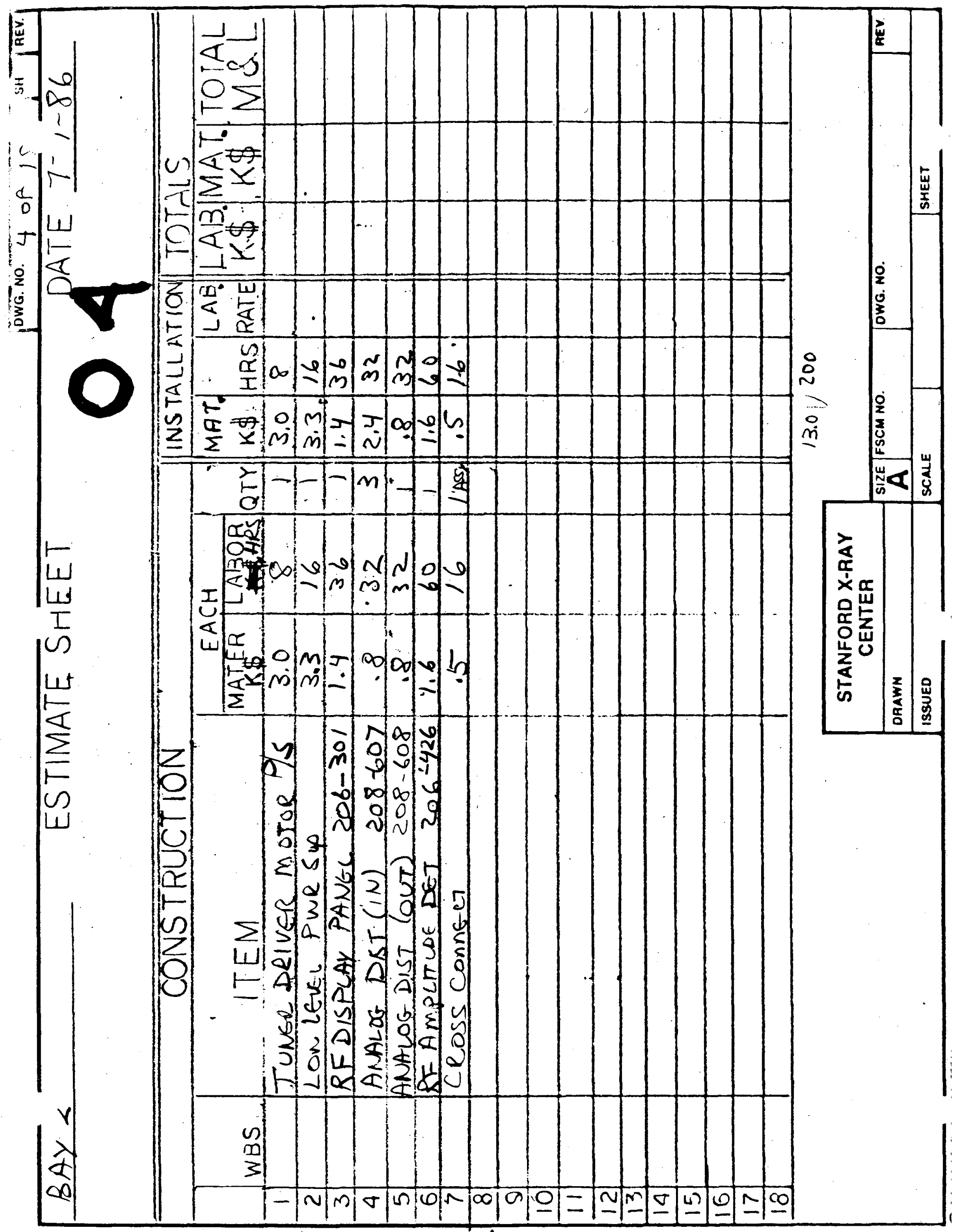




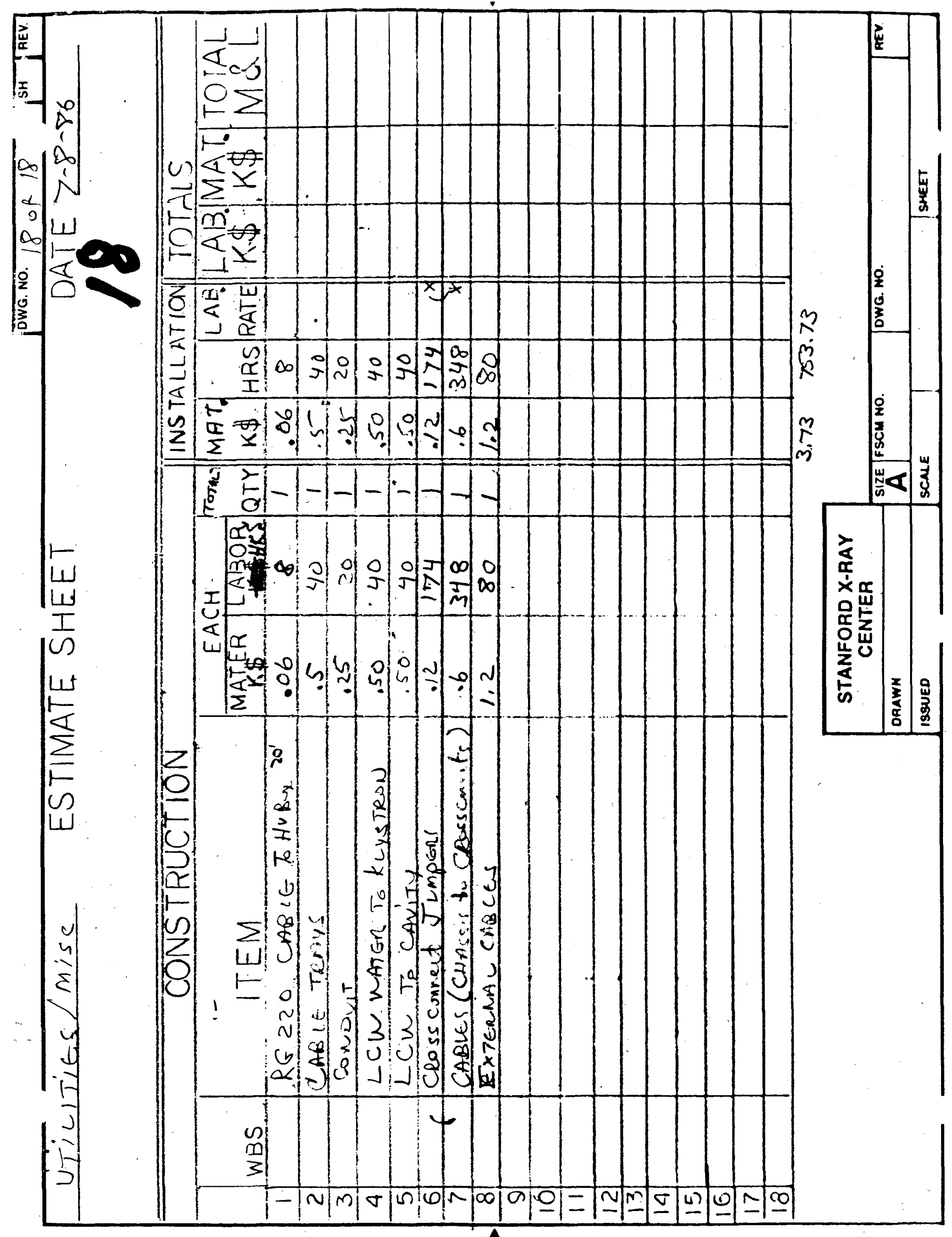




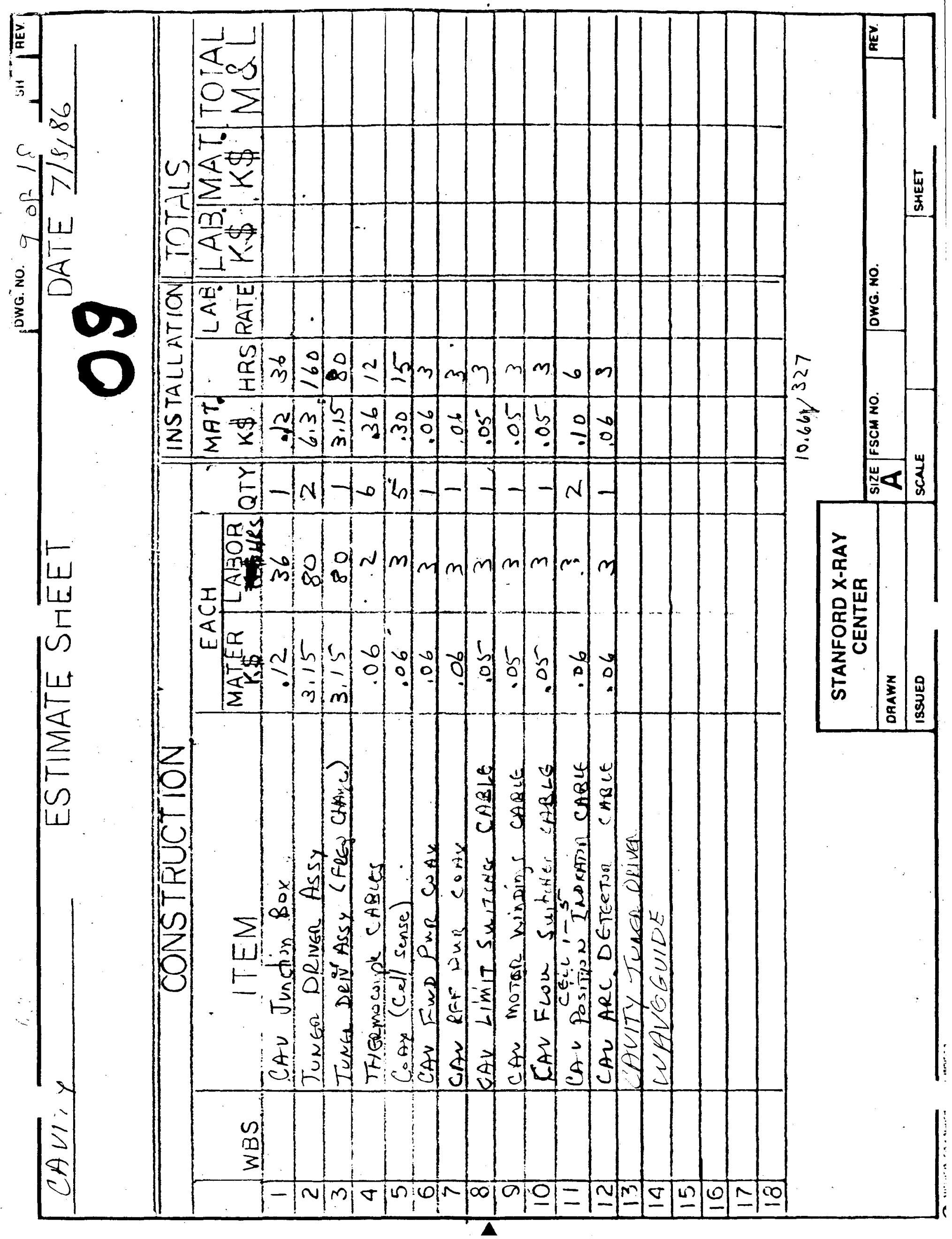




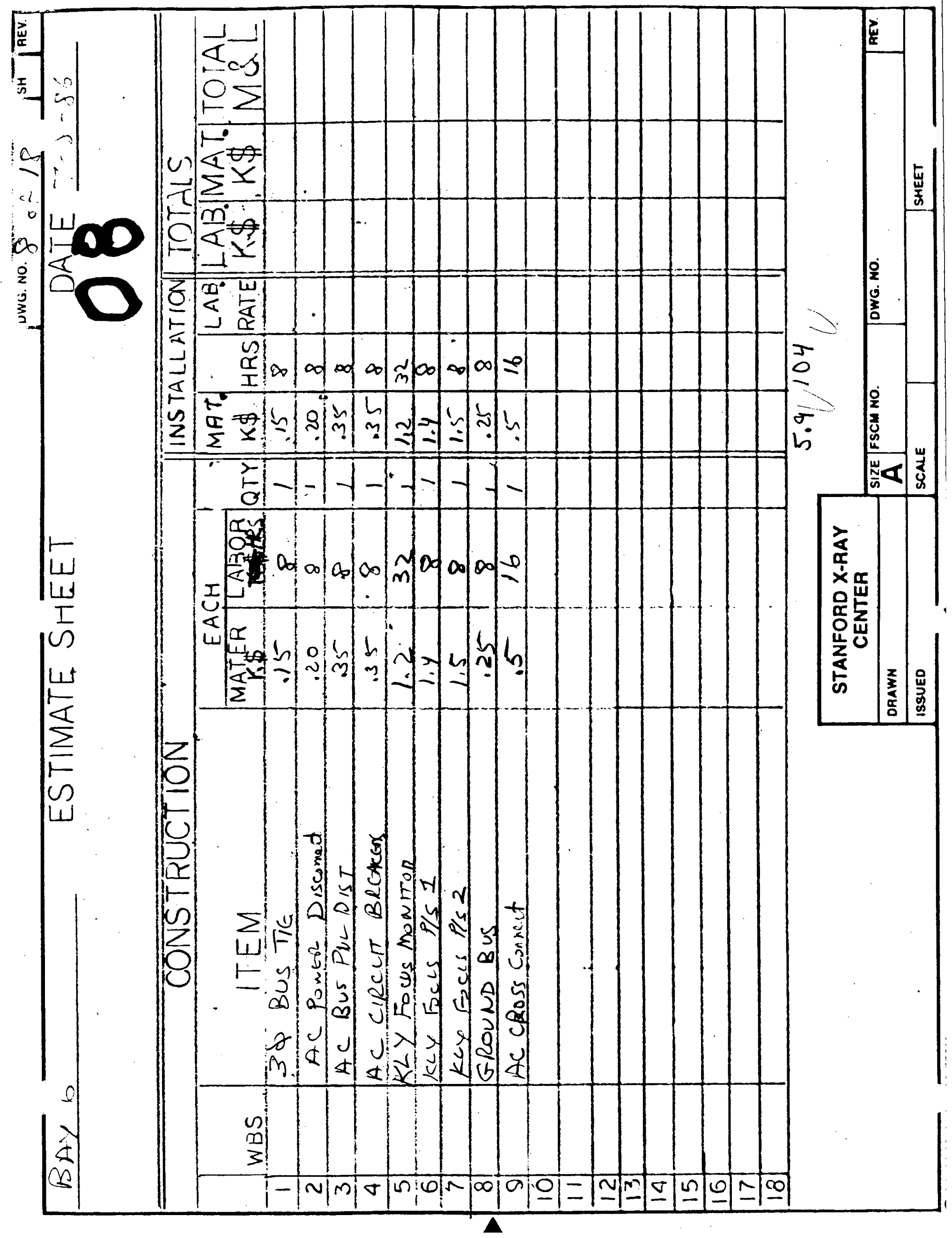




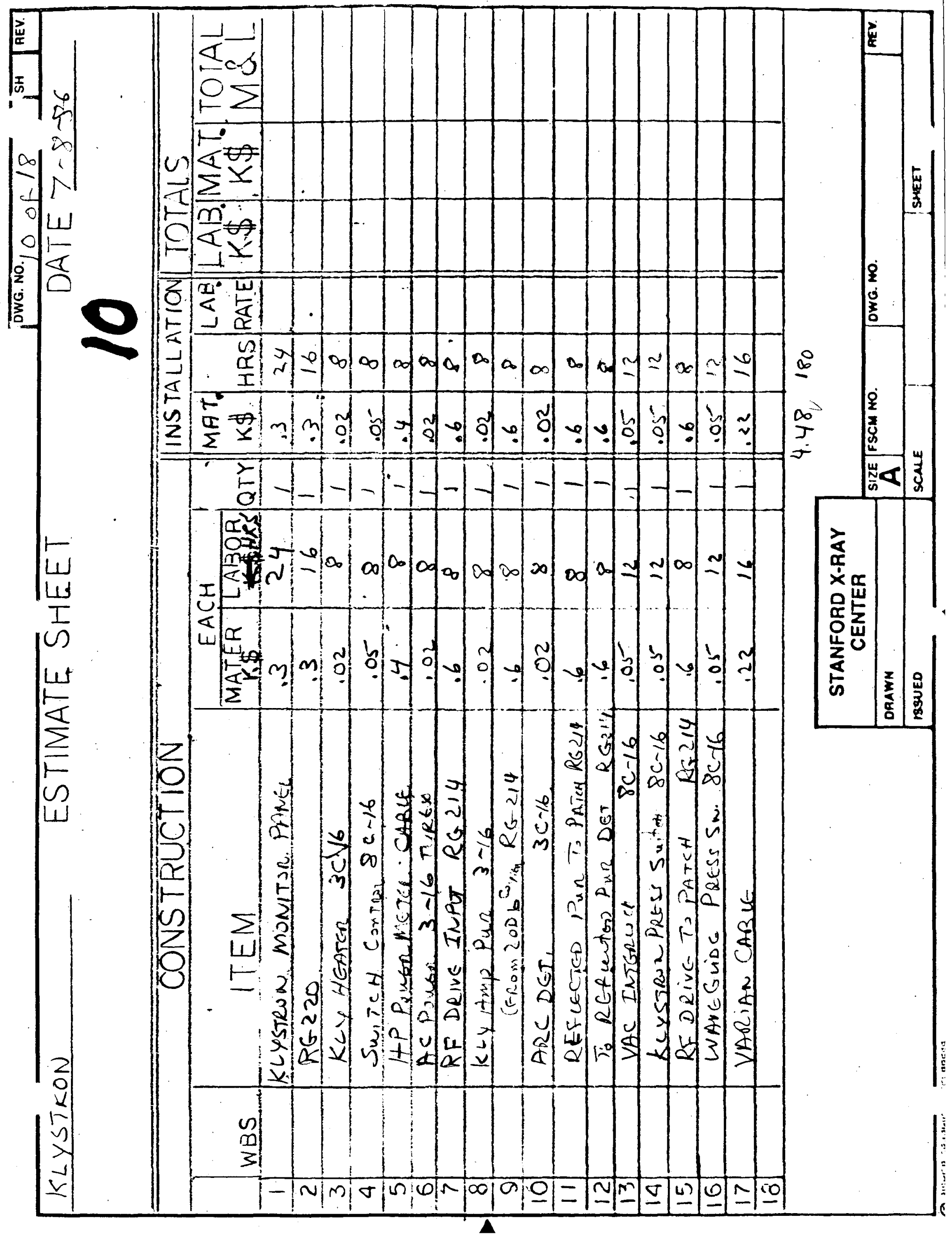




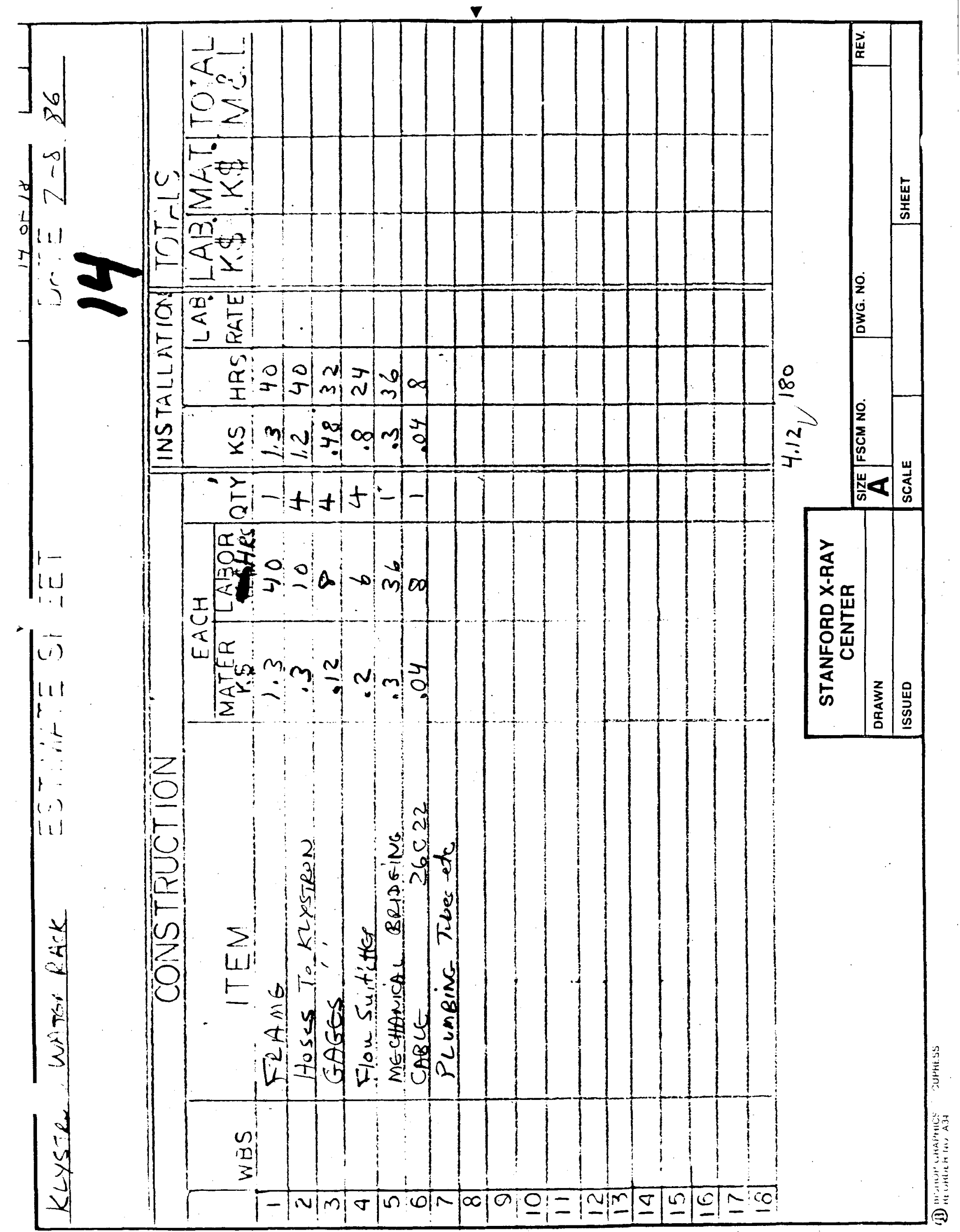




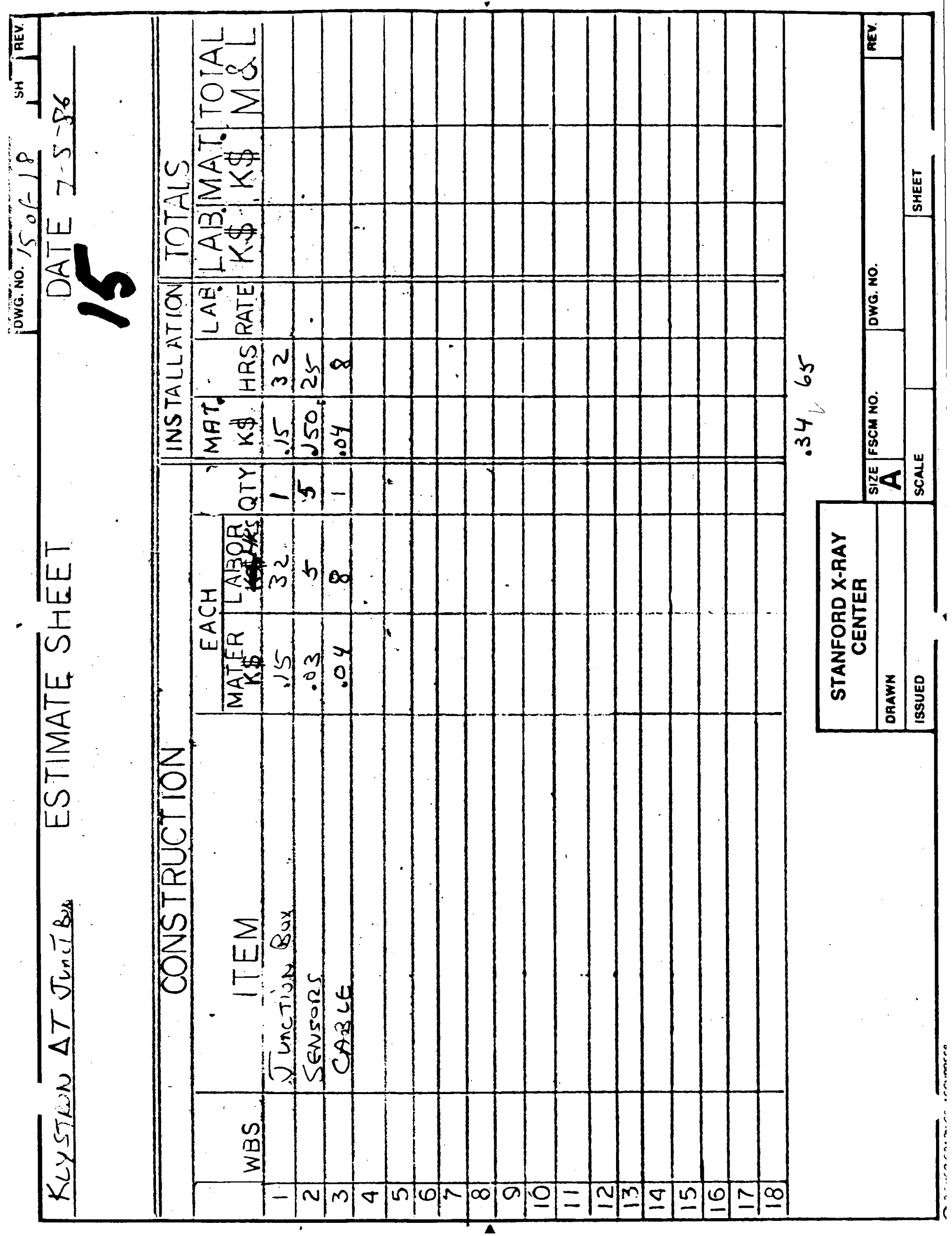




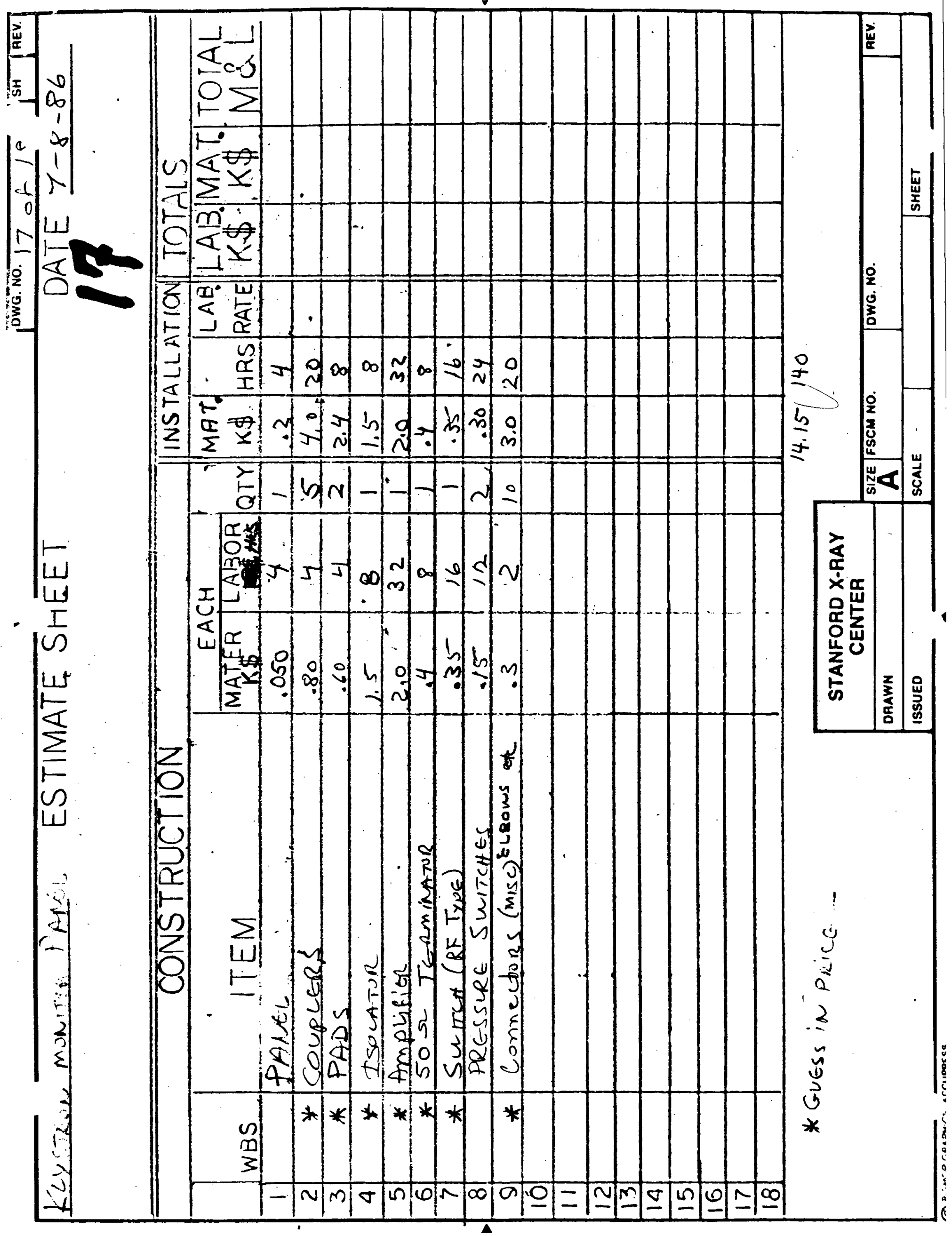




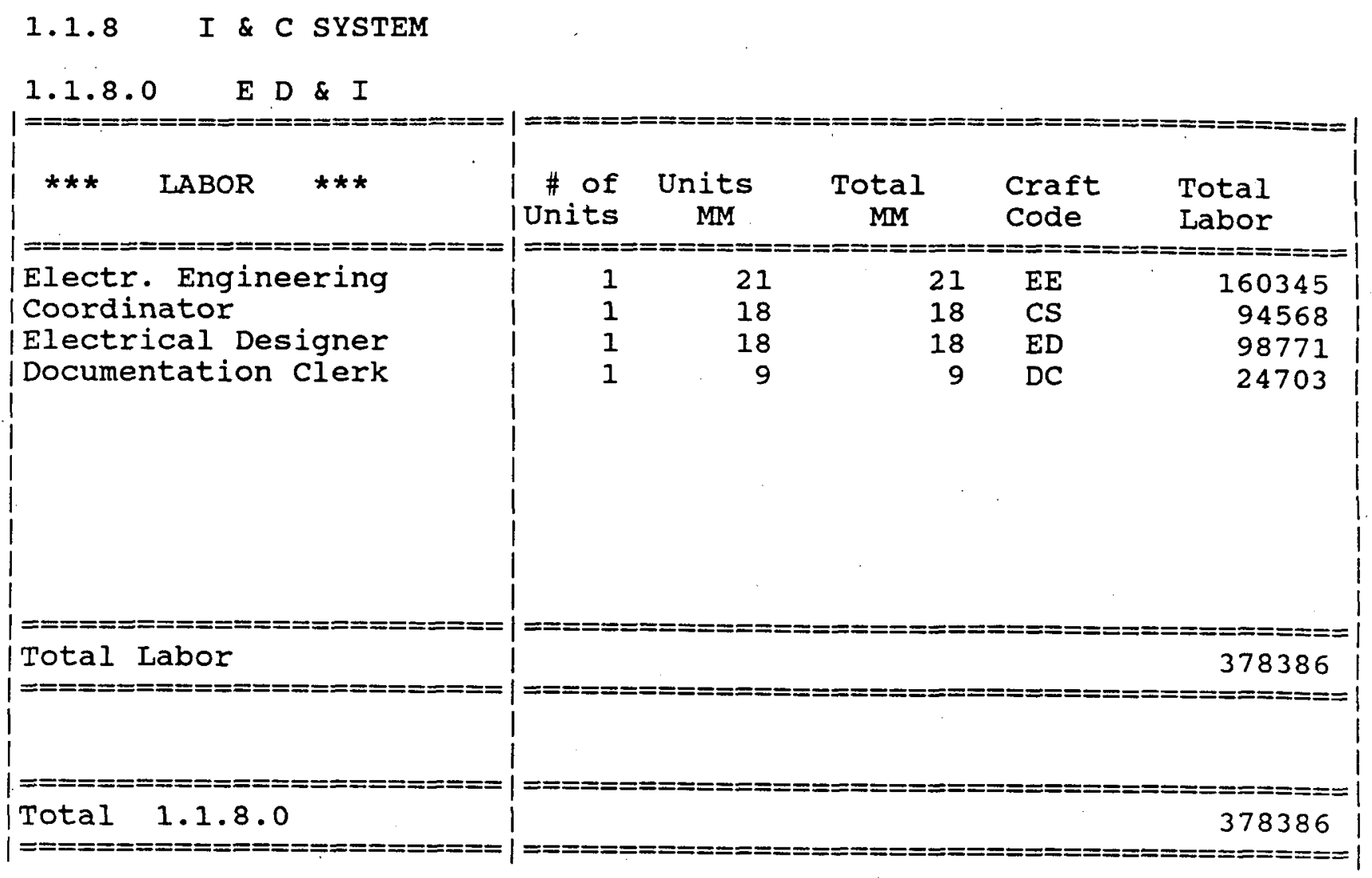


1.1.8 I \& C SYSTEM

1.1.8.1 Beam Diagnostics

1.1.8.1.1 Beam Position Monitoring

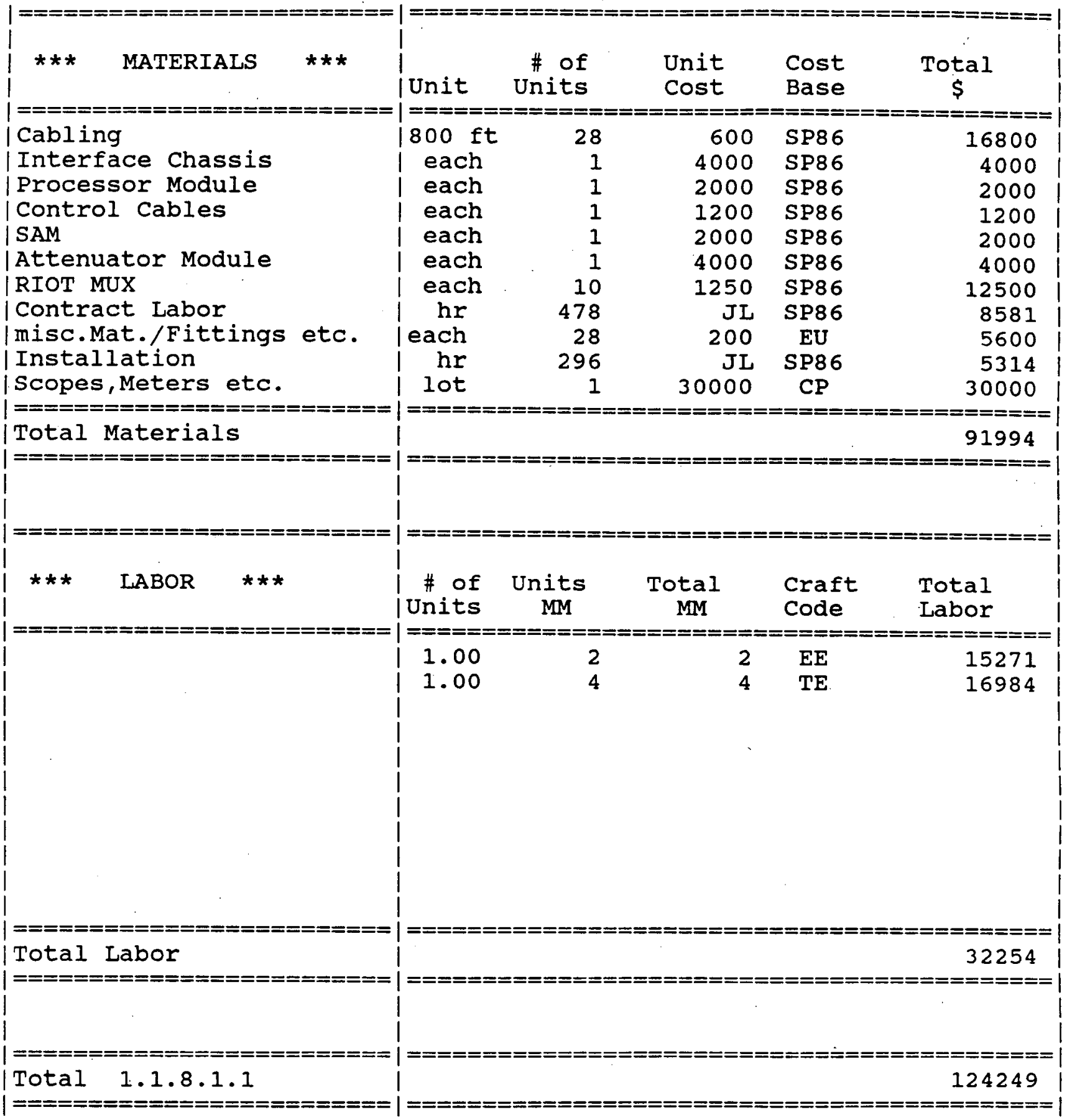




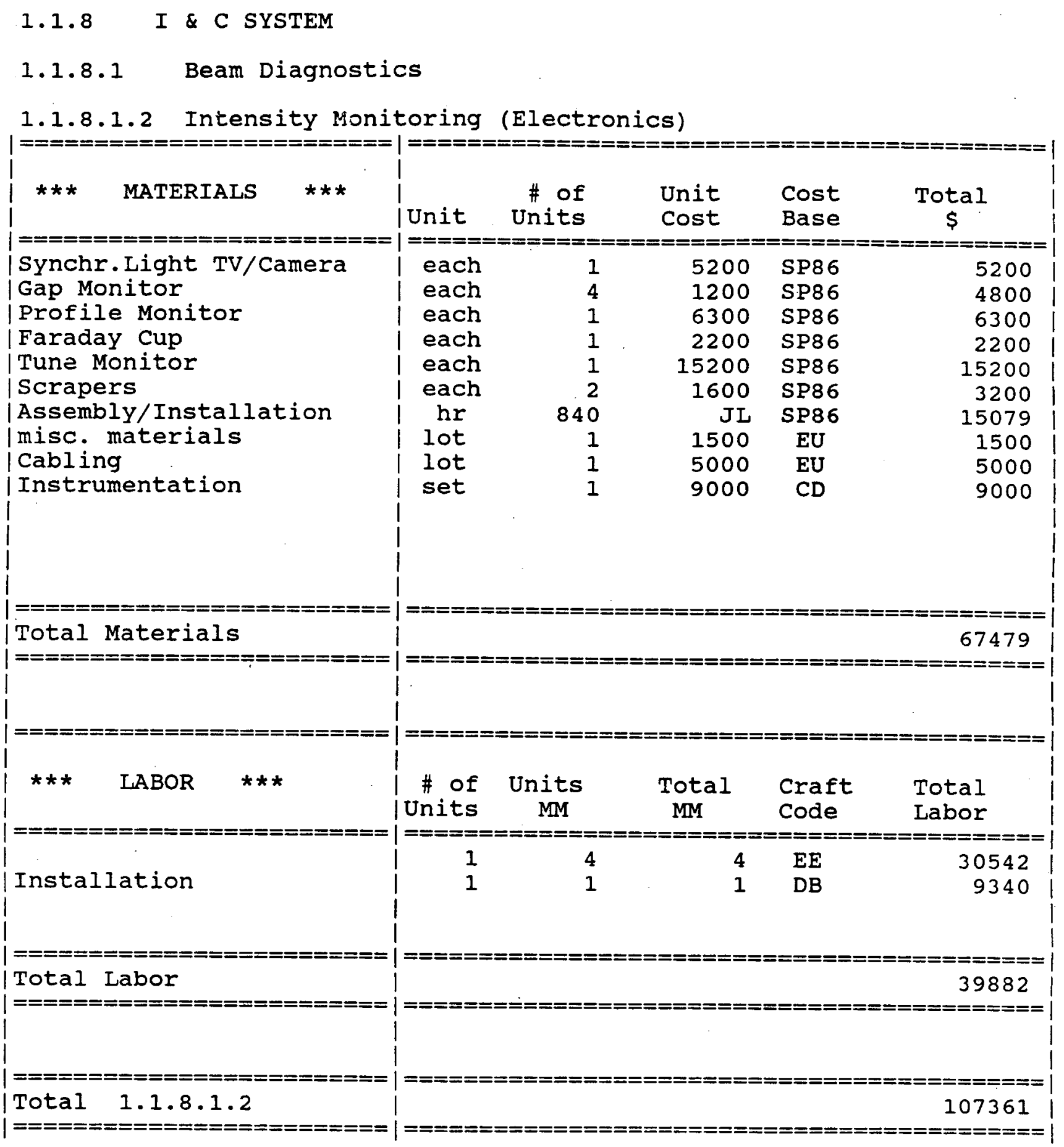




\section{1 .8 I \& C SYSTEM}

\subsubsection{Beam Diagnostics}

\subsection{Timing System}

$\mid=============1$

*** MATERIALS $* * *$

|

| Master Oscillator

Set of Prog. Delay Units

Inj./Ejec. Timing

contract Labor

Instrumentation$$
\text { I }
$$

$$
1
$$

$$
1
$$

$$
\text { | }
$$

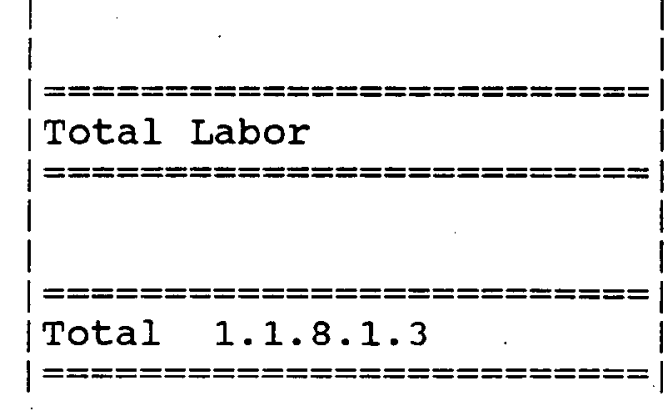




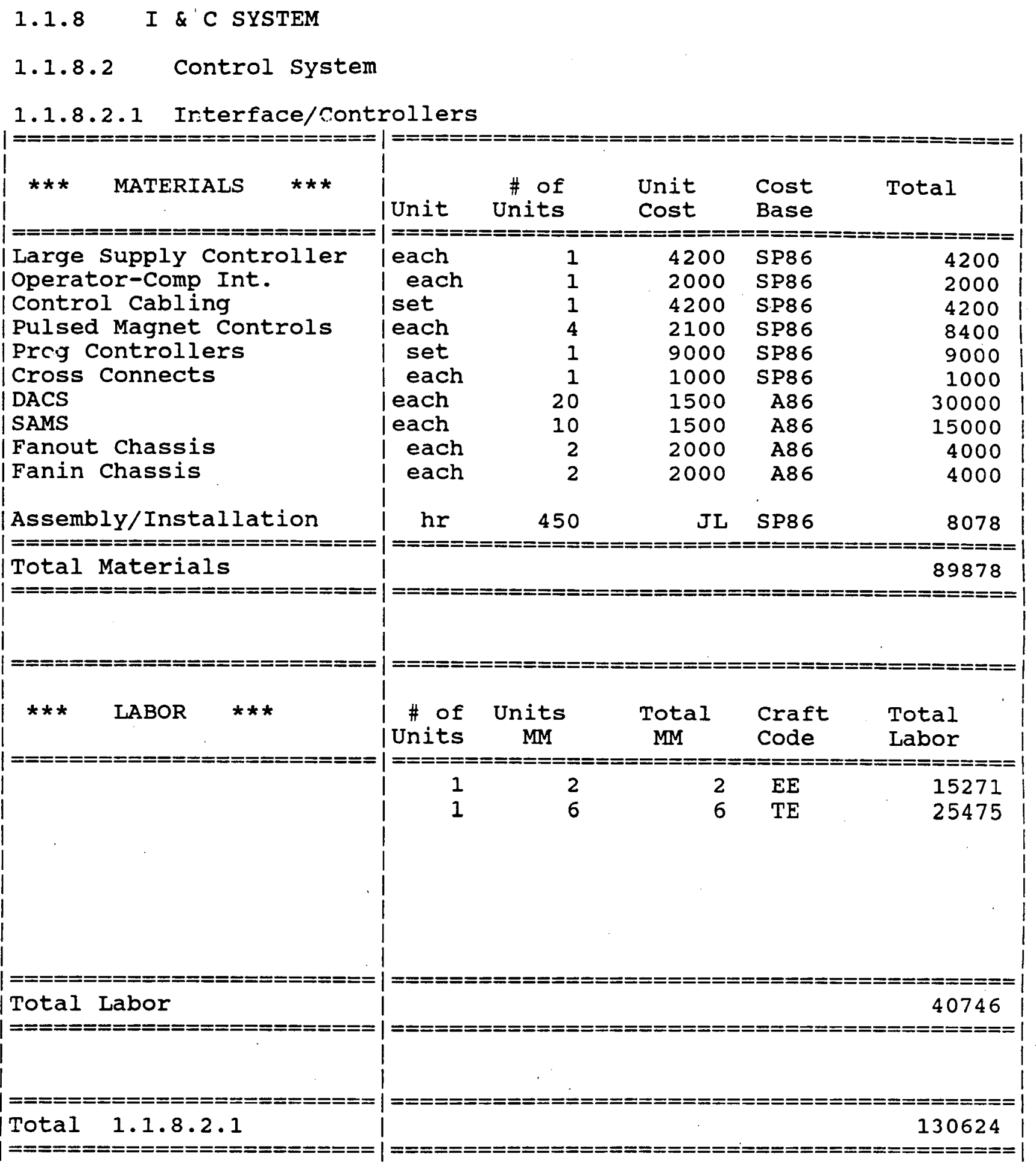


1.1 .8

I \& C SYSTEM

1.1.8.2 Control system

\subsection{Software}

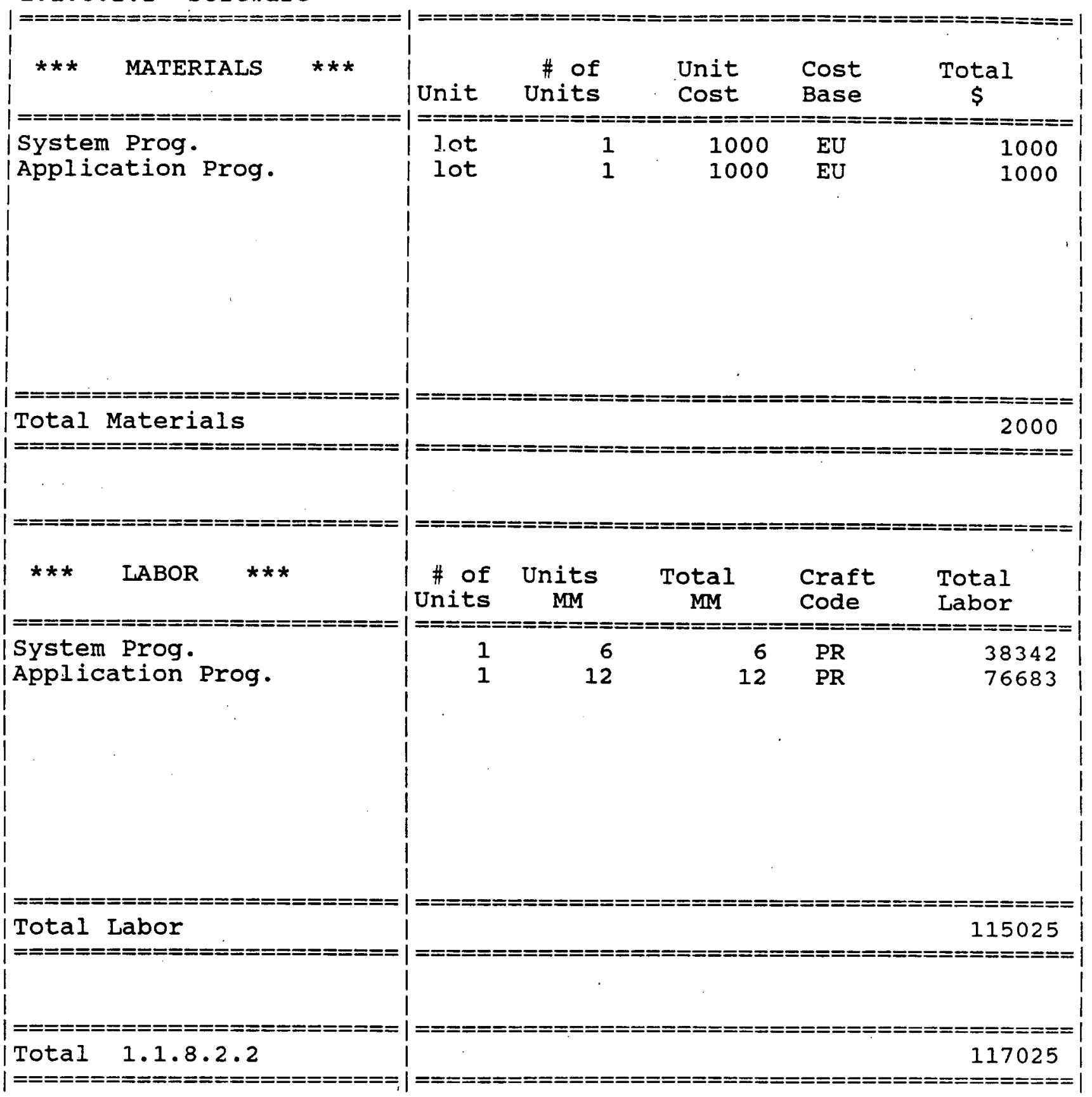


1.1.8. I \& C SYSTEM

1.1.8.2 Control System

1.1.8.2.3 Racks/Cables/Tr

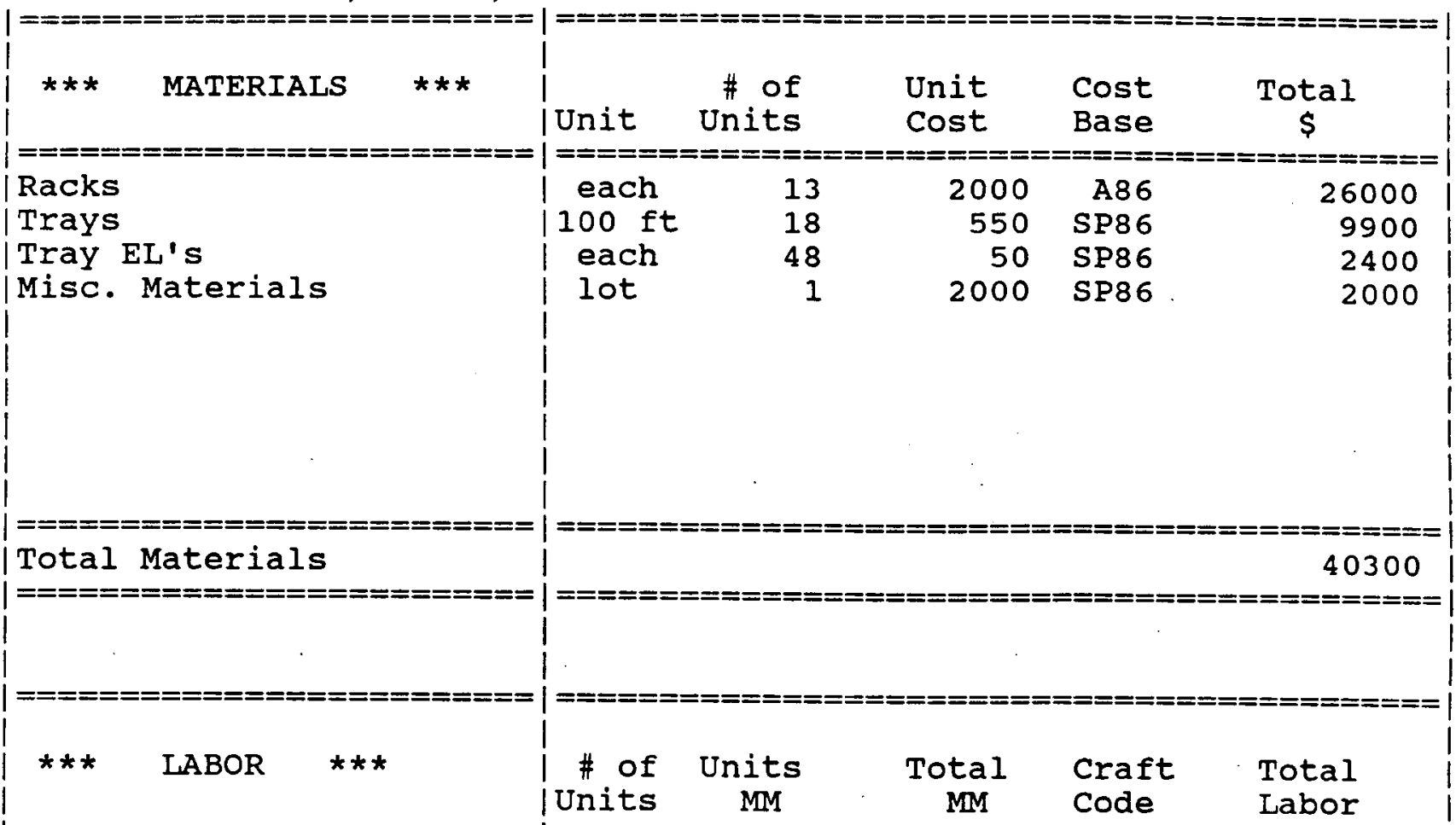

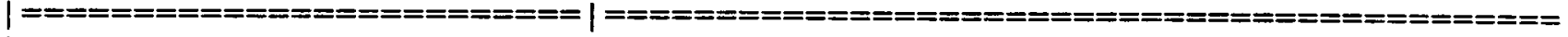

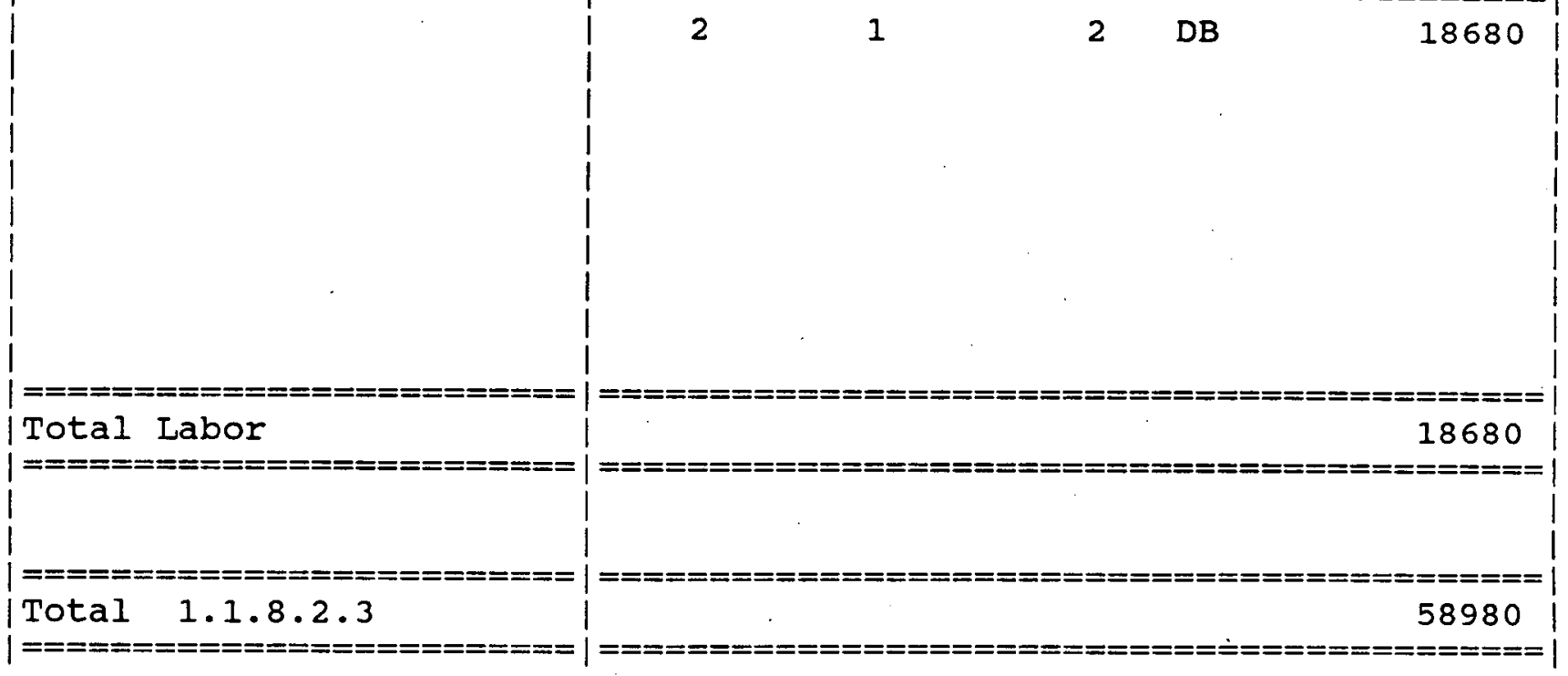


1.1 .8 I \& C SYSTEM

\subsubsection{Control System \\ 1.1.8.2.4 Computer controls}

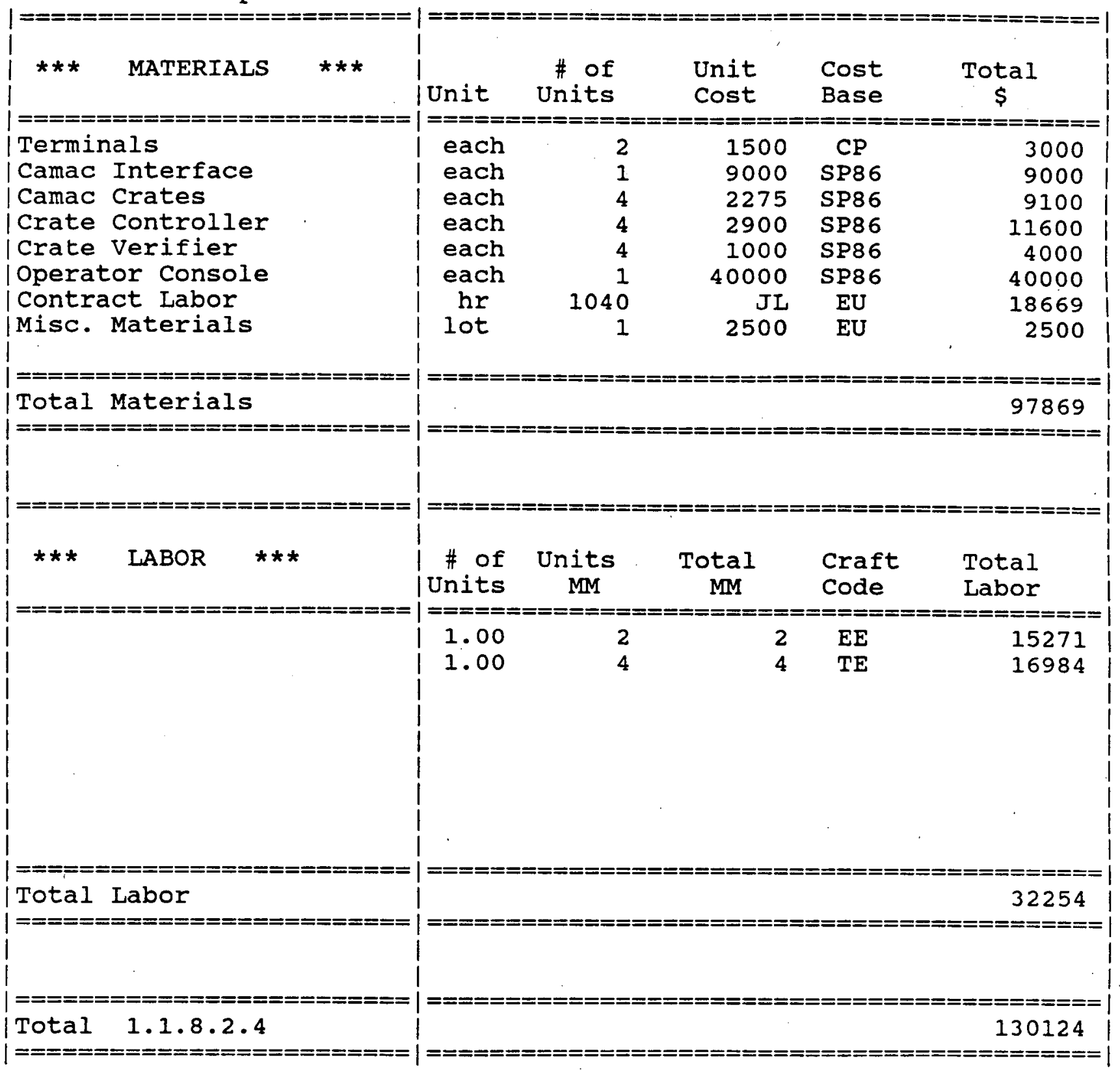




\subsubsection{I \& C System}

\subsubsection{Protection System}

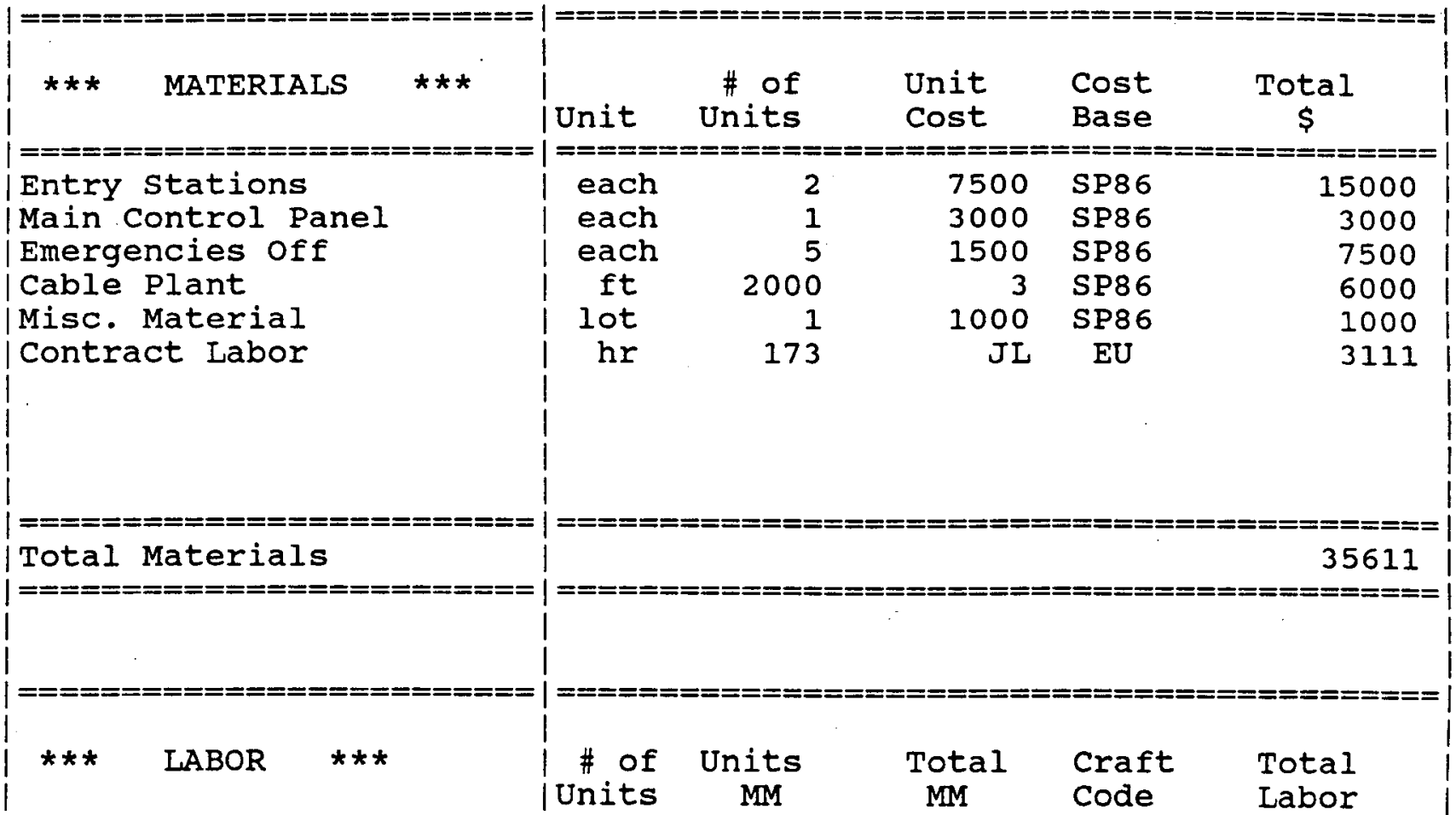

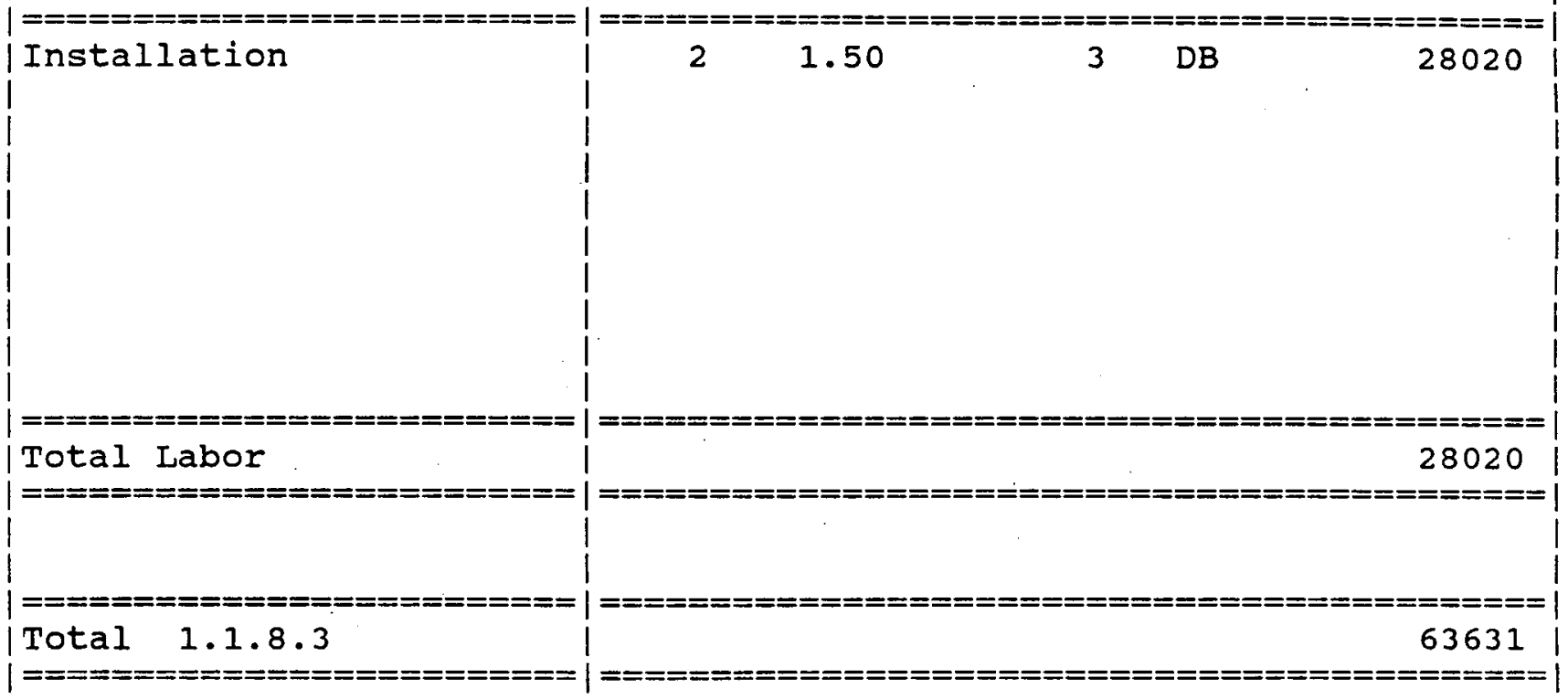




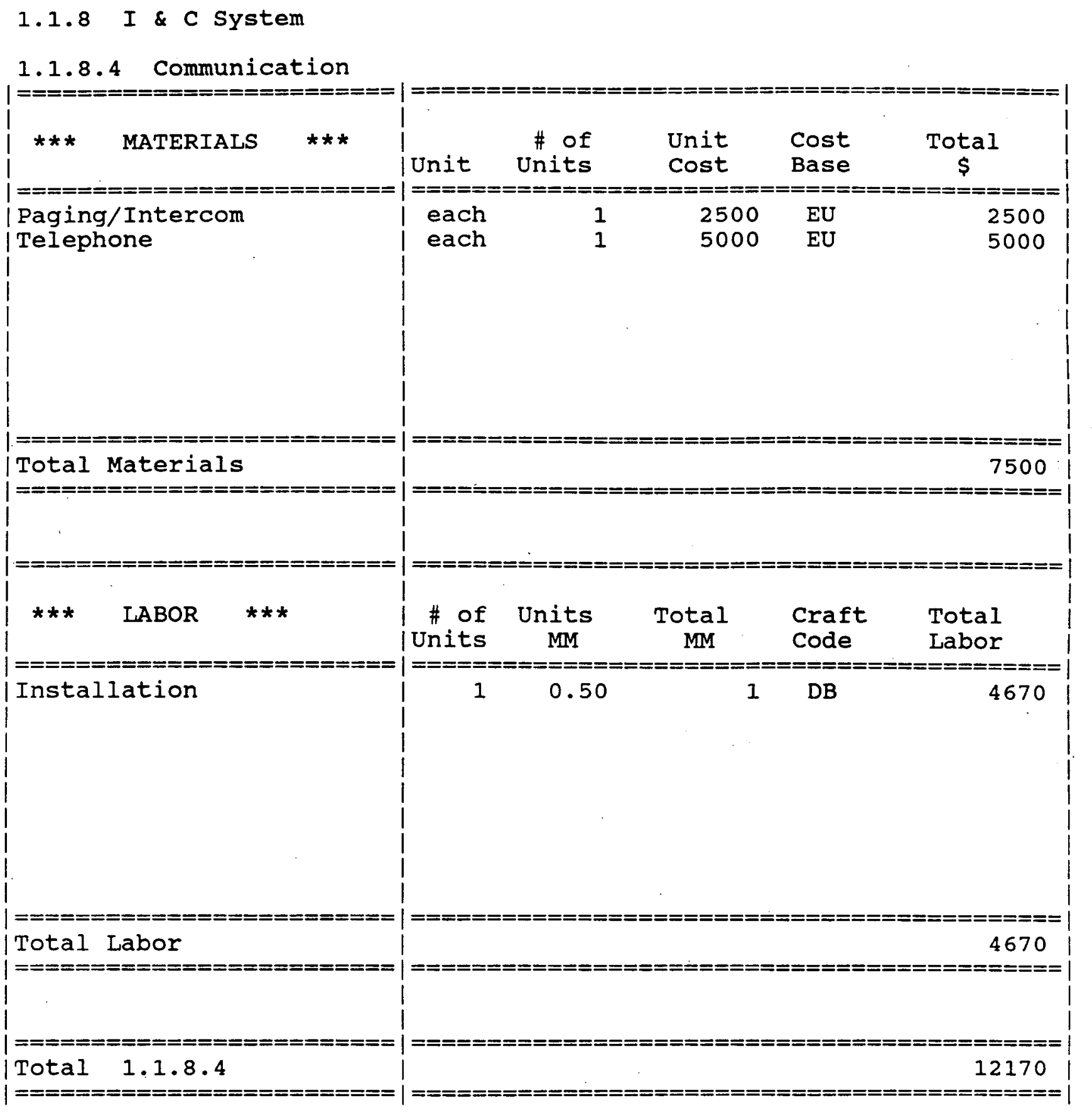




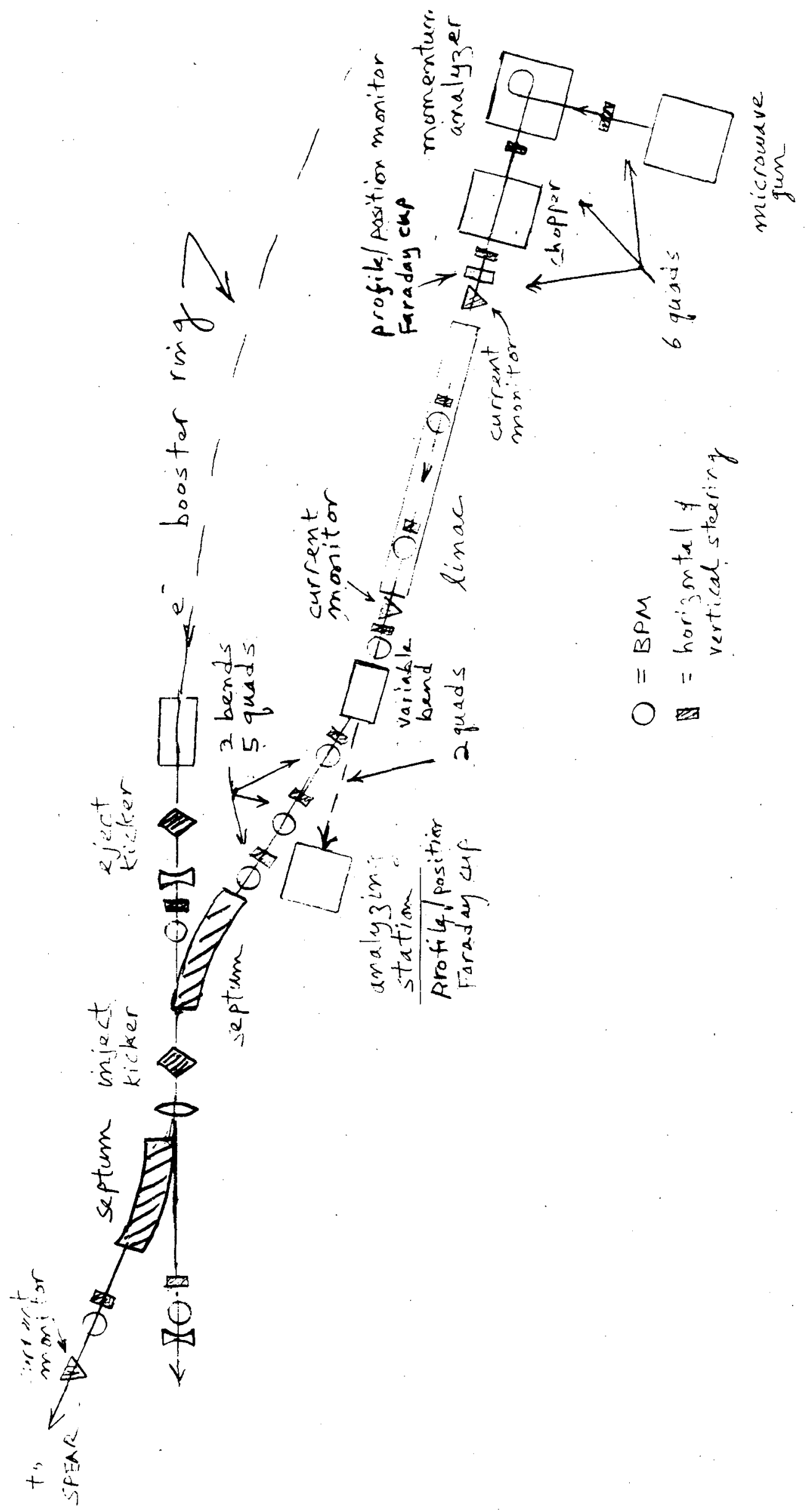




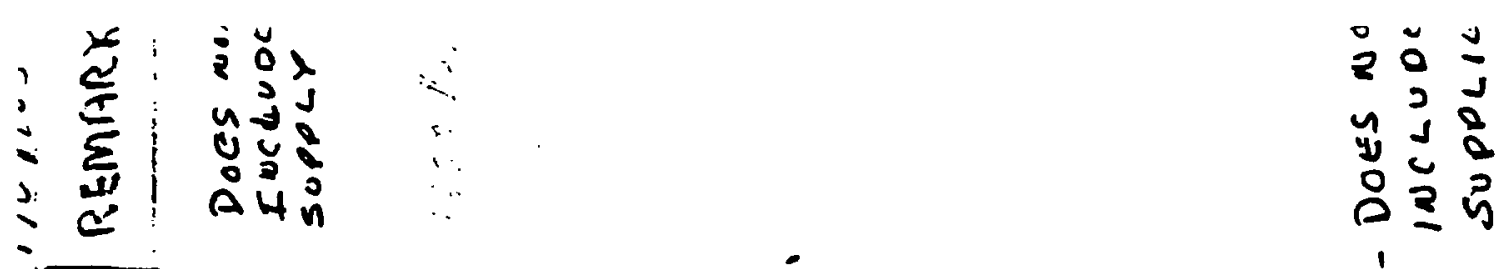

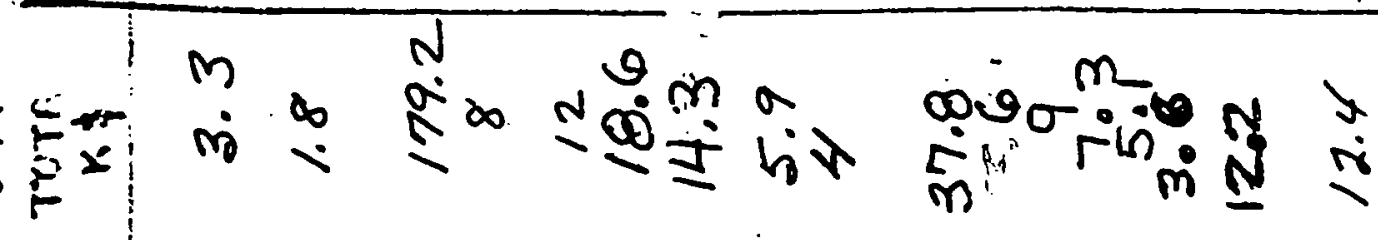

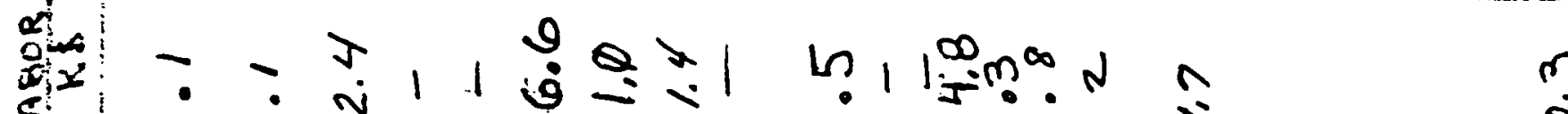

;

(i)

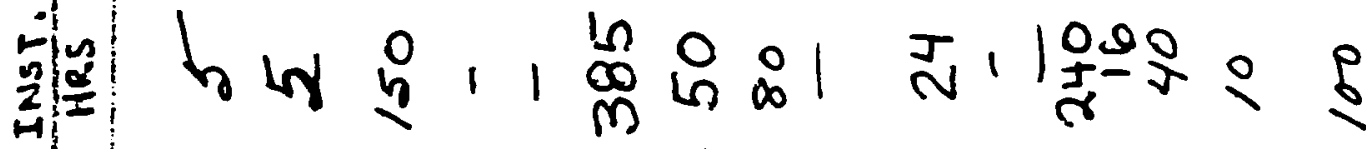

$\underline{9}$

E

$=1 x$

b. $1111-1$ ist $111-1 \div$

ns

ó

it

$\frac{2}{2} \int_{0}^{2}$

ก. 1

$1,1, \frac{m}{2} 1$

100,1

वृ के

요 1 f

$\infty$

$\pm$

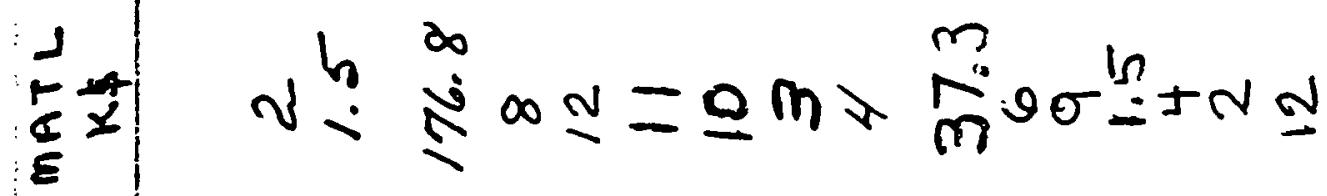

$\infty$

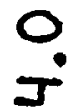

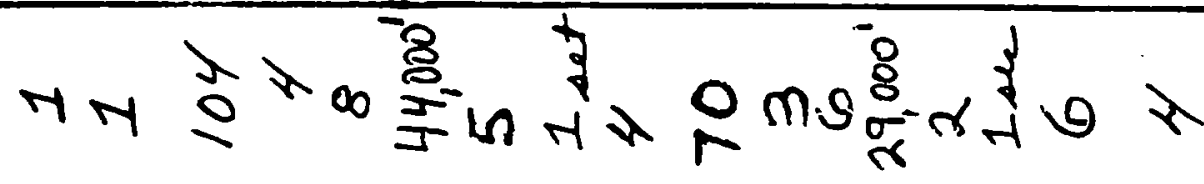

0

-

$\frac{8}{21}$

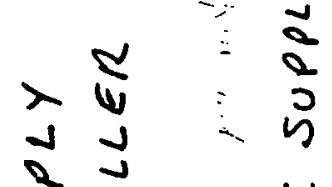

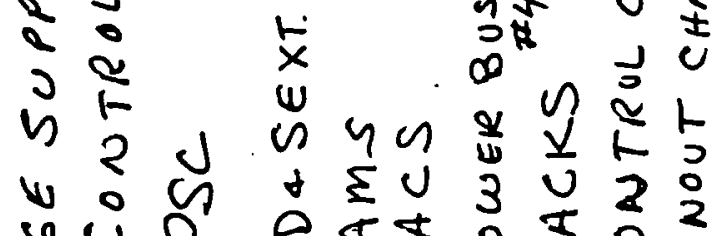

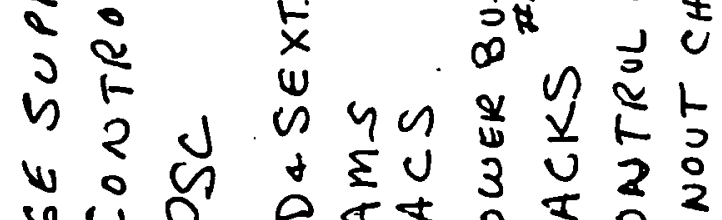

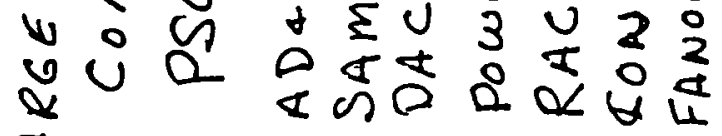

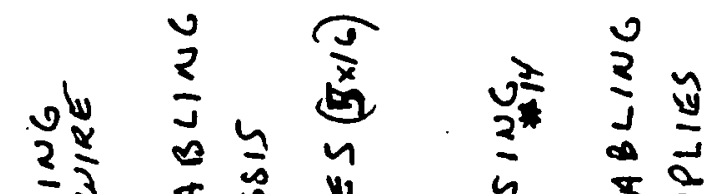

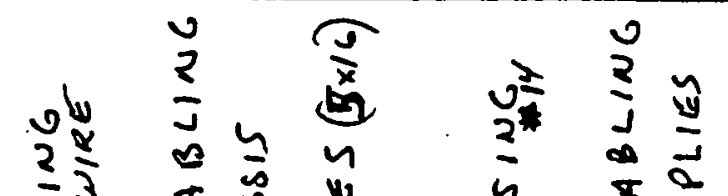

$\stackrel{0}{2}$

$-3$

+ is $v$

u

v $\quad 00 \frac{L \varepsilon l}{2 h)}$

v $\quad 00 \frac{L \varepsilon l}{2 h)}$

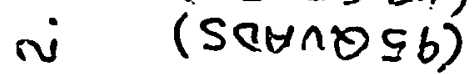

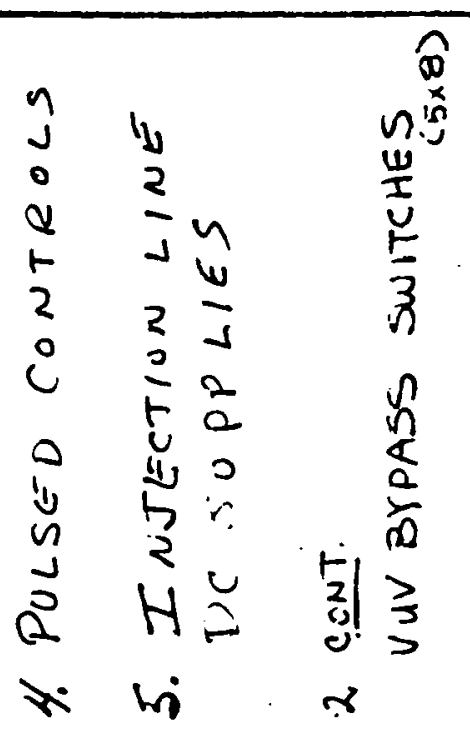


n

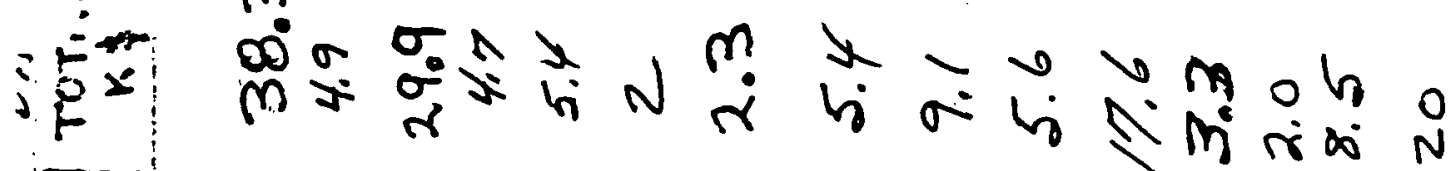

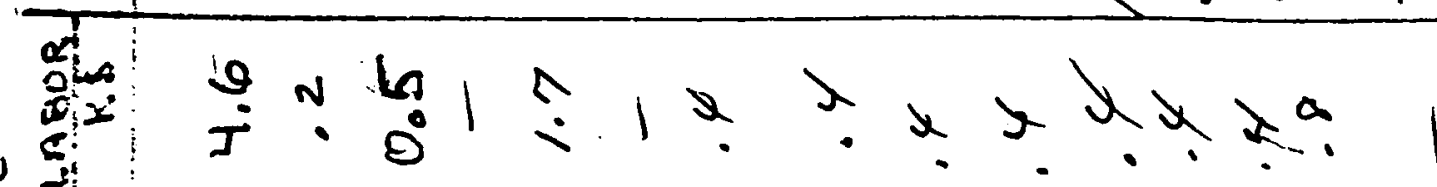

-

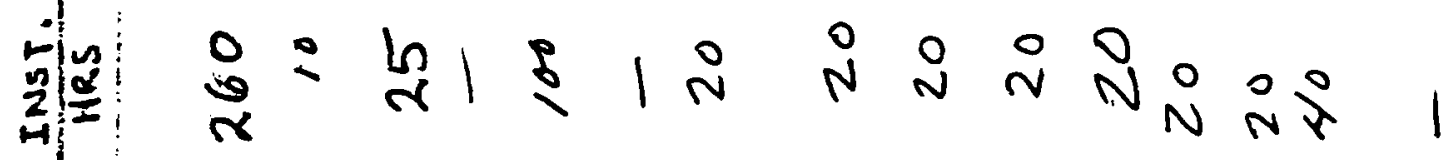

$:$ 官

$\frac{1}{2} 2$

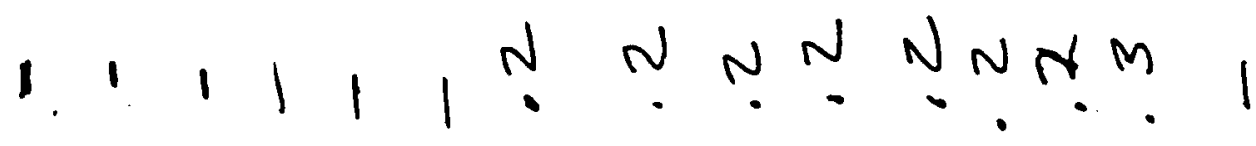

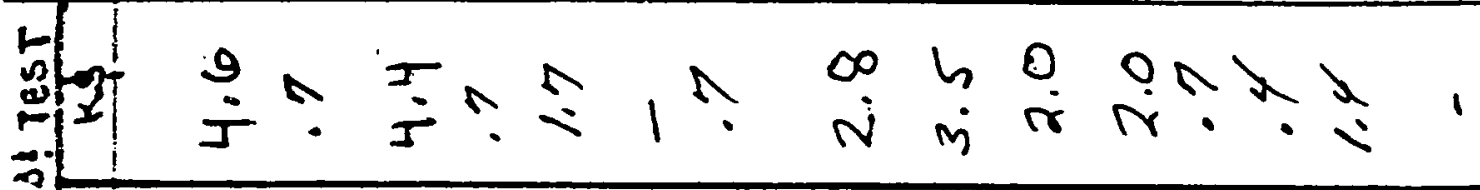

部

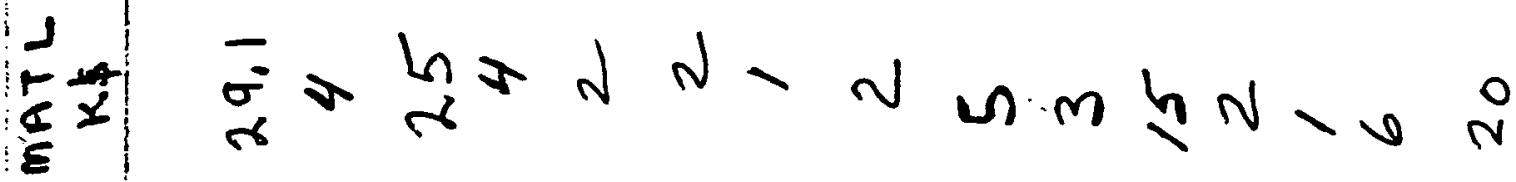

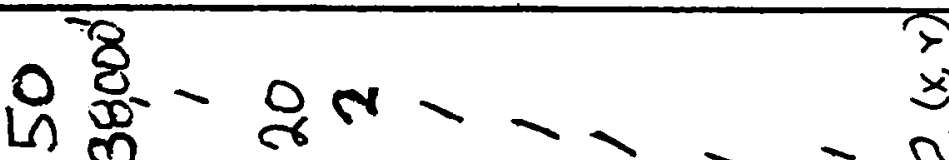

n

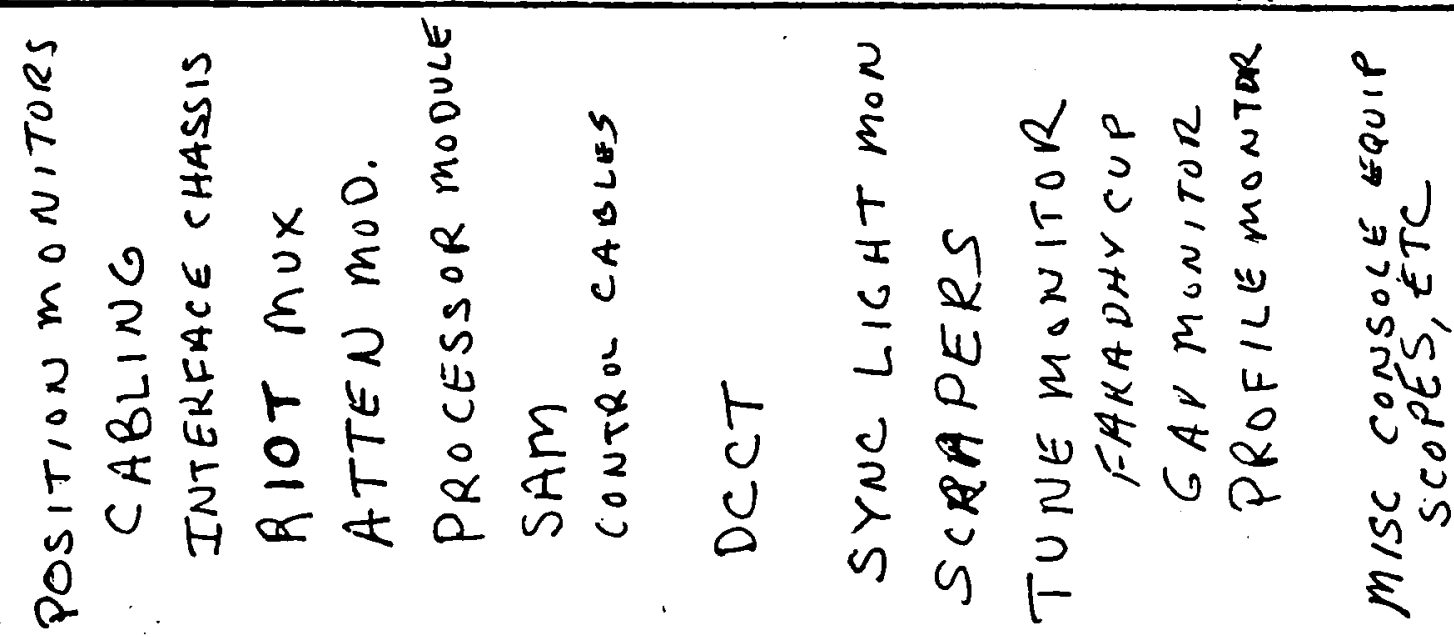

ri $\dot{m}$ i 


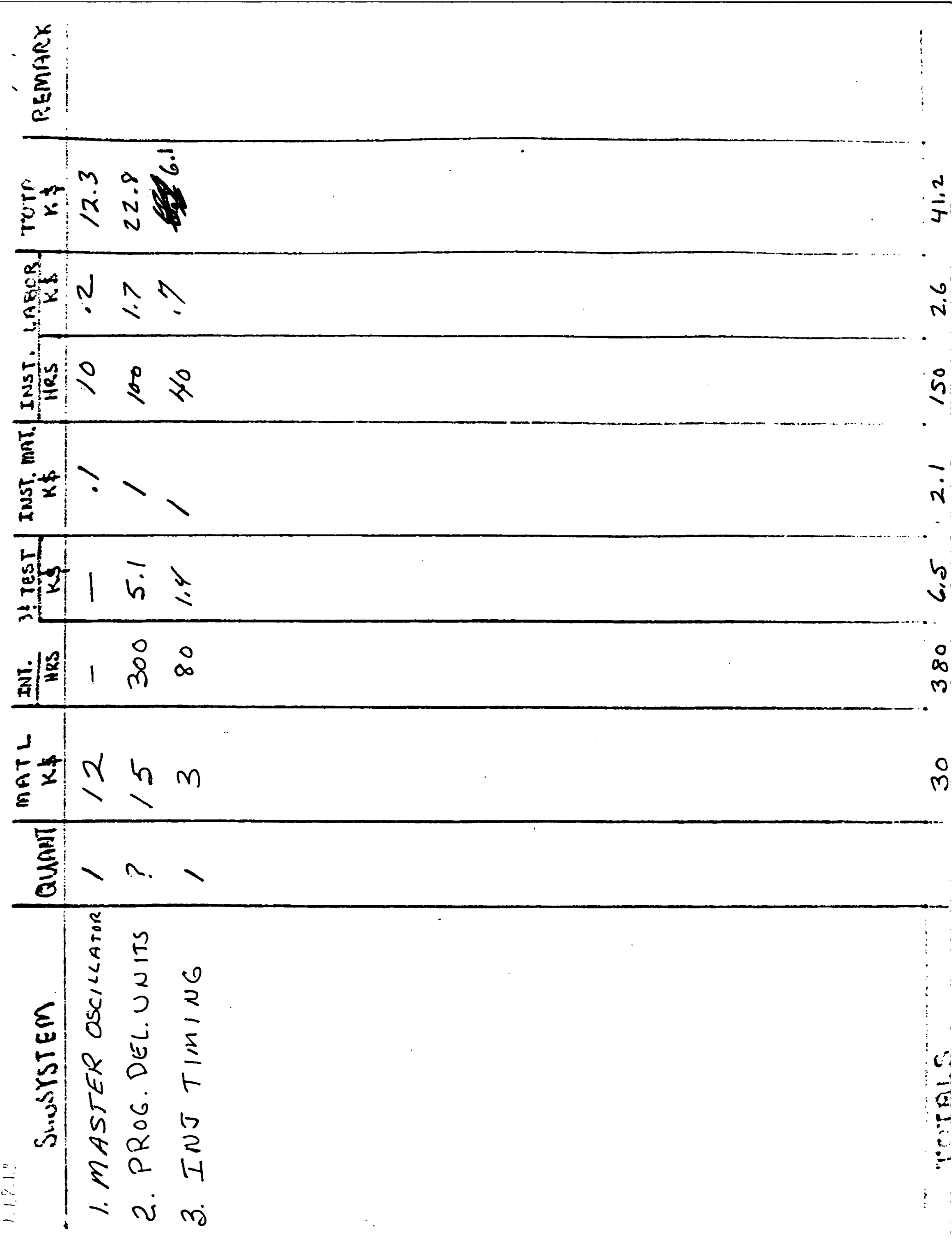




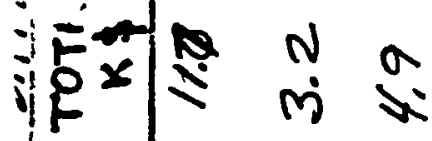

a

$\sum_{-1}^{n} \begin{array}{llll}n & 0 & 0 & 0 \\ 2 & 0 & N\end{array}$

E

$\left.: \frac{\pi}{2} \times\right) \quad N$

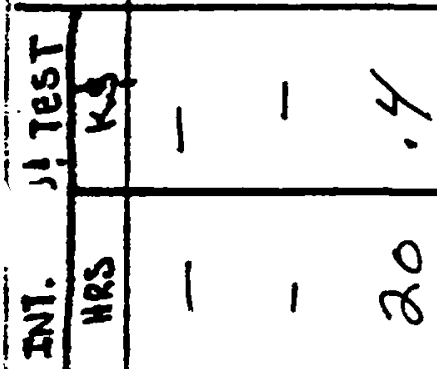

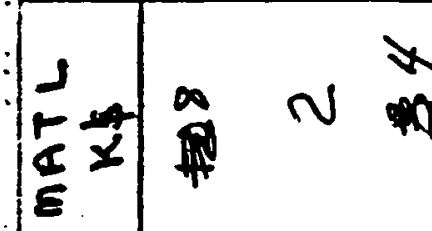

$\sum_{3}^{\frac{E}{3}} H \mathrm{H}$

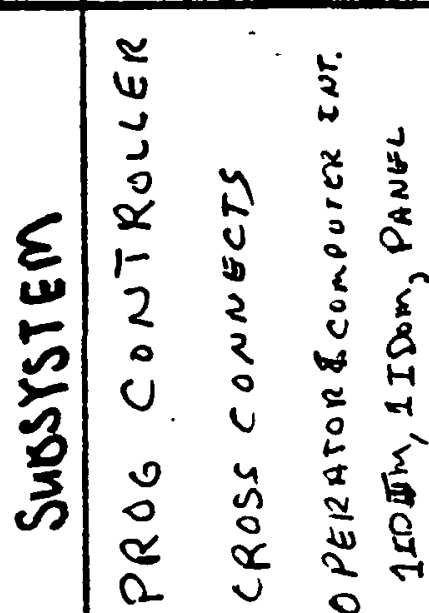

$=\dot{n}$ 


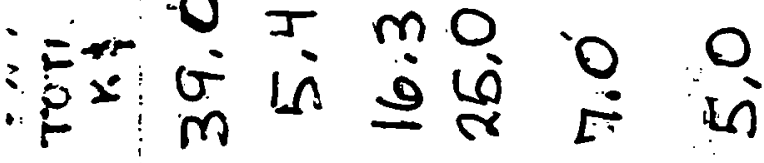

$n$
0

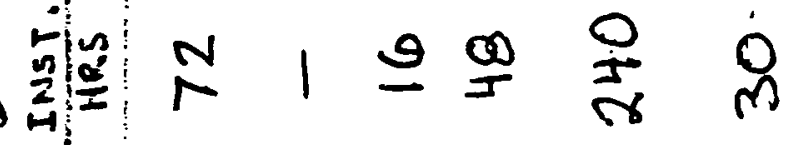

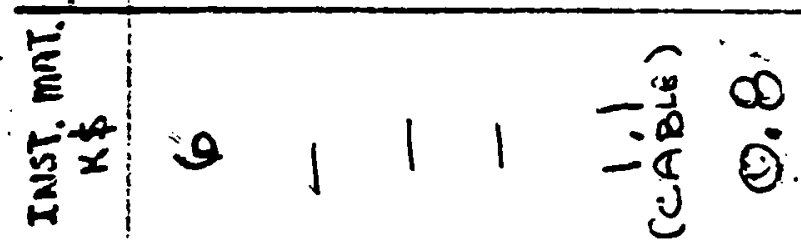

$\operatorname{lil}_{i=1}=111$

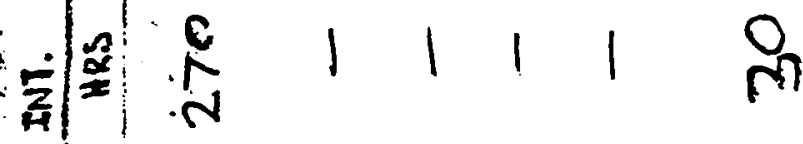

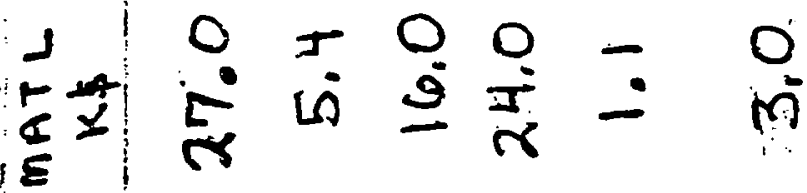

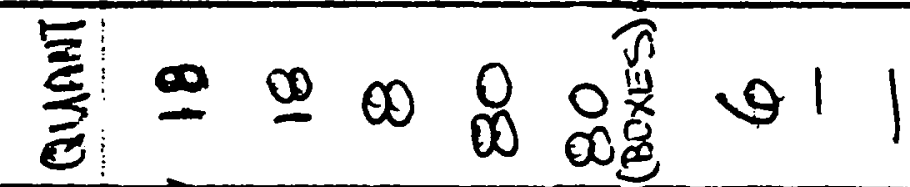

मू⿺

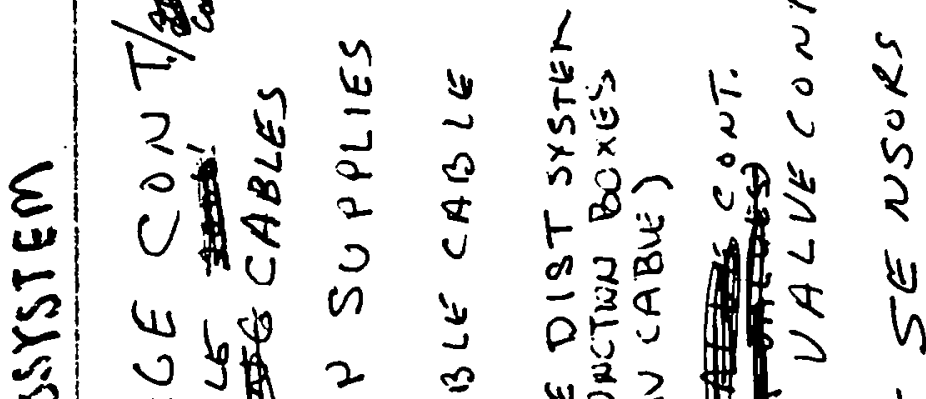

0
\pm

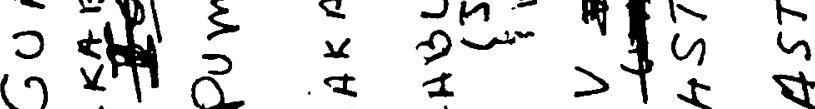

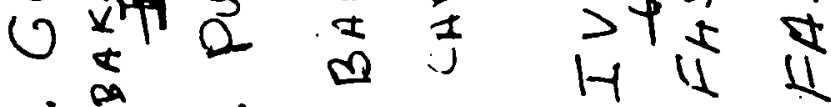

- $\dot{0}$ के 


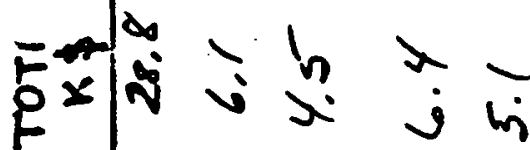

of

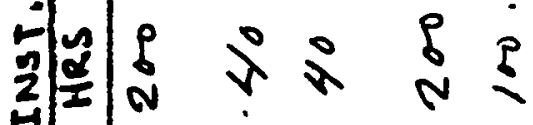

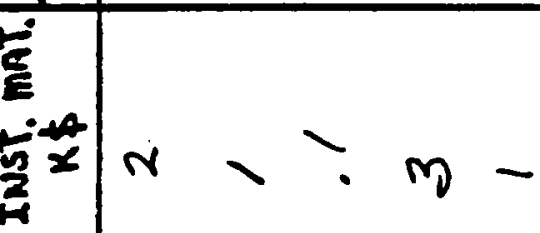

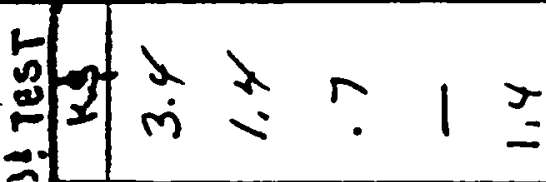

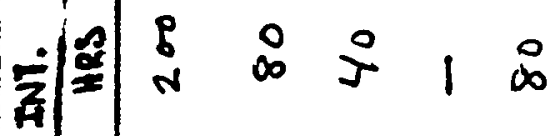

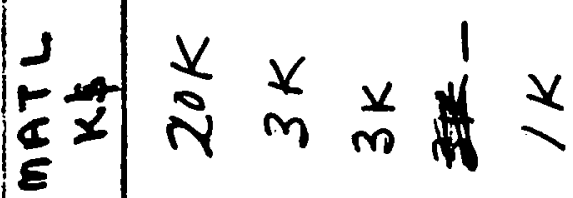

$\sum_{3} d-\circ \frac{p}{b}$

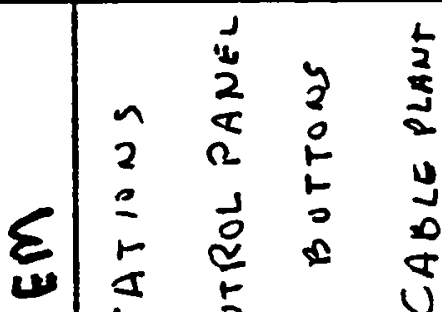

-15 L

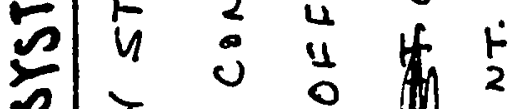

$\begin{array}{llllll} & y & & 0 \\ 5 & \alpha & 2 & 0\end{array}$

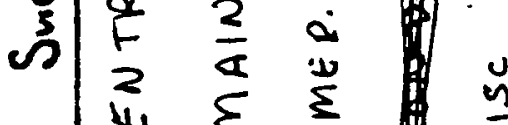

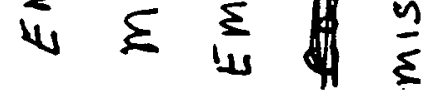

$\rightarrow \dot{\sim}$ r $\dot{\sim}$ i 
괄

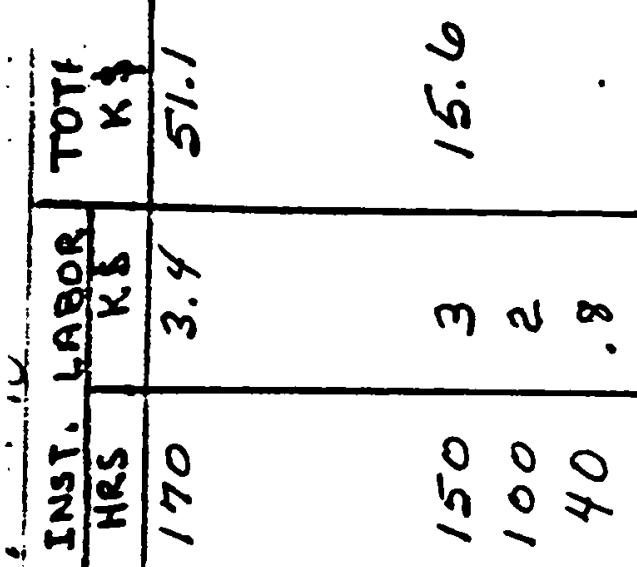

象

$: \frac{1}{3}$

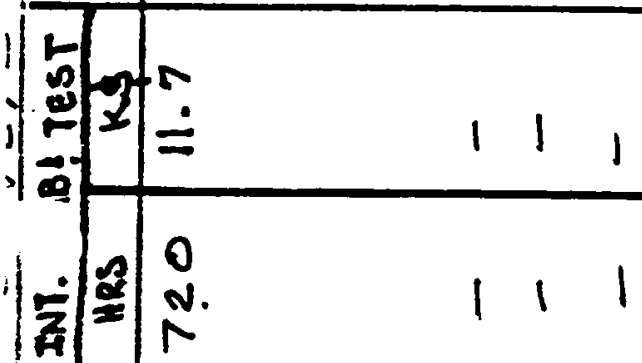

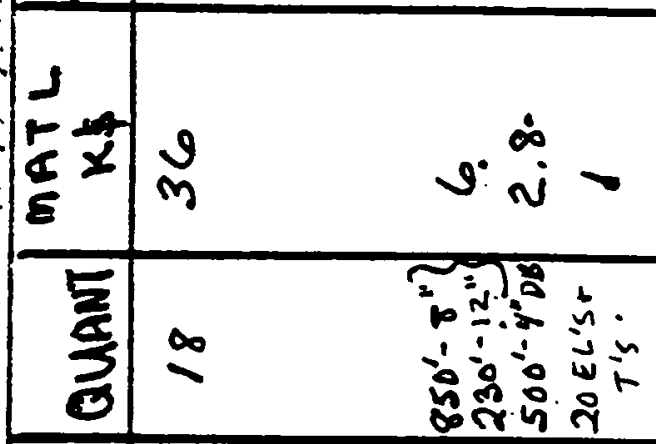

(4)

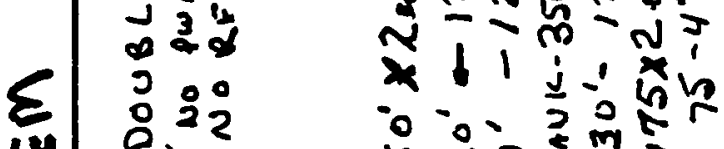

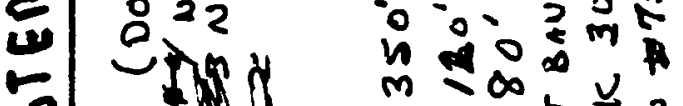

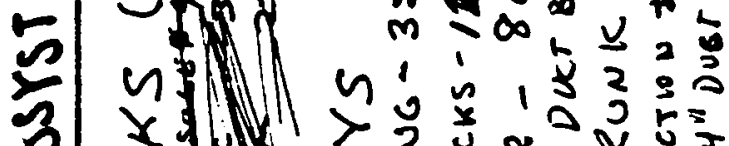

X

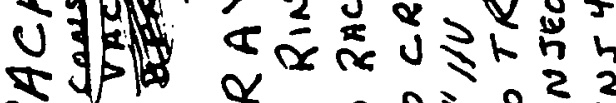

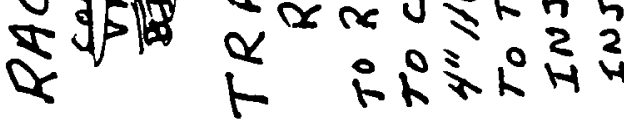

ni 


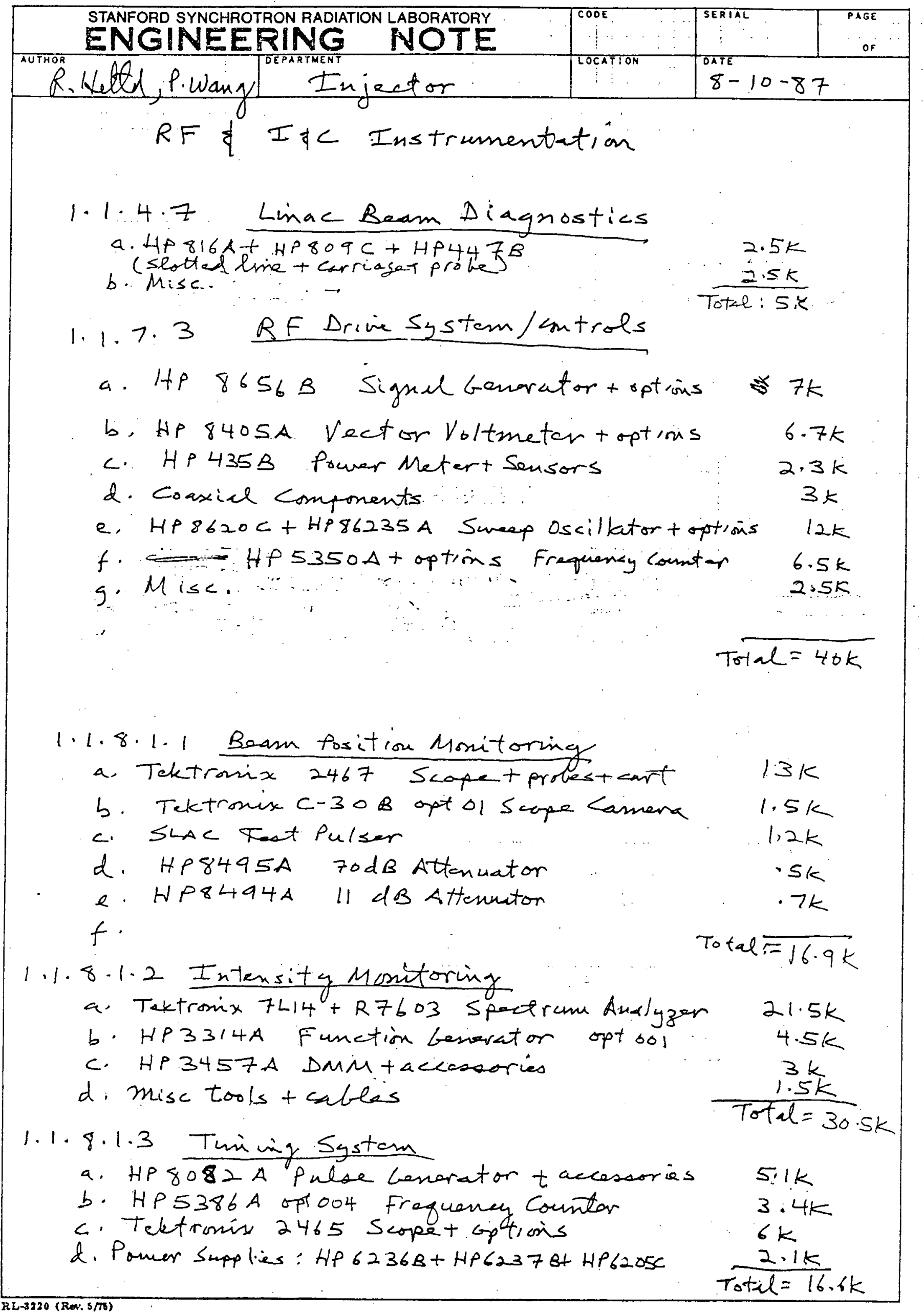




\subsubsection{INJECTION/EJECTION}

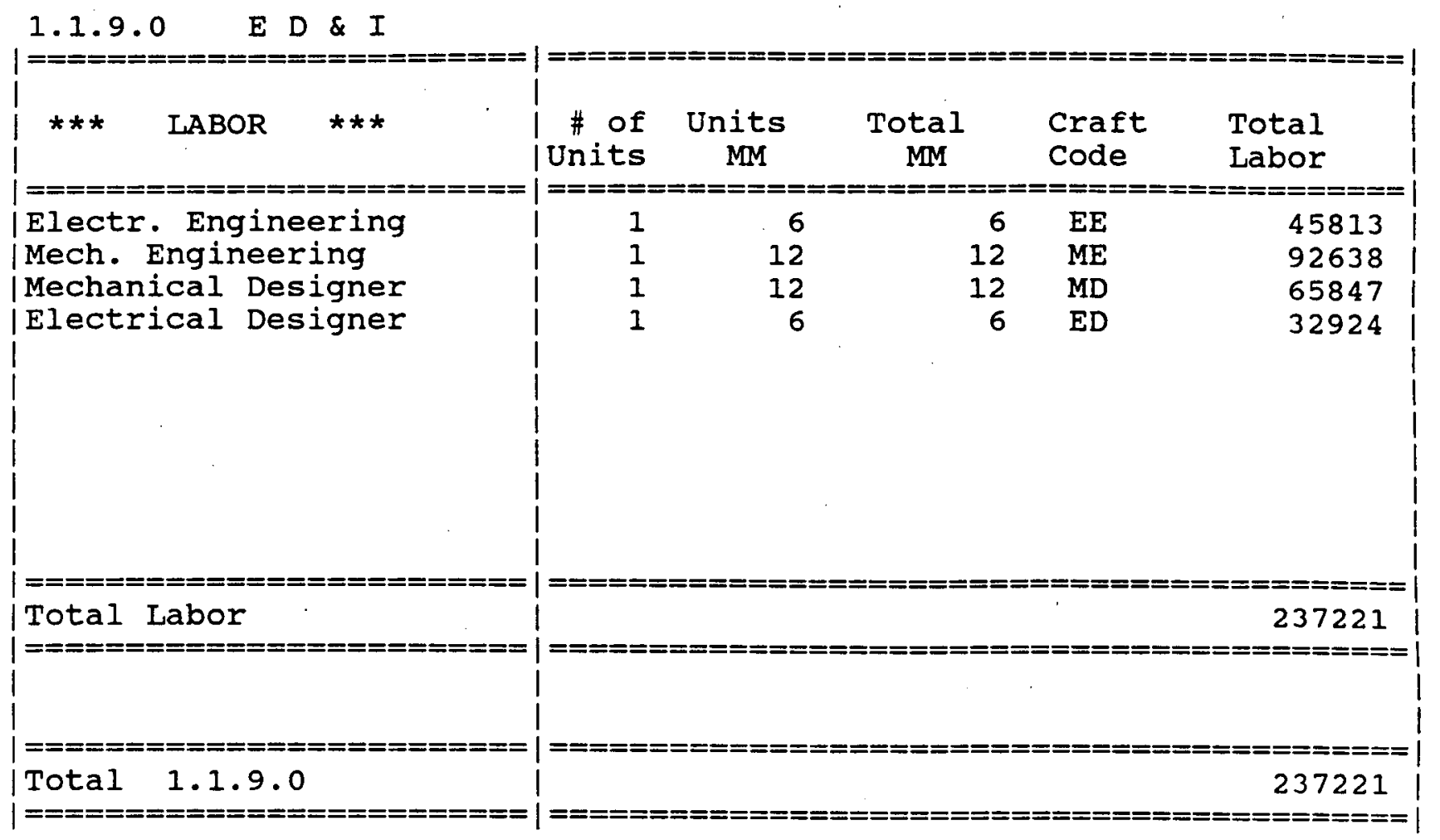




\subsubsection{INJECTION/EJECTION}

\subsubsection{Transport Lines}

\subsection{Linac-Booster $150 \mathrm{MeV}$}

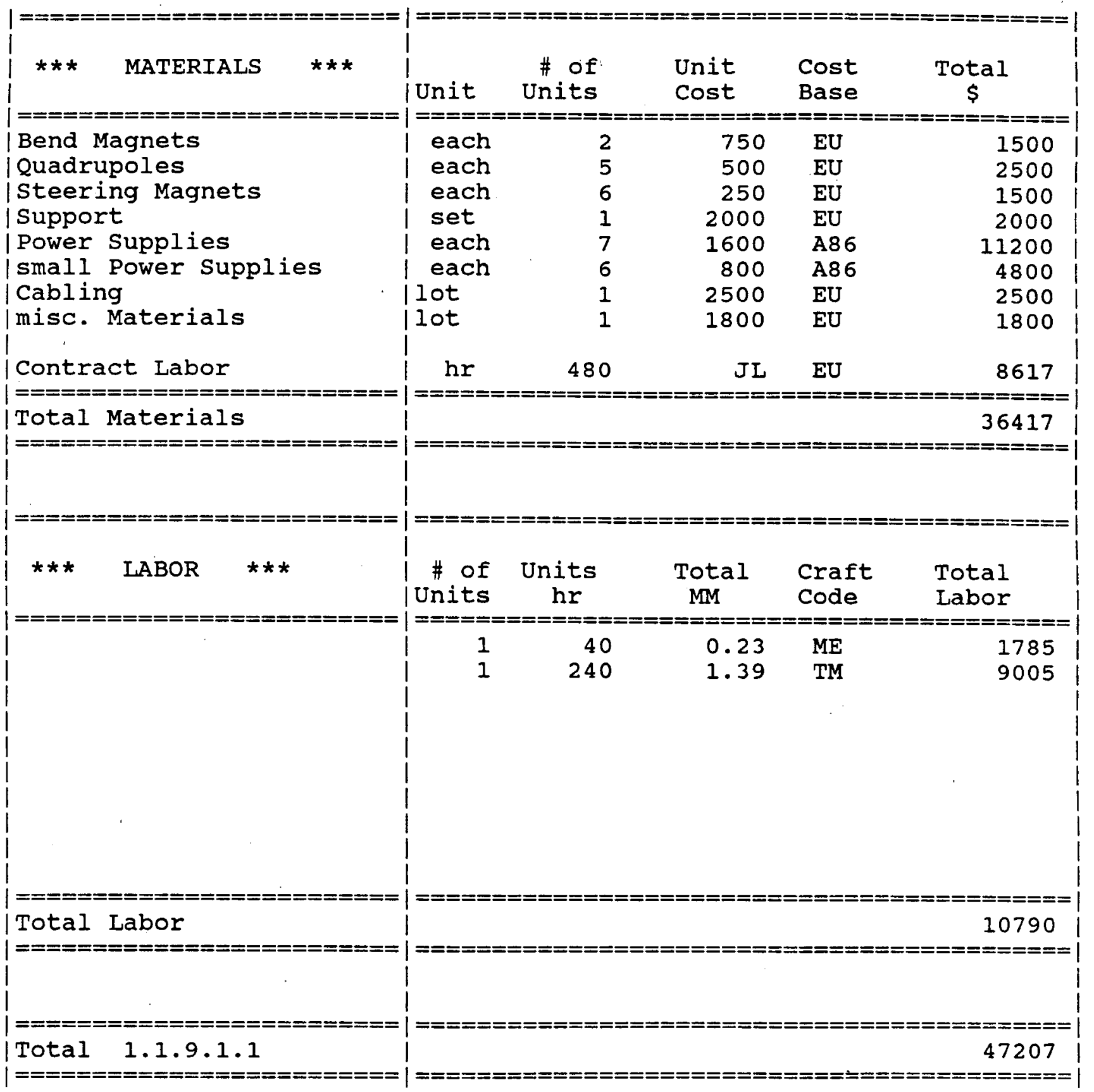




\section{1 .9 INJECTION/EJECTION}

\subsubsection{Transport Lines}

1.1.9.1.2 Booster-SPEAR $3.0 \mathrm{GeV}$

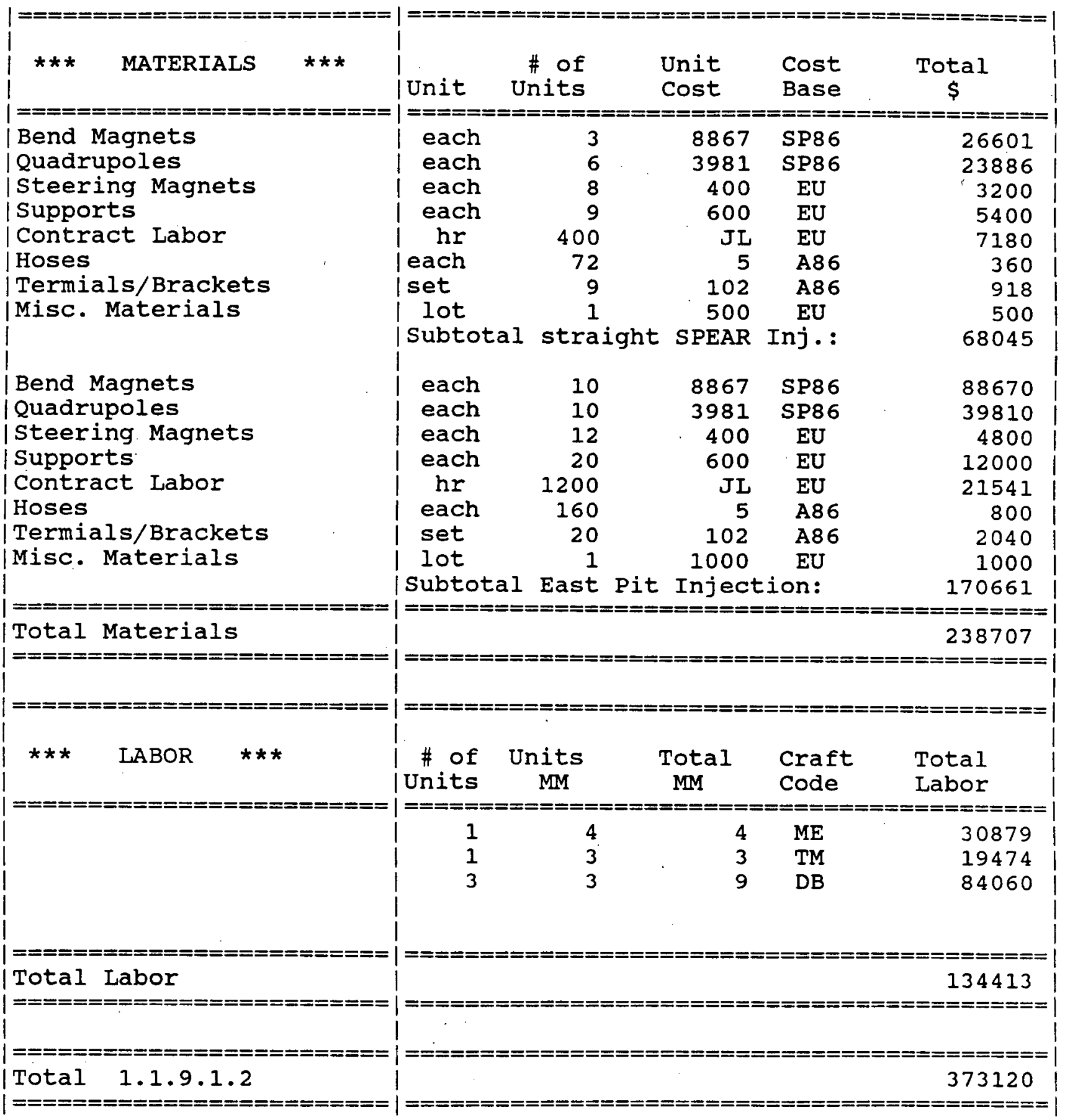




\subsubsection{INJECTION/EJECTION}

\subsubsection{Transport Lines}

\subsection{Power Suppiies}

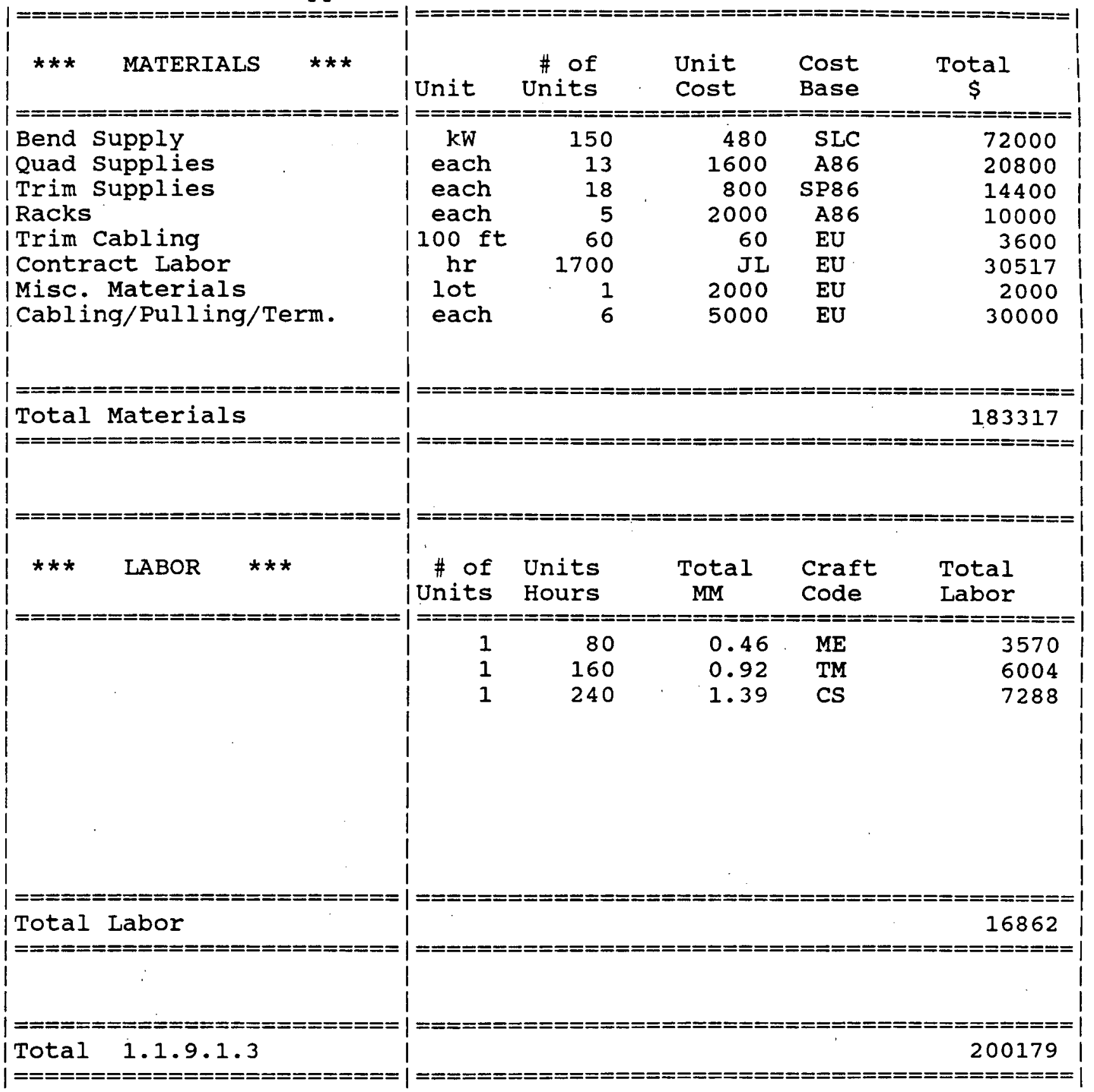




\subsubsection{INJECTION/EJECTION}

\subsubsection{Transport Lines}

1.1.9.1.4 Vacuum System

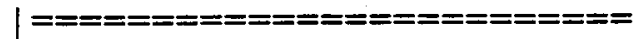

$\star * \star$ MATERIALS $* * *$

|

\# of Unit

Cost

Cost Base

Total

Unit Units Cost Base \$

| Chamber

| Position Monitors

| Roughing system

| Pressure Monitoring

I Supports

$1=$

Misc. Materials

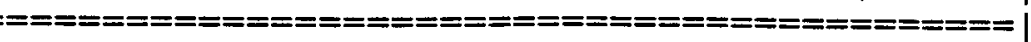

| misc.Valves/Flanges/Bolts |

|Mobile Mechanical Pump

|cleaning/Installation |

each

each

each

m

lot

set

each

| contract Labor

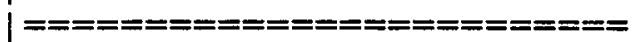

| Total Materials

lot

MM

100

500

950

EU

1381

1332

150

1379

6800

2350

5000

JI

1

8

SLC

50000

8550

4143

3996

CP

EU

15000

1379

6800

2350

5000

24844

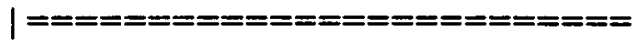

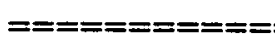

122062

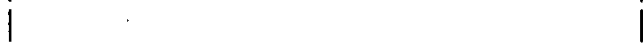

|

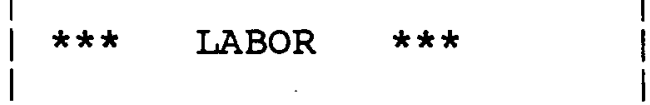

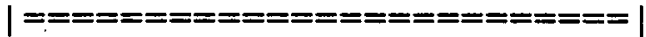

1

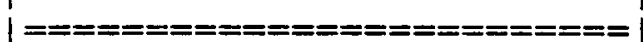

Total Labor

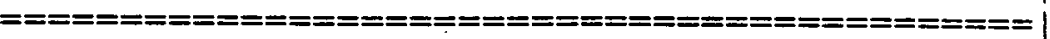

\# of Units Total craft Total

Units $\mathrm{hr}$

MM

Code

Labor

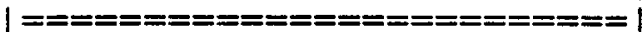

1160

960

0.92

ME

5.55 TV

1480

2.77

TO 


\subsubsection{Injection/Ejection}

\subsubsection{Pulsed Magnets}

\subsection{Kicker Magsets/Pulser}

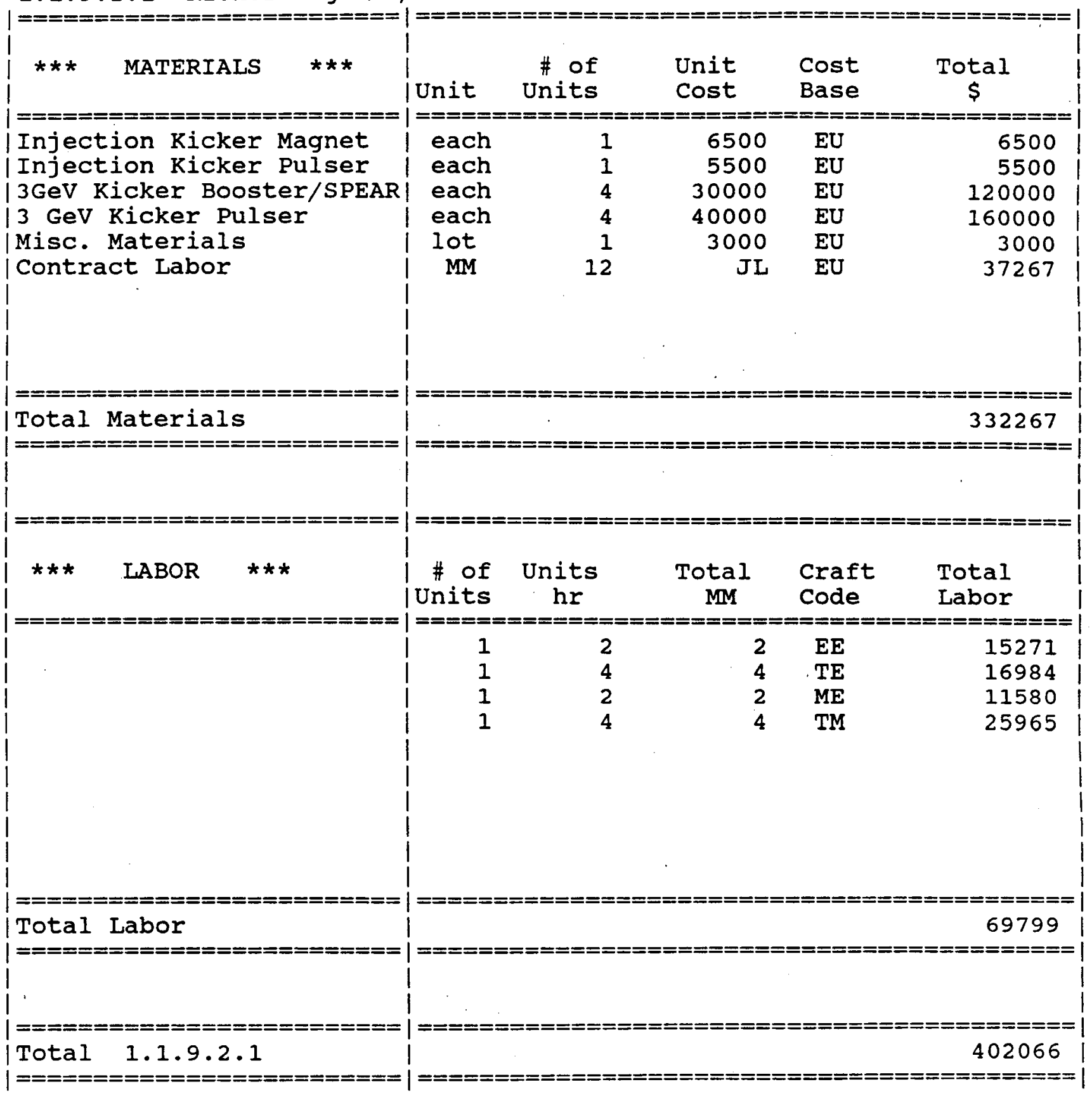




\subsubsection{Pulsed Magnets}

\subsection{Septa Magnets}

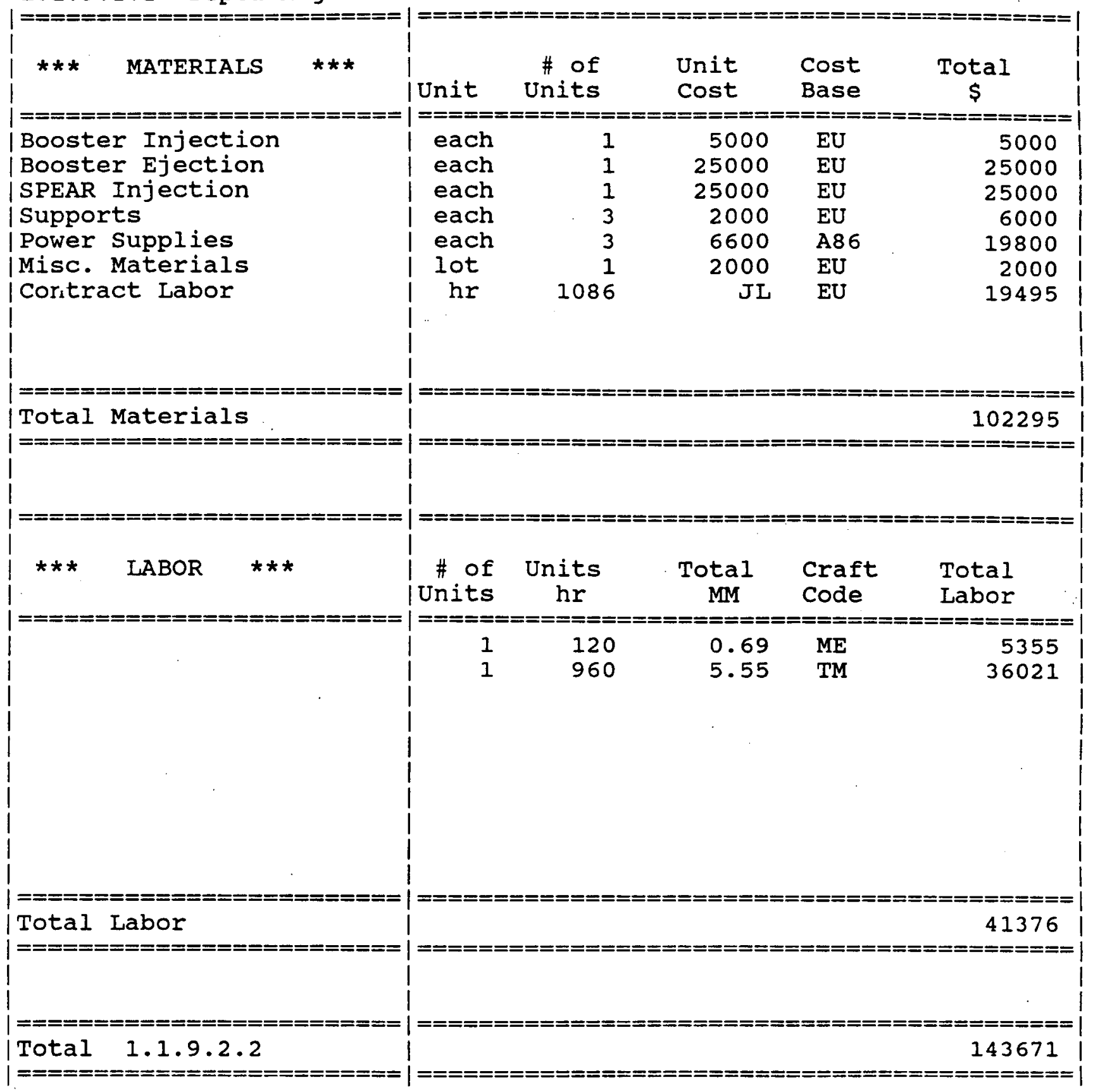




\subsubsection{Injection/Ejection}

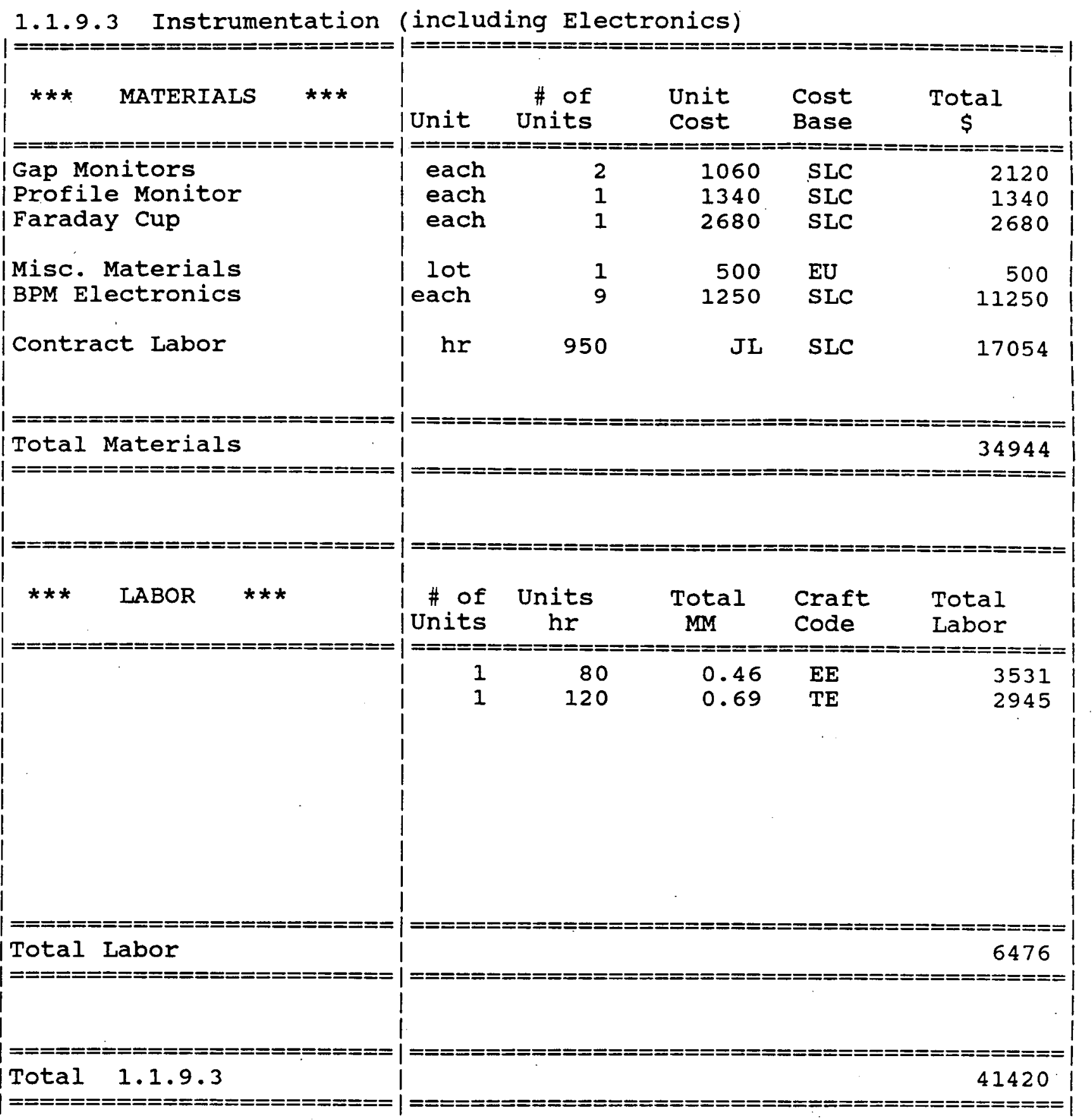




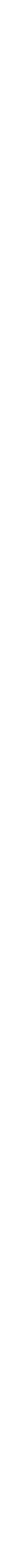


ETH MAGNETE for traunger Liec tahe 3 SPRL -urguct:

Stec $3 \times 17996=02688$

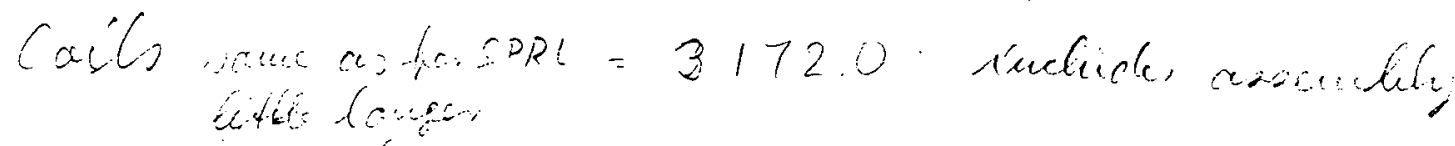
unter lowe

8540.6

reviac suct

326.

28662

vahe for ingector

GUPJEROE.

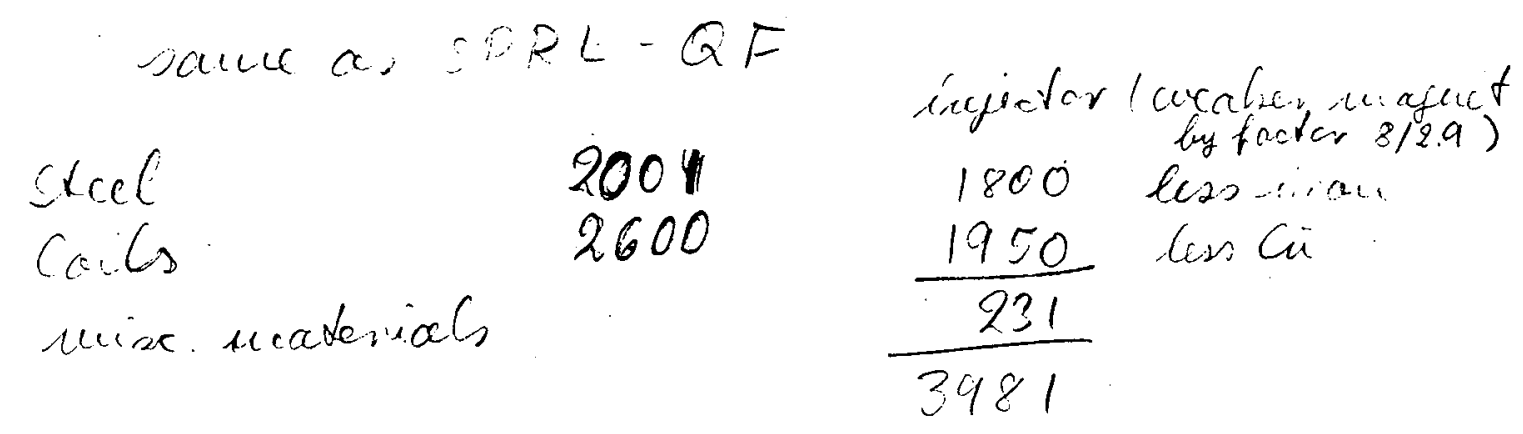


TrPnport Line

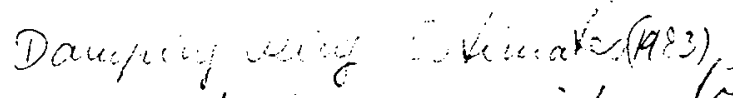

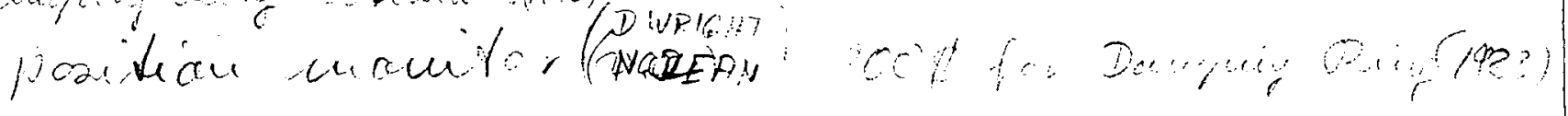

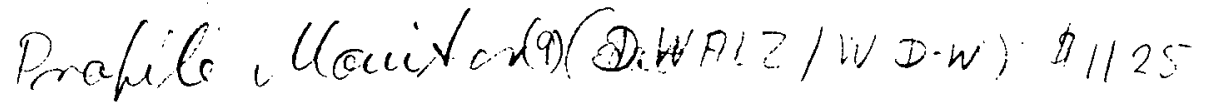

Serape o (2)

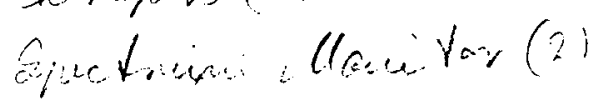

6100

Tarodey ling (2)

SLH (1)

Tonaid/Giag Hou(G)

5300

2250 mo add

2280
16,000
890

58765 
1.2 Project Management and Administration

1.2.1 Technical Project Management

1.2.1.1 Technical Coordination

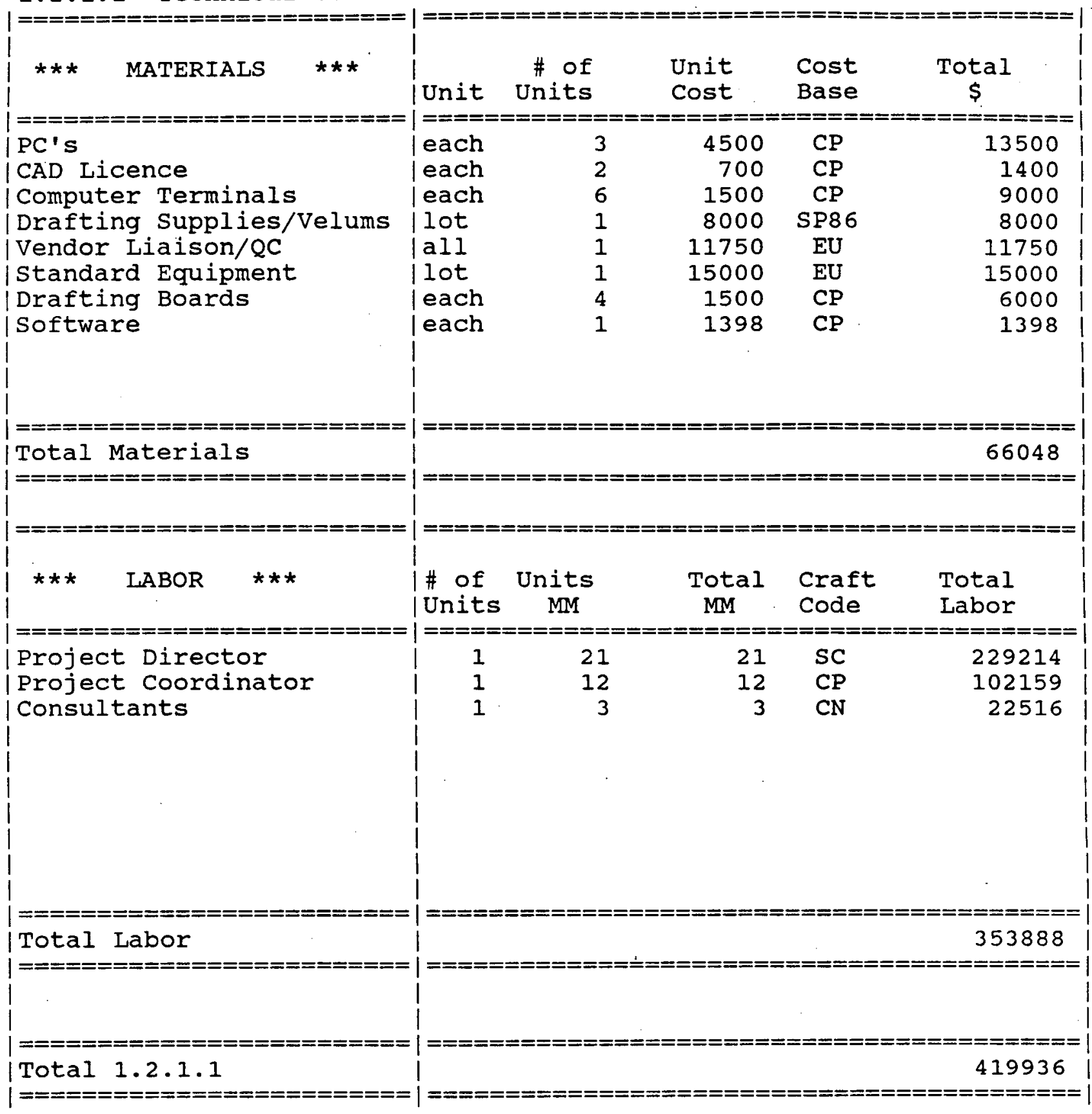


VENDOR LIAISON

2 local trips/wech for 2 years $2 \$ 30$

$$
100 \times 2 \times 30=6000
$$

5 area trips ( $2 A$ etc)

$$
5 \times 350=1750
$$

4 I nips to east coast

$$
\begin{aligned}
4 \times 1000= & 4000 \\
& 11750
\end{aligned}
$$




$$
\text { M.COX SPRL }
$$

ALIGNMENT

Secule

TRIPODS

INST SIAND

TARGET

BUBDLTS

PDAPTER

Aliger Stand

Monian.

Seale Holder $88 \mathrm{CP}$

Zustr. Stounds 500 EU

Align Equing. 1084 CP IRUSON

$8563 \mathrm{CP}$

Theodolite $23065 \mathrm{CP}$

Af. Monim, 1200 CP Vasper Eng, Dear Fab

Precision Lifl 3436 CP

Algu. Tools $\frac{8132}{51664}$ CP DRUNOON

Hasellad sirvey

Kern Jush,

Madivie Parts 8000

RT Eutoryouize

tall trigad (3) 4500 .

Lighting tewand 500

for rallimation 2000

$$
66664
$$

Barnieades $\frac{1,350}{67014}$ 


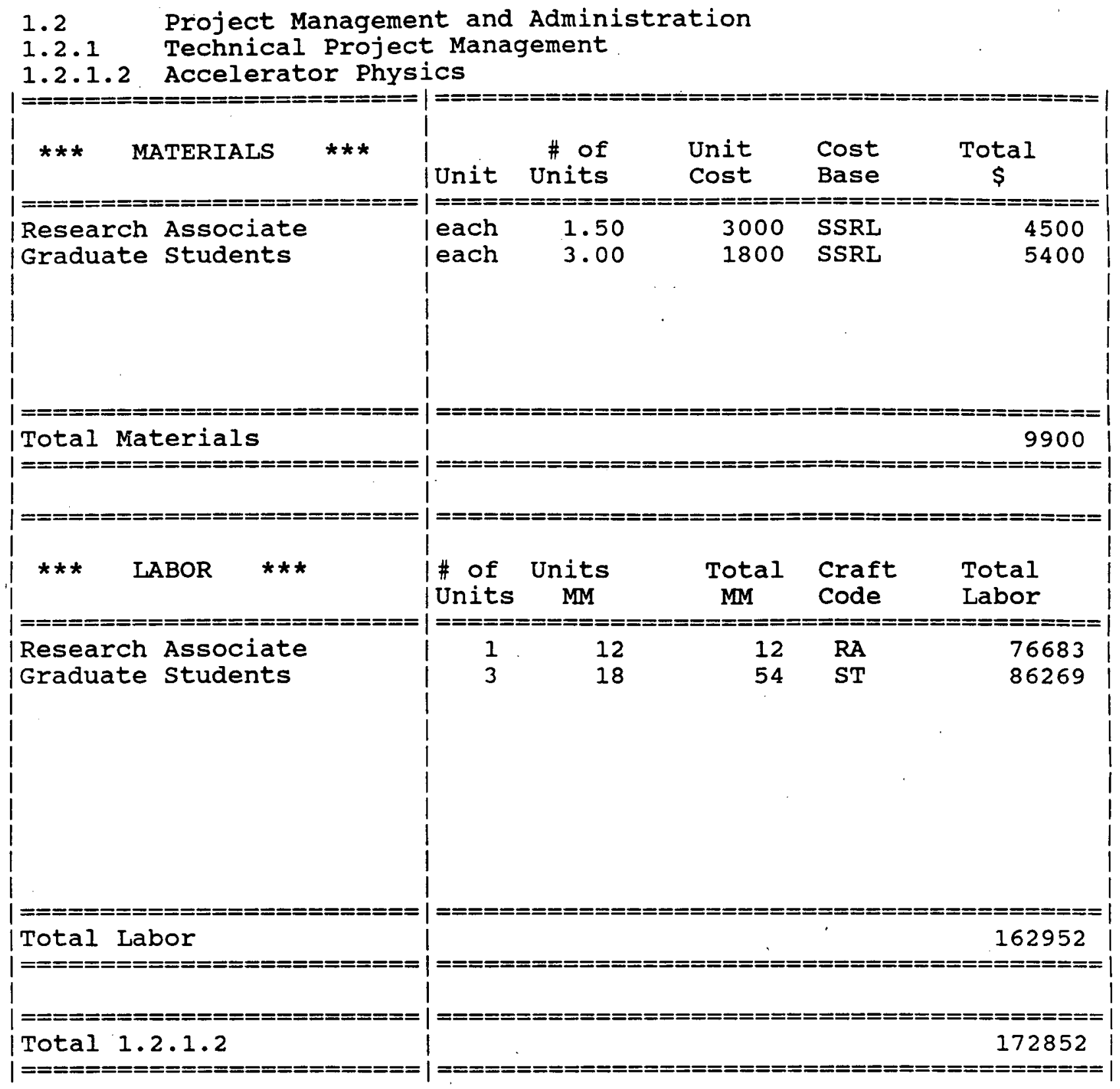




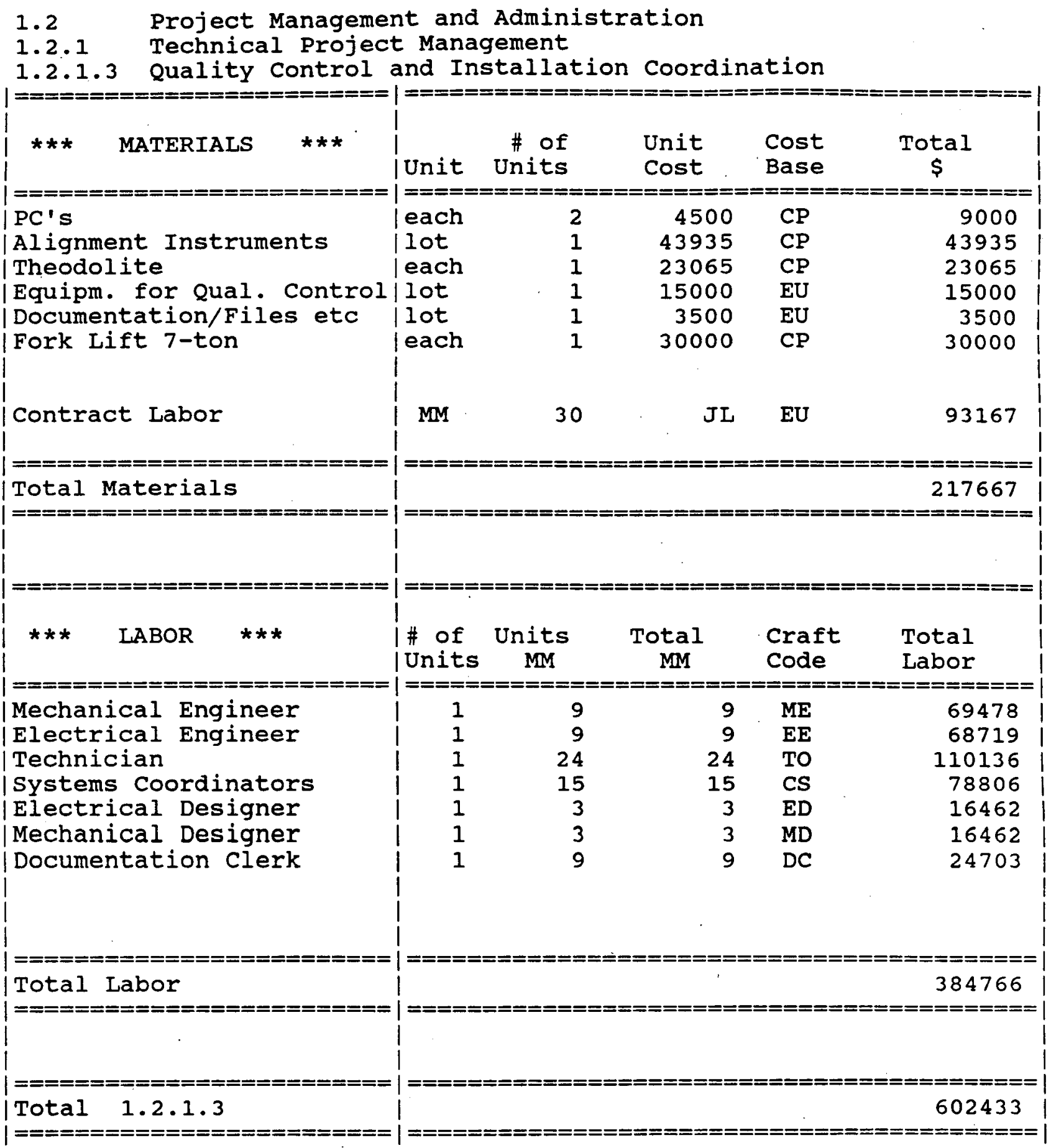


1.2 Project Management and Administration

1.2.2 Administrative Services

1.2.2.1 Project Planning and Budget office

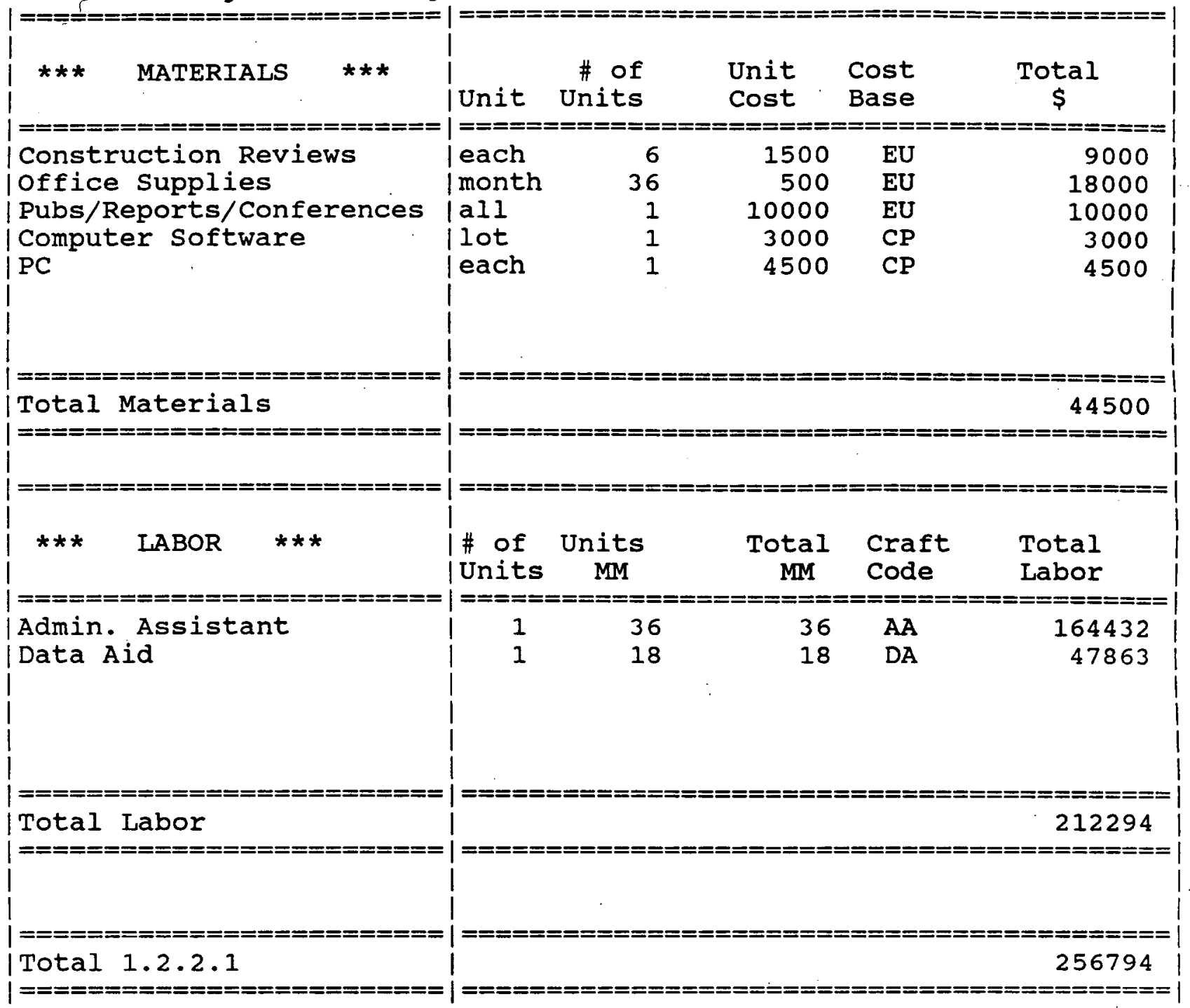




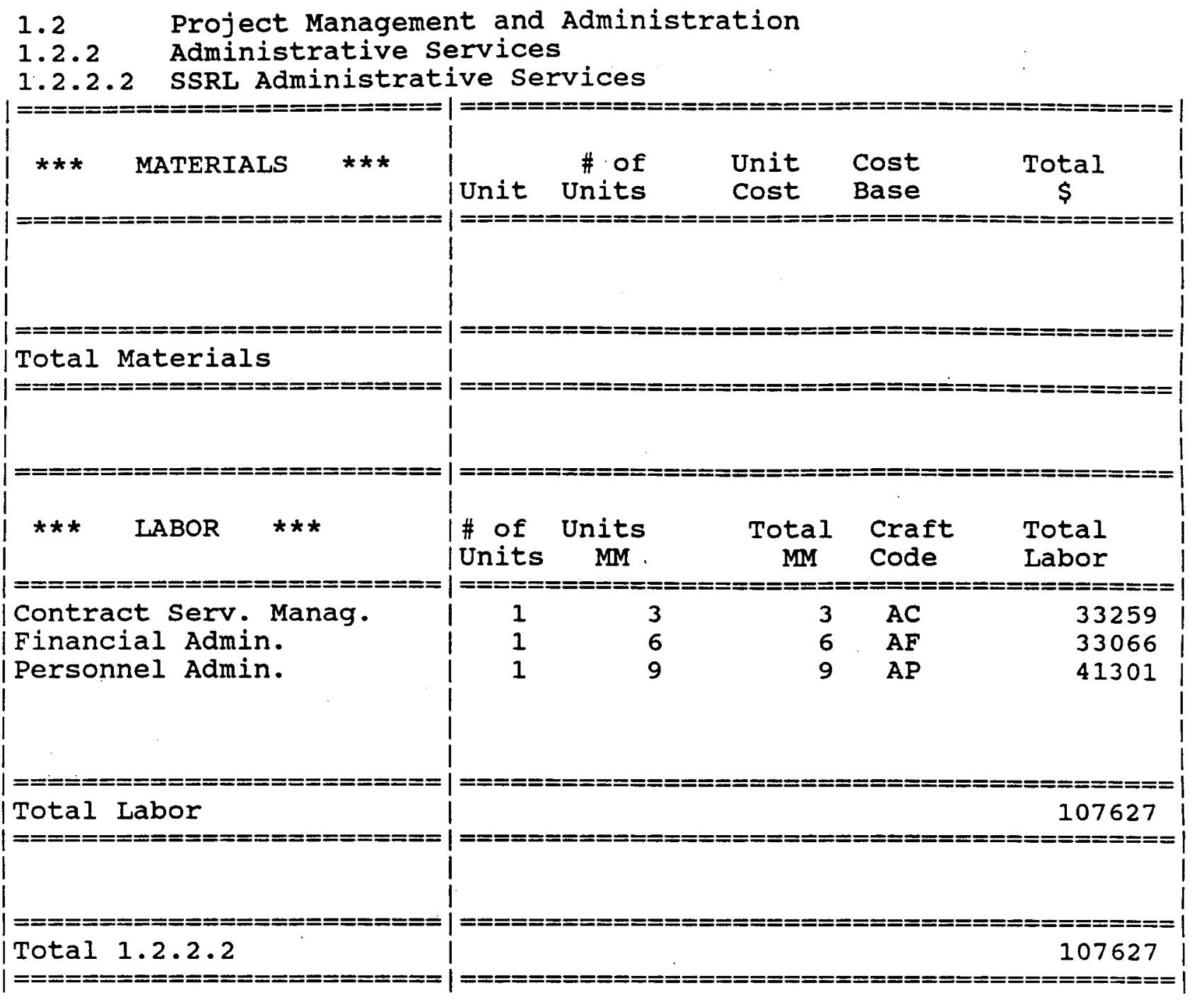




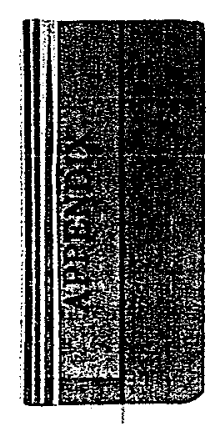




\section{Appendix}

\section{Detailed}

\section{Booster Lattice Information}


THIS VERSION OF PATRICIA ALIONS :

$\begin{array}{ll}\text { THIS VERSION OF PATRICIA ALIONS : } & \text { A MAXIMUM OF } 1000 \text { EIEMENTS PER SUPERPERIOD } \\ & \text { A MAXIMUM OF } 200 \text { DIFFERENT ELEMENTS AND } \\ & \text { A MAXIMUM OF } 300 \text { MUTIPOLE MAGNETS PER SUPERPERIOD }\end{array}$

INPUT-DATA FOR THE PROGRAM PATRICIA,

3 GEV BOOSTER

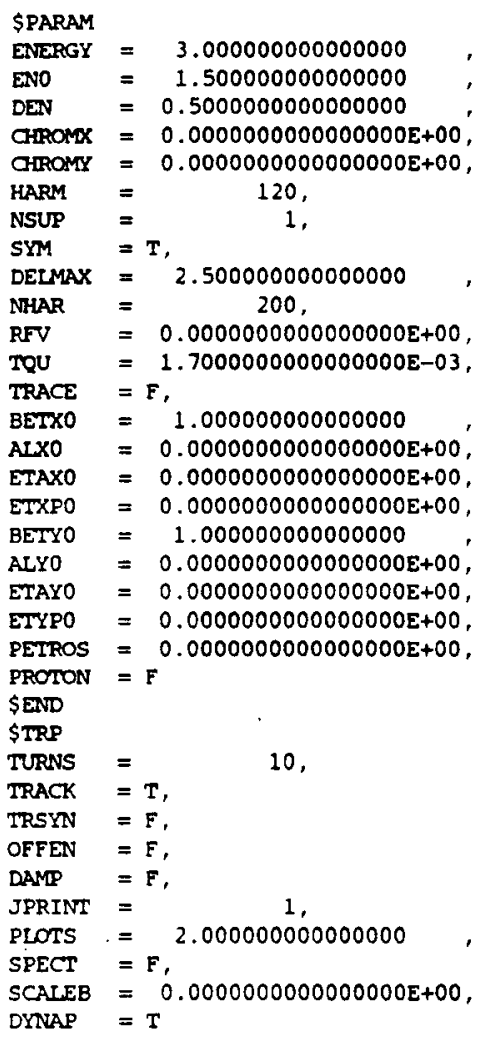
\$END

\begin{tabular}{|c|c|c|c|c|c|c|c|c|c|c|c|c|c|c|c|c|c|}
\hline 1 & 1 & 1 & 1 & $b$ & 1 & 1 & 1 & 0 & 0 & 0 & \multirow{2}{*}{\multicolumn{2}{|c|}{$\begin{array}{cc}0 & 0 \\
6.00000\end{array}$}} & 0 & 0 & \multirow[t]{2}{*}{0} & & \\
\hline-26.0 & 8080 & & 26.0 & 8080 & & & 0000 & & .889 & & & & & & & & \\
\hline & 0 & & 0 & 0 & & & 0.00 & 0000 & 100Dt & & & 0. & 10000 & $00 D+00$ & 0.0 & 0.0 & 0.00000 \\
\hline STRT & 1 & & 0 & 0 & & & 0.00 & 0000 & $1000+$ & .00 & & 0. & 0000 & $00 D+00$ & 0.0 & 0.0 & 0.00000 \\
\hline DR & 1 & & 0 & 0 & & & 0.00 & 0000 & 100D+ & 00 & & 0. & 10000 & $000+00$ & 0.0 & 0.0 & 0.00000 \\
\hline Lo & 1 & & 0 & 0 & & & 0.12 & 2500 & 100Dt & 00 & & & 00000 & $100 D+00$ & 0.0 & 0.0 & 0.00000 \\
\hline LI & 1 & & 0 & 0 & & & 0.25 & 5000 & 100Dt & .00 & & & 0000 & $1000+00$ & 0.0 & 0.0 & 0.00000 \\
\hline L.2A & 1 & & 0 & 0 & & & 0.20 & 0000 & 100Dt & 01 & & & 0000 & $100 D+00$ & 0.0 & 0.0 & 0.00000 \\
\hline L2B & 1 & & 0 & 0 & & & 0.30 & 000 & 100Dt & 01 & & & 0000 & $000+00$ & 0.0 & 0.0 & 0.00000 \\
\hline 13 & 1 & & 0 & 0 & & & 0.75 & 5000 & $100 \mathrm{Dt}$ & .00 & & & 0000 & $1000+00$ & 0.0 & 0.0 & 0.00000 \\
\hline$L 4$ & 1 & & 0 & 0 & & & 0.35 & 5000 & 00Dt & .00 & & & 10000 & $100 D+00$ & 0.0 & 0.0 & 0.00000 \\
\hline LS & 1 & & 0 & 0 & & & 0.15 & 5000 & $000 t$ & 00 & & & 0000 & $100 D+00$ & 0.0 & 0.0 & 0.00000 \\
\hline L6 & 1 & & 0 & 0 & & & 0.50 & 1000 & $000 t$ & 00 & & 0. & 00000 & $100 D+00$ & 0.0 & 0.0 & 0.00000 \\
\hline B & 2 & & 0 & 0 & & & 0.20 & 1000 & $1000 t$ & 01 & & -0 . & 76394 & $37 D+01$ & 30.0 & 17.0 & 0.00000 \\
\hline B1 & 2 & & 0 & 0 & & & 0.12 & 2000 & 10004 & 01 & & -0 . & 76394 & $37 D+01$ & 30.0 & 17.0 & 0.00000 \\
\hline B2 & 2 & & 0 & 0 & & & 0.12 & 2000 & $1000+$ & 01 & & -0 . & 1459 & $15 D+02$ & 30.0 & 17.0 & 0.00000 \\
\hline QDH & 3 & & 0 & 0 & & & 0.14 & 360 & $000 t$ & 00 & & & 4478 & $11[+01$ & 30.0 & 30.0 & 0.00000 \\
\hline QFH & 3 & & 0 & 0 & & & 0.14 & $\$ 360$ & $000+$ & .00 & & -0 . & 9766 & $23 D+01$ & 30.0 & 30.0 & 0.00000 \\
\hline SF & 4 & & 0 & 0 & & & 0.00 & 000 & OODt & .00 & & & 00000 & $100 D+00$ & 0.0 & 0.0 & 0.00000 \\
\hline SD & 4 & & 0 & 0 & & & 0.00 & 000 & $00 \mathrm{Dt}$ & 00 & & & 00000 & $100 D+00$ & 0.0 & 0.0 & 0.00000 \\
\hline END & 0 & & 0 & 0 & & & 0.00 & 000 & OODt & .00 & & 0. & 0000 & $000+00$ & 0.0 & 0.0 & 0.00000 \\
\hline STRT & & & & & & & & & & & & & & & & & \\
\hline 1 & 0 & 0 & 0 & 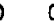 & 0 & 0 & 0 & 0 & 0 & 0 & 0 & 0 & 0 & 0 & 0 & 0 & 0 \\
\hline
\end{tabular}




\begin{tabular}{|c|c|c|c|c|c|c|c|c|c|c|c|c|c|c|c|c|c|c|c|}
\hline $\mathrm{QDH}$ & LO & SD & LO & B & L1 & QFH & QFH & LO & SF & LO & B & L1 & QDH & & & & & & \\
\hline 1 & 1 & 1 & 1 & 1 & 1 & 1 & 1 & 1 & 1 & 1 & 1 & 1 & 1 & 0 & 0 & 0 & 0 & 0 & 0 \\
\hline QDA & LO & SD & LO & B & L1 & QFH & QFH & LO & SF & Lo & B & L1 & QDH & & & & & & \\
\hline 1 & 1 & 1 & 1 & 1 & 1 & 1 & 1 & 1 & 1 & 1 & 1 & 1 & 1 & 0 & 0 & 0 & 0 & 0 & 0 \\
\hline QRH & 5 & SD & 16 & B1 & L6 & I5 & QFH & QFH & L5 & $\mathbf{S F}$ & L6 & B1 & L6 & L5 & QDH & & & & \\
\hline 1 & 1 & 1 & 1 & 1 & 1 & 1 & 1 & 1 & 1 & 1 & 1 & 1 & 1 & 1 & 1 & 0 & 0 & 0 & 0 \\
\hline QDH & L6 & L6 & B2 & 1.5 & LS & LS & $\mathrm{QFH}$ & QFH & LA & L6 & $\mathrm{B} 2$ & L.5 & L5 & QDH & & & & & \\
\hline 1 & 1 & 1 & 1 & 1 & 1 & 1 & 1 & 1 & 1 & 1 & 1 & 1 & 1 & 1 & 1 & 1 & 1 & 1 & 0 \\
\hline $\mathrm{QDH}$ & L2B & QH & & & & & & & & & & & & & & & & & \\
\hline 1 & 1 & 1 & 0 & 0 & 0 & 0 & 0 & 0 & 0 & 0 & 0 & 0 & 0 & 0 & 0 & 0 & 0 & 0 & 0 \\
\hline QFH & $2.2 A$ & QDH & & & & & & & & & & & & & & & & & \\
\hline 1 & 1 & 1 & 0 & 0 & 0 & 0 & 0 & 0 & 0 & 0 & 0 & . & 0 & עחת & 0 & 0 & 0 & 0 & 0 \\
\hline QDH & LS & LS & B2 & 26 & L6 & $\mathrm{DR}$ & QFH & QFH & LS & L5 & B2 & L6 & L6 & QDH & & & & & \\
\hline 1 & 1 & 1 & 1 & 1 & 1 & 1 & 1 & 1 & 1 & 1 & 1 & 1 & 1 & 1 & 0 & 0 & 0 & 0 & 0 \\
\hline QDH & L5 & L6 & B1 & L6 & L5 & $\mathrm{QFH}$ & QFH & 25 & SF & L6 & B1 & L6 & L5 & QDH & & & & & \\
\hline 1 & 1 & 1 & 1 & 1 & 1 & 1 & 1 & 1 & 1 & 1 & 1 & 1 & 1 & 1 & 1 & 0 & 0 & 0 & 0 \\
\hline QDH & LO & SD & LO & B & $\omega$ & QFH & QFH & LO & SF & LO & B & L1 & QDH & & & & & & \\
\hline 1 & 1 & 1 & 1 & 1 & 1 & 1 & 1 & 1 & 1 & 1 & 1 & 1 & 1 & 0 & 0 & 0 & 0 & 0 & 0 \\
\hline QDH & L & SD & LO & B & Ll & QFH & QFH & LO & SF & LO & B & L1 & QDH & & & & & & \\
\hline 1 & 1 & 1 & 1 & 1 & 1 & 1 & 1 & 1 & 1 & 1 & 1 & 1 & 1 & 0 & 0 & 0 & 0 & 0 & 0 \\
\hline \multicolumn{3}{|c|}{0.00000} & \multicolumn{2}{|c|}{0.00000} & \multirow{2}{*}{\multicolumn{3}{|c|}{0.00000}} & \multirow{2}{*}{\multicolumn{2}{|c|}{0.00000}} & \multirow{2}{*}{\multicolumn{3}{|c|}{0.00000}} & \multirow{2}{*}{\multicolumn{2}{|c|}{0.00000}} & \multirow{2}{*}{\multicolumn{2}{|c|}{0.00000}} & \multirow{2}{*}{\multicolumn{3}{|c|}{0.00000}} \\
\hline & & & & & & & & & & & & & & & & & & & \\
\hline
\end{tabular}


3 GEV BOOSTER

LATTICE-PARAMETER

NR

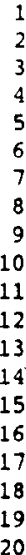

STRT

QDH

LO

SD

LO

LI

QFH

QFH

SF

Lo

QDH

ODH

SD

LO
B

OFH

QFH

LO

SF
LO

B

QDH

QDH

QDH
L5

SD

L6
B1

L6

L5

QFH

QFH

L5

SF

B1
L6

56

LD

QDH
QDH

L6

I6

B2

L5

45

$\mathrm{QFH}$

QFH

L 6

82

L5

L5

QDH

QDH

L2B

OFH

L2A

$\mathrm{OOH}$

QDH

L5

UNITS: RHO(M), K(1/M**2),SM(1/M**2),FDRIF (M), LENGTH(M), LTOT(M)

0.0000000

0.0000000

1. 4478109

0.0000000

0.0000000

0.0000000

$-7.6394373$

0.0000000

$-1.9766225$

$-1.9766225$

0.0000000

0.0000000

0.0000000

$-7.6394373$

0.0000000

1. 4478109

1. 4478109

0.0000000

0.0000000

0.0000000

$-7.6394373$

0.0000000

$-1.9766225$

$-1.9766225$

0.0000000

0.0000000

0.0000000

$-7.6394373$

0.0000000

1. 4478109

1. 4478109

0.0000000

0.0000000

0.0000000

$-7.6394373$

0.0000000

0.0000000

$-1.9766225$

$-1.9766225$

0.0000000

0.0000000

0.0000000

$-7.6394373$

0.0000000

0.0000000

1. 4478109

1.4478109

0.0000000

0.0000000

$-11.4591500$

0.0000000

0.0000000

0.0000000

$-1.9766225$

$-1.9766225$

0.0000000

0.0000000

$-11.4591500$

0.0000000

0.0000000

1.4478109

1. 4478109

0.0000000

$-1.9766225$

$-1.9766225$

0.0000000

1.4478109

1. $\$ 478109$

0.0000000

0.0000000

$-11.4591500$
0.0000000

0.0000000

0.0000000

0.0000000

0.0000000

0.0000000

0.0000000

0.0000000

0.0000000

0.0000000

0.0000000

0.0000000

0.0000000

0.0000000

0.0000000

0.0000000

0.0000000

0.0000000

0.0000000

0.0000000

0.0000000

0.0000000

0.0000000

0.0000000

0.0000000

0.0000000

0.0000000

0.0000000

0.0000000

0.0000000

0.0000000

0.0000000

0.0000000

0.0000000

0.0000000

0.0000000

0.0000000

0.0000000

0.0000000

0.0000000

0.0000000

0.0000000

0.0000000

0.0000000

0.0000000

0.0000000

0.0000000

0.0000000

0.0000000

0.0000000

0.0000000

0.0000000

0.0000000

0.0000000

0.0000000

0.0000000

0.0000000

0.0000000

0.0000000

0.0000000

0.0000000

0.0000000

0.0000000

0.0000000

0.0000000

0.0000000

0.0000000

0.0000000

0.0000000

. FDRI

0.00000

0.00000

0.00000

0.00000

0.00000

0.00000

0.00000

0.00000

0.00000

0.00000

0.00000

0.00000

0.00000

0.00000

0.00000

0.00000

0.00000

0.00000

0.00000

0.00000

0.00000

0.00000

0.00000

0.00000

0.00000

0.00000

0.00000

0.00000

0.00000

0.00000

0.00000

0.00000

0.00000

0.00000

0.00000

0.00000

0.00000

0.00000

0.00000

0.00000

0.00000

0.00000

0.00000

0.00000

0.00000

0.00000

0.00000

0.00000

0.00000

0.00000

0.00000

0.00000

0.00000

0.00000

0.00000

0.00000

0.00000

0.00000

0.00000

0.00000

0.00000

0.00000

0.00000

0.00000

0.00000

0.00000

0.00000

0.00000

0.00000

0.00000

\section{LENGIH}

0.00000

0.14360

0.12500

0.00000

0.12500

2.00000

0.25000 


\begin{tabular}{|c|c|c|c|c|c|c|}
\hline 71 & L6 & 0.0000000 & 0.0000000 & 0.00000 & 0.50000 & 30.01560 \\
\hline 72 & L6 & 0.0000000 & 0.0000000 & 0.00000 & 0.50000 & 30.51560 \\
\hline 73 & $\mathrm{DR}$ & 0.0000000 & 0.0000000 & 0.00000 & 0.00000 & 30.51560 \\
\hline 74 & $\mathrm{QFH}$ & -1.9766225 & 0.0000000 & 0.00000 & 0.14360 & 30.65920 \\
\hline 75 & $\mathrm{QFH}$ & -1.9766225 & 0.0000000 & 0.00000 & 0.14360 & 30.80280 \\
\hline 76 & L5 & 0.0000000 & 0.0000000 & 0.00000 & 0.15000 & 30.95280 \\
\hline 77 & 25 & 0.0000000 & 0.0000000 & 0.00000 & 0.15000 & 31.10280 \\
\hline 78 & B2 & -11.4591500 & 0.0000000 & 0.00000 & 1.20000 & 32.30280 \\
\hline 79 & 26 & 0.0000000 & 0.0000000 & 0.00000 & 0.50000 & 32.80280 \\
\hline 80 & $\llcorner 6$ & 0.0000000 & 0.0000000 & 0.00000 & 0.50000 & 33.30280 \\
\hline 81 & QDH & 1.4478109 & 0.0000000 & 0.00000 & 0.14360 & 33.44640 \\
\hline 82 & QDA: & 1.4478109 & 0.0000000 & 0.00000 & 0.14360 & 33.59000 \\
\hline 83 & LS & 0.0000000 & 0.0000000 & 0.00000 & 0.15000 & 33.74000 \\
\hline 84 & L6 & 0.0000000 & 0.0000000 & 0.00000 & 0.50000 & 34.24000 \\
\hline 85 & $\mathbf{8 1}$ & -7.6394373 & 0.0000000 & 0.00000 & 1.20000 & 35.44000 \\
\hline 86 & L6 & 0.0000000 & 0.0000000 & 0.00000 & 0.50000 & 35.94000 \\
\hline 87 & L5 & 0.0000000 & 0.0000000 & 0.00000 & 0.15000 & 36.09000 \\
\hline 88 & QFH & -1.9766225 & 0.0000000 & 0.00000 & 0.14360 & 36.23360 \\
\hline 89 & QFH & -1.9766225 & 0.0000000 & 0.00000 & 0.14360 & 36.37720 \\
\hline 90 & L5 & 0.0000000 & 0.0000000 & 0.00000 & 0.15000 & 36.52720 \\
\hline 91 & SF & 0.0000000 & 0.0000000 & 0.00000 & 0.00000 & 36.52720 \\
\hline 92 & $L 6$ & 0.0000000 & 0.0000000 & 0.00000 & 0.50000 & 37.02720 \\
\hline 93 & $\mathbf{B 1}$ & -7.6394373 & 0.0000000 & 0.00000 & 1.20000 & 38.22720 \\
\hline 94 & L6 & 0.0000000 & 0.0000000 & 0.00000 & 0.50000 & 38.72720 \\
\hline 95 & L5 & 0.0000000 & 0.0000000 & 0.00000 & 0.15000 & 38.87720 \\
\hline 96 & QDH & 1.4478109 & 0.0000000 & 0.00000 & 0.14360 & 39.02080 \\
\hline 97 & QDH & 1.4478109 & 0.0000000 & 0.00000 & 0.14360 & 39.16440 \\
\hline 98 & Lo & 0.0000000 & 0.0000000 & 0.00000 & 0.12500 & 39.28940 \\
\hline 99 & SD & 0.0000000 & 0.0000000 & 0.00000 & 0.00000 & 39.28940 \\
\hline 100 & 20 & 0.0000000 & 0.0000000 & 0.00000 & 0.12500 & 39.41440 \\
\hline 101 & B & -7.6394373 & 0.0000000 & 0.00000 & 2.00000 & 41.41440 \\
\hline 102 & Li & 0.0000000 & 0.0000000 & 0.00000 & 0.25000 & 41.66440 \\
\hline 103 & QFH & -1.9766225 & 0.0000000 & 0.00000 & 0.14360 & 41.80800 \\
\hline 104 & QFH & -1.9766225 & 0.0000000 & 0.00000 & 0.14360 & 41.95160 \\
\hline 105 & 20 & 0.0000000 & 0.0000000 & 0.00000 & 0.12500 & 42.07660 \\
\hline 106 & SF & 0.0000000 & 0.0000000 & 0.00000 & 0.00000 & 42.07660 \\
\hline 107 & LO & 0.0000000 & 0.0000000 & 0.00000 & 0.12500 & 42.20160 \\
\hline 108 & B & -7.6394373 & 0.0000000 & 0.00000 & 2.00000 & 44.20160 \\
\hline 109 & L1 & 0.0000000 & 0.0000000 & 0.00000 & 0.25000 & 44.45160 \\
\hline 110 & QDH. & 1. 4478109 & 0.0000000 & 0.00000 & $0.14360^{\circ}$ & .44 .59520 \\
\hline 111 & QDH & 1.4478109 & 0.0000000 & 0.00000 & 0.14360 & 44.73880 \\
\hline 112 & LO & 0.0000000 & 0.0000000 & 0.00000 & 0.12500 & 44.86380 \\
\hline 113 & SD & 0.0000000 & 0.0000000 & 0.00000 & 0.00000 & 44.86380 \\
\hline 114 & LO & 0.0000000 & 0.0000000 & 0.00000 & 0.12500 & 44.98880 \\
\hline 115 & B & -7.6394373 & 0.0000000 & 0.00000 & 2.00000 & 46.98880 \\
\hline 116 & L1 & 0.0000000 & 0.0000000 & 0.00000 & 0.25000 & 47.23880 \\
\hline 117 & $\mathrm{QFH}$ & -1.9766225 & 0.0000000 & 0.00000 & 0.14360 & 47.38240 \\
\hline 118 & QFH & -1.9766225 & 0.0000000 & 0.00000 & 0.14360 & 47.52600 \\
\hline 119 & LO & 0.0000000 & 0.0000000 & 0.00000 & 0.12500 & 47.65100 \\
\hline 120 & SF & 0.0000000 & 0.0000000 & 0.00000 & 0.00000 & 47.65100 \\
\hline 121 & LO & 0.0000000 & 0.0000000 & 0.00000 & 0.12500 & 47.77600 \\
\hline 122 & $\mathbf{8}$ & -7.6394373 & 0.0000000 & 0.00000 & 2.00000 & 49.77600 \\
\hline 123 & LI & 0.0000000 & 0.0000000 & 0.00000 & 0.25000 & 50.02600 \\
\hline 124 & QDH & 1.4478109 & 0.0000000 & 0.00000 & 0.14360 & 50.16960 \\
\hline
\end{tabular}




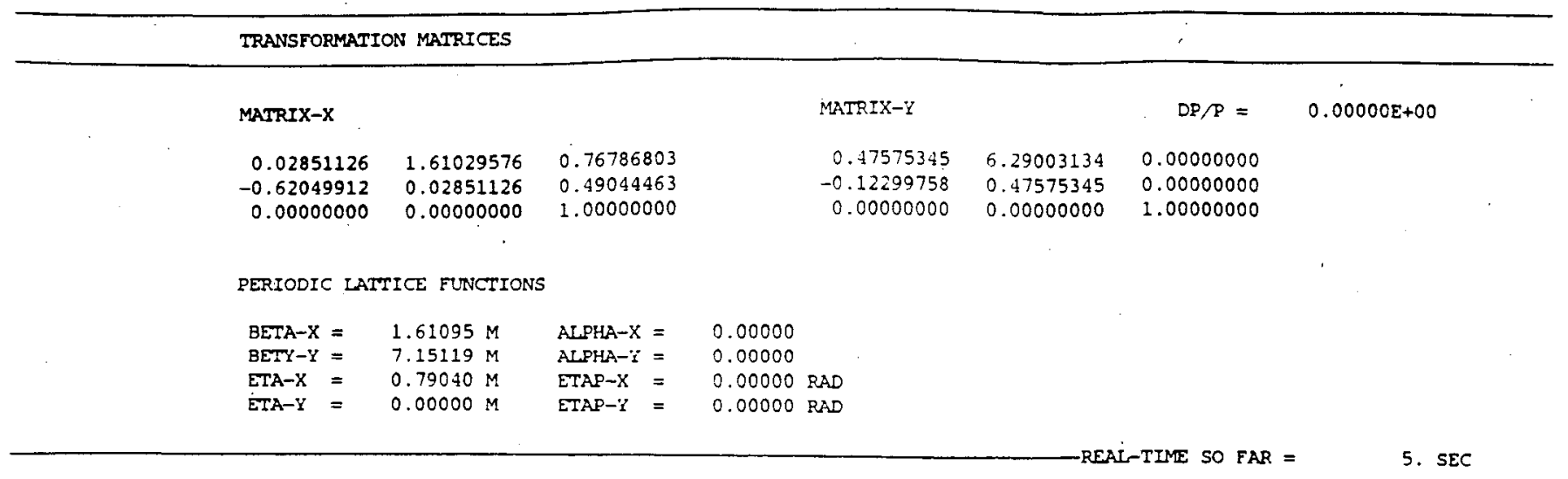


DEFINITION: (FUNCT) = INTEGRAL OF FUNCT ALONG NSUR SUPERPERIODS DIVIDED BY TOTAL INTEGRATION LENGTH ORROMATIC TERMS (SEE H.WIEDEMANN DESY H5/71-10)

ELECTRON STORAGE RING PARAMETERS

\begin{tabular}{|c|c|c|c|}
\hline CIRCUMFERENCE (M) & & 00.33920 & \\
\hline RF-FREQUENCY (MZ) & & 58.53485 & \\
\hline MOMENTUM COMPACTION FACTO & & 0.0540384 & \\
\hline ENERGYSPREAD (多) & & 0.0305393 & E $(G E V)$ \\
\hline DAMPING PARTITION NUMBERS & $J S=$ & 2.000 & \\
\hline & $J X=$ & 1.000 & \\
\hline & $\Gamma=$ & 1.000 & \\
\hline
\end{tabular}

REVOLUTIONFREOUENCY (KHZ)

HARMONIC MUNBER

MAT. EMITTANCE ( HORIZ) (RAD*M)

TRANSITION ENERG $i$

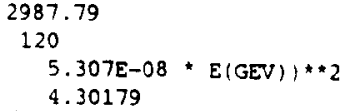

RADIATION AND OTHER INTEGRALS (SEE R.H.HELM ET AL. SLAC-FUB-1193 AND H.WIEDEMANN FEP-NCTE 39 :)

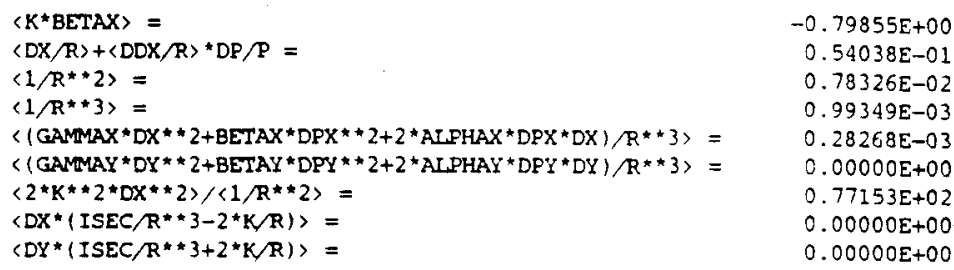

\begin{tabular}{|c|c|}
\hline$\left\langle-K^{\star} \mathrm{BETAY}\right\rangle=$ & $0.63690 \mathrm{E}+00$ \\
\hline$\angle \mathrm{BETAX}=$ & $4.3902 \mathrm{M}$ \\
\hline$\langle B E T A Y\rangle=$ & $6.3178 \mathrm{M}$ \\
\hline$\langle$ GAMAX $\rangle=$ & $0.8059 \mathrm{1} / \mathrm{M}$ \\
\hline$\langle G A M A Y\rangle=$ & $0.5882 \mathrm{I} / \mathrm{M}$ \\
\hline$\langle\operatorname{ETAX}\rangle=$ & $0.6907 \mathrm{M}$ \\
\hline$\langle\operatorname{ETAXP} * * 2\rangle=$ & $0.56070 \varepsilon-01$ \\
\hline$\langle\operatorname{ETAYP} * 2\rangle=$ & $0.00000 \mathrm{E}+00$ \\
\hline$\left\langle(\operatorname{ETAX} / R)^{\star \star 2}\right\rangle=$ & $0.70256 \mathrm{E}-02$ \\
\hline$\langle(\operatorname{ETAY} / R) * * 2\rangle=$ & $0.00000 \mathrm{E}+00$ \\
\hline
\end{tabular}

MOMENTUM (GEV/C)

3.000

1.500

2.000

2.500

$3.000 \cdot 3.500$

4.000

4.500

5.000

ENERGYLOSS/TURN (MEV)

RF-PHASE (DEGREE)

RF-VOLTAGE (MNOLT)

SYNCHR.FREQUENCY (KC)

0.896

0.056

0.177

0.432

0.896

1.660

2.833

4.537

6.915

$29.852 \quad 21.130 \quad 24.646 \quad 27.482 \quad 29.852$

31.645

32.88

34.137

1.801

3.165

5.218

8.085

0.425
42.160

55.337

69.252

84.213

100.461

$23.178 \quad 9.986$

14.111

18.521

QUANTUMLIFETIME (HOURS)

0.002

0.019

0.008

0.004

23.178

28.186

33.624

117.053

39.177

0.002

0.002

0.002

0.002

BET-DAMP-TIME-HOR (MSEC)

2.241

17.925

7.562

1.936

1.120

0.473

0.332

2.241

1.411

0.945

0.664

0.945

0.664

$4.78 \mathrm{E}-07 \quad 1.19 \mathrm{E}-07 \quad 2.12 \mathrm{E}-07 \quad 3.32 \mathrm{E}-07$

$4.785-07 \quad 6.505-07$

NAT. EMITTANCE (RAD*M)

34.111

39.586

37.354

35.574

34.111

32.726

$8.49 E-07$

$1.07 \mathrm{E}-06$

BUNCHLENGTH (PSEC)

113.781
0.092

132.046
0.046

0.061

118.661

113.781

109.161

31.352

104.579

30.271

100.974

0.137

35.126

12.019

134.586

45.045

0.002

0.242

0.484

0.484

$.33 E-06$

29.253

97.578

0.153

RING ACCEPTANCE FOR A MONOCRROMATIC BEAM IN MM*MRAD (DP/P $=0.000000)$ 
BEAM-DYNAMICS-PARAMETER

$0 \mathrm{P}=0.00000 \mathrm{E}+00$

UNITS OF BETA, ETA AND IDNGTH ARE METERS;BSC IS FOR 10 SIGMA-TOT; PARAMTERS AT THE END OF ELEMENTS

\begin{tabular}{|c|c|c|c|c|c|c|c|c|c|c|c|c|}
\hline MAGNET & $J$ & BETAX & ALFAX & $\mathrm{BSCX}(\mathrm{MM})$ & ETAX & DNUEX & BETAY & ALFAẌ & $\mathrm{BSC}(\mathrm{M})$ & ETAY & DNUEY & $T O T-L$ \\
\hline STRT & 1 & 1.61095 & 0.00000 & 11.37494 & 0.79040 & 0.00000 & 7.15119 & 0.00000 & 13.06883 & 0.00000 & 0.00000 & 0.0000 \\
\hline QDH & 2 & 1.67245 & -0.43256 & 11.57188 & 0.80223 & 0.01401 & 6.94266 & 1.43767 & 12.87688 & 0.00000 & 0.00323 & 0.1436 \\
\hline LO & 3 & 1.79168 & -0.52128 & 11.93397 & 0.82288 & 0.02551 & 6.59014 & 1.38245 & 12.54570 & 0.00000 & 0.00617 & 0.2686 \\
\hline SD & 4 & 1.79168 & -0.52128 & 11.93397 & 0.82288 & 0.02551 & 6.59014 & 1.38245 & 12.54570 & 0.00000 & 0.00617 & 0.2686 \\
\hline LO & 5 & 1.93310 & -0.61001 & 12.33133 & 0.84352 & 0.03621 & 6.25143 & 1.32724 & 12.21905 & 0.00000 & 0.00927 & 0.3936 \\
\hline B & 6 & 7.12026 & -2.01344 & 22.62397 & 1.43036 & 0.12567 & 2.46895 & 0.49882 & 7.57899 & 0.00000 & 0.09428 & 2.3936 \\
\hline $\mathrm{LI}$ & 7 & 8.17134 & -2.19089 & 24.26385 & 1.53748 & 0.13089 & 2.25116 & 0.37237 & 7.33248 & 0.00000 & 0.11118 & 2.6436 \\
\hline $\mathrm{QFH}$ & 8 & $8.4694 \mathrm{~B}$ & 0.14298 & 24.71362 & 1.56736 & 0.13362 & 2.24487 & -0.32797 & 7.32222 & 0.00000 & 0.12143 & 2.7872 \\
\hline $\mathrm{QFH}$ & 9 & 8.09143 & 2.45386 & 24.16424 & 1.53357 & 0.13636 & 2.44471 & -1.08251 & 7.64119 & 0.00000 & 0.13126 & 2.9308 \\
\hline LO & 10 & 7.49152 & 2.34539 & 23.25672 & 1.47666 & 0.13891 & 2.72921 & -1.13355 & 8.07358 & 0.00000 & 0.13896 & 3.0558 \\
\hline$S F$ & 11 & 7.49152 & 2.34539 & 23.25672 & 1.47666 & 0.13891 & 2.72921 & -1.19355 & 8.07358 & 0.00000 & 0.13896 & 3.0558 \\
\hline LO & 12 & 6.91873 & 2.23692 & 22.35350 & 1.41975 & 0.14168 & 3.04148 & -1.30460 & 8.52296 & 0.00000 & 0.14587 & 3.1808 \\
\hline B & 13 & 1.46538 & 0.52115 & 11.00211 & 0.77986 & 024831 & 11.42749 & -2.74389 & 16.52050 & 0.00000 & 0.20095 & 5.1808 \\
\hline L1 & 14 & 1.25904 & 0.30421 & 10.25183 & 0.73187 & 0.27777 & 12.84608 & -2.93047 & 17.51592 & 0.00000 & 0.20424 & 5.4308 \\
\hline QDH & 15 & 1.22595 & -0.07155 & 10.07398 & 0.71511 & 0.29630 & 13.30658 & -0.24435 & 17.82710 & 0.00000 & 0.20598 & 5.5744 \\
\hline QDH & 16 & 1.30096 & -0.45594 & 10.27754 & 0.71976 & 0.31452 & 12.98366 & 2.47066 & 17.60947 & 0.00000 & 0.20771 & 5.7180 \\
\hline 20 & 17 & 1.42945 & -0.57200 & 10.64868 & 0.73312 & 0.32913 & 12.37454 & 2.40227 & 17.19144 & 0.00000 & 0.20928 & 5.8430 \\
\hline SD & 18 & 1.42945 & -0.57200 & 10.64868 & 0.73312 & 0.32913 & 12.37454 & 2.40227 & 17.19144 & 0.00000 & 0.20928 & 5.8430 \\
\hline LO & 19 & 1.58696 & -0.68805 & 11.07144 & 0.74648 & 0.34236 & 11.78253 & 2.33387 & 16.77517 & 0.00000 & 0.21092 & 5.9680 \\
\hline B & 20 & 7.93757 & -2.52382 & 22.44304 & 1.21807 & 0.43640 & 4.15924 & 1.34640 & 9.96678 & 0.00000 & 0.25704 & 7.9680 \\
\hline L1 & 21 & 9.25751 & -2.75593 & 24.21531 & 1.31061 & 0.44104 & 3.52831 & 1.17733 & 9.17975 & 0.00000 & 0.26743 & 8.2180 \\
\hline QFH & 22 & 9.67433 & -0.10718 & 24.74082 & 1.33678 & 0.44344 & 3.34083 & 0.14592 & 8.93254 & 0.00000 & 0.27413 & 8. 3616 \\
\hline QFH & 23 & 9.31741 & 2.55881 & 24.26548 & 1.30866 & 0.44583 & 3.44220 & -0.86138 & 9.06704 & 0.00000 & 0.28092 & 8.5052 \\
\hline Lo & 24 & 8.69037 & 2.45755 & 23.42053 & 1.26071 & 0.44804 & 3.66545 & -0.92463 & 9.35646 & 0.00000 & 0.28652 & 8.6302 \\
\hline SF & 25 & 8.69037 & 2.45755 & 23.42053 & 1.25071 & 0.44804 & 3.66545 & -0.92463 & 9.35646 & 0.00000 & 0.28652 & 8.6302 \\
\hline LO & 26 & 8.08864 & 2.35630 & 22.57928 & 1.21277 & 0.45041 & 3.90452 & -0.98789 & 9.65676 & 0.00000 & 0.29178 & 8.7552 \\
\hline B & 27 & 1.93756 & 0.75466 & 11.63714 & 0.71467 & 0.53365 & 9.47962 & -1.70358 & 15.04677 & 0.00000 & 0.34510 & 10.7552 \\
\hline L1 & 28 & 1.61086 & 0.55214 & 10.78362 & 0.68461 & 0.55624 & 10.35714 & -1.80650 & 15.72779 & 0.00000 & 0.34911 & 11.0052 \\
\hline QDH. & 29 & 1.51455 & 0.12518 & 10.52963 & 0.67750 & 0.57097 & 10.56796 & 0.35307 & 15.88705 & 0.00000 & 0.35129 & 11.1488 \\
\hline QDH & 30 & 1.53751 & -0.28669 & 10.65280 & 0.69066 & 0.58604 & 10.15836 & 2.47088 & 15.57612 & 0.00000 & 0.35348 & 11.2924 \\
\hline L5 & 31 & 1.63936 & -0.39227 & 11.01042 & 0.71509 & 0.60110 & 9.43283 & 2.36596 & 15.00958 & 0.00000 & 0.35592 & 11.4424 \\
\hline SD & 32 & 1.63936 & -0.39227 & 11.01042 & 0.71509 & 0.60110 & 9.43283 & 2.36596 & 15.00958 & 0.00000 & 0.35592 & 11.4424 \\
\hline L6 & 33 & 2.20759 & -0.74419 & 12.59775 & 0.79652 & 0.54343 & 7.24173 & 2.01624 & 13.15130 & 0.00000 & 0.36555 & 11.9424 \\
\hline$B 1$ & 34 & 4.99156 & -1.58535 & 18.36520 & 1.08520 & 0.70205 & 3.29184 & 1.23464 & 8.86680 & 0.00000 & 0.40507 & 13.1424 \\
\hline L6 & 35 & 6.75288 & -1.93728 & 21.27762 & 1.24533 & 0.71577 & 2.24891 & 0.85122 & 7.32881 & 0.00000 & 0.43449 & 13.6424 \\
\hline L5 & 36 & 7.34990 & -2.04286 & 22.16961 . & 1.29336 & 0.71916 & 2.01079 & 0.73619 & 6.92997 & 0.00000 & 0.44573 & 13.7924 \\
\hline QFH & 37 & 7.63958 & 0.05306 & 22.57376 & 1.31277 & 0.72219 & 1.89268 & 0.09750 & 6.72335 & 0.00000 & 0.45753 & 13.9360 \\
\hline $\mathrm{QFH}$ & 38 & 7.32024 & 2.14045 & 22.06676 & 1.27885 & 0.72522 & 1.95325 & -0.52507 & 6.83010 & 0.00000 & 0.46951 & 14.0796 \\
\hline L5 & 39 & 6.69526 & 2.02608 & 21.06890 & 1.21586 & 0.72863 & 2.12547 & -0.62304 & 7.12484 & 0.00000 & 0.48124 & 14.2296 \\
\hline SF & 40 & 6.69526 & 2.02608 & 21.06890 & 1.21586 & 0.72863 & 2.12547 & -0.62304 & 7.12484 & 0.00000 & 0.48124 & 14.2296 \\
\hline 26 & 41 & 4.85980 & 1.64484 & 17.80640 & 1.00590 & 0.74260 & 2.91179 & -0.94960 & 8.33926 & 0.00000 & 0.51344 & 14.7296 \\
\hline $\mathrm{B} 1$ & 42 & 2.01737 & 0.73362 & 11.24234 & 0.59810 & 0.80493 & 6.03158 & -1.61809 & 12.00227 & 0.00000 & 0.55966 & 15.9296 \\
\hline L6 & 43 & 1.47437 & 0.35238 & 9.41908 & 0.46684 & 0.85174 & 7.79965 & -1.91803 & 13.64851 & 0.00000 & 0.57128 & 16.4296 \\
\hline L5 & 44 & 1.38581 & 0.23801 & 9.02955 & 0.42746 & 0.86847 & 8.38855 & -2.00801 & 14.15439 & 0.00000 & 0.57423 & 16.5796 \\
\hline QDH & 45 & 1.37375 & -0.15321 & 8.87583 & 0.39597 & 0.88515 & 8.71813 & -0.26422 & 14.42977 & 0.00000 & 0.57689 & 16.7232 \\
\hline
\end{tabular}




\begin{tabular}{|c|c|c|c|c|c|c|c|c|c|c|c|c|}
\hline MAGNET & $\mathrm{J}$ & BETAX & AIFAX & $\operatorname{BSCX}(\mathrm{MM})$ & ETAX & DNUEX & BETAY & ALFAY & $\operatorname{BSCI}(\mathrm{M})$ & ETAY & DNUEY & TOT-L \\
\hline & & & & & & & & & & & & \\
\hline QDH & 46 & 1.47557 & -0.56290 & 9.07584 & 0.37633 & 0.90131 & 8.53732 & 1.51082 & $14: 27935$ & 0.00000 & 0.57952 & 16.8668 \\
\hline L6 & 47 & 2.26158 & -1.00912 & 10.81886 & 0.32780 & 0.94544 & 7.12263 & 1.31857 & 13.04271 & 0.00000 & 0.58974 & 17.3668 \\
\hline ᄂ6 & 48 & 3.49381 & -1.45534 & 13.16945 & 0.27927 & 0.97390 & 5.90018 & 1. 12632 & 11.87081 & 0.00000 & 0.60202 & 17.8668 \\
\hline $\mathrm{B2}$ & 49 & 8.26067 & -2.52431 & 19.97158 & 0.22578 & 1.00968 & 3.70094 & 0.69632 & 9.40164 & 0.00000 & 0.64336 & 19.0668 \\
\hline L5 & 50 & 9.03804 & -2.65817 & 20.88158 & 0.22695 & 1.01245 & 3.50107 & 0.63614 & 9.14425 & 0.00000 & 0.64999 & 19.2168 \\
\hline L5 & 51 & 9.85557 & -2.79204 & 21.79761 & 0.22811 & 1.01498 & 3.31925 & 0.57596 & 8.90365 & 0.00000 & 0.65700 & 19.3668 \\
\hline L5 & 52 & 10.71326 & -2.92591 & 22.71893 & 0.22927 & 1.01730 & 3.15549 & 0.51578 & 8.58123 & 0.00000 & 0.66438 & 19.5168 \\
\hline QFH & 53 & 11.11832 & 0.14361 & 23.13789 & 0.22572 & 1.01938 & 3.14206 & -0.42100 & 8.66274 & 0.00000 & 0.67169 & 19.6604 \\
\hline $\mathrm{QFH}$ & 54 & 10.63299 & 3.19004 & 22.62104 & 0.21300 & 1.02147 & 3.40394 & -1.42735 & 9.01651 & 0.00000 & 0.67872 & 19.8040 \\
\hline L4 & 55 & 8.52873 & 2.82215 & 20.24472 & 0.17117 & 1.02732 & 4.51239 & -1.73965 & 10.38128 & 0.00000 & 0.69296 & 20.1540 \\
\hline L6 & 56 & 5.96935 & 2.29660 & 16.91680 & 0.11141 & 1.03848 & 6.47511 & -2.18580 & 12.43573 & 0.00000 & 0.70770 & 20.6540 \\
\hline B2 & 57 & 1.97563 & 1.03759 & 9.71855 & 0.03103 & 1.09519 & $12.90626^{\circ}$ & -3.14408 & 17.55690 & 0.00000 & 0.72865 & 21.8540 \\
\hline L5 & 58 & 1.68801 & 0.87992 & 8.98333 & 0.02883 & 1.10827 & 13.86847 & -3.27060 & 18.19960 & 0.00000 & 0.73044 & 22.0040 \\
\hline 25 & 59 & 1.44768 & 0.72226 & 8.31928 & 0.02662 & 1.12357 & 14.86862 & -3.39711 & 18.84443 & 0.00000 & 0.73210 & 22.1540 \\
\hline QDH & 60 & 1.30164 & 0.30485 & 7.88841 & 0.02490 & 1.14033 & 15.40268 & -0.28488 & 19.17988 & 0.00000 & 0.73360 & 22.2976 \\
\hline QDH & 61 & 1.26907 & -0.07579 & 7.78892 & .0 .02392 & 1.15824 & 15.02902 & 2.86103 & 18.94580 & 0.00000 & 0.73510 & 22.4412 \\
\hline $\mathrm{L} 2 \mathrm{~B}$ & 62 & 8.85639 & -2.45331 & 20.56820 & 0.01104 & 1.33460 & 3.36350 & 1.02748 & 8.96280 & 0.00000 & 0.80442 & 25.4412 \\
\hline $\mathrm{QFH}$ & 63 & 9.20200 & 0.07931 & 20.96564 & 0.01020 & 1.33711 & 3.21207 & 0.04135 & 8.75871 & 0.00000 & 0.81143 & 25.5848 \\
\hline QFH & 64 & 8.81206 & 2.59918 & 20.51657 & 0.00895 & 1. 33963 & 3.33910 & -0.93794 & 8.93022 & 0.00000 & 0.81845 & 25.7284 \\
\hline L.2A & 65 & 1.93585 & 0.83892 & 9.61663 & -0.01114 & 1.42009 & 9.34266 & -2.06384 & 14.93767 & 0.00000 & 0.87674 & 27.7284 \\
\hline QDH & 66 & 1.76679 & 0.35007 & 9.18735 & -0.01276 & 1.43252 & 9.65899 & -0.11710 & 15.18845 & 0.00000 & 0.87913 & 27.8720 \\
\hline $\mathrm{QDH}$ & 67 & 1.73075 & -0.09657 & 9.09342 & -0.01476 & 1.44567 & 9.40859 & 1.84347 & 14.99029 & 0.00000 & 0.88152 & 28.0156 \\
\hline LS & 68 & 1.77284 & -0.18404 & 9.20364 & -0.01707 & 1. 45931 & 8.86607 & 1.77335 & 14.55168 & 0.00000 & 0.88413 & 28.1656 \\
\hline 25 & 69 & 1.84117 & -0.27152 & 9.37967 & -0.01937 & 1.47254 & 8.34458 & 1.70323 & 14.11724 & 0.00000 & 0.88691 & 28.3156 \\
\hline $\mathrm{B2}$ & 70 & 3.32833 & -0.97005 & 12.61093 & 0.02498 & 1.55293 & 4.86111 & 1.18373 & 10.77495 & 0.00000 & 0.91707 & 29.5156 \\
\hline L6 & 71 & 4.44417 & -1.26163 & 14.58393 & 0.06970 & 1.57368 & 3.80086 & 0.93675 & 9.52771 & 0.00000 & 0.93563 & 30.0156 \\
\hline 26 & 72 & 5.85159 & -1.55322 & 16.75143 & 0.11442 & 1.58931 & 2.98760 & 0.68977 & 8.44713 & 0.00000 & 0.95933 & 30.5156 \\
\hline $\mathrm{DR}$ & 73 & 5.85159 & -1.55322 & 16.75143 & 0.11442 & 1.58931 & 2.98760 & 0.68977 & 8.44713 & 0.00000 & 0.95933 & 30.5156 \\
\hline $\mathrm{QFH}$ & 74 & 6.06223 & 0.10637 & 17.05524 & 0.12485 & 1.59312 & 2.91784 & -0.19735 & 8.34792 & 0.00000 & 0.96713 & 30.6592 \\
\hline $\mathrm{QFH}$ & 75 & 5.79214 & 1.74885 & 16.67617 & 0.13021 & 1.59695 & 3.10407 & -1.11709 & 8.61020 & 0.00000 & 0.97478 & 30.8028 \\
\hline L5 & 76 & 5.28325 & 1.64374 & 15.93267 & 0.13307 & 1.60126 & 3.45549 & -1.22572 & 9.08453 & 0.00000 & 0.98207 & 30.9528 \\
\hline LS & 77 & 4.80590 & 1.53864 & 15.20239 & 0.13593 & 1.60600 & 3.83950 & -1.33435 & 9.57602 & 0.00000 & 0.98863 & 31.1028 \\
\hline $\mathrm{B} 2$ & 78 & 2.12520 & 0.69936 & 10.27777 & 0.22151 & 1.66715 & 8.02514 & -2.13455 & 13.84439 & 0.00000 & 1.02331 & 32.3028 \\
\hline L6 & 79 & 1.60102 & 0.34901 & 9.12243 & 0.28344 & 1.71084 & 10.33278 & -2.48072 & 15.70927 & 0.00000 & 1.03205 & 32.8028 \\
\hline L6 & 80 & 1.42718 & -0.00133 & 8.84214 & 0.34536 & 1.76449 & 12.98659 & -2.82690 & 17.61145 & 0.00000 & 1.03892 & 33.3028 \\
\hline QDH & 81 & 1.48519 & -0.40670 & 9.07388 & 0.36841 & 1.78029 & 13.41268 & -0.11067 & 17.89803 & 0.00000 & 1.04064 & 33.4464 \\
\hline QDH & 82 & 1.66546 & -0.86113 & 9.65146 & 0.40248 & 1.79492 & 13.04890 & 2.51865 & 17.65365 & 0.00000 & 1.04236 & 33.5900 \\
\hline L5 & 83 & 1.94733 & -1.01798 & 10.46785 & 0.44415 & 1.80819 & 12.27686 & 2.52833 & 17.12345 & 0.00000 & 1.04425 & 33.7400 \\
\hline L6 & 84 & 3.22673 & -1.54082 & 13.51536 & 0.58305 & 1.84015 & 9.89907 & 2.22725 & 15.37605 & 0.00000 & 1.05147 & 34.2400 \\
\hline B1 & 85 & 8.40294 & -2.79048 & 22.06479 & 1.00911 & 1.87700 & 5.24359 & 1.60435 & 11.19082 & 0.00000 & 1.07810 & 35.4400 \\
\hline LE & 86 & 11.45484 & -3.31332 & 25.95134 & 1.22671 & 1.88512 & 3.80963 & 1.26356 & 9.53870 & 0.00000 & 1.09595 & 35.9400 \\
\hline L5 & 87 & 12.47237 & -3.47017 & 27.12706 & 1.29199 & 1.88712 & 3.44590 & 1.16132 & 9.07191 & 0.00000 & 1.10254 & 36.0900 \\
\hline QFH & 88 & 12.96191 & 0.10756 & 27.69731 & 1.32782 & 1.88890 & 3.25985 & 0.15184 & 8.82361 & 0.00000 & 1.10940 & 36.2336 \\
\hline QFH & 89 & 12.41225 & 3.66799 & 27.14547 & 1.30972 & 1.89069 & 3.35629 & -0.83255 & 8.95318 & 0.00000 & 1.11636 & 36.3772 \\
\hline L5 & 90 & 11.33806 & 3.49331 & 25.98871 & 1.26270 & 1.89270 & 3.61740 & -0.90822 & 9.29493 & 0.00000 & 1.12322 & 36.5272 \\
\hline SF & 91 & 11.33806 & 3.49331 & 25.98871 & 1.26270 & 1.89270 & 3.61740 & -0.90822 & 9.29493 & 0.00000 & 1.12322 & 36.5272 \\
\hline L6 & 92 & 8.13587 & 2.91106 & 22.16514 & 1.10596 & 1.90099 & 4.65174 & -1.16045 & 10.54036 & 0.00000 & 1.14266 & 37.0272 \\
\hline $\mathrm{B} 1$ & 93 & 2.84117 & 1.51939 & 13.88884 & 0.82540 & 1.94097 & 8.01452 & -1.60722 & 13.83523 & 0.00000 & 1.17415 & 38.2272 \\
\hline L6. & 94 & 1.61290 & 0.93714 & 11.13231 & 0.74737 & 1.97849 & 9.73351 & -1.83076 & 15.24693 & 0.00000 & 1.18316 & 38.7272 \\
\hline L.S & 95 & 1.35796 & 0.76246 & 10.43357 & 0.72396 & 1.99465 & 10.29280 & -1.89783 & 15.67886 & 0.00000 & 1.18555 & 38.8772 \\
\hline QDH & 96 & 1.19980 & 0.34989 & 9.99477 & 0.71228 & 2.01269 & 10.53195 & 0.2 .9903 & 15.85996 & 0.00000 & 1.18773 & 39.0208 \\
\hline
\end{tabular}


3 GEV BOOSTER

*** MUTIPOLE-STRUCTURE IN ONE HALF-SUPERPERIOD ****

$J$ MULTIPOLE 〈BETX $(M)\rangle\langle\operatorname{BETY}(M)\rangle\langle\operatorname{PHIX}\rangle\langle\operatorname{PHIY}\rangle\langle\operatorname{ETAX}(M)\rangle \operatorname{SM}\left(1 / M^{* *} 2\right)$

\begin{tabular}{|c|c|c|c|c|c|c|c|c|c|}
\hline 1. MULTIPOLE & AT: $J=$ & $=$ & SD & 1.792 & 6.590 & 0.026 & 0.006 & 0.823 & 1.43297 \\
\hline 2. MULTIPOLE & AT: $J=$ & 11 & SF & 7.492 & 2.729 & 0.139 & 0.139 & 1.477 & -0.74592 \\
\hline 3. MULTIPOLE & Ar: $J=$ & 18 & SD & 1.429 & 12.375 & 0.329 & 0.209 & 0.733 & 1.43297 \\
\hline 4. MULTIPOLE & AT: $J=$ & 25 & SF & 8.690 & 3.665 & 0.448 & 0.287 & 1.261 & -0.74592 \\
\hline 5. MULTIPOLE & AT: $\mathbf{J}=$ & 32 & SD & 1.539 & 9.433 & 0.601 & 0.356 & 0.715 & 1.43297 \\
\hline 6. MUTTIPOLE & AT: $\mathrm{J}=$ & 40 & $\mathrm{SF}$ & 6.695 & 2.125 & 0.729 & 0.481 & 1.216 & -0.74592 \\
\hline 7. MULTIPOLE & AT: $J=$ & 91 & SF & 11.338 & 3.617 & 1.893 & 1.123 & 1.263 & -0.74592 \\
\hline 8. MUTIPOLE & AT: $J=$ & 99 & SD & 1.172 & 9.571 & 2.049 & 1.192 & 0.740 & 1.43297 \\
\hline 9. MULTIPOLE & AT: $\mathrm{J}=$ & $=106$ & SF & 6.350 & 2.146 & 2.220 & 1.314 & $1.349^{\circ}$ & -0.74592 \\
\hline 10. MULTIPOLE & AT: $\mathbf{J}=$ & 113 & SD & 2.326 & 8.010 & 2.366 & 1.416 & 0.759 & 1.43297 \\
\hline 11. MULTIPOLE & AT: $J=$ & 120 & SF & 9.001 & 3.190 & 2.453 & 1.523 & 1.424 & -0.74592 \\
\hline
\end{tabular}

TOTAL NUMBER OF MULTIPOLES IN STORAGE RING: 22.

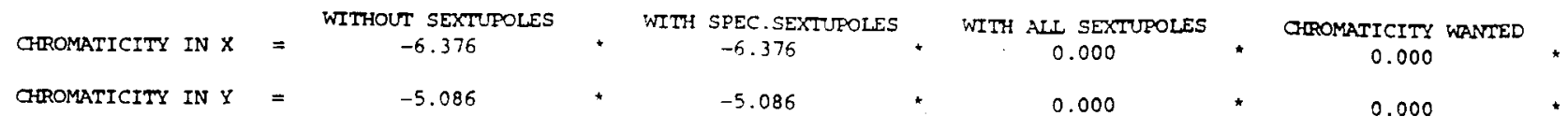

TOTAL CORRECTED ORROMATICITI

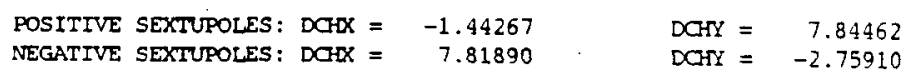


TUNE SHIFT WITH AMPLTTUDE (SEE H.WIEDEMANN PEP-NOTE 220)

$\begin{array}{rr}\text { HARM } & \text { JSEX } \\ 0 & 91 \\ 1 & 120 \\ 3 & 91 \\ 5 & 25 \\ 7 & 91 \\ 9 & 120 \\ 11 & 91 \\ 13 & 120 \\ 15 & 91 \\ 17 & 120 \\ 19 & 91 \\ 21 & 91 \\ 23 & 25 \\ 25 & 91 \\ 27 & 120 \\ 29 & 91 \\ 31 & 120 \\ 33 & 91 \\ 35 & 91 \\ 37 & 91 \\ 39 & 91 \\ 41 & 25 \\ 43 & 91 \\ 45 & 120 \\ 47 & 91 \\ 49 & 120\end{array}$

$\begin{array}{rr}\text { DAN (JSEX) } & \text { A-HARM } \\ -57 . & -184 . \\ 39 . & 21 . \\ -49 . & -16 . \\ 34 . & 10 . \\ 56 . & 42 . \\ -10 . & -13 . \\ -56 . & -56 . \\ -35 . & 0 . \\ 49 . & 45 . \\ -38 . & 7 . \\ -35 . & -16 . \\ 50 . & 0 . \\ -37 . & -11 . \\ -56 . & -2 . \\ 28 . & 81 . \\ 56 . & 116 . \\ 40 . & 35 . \\ -48 . & -30 . \\ 39 . & -13 . \\ 34 . & -14 . \\ -51 . & -35 . \\ 38 . & -10 . \\ 57 . & -10 . \\ -39 . & -97 . \\ -55 . & -125 . \\ -35 . & -13 . \\ & \end{array}$

NUE-TERM 3NUE-TERM -17 . 17.

0 .

-1.
2.

2 .

1.

0.

0 .

0 .

0 .

0.

0 .

0.

0.

0 .

0.

0.

0 .

0.

0.

TUNE SHIFT WITH BETATRON AMPLITUDE XO: DNUEX =

$K W(4)=1$

HARM JSEX DAN(JSEX) A-HARM

NUE-TERM 3NUE-TERM

2
4
6
8
10
12
14
15
18
20
22
24
26
28
30
32
34
36
38
40
42
44
46
48
50

$\begin{array}{rr}-4 . & 0 . \\ -7 . & 0 . \\ 1 . & 0 . \\ 1 . & 0 . \\ 1 . & -1 . \\ 0 . & 0 . \\ 0 . & -1 . \\ 1 . & 26 . \\ 4 . & 17 . \\ 1 . & 1 . \\ 0 . & 0 . \\ 0 . & 0 . \\ 0 . & 0 . \\ 0 . & 0 . \\ 0 . & 0 . \\ 0 . & 0 . \\ 0 . & 0 . \\ 0 . & 1 . \\ 0 . & 0 . \\ 0 . & 0 . \\ 0 . & 0 . \\ 0 . & 0 . \\ 0 . & 0 . \\ 0 . & 0 . \\ 0 . & 0 . \\ & \end{array}$

$\begin{array}{rrr}120 & -37 . & -63 . \\ 91 & 53 . & 56 . \\ 25 & 38 . & -15 \\ 91 & -43 . & -33 \\ 91 & 44 . & 59 . \\ 25 & -38 . & 17 . \\ 91 & -54 . & -55 . \\ 120 & 40 . & 93 . \\ 91 & 57 . & 229 . \\ 11 & 30 . & 87 . \\ 91 & -53 . & -58 . \\ 25 & -36 . & 10 . \\ 91 & 42 . & 29 . \\ 91 & -45 . & -79 . \\ 120 & -40 . & -52 . \\ 91 & 55 . & 42 . \\ 120 & -33 . & -54 . \\ 91 & -57 . & -158 . \\ 11 & -31 . & -35 . \\ 91 & 52 . & 70 . \\ 25 & 33 . & -7 . \\ 91 & -41 . & -11 . \\ 91 & 46 . & 97 . \\ 120 & 38 . & 51 . \\ 91 & -55 . & -54 .\end{array}$

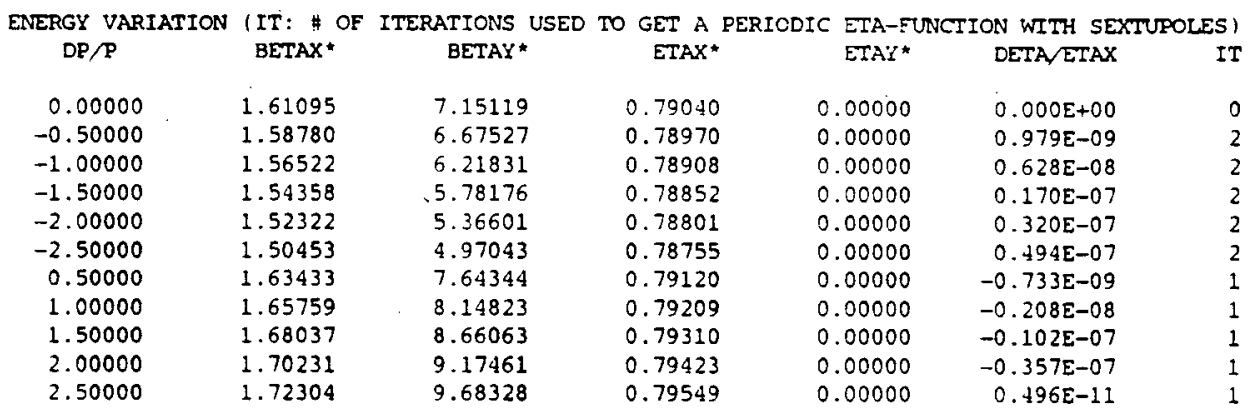




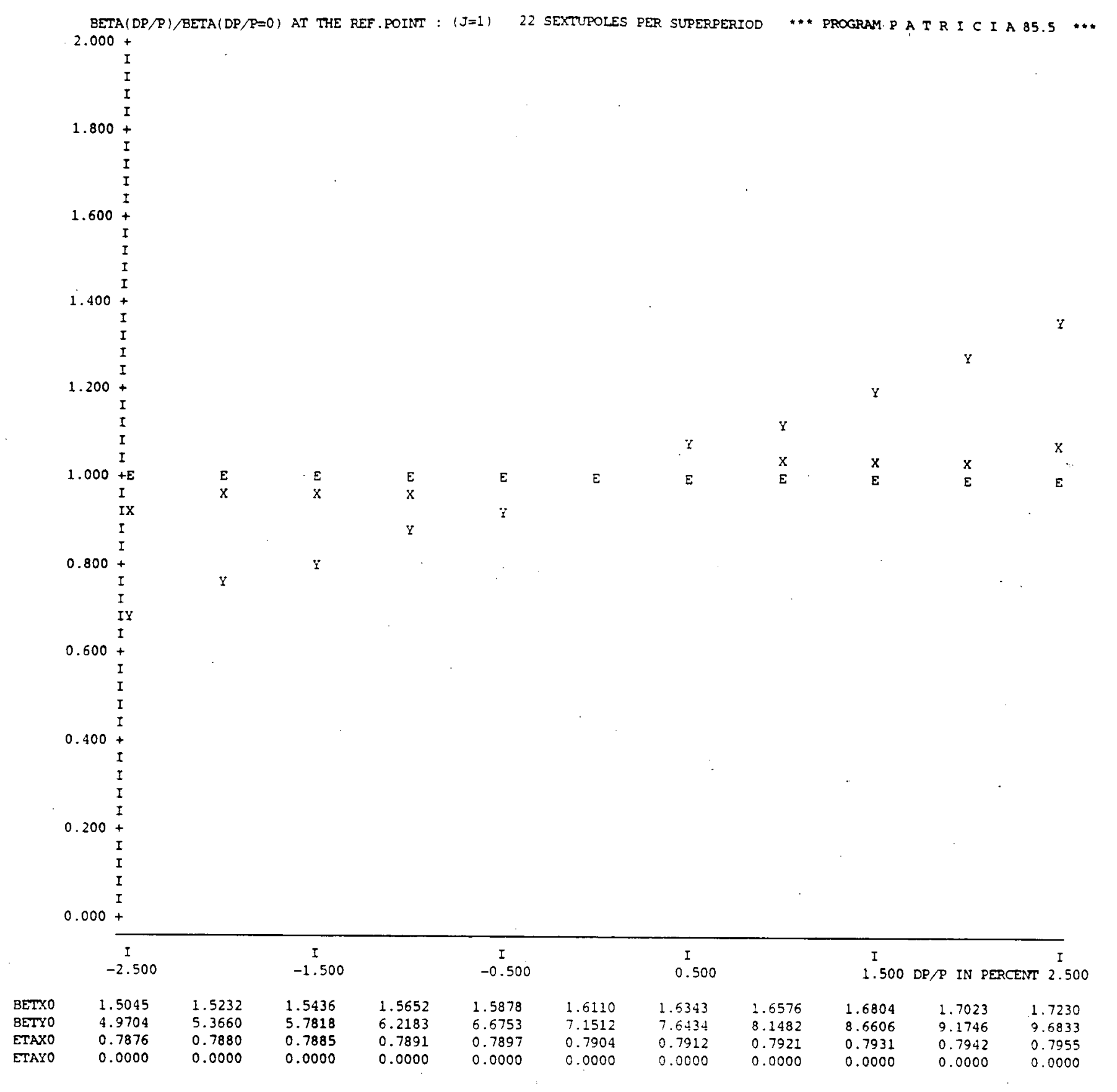


NONINIEGRAL PART OF THE TUNE VS. MOMENTUM

1.000

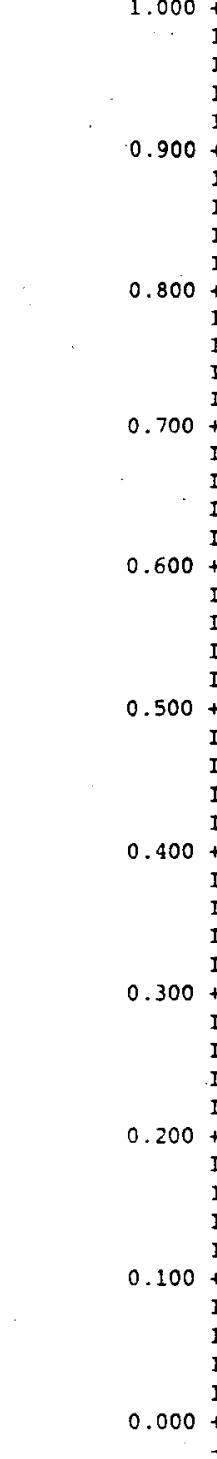

$$
\text { I }
$$$$
\text { I }
$$$$
-2.500
$$

$\mathrm{X}$

$Y$

$\mathrm{X}$

X

$\mathrm{x}$

$\mathrm{x}$

$x$

$Y$

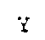

$\ddot{i}$

Y

$Y$

NUEX
NUEY

$0.2456 \quad 0.2456 \quad 0.2456$

$0.2456 \quad 0.2456$

0.1662 
BETA VARIATION WITH MOMIENTUM : (DBETAMEETA)/(DP/P) VS. PHASE

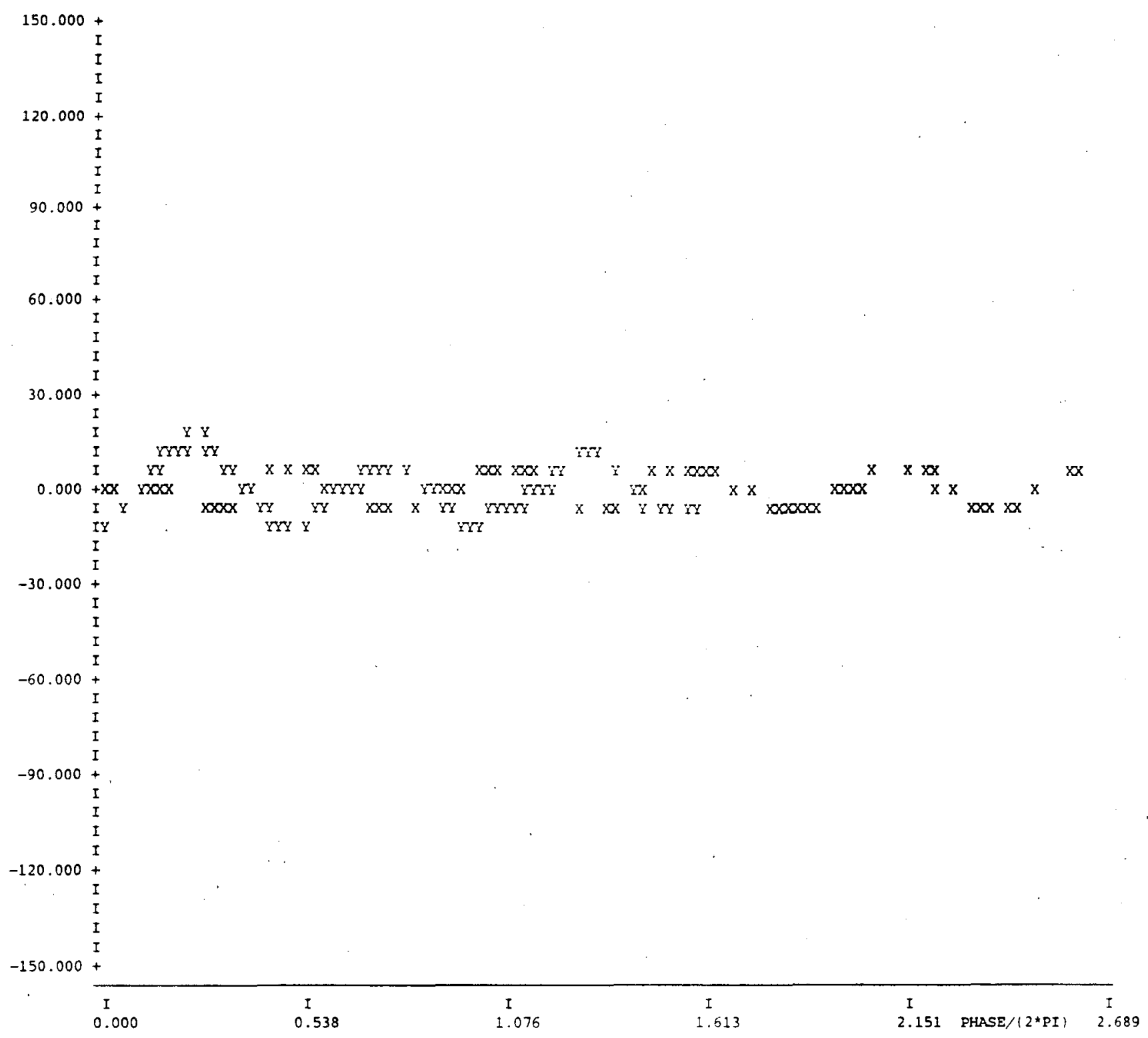




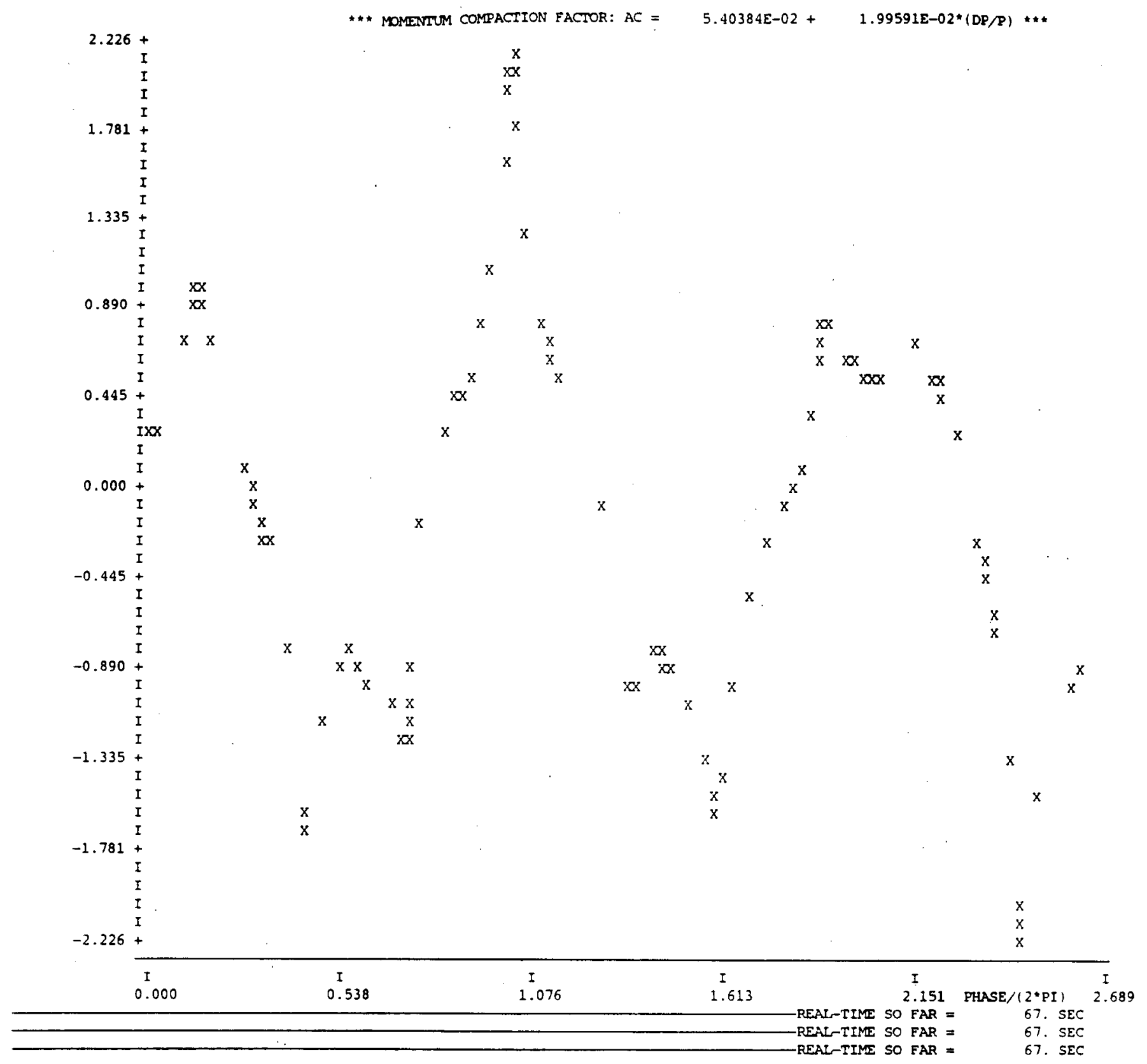




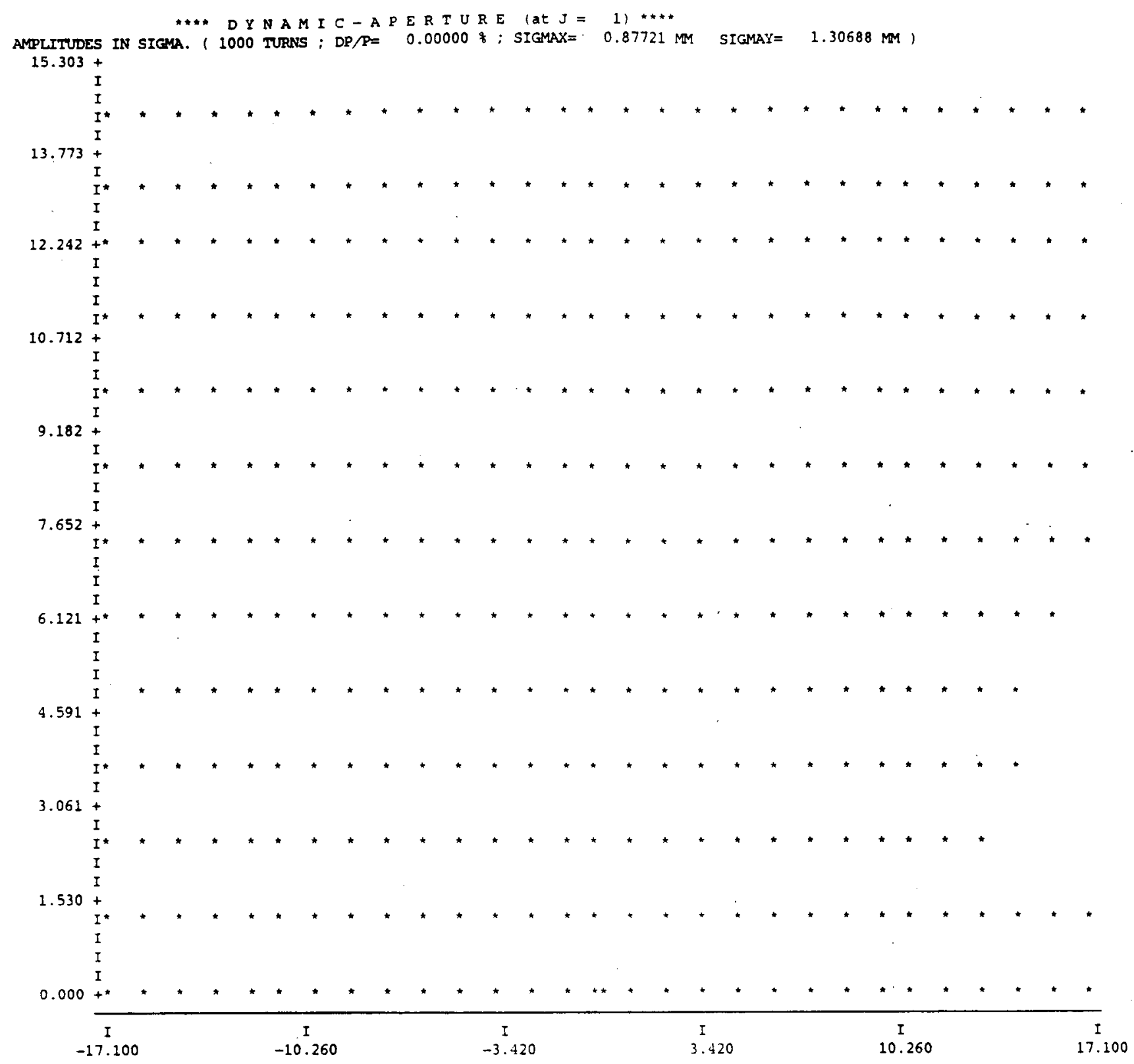




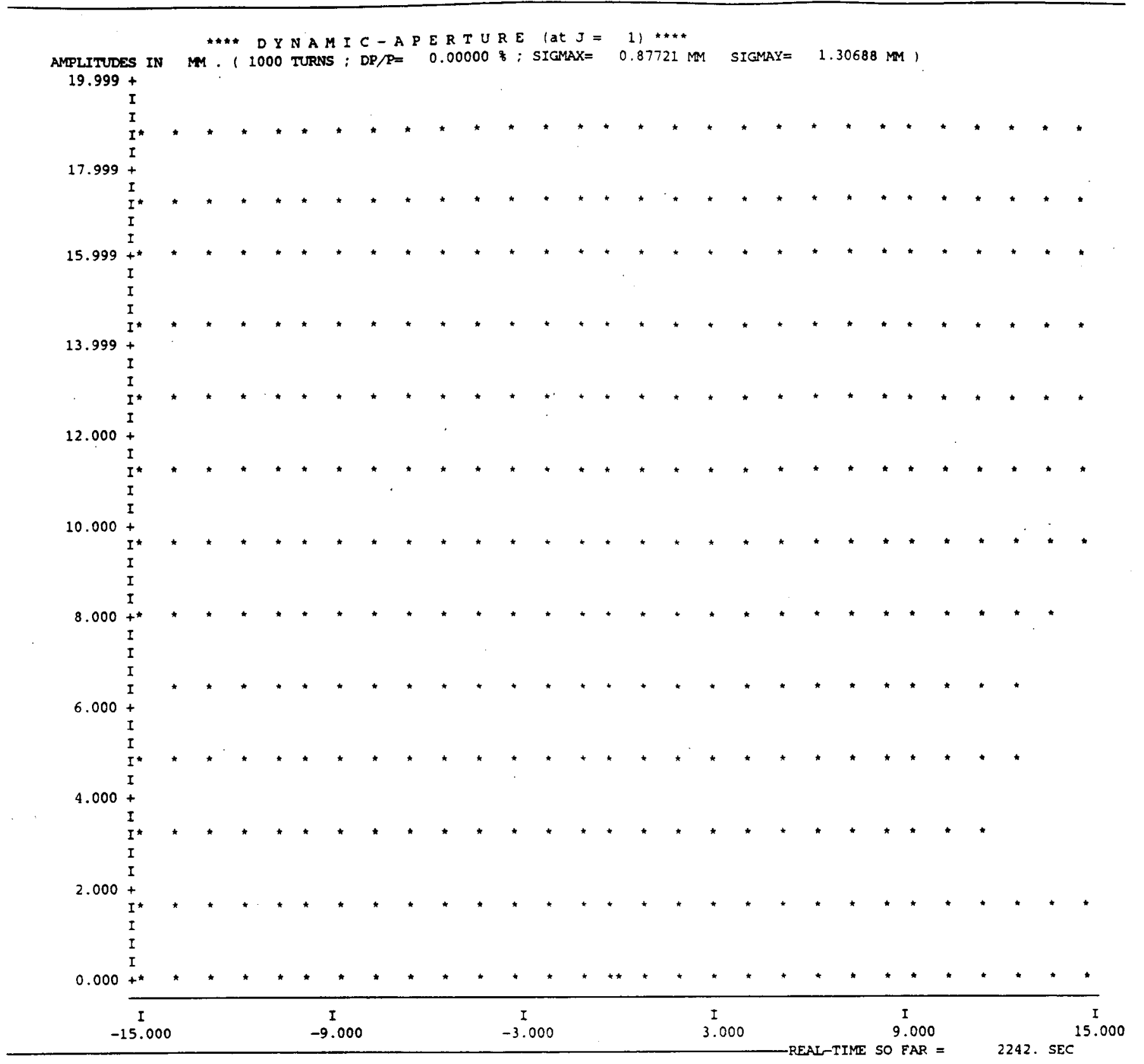


